\title{
Interrogating Internships:
}

Unpaid Work, Creative Industries, and Higher Education

Edited by Greig de Peuter, Nicole S. Cohen, and Enda Brophy

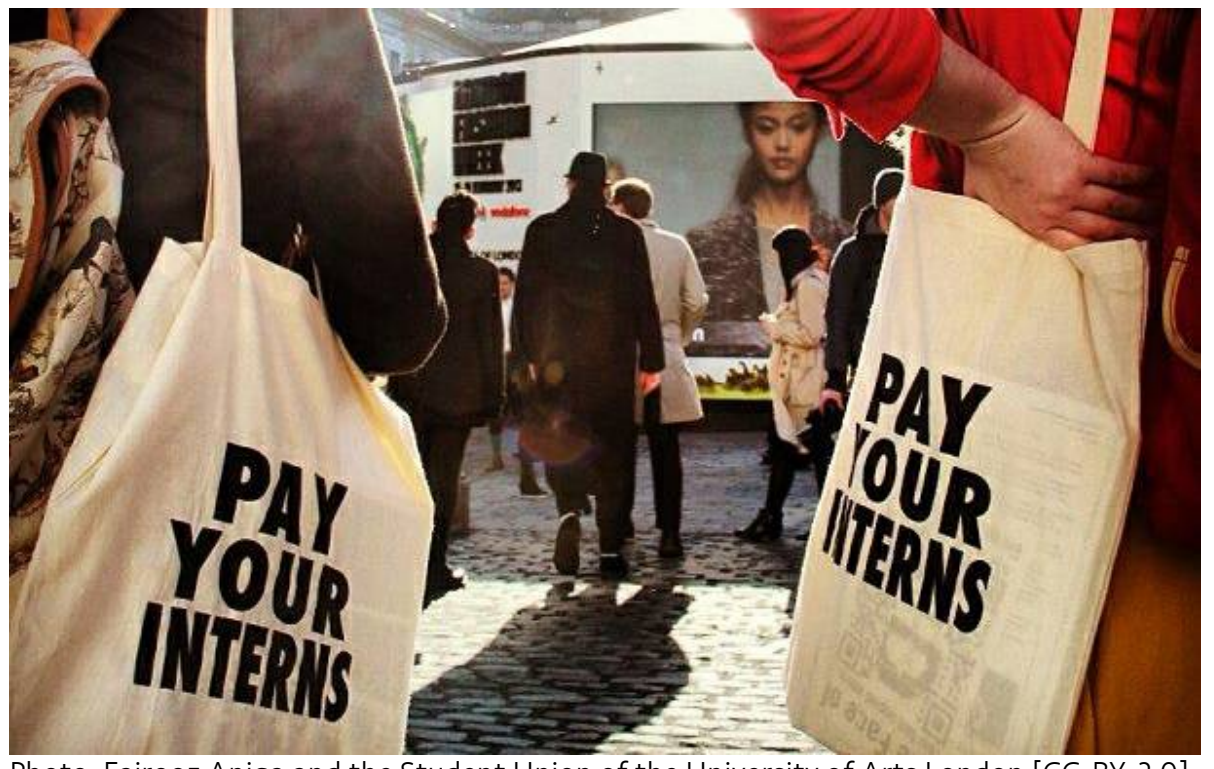

Photo: Fairooz Aniqa and the Student Union of the University of Arts London [CC-BY-2.0]

\section{triple $C$}

Volume 13, Number 2: 329-602 


\section{Table of Contents}

Introduction

Greig de Peuter, Nicole S. Cohen, and Enda Brophy

$329-335$

\section{Conceptualizing Internships}

Media and Cultural Industries Internships: A Thematic Review and Digital Labour Parallels

Thomas F. Corrigan

$336-350$

From Apprenticeship to Internship: The Social and Legal Antecedents of the Intern Economy

Alexandre Frenette

$351-360$

Interning and Investing: Rethinking Unpaid Work, Social Capital, and the "Human Capital Regime"

Sophie Hope and Joanna Figiel

What Killed Moritz Erhardt? Internships and the Cultural Dangers of "Positive" Ideas Bogdan Costea, Peter Watt, and Kostas Amiridis

\section{Internships and Creative Industries}

Under the Cloak of Whiteness: A Circuit of Culture Analysis of Opportunity Hoarding and Colour-blind Racism Inside US Advertising Internship Programs

Christopher Boulton $390-403$

Reality TV's Embrace of the Intern

Tanner Mirrlees

$404-422$

Expo Milano 2015: The Institutionalization of Working for Free in Italy Roberto Ciccarelli

A History of Internships at CBC Television News

Marlene Murphy

$428-437$

(De)valuing Intern Labour: Journalism Internship Pay Rates and Collective Representation in Canada

Errol Salamon

Internships, Workfare, and the Cultural Industries: A British Perspective David Lee 


\section{Internships and Higher Education}

Nothing for Money and Your Work for Free: Internships and the Marketing of Higher Education

Mara Einstein

$471-485$

"You Kind of Have to Bite the Bullet and do Bitch Work": How Internships Teach

Students to Unthink Exploitation in Public Relations

Michelle Rodino-Colocino and Stephanie N. Berberick

$486-500$

Negotiating Educated Subjectivity: Intern Labour and Higher Education in Hong Kong Ip lam Chong

Interrogating Course-Related Public Interest Internships in Communications

Sandra Smeltzer

$509-525$

Educating the Precariat: Intern Labour and a Renewed Approach to Media Literacy Education

Doug Tewksbury

$526-532$

Unwaged Posts in UK Universities: Controversies and Campaigns

Kirsten Forkert and Ana Lopes

$533-553$

\section{Intern Labour Activism}

Art Struggles: Confronting Internships and Unpaid Labour in Contemporary Art Panos Kompatsiaris

Report on Intern Rights Advocacy in 2013-2014

Intern Labor Rights

$567-578$

Ontario Interns Fight Back: Modes of Resistance Against Unpaid Internships William Webb

Challenging Intern Nation: A Roundtable with Intern Labour Activists in Canada Nicole S. Cohen and Greig de Peuter

Exploited for a Good Cause? Campaigning Against Unpaid Internships in the UK Charity Sector

Vera Weghman 


\title{
Interrogating Internships: Unpaid Work, Creative Industries, and Higher Education
}

\section{Introduction}

\author{
Greig de Peuter, ${ }^{*}$ Nicole S. Cohen, ${ }^{* *}$ and Enda Brophy*** \\ *Wilfrid Laurier University, Waterloo, Canada, gdepeuter@wlu.ca \\ ** University of Toronto, Mississauga, Canada, nicole.cohen@utoronto.ca \\ *** Simon Fraser University, Vancouver, Canada, ebrophy@sfu.ca
}

Keywords: internships, labour, creative industries, higher education, activism

\begin{abstract}
Acknowledgement: We would like to thank the contributors for their commitment to this special issue, the many reviewers for their valuable feedback on the articles, and Isabel Fine, our editorial assistant, for her diligent work.
\end{abstract}

Unpaid work has never looked so good. Internships, especially those in creative industries, enjoy a glamorous aura: celebrities like Kanye West and Lady Gaga intern at fashion labels, movies like The Internship make working for nothing look like fun, universities design sleek online promotional materials for their internship programs, and Malia Obama, the daughter of the President of the United States, lands a prized internship on the set of the HBO series Girls, cementing the number one rule of the intern game: who you know matters. In barely five years, internships have gone from being largely hidden to becoming a highly visible feature of the contemporary labour economy. They are also hotly debated. Controversy surrounding the legality of internships was brewing when magazine publishing giant Condé Nast cancelled its internship program in 2013. The response to the publisher's decision captures the opposing perspectives in the internship debate: many cheered the end of a scheme that asked debt-laden young people to labour for free for a profitable corporation, while others lamented the closure of what appears to be one of the only routes into hyper-competitive media work.

Opinions on internships may be split, but the gloss on this quasi-employment arrangement is becoming increasingly difficult to sustain. Today, internships are a site of contestation. They are a target of student activism, a topic of policy deliberation among politicians, and a subject of media coverage. Two intern stories grabbed headlines as we completed this special issue. One was the announcement that some 40 interns filed a class-action lawsuit against Dualstar Entertainment Group, the US company owned by celebrity twins Mary-Kate and Ashley Olsen. The suit alleges wage-theft, with reports that interns clocked 50 -hour workweeks without receiving monetary payment or academic credit in exchange for their time and effort (McGrath 2015). The second story was of a young New Zealander, David Hyde, who took an unpaid internship with the United Nations (UN) at the cost of living in a tent in Geneva, a prohibitively expensive city teeming with interns. Hyde revealed that he had all along intended to leak the truth about his accommodations. The savvy intern leveraged the media interest as a chance to speak out: "I strongly believed that unpaid internships are unjust because they further perpetuate inequality" (cited in Brooks-Pollock 2015). As Hyde used the soapbox to call on interns globally to unite, the UN faced pressure to review its internship system. Internships, and the questions of social and economic justice that are intrinsic to them, are not confined to the ostensibly prestigious working worlds of media and politics. Taiwan-based electronics manufacturer Foxconn was caught staffing its assembly lines in China with student interns, and Tesco Ireland has used the government welfare program JobBridge to advertise internships in shelf-stacking at its supermarkets. 
Internships have particular resonance for researchers and teachers in media, communication, and cultural studies. For starters, many departments in these fields operate internship programs. Internship schemes are hardly unique to media, culture, and communication programs, but what is unique is that the curricula of these departments are often devoted to scrutinizing the institutional structures, social implications, and symbolic products of the very industries that are routinely singled out as playing a key role in recruiting and normalizing unpaid or low-paid intern labour. "The real abusers of the intern economy", as Jim Frederick (1997) put it in one of the first major critiques of internships, "are the glamour industries." Boosting the supply of intern labour for these industries is the allure of occupations that promise opportunity for self-expression, which in turn dovetails with the injunction to "do what you love" (see Tokumitsu 2015). Internships also are pertinent to communication studies because internships are an emerging trope in popular media culture, from the depiction of interns on reality TV programs to the launch of the stylish magazine Intern, whose editorial mission is to showcase and celebrate interns' creative talents. Research on media representations of interns, institutional discourses on internships, and the material conditions of interns in the arts, media, and cultural industries can both draw upon and add to the growing literature on labour in media, cultural, and communication studies (see for example Ross 2000, 2009; McRobbie 2002, 2015; Deuze 2005; Gill and Pratt 2008; Hesmondhalgh and Baker 2010; Banks, Gill and Taylor 2013; Fuchs 2014; Huws 2014; Gregg 2012).

Until recently, internships have tended to escape critical attention. There are, however, significant exceptions, including Frederick's (1997) classic essay, "The Internment Camp", published in The Baffler, Naomi Klein's (2000) inclusion of intern issues in her counterglobalization epic, No Logo, and Gina Neff and Giovanni Arata's (2007) trailblazing study of academic internships in communication industries. The widening of public discussion of internships was prompted by the confluence of the 2008 financial crisis, rising levels of youth unemployment, and Occupy Wall Street. These factors readied the warm reception of Ross Perlin's exposé, Intern Nation: How to Earn Nothing and Learn Little in the Brave New Economy (2011), a book that was vital in pushing internships into a critical spotlight internationally. Thanks to Perlin's research, labour journalists attuned to the intern issue, and, most importantly, pushback by interns themselves, the perception of the internship as a benign stepping-stone on a young person's path to gainful employment has been shattered. Nor are internships any longer a neglected subject in media, communication, and cultural studies. Indeed, this special issue of triple $C$ joins a steadily expanding body of activist and critical scholarly accounts of internships (e.g., Carrotworkers' Collective 2011; Figiel 2012; Hope and Figiel 2012; Daniel and Daniel 2013; Frenette 2013; Seibert and Wilson 2013; Hesmondhalgh and Percival 2014; Ashton and Noonan 2013; Chillas, Marks and Galloway 2015; Shade and Jacobson 2015; Leonard, Halford and Bruce, forthcoming).

Critiques of the intern economy are trenchant and plentiful. A grievance list would include the arguments that glamourizing unpaid internships naturalizes the performance of unpaid labour and diminishes workers' expectations of employers; that young workers graduating with student debt and facing grim job prospects amid high unemployment (see Geobey 2013) often have little choice but to undertake unpaid internships; that unpaid interns displace paid employees; that higher education institutions, whose formal involvement in an internship is frequently required to comply with the law, economically benefit when tuition is charged to a student working unpaid to earn course credit; that interns' vague employment status often excludes them from certain entitlements and health and safety protections; that there is inadequate oversight of internships on the part of government regulators; that unpaid internships have a poor record of leading to paid jobs, with one survey by the National Association of Colleges and Employers (2014) in the US revealing that only 38.5 percent of unpaid interns in for-profit businesses were offered paid employment; and that companies, particularly those in culturally attractive industries, capitalize on young workers' passions by using un- or lowpaid interns rather than hire entry-level employees, who require training, mentorship, and commitment.

Crosscutting those mentioned above are critiques that focus sharply on systemic inequalities that are reflected, silenced, and reinforced in and through the internship system in a 
variety of ways. Refusing discourses of meritocracy to explain employment opportunity (or lack thereof), critics of unpaid internships consistently point out the class barrier: those unable to afford to work for free are shut out. When an intern takes out a loan or holds down a part-time job to subsidize an unpaid placement, internships interlock with debt and the wider precarious employment regime. Class-based social networks, such as family-linked contacts, are also an informal gateway to internships in competitive professional fields (Richards 2011). Class is neither the sole basis nor an isolated axis of inequality in the intern economy, of course. Although not all interns are young, the prevailing ageist assumption holds that it is more acceptable for a young person to work without a wage. Preliminary research indicates that more women than men do unpaid internships, continuing and deepening gendered divisions in the labour market (see Attfield and Couture 2014). Institutional racism keeps people of colour out (see Boulton, this issue). And new immigrants face pressure to accept unpaid work as a way to get nationally recognized experience. In these and other ways, we begin to see the internship system as a set of social mechanisms that differentially include and exclude populations along intersecting lines of age, class, gender, race, and status. As Alexandre Frenette et al. (2015) found in a survey of 10,698 arts-school graduates in the US, "women, Black, Hispanic/Latino, and first-generation college graduate arts alumni all appear to have held a disproportionate number of unpaid internships-which... are tied to significantly weaker career payoffs than paid internships" (8-9). That existing social divisions structure entry into work in the communication, media, and cultural industries is not only a problem of access, however. It is simultaneously a problem of representation. As Klein (2000, 246) wrote of media internships fifteen years ago, "This racket is not only exploitative in the classic sense, it also has some very real implications for the future of cultural production: today's interns are tomorrow's managers, producers and editors... ."

The cumulative effect of serial internships and zero-wages is the hardening of established social exclusions in the labour market, the devaluation of labour, wage depression across the labour economy, and the acclimatization of a generation of indebted workers to hustling from gig to gig with few expectations of their employers. Internships are, then, an entry point for interrogating contested conditions of life, labour, and learning at a historical moment when precarity is an encroaching structure of feeling. It should be acknowledged, however, that our key term, internships, is an expansive category, referring to a vast and varied range of experiences: a weeks-long, unpaid, informally-obtained position with a multinational corporation; a semester-length paid placement in the context of a structured cooperative education program; a short-term stint at a small non-profit organization that provides a stipend to cover travel and food expenses; or countless other iterations. The sheer heterogeneity of work arrangements that can be labelled an "internship" is one reason why it is not overly useful to organize the debate about internships around contending poles of being "for" or "against" the practice. By framing this special issue as devoted to interrogating internships, we instead seek to advance analyses of the power relations that underpin the intern economy, and to examine internship phenomena from perspectives alert to contextual specificities. While all of the contributions to this issue are broadly concerned with investigating some of the multiple articulations between and among internships, capitalism, communication, culture, and subjectivity, the articles are structured around four thematic areas: conceptualizing internships; internships and creative industries; internships and higher education; and intern labour activism.

The articles in the first section, Conceptualizing Internships, contextualize and theorize internships from a variety of critical perspectives. Thomas F. Corrigan sets a stage for the issue by surveying existing literature on intern experiences in media and cultural industries and recasting this literature's findings through conceptual lenses drawn from digital labour studies, such as self-exploitation, self-branding, and hope labour. Exploring the history of work-based learning and legal dimensions of internships in the US context. Alexandre Frenette draws parallels between the earlier apprenticeship system and the present-day intern economy, particularly with respect to minimum wage standards, government intervention, and understandings of the school-to-labour market transition. Contemporary internships are deeply shaped by neoliberal political and cultural regimes, under which periods of unwaged 
work are viewed as future investments that sharpen young workers' competitiveness, enhance their "employability", and produce responsible, entrepreneurial subjects who are ready to work-themes that are central to Sophie Hope and Joanna Figiel's analysis of the "human capital regime" in the UK and how the arts and creative industries in particular are implicated in this regime. The pressure on interns to demonstrate passion and commitment to their work can lead to troublesome working situations, sexual harassment, excessive hours, and, in extreme cases, death (Tomlinson 2013). Bogdan Costea, Peter Watt, and Kostas Amiridis conclude this section with an essay taking as its point of departure the tragic death of Moritz Erhardt, an intern with the Bank of America Merrill Lynch. Interrogating the figure of the graduate, their article engages the emergence of such themes as self-realization and potentiality, and argues that the latter themes can become "dangerous once they are constituted as ideal measures of an unattainable level of performativity...", an argument that opens the possibility of thinking about internships as a training ground for hyper-commitment to work.

The second section of the issue, Internships and Creative Industries, examines internship programs, discourses, and experiences in different sectors and national contexts. Based on fieldwork at advertising agencies in New York City, Christopher Boulton shows that despite the existence of affirmative-action placement programs, racial discrimination persists as social connections linking intern candidates to agency executives and big clients are decisive in determining access to limited internship spots, a dynamic both reflecting and reproducing systemic white privilege in advertising agency settings. Tanner Mirrlees reports on a study of job postings for internships with production companies in the US reality TV industry, finding that employers expect candidates for unpaid internships to be highly skilled and thus prepared to perform actual work-a reality that undermines the intern category altogether. Writing from Italy, Roberto Ciccarelli offers a commentary on the contested deployment of a massive unpaid workforce for the 2015 World's Fair, Expo Milano, a stark instance of the institutionalization of unpaid work that proceeded with the support of major Italian trade unions. Addressing journalism internships in Canada, the next two articles look at how companies and unions struggle to define what is fair, how much (if anything) interns should be paid, and how interns fit into the broader labour economy of journalism. Based on survey and interview research, journalist Marlene Murphy provides a historical account of the development of internships at Canada's national broadcaster, the Canadian Broadcasting Corporation $(\mathrm{CBC})$, and the relations between and among $\mathrm{CBC}$ staff, education institutions, the CBC union, and interns themselves. Errol Salamon documents the pay rates and collective representation for interns at newspapers and magazines in Canada, revealing that organized labour can play contradictory roles, either helping to resist un- or low-paid work, or enshrining un- or underpaid work into collective agreements. Concluding this section is David Lee's article, which shows that in the UK context, the "opportunity" to work for free spills beyond the glitz of creative industries into other sectors, where young people can intern in fast food and retail outlets, for example. Internships and the discourse surrounding them, Lee contends, can be seen as overlapping with neoliberal social welfare reform in general and the turn to "workfare" in particular.

Higher education plays a complicated role in the intern economy. In many jurisdictions, university and college programs provide the only technically legal internship placements, which offer students work experience they want-and in many cases need-to be employable upon graduation. But academic internship programs are often unregulated and poorly managed. Not only do they prime aspiring media and cultural workers for doing whatever it takes to land work, but internship-for-credit programs help sustain employers' offloading of labour costs onto the public and capitalize on students' willingness to pay to work. The third section, Internships and Higher Education, opens with Mara Einstein's analysis of how American universities and colleges use internships as part of their marketing strategies, which push internship programs in a bid to gain a competitive edge in recruitment. Informed by focus groups with student-interns in the gendered field of Public Relations, Michelle Rodino-Colocino and Stephanie Berberick explore how interns occupy a blurred space between being a student and being a worker and identify how internships teach students to "unthink 
exploitation." Ip lam Chong reports on an interview-based study of an internship program offered by his Cultural Studies department at Lingnan University in Hong Kong, exploring the sometimes surprising ways that students select, negotiate, and reflect upon their placements. Drawing on her experience at Western University, Sandra Smeltzer presents a critical model of service learning that is rooted in engagement with community and activist groups. Smeltzer shows that while developing internship placements with public-interest groups is important for community building and students' understanding of themselves as citizens, such relationships are bound up in power dynamics that must be carefully reflected upon and continually negotiated. Shifting focus, Doug Tewksbury urges proponents of critical media literacy to do much more to encourage students to think about work and working conditions in media and cultural industries, including internships. While academic internships tend to be associated with students, Kirsten Forkert and Ana Lopes investigate the under-examined phenomenon of unpaid academic posts in the UK university sector. Forkert and Lopes detail how, in a context of growing public condemnation of unpaid internships, academic activists worked to block these posts.

Internships are in the media spotlight thanks to the spread and impact of advocacy efforts of interns themselves and their allies: interns have turned their communicative capacities to alternative ends, raising awareness about intern exploitation and workplace rights through direct action, creative online protest, and naming-and-shaming intern employers via social media (Cohen and de Peuter 2014). The fourth and final section of the issue, Intern Labour Activism, takes stock of interns' resistance-their strategies, accomplishments, challenges, and potential future directions. Panos Kompatsiaris examines conflicts around internships in art institutions, primarily in the UK, reading this collective political action and the labour discourse surrounding it as in tension with prevailing tendencies marking the identity of the artist in contemporary capitalism. Intern Labor Rights, an activist group that emerged within the Occupy Wall Street movement in New York, reports on recent intern advocacy in the US, reviewing a range of interventions, from legal cases to student organizing, and emphasizing the importance of solidarity between interns and other workers in precarious employment. Next, a pair of articles addresses the politicization of internships in the Canadian province of Ontario, where intern advocacy has involved student activists, progressive lawyers, elected officials, and government regulators. William Webb describes and assesses elements of the intern activism in Ontario, which he thematizes as awareness-raising, legal challenges, and regulatory responses. And Nicole Cohen and Greig de Peuter interview some of the protagonists of intern activism in Ontario, a group of young lawyers and law students with astute perspectives on the possibilities and challenges for transforming the intern economy in the name of greater social and economic justice. This section concludes with a personal story from Vera Weghman about her involvement in a campaign to end the use of unpaid internships at an anti-poverty charitable organization in the UK, highlighting the contradictions lurking within the use of interns in the social sector.

The contributions to this special issue demonstrate that internships are a deeply fraught institution with a growing presence both within and beyond the vaunted creative industries. The accounts in this issue also indicate the extent to which employability is increasingly the primary ideal to which managers of higher education institutions and many students adhere, both parties keenly aware of the competitive environments in which they sell what they have to sell. Articles in this issue nonetheless provide evidence of alternative possibilities for interns and internships. This issue leaves us with many questions that might guide future engaged research: If internships provide many young people with their first encounter with the labour market, then what do internships-and, just as significantly, the process of obtaining an internship-teach students about the values of the dominant social order? If age, class, gender, race, and status are among the intersecting axes of exploitation in the internship system, then how might intern labour activism, and the broader labour movement, respond? If internships are predominately a mechanism that perpetuates inequality in the labour market, then how might internships be governed so that they are a mechanism for combatting inequality? If universities and colleges are one of the few places where interns are aggregated and internships are formalized, then how might academic workers and student unions 
make their places of work and learning a site for mobilizing interns, advancing intern rights, and designing internships differently?

\section{References}

Ashton, Daniel and Caitriona Noonan, eds. 2013. Cultural Work and Higher Education. New York: Palgrave Macmillan.

Attfield, James and Isabelle Couture. 2014. An Investigation into the Status and Implications of Unpaid Internships in Ontario. University of Victoria. Accessed August 24, 2015.

http://dspace.library.uvic.ca/bitstream/handle/1828/5294/Attfield_James_and_Couture_Isabelle_M PA 2014.pdf? sequence $=1$ \&isAllowed $=y$.

Banks, Mark, Rosalind Gill and Stephanie Taylor, eds. 2013. Theorizing Cultural Work: Labour, Continuity and Change in the Cultural and Creative Industries. London: Routledge.

Brooks-Pollock, Tom. 2015. UN Intern "Living in a Tent" David Hyde Admits it was a Stunt to Highlight "Injustice of Unpaid Work." The Independent, August 15. Accessed August 20, 2015. http://www.independent.co.uk/news/world/europe/un-intern-tent-david-hyde-unpaid-stunt-geneva10457021.html.

Carrotworkers' Collective. 2011. Surviving Internships: A Counter-Guide About Surviving Free Labour in the Arts. London: Carrotworkers' Collective.

Chillas, Shiona, Abigail Marks and Laura Galloway. 2015. Learning to Labour: An Evaluation of Internships and Employability in the ICT Sector. New Technology, Work and Employment 30 (1): 1-15.

Cohen, Nicole S. and Greig de Peuter. 2014. Narratives and Counter-Narratives of Unpaid Internships. Paper presented at the seminar Labour in Circulation: Perspectives from Communication and Cultural Studies. York University, Toronto. April 25.

Daniel, Ryan and Leah Daniel. 2013. Enhancing the Transition from Study to Work: Reflections on the Value and Impact of Internships in the Creative and Performing Arts. Arts \& Humanities in Higher Education 12 (2-3): 138-153.

Deuze, Mark. 2007. Media Work. Cambridge: Polity.

Figiel, Joanna. 2012. Work Experience Without Qualities? A Documentary and Critical Account. ephemera 13 (1): 33-52.

Frederick, Jim. 1997. Internment Camp. Baffler 9, 51-59.

Frenette, Alexandre. 2013. Making the Intern Economy: Role and Career Challenges of the Music Industry Intern. Work and Occupations 40 (4): 364-397.

Frenette, Alexandre, Amber D. Dumford, Angie L. Miller, and Steven J. Tepper. 2015. The Internship Divide: The Promise and Challenges of Internships in the Arts. Bloomington, IN: Indiana University and Arizona State University, Strategic National Arts Alumni Project.

Fuchs, Christian. 2014. Digital Labour and Karl Marx. New York: Routledge.

Geobey, Sean. 2013. The Young and the Joblesss: Youth Unemployment in Ontario. Canadian Centre for Policy Alternatives, Ontario.

Gill, Rosalind and Andy Pratt. 2008. In the Social Factory? Immaterial Labour, Precariousness, and Cultural Work. Theory, Culture \& Society 25: 1-30.

Gregg, Melissa. 2011. Work's Intimacy. Cambridge, UK: Polity.

Hope, Sophie and Joanna Figiel. 2012. Intern Culture. Accessed August 20, 2015. http://www.artquest.org.uk/articles/view/intern culture.

Hesmondhalgh, David and Sarah Baker. 2011. Creative Labour: Media Work in Three Cultural Industries. London: Routledge.

Hesmondhalgh, David and Neil Percival. 2014. Unpaid Work in the UK Television and Film Industries: Resistance and Changing Attitudes. European Journal of Communication 29 (2): 188-203.

Huws, Ursula. 2014. Labor in the Global Digital Economy. New York: Monthly Review Press.

Klein, Naomi. 2000. No Logo: Taking Aim at the Brand Bullies. Toronto: Knopf.

Leonard, Pauline, Susan Halford and Katie Bruce. Forthcoming. "The New Degree?" Constructing Internships in the Third Sector. Sociology.

McGrath, Michael. 2015. Olsen Twins' Interns Do Double-Take Over Work Schedule. The Guardian, August 12. Accessed August 20, 2015. http://www.theguardian.com/money/2015/aug/12/marykate-ashley-olsen-twins-intern-lawsuit.

McRobbie, Angela. 2002. From Holloway to Hollywood: Happiness at Work in the New Cultural Economy? In Cultural Economy, edited by Paul du Gay and Michael Pryke, 97-114. London: Sage.

McRobbie, Angela. 2015. Be Creative: Making a Living in the New Culture Industries. Oxford: Wiley.

National Association of Colleges and Employers. 2014. The Class of 2014 Student Survey Report. Bethlehem, PA. National Association of Colleges and Employers. 
Neff, Gina and Giovanni Arata. 2007. The Competitive Privilege of Working for Free: Rethinking the Roles that Interns Play in Communication Industries. Paper presented at the Annual Meeting of the American Sociological Association. Accessed June 19, 2014.

http://citation.allacademic.com/meta/p mla apa research_citation/1/8/3/9/6/p183960 index.html.

Perlin, Ross. 2011. Intern Nation: How to Earn Nothing and Learn Little in the Brave New Economy. London: Verso.

Richards, Dai, dir. 2011. Who Gets the Best Jobs? [Documentary] BBC.

Ross, Andrew. 2000. The Mental Labor Problem. Social Text 63 (18.2): 1-31.

Ross, Andrew. 2009. Nice Work if You Can Get It: Life and Labour in Precarious Times. New York: New York University Press.

Seibert, Sabini and Fiona Wilson. 2013. All Work and No Pay: Consequences of Unpaid Work in the Creative Industries. Work, Employment \& Society 27 (4): 711-721.

Shade, Leslie Regan and Jenna Jacobson. 2015. Hungry for the Job: Gender, Unpaid Internships, and the Creative Industries. The Sociological Review 63 (1): 188-205.

Tokumitsu, Miya. Do What You Love and Other Lies about Success and Happiness. New York: Regan Arts.

Tomlinson, Kathy. 2013. Intern's Death after Overnight Shift Sparks Outcry. CBC News. September 9. Accessed August 20, 2015. http://www.cbc.ca/news/canada/british-columbia/intern-s-death-afterovernight-shift-sparks-outcry-1.1704532.

\section{About the Authors}

Greig de Peuter, Nicole S. Cohen, and Enda Brophy

Greig, Nicole, and Enda collaborate on the project Cultural Workers Organize (culturalworkersorganize.org), which examines cultural and media workers' collective responses to precarity. 


\title{
Media and Cultural Industries Internships: A Thematic Review and Digital Labour Parallels
}

\author{
Thomas F. Corrigan \\ California State University-San Bernardino, San Bernardino, USA, corrigan@csusb.ed
}

\begin{abstract}
This article reviews existing research on the motivations and experiences of interns in media and cultural industries. Digital labour theories are used to organize and make sense of the existing internship literature. Throughout the article, parallels are also drawn between the experiences of interns and those of digital creative labourers-both professionals and peer producers. Three key themes are identified within the internship literature: 1) interns derive satisfaction from work they consider meaningful, particularly hands-on work executed under the training and trust of effective supervisors; 2) interns see their work as future-oriented investments in their skills, professional networks, and personal brands; and 3) the ambiguity and professional necessity of media and cultural industries internships make them fertile ground for exploitation and self-exploitation. In conclusion, I argue that attentiveness to meaning, temporality, and ambiguity will be essential to future critical investigations of internships.
\end{abstract}

Keywords: media and cultural industries, internships, motivations and experiences of interns, digital labour

Acknowledgement: Thank you to the reviewers and special issue editors for their detailed feedback.

Ross Perlin's Intern Nation (2012) details an ingrained contemporary internship economy in which students "earn nothing and learn little"; however, many interns see this systemrelatively new as it is - as a valuable and necessary route to employment, particularly in media and cultural industries. Interns' motivations and understandings of their experiences are fundamental to the perpetuation of internships. After all, many students are not paid during their media and cultural industries internships (Jenkins 2003), so they must participate in these arrangements for reasons beyond an immediate paycheck.

This article offers a thematic review of scholarship on the motivations and experiences of interns working in media and cultural industries. Researchers often note a dearth of scholarly attention to interns' experiences (e.g., Daugherty 2011; Neff and Arata 2007); however, more literature exists than is typically acknowledged, and what does exist is instructive. Previous findings show that students evaluate their internships quite favourably. This is especially so when supervisors train and trust them to execute hands-on work, which they consider meaningful. Students also view internships as a means of increasing their future employment prospects through skill acquisition, expansion of professional networks, and crafting a personal brand. With few alternatives for gaining crucial work experience and networking, though, internships in the media and cultural industries are fertile ground for exploitation and selfexploitation. Many internships are unpaid, menial work is not uncommon, and supervisors can be indifferent to their interns' experiences. What an internship should entail is ambiguous, so interns seek to secure more meaningful, professionally promising work responsibilities by demonstrating their initiative and enthusiasm-even for menial tasks. Interns also find a silver lining in the most disappointing of circumstances.

To construct this review of the existing internship literature, this article uses digital creative labour-both professional and peer production-as a point of comparison. As Perlin (2012) writes, "The position of interns is not unlike that of many journalists, musicians, and filmmakers, who are now expected to work online for no pay as a way to boost their portfolios" (125). The parallels between internships and digital creative labour are not perfectly congruent; however, both groups do engage in complex and contradictory labour processes that are marked by personal and social pleasures, the pursuit of (potential) employment prospects, 
and (self-)exploitation. This article does not draw these parallels simply for comparison's sake, though: the theorizations of digital labour scholars provide fruitful frameworks for understanding interns' motivations and experiences. Whereas existing internship research tends to pursue "administrative" goals (e.g., assessing and improving intern satisfaction), many digital labour scholars take a more "critical" approach (Lazarsfeld 1941); they interrogate the ways in which digital labour reproduces or challenges power asymmetries. Thus, this article uses the critical frameworks of digital labour theorists to organize and make sense of the more administrative findings of existing internship research. Ultimately, I argue that the emerging area of critical internship studies must account for the meaning, temporality, and ambiguity of internships.

Before undertaking this analysis, the following section provides a brief overview of digital labour scholarship. I then explain my approach to thematically analyzing the existing internship research, and I offer a few cautionary notes about that literature.

\section{Delimiting Digital Creative Labour}

This article uses theories of digital creative labour to organize and make sense of interns' motivations and experiences; however, what is and is not "digital labour" is a matter of considerable debate (Fuchs and Sandoval 2014; Huws 2013; Scholz 2013). One debate concerns the range of productive processes classified as digital labour. The symbolic work of graphic designers, online journalists, transmedia storytellers, and other digital "creatives" certainly deserves attention. Their involvement in the "communication of experience through symbolic production" means that these labourers have an unusual capacity to shape society through information, entertainment, and persuasion (Hesmondhalgh and Baker 2011, 60-61). Alternatively, some scholars argue for conceptions of digital labour that account for a wider range of productive roles along the digital value chain (Fuchs and Sandoval 2014; Mosco and McKercher 2008). Slaves mining resources for smartphones, factory workers assembling those phones, software project managers working on app rollout, and telecommunications workers upgrading cell towers: is all this work not digital labour?

Digital media's interactivity also means that media consumers are increasingly producers, too, expanding the universe of public symbol-creators from the professional creatives just noted to countless "prosumers" (Ritzer and Jurgenson 2010) and "pro-ams" (Leadbeater and Miller 2004). Most digital media users engage in creative production for the fun of it (Arvidsson 2008), but that does not stop corporations from trying to monetize their creative work or the audience attention it generates (Baker 2008; Murdock 2011; Zwick, Bonsu and Darmody 2008). Our clicks, searches, purchases, and posts also produce marketing data that are valuable to web firms and corporate advertisers (Turow 2011). These productive activities may not be "labour" in its "quintessential," waged form (Huws 2013); however, the commercial appropriation and monetization of prosumers' content, audience attention, and marketing data still make "labour" a useful concept for understanding digital media users' relationships to digital capitalism (Andrejevic 2009; Cohen 2008; Fuchs 2012).

A second set of debates concerns the lived experience of digital labour. People use digital tools to collaboratively code software, write about sports teams, and edit countless Wikipedia entries, among a host of other "peer production" activities (Benkler and Nissenbaum 2006). Should this production-carried out primarily for personal and social pleasures rather than pay-be regarded as "labour" in the same way a professional software coder or journalist's work is? (Or, for that matter, a factory worker assembling smartphones?) On the one hand, this "free labor" (Terranova 2000) is consistent with Marxist models of capitalist value creation: in harnessing peer production online, corporations can avoid paying creators for the full value such activity produces, driving capital accumulation and, ultimately, class antagonisms. As George Ritzer and Nathan Jurgenson (2010) write, "From the capitalist's point of view ... the only thing better than a low-paid worker is someone (the consumer as prosumer) who does the work for no pay at all" (26). On the other hand, Mark Andrejevic (2009) points out that this digital labour is also "free" in that it is "freely given, endowed with a sense of autonomy" (416). People engage in peer production for the pleasure of creating on their own terms 
in a community of others who share their interests (Arvidsson 2008; Shirky 2010). These freely given, pleasurable production experiences clash with Marxist formulations of labour exploitation as coercive and alienating. And these contradictions have led to novel theorizing, including the concepts of "playbour," or the fusion of play and labour (Kücklich 2005), and the pro-am, remembering that "amateur" derives from amor. Similarly, pleasure and (self-)exploitation also co-mingle in professional digital creative work (Hesmondhalgh and Baker 2011; Ross 2003; Neff 2012).

While acknowledging digital labour's contested status, in this article I selectively draw on scholarly examinations of a subset of digital labour: creative, public symbol-making carried out in professional and peer production contexts. The labour of miners, factory workers, and others not directly involved in crafting public, symbolic texts is not considered here. Further, this article only examines intentional creative production; digital media users' unintended production of valuable audience attention or marketing data is not considered here. Why focus on this creative, intentional, and public subset of digital labour? Because, as I explain later, these digital creatives constantly navigate tensions between personal fulfillment, future career aspirations, and (self-)exploitation. In this respect, digital creatives offer fruitful points of comparison to interns in the media and cultural industries.

\section{Methodological Considerations}

In my survey of the literature on the motivations and experiences of media and cultural industries interns, I specifically examine interns' experiences in mass media, the arts, journalism, public relations, and advertising -industries and institutions that all produce and circulate texts for public consumption. Previous research has attended more to the internship experiences of journalism, public relations, and advertising students and less to those in entertainment media and the arts; however, internship experiences across these industries and institutions are consistent enough to consider together.

To compose this thematic survey, I began by reviewing the relevant internship literature and identifying salient themes and sub-themes, such as "hands-on experience," "networking," "menial work," and "initiative." I had no illusions that these themes emerged from the data (as some grounded theorists claim). Instead, my interest in comparing internships to digital labour shaped my identification and understanding of salient themes. As I read, I reflected on theoretical constructs from the digital labour scholarship that resonated with interns' experiences, including socially recognized self-realization, hope labour, venture labour, aspirational labour, self-branding, and self-exploitation. These theoretical constructs helped me organize and make sense of the key themes I generated from the internship literature.

Ultimately, I organized this review around three key processes. First, I examine the nonmonetary motivations of interns and digital creative labourers. Both derive pleasure from carrying out work they consider meaningful and gaining approval from important others (whether peers, consumers, or supervisors). Second, I discuss the temporal logic through which interns and digital creatives rationalize their present work as future-oriented investments. These investments operate on the assumption that "experience + exposure = employment opportunities." Third, I reflect on the exploitative and self-exploitative potential of internships and digital creative labour. Both groups report actively pouring themselves into their work, even if that work can, at times, be menial, demanding, and offer little-to-no pay. Such selfexploitation may seem a choice; however, oversupplied labour markets make this fertile ground for coercion, particularly for those early in their career trajectories.

Given this review's reliance on existing internship research, it is important to highlight some of that literature's characteristics and limitations. With the exception of a few recent, critical interventions (e.g., Neff and Arata 2007, Frenette 2013; Siebert and Wilson 2013), I was struck by interns' glowing reviews of their experiences (e.g., Beard and Morton 1999; Beebe, Blaylock and Sweetser 2009; Getz 2002; Gugerty 2011; Hilt and Lipschultz 1996; Schambach and Dirks 2002). This may be explained, in part, as a function of how researchers gather internship accounts. Faculty often collect survey, interview, or focus group data from interns they supervise (e.g., Beard 1997; Beard and Morton 1999; Forde and Meadows 
2011; Schambach and Dirks 2002), and some also rely on interns' journals or site supervisors' evaluations (e.g., Barber 1987; Forde and Meadows 2011; Gugerty 2011; Getz 2002). It is unsurprising that such approaches produce favourable accounts of internships; students, faculty, and employers can each have vested interests in positively portraying these experiences. Further, existing internship research often pursues "administrative" rather than "critical" goals (Lazarsfeld 1941). That is, researchers aim to assess and improve student satisfaction with internship experiences, rather than interrogate the role of internships in reproducing or challenging power asymmetries (e.g., Beard and Morton 1999; Beebe, Blaylock and Sweetser 2009; Daugherty 2011). Students may indeed be satisfied with their internships; however, administrative goals can also blind researchers to the more troubling dynamics of internships. In fact, some literature reviews highlight the potential benefits of internships while giving little-to-no attention to their costs (e.g., Beard and Morton 1999; Schambach and Dirks 2002). Finally, many studies make a questionable leap in suggesting that students' assessments of internships are evidence of their value. Coll and Kalnins (2009) explain that while it is common to study interns' perceptions of personal and professional growth, those perceptions are not necessarily evidence of actual growth (e.g., skill development, crystallization of personal and professional values, employability).

These issues notwithstanding, the existing internship literature provides insightful accounts of students' experiences (or at least students' perception of their internships, as gathered by their faculty supervisors). The following review synthesizes this literature, draws comparisons between internships and digital creative labour, and uses digital labour theories to organize and make sense of interns' reported experiences.

\section{Internships as Meaningful Work}

Ursula Huws (2013) describes labour in its "quintessential form" as activity "carried out directly for a capitalist employer by a worker who is dependent on this labour for subsistence" (84). It is the worker's dependence on money to survive that allows capitalists to derive more value from one's labour time than wages account for, driving both profits and class antagonisms. Much digital creative labour operates on these terms; waged and salaried creatives work so they can earn money to subsist. Digital media have also contributed to a boom in freelance creative work, which is executed on a piecework basis, but is no less exploitative (Cohen 2012).

That said, creative labourers (digital or otherwise) often undertake their work for reasons over and above a paycheck. With its focus on symbol-making and the communication of experience, this work is often pleasurable, satisfying intrinsic motivations for creativity and identification. They also typically enjoy levels of creative and professional autonomy rarely seen in other forms of work (Gill 2002; Hesmondhalgh and Baker 2011; Neff 2012; Ross 2003). Indeed, firms in the media and cultural industries recognize that a degree of autonomy for creative workers is necessary if they are to produce texts that will satisfy consumers' fickle tastes and cultural expectations about creative independence (Hesmondhalgh 2007; Ryan 1992). Digital media have intensified and complicated these processes (Gill 2002; Neff 2012; Ross 2003). Andrew Ross (2003) explains how digital media consultancies in New York City's Silicon Alley attracted talent and piqued their creative urges through fun, free, collaborative, and exciting "no collar" work that, at times, looked more like play. This work came with occupational hazards, however, including a tendency toward self-exploitation. In exchange, though, digital creatives exercised a degree of autonomy conducive with the pursuit of creativity, authenticity, and productivity. In these ways, digital creative labour promises opportunities to "do what you love"-an orientation to work that Miya Tokumitsu (2014) calls the "unofficial work mantra of our time." Cultural representations of digital labour reinforce this mythology (Gill 2002; Neff, Wissinger and Zukin 2005).

Creativity's pleasures are also pronounced in digital peer production. In countless online communities, individuals come together to collaboratively produce and freely distribute socially useful products and services, such as encyclopedia entries, software, and citizenjournalism. Contributors do so primarily for personal and social reasons rather than financial 
compensation (Benkler 2006; Shirky 2010). This volunteerism satisfies creators' personal desires to autonomously pursue mastery in a given area. Social motivations-particularly peer recognition-tend to reinforce those personal motivations (Arvidsson 2008; Shirky 2010). As Adam Arvidsson (2008) says of peer producers, "It is not enough for me to know that [I have done excellent work]. I need a community of people whom I recognize as my peers to recognize this fact in turn" (332). Arvidsson refers to these mutually reinforcing social and personal motivations as "socially recognized self-realization" (ibid., 332), and numerous studies have identified this as a primary motivation for digital peer producers (e.g., Daugherty, Eastin and Bright 2008; Kuehn and Corrigan 2013; Oreg and Nov 2008; Shao 2009). Corporations that seek to harness digital peer producers' passion and creativity must also acknowledge and work to satisfy these motivations (Baker 2008; Murdock 2011). As Detlev Zwick et al. (2008) explain, "the ideological recruitment of consumers into productive co-creation relationships hinges on accommodating consumers' needs for recognition, freedom, and agency" (185).

Like professional creatives, media and cultural industries interns do want to be paid while completing their internships (Beebe, Blaylock and Sweetser 2009; Filak and Pritchard 2008); however, students also undertake internships for extra-monetary reasons. Catherine Gugerty (2011) argues that interns engage in a constant pursuit of "meaningful work," and students assign particular significance to practical experiences that are both consequential and afford a degree of autonomy and responsibility (Beard 1997; Daugherty 2011; Getz 2002; Gugerty 2011; Siebert and Wilson 2013).

First, students value internships that are practical in that they provide opportunities for "hands-on" work experiences in "real world" professional contexts (Beard 1997; Beebe, Blaylock and Sweetser 2009; Daniel and Daniel 2013; Daugherty 2011; Filak and Pritchard 2008; Getz 2002; Gugerty 2011; Hilt and Lipschultz 1996; Schambach and Dirks 2002; Siebert and Wilson 2013). These phrases_-"hands-on" and "real world"-signify interns' elevation of "authentic" work experiences over other forms of professional development, including classroom learning (which is not the "real world") and workplace observation (which may be part of an internship, but is not "hands-on"). It is worth noting that "authenticity" and "the real" are sought-after aesthetics in digital creative labour, from reality TV and fashion magazines to blogs and YouTube (Duffy 2013, 2015; Hesmondhalgh and Baker 2011). Cynically, interns' emphases on "real world" work can be seen (like reality TV) as the shrewd marketing of authenticity; such experiences signal one's genuine workplace-readiness to potential employers.

There is good reason to believe, though, that interns' emphasis on authenticity is more than just a means to an end. Existing research indicates that media and cultural industries interns associate hands-on learning with greater levels of self-esteem and confidencefeelings that are accentuated when they have the time and training to see a project through to fruition (Beard 1997; Daugherty 2011; Forde and Meadows 2011; Gugerty, 2011; Siebert and Wilson 2013). In other words, interns may achieve a sense of self-realization from the process and end-product of their "real world" work. To the extent that interns self-select into organizations that align with their personal passions and professional aspirations, this should not be surprising. Like digital creative labourers, they are pursuing mastery in their chosen field-even if that pursuit is at an introductory phase.

If there is a disjuncture here between the potential for self-realization in digital creative labour compared to internships, it is in the former's emphasis on the communication of experience and the latter's emphasis on learning-by-doing. Digital creative labour does present relatively unique possibilities for creativity and identification; however, learning can also be exciting and satisfying. In fact, journalists and documentary filmmakers report that learning about their subject matter can be deeply gratifying (Hesmondhalgh and Baker 2011). While acknowledging the potential pitfall of mistaking students' perceptions for actual learning, media and cultural industries interns do report extensive learning from their internships. In fact, it is not uncommon for students to describe their internships as the most important learning experience in their college career, and some go as far as to say it trumps their college learning, cumulatively (Gugerty 2011; Moore 2000). To the extent that learning-by-doing can be 
intrinsically satisfying, these reports would indicate substantial pleasures from interns' work experiences.

Second, media and cultural industries interns value effective on-the-job supervision (Beard 1997; Beard and Morton 1999; Beebe, Blaylock and Sweetser 2009; Daugherty 2011; Gugerty 2011). Fred Beard and Linda Morton (1999) found that supervision quality was the "most important single predictor" of what advertising and public relations students consider a "good internship" (50). Like their emphasis on authenticity, interns' attention to supervision can be seen as a shrewd calculation. Supervisors are (potentially) central to interns' future employment. They can provide access to marketable training and professional networks, and they can vouch for an intern's employability or even extend a job offer.

Interns' interactions with their supervisors can be meaningful in their own right, though. Gugerty (2011) explains that "site supervisors who provide interns with specific directions and examples, some autonomy and independence, and constructive feedback influence positive internship outcomes" (68). Much as digital creative labourers derive satisfaction from the autonomous pursuit of mastery (Arvidsson 2008; Shirky 2010), supervisors that can strike this balance between training (mastery) and trust (autonomy) stand to maximize the selfrealization their interns derive from hands-on work experiences. Take, for instance, Emma Daugherty's (2011) theme of "willingness" in interns' descriptions of "good site supervisors." Such supervisors are "willing to help the intern get the most out of the experience" and "willing to let you try and fail and learn" (473). Furthermore, supervisors that provide feedback offer more than training; they are also an intern's "audience." When interns execute meaningful, hands-on work, they turn to their supervisors for approval and feedback-for social recognition. In peer production, Clay Shirky (2010) describes a "feedback loop" between social recognition (whether from consumers or peers) and the personal satisfactions of creative processes. Social recognition makes creativity more satisfying. Similarly, supervisor feedback may amplify the meaningfulness of interns' hands-on work experiences.

There are practical limits to supervisors' "willingness," though. Professional standards and organizational imperatives mean that supervisors only have so much time for training and flexibility for failure (Frenette 2013; Daugherty 2011). These dynamics bear similarity to the "relative autonomy" long institutionalized in professional creative labour (Hesmondhalgh 2007; Ryan 1992) and celebrated by many digital creatives (Gill 2002; Neff 2012; Ross 2003). In these fields, a degree of autonomy for workers is commonly seen as a necessary condition for producing work that satisfies one's creative urges and that resonates with audiences-whether consumers or peers; however, that autonomy is ultimately constrained by management's control over productivity targets and the eventual marketing of creative works. Likewise, interns may pursue and derive satisfaction from hands-on work under effective supervision, but those processes unfold within an organizational context that can constrain practical opportunities for training and trust.

In short, people like getting better at things they care about on their own terms and receiving social recognition from important others for doing so. Both digital creative labour and internships offer opportunities for satisfying these desires. Socially recognized self-realization does not fully explain the motivations and experiences of either digital creatives or interns, though. Students also participate in internships as a means of positioning themselves for future employment opportunities in media and cultural industries. The following section looks at both internships and digital creative labour as future-oriented investments.

\section{Internships as Braggable Investments}

Digital creative labourers derive pleasure from creating and sharing for its own sake. In the Web 2.0 era, though, people increasingly view their voluntary creative endeavors as "investments" in experience and exposure that may translate, one day, into paid employment (Brabham 2008; Deuze 2007; Kücklich 2005; Postigo 2007). Success in this model hinges on one's ability to build a "networked reputation" (Deuze 2007). For instance, some SB Nation sports bloggers and Yelp! consumer reviewers told Kathleen Kuehn and myself (Kuehn and Corrigan 2013) that they see their work as a means of gaining creative experience, develop- 
ing their portfolios, building an audience for their work, and making strategic industry connections. Paid opportunities would follow-they hoped. We refer to these investments as "hope labor"- "un- or under-compensated work carried out in the present, often for experience or exposure, in the hope that future employment opportunities may follow" (ibid., 9). Similarly, Brooke Duffy (2015) found that fashion bloggers engage in "aspirational labor," "a highly gendered, forward-looking, and entrepreneurial enactment of creativity that ... hold[s] the promise of social and economic capital" (1).

This investment logic is not restricted to peer production. The high supply of aspiring professional creators has long contributed to precarity in cultural labour markets (Miège 1989). And in recent decades, neoliberal policies, corporate flexible accumulation strategies, and digital technologies have all contributed to greater employment uncertainty for creative workers and a shift of risk to individuals (Gill 2002; Harvey 2006; Hearn 2008; Neff 2012). Amid the precarity of their "project-based work" (Gill 2002), creatives organize themselves into "portfolio careers" (Flew and Cunningham 2010), where one's track record and industry connections are leaned on to secure employment on the next project (Ursell 2000; McRobbie 2002). The professional importance of social networks has also given rise to highly individual and instrumental social relations that Andreas Wittel (2001) calls "network sociality." This is pronounced in digital creative labour. During the volatile late-1990s dot-com boom, new media professionals in New York City's Silicon Alley managed risk by investing in themselves and the companies where they worked, a process Gina Neff (2012) theorizes as "venture labor." Workers deferred compensation through stock options, spent off-hours time at industry networking events, and sought to develop or hone their skills. They made these investments in an effort to sustain, propel, and capitalize on their companies' (potential) successes, but also as a hedge against industry uncertainty. Should one's specific company fail, Silicon Alley workers saw their skills (i.e., experience) and networks (i.e., exposure) as assets that would hasten their transition to another firm.

Students also rationalize their (often unpaid) internships in media and cultural industries as future-oriented investments, connecting their internship experiences to employment aspirations (Daniel and Daniel 2013; Daugherty 2011; Frenette 2013; Getz 2002; Gugerty 2011; Neff and Arata 2007; Siebert and Wilson 2013). For example, Daugherty (2011) found that public relations interns seek both "internal immediate rewards" and "external future rewards":

The internal immediate rewards included skill acquisition (writing, editing, professional experience in social media, production of printed materials), obtaining real-world experience, getting class credit to graduate, discovering if the field is for them, and gaining a better understanding of the field. The external future rewards were to make contacts to get a good job, get hired by their site supervisor, and develop a portfolio or work samples that will help them get a position. (427)

This excerpt illustrates that students pursue internships for meaningful, extra-monetary reasons (e.g., "real-world experience," "understanding of the field") and as future-oriented investments in their employment prospects (e.g., to "get a good job"). Moreover, the excerpt demonstrates that-like hope, aspirational, and venture labourers-interns employ an "experience + exposure $=$ employment opportunities" calculus in rationalizing their internships. "Work samples" and "contacts" were presumed to lead to job opportunities. On the face of it, this investment logic is compelling. Given the tendency toward portfolio careers in media and cultural industries, aspiring creatives face a "career progression paradox" (O'Mahony and Bechky 2006, 919); they need a track record and industry connections to get work, but they need work experience to acquire these assets. If one hopes to get and keep work in the media and cultural industries, it may make sense to undertake an internship where, even if unpaid, one can develop the skills and professionalism employers desire, while constructing a resume or portfolio that evinces those qualities. Moreover, through those experiences, one can get exposure to an office or supervisor that could potentially lead to a job offer at that organization or to work at another organization via networking and professional recommendations. 
Interns' characterization of their experience as "something you can put on your resume" (Gugerty 2011,30 ) demonstrates that such experiences have an important discursive quality. Students see strategic marketing value in what internships can "say" or "signal" to potential employers about their employability (Daugherty 2011; Frenette 2013; Getz 2002; Gugerty 2011). In this manner, internships function as a form of "self-branding" (Hearn 2008)-the process through which individuals construct and project a professional image to colleagues, clients, and current and future employers. Alison Hearn (2008) has argued that in flexible, networked economies, individuals strategically "brand" themselves "to rhetorically persuade employers of [their] competitive viability" (214). Again, a temporal, investment logic is at play. The self-branding process is "purely rhetorical; its goal is to produce cultural value and, potentially, material profit" (ibid.,198). Personal branding "gurus" such as Stedman Graham, Tom Peters, and Peter Montoya encourage individuals to think of themselves as "products" to be marketed to their "customers" (i.e., potential employers or clients). Aspiring professionals identify their most valuable skills and attributes and then communicate those "braggables" to their "target market" (ibid., 205).

Internships can be thought of as proxies for one's "braggable" skills and attributes. As one intern told Gugerty (2011), "I feel like people are impressed when I tell them I'm interning at [agency name]" (31). Here, the specific activities of an internship are not as important as the message that an internship conveys about the intern to potential future employers. As Perlin (2012) explains, internships function as a "signaling" mechanism for employers: "even if their exact content remains murky, [internships] signal a go-getter applicant, already fluent in office culture (and possibly in industry culture), able to take on a new role immediately with less time and investment from the firm" (182). Experimental research underscores the importance firms place on internship experiences. When sent the same resumes with and without internships listed, employers were significantly more likely to take positive action on an application (e.g., holding onto a resume, initiating an interview) when the applicant had completed an internship (Taylor 1988; Nunley, Pugh, Romero and Seals 2014). As internships become more common among graduates in media and cultural industries some students are stringing together multiple internships to distinguish their applications, branding themselves as the gogetters of the go-getters (Frenette 2013; Neidorf 2008).

Internships are not just a means of developing skills and professionalism or getting one's foot in the door and networking. They are also a means of discursively presenting one's self as an employable professional. There is a risk in this characterization, though. As "investments" and "opportunities," internships sound like a "smart move" undertaken by enterprising students, which implies that interning is an individual choice. But to the extent that internships are perceived as necessary for securing work in the media and cultural industries, that choice may be illusory, particularly for students without the resources to participate in unpaid internships. Students' lack of choice in pursuing internships and ambiguity about what internships should entail open the door to exploitation and self-exploitation.

\section{Internships as Ambiguous (Self-)Exploitation}

There is much debate over whether, and how, digital creative labour is "exploited" (Andrejevic 2009, 2012; Cohen 2012; Hesmondhalgh 2010; Hesmondhalgh and Baker 2011; Fish and Srinivasan 2012). Following Holmstrom (1997), Andrejevic (2012) describes capitalist exploitation as a two-part process, entailing (1) the extraction of surplus value through coerced labour and (2) a loss of control over one's productive activity (i.e., alienation). With respect to coercion, professional creatives depend on money from wages (or piecework payments or royalties) for their subsistence. This dependency produces a relationship wherein capitalists can pay workers less in wages than the full value their labour creates-a dynamic that is exacerbated by the excess supply of aspiring creatives. With respect to control, though, professional creatives can enjoy autonomy at work rarely seen among other labourers, such as factory workers (Hesmondhalgh 2007; Ryan 1992). This measure of freedom and independence is always relative and, ultimately, revocable through termination (Garnham 2006); however, this autonomy, paired with possibilities for creativity and identifi- 
cation, means that creative labourers can experience pleasures at work that are at odds with conventional notions of alienation and exploitation (Hesmondhalgh and Baker 2011).

Digital creative labour is no workers' paradise, though (Gill 2002; Neff 2012; Ross 2003). Amid this work's self-directed pleasures and relative autonomy, digital creative labourers can engage in "self-exploitation"- "the worker drives herself or himself harder and harder in order to achieve excellence, further status and perhaps even to maintain the very freedom they have struggled to achieve in the first place" (Hesmondhalgh and Baker 2011, 226). Ross (2003) notes that Silicon Alley's "no collar" workers integrated the art world's "sacrificial labor" and bohemian lifestyle into commercial contexts, working extraordinary hours in sub-par conditions for deferred compensation while dispensing with any semblance of work-life balance. Hesmondhalgh and Baker $(2011,227)$ explain that creative labourers' "special bond" with their work and the "starving artist" myth make them particularly susceptible to such selfexploitation. In short, digital creatives may enjoy a degree of independence, but their labour is still coerced, and their pursuit of autonomy and creative pleasures may manifest as selfexploitation.

Whether or not digital peer production is exploitative is a murkier question. Tiziana Terranova (2000) describes online free labour as "simultaneously voluntarily given and unwaged, enjoyed and exploited" (74). As a labour of love-and perhaps as a route to satisfying future employment-it is not uncommon for peer producers to pour extraordinary time and effort into their creative endeavours. Web firms and marketers actively seek to appropriate those labours for commercial purposes (Baker 2008; Murdock 2011; Zwick et al. 2008); however, the appropriation of free labour is not necessarily exploitative (Andrejevic 2009; Hesmondhalgh 2010; Huws 2013). Most peer producers are not dependent on compensation from these creative labours for subsistence, and, as a labour of love, most would continue this work even if never paid. Further, peer producers typically enjoy wide creative latitude, as this is often the best way to maximize their time and effort absent the threat of termination (Corrigan 2012; Zwick et al. 2008). Thus, commercial firms do appropriate peer producers' unpaid creative labour, but not necessarily under the coercive, alienating dynamics of direct exploitation.

On the question of exploitation, internships appear, at first glance, to be more akin to digital peer production than professional creative labour. As long as an internship is not a graduation requirement, students can always choose not to participate. In fact, when one adds up costs for gas, tuition, and foregone compensation from a part-time job, participating in an internship may actually make subsistence more difficult in the short-run, especially if the internship is unpaid. Yet, if internships are all but necessary for entry into media and cultural industries careers, then the potential for exploitation is very real. Jim Frederick (1997) argues that the glamour and desirability of media and cultural industries work makes these firms hotbeds for intern exploitation. Indeed, the career information service Vault reports that unpaid internships are concentrated in political, media, and cultural industries (Jenkins 2003). Some internship supervisors admit that an important, if not primary, impetus for taking on interns is to get "free labour" or "extra hands" to relieve their individual or organizational workloads (Beard 1997; Frenette 2013; Siebert and Wilson 2013). Faced with few good options, arts interns state that they are "prepared to work up to a thousand hours for free to 'ingratiate themselves with the industry,' 'get their face noticed,' or 'get ahead'" (Siebert and Wilson 2013, 715). If experience and exposure are what interns are "paid" in, and their longrun subsistence as creatives necessitates acquisition of these resources, then we can see their unpaid or under-paid labour as the product of coercion.

The counter-argument is that learning is the basic rationale for internships rather than payment or even enhancing one's job prospects. This argument presumes that interns are learning something, though. Students do ascribe particular value to internships that offer meaningful, hands-on experiences, and effective supervision; however, not all internships deliver on this potential. Some interns describe their supervisors and other employees as "indifferent," "disinterested," and "unwilling" (Daniel and Daniel 2013; Daugherty 2011; Frenette 2013; Forde and Meadows 2011; Gugerty 2011; Siebert and Wilson 2013). Supervisors often expect interns to perform at a high level upon arrival. Others approach interns with a 
degree of "presumed incompetence" (Frenette 2013) - an assumption about interns in popular culture representations. Either way, supervisors complain about being too busy to spend time and energy training and mentoring interns that may only be around for a few months. And they also express concerns about assigning important work to interns with limited experience (Daniel and Daniel 2013; Frenette 2013; Daugherty 2011; Siebert and Wilson 2013).

Whether a function of practical workplace constraints or cultural assumptions about interns, some supervisors prefer that their interns observe rather than execute work, and what work supervisors do assign to interns can be menial (Barber 1987; Beard 1997; Daugherty 2011; Daniel and Daniel 2013; Frenette 2013; Getz 2002; Siebert and Wilson 2013). One music industry employee bluntly told Alexandre Frenette (2013) that interns were assigned "shit work" that needed to "get done." Susan Barber (1987) analyzed site supervisors' evaluation forms and found that interns most frequently executed "desk work," including "research," "administrative/clerical" work, and "client communication," such as answering phones. Interns also face the all-too-common problem of having nothing to do (Beard 1997; Daugherty 2011; Frenette 2013; Gugerty 2011). To try to keep interns busy, some supervisors assign long-term projects and "to-do" lists, but this often results in only more "busy work" (Beard 1997; Frenette 2013; Gugerty 2011). Interns' reports of menial work and indifferent/unwilling supervisors suggest that they are not just coerced into unpaid or under-paid labour, but that they can also face an alienating loss of control over their work-exploitation's second criteria. Indeed, some public relations interns reported that they "felt powerless to get enough work and experience" and "to be assigned meaningful tasks" (Daugherty 2011, 472).

Interns report dealing with this powerlessness in one of two ways. First, to break out of the cycle of downtime and menial tasks, interns are presented with a "vague promise" (Frenette 2013): should they perform mundane tasks well, they could expect more meaningful work and responsibility in the future. In other words, interns are encouraged to self-exploit: to assign duties to themselves, to ask for more tasks, or to pitch work ideas to supervisors (ibid.). Expectations that interns be "proactive," show "initiative," and have a "positive attitude" appear regularly in the accounts of interns and their supervisors (Beard 1997; Daniel and Daniel 2013; Daugherty 2011; Frenette 2013; Gugerty 2011; Forde and Meadows 2011; Frenette 2013; Neff and Arata 2012). There is a discursive component to these processes. Drawing on Michael Hardt and Antonio Negri's (2000) concept of "affective labor," Gina Neff and Giovanni Arata (2012) call interns' demonstrations of initiative "performative passion"- "displays of enthusiasm for the tasks at hand-even mundane ones-and the savvy to figure out which tasks to undertake without supervision" (14).

The second tactic interns use to deal with their powerlessness is assigning meaning and value to otherwise menial work (Beard 1997; Forde and Meadows 2011; Getz 2002). As Gugerty (2011) explains, "The differentiation between meaningful and menial work was often blurred in students' minds, confused by their desire to feel productive and appreciated" (55). With photocopying and fetching coffee as the low bar, interns can find a silver lining in nearly anything they do. Sometimes this is accomplished by elevating the importance of menial tasks. As one intern bragged to Gugerty (2011), "I sat at the front desk and everyone had to come through me" (57-58). In other cases, students ascribe a deeper significance to otherwise disappointing experiences; the internship offered a window on the "real world," a test of one's determination, or insight that a particular field isn't for them (Forde and Meadows 2011; Getz 2002). On this basis, John Getz (2002) argues that "even a miserable internship has its lessons to teach"; however, Perlin (2012) cautions against taking this line of thinking too far: "many educators have never seen an internship they didn't like-one supposedly learns as much from terrible experiences as from good ones" (94).

Frenette (2013) and Perlin (2012) both argue that interns' experiences are deeply ambiguous. Much as work and play are often intertwined in digital creative labour, internships operate somewhere between education and employment, the present and future, and monetary and non-monetary forms of compensation. In this ambiguous, "elastic role"-with multiple, competing interpretations about what interns should do and achieve-interns assume responsibility for making the most of the experience (Frenette 2013). But interns do not control access to the meaningful, hands-on experiences that they value and that may be important 
to their future employment prospects-their supervisors do. This combination of ambiguity and dependency makes internships fertile ground for exploitation and self-exploitation. Acts of initiative and performative passion-even for menial tasks—provide interns with a sense of control and may persuade a supervisor to assign more meaningful work; however, what appears an autonomous choice can mask the internship's exploitative relations of coercion and alienation. Media and cultural industries interns may have little choice but to undertake menial tasks or to invest meaning in the menial: entry into their chosen field may depend on that internship.

\section{Conclusion: Meaning, Temporality, and Ambiguity}

In this article, I provided a thematic review of the scholarly literature on the motivations and experiences of media and cultural industries interns. To summarize, students generally report positive internship experiences, and they consider internships particularly meaningful when supervisors provide practical training and trust interns to execute hands-on work. Students also undertake internships as future-oriented investments in their skills, professional networks, and personal brands. This makes sense, as work experience and networking are increasingly prerequisites for employment in these popular industries. But this dependency, paired with ambiguity about what internships should entail, exposes interns to exploitation and self-exploitation. Unpaid, menial, and poorly supervised internships do occur. To earn supervisors' trust and access to more meaningful, professionally promising work responsibilities, interns are expected to demonstrate initiative and perform menial tasks with passion. Or, interns simply invest meaning in menial tasks.

This article juxtaposed the motivations and experiences of media and cultural industries interns with those of digital creative labourers-both professionals and peer producers. Interns place greater emphasis on learning than digital creatives do; however, both groups derive satisfaction from developing their skills under conditions of relative autonomy and from receiving social recognition from an audience of important others (whether customers, peers, or supervisors). Interns and digital creative labourers both also view their work as futureoriented investments, and they make those investments under the assumption that "experience + exposure $=$ employment opportunities." Finally, both groups operate under conditions conducive to exploitation and self-exploitation. They are dependent on work experience and networking to launch and propel their careers, yet this coercive potential is often masked by participants' enthusiasm for their work. The ambiguity of internships-like the ambiguity between work and play in creative labour-means that responsibility falls on the intern to make the most out of the experience.

While the existing internship literature is instructive, internships are still a nascent research area ripe for critical investigation. The literature's most glaring gap concerns the role of race, class, gender, and other intersecting social stratifications on internship experiences, as well as the impact of internships on those social stratifications. Such oversight is not unique to internship studies, of course. Digital labour researchers only recently began correcting their area's own lack of attention to gender (e.g., Banks and Milestone 2011; Duffy 2015; Gill 2002; McRobbie 2002). Some key themes from the current review, including interns' elevation of "hands-on work" and "initiative," may offer fruitful entry points for interrogating the socio-cultural assumptions embedded in internship experiences: Are internships implicitly racialized, classed, or gendered? And what are the social implications of those assumptions? In addition to the substance of internships, critical scholars should also interrogate asymmetries in access to internships. Charles Murray (2012) has called unpaid internships "career assistance for rich, smart children," and over-reliance on unpaid internships in media and cultural fields may narrow the range of public voices and perspectives (Neff and Arata 2007). Such critiques await further study.

As critical internship studies interrogates these and other processes, I argue-based on the preceding review-that researchers will need to account for three key dynamics in interns' experiences: meaning, temporality, and ambiguity. First, critical scholars will rightfully critique the under-compensation, menial work, and lackluster supervision of exploitative in- 
ternships; however, each of these concerns hinges on an assumption about what a "good internship" is (as well as "good work" more generally). Students have their own ideas about what makes an internship meaningful (e.g., "willing" supervisors trusting them with "handson" work). If we fail to attend to the meanings interns ascribe to their experiences, we will blind ourselves to the ways in which this institution's exploitative and self-exploitative dynamics are rationalized ideologically. Again, interns don't undertake menial work for the heck of it; they do so under a vague promise that more meaningful, professionally promising responsibilities will follow. Attention to meaning will also be important in envisioning and building more fair, just, and beneficial internship structures.

Second, much of the existing internship literature seeks to answer a single question: "What do students find satisfying about internships?" The problem with this question is not only that it focuses narrowly on benefits, but that it also misses the temporal relationship between interns' present experiences and their future employment aspirations. Researchers must seek to make sense of internship experiences within the career structures of their respective industries. Indeed, this is how interns rationalize their work-as future-oriented investments. For instance, Neff and Arata (2007) argue that internships may function to socialize students into post-industrial work. Such a line of inquiry also opens the door to comparative analysis: how do internship experiences in media and cultural industries differ from those in other, less glamorous and network-driven industries? Further, few existing studies followup with interns (and non-interns) to evaluate the impact of those experiences on their personal and professional lives (Neidorf 2008; Taylor 1988). Such studies are methodologically challenging, but without longitudinal and comparative data, the investment logic of internships remains a matter of faith. Even if internships do lead to jobs, we should not assume that they are a fair and just way to organize labour markets. Some paid employees point the finger at unpaid internships and other "atypical labour" (e.g., freelancing) for deteriorations of pay and security (Gollmitzer 2014; Siebert and Wilson 2013). These assertions deserve further empirical study.

Finally, critical internship studies needs to continue to wrestle with the ambiguity of internships. Interns are not yet employees, but not fully students. They receive compensation, but it may not be in the form of a fair wage. Their roles and responsibilities are vague, as is their route to meaningful work and future employment. Internships are part learning experience, part resume workshop, part networking event, part unpaid labour. It is in the ongoing negotiation of this ambiguity by students, faculty, and supervisors that the promise and depravity of internships play out.

\section{References}

Andrejevic, Mark. 2009. Exploiting YouTube: Contradictions of User-Generated Labor. In The YouTube Reader, 2nd ed., edited by Pelle Snickars and Patrick Vonderau, 406-423. Stockholm: National Library of Sweden.

Andrejevic, Mark. 2012. Exploitation in the Data Mine. In The Internet and Surveillance: The Challenges of Web 2.0 and Social Media, edited by Christian Fuchs, Kees Boersma, Anders Albrechtslund and Marisol Sandoval, 71-88. London and New York: Routledge.

Arvidsson, Adam. 2008. The Ethical Economy of Customer Coproduction. Journal of Macromarketing 28 (4): 326-338.

Baker, Stephen. 2008, December 28. Will Work for Praise: The Web's Free-Labor Economy. Bloomberg Businessweek. Accessed November 15, 2014. http://www.businessweek.com/stories/200812-28/will-work-for-praise-the-webs-free-labor-economybusinessweek-business-news-stockmarket-and-financial-advice.

Banks, Mark and Katie Milestone. 2011. Individualization, Gender and Cultural Work. Gender, Work \& Organization 18 (1): 73-89.

Barber, Susan. 1987. What Media Internships Really Offer Students! (Or Matching Skill Use with the Right Agency). Journal of Cooperative Education 23 (3): 63-71.

Beard, Fred. 1997. Inside the Advertising and Public Relations Internship. Paper presented at the Annual Conference of the Association for Education in Journalism and Mass Communication, Chicago, IL. Accessed June 19, 2014. http://list.msu.edu/cgibin/wa?A2=ind9710A\&L=AEJMC\&P=R24962. 
Beard, Fred and Linda Morton. 1999. Effects of Internship Predictors on Successful Field Experience. Journalism and Mass Communication Educator 53 (4): 42-53.

Beebe, Ashley, Abigail Blaylock and Kaye D. Sweetser. 2009. Job Satisfaction in Public Relations Internships. Public Relations Review 35 (2): 156-158.

Benkler, Yochai. 2006. The Wealth of Networks: How Social Production Transforms Markets and Freedom. New Haven, CT: Yale University Press.

Benkler, Yochai and Helen Nissenbaum. 2006. Commons-Based Peer Production and Virtue. Journal of Political Philosophy 14 (4): 394-419.

Brabham, Daren C. 2008. Crowdsourcing as a Model for Problem Solving: An Introduction and Cases. Convergence 14 (1): 75-90.

Cohen, Nicole S. 2008. The Valorization of Surveillance: Towards a Political Economy of Facebook. Democratic Communiqué 22 (1): 5-22.

Cohen, Nicole S. 2012. Cultural Work as a Site of Struggle: Freelancers and Exploitation. tripleC 10 (2): 141-155.

Coll, Richard K. and Tatiana Kalnins. 2009. A Critical Analysis of Interpretive Research Studies in Cooperative Education and Internships. Journal of Cooperative Education \& Internships 43 (1): 113.

Corrigan, Thomas F. 2012. Manufacturing Sports Blogs: The Political Economy and Practice of Networked Sports Blogging. Ph.D. dissertation, Pennsylvania State University.

Daniel, Ryan and Leah Daniel. 2013. Enhancing the Transition from Study to Work: Reflections on the Value and Impact of Internships in the Creative and Performing Arts. Arts \& Humanities in Higher Education 12 (2-3): 138-153.

Daugherty, Emma L. 2011. The Public Relations Internship Experience: A Comparison of Student and Site Supervisor Perspectives. Public Relations Review 37 (5): 470-477.

Daugherty, Terry, Matthew S. Eastin and Laura Bright. 2008. Exploring Consumer Motivations for Creating User-Generated Content. Journal of Interactive Advertising 8 (2): 16-25.

Deuze, Mark. 2007. Media Work. Cambridge, MA: Polity.

Duffy, Brooke E. 2013. Manufacturing Authenticity: The Rhetoric of "Real" in Women's Magazines. The Communication Review 16 (3): 132-154.

Duffy, Brooke E. 2015. The Romance of Work: Gender and Aspirational Labour in the Digital Culture Industries. International Journal of Cultural Studies. Accessed February 25, 2015. DOI: 10.1177/1367877915572186.

Filak, Vincent F. and Robert S. Pritchard. 2008. Fulfilling Psychological vs. Financial Needs: The Effect of Extrinsic Rewards on Motivation and Attachment to Internship Opportunities. Paper presented at the Annual Conference of the Association for Education in Journalism and Mass Communication. Chicago, IL. Accessed June 19, 2014. http://citation.allacademic.com/meta/p mla apa research_citation/2/7/2/3/1/p272318 index.html.

Fish, Adam and Ramesh Srinivasan. 2012. Digital Labor is the New Killer App. New Media \& Society 14 (1): 137-152.

Flew, Terry and Stuart Cunningham. 2010. Creative Industries After the First Decade of Debate. The Information Society 26 (2): 113-123.

Forde, Susan and Michael Meadows. 2011. Industry Placements in Journalism Education: Exploring Enhanced Learning and Professional Growth for Interns. JRE Journal. Accessed June 19, 2014. http://jrejournal.com/ojs-2.3.7/index.php/jre/article/view/12.

Frederick, Jim. 1997. Internment Camp: The Intern Economy and the Culture Trust. The Baffler 9. Accessed June 19, 2014. http://www.thebaffler.com/past/internment_camp.

Frenette, Alexandre. 2013. Making the Intern Economy: Role and Career Challenges of the Music Industry Intern. Work and Occupations 40 (4): 364-397.

Fuchs, Christian. 2012. Dallas Smythe Today-The Audience Commodity, the Digital Labour Debate, Marxist Political Economy, and Critical Theory. Prolegomena to a Digital Labour Theory of Value. tripleC 10 (2): 692-740.

Fuchs, Christian and Marisol Sandoval. 2014. Digital Workers of the World Unite! A Framework for Critically Theorising and Analysing Digital Labour. tripleC 12 (2): 486-563.

Garnham, Nicholas. 2006. Contribution to a Political Economy of Mass-Communication. In Media and Cultural Studies: Keyworks, 2nd ed., edited by Meenakshi G. Durham and Douglas. M. Kellner, 201-229. Malden, MA: Blackwell.

Getz, John E. 2002. Journalism Students' Perceptions of the Value of Internships. Paper presented at the Annual Conference of the Association for Education in Journalism and Mass Communication. 
Miami Beach, FL. Accessed June 19, 2014. http://list.msu.edu/cgibin/wa?A2=ind0209A\&L=AEJMC\&P=R11883.

Gill, Rosalind. 2002. Cool, Creative and Egalitarian? Exploring Gender in Project-Based New Media Work in Europe. Information, Communication \& Society 5 (1): 70-89.

Gollmitzer, Mirjam. 2014. Precariously Employed Watchdogs? Perceptions of Working Conditions Among Freelancers and Interns. Journalism Practice. Accessed March 10, 2014. DOI: 10.1080/17512786.2014.882061.

Gugerty, Catherine A. 2011. Internships in Public Relations and Advertising: The Nature of the Experience From the Student's Perspective. Master's thesis, University of South Florida.

Hardt, Michael and Antonio Negri. 2000. Empire. Cambridge, MA: Harvard University Press.

Harvey, David. 2006. The Limits to Capital. London and New York: Verso.

Hearn, Alison. 2008. "Meat, Mask, Burden": Probing the Contours of the Branded "Self." Journal of Consumer Culture 8 (2): 197-217.

Hesmondhalgh, David. 2007. The Cultural Industries, $2^{\text {nd }}$ Edition. Los Angeles, CA: Sage.

Hesmondhalgh, David. 2010. User-Generated Content, Free Labour and the Cultural Industries. ephemera 10 (3/4): 267-284.

Hesmondhalgh, David and Sarah Baker. 2011. Creative Labour: Media Work in Three Cultural Industries. London \& New York: Routledge.

Hilt, Michael L. and Jeremy Harris Lipschultz. 1996. Broadcast Newsroom Hiring and Career Preparation. Journalism \& Mass Communication Educator 51 (1): 36-43.

Holmstrom, Nancy. 1997. Exploitation. In Exploitation: Key Concepts in Critical Theory, edited by Kai Nelson and Robert Ware, 81-102. Atlantic Highlands: Human Press International.

Huws, Ursula. 2013. The Underpinnings of Class in the Digital Age: Living, Labour, and Value. Socialist Register 50: 80-107.

Jenkins, Chris L. 2003. Cost of Experience: Priceless Law School Graduate Waits Tables to Fund Unsalaried Dream Job. The Washington Post, July 1. Accessed May 26, 2015.

http://www.lexisnexis.com.libproxy.lib.csusb.edu/Inacui2api/results/docview/docview.do?docLinkInd $=$ true\&risb=21 T22078107275.

Kücklich, Julian. 2005. Precarious Playbour: Modders and the Digital Games Industry. The Fibreculture Journal 5. Accessed June 19, 2014. http://five.fibreculturejournal.org/fcj-025-precariousplaybour-modders-and-the-digital-games-industry/.

Kuehn, Kathleen and Thomas F. Corrigan. 2013. Hope Labor: The Role of Employment Prospects in Online Social Production. The Political Economy of Communication 1 (1): 9-25. Accessed June 19, 2014. http://academic.wwwss2.a2hosting.com/ojs/index.php/polecom/article/view/9.

Lazarsfeld, Paul F. 1941. Remarks on Administrative and Critical Communications Research. Studies in Philosophy and Social Science 9: 2-16.

Leadbeater, Charles and Paul Miller. 2004. The Pro-Am Revolution: How Enthusiasts are Changing our Economy and Society. London: Demos.

McRobbie, Angela. 2002. Clubs to Companies: Notes on the Decline of Political Culture in Speeded Up Creative Worlds. Cultural Studies 16 (4): 516-531.

Miège, Bernard. 1989. The Capitalization of Cultural Production. New York: International General.

Moore, Robert C. 2000. I Learned More Than In All of My Classes. ASJMC Insights. Winter/Spring. 13-16.

Mosco, Vincent and Catherine McKercher. 2008. The Laboring of Communication: Will Knowledge Workers of the World Unite? Lanham, MD: Lexington Books.

Murdock, Graham. 2011. Political Economies as Moral Economies: Commodities, Gifts, and Public Goods. In The Handbook of Political Economy of Communications, edited by Janet Wasko, Graham Murdock and Helena Sousa, 13-40. Malden, MA: Blackwell Publishing.

Murray, Charles A. 2012. Narrowing the New Class Divide. The New York Times, March 7. Accessed June 19, 2014. http://www.nytimes.com/2012/03/08/opinion/reforms-for-the-new-upper-class.html.

Neff, Gina. 2012. Venture Labor: Work and the Burden of Risk in the Innovative Industries. Cambridge, MA \& London: The MIT Press.

Neff, Gina and Giovanni Arata. 2007. The Competitive Privilege of Working for Free: Rethinking the Roles that Interns Play in Communication Industries. Paper presented at the Annual Meeting of the American Sociological Association. Accessed June 19, 2014.

http://citation.allacademic.com/meta/p mla_apa_research_citation/1/8/3/9/6/p183960 index.html.

Neff, Gina, Elizabeth Wissinger and Sharon Zukin. 2005. Entrepreneurial Labor Among Cultural Producers: "Cool" Jobs in "Hot" Industries. Social Semiotics 15 (3): 307-334. 
Neidorf, Shawn M. 2008. Wanted: A First Job in Journalism-An Exploration of Factors that May Influence Initial Job-Search Outcomes for News-Editorial Students. Journalism \& Mass Communication Educator 63 (1): 56-65.

Nunley, John M., Adam Pugh, Nicholas Romero and R. Alan Seals. 2014. College Major, Internship Experience, and Employment Opportunities: Estimates from a Résumé Audit. Auburn University Department of Economics Working Paper Series. http://cla.auburn.edu/econwp/Archives/2014/2014-03.pdf.

O'Mahony, Siobhan and Beth A. Bechky. 2006. Stretchwork: Managing the Career Progression Paradox in External Labor Markets. Academy of Management Journal 49 (5): 918-941.

Oreg, Shaul and Oded Nov. 2008. Exploring Motivations for Contributing to Open Source Initiatives: The Roles of Contribution Context and Personal Values. Computers in Human Behavior 24 (5): 2055-2073.

Perlin, Ross. 2012. Intern Nation: How to Earn Nothing and Learn Little in the Brave New Economy. London: Verso.

Postigo, Hector. 2007. Of Mods and Modders: Chasing Down the Value of Fan-Based Digital Game Modifications. Games and Culture 2 (4): 300-313.

Ritzer, George and Nathan Jurgenson. 2010. Production, Consumption, Prosumption: The Nature of Capitalism in the Age of the Digital 'Prosumer.' Journal of Consumer Culture 10 (1): 13-36.

Ross, Andrew. 2003. No-Collar: The Humane Workplace and its Hidden Costs. New York, NY: Basic Books.

Ryan, Bill. 1992. Making Capital from Culture: The Corporate Form of Capitalist Cultural Production. Berlin and New York: Walter de Gruyter

Schambach, Thomas P. and Jim Dirks. 2002. Student Perceptions of Internship Experiences. Paper presented at the International Academy for Information Management (IAIM) Annual Conference. Accessed June 19, 2014. http://eric.ed.gov/?id=ED481733.

Scholz, Trebor, ed. 2013. Digital Labor: The Internet as Playground and Factory. New York \& London: Routledge.

Shao, Guosong. 2009. Understanding the Appeal of User-Generated Media: A Uses and Gratification Perspective. Internet Research 19 (1): 7-25.

Shirky, Clay. 2010. Cognitive Surplus: Creativity and Generosity in a Connected Age. New York: Penguin.

Siebert, Sabina and Fiona Wilson. 2013. All Work and No Pay: Consequences of Unpaid Work in the Creative Industries. Work, Employment and Society 27 (4): 711-721.

Taylor, Susan. M. 1988. Effects of College Internships on Individual Participants. Journal of Applied Psychology 73 (3): 393-401.

Terranova, Tiziana. 2000. Free Labour: Producing Culture for the Digital Economy. Social Text 18 (2): 33-58.

Tokumitsu, Miya. 2014. In the Name of Love. Slate. Accessed June 19, 2014. http://www.slate.com/articles/technology/technology/2014/01/do what you love_love_what_you_d o_an_omnipresent_mantra_that_s_bad_for_work.html.

Turow, Joseph. 2011. The Daily You: How the New Advertising Industry is Defining Your Identity and Your Worth. New Haven: Yale University Press.

Ursell, Gillian. 2000. Television Production: Issues of Exploitation, Commodification and Subjectivity in UK Television Labour Markets. Media, Culture \& Society 22 (6): 805-825.

Wittel, Andreas. 2001. Toward a Network Sociality. Theory, Culture \& Society 18 (6): 51-76.

Zwick, Detlev, Samuel K. Bonsu and Aron Darmody. 2008. Putting Consumers to Work: 'Co-Creation' and New Marketing Govern-mentality. Journal of Consumer Culture 8 (2): 163-196.

\section{About the Author}

Thomas F. Corrigan

Thomas F. Corrigan is an Assistant Professor of Mass Communication in the Department of Communication Studies at California State University, San Bernardino. His research examines the political economy of new media, particularly sports media, digital labour, and critical research methods. His work has been published in The Political Economy of Communication, Journalism: Theory, Practice, \& Criticism, Cultural Studies $<=>$ Critical Methodologies, International Journal of Sport Communication, and Journal of Sports Media. 


\title{
From Apprenticeship to Internship: The Social and Legal Antecedents of the Intern Economy
}

\author{
Alexandre Frenette \\ Arizona State University, Tempe, USA, alexandre.frenette@asu.edu
}

\begin{abstract}
This article looks towards the future of the intern economy by focusing on its past. What led to recent debates about the intern economy? How did it become legally possible for interns to work for free? Using the United States as my case study, I draw parallels between the current intern economy and its closest historical antecedent, the apprenticeship system. By providing a brief overview of the history of work-based learning and the unpaid internship's legal underpinnings, this article ultimately frames current lawsuits and debates as a correction to today's insufficiently scrutinized youth labour regime not unlike the apprenticeship systems of the past. In the attempt to facilitate youth transitions from school to work, yet maintain minimum wage standards, government intervention and-more imminently likely-legal decisions will, I anticipate, eventually transform the intern economy much like the Fitzgerald Act of 1937 drastically formalized apprenticeships in the United States.
\end{abstract}

Keywords: intern economy, internships, apprenticeships, school-to-work, lawsuits, legality

Acknowledgements: I would like to thank the reviewers, special issue editors, Paul Attewell, Michael Crowder, Eric Glatt, and Daniel Jacoby for their helpful comments on this article.

\section{Introduction}

Over the past three years, something surprising yet quite overdue happened in the United States: people became increasingly critical of the intern economy. As the Great Recession exacerbated the plight of the young and the jobless (Shierholz and Edwards 2011), the unpaid internship began drawing the ire of politicians, educators, labour rights activists, as well as students and their worried parents (Greenhouse 2010; Harris 2013; Mosley 2013; Perlin 2011). Before 2010, only a few newspaper articles (mostly op-eds in The New York Times) occasionally questioned the fairness of the intern economy. The only consistent source of critical analysis of the intern economy over the previous decades could be found in legal reviews pondering whether unpaid interns should be considered employees (e.g., Curiale 2010; Gregory 1998; Ortner 1998; Yamada 2002). It is in great part this legal grey area that has brought the intern economy to the forefront as a social issue.

An increasing number of former unpaid interns have been suing companies for back pay (and damages). Two such lawsuits were filed in 2011, seven in 2012, and at least 23 in 2013 (Suen and Brandeisky 2014). The growing public scrutiny of internships escalated in June 2013 when Federal Judge William Pauley handed two unpaid interns, Eric Glatt and Alex Footman, a summary judgment win against Fox Searchlight Pictures. The two ex-interns worked on the film Black Swan and filed a lawsuit against the company in 2011 for violating federal and state labour laws. The judge not only agreed the plaintiffs should be considered employees, but also certified a class action suit on behalf of an entire class of employees (i.e., unpaid interns) at the parent company, Fox Entertainment Group (Greenhouse 2013). Companies, interns, and even the courts appear to be increasingly unclear about how to define and justify a legal unpaid internship. Employers have scrambled to catch up with the threat of litigation, and several companies agreed to pay considerable settlements to former interns, including Viacom ( $\$ 7.2$ million), NBCUniversal ( $\$ 6.4$ million), Condé Nast ( $\$ 5.85$ million), and Warner Music Group (\$4.2 million) (Raymond 2015).

This article looks towards the future of the intern economy by focusing on its past. What led to the recent debates about the intern economy? How did it become legally possible for 
interns to work for free? Using the United States as my case study, I draw parallels between the current intern economy and its closest historical antecedent, the apprenticeship system. By providing a brief overview of the history of work-based learning and the unpaid internship's legal underpinnings, this article ultimately frames current lawsuits and debates as a correction to an insufficiently scrutinized youth labour regime not unlike the apprenticeship systems of the past. In the attempt to facilitate youth transitions from school to work, yet maintain minimum wage standards, government intervention and-more imminently likelylegal decisions will, I anticipate, eventually transform the intern economy much like the Fitzgerald Act of 1937 drastically formalized apprenticeships in the United States.

\section{History of Work-based Learning}

Throughout most of history, teenagers and young adults have engaged in training for occupations via work-based learning opportunities, primarily in the form of apprenticeships. Workbased learning is consistent with the idea of "learning by doing" and can be linked to the larger pedagogical philosophy of experiential education. The idea that a student should learn based on active, situated experience and interaction with the world-in this case the workplace-is often identified with John Dewey's philosophy that life and learning should be integrated: "The inclination to learn from life itself and to make the conditions of life such that all will learn in the process of living is the finest product of schooling" (Dewey 1916, 51). Dewey provided an intellectual argument for experiential learning in The School and Society ([1899] 1956) and The Child and the Curriculum ([1902] 1956), asserting that a child's education must be linked to experience more than abstract thought. However, individuals started learning within work contexts far before Dewey's writings.

The history of work-based learning starts with the apprenticeship and leads to the internship. An apprenticeship is much longer and more educationally ambitious than an internship, usually lasting a few years compared to a few months (or weeks) for internships. Apprenticeships are referred to as the oldest form of training and have been a traditional part of the life cycle at least since the Middle Ages (Rorabaugh 1986). For centuries, apprenticeships have provided a way to train people for crafts and trades, but should also be understood as a complex social and economic system. Apprenticeships have always involved the exchange of training for labour. Skilled masters host apprentices in the workplace for an agreed period of time. Until the 19th century, the relationship between a master and apprentice in some ways resembled the relationship between parent and child. The training provided during an apprenticeship went beyond simply learning a craft or trade. Masters ideally took on the role of parents to serve the apprentices in learning their craft, but also taught them religion and morality (Smith 1981). Apprentices were expected to obey their master much as they would a parent, providing valuable labour as well as loyalty and child-like love. It should be noted that this relationship did not always live up to its ideal form, notably because the relationship was bound by a contract (i.e., indenture) whereby the apprentice served the master for numerous years before earning the right to become a journeyman (Smith 1981).

The arrangement between apprentice and master has varied historically, partly based on era, geography (including local laws and customs), and type of craft or trade. In Keith Snell's (1996) analysis of the apprenticeship as a cultural institution in Britain, he notes a general tendency to group apprenticeship systems into three distinct historical periods: the guild apprenticeship period (12th century to 1563); the statutory apprenticeship period (1563-1814), which was marked by the decrease of guild influence; and the voluntary apprenticeship period (1814-present), where arrangements have come in a variety of forms, often articulated between employers and unions. The key marker between the three periods is the Statute of Artificers from 1563, an Elizabethan enactment that helped formalize the apprenticeship system, though several important clauses were later repealed in 1814. The introduction of the statute brought together the various apprenticeship systems then in existence in England and established their legal standing. The enactment set the length of apprenticeships (usually seven years, as opposed to three to five in countries like France and Germany), limited the number of apprentices in certain trades, prohibited poaching of apprentices by other masters, 
and, in the name of "social order and hierarchy" (Snell 1996, 304), restricted access to profitable trades to the children of masters and owners of certain property. The Statute of Artificers made it statutory for parents to apprentice their sons for craft or agriculture unless they could afford to educate them for a profession. Until 1814, the Statute of Artificers brought considerable formality and legal structure to an apprenticeship system that trained youth (mostly men) employed outside the professions.

Adam Smith was a vocal critic of the then-prevalent 18th-century apprenticeship system, arguing that it served as a mechanism to restrict the supply of workers and confine knowledge to the hands of a select few (Wallis 2008). And yet much like interns today are sometimes limited by a high intern-to-employee ratio, from time to time masters took on more apprentices than desired by their pupils, particularly in those periods and areas where apprenticeship regulation was scarce (Aldrich 1999). Part of Smith's dismay about apprenticeships can be linked to his criticism of guilds, the corporations of masters that (along with local governments) used to regulate apprenticeships. Smith famously portrayed guilds as "a conspiracy against the public" (Epstein and Prak 2008, 1) since they served the masters' interests to the detriment of the economy. Smith's argument about labour market monopsony (i.e., lack of free-flowing labour market) held great weight for some time, though historical research calls for a slightly more nuanced view; it was relatively easy and not uncommon to sidestep restrictions on apprenticeship numbers and the statutory lengths of apprenticeships were sometimes negotiable (Epstein 1998).

Some apprenticeships were better than others, of course, and parents vied to arrange the best possible placement for their children. Since apprenticeships were a crucial mechanism to ensure a child's economic future as well as moral upbringing, parents would give money to masters for some apprenticeships (such as law) while paupers and orphans might end up in less lucrative areas, like farming (Aldrich 1999; Snell 1996). The apprenticeship system Smith criticized has nonetheless been defended as the best solution available during a period noted by the absence of compulsory schooling (Epstein 1998). Yet the apprenticeship system and the institution of enforced indenture did not translate as well in American society.

Apprenticeships thrived in colonial America, a time when the Statute of Artificers mandated the colony's apprenticeship system; however, this institution was organized differently than in Britain. The tradition of guilds never held the same authority in the New World as it did in Europe. In the face of increased demand for skilled workers, colonial America was marked by a scarcity of them. America was a land of settlers in search of opportunity and thus was the site of continual immigration, including that of adult labourers trained elsewhere. America had a considerable rural economy, one where settlers worked their own land. None of these factors were conducive to building strong guilds or otherwise enforcing an indenturedriven apprenticeship system since youth (as well as adults) could usually enter skilled occupations without certification (Elbaum 1989).

An additional reason why apprenticeships did not flourish in America was the country's culture of independence, notably during and after the revolutionary era (Rorabaugh 1986). The rhetoric of independence and belief in governing one's self permeated all aspects of political and economic life, even the deference in status necessary to pursue apprenticeship training. In this way, according to William Rorabaugh (1986), authority based on contractual control weakened the position of masters; apprentices challenged the apprenticeship system that was imported from Britain. Bernard Elbaum's (1989) study of apprenticeships in America supports this reading as he also notes the problem of runaway apprentices; in fact, apprenticeship laws were passed in twelve states between 1783 and 1799 to address this problem, though with very limited effectiveness. By the end of the 18th century, apprenticeships in America became increasingly rare; it seems like the enforcement of written indentures was difficult and ineffective. Youth were therefore trained for occupations much more informally than in previous generations (Elbaum 1989). 


\subsection{From Apprenticeship System to Intern Economy}

In his overview of the apprenticeship system, Ross Perlin $(2011,54)$ praises the Fitzgerald Act (or National Apprenticeship Act) of 1937 because it "finally stabilized and revived apprenticeship in the United States." The Act marks an effort to formalize apprenticeships and stipulates as its goal "to formulate and promote the furtherance of labour standards necessary to safeguard the welfare of apprentices and to cooperate with the States in the promotion of such standards" (50 Stat. 664; 29 U.S.C. 50). Instead of a precursor, others argue that the Act was passed as a reaction to the revival of apprenticeships between 1880 and 1920 (Jacoby 1991). According to this view, apprenticeships were becoming so popular-and the threat of low-paid or unpaid aspiring workers so unwieldy-that this surge led to the passing of the Fitzgerald Act. The Fitzgerald Act is therefore credited by some for limiting apprenticeships to marginal status in the United States, not least because it made training apprentices "prohibitively costly" (Coy 1989, 9). As apprenticeship programs became more formalized they also grew less frequent. In 1920, 2.11 percent of operatives and kindred workers were apprentices, compared to 0.96 percent and 1.01 percent in 1940 and 1950 (Gartner et al, 2006). Nonetheless, Perlin (2011) is correct in portraying the Fitzgerald Act as an example of what well-supervised and planned work-based training can accomplish. The government established standards for apprenticeship programs with the aim for employers to recognize apprentices as employees, and therefore to ensure pay as well as training in crafts and trades deemed "apprenticeable" (U. S. Bureau of Apprenticeship and Training 1964).

By the beginning of the 20th century, America's formal institutions of work-based learning grew beyond the realm of crafts and trades. The apprenticeship model of training remained nearly constant throughout America's history in the form of medical training, though with some variation. Medical schooling shifted from an apprenticeship arrangement to education with little practical content in the early 1800 s, to an educational curriculum incorporating an internship requirement later that century. Medical school eventually was deemed "insufficient preparation" for work and the internship became the norm of American medical training by the 1930s (Thorne 1973). Work-based training gained traction in other fields as well. In 1906, Herman Schneider established the country's first cooperative education program at University of Cincinnati's engineering school, an arrangement Northeastern University emulated in 1909. Cooperative education provides an avenue for students to divide their time between substantive work and classroom learning, yet this and other forms of work-based learning remained marginal until the 1960s.

Work-based learning did not grow in importance in one swift, coordinated movement, but incrementally until the 1990s. The growth and formalization of internships, as with any major change in curriculum, represents a convergence of numerous social forces and the result of larger cultural debates (Rose 2004). An important facilitator for the rise of internships and work-based learning in general has come in the form of government policies. Some ground was set in the 1960s and 1970s pursuant to President Johnson's War on Poverty; tens of millions of dollars were provided to educational institutions to help disadvantaged minorities transition into the workforce via work-based learning programs (Knowles 1975). These policies were coherent with the Coleman Commission report of 1974, which blamed schooling for impeding youth's transition into adulthood because it isolates students from the world of work and contact with adults (Bailey et al. 2004). As James Coleman (1977) also discussed elsewhere, work-based learning provides an opportunity for youth to develop "social maturity" and it can benefit students of diverse backgrounds. However, the political push towards work-based learning in the late 1980s into the 1990s initially focused on a particular population and social problem, i.e., the difficulties of low-income high school graduates (and dropouts) to find employment in their late teens.

"School-to-work" policies of the 1980s financed the establishment of secondary school work-based learning programs (including internships) and, in the early 1990s, a shift in rationale led to postsecondary expansion of these policies in the form of the School-to-Work Opportunities Act of 1994 (Hughes, Bailey, and Mechur 2001). Work-based learning was seen as an educational strategy useful for all students and more than simply training for oc- 
cupations, but also as training through occupations (Bailey et al. 2004). Thomas Bailey, Katherine Hughes, and David Moore (2004) note with irony how work-based learning policies were considered an innovative new strategy to educate and train young adults in the 1990s, although these policy ideas are centuries old. The authors explain this shift as a conjunction of economic and pedagogical developments in the 1980s and 1990s. First, the U.S. appeared to model the School-to-Work Opportunities Act in part based on the apprenticeship systems of their strongest economic competitors, Germany and Japan. During the same time period, constructivist pedagogy and developmental cognitive psychology advocating "learning in context" became increasingly dominant (Bailey et al. 2004). To these two factors should be added a demographic reason for the rise of the intern economy, i.e., the increasing number of college-age youth. During the first decade of the 21 st century, the number of 18to 24 -year olds in the U.S. increased by 11 percent (from 28 to 31.1 million). Simultaneously, the rate of college enrolment among such youth increased from 36 percent in 2001 to 42 percent by 2011 (U. S. Department of Education 2013).

Moreover, the ascent of the internship is consistent with the changing nature of work in the post-industrial era (Beck 2000; Boltanski and Chiapello, 2006; Ross 2003; Sennett 1999). In recent decades, firms have become increasingly flexible and jobs have become less permanent. Arne Kalleberg (2000) and others (Hatton 2011; Hipple 2001; Matusik and Hill 1998) document the rise of "non-standard" work arrangements, i.e., various forms of employment that deviate from the full-time, permanent jobs held more prominently by previous generations (Mills 1951; Whyte 1956). In this context, internships grew as a more purely marketbased regime, as opposed to apprenticeships, which have, to varying extents, been guided or guarded by governments (from local to national), guilds, and unions.

Over the last few decades, what began as a policy (and rhetoric) to facilitate the transition from school to work grew into an unwieldy intern economy where companies welcomed the addition of low-paid or unpaid labour (Frenette 2013). Internships now function as a sorting mechanism and credential system (at least in principle) aimed at rationalizing the transition from school to work, even in occupations that were previously excluded from work-based training schemes. Also, as the Black Swan lawsuit and others attest, interns today are frequently college graduates with no academic affiliation. Nonetheless, the link between higher education and work environments has proved significant in legally justifying the existence of unpaid internships.

\section{History and Legality of Work-based Learning}

According to the Fair Labor Standards Act (FLSA), the 1938 federal legislation regulating employment, interns should be paid. However, this point seems to be a matter of interpretation. An employee is defined in a spectacularly broad way; as Senator Hugo Black put it shortly before the FLSA became law: the definition of an employee is "the broadest definition that has ever been included in any one act" (Curiale 2010, 1539, quoting 81 Congressional Record 7657, 1937). An "employee" is defined as "any individual employed by an employer" and "employ" means "to suffer or permit to work" (29 U.S.C. section 203).

Some exceptions exist to minimum wage laws, notably for "learners," "apprentices," and "handicapped" individuals who, if they meet the defined requirements and the employer applies for special permission, can be paid between 75 percent and 95 percent of the minimum wage. The Wage and Hours Division (WHD) later added the "student-learner" exception for students who are part of a vocational training program, also making this group eligible for this slightly subminimum wage exception (Curiale 2010). Despite these exceptions, the term "employee" remained in need of clarification, which occurred in 1947 when the Supreme Court ruled on Walling v. Portland Terminal Co. (330 U.S. 148), a case opposing railway trainees and a railway company. ${ }^{1}$ To become eligible for employment as railway brakemen, trainees first took part in a program that lasted seven to eight days. Applicants chosen by the company to take part in this program worked with railway yard employees over this period,

\footnotetext{
${ }^{1}$ By this time Hugo Black, who had championed the Black-Connery Bill that eventually became the FLSA, was a Supreme Court judge.
} 
progressing from generally observing activities to doing some work under close supervision (Yamada 2002). Trainees claimed they should be paid minimum wage during their training, but the Supreme Court ultimately disagreed.

The Supreme Court acknowledged that in some instances-though not this one-trainees could be paid 75 percent to 95 percent of the minimum wage under the FLSA, noting:

Without doubt, the Act covers trainees, beginners, apprentices, or learners if they are employed to work for an employer for compensation. This is shown by [section] 14 of the Act, which empowers the Administrator to grant special certificates for the employment of learners, apprentices, and handicapped persons at less than the general minimum wage. The language of this section and its legislative history reveal its purpose. Many persons suffer from such physical handicaps, and many others have so little experience in particular vocations that they are unable to get and hold jobs at standard wages. Consequently, to impose a minimum wage as to them might deprive them of all opportunity to secure work, thereby defeating one of the Act's purposes, which was to increase opportunities for gainful employment. (Walling v. Portland Terminal Co., 330 U.S. 148, 151, 1947)

It is striking how, in the eyes of the law, untrained workers, marked by their youthful inexperience, are akin to people with physical disabilities in their shared inability to find gainful employment. Although the two groups must deal with various prejudices, the law acknowledged as early as 1938 and 1947 the comparative disadvantages of certain workers in the job market. Nonetheless, the Supreme Court found that in some cases a special permit to pay subminimum wages, or even to pay no wages at all, is not necessary according to the spirit of the FLSA:

The definition "suffer or permit to work" was obviously not intended to stamp all persons as employees who, without any express or implied compensation agreement, might work for their own advantage on the premises of another. Otherwise, all students would be employees of the school or college they attended, and as such entitled to receive minimum wages. So also, such a construction would sweep under the Act each person who, without promise or expectation of compensation, but solely for his personal purpose or pleasure, worked in activities carried on by other persons either for their pleasure or profit. (Walling v. Portland Terminal Co., 330 U.S. 148, 152, 1947)

The notion that students doing work at a school cannot claim to be employees is powerful in this case, especially when considering that Portland Terminal Co. trainees were described as students housed by an employer under school-like conditions. The decision further clarifies the intention of the FLSA regarding who is or is not an employee:

The Act's purpose as to wages was to insure that every person whose employment contemplated compensation should not be compelled to sell his services for less than the prescribed minimum wage. The definitions of "employ" and "employee" are broad enough to accomplish this. But, broad as they are, they cannot be interpreted so as to make a person whose work serves only his own interest an employee of another person who gives him aid and instruction. (Walling v. Portland Terminal Co., 330 U.S. 148, 152, 1947)

In this way, the railway brakemen trainees were not deemed to be employees and therefore not subject to further compensation. The 1947 Supreme Court decision cited numerous reasons why these trainees could not be considered employees; for example, the work done through training is to the trainees' benefit. The WHD used much of the same language and reasoning from the Supreme Court ruling to articulate a six-factor test to decide whether a trainee is an employee at a for-profit business:

1. The training, even though it includes actual operation of the facilities of the employer, is similar to that which would be given in a vocational school.

2. The training is for the benefit of the trainees or students.

3 . The trainees or students do not displace regular employees, but work under their close observation. 
4. The employer that provides the training derives no immediate advantage from the activities of the trainees or students, and on occasion his/her operations may actually be impeded.

5. The trainees or students are not necessarily entitled to a job at the conclusion of the training period.

6. The employer and the trainees or students understand that the trainees or students are not entitled to wages for the time spent in training.

(U.S. Department of Labor, Wage and Hour Division 1993, Field Operations Handbook, Section 10b11) ${ }^{2}$

According to the WHD, all six factors must be met in order for a worker to not be considered an employee. In 1982, the Fifth Circuit Court upheld the six-factor test in the all-or-nothing fashion, finding airline trainees not to be employees (Yamada 2002); the same court cited this case and applied identical logic in a 1983 decision (Curiale 2010). However, various courts in the U.S. have applied the six-factor test differently (see Table 1 for sample cases; data drawn from Curiale 2010; Yamada 2002; and court records).

\begin{tabular}{|c|c|c|c|c|}
\hline Case & Court & Year & Context & Ruling \\
\hline $\begin{array}{c}\text { Donovan v. American Airlines Inc. } \\
\text { Atkins v. General Motors Corp. }\end{array}$ & 5th Circuit Court & $\begin{array}{c}1982 \\
1983\end{array}$ & $\begin{array}{c}\text { Flight attendant \& reservation sales agent trainees } \\
\text { State-sponsored program to provide company } \\
\text { with pool of trained workers }\end{array}$ & All-or-Nothing (WHD test) \\
\hline $\begin{array}{c}\text { Tony \& Susan Alamo Foundation } \\
\text { v. Secretary of Labor }\end{array}$ & Supreme Court & 1985 & $\begin{array}{c}\text { Individuals allegedly volunteered for commercial } \\
\text { business of a nonprofit religious organization }\end{array}$ & Economic Reality Test \\
\hline $\begin{array}{c}\text { McLaughlin v. Ensley } \\
\text { Reich v. Parker Fire Prot. Dist. }\end{array}$ & 4th Circuit Court & 1989 & $\begin{array}{c}\text { Trainees/potential workers at snack foods } \\
\text { distribution business }\end{array}$ & Primary Beneficiary Test \\
\hline Archie v. Grand Central Partnership Inc. & 2nd Circuit Court & 1998 & $\begin{array}{c}\text { Formerly homeless individuals sued non-profit; } \\
\text { took part in Pathways to Employment Program }\end{array}$ & Applied all tests above \\
\hline
\end{tabular}

Table 1: Supreme Court \& Circuit Court decisions related to six-factor test

In a 1985 Supreme Court decision, individuals who were allegedly volunteers for the commercial activities of a charity were found to be employees under the Economic Reality Test; according to the court, these individuals carried out activities for which one would usually expect financial compensation (Curiale 2010, 1543). Instead of applying the all-or-nothing six-factor test, the Supreme Court decided that employment status would not depend on isolated factors and it did not matter that volunteers vehemently denied coverage as employees. While a Supreme Court decision could be seen as the final word on the topic, this case is not widely cited in cases regarding trainees or interns, perhaps since it involves the line between volunteer/employee instead of trainee/employee (Curiale 2010). The WHD makes an exception for individuals who volunteer "without expectation of compensation" for non-profits or government entities, and therefore these individuals are not covered under the six-factor test to this day (Yamada 2002; U.S. Department of Labor, Wage and Hour Division 2010, Fact Sheet \#71). Nonetheless, more recent cases involving trainees also interpreted the six-factor test inconsistently.

The Fourth Circuit Court rejected the six-factor test altogether, basing a 1989 decision on the Primary Beneficiary Test, deciding based on who benefits principally between trainee and employer. Similarly, in 1993, the Tenth Circuit Court did not use an all-or-nothing interpretation of the six-factor test, but it did not decide based on the presence or absence of one factor, preferring instead the "Totality of Circumstances" test. The court acknowledged how "the

\footnotetext{
2 The WHD issued Fact Sheet \#71 in April 2010, a clarification of its six-factor test as it applies to interns. The statement updates part one of the six-factor test, specifying that an internship must be similar to training that would be given in an "educational environment" instead of "vocational school" as previously recorded.
} 
expectation of employment upon successful completion of the course" (Yamada 2002, 231) weighed in the trainees' favour, but ultimately decided that firefighter trainees at a firefighting academy were not employees.

Finally, in a decision that noted the lack of consistent interpretation of the six-factor test, the Second Circuit Court applied all of the tests noted above and found that formerly homeless individuals who took part in the Pathways to Employment Program were entitled to minimum wage. The defendants claimed that plaintiffs received counselling and basic skills training so therefore were not entitled to more than the subminimum wage they received, but the court disagreed based on the Economic Reality Test (Curiale 2010).

The line between "student" and "employee" is blurry, even when an intern is paid. In Mayo Foundation for Medical Education and Research et al. v United States, the Supreme Court ruled that medical residents do not fall into a special (tax exempt) "student" category in the Treasury Department's tax regulation since their standing resembles employment more so than an educational activity. This decision (\#09-837, decided January 11, 2011) supports a previous ruling by the Eighth Circuit Court. As a result of the various interpretations of the six-factor test by the courts, there is no clear, legally agreed-upon standard by which to decide if an unpaid intern is an employee.

\section{Conclusion}

As more unpaid interns file lawsuits for back pay and a growing, global intern labour rights movement exerts pressure on companies and governments alike, this article considers the future of the intern economy by highlighting its past. The intern economy is the latest iteration of a millennia-old tradition of work-based learning. Much like apprenticeships were part of a social and economic system marked by guild and state control in lieu of widespread schooling, internships today are greatly facilitated by institutions of higher education as a complement to classroom learning (and, in some cases, a stepping stone to employment). ${ }^{3}$ The contemporary intern economy in the U.S. represents a continuation of the pre-1937 apprenticeship system; both should be understood as complex social and economic systems that (in principle) have involved the exchange of training for labour, aimed to facilitate youth's transition from school to work, and became increasingly formalized over time. However, despite these similarities, the current intern economy operates in a far different context marked by the decline of unions, the rise of non-standard work arrangements, and an environment where "enterprising subjects" (Vallas 2012) must assume the predominant burden of building their employability (Smith 2010) to start and sustain careers.

After a decrease in work-based learning earlier in the 20th century, internships made a considerable ascent due to political, economic, and demographic factors. Nonetheless, the legality of unpaid internships has become a matter of vigorous debate. While the U.S. Department of Labor set guidelines for the educational exception of the FLSA, their six-factor test has been interpreted in several different ways by the courts. No matter which legal interpretation of the six-factor test is applied, as David Yamada (forthcoming) recently concluded, "a good number of unpaid internships-especially in the private sector-run afoul of current federal and state wage and hour laws." Therefore, current lawsuits and debates regarding unpaid internships should be seen as a correction to a legally ambiguous and insufficiently scrutinized youth labour regime not unlike the apprenticeship systems of the past. In the coming years, further legal enforcements will catch up to and alter the internship economy, perhaps as considerably as the Fitzgerald Act or Statute of Artificers transformed apprenticeships.

\section{References}

Aldrich, Richard. 1999. The Apprentice in History. In Apprenticeship: Towards a New Paradigm of Learning, edited by Patrick Ainley and Helen Rainbird, 14-24. London: Kogan Page.

\footnotetext{
${ }^{3}$ Moore (2013) nonetheless notes how internships paradoxically hold a marginal status within postsecondary institutions.
} 
Bailey, Thomas R., Katherine L. Hughes and David T. Moore. 2004. Working Knowledge: Work-based Learning and Education Reform. New York: Routledge.

Beck, Ulrich. 2000. Brave New World of Work. Oxford: Polity/Blackwell.

Boltanski, Luc and Ėve Chiapello. 2006. The New Spirit of Capitalism. London: Verso.

Coleman, James S. 1977. Differences Between Experiential and Classroom Learning. In Experiential Learning: Rationale, Characteristics, and Assessment, edited by Morris T. Keaton, 49-61. Washington, DC: Jossey-Bass Publishers.

Coy, Michael W. 1989. Apprenticeship: From Theory to Method and Back Again. Albany, NY: SUNY Press.

Curiale, Jessica L. 2010. America's New Glass Ceiling: Unpaid Internships, the Fair Labor Standards Act, and the Urgent Need for Change. Hastings Law Journal 61: 1531-1560.

Dewey, John. 1916. Democracy and Education. New York: The Free Press.

Dewey, John. (1899) 1956. The School and Society. Chicago: University of Chicago Press.

Dewey, John. (1902) 1956. The Child and the Curriculum. Chicago: University of Chicago Press.

Elbaum, Bernard. 1989. Why Apprenticeship Persisted in Britain but Not in the United States. The Journal of Economic History 49 (2): 337-349.

Epstein, Stephan R. 1998. Craft Guilds, Apprenticeship, and Technological Change in Preindustrial Europe. Journal of Economic History 53 (4): 684-718.

Epstein, Stephan R. and Maarten Prak. 2008. Introduction. In Guilds, Innovation, and the European Economy, 1400-1800, edited by Stephan R. Epstein and Maarten Prak, 1-24. New York: Cambridge University Press.

Fair Labor Standards Act, 29 U.S.C. Sec. 206.

Frenette, Alexandre. 2013. Making the Intern Economy: Role and Career Challenges of the Music Industry Intern. Work and Occupations 40 (4): 364-397.

Gartner, Scott Sigmund, Michael R. Haines, Alan L. Olmstead, Richard Sutch and Gavin Wright. 2006. Historical Statistics of the United States, edited by Susan B. Carter. New York: Cambridge University Press.

Greenhouse, Steven. 2010. The Unpaid Intern, Legal or Not. The New York Times, April 2. Accessed April 4, 2015. http://www.nytimes.com/2010/04/03/business/03intern.html?ref=stevengreenhouse.

Greenhouse, Steven. 2013. Judge Rules that Movie Studio Should Have Been Paying Interns. The New York Times, June 11. Accessed April 4, 2015.

http://www.nytimes.com/2013/06/12/business/judge-rules-for-interns-who-sued-foxsearchlight.html? $r=1 \&$.

Gregory, David L. 1998. The Problematic Employment Dynamics of Student Internships. Notre Dame Journal of Law, Ethics and Public Policy 12: 227-264.

Harris, Malcolm. 2013. The Unpaid Internship for Credit Must End. Al Jazeera America, November 14. Accessed April 4, 2015. http://america.aljazeera.com/opinions/2013/11/unpaidinternshipscollegecredit.html.

Hatton, Erin. 2011. The Temp Economy: From Kelly Girls to Permatemps in Postwar America. Philadelphia, PA: Temple University Press.

Hipple, Steven. 2001, March. Contingent Work in the Late-1990s. Monthly Labor Review 124, 3-27.

Hughes, Katherine L., Thomas R. Bailey and Melinda J. Mechur. 2001. School-to-Work: Making a Difference in Education. A Research Report to America. New York: Institute on Education and the Economy (IEE), Teachers College, Columbia University.

Jacoby, Daniel. 1991. The Transformation of Industrial Apprenticeship in the United States. The Journal of Economic History 51 (4): 887-910.

Kalleberg, Arne L. 2000. Nonstandard Employment Relations: Part-Time, Temporary, and Contract Work. Annual Review of Sociology 26: 341-365.

Knowles, Asa S. 1975. Cooperative Education: The Catalyst for Innovation and Relevance. Daedalus 104 (1): 202-209.

Matusik, Sharon F. and Charles W. L. Hill. 1998. The Utilization of Contingent Work, Knowledge Creation, and Competitive Advantage. Academy of Management Review 23 (4): 680-697.

Mills, C. Wright. 1951. White Collar. New York: Oxford University Press.

Moore, David T. 2013. Engaged Learning in the Academy: Challenges and Possibilities. New York: Palgrave Macmillan.

Mosley, Ashley. 2013. Why Unpaid Internships Negatively Impact Women. The Huffington Post, December 3. Accessed April 4, 2015. http://www.huffingtonpost.com/ashley-mosley/why-unpaidinternships-negatively-impact-women b 4371987.html.

National Apprenticeship Act, 50 Stat. 664; 29 U.S.C. 50. 
Ortner, Craig J. 1998. Adapting Title VII to Modern Employment Realities: The Case for the Unpaid Intern. Fordham Law Review 66: 2613-2647.

Perlin, Ross. 2011. Intern Nation: How to Earn Nothing and Learn Little in the Brave New Economy. New York: Verso.

Raymond, Nate. 2015. Warner Music to Pay \$4.2 Million to End Intern Wage Lawsuit. Reuters, June 10. Accessed July 6, 2015. http://www.reuters.com/article/2015/06/10/us-warnermusic-lawsuit-internsidUSKBN00Q2KC20150610.

Rorabaugh, William J. 1986. The Craft Apprentice from Franklin to the Machine Age in America. New York: Oxford University Press.

Rose, Mike. 2004. The Mind at Work: Valuing the Intelligence of the American Worker. New York: Viking/Penguin.

Ross, Andrew. 2003. No-Collar: The Humane Workplace and Its Hidden Costs. New York: Basic Books.

Sennett, Richard. 1999. The Corrosion of Character: The Personal Consequences of Work in the New Capitalism. New York: Norton.

Shierholz, Heidi and Kathryn A. Edwards. 2011. The Class of 2011: Young Workers Face a Dire Labor Market Without a Safety Net. Economic Policy Institute. Briefing Paper \#306, April 20.

Smith, Steven R. 1981. The Ideal and Reality: Apprentice-Master Relationships in Seventeenth Century London. History of Education Quarterly 21 (4): 449-459.

Smith, Vicki. 2010. Enhancing Employability: Human, Cultural, and Social Capital in an Era of Turbulent Unpredictability. Human Relations 63 (2): 279-303.

Snell, Keith D.M. 1996. The Apprenticeship System in British History: The Fragmentation of a Cultural Institution. History of Education 25 (4): 303-321.

Suen, Stephen and Kara Brandeisky. 2014. Tracking Intern Lawsuits. ProPublica, April 15. Accessed April 4, 2015. http://projects.propublica.org/graphics/intern-suits

Thorne, Barrie. 1973. Professional Education in Medicine. In Education for the Professions of Medicine, Law, Theology, and Social Welfare, edited by Everett C. Hughes, Barrie Thorne, Agostino M. DeBaggis, Arnold Gurin and David Williams, 17-99. New York: McGraw-Hill Book Company.

U.S. Bureau of Apprenticeship and Training, Department of Labor. 1964. The National Apprenticeship Program.

U.S. Department of Education, National Center for Education Statistics. 2013. Digest of Education Statistics, 2012 (NCES 2014-015), Chapter 3.

U.S. Department of Labor, Wage and Hour Division. 1993. Field Operations Handbook.

U.S. Department of Labor, Wage and Hour Division. 2010, April. Fact Sheet \#71: Internship Programs under the Fair Labor Standards Act. Accessed April 4, 2015. http://www.dol.gov/whd/regs/compliance/whdfs71.pdf.

Vallas, Steven P. 2012. Work: A Critique. Malden, MA: Polity Press.

Walling v. Portland Terminal Co., 330 U.S. 148, 152 (1947).

Wallis, Patrick. 2008. Apprenticeship and Training in Premodern England. Journal of Economic History 68 (3): 832-861.

Whyte, William H., Jr. 1956. The Organization Man. New York: Doubleday Anchor.

Yamada, David C. 2002. The Employment Law Rights of Student Interns. Connecticut Law Review 3; 215-259.

Yamada, David C. Forthcoming. The Legal and Social Movement Against Unpaid Internships. Northeastern University Law Journal.

\section{About the Author}

\section{Alexandre Frenette}

Alexandre Frenette specializes in the study of work, creative industries, and youth labour markets. He earned his Ph.D. in sociology at the Graduate Center, City University of New York (CUNY) in 2014 and is currently a Postdoctoral Scholar at Arizona State University's Herberger Institute for Design and the Arts. Using the music industry as a case study, he is currently working on a monograph about the challenges and the promise of internships as part of higher education, tentatively titled The Intern Economy: Laboring to Learn in the Music Industry. 


\title{
Interning and Investing: Rethinking Unpaid Work, Social Capital, and the "Human Capital Regime"
}

\author{
Sophie Hope* and Joanna Figiel** \\ *Birkbeck, University of London, London, UK, s.hope@bbl.ac.uk; **City University, London, \\ UK, joanna.figiel.1@city.ac.uk
}

\begin{abstract}
For young workers, interning is a strategy for speculating on one's asset portfolio. Students and graduates undertake internships as a way of maintaining their self-appreciation and avoiding depreciation in a "human capital regime." In this article, we explore the specific example of interning in the creative industries as the self-management of human capital vis-à-vis the human capital theses. Taking three cultural objects and recent representations of the issue of unpaid internships-Intern magazine, an advert for a "volunteering opportunity" student placement, and testimonies from interns-we analyze how unpaid work in the creative industries and the neoliberal version of human capital entrepreneurship can be seen as embodied by interns.
\end{abstract}

Keywords: internships, labour, unpaid work, social capital, human capital, self-management

Interning is one of the strategies employed by students and graduates to speculate on their asset portfolio. Students and graduates intern to maintain their self-appreciation and avoid depreciation in a "human capital regime." By human capital, we mean an individual's speculative relationship to their skills and knowledge. In this article, we explore interning in the creative industries as a specific example of the self-management of human capital. We take three recent cultural objects aimed at interns-a magazine, an advert, and a website-through which to analyze the labour relations of unpaid work in the creative industries, the forms of discrimination at play, and the weak ties and damaging capabilities that are a part of the practice of managing human capital. We re-imagine how the intern as an entrapped neoliberal subject investing in their portfolio career so as to affect and speculate on their human capital might disrupt the structural conditions of survival for the entrepreneurial self.

This article follows from our literature review of internship reports, guidelines, and toolkits published in the UK between 2009 and 2011 (Hope and Figiel 2012). ${ }^{1}$ In this report, we concluded, "The growing use of the word and application of internships perhaps continues to hide those more fundamental unresolved issues of elitism, inequality, bad-management, bullying and underfunding in the arts" (40). The literature we reviewed reflected a spectrum of positions, advice, and proposals, from suggestions of phasing out unpaid internships altogether, to "equalizing opportunities" for access to unpaid internships. Ten of the 23 documents we reviewed made recommendations that interns, if they fulfil worker status, should be paid National Minimum Wage while six did not. The HM Government's Unleashing Aspiration reports (2009 and 2010) emphasized the individual motivating himself or herself into employment, and that those with talent and potential will succeed. The unpaid internship, it seems, has become a necessary part of the doctrine of employability, an umbrella term used to describe the work of making oneself employable.

The language used in some of the literature we reviewed, including terms such as appreciation, aspiration, valorization, and entrepreneurship, embraces the capacity for someone to make the effort to maintain high levels of human capital. This is also the language of

${ }^{1}$ This report, Intern Culture, formed part of Artquest's research toward establishing a paid internship programme for 
internship adverts and interns themselves when describing their experiences. Many of the reports also recognized and problematized the necessary social and cultural capital needed to carry out an unpaid internship, such as one's family background and standing and network of connections. Reports such as Unleashing Aspiration were focused on generating equality of access to the professions rather than acknowledging the labour involved in establishing and maintaining cultural and social capital and the exclusions of individuals lacking the right kind of capital. Rather than address inequalities in terms of labour rights, employability appropriates the language of finance to describe education and interning as speculative investments.

The promotion of employability and the entrepreneurial self through university courses is now a key factor in how individuals and potential employers approach unpaid internships (Chertkovskaya et al. 2013). As declared on the website of the Higher Education Academy (HEA, the national body for enhancing learning and teaching in higher education), graduate employability is at the centre of the UK's Higher Education agenda. The HEA describe graduate employability as the "need to ensure that graduates are prepared for, and able to contribute to, the economy and society" (HEA 2015). In her 2003 article, "Neo-liberalism and the End of Educated Democracy," Wendy Brown questions the move away from a "broad and deep university education" towards job training: "What kind of world will be made through conceptions and practices of postsecondary education that reduce students to future human capital, citizens to manipulable consumers, and the public to GDP?" (Brown 2003, 22). This could be the kind of world in which the mis/over-use of the concepts of social and human capital is responsible for a state of generalized commodity fetishism where, as Ben Fine writes, "everything from our abilities to our states of mind becomes capital-like" (Fine 2010, ix).

The notion that education should above all service the economy was also highlighted in a recent speech by the Minister of State for Skills and Enterprise, Matthew Hancock MP: "One of the central goals of our reforms is to bring together employment and education. We are making education more rigorous and more responsive to employers" (Hancock 2014). The reports we examined in Intern Culture failed to address in any substantial way, however, the question of how this occurs. How does education service employers when so many graduates, especially in the creative industries, are self-employed? In our view, education, employability, and the internship are incubators for entrepreneurial selves where learning is put to work. It could be argued that interning appropriates and reproduces mechanisms of gendered unpaid reproductive and domestic labour, specifically, the invisible care and maintenance that interns perform both on themselves and for the organizations they work for. Rather than acknowledge these activities as exploitative forms of unpaid labour however, they are often presented as necessary (even desirable) for a functioning, productive, profitable society. The intern learns to become responsible for maintaining her own employability. In this article, we take some further steps towards understanding the intern as a subject who embraces the challenges of maintaining the entrepreneurial self.

The aim of this article is to reflect on the research on the proliferation of internships in the UK context, where intensifying processes of neoliberalization lead to an increased need and necessity for individuals to become entrepreneurs. While such processes affect employees across different sectors, they seem particularly visible and rife among those working for free in the hope of getting future employment in cultural and creative industries. The ill-defined interval of the internship that often exists between the expectations of learning and earning is integral to the protean career of entrepreneurial graduates (Bridgstock 2012). The internship is a period during which the graduate-symbolically, via their CV and/or physically and affectively via an embodied and passionate performance of commitment to the job-builds on and demonstrates their important connections and enthusiasm for work and offers their talent up to be tapped. In Vicki Smith's words, this participation is "performance, as people strive to demonstrate that they are employable; workers perform identity and emotion work in the service of this performance [...]" $(2010,291)$. This understanding of human capital as an enduring condition of speculative 
employment-being in a constant work-ready state-has led to all-pervasive relationships to work. As Smith points out, "definitions of work must be broadened to incorporate multiple types of labour," including, we argue, unpaid intern labour (294).

The three cultural objects we refer to in this article are Intern, a magazine launched in October 2013 by Alec Dudson, once an intern himself; ${ }^{2}$ a recent advertisement by the Institute for Contemporary Arts (ICA) in London seeking a student to fill a "volunteering opportunity" role; and Ragpickers Collection, an online archive of intern testimonies maintained by the UK-based collective Ragpickers. We chose these three examples to reflect different perspectives on the public presentation of interning, from the publicly-funded institution offering "opportunities" to the aspiring creative industry worker with a foot in the door to disillusioned individuals naming and shaming exploitative situations. Intern, a magazine put together by interns, for interns, has been created, we argue, to highlight the positive and rewarding aspects of unpaid internships, acting as an autoportrait of a certain section of this "workforce" in the UK. At the same time, the magazine reveals the kinds of activities interns undertake in order to get ahead in the creative and cultural industries. To complement and contrast this account, we include a recent student placement advert by the ICA that provides evidence of the continuing complicity of arts organizations perpetuating conditions of unpaid work. The placement advertised was meant for students, not necessarily as part of a credited work placement, but rather as a commitment "complimentary" to academic studies. ${ }^{3}$ Our third object is the collection of items on the website of Ragpickers collective, a London-based group raising awareness of internships and unpaid work in the arts. This material consists of evidence/personal accounts contributed by anonymous interns revealing aspects of their experiences at work. These accounts offer alternative narratives of interning that are often self-censored, and at worst silenced, in the quest for successful maintenance of one's social capital via an internship.

One of the goals of this paper is to bring a feminist reading of social and human capital to our understanding of interning as a contemporary neoliberal phenomenon. Departing from concepts of social and human capital defined by Pierre Bourdieu $(1984 ; 1986)$ and James Coleman (1988), we introduce a feminist challenge to the concept of human capital (and its vehicle, employability), which insists on analyzing the development and maintenance of networks of social relationships involved in gaining social capital as a series of gendered labour relations. These relations involve capitalizing on networks and personal relationships and friendships while the invisible social capital required to maintain these entrepreneurial bodies goes unnoticed, unpaid, and unrecognized as labour. We explore how developing these relationships as sets of capabilities can have positive and negative impacts on others around you and question the relevance or meaning of trust or strong ties that are supposedly important to gaining social capital. We then turn to Michel Feher's (2009) call to inhabit the neoliberal subject-our example being the intern-in order to think of possible ways to politicize the social relations involved in the unpaid work carried out by the intern.

\section{From Social Capital to Labour Relations: In Search of Spaghetti Cheesestrings}

Human capital is a contested term that has been tackled by, among others, Theodore Schulz (1961) and Gary Becker (1964) in the context of neo-classical economics; Bourdieu (1984; 1986), Coleman (1988), and Robert Putnam (2000) in relation to social capital; Foucault (2008/1978-9), Wendy Brown (2003; 2013), and Feher (2009) as part of the neoliberal, entrepreneurial economy; and Paula England and Nancy Folbre (1997), and Irene Bruegel

\footnotetext{
${ }^{2}$ Dudson states: "I did two internships: one at Domus and one at Boat Magazine. My internship at Boat was instrumental to what I'm doing now. I was able to make it work financially. I spent seven months sleeping on friends' couches. I went around by bike, didn't use public transport and worked a bar job for 30 hours a week. Which is fine but that's not a situation that everyone can magic up-it's not that simple" (cited in Segal Hamilton 2013).

${ }^{3}$ Arts universities in particular are trying actively to oppose such practices; see, for instance, Page 2014.
} 
(2005), who bring a feminist critique. Bourdieu divides capital into economic, cultural, and social forms. Economic capital refers to resources that can be converted into money and cultural capital-whether embodied, objectified or institutionalized-relates to a set of acquired knowledges, skills, and tastes (Bourdieu 1986). Social capital is the "sum of the resources, actual or virtual, that accrue to an individual or a group by virtue of possessing a durable network of more or less institutionalised relationships of mutual acquaintance and recognition" (Bourdieu and Wacquant 1992, 119). In this sense, we can view the internship as a process of or an extension of the investment in education to increase prospects in the long term.

Whereas Bourdieu refers to economic, cultural, and social capital, Coleman (1988) defines human capital as being "embodied in the skills and knowledge acquired by an individual [...] that make them able to act in new ways." Social capital exists in the relations between people (1001) and can impact on the creation of human capital. Indeed, human capital is dependent on the effectiveness of those social relations. Coleman explores the role social capital plays in different classes through a study of high school drop-outs in the US and their lack of access to social capital, such as parents' presence, number of children in the family, and a mother's expectations for her child to go to college. His understanding of social capital combines the "norms, rules and obligations" a person deals with together with their money-driven, self-interestedness (104-5). For example, social capital implies how a person's actions are influenced, shaped, and constrained by their environment but also understands people as being capable of independent action. For Coleman, social capital exists in the relation between people and is improved by the level of trust in that group (100-101). Smith, quoting Jone. L. Pearce, also highlights how "trustworthiness is a necessary-and underappreciated—condition of employability" (Smith 2010, 291). Coleman's understanding of human capital is based on an individual building up social capital in order to benefit from it in the long run in terms of money, pleasure, and/or satisfaction $(1988,116)$. In this article we understand the social capital of the intern to be the accumulation of a network of relationships. These connections might lead to an unpaid internship, which then promises to enhance an individual's network. The internship is considered a site for investing in human capital in the form of skills and knowledge, including training in how to acquire more social capital (through contacts, confidence, and charisma). Human and social capital are interconnected and co-dependent resources that the intern both requires and desires in a habitual dance of labour relations.

While concepts of social and human capital such as Coleman's might help explain the selfserving interests of an individual aiming to develop some semblance of a career, we look to a feminist reading of social capital to destabilize the norm of unpaid internship. A feminist rereading involves thinking about social relations beyond the cliques of family, community, and school and looking sideways to make connections and solidarities with others experiencing exploitative working conditions. Irene Breugel (2005), for example, referring to the dominance of social mobility discourse, writes "social capital sold itself as dealing with problems of deprivation and social cohesion, not inequalities of class, race or gender and therefore needs rethinking from a feminist perspective" (5). Working through these problems of deprivation reinforces and reproduces disadvantages of race, class, and gender, which are not accounted for in the theories of social capital to begin with, but instead are "brought back in" (Fine 2010, 60). In the case of the unpaid internship, we are less interested in equalizing access to opportunities to work for free than tackling the underlying inequalities that permeate and are perpetuated by the fragmentary forms of labour in which internships play a part.

As Emma Dowling $(2012,484)$ points out, not included in discussions of social capital but that must be addressed are the realities of labour: perspectives of labour need to be made visible in the "analysis of social capital." Dowling traces the recent trajectory of the concept of social capital in the service of austerity and "Big Society" discourses in the UK. In relation to these discourses, Dowling $(2012,485)$ calls for a politicization of social capital by drawing attention to 
the material realities of the double bind in which an individual finds herself in the current political and labour market climate, where neoliberal subjectivity is

on the one hand subsuming us completely into the production machine and relying on our cooperative and communicative connections to do so, while on the other pitting us against one another, turning us into competitive utility-maximising beings caught up in the affective anxieties of a rat race that is only being intensified by austerity.

How is free labour, such as the unpaid internship, harnessed at the same time as state disinvestment in "the reproduction of labour through the imposition of cuts and austerity"? (ibid. 484). The labour of reproducing working bodies (e.g., the domestic work of feeding, caring, and cleaning) remains invisible and unpaid, whilst qualities of social capital are being harnessed and reproduced in an effort to prove ourselves employable.

A good example for this discussion might be one of the items in the Ragpickers Collection: a packet of Spaghetti Cheestrings donated by an intern working at Blink Productions in Soho, London. This intern recalls spending "an entire day looking all around the area for a packet of Spaghetti Cheestrings" because one of the producers wanted to measure the length of a single Cheestring with a ruler for an advert they were making. The intern says this experience was "so utterly degrading and pointlessly stupid," expressing the "soul destroying" nature of the mission they were sent on, as was the content of the creative work being produced by the company they were interning for (Ragpickers 2013, Item \#4). For another intern, the job of interning "introduced [her] to real business" and she lists the seepage of unpaid work into her private life: "He [her supervisor] was telling me that I have to lose 15 kilos and my skirts are too short. He was cooking for me. He was washing my clothes. He was sleeping with me in one bed. Together we set up 3 shows during 2 weeks. Together we went for a couple of art fairs. Then I quitted [sic] and he deleted me on Facebook" (Ragpickers 2013, Item \#5). The chores illustrated in the Ragpickers Collection border on complex versions of modern day slavery. Although they wittingly entered into internships, these interns seem to be experiencing a kind of entrapment involving "affective anxieties" (Dowling 2012, 485). They acknowledge the absurdity of what they are doing but sign up for it anyway. While in the above cases the interns managed to escape, who knows for how long as their entrapment is embedded and embodied. Brown (2010) might call the experience of these interns "quotidian nihilism": "[neoliberalism] tells you what you should do: you should understand yourself as a spec of human capital, which needs to appreciate its own value by making proper choices and investing in proper things."

The Ragpickers Collection was set up as a space for expressions of exploitation and evidence gathering of labour relations in the context of interning. By exposing these problematic labour relations, the interns risk depreciating their own human capital by losing "friends" through making visible often-exploitative conditions. Despite the risk of burning bridges, the Low Pay Commission reported that in just over a year (from August 2012 to the end of September 2013), there had been 95 intern complaints to the Pay and Work Rights Helpline and arrears of pay for 171 workers totalling $£ 193,873$ had been identified in 12 cases (LPC 2014, 143). The Commission's report outlined a number of recommendations including a new legal definition of an internship; continued targeted enforcement; enforcement activity being publicised more widely; penalties for non-compliance being increased; and better advice being made available (144). While this is a welcome step towards recognizing the realities of labour involved in interning, it is of some concern that existing research we have engaged with often reveals little acknowledgement on the part of interviewed interns that there might be issues of inequality and exclusion in the intern culture they are a part of. David Lee $(2011,559)$, for example, states: "a number of my participants denied the importance of networks, and indeed denied it was an industry structured by anything less than sheer merit and talent." This could be because students, graduates, and novices are in the process of investing in their own self-appreciation 
and so it might be hard to step back and get some critical distance. Such conditions are challenged by the Ragpickers Collection, which goes some way to reverse the issue that interns themselves might be blind to problems of accepting unpaid work, particularly because, unlike the helpline, they make public the emotional and economic costs of maintaining one's human capital.

\section{Discrimination at the Gates: “We Don't Need to Tell Them, They Just Know From the Start"}

According to Lee's interviews with freelancers working in the British independent television production sector, jobs in the creative industries do not come through responding to adverts but via word of mouth through "loose acquaintances" or "weak ties" (2011, 553-4). Unlike Coleman's suggestion that trust between people increases their social capital, Lee points out that these career networks are distinguishable from "strong ties" built on trust. Instead, the kinds of networks relied on in the creative industries are weak, "based on thin, impersonal trust of acquaintances." Lee draws on the work of Mark Granovetter (1973) who found that job opportunities are often heard about via someone you do not have a strong connection to because they network with different social circles and have different kinds of information that might be useful to you. While this may be the case for individuals as they continue to work in the creative sector, of Lee's interviewees, all but one entered the industry through work experience that was "often gained through family networks" $(2011,556)$.

It is an open secret that nepotism is core to freelance careers in the creative industries but not everyone has the same privileges of access to friends or relatives with power or influence, or indeed the confidence to muscle in. The independent British public policy think tank The Social Market Foundation (2010) identified other entry barriers as being the requirement of a degree, poor career advice, and the unstable and precarious employment patterns in the creative industries making the career less viable for those without a financial safety net. Lee $(2011,549)$ focuses on networking as a mechanism of exclusion that "favours individuals with high levels of cultural and social capital" and thereby can be "a means of sustaining inequality, excluding social actors on the basis of class, race and social status" (552). He looks at the way people use their cultural capital to improve their social capital in order to climb the career ladder, focusing on the levels of confidence and the communication skills built up through "middle class socialization and life-styles" needed to access the networks on which a livelihood in the cultural sectors often depends (556).

Lee suggests networked freelancers need to present themselves as "flexible, enthusiastic and mobile." This language is echoed in the ICA volunteer placement advert, which requires "individuals able to think and react fast [...]" in their "very busy and lively office" (ICA 2014). An intern at Sprüth Magers Gallery contributed a set of emails to the Ragpickers Collection in which they were informed that their internship had been terminated after three days. The language used by the director is similar to that used by the ICA:

We are approaching our busiest time and we need to feel confident that everyone here is fully committed and willing to muck in and I am afraid this wasn't really the impression you have given. As a consequence, we think a continuation of the internship here is not the right thing for us, nor for you. (Ragpickers 2013, Item \#3)

The intern responds, pointing out her disappointment and the lengths she has gone to secure the internship, including the cost of organizing child care "in order to be as flexible as possible," and points out feeling voiceless in the process of her dismissal. In another email, the director explains that every other intern they have worked with "shows an innate sensitivity and respect towards their role" and have an "immediate awareness of what is and what is not appropriate in the gallery. We don't need to tell them, they just know it from the start" (ibid). This level of 
expectation of internalized and embodied modes of behaviour at work is also evident in the ICA advert, where students are required to "deliver exceptionally high standards of front-line customer service, support public access and engagement with contemporary art and quality of visitor experience" as well as "contribute to visitors' enjoyment, understanding and opportunities for learning through narrated interpretation, guiding and communication of stories and information about the ICA" (ICA 2014). The unpaid job being advertised already requires wellhoned communication and affective work skills and knowledge, meaning many students would not have access to this "opportunity" to preen their human capital.

In its report Work Placements in the Arts and Cultural Sector: Diversity, Equality and Access, the Equality Challenge Unit (2010) found that students, especially "disabled students, black and minority ethnic students, and those from disadvantaged socioeconomic backgrounds" experience difficulties trying to access or complete a work placement or an internship. Creative Skillset's 2012 census of the creative media industries found that representation of Black, Asian and minority ethnic people declined from 7.4 percent of the total workforce in 2006 to 6.7 percent in 2009 and just 5.4 percent in 2012 (Creative Skillset 2012, 4). "The proportion of the workforce described by their employers as disabled has remained the same since 2006, at 1.0 percent" (ibid., 5). This implies: "[...] those who don't make it are invisible to the successful. The excluded disappear" (Lee 2011, 561).

Tim Lindsay, CEO of the charity Design and Art Direction in London, writes in Intern magazine's first issue about why some might not take up an unpaid internship/work placement: "Anecdotally, women are less likely to be happy roughing it on a mate's floor. Agencies subsequently become dominated by a boisterous culture, and even less likely to attract female employees" (2013, 2-3). Lindsay goes on to note, "people from less well-off families may not know anyone to crash with... Seemingly unrelated problems such as cultural and gender diversity in the creative industries suddenly become a direct result of unpaid internships" (ibid., $3)$. He asks if the banning of unpaid intern adverts might "exacerbate the already endemic nepotism" (ibid., 8).

The lack of equal access to internships and, as a result, to creative professions could (and perhaps should) be understood as a form of discrimination. The Sprüth Magers intern found the director's actions to exhibit a "blind allegiance to concealed chauvinism" (Ragpickers 2013, Item \#3). We could add to this accusation by suggesting that the gallery director discriminates against those who do not know the codes of behaviour that are a prerequisite of the job. Interning in this case is about demonstrating and donating one's existing social and human capital to the organization rather than being a space for learning new skills from them.

\section{Weak Ties and Damaging Capabilities: Learning to Wait}

Paula England and Nancy Folbre (1997) present an expanded notion of human capital by replacing capital with capabilities. They define capabilities as a "state (involving a combination of motivation, skill and/or health) that requires some effort to develop, and that when developed, enables one to function in ways that contribute to the well-being of oneself or others" (2). The development of capabilities, they claim, is "beneficial for human well being at the collective level" (ibid.). Relating this concept to the case of the intern, rather than focus on individual self-gain (in terms of the intern's future earned income), we might consider the exercise of capabilities as benefiting, or indeed harming, people other than the intern. For example, we could think through the impact of interns on their co-workers, as highlighted by Sabina Siebert and Fiona Wilson (2013). Their study of unpaid work placements in media and creative environments shows the relationship of those undertaking unpaid work placements to their social capital is complicatedthe nature of social capital is multifaceted. Unpaid internships, they suggest, can have detrimental effects on labour relations and can constitute the erosion of trust between paid and unpaid workers (Siebert and Wilson 2013, 718). This contradicts Coleman's (1988) suggestion 
that social capital is built on trust: "The empirical evidence collected here suggests erosion of trust between unpaid workers motivated by a desire to enter the industry, freelance workers already in the sector and the employers, "Siebert and Wilson write (718).

Similarly, one Ragpickers Collection contributor reports on the strained relationship between them and the other staff in Sprüth Magers gallery where they were interning:

On a couple of occasions I have asked the gallery manager and other staff if there is any work for me to do but have been mostly told to sit and wait because everybody is "too busy with their work." I felt uncomfortable sitting next to the receptionist all the time because she acted very arrogant and self-important, making me feel like I am invading her sacred and adorned front of house kingdom. (Ragpickers 2013, Item \#3)

One of the basic capabilities that England and Folbre introduce is self-regulation: will power, attention, and restraint $(1997,4)$. The intern learns to sit and wait. The skill (or muscle memory) of self-regulation is learned over time by grabbing a series of perpetual "opportunities" in the hope that they will potentially translate into a career path. Self-regulation could be a prolonged period of adolescence, as pointed out by Ross Perlin (2011), but also a reflection of the type of work or person in an economic and political climate that relies on self-promotion. The interning phenomena is not just a temporary "strategy for waiting out economic downturn" (135) but a necessary term of (un-) employment and extended work experience that is considered part of the creation of the sole trader. The preference or desire to intern and the skill of self-regulation it requires (such as foregoing other activities and pay), have been internalized. As England and Folbre $(1997,5)$ state: those people "can be relied upon more to exercise the skill even under loose or no surveillance."

Smith (2010) explores three ways that people try and enhance their employability: identity work, training and networking, and labouring in unpaid and marginal paid positions. She writes: "The unemployed and underemployed spend hours, often full-time, learning the self-presentation and interactional ropes of flexible workplaces, reconstructing themselves, and searching for jobs" (285). She goes on to suggest that "volunteering also provides the opportunity for volunteers to audition: to demonstrate their work ethic, their trustworthiness, and their fit with an organization" (291). The internship is a place for practicing social skills and presentation of the self. In an article in Intern, for example, Ben from design collective OWT, stresses how "people skills are imperative for a successful internship" (Bennett 2013, 2). The blurring of work and nonwork identities is echoed in the words of Sarah of OWT who suggests that if interns "go for a pint with them, that's a promising relationship [...] As an intern you have to show you want to work with these people, not simply because of the company they work for, but because of who they are" (ibid., 2-3). Networking becomes something you should be doing: "it takes on a hegemonic and normative force" (Lee 2011, 562). Entrepreneurial tendencies are embodied in the intern for whom, as OWT point out, contacts have become a form of currency (Bennett 2013).

Irena Grugulis and Dimitrinka Stoyanova's research on a television production company acknowledges the way people learn through socialization and gain experience by observing and working with others (2011). They point to the problematic assumption, however, that workplaces are "coherent communities, containers of competence where the skilful are available for novices to consult and observe" (343). Their research questions how much can be learnt through social interaction (and the trust that is needed for social capital to grow, according to Coleman), when the workforce is notoriously fragmented and freelance. How and where do those networks of trust develop? 'Outsourcing 'at will' contracts and freelance work are much less effective at supporting communities of practice than stable work groups or vertically integrated bureaucracies" (Grugulis and Stoyanova 2011, 343). Their term the missing middle refers to the community of trainees who have contact with other "novices" and occasionally "company ownermanagers," but not to the experienced professionals who could aid their learning. In the 
research they carried out (2005-2006 fieldwork at an independent production company), the novices had little contact with the professional freelancers, who were geographically separate and only around for short-term contracts. There was "no continuity of relationships" or chance to do tasks that would challenge them (344). The novices were left to support and train each other, an experience of "the blind leading the blind," according to one novice. This is a result, Grugulis and Stoyanova suggest, of labour market structure (fragmented, overworked, based on shortterm contracts): "...without ready access to visible, transparent expertise novices struggle to learn, or even know what they need to learn" (349). They end on a depressing note: "it is not clear how the industry's current cohort of novices will ever acquire the skills taken for granted by previous generations of workers" (350). The pursuit of capabilities has negative and positive effects on the intern and those around them. Further, such capabilities can also be questionable in themselves. For example, the ability to wait and not ask questions, develop superficial relationships and false friendships. For whom are these capabilities desirable and who do they benefit?

\section{Intern as Neoliberal Subject, or "The Constant Need to Organize Myself to the Minute"}

Feher $(2009,24)$ describes human capital as a "dominant subjective form," a "defining feature of neo-liberalism." Human capital, he argues, is to be embraced, in order to be transformed: "Instead of denouncing and lamenting the personalization of politics as the strategy through which neoliberalism causes people to lose sight of their collective interests, playing the human capital card could thus be a way of relaunching the politicization of the personal" (25).

Feher makes a link between the shift towards globalized, unregulated markets and the neoliberal version of human capital. Whereas old forms of capitalism were based on investing for future commercial profits over a period of time, the focus now is on maximizing "distribution of dividends in the short term," "capital growth or appreciation," and "stock value" (27). Let us try and map this financial language onto the case of an "unpaid voluntary placement" advertised at the ICA. Theodore Schultz (1961) and Becker (1964) might have understood the intern as being motivated to work unpaid in the hope that there will be delayed returns on that investment in terms of future earnings, material rewards, or "psychic" benefits. Taking Feher's view on human capital, the intern as a neoliberal subject is investing in his or her own stock value. The placement at the ICA reflects a system that relies on students undervaluing their stock value so that they willingly and competitively take up the "opportunity" of an unpaid placement to increase their value in the future. In economic terms, appreciation means an increase in value of an asset. Significantly, value does not increase because of improvements or additions to the asset but because of other economic factors such as scarcity or inflation. In the case of the intern, there is a pressure to increase their own value-for example by improving their skills, networks, confidence etc.-but their levels of appreciation are also dictated by the fluctuating, "turbulent," unpredictable labour markets around them. The intern can invest all they can in their human capital, but their appreciation or depreciation might be dependent on factors beyond their control. Feher suggests that the neoliberal subject cannot own her human capital. Unlike the "free labourer" who sells their labour power to the capitalist in return for a wage, the neoliberal subject-in our example, the intern-can only ever have a speculative relationship to their human capital. The intern can modify, upgrade, and improve but not sell their human capital (34).

This speculative relationship to human capital is evident in the pages of Intern magazine. For the interns presenting their stories, it is as if work wraps around them like a second skin and becomes an integral part of their identity. "Each feature that tackles the [internship] debate headon offers a subjective take on things and while this structure may frustrate some, internships are by their very nature, personal experiences" (Dudson 2014, 5), the editorial foreword warns, and 
delivers on its promise. Most case studies in the magazine are both personal and highly individualized accounts. While contributors to the magazine are paid, an overwhelming majority of features and internship reports talk about placements and internships that were unpaid. For example, one interviewee who has already made her name in the business, Jessica Walsh, says on interns: "Ours are unpaid. We pay for their lunches. I think it's on a situational basis whether people are comfortable with that, and can handle that." Her own internship, eventually leading to partnership at Sagmeister and Walsh, was presumably also unpaid (Quito 2014, 26). The narratives here give various accounts of the self-investment process, for example:

I understand just how valuable free [labour] can be. I spend around about $60 \%$ of my working life in non-fee paying work. I work for free/ [goes on to describe various activities] Everything I do for free I do because there will be, somewhere not too far down the line, a payback. [...] It is a selfish act [...] to keep myself working on terms that suit my lifestyle. (Germains 2014, 21)

A contributor to issue 1, Daniel Cooper, devised a project where he travelled around the world working for free for two days at a time for design companies, in exchange for one day of their time in return. This proposition was well received, he writes, because "it wasn't much of an investment on their part" (Cooper 2013, 6). The kind of things the design companies gave Cooper in return included showing him around their city, a bike trip, breakfast, and access to nightlife. One could argue that these were mutually beneficial leisure pursuits rather than the company working for free for Cooper for a day. During his project to test out the nomadic, transient lifestyle of the creative workforce, he found "the constant need to organise [him]self to the minute" extremely tiring (ibid.).

According to the investment model of human capital, the nomadic design intern swapping two days of unpaid work for one day of the company's time, or the person spending 60 percent of their work time unpaid would supply a credit slip to the place they are doing the internships to be cashed in at a later date. In neoliberal reality, however, these undelivered symbolic credit slips accumulate in the shape of what Feher (2009) refers to as self-appreciation (they remain speculative). As Perlin $(2011,132)$ reminds us, investing in education, training, and the "internship bonus" with the hope of future higher wages is a risk, especially in a sector that does not have many paid permanent posts: "For many, the return on investment doesn't come, the economic landscape changes in the meantime, or an incomplete investment spells disaster."

Self-esteem is the key to maximizing human capital, and "life may be thought of as a strategy aimed at self-appreciation" (Feher 2009, 28). Distinguishing the subject form of human capital from the pre-neoliberal subject of the free labourer (who relies on the separation between the alienated worker-self and the self that resists commodification), neoliberalism "treats people not as consumers but as producers, as entrepreneurs of themselves or, more precisely, as investors in themselves, as human capital that wishes to appreciate and to value itself and thus allocate its skills accordingly" (30-31). The intern is concerned with the "impact of their conducts" as this may have an effect on the "level of their self-appreciation or self-esteem" (27). As investees in their own career destinies, they are responsible for managing their own value, frantically trying to avoid any depreciation in value. "Neo-liberal subjects," Feher writes, "do not exactly own their human capital; they invest in it. In fact, anything they do, no matter how ill advised or mundane, is an investment in their human capital" (26). This often means an additional portion of unpaid work performing enthusiasm for a speculative career. This demonstration of commitment and enthusiasm that takes place in the space of the internship becomes the self-management of self-appreciation. As well as being motivated by the hope of future pay-off, it is part and parcel of investing in the entrepreneurial self.

As a magazine focused on the creative industries, the articles in Intern embrace selfpromotion and the importance of "making a name for yourself." Articles reflect the characteristics of cultural and social capital needed to enter the profession. These "capabilities" (a mix of 
enthusiasm, confidence and access to networks) are learnt and built up through "middle class socialisation and life-styles" (Lee 2011, 556). There is a sense that the more you believe in yourself and the work you do, the more successful you will become. The magazine is a demonstration of this self-appreciation. In one article, OWT state: "not being paid doesn't matter if you're gaining a lot of information and contacts" (Bennett 2013, 9). Such statements seem typical of those who have internalized the relentless neoliberal calls to perpetual selfimprovement that surrounds the subject of working for no pay, language that is echoed in the advertisements, career fairs, workfare and university prospectuses at the same time. Phoebe Moore (2009) suggests employability "requires people to use every waking minute for preparation for entering into an unpredictable job market, or for management or education of the self ... in work, meaning that everyday life is subordinated to these preparations and activities" (245). While, according to Feher, "individuals must have access to training programs during periods of unemployment to increase their employability and thus ward off the depreciation of their human capital" $(2009,39)$. This relates in equal measures to interns who do not take on government provided or otherwise required training programmes, but multiple unpaid internships and work placements in the attempt to achieve employability and subsequently, gainful employment. These are often facilitated and encouraged by universities and, as we have shown in the Intern Culture report, encouraged by the policy surrounding the issue.

\section{Conclusions: From Organizing Myself to Organizing With Others}

In this article, we have reflected on three approaches to the internship: Intern magazine, an advert for an unpaid placement at the ICA, and a collection of items from interns on the Ragpickers website. All three examples illustrate the ways, both in terms of ideology and in terms of the qualities of interning, that the individual is expected to (im)prove their employability through, for example, the ability to follow orders without question (the Cheestring mission), to learn the discipline of waiting patiently (the silenced Sprüth Magers intern), to enthusiastically network (a strategic drinking session), and to perform high levels of customer service (on the ICA front-line). The audiences of the advert, magazine, and website might overlap-they are all aimed at interns - and they share the language of investment and opportunity. While the advert and Intern magazine tend to reproduce this language, the Ragpickers Collection attempts to undo some of the assumptions by exposing the realities of labour that interning entails. The Collection is an example of interns looking critically at the conditions they are in and building awareness of the impact their labour relations and armoury of capabilities are having on themselves and those around them.

While individual cases outlined in Intern and the Ragpickers Collection are important in understanding the terrain of exploitation, there is a need to move beyond singular cases. We have attempted to join up these examples so as to consider the underlying systemic inequalities that have allowed internships to become the norm. Re-imagining the intern as an entrapped neoliberal subject investing in their portfolio career might disrupt the structural and implicit conditions of survival for the entrepreneurial self. This involves acknowledging and drawing attention to the labour of unpaid work and its all-pervasiveness, problematizing the powerrelations and exploitative characteristics of capability-building (who is left in the wake of an individual's human capital expansion?), and recognizing the possible solidarities that could result from this. It would also bring the realities of inequalities to the fore. In such a guise, interning would be a subjectivizing experience, but also a collectivizing one, where working conditions are challenged not just to improve an (already privileged) individual's experience, but to recognize broader exclusions and exploitations necessary for the space of the internship to exist in the first place.

From the perspective of employability, by subverting the "proper choices," as neoliberal subjects we could begin to question, as Feher does, "what constitutes an appreciable life"? 
$(2009,41)$. He suggests that it is through the personalization of the political that steers people away from their collective interests. He asks if it is possible to play the human capital card strategically, in an attempt to achieve the reverse-the politicization of the personal-although does not elaborate on how that could be possible. Through our mapping of the context of internships and the examples of human capital at work, we are thinking towards a politicization of the intern.

Internships could be seen as a force for perpetuating inequalities, exploitation, and discrimination by developing a closed social system of self-serving capabilities that interns alone can excel in but that necessarily excludes others - the "disappeared majority," as Lee (2011) notes, that needs to be "brought back in," as discussed by Fine (2010). Rather than demonize the intern, however, could we embrace this figure and instead explore how networks of solidarity among co-workers stretch beyond the individual's self-interest towards an alternative coappreciation that can disrupt and crack open the closed networks that perpetuate inequality in the sector? Rather than the social networks being built for personal gain, for example, can they be reconsidered as social networks of solidarity that acknowledge systemic inequalities and difference? At present, there seems to be a race towards improving the quality of exploitation for all.

While there is increasing awareness of these issues in academic discourses, public policy, higher education teaching the creative industries themselves, the discrimination inherent in the internship system continues as the loopholes multiply to protect vested interests, including those of the entrepreneurial self. From our readings of the texts for this article, we have learnt that human capital can be seen as affecting not just future earnings: it is also becoming a prerequisite of one's life-work. If we recognize the collective aspect of human capability development, however, might we be able to do something different with it? How can the creative capabilities inherent in the intern be understood, developed, and exercised in a form of solidarity that benefits others?

\section{References}

Becker, Gary. 1964. Human Capital: A Theoretical and Empirical Analysis with Special Reference to Education. Princeton: Princeton University Press.

Bennett, Andy. 2013. You Get OWT What You Put In. Intern 1: 1-9.

Bourdieu, Pierre. 1984. Distinction: A Social Critique of the Judgement of Taste. London: Routledge.

Bourdieu, Pierre. 1986. The Forms of Capital, In Handbook for Theory and Research for the Sociology of Education, edited by J. Richardson, 241-258. New York: Greenwood Press.

Bourdieu, Pierre and Loic Wacquant. 1992. An Invitation to Reflexive Sociology. Chicago, IL.: University of Chicago.

Bridgstock, Ruth. 2012. Not a Dirty Word: Arts Entrepreneurship and Higher Education. Arts and Humanities in Higher Education 12 (2-3): 122-137.

Brown, Wendy. 2003. Neo-liberalism and the End of Liberal Democracy. Theory \& Event 7 (1). Accessed June 15, 2014. http://lchc.ucsd.edu/cogn_150/Readings/brown.pdf.

Brown, Wendy. 2010. Wendy Brown Interview. Accessed June 15, 2014. http://marxlacanzizek.wordpress.com/2010/02/28/wendy-brown-interview/.

Brown, Wendy. 2013. Neoliberalism, De-Democratization, Sacrifice. La Clé des Langues. Lyon: ENS LYON/DGESCO. Accessed June 13 2014. http://cle.ens-lyon.fr/anglais/neoliberalism-dedemocratization-sacrifice-181089.kjsp?RH=CDL INF010000\#page.

Breugel, Irene. 2005. Social Capital and Feminist Critique. In Women and Social Capital, edited by Jane Franklin, 4-17. London: London South Bank University. Accessed June 132014. http://www.Isbu.ac.uk/ data/assets/pdf file/0007/9439/women-social-capital-families-researchworking-paper.pdf.

Coleman, James. 1988. Social Capital in the Creation of Human Capital. American Journal of Sociology, Vol. 94: 95-120.

Cooper, Daniel. 2013. Reflections of a Nomadic Designer. Intern 1: 1-8 
Creative Skillset. 2012. Annual Report 2011-2012. Accessed June 22, 2014. http://creativeskillset.org/about us/publications.

Dowling, Emma. 2012. Tales of "Much of a Muchness": Adventures in the Land of Social Capital. Ephemera: Theory and Politics in Organization, 12 (4): 480-485.

Dudson, Alec. 2014. Editor's Letter. Intern 2: 5.

Equality Challenge Unit. 2010. Work Placements in the Arts and Cultural sector: Diversity, Equality and Access. Accessed June 15, 2014. http://www.ecu.ac.uk/publications/files/work-placements-in-the-artsand-cultural-sector.pdf/view.

England, Paula and Nancy Folbre. 1997. Reconceptualizing Human Capital. Presented at the annual meetings of the American Sociological Association, Toronto, Canada, August 1997. Accessed June 12 2014. http://apps.olin.wustl.edu/macarthur/working\%20papers/wp-englandfolbre2.html.

Feher, Michel. 2009. Self-Appreciation; or, The Aspirations of Human Capital. Public Culture 21 (1): 2141.

Fine, Ben. 2010. Theories of Social Capital: Researchers Behaving Badly. London: Pluto.

Foucault, Michel. 2008/1978-9. The Birth of Biopolitics: Lectures at the Collège de France 1978-1979. New York: Palgrave Macmillan.

Germains, Gemma. 2014. The Lost Generation. Intern 2: 17-21.

Granovetter, Mark. 1973. The Strength of Weak Ties. American Journal of Sociology 78 (6): 1360-1380

Grugulis, Irena and Dimitrinka Stoyanova. 2011. The Missing Middle: Communities of Practice in a Freelance Labour Market. Work, Employment \& Society 25: 342-351.

Hancock, Matthew. 2014. Speech. Accessed June 15, 2014. https://www.gov.uk/government/speeches/strengthening-links-between-education-andemployment.

HEA. 2015. Employability. Accessed April 2015. https://www.heacademy.ac.uk/workstreamsresearch/themes/employability.

Hope, Sophie and Joanna Figiel. 2012. Intern Culture. Accessed June 15, 2014. http://www.artquest.org.uk/uploads/recovered files/Intern\%20Culture\%20report.pdf.

ICA. 2014. ICA Student Placement: Creative Department - Exhibitions. Voluntary Role Description. London: ICA.

Lee, David. 2011. Networks, Cultural Capital and Creative Labour in the British Independent Television Industry. Media, Culture \& Society 33 (4): 549-565

Lindsay, Tim. 2013. Ideas Need People. Intern 1: 1-10.

Low Pay Commission. 2014. National Minimum Wage Report. Accessed April 2015. https://www.gov.uk/government/uploads/system/uploads/attachment_data/file/288847/The_National_M inimum Wage LPC Report 2014.pdf.

Moore, Phoebe. 2009. UK Education, Employability, and Everyday Life. Journal for Critical Education Policy Studies 7 (1): 243-274.

Page, Libby. 2014. Arts Universities Oppose Unpaid Internships. The Guardian, January 9. Accessed September 12, 2015. http://www.theguardian.com/education/2014/jan/09/arts-universities-againstunpaid-internships.

Perlin, Ross. 2011. Intern Nation: How to Earn Nothing and Learn Little in the Brave New Economy. London \& New York: Verso.

Pearce, Jone.L. 2000. Employability as Trustworthiness. In Relational Wealth: The Advantages of Stability in a Changing Economy, edited by C. R. Leana and D. M. Rousseau, 79-90. New York: Oxford University Press.

Putnam, Robert. 2000. Bowling Alone: The Collapse and Revival of American Community. New York: Simon Schuster.

Quito, Anne. 2014. Casting Jessica Walsh. Intern 2: 22-28.

Ragpickers. 2013. Ragpickers Collection. Accessed November 20, 2014. http://ragpickers.tumblr.com/collection.

Schultz, Theodore. 1961. Investment in Human Beings. Chicago: Chicago University Press.

Segal Hamilton, Rachel. 2013. Alec Dudson: Intern Magazine. Ideas Tap, September 16. Accessed September 12, 2015. http://www.ideastap.com/ldeasMag/the-knowledge/alec-dudson-intern-magazineinterview. 
Siebert, Sabina and Fiona Wilson. 2013. All Work and No Pay: Consequences of Unpaid Work in the Creative Industries. Work Employment Society 27: 711-721.

Smith, Vicki. 2010. Enhancing Employability: Human, Cultural, and Social Capital in an Era of Turbulent Unpredictability. Human Relations 63: 279-300.

Social Market Foundation (SMF). 2010. Disconnected: Social Mobility and the Creative Industries. London: SMF.

\section{About the Authors}

Sophie Hope

Sophie Hope is a practice-based researcher in the Film, Media and Cultural Studies Department at Birkbeck, University of London. She has worked as an independent curator and evaluator of public and socially engaged art and developed a number of practical projects through which to research cultural policy, labour conditions and community art histories. Her PhD (completed in 2011), entitled "Participating in the Wrong Way? Practice Based Research into Cultural Democracy and the Commissioning of Art to Effect Change," explored the limits and possibilities of criticality in the context of an artists' contract.

\section{Joanna Figiel}

Joanna Figiel is a doctoral candidate at the Centre for Culture Policy Management, City University London. Her research focuses on labour issues, unpaid work, precarity and policy within the creative and cultural sectors. She is a member of the ephemera editorial collective and collaborates, among others, with Minor Compositions, Artleaks, and the Free/Slow University of Warsaw. 


\title{
What Killed Moritz Erhardt? Internships and the Cultural Dangers of "Positive" Ideas
}

\author{
Bogdan Costea*, Peter Watt**, and Kostas Amiridis* \\ *Lancaster University, Lancaster, UK; ${ }^{* *}$ York St John University, York, UK; \\ b.costea@lancaster.ac.uk
}

\begin{abstract}
Moritz Erhardt's tragic death as an intern at Bank of America Merrill Lynch in August 2013 provides an illustration of the cultural intensity and complexity that has come to imbue internships in higher education degree schemes. We offer an analysis of internships as part of a wider process of dissemination and proliferation of managerial vocabularies and images that underpin certain hyperperformative practices that permeate the powerful cultures stimulated by and sustained in many organizations. We analyze the cultural ground from which such practices might be seen to arise and present an interpretation of how certain "positive" themes and motifs-such as "potentiality", "selfexpression", or "self-realization"-can become dangerous. These categories become dangerous once they are constituted as ideal measures of an unattainable level of performativity which can then become destabilizing and disorienting for any individual's sense of self. In this sense, the paper contributes to the growing body of literature investigating the significance of internships in the new cultures of work characterizing the broader context of neoliberalism.
\end{abstract}

Keywords: internships, management, performativity, employability, self-actualization, self-realization, potential, work culture, soft capitalism

\section{Introduction}

This paper begins with a section discussing the tragic episode in which an intern lost his life in a direct attempt to demonstrate his passion and commitment to a financial institution in order to secure a future position in it. In the second part (sections 2 and 3 ), we analyze how internships have become part of a much more extensive cultural process in which management vocabularies and images seek to mobilize certain values and inclinations that reach deep into the sensibilities of the current young generations. Finally, in sections 4 and 5 , we provide an interpretation of how management is able to use broader cultural motifs and tendencies in such a way that they become indistinguishable from two central values of our time: "self-expression" and "self-realization" (see also Rose 1999a, 103-119).

We consider the ways in which internships have become regimes connecting certain cultural ideals and promises that have the capacity to mobilize extreme forms of practical engagement with work and organizations. Even though internships may appear to be relatively limited episodes of a working life, we will try to show how they are part of a cultural process in which management and business constitute ways of defining what an individual might be worth, and thus how management ideas play an increasingly subtle and far-reaching role in relation to the self.

In an extensive autobiographical interview, the distinguished philologist George Steiner made a comment, which seemed (and still seems), at first sight, to capture very well a sense of loss of cultural direction and a disoriented system of values:

The young in Europe have never been as hopeless [...] [They have] no sense of an ideology, no sense of any political or utopian future [...] Never forget that if you don't commit great creative mistakes when you're young the rest of your life is largely wasted. You have at least lived the essential passion of commitment which should be that of the young. There is nothing of the kind today. Nobody is going to die for a hedge-fund, nobody is going to die for the enormous entertainment industries, for the mass media, for the athletic worship-which is all the young have. (Steiner 2007) 
It seems so unproblematic to agree with Steiner's comment and its formulation. It seems especially easy to grasp the idea of an unwillingness to "die for" what amounts to a set of hollow cultural objects and institutional sites which claim exclusive attention and yet are just as easy to dismiss on grounds of their apparent worthlessness. And yet, we will try to argue, there is a serious danger accompanying this very manner of dismissing a cultural process that seems, despite its alleged vacuity, to be still able to mobilize the energies of contemporary youth. Who would declare his or her willingness "to die for a hedge-fund"? Probably not a single individual.

Nonetheless, to take this statement at its face value would also leave out, in our view, the other side of the phenomenon Steiner seeks to elucidate: the fact that all those hollow, empty sites currently claiming the passion and commitment of the young are actually capable of mobilizing something that Steiner does not account for, namely, their power to take individuals willingly to the limit of their own capacities. Steiner appears unable to see that hedgefunds, entertainment products, and certainly the manifold forms of advertising and social media are capable of formulating a new kind of promise which can, in the current cultural context, become the ground for intense, passionate, and dangerous personal engagement (see also Ewen 2008). What Steiner overlooks is that these institutional and discursive sites are permeated and sustained by a political orientation which, whilst not conforming to the traditional forms he invokes, has nevertheless become an equally powerful force in the mobilization of youth and its energies towards an "essential passion of commitment."

In the spirit of Michel Foucault's (1970; 1980) and Nikolas Rose's (1999a; 1999b) analyses of the rise of neoliberal regimes of power, however, we argue that the system of ideas circulating throughout the sphere of management has acquired far more subtle and dangerous forms of dissemination and communication. The domain of internships, as one instance amongst many, shows how a set of discursive themes (such as potentiality, performativity, self-development, or self-actualization) makes possible not only the diffusion of their own power throughout the culture of work organizations, but their very insertion in the private, intimate domain of the self (also discussed by Gregg 2011, albeit with a different focus). As shown by Rose, the context of employment has come to be precisely a place where "[t]he division of work and life has not only become blurred at the level of reality, it has also become permeable at the level of images and strategies" (1999b, 158). The result has been the rise of a performative culture that surrounds work but also goes well beyond it, certainly now in the culture of higher education, a culture characterized by "a more dispersed, but more intensive, inscription of the obligation to work into the soul of the citizen, not a reduction of the principle or ethic of work but, in many ways, its intensification" (ibid.).

Perhaps what makes graduate internships notable, as part of the contemporary labour market, is the way in which they illustrate Karl Marx's intuition that the production of value in the work process comes to be displaced, in the context of modern capitalism, from the production of "direct use values" and "subjugated", in its "every moment", to "exchange" as such (Marx 1973, 408). Whilst we cannot fully develop this aspect here, it is important to make this insight explicit. It indicates a way in which it becomes clearer how pure performativity in work-in other words, the pure acting out of the appearance of work-becomes the basis upon which the value of work is perceived and ascertained. In Marx's understanding, "Commerce [...] appears here [...] as an essentially all-embracing presupposition and moment of production itself" (ibid.). "Exchange", expressed in "commerce" as an overwhelming feature of capitalism, becomes the manner in which performativity begins to dominate the understanding of value in the current context of capitalism and thus becomes a defining parameter of work as such.

\section{The Case of Moritz Erhardt}

At 8:30pm on Thursday, 15 August 2014, Moritz Erhardt, a twenty-one year old student intern at Bank of America Merrill Lynch, was found dead in the bathroom of his shared accommodation in London, England. Colleagues raised the alarm when Erhardt did not turn up for a 2 
pm meeting that day (Day 2013). The cause of Erhardt's death was eventually considered unsuspicious and has since been understood as the result of an epileptic seizure, a seizure believed by the coroner investigating the case to have been triggered by a prolonged lack of sleep (Kennedy 2013).

Erhardt was a German student from Staufen who, at the time of his death, was coming to the end of a seven-week placement with the bank. Toward the end of his summer internship, Erhardt decided to work three days and nights in a row (roughly 21 hours of 24) in order to show his commitment in the hope that he will be offered a full-time position at the end of his studies. This hope has been captured by the notion of "hope labor" by Kathleen Kuehn and Thomas Corrigan $(2013,9)$, which explores the inherent tensions between working in the present "for free", as it were, in the hope that "future employment opportunities may follow." Unaware that he had already shown himself to be so capable that the bank was indeed preparing to offer him a full-time job as a $£ 45,000$ per year analyst after his graduation, Erhardt engaged in a practice well-known amongst interns and other employees in the sector: the "magic-roundabout":

Over a 72-hour period, he got a taxi back from the office to his flat in Bethnal Green, east London, at around 5am each morning. He would then shower briefly before returning to his desk. This exhausting ritual is known in banking circles as the "magic roundabout"so-called because the taxi driver will sometimes wait outside while an intern washes, puts on a fresh shirt and re-emerges blinking in the dawn light. (Day 2013)

In another report, a fellow intern "claimed that Mr. Erhardt '[...] apparently pulled eight allnighters in two weeks. They get you working crazy hours and maybe it was just too much for him in the end"' (Gallagher 2013).

The reports of Erhardt's death did not have much to go on other than the subsequent interpretations offered by those who knew him; however, these too are limited by the fact that Erhardt was not doing anything new within the work culture characterizing this particular bank, nor was his own tendency to work long hours new in itself: "Users of the popular finance blog wallstreetoasis.com insisted Mr. Erhardt regularly worked long hours, with his final three days consisting of 21-hour stints in the office" (Gallagher 2013). Moreover, nothing out of the ordinary was noted perhaps also because Erhardt did not declare his condition to anybody around him in London, including his employers. Jürgen Schroeder, Erhardt's Development Officer at the bank, told the inquest that no one at the bank had been aware of the intern's history of epilepsy. He told the inquiry that Erhardt was highly rated, well-liked, and was going to be offered a job, adding that "he had hinted as much to Erhardt the day before he died" (Malik 2013).

The reports noted that Erhardt was a bright and handsome young man who had a tendency to work hard and party equally hard. His father, Hans-Georg Dieterle, a psychoanalyst and "life coach", warned him about the possibility of exhaustion, "but, like many young people, Moritz took parental advice lightly" (Day 2013). Yet this was no simple adolescent refusal; rather, his father explained, Erhardt was moved by a more fundamental sense of good intention: "He wasn't just interested in the money. He wanted to do good in the world. I've been sorting through some of his things and I found a quote from Marilyn Monroe he'd made a note of which went, 'I don't want to make money, I just want to be wonderful,"' his father said (ibid.).

However, the reports note that his father told everyone that the bank's staff could not have been more supportive in the aftermath of Erhardt's death, and that he does not blame them for not spotting the warning signs earlier. If there was any sense of anger, Mr. Dieterle said, "it would only be 'with Moritz for not having taken care of himself" (ibid.):

He can imagine, he says, that part of what Moritz loved about the work was the intensity and the esprit de corps that developed during those long days and nights in the office. He compares it to the endorphin rush experienced by long-distance runners or mountaineers who push themselves to climb further without oxygen. The bank wasn't exploiting his son, he insists. Instead, Moritz "was exploiting himself." (ibid.) 
This analogy was professed in a similar way by a Deutsche Bank executive interviewed for the Harvard Business Review: "My work gives me this adrenalin rush. Like a drug, it's irresistible and addictive" (Hewlett 2007). This tendency to respond to the demands of highly pressured roles by participating in long-hour cultural regimes of work has been categorized as "extreme work" (Hewlett and Luce 2006). Internships have become part of this tendency and the reports following Erhardt's case have revealed the widespread nature of long working hours and its close connection with high levels of competitiveness amongst interns and graduates. Erhardt was indeed seen by those around him precisely in this light: he was described by them as a "superstar" (Malik 2013); but he also saw himself in these terms: "... according to his biography on the social media platform Seelio, Erhardt had spoken about his 'highly competitive and ambitious nature' and shown all the outward signs of wanting to be a high achiever and driving himself to that end" (Malik 2013).

However, what emerged at the same time was that the culture of long hours and the more extreme practices that arise from it are not rejected by those who engage in them, rather they often stem from their own initiative and are not elements of formal management systems:

One City intern, who wanted to be known only as Alex, told the Guardian that working for more than 100 hours was normal, but said that despite the pressures he and other interns enjoyed the experience. "On average, I get four hours' sleep about $70 \%$ of the time ... [but] there are also days with eight hours of sleep", Alex said. "Work-life balance is bad. We all know this going in. I guess that's the deal with most entry level jobs these days." He added that despite the amount of time spent in the office, he "enjoyed it greatly."

Alex said it was not uncommon for interns to leave the office in the small hours in a cab only to have it wait outside their flat while they showered, changed and returned to the office. But he said that the practice, known as "the magic roundabout", was an exercise in comradeship. "It's more like a college all-nighter; everybody has to do it. It is more fun that way."

Abdurrahman Moallim, 21, a recent intern at a major multinational bank, said there was an element of one-upmanship involved in working flat-out. "All-nighters are often worn as a badge of honor-it's common for interns to brag in the morning about the long hours they've worked the night before. Everybody wants to show they have what it takes to succeed in an industry which demands stamina." (Malik 2013)

In the end, perhaps the key comments remain those of Erhardt's father: he saw in Erhardt's death an expression of an internal drive expressing his son's own sense of personal direction and aspiration. But is it all that simple to interpret what happened to Moritz Erhardt and to see the significance of his passing? Erhardt's intense involvement in his summer internship seems to have been more than a mere exception. Rather, he internalized an overpowering culture of performance whose dynamic is much more equivocal than could be deciphered if we allow his drama to remain understood as a mere "industrial accident." The entanglement of self-declared personal aspirations with cultures of extreme office work encouraged by corporate institutions in various sectors makes the question "what killed Moritz Erhardt?" not as simple as any one-sided answer might make it seem: Was Erhardt exploited by the banking sector? Or did Erhardt exploit himself? The problem is that both these questions are not helpful in this formulation. Both presuppose a known subject (either the bank, or Erhardt) and a known predicate (exploitation); and both presuppose that it is possible to operate a clear separation between one subject and the other, between one sphere of interests and the other; both can be reduced in fact to the formulation: "Who killed Moritz Erhardt?" And this is the most tempting one, because it is the simplest: it provides a crime and a victim. To such a question there can be but a single answer, one predicated moreover upon an unequivocal logic: as the victim of an institutional practice, Erhardt can only be innocent. Once the culprit is found, the complexity of conditions that made possible the entire story would disappear leaving a simple, cleansing, and redeeming picture in its stead. We would then "know", as it were, who is to blame, who is "good" and who is "bad." Unsurprisingly, in the current circum- 
stances, the reports of the case in the ensuing months were clear: the bank and the financial sector are responsible for generating and tolerating a culture of work around internships and early graduate career positions which allow rather punishing forms of individual behaviour.

More importantly, that "who" would be confined to a particularity, to a singular context in which an "error of judgment" occurred and which then requires a correction. Erhardt's case would not represent "us" then, and by "us" we mean a more universal set of possible conditions and values in the name of which, to speak against Steiner's statement, there may well be a form of more generalized willingness to "die for a hedge-fund." In other words, we will try to show that simply asking the question "who killed Moritz Erhardt?" in order to dispense with this particular case would be to miss the opportunity to ask instead "what killed Moritz Erhardt?" We argue that this would provide a different kind of starting point in an interpretation of the conditions of possibility that seem to bring together and align to a significant cultural extent, the values and orientations of interns and graduates such as Erhardt, with the values and orientations of corporate cultures. In other words, one of the questions which seems to us to be equally legitimate, following on from Erhardt's tragic experience, can be formulated in the following terms: what were the conditions in which he took himself to the limit, and how was an internship the place of testing boundaries, rather than adhering to them?

\section{3. "Unlimited Plenitude" as an Underlying Feature of Internship Culture}

The answers to these questions can take various forms. On the one hand, it can be argued that Erhardt's tragic end was driven by a specific and unfortunate set of physio-pathological factors, combined with a failure on his behalf to manage his own physical condition, or to ask for help. On the other hand, it can also be argued that it was a failure of the work organization to provide systems of containment of possibly harmful exertion: a system of time management, perhaps. In both cases, Erhardt's case would be regarded as an unfortunate "industrial accident"-an accident caused by a badly managed system of production. It is important to note that these possible responses have one thing in common: the premise that something was lacking, that there was an oversight somewhere or other-that systems of collective and individual management have failed.

However, we propose it is worthwhile exploring what might be revealed if we change this premise and look at this case from a different angle. Instead of trying to find the dangers caused by failures and shortcomings of management systems, we suggest that it is just as important to analyze the dangers of those cultural processes in which new management discourses and communications processes succeed. That means that we might be witnessing, in the case of Erhardt, the outcome of a particular way in which managerial themes have succeeded in positing and proliferating an image of work and human resourcefulness through which an individual is aligned to an ideal type characterized by what might be termed unlimited plenitude. As we seek to illustrate in this section, management vocabularies and images surrounding internships and graduate jobs have grown to an unprecedented extent precisely around the themes of plenitude. As we have shown elsewhere (Costea, Amiridis, and Crump 2012), the motifs of individual potentiality, performativity, and perfectibility suffuse the culture of graduate work. "Unlimited plenitude" aims to capture what Foucault termed a discursive "strategy": a "theme" (rather than a "concept") which connects the different ways in which various media channels construct an idealized image of the intern as a subject who is not only characterized by an abundance of potential and possibilities, but is also driven by a sense that this abundance can and indeed must be endlessly sustained (Foucault 1972, 64).

The word "plenitude" comes from the Latin plenus which means full and from which derives the word plenitudo which denotes completeness and abundance (Lewis and Short $1879,1386-1387)$. It is important to pause upon these two meanings. As we will try to show in this section, our argument is that what happened to Erhardt was not simply an experience of his own "self" as being abundantly full of possibilities. Rather, it is not only that he thought of himself as abundantly capable of handling work to the limit, but it might be the case of a more subtle and more crucial cultural mechanism that triggered Erhardt's carelessness with 
himself and his condition: the idea that he can actually go beyond the limit. What he seems to have succumbed to is a mentality whose ground is that he can hold and live in the name of the idea that he has no limits, that there is always "more" to be brought out, actualized, from the plenitude of his potential. Erhardt did not feel complete, formed, full-he rather seems to have felt compelled by, and towards, a far more dangerous horizon: a horizon through which managerialism has succeeded to represent work as a form of ultimate self-empowerment, self-expression, and self-realization. This is an argument pursued by Kathi Weeks (2011) in her analysis of the ways in which work is not simply represented as a necessity, but also as a "good" in itself: working more, performing more, means at the same time a chance to become more involved with the so-called "realization" of one's possibilities.

How can we explain this success of managerial culture? How could management themes of such dangerous and tragic intensity have become so subtly inserted in the context of internships and graduate positions? Erhardt's life and death thus enable another kind of question: not just how many failures of management can be detected here, but rather how can we understand the very success of managerial, organizational, and societal cultures which is expressed in their ability to reach into the deepest recesses of the modern soul, into its very sense of mortality?

A further comment must be added here. The first internal response of the bank Erhardt worked for was to set up a panel of senior managers to review the entire case. The outcomes of this review were presented in a memo to staff sent on 10 January 2014 in which Bank of America Merrill Lynch begins to address the question of how to maintain its "effectiveness" whilst finding some way of limiting the work regime driven by the bank's culture and practices (Wright 2014). The memo appears, unsurprisingly, confined to some measures of work reduction, further "support" for "work-life balancing", and obligatory days off. However well-intended these measures might be, what appears to be at stake here is not a failure of management systems and principles. In fact, the problem organizations such as this bank face is not their inability to "motivate", but their excessive ability to mobilize the will to work: "empowerment", it seems, is not lacking -it is, it seems, all too successful.

In order to understand how internships have become so important, it is necessary to contextualize their growth in the context of the rise of the "graduate" as a central dimension of the corporate labour market. Over the last two decades, the "graduate" has become a recurrent figure and a core motif in management discourses and in contemporary culture more broadly. Significant efforts in official public policy, both in the "old" economies of the West, but also in the emerging economies of the East and South, have made the idea of having (at least) a higher education degree as an almost sine qua non condition of full participation in what began to be projected in the 1990s by highly prominent political and business figures around the world as the coming "society of knowledge"-termed variously as "the information superhighway" (first coined by Al Gore Jr. in 1978), "Infobahn" in German circles, a concept which settled later in the much broader and more significant concepts of "knowledge economy" and "knowledge society". The extent of the importance of these terms for the evolution of the "graduate" became manifest in targeted policies to increase numbers of school leavers joining higher education, of which one of the more notorious examples was New Labour's promise in the 1997 Manifesto for the General Election that "half of eighteen year olds to go into university studies" (Labour Party, Great Britain 1997).

As management circles also became intensely preoccupied with capturing the rise of what appears to be the "new economy" (Drucker 1994, 2002; Böhme and Stehr 1986; Nonaka and Takeuchi 1995; Castells 2011), an important organizational trend became established: the steady separation of a new system of job allocation for graduates and the consolidation of graduate schemes across all sectors of activity and industry. This consolidation took place through the steady growth of the "graduate scheme" as a new form of employment, whose explicit focus is the "graduate" (see, for example, one of the core sources in Europe and the UK: Birchall 2011; 2013). These are a kind of apprenticeship programme structured through a combination of work and training and are targeted to recent graduates. They are highly competitive, operating in the context of a normal open labour market. They are offered mainly by large employers; they may last for a period of three months to three years, and, on suc- 
cessful completion, the incumbents normally tend to be offered permanent positions and sometimes a professional qualification. In many sectors of the economy, private and public organizations, large, medium, or small, now follow this path and generate such schemes to the extent that they have now become nearly obligatory elements of employment policies and practices. Companies vie for the attention of "graduates" in various contexts and especially seek to take this new form of labour market competition to the university campus itself. In this context, internships become an almost obligatory point of passage towards a graduate job. In fact, in many cases the internship is a necessary condition for any realistic chance of securing employment.

Some of the most recent available data show that this pattern of employment becomes of further importance to any future graduate through the fact that 40 percent of all job offers in these highly sought-after schemes (e.g., Aldi, Accenture, and PricewaterhouseCoopers, but also the Civil Service in the UK, or charities such as Cancer Research UK) are made through internships that are part of degree programs (Paton 2014). This trend is significant because it has led to the emergence of a cultural machinery of promotion and recruitment, which has, in turn, generated an inextricable entanglement of work and study. This extensive preoccupation with work, rather than the preoccupation with study as such, has accompanied the rise of the "graduate" as a figure of prime importance even before university studies are concluded. It is in this reordering of priorities that internships have come to occupy such a prominent place in the expectations of both students and academic institutions themselves, and is central to what has come to be known as "employability".

\section{Internships in the Culture of Soft Capitalism}

From every corner of secondary school career advisory services, colleges and universities, from various notice boards and websites, to family dinner tables, as much as in governmental policy documents, current generations of students are surrounded by the exhortation to pursue academic study as a path to becoming employable, as well as a path towards a promised future of personal development, self-actualization, and success. Rebecca Boden and Maria Nedeva note that the narrow sense of what a graduate has to do to become employable in terms of "simply gaining and retaining fulfilling work" has been superseded by an expanded sense seized upon by Lee Harvey as "the propensity of the graduate to exhibit attributes that employers anticipate will be necessary for the future effective functioning of their organization" (Harvey 2000 in Boden and Nedeva 2010). And there is no shortage of statements that describe and display these attributes, so much so that it can be argued that the images of the ideal type that comes under the label "graduate", and which includes the culture of internships as its preliminary stage, have come to constitute a media genre in itself both in management discourses and in popular culture.

The proliferation of these images is relatively new in its intensity and omnipresence. It seems to have emerged over the last decade or so. Yet the complexity of this genre and its manifold forms of expression has grown to such an extent that they became key reference points for what it might mean to have the sense not just of work, but of a "worthwhile life" as a whole. This sui generis media genre takes multiple forms: highly complex job advertisements, even more complex internet recruitment campaigns, dedicated collections of job and internship opportunities (see, for example, The Times Top 100 Graduate Employers annual collections), specialized consultancies and counselling publication series, dedicated newspaper columns, but also school and university "employability" services, and its apparatus is self-disseminating in the sphere of social media. This plethora of means is suffused with images of work and personal success whose status has now become iconic. Through the diffusion of such images, texts, and practices, the "graduate" is configured as an ideal of personal achievement and, more importantly, as a process of self-development and self-realization. The promises made by management discourses are significant and have already weighty cultural consequences.

A survey of these cultural effects has been produced by Carina Paine and Sue Honore for the Institute of Leadership \& Management at the Ashridge Business School in 2011 (Paine 
and Honore 2011). It follows a series of previous analyses of the cultural phenomenon termed "Generation Y" by the two authors. In this survey, Paine and Honore outline a series of themes that provide important starting points for thinking about the nature of the ideal type of the "intern" and the "graduate" in the contemporary imagination.

To begin with, Paine and Honore identify a tendency to expect that higher education degrees will offer a particular life direction and enable the definition of a path in life. Students and aspirants enroll in higher education programs thinking that the process will uncover numerous possibilities for both career growth and for a direction in life. They show that current generations of students and graduates are strongly motivated not just by salary levels but also and especially by "status and career advancement, and expect rapid progress in these areas" (ibid., 2). Such expectations are significant in terms of their intensity and rhythm of career mobility. They found that " $56 \%$ of graduates expect to be in a management role within three years of starting work, while $13 \%$ of graduates expect a management role within a year" (ibid.). Inevitably, they also found that more than a third of graduates find their sense of direction somewhat confounded by the limits of organizational environments with respect to such expectations. The impression that being a graduate, especially on a management training scheme, ought to be accompanied by an almost automatic entitlement to promotion, power, and authority is not, indeed could not be, borne out by entry-level positions, yet a sense of entitlement appears to be more prevalent amongst members of Generation $Y$ than previously.

The second core aspect of Generation Y's expectations of work is "a high degree of freedom and autonomy" in organizational settings: "Graduates want their organizations to: respect and value them (43\%); support them with career progression (36\%); trust them to get on with things (35\%); and communicate well with them (34\%)" (ibid., 3 ). This is combined with the expectation that organizational membership functions more in a cultural paradigm of friendship rather than mere hierarchical authority. Paine and Honore found that graduates of Generation $Y$ prefer to see their superiors as coaches, mentors, and friends: 'Graduates' ideal manager is a coach/mentor $(56 \%)$ or friend $(21 \%)$ rather than someone who directs $(8 \%)$ or examines and audits (2\%)" (ibid., 2-3). Moreover, the high expectations of personal progress in work are combined with the tendency to see the future in terms of high mobility. Students today, whilst being broadly engaged at work, are not offering "long-term commitment to their employer, with most looking to move on within two years" (ibid., 3). The expectation of personal independence and unrestrained mobility in employment is, at the same time, combined with the demand that every organization will provide respect and trust as well as open and "friendly" communication and relationships. Paine and Honore conclude with an essential point: the images of what it means to be a graduate, of what work as a graduate entails, and of the general horizon of personal life and "progress" have come to be shaped by a sense of "ambition, expectations and focus on the self [that] are part of Generation Y's fundamental make-up" (ibid.). In essence, whilst not explored explicitly in the report, Paine and Honore's work can be interpreted as showing how the cultural expectations of students tend to revolve around four core themes: the sense of a promised path through life, the sense of freedom as a promise and requirement to feel "fulfilled", the expectation of "personal progress" as a constant feature of "graduate" life, and the ambiguous sense that to be a "graduate" becomes both a source of inexhaustible personal mobility as well as the platform for always finding a "home" anywhere where life might take an individual (i.e., the sense that organizations can be expected to function as contexts of trust, respect, and friendship). How did such complex and overestimated expectations come about? What processes prepared their emergence?

To answer such questions, it is important to return to Paine and Honore's survey in which certain aspects of the phenomenon they describe cannot, by the nature of their research, be either apprehended or interpreted within their own empirical data collection process (2011). Their survey focuses the attention on students as isolated participants responding from within an individual's own sense of the present. The response appears to represent the respondent's consciousness over and against a broader context from which he or she is separated. The effect of this positioning is that the image generated by the research frames and focuses 
responses as purely interior reflections and perceptions. As a consequence, the authors make an important argument: they focus on the apparent gap between the expectations of Generation $Y$ and those of their managers and organizations. The outcome is that students' expectations are characterized by a novelty that both surprises and confounds the expectations of their future institutions. It seems that Generation $Y$ brings with it an unprecedented kind of cultural matrix in which a new set of values, ideas, and attitudes are manifest. The authors thus run the risk of missing a key cultural dimension of their research: namely, that the responses provided by Generation $Y$ graduates are not separate from, and simply internal to, this demographic group. They are not separated from the broader culture of management which has emphasized over the last several decades precisely the values that Generation $Y$ now embraces in relation to work. This is evident in the authors' conclusion noted above: "ambition, expectations and focus on the self are part of Generation Y's fundamental make-up" (ibid.).

If this is the case, then this conclusion almost inevitably draws attention to the continuity of values shared between Generation $Y$ and its predecessors, rather than to a gap between them. A more systematic picture of the relationship of continuity between Generation $Y$, contemporary cultural values as a whole, as well as managerial values and tropes in the last three decades is drawn by Paul Heelas (2002). He explores the way in which the values described above as specific to Generation $Y$ actually developed throughout the latter half of the $20^{\text {th }}$ century as part of a much deeper cultural process characterizing secularized modernity. Heelas demonstrates, using Tipton's analysis of four "styles of ethical evaluation" and their transformation since the 1960s (Tipton 1984), that the current period is characterized by a turn both in culture as a whole as well as in management thinking towards what Heelas terms "the ethics of self-work" (Heelas 2002, 79), the ethics of the expressivist culture of the self that became dominant in the last four or five decades. The "focus on the self" noted by Paine and Honore is thus correct but their interpretation as a novelty is historically inaccurate. As Heelas shows, the focus on the self is a tendency that runs deeper in contemporary Westernized culture, which begins to explain more precisely why Generation Y's attitudes towards, and expectations of, work are not split from the existing cultural context. Exploring the meaning of the "ethics of self-work", Heelas shows that it initiates a specific mode of thinking, or mentality, regarding what it means to be an "individual today." He shows that the sources of both authority and value rest with the "self", as seen in the following light:

Not the self as constituted by consumer culture, but the self as a self which considers itself to be something more, something much "deeper", more natural and authentic than the self of what is taken to be involved with the superficialities of the "merely" materialistic-cum-consumeristic; the self as a self which has to work on itself to enrich and explore itself, in the process dealing with its problems. The self-work ethic, that is to say, treats work as something to be valued as the means to those ends espoused by expressive or therapeutic culture. (ibid., 80-81)

He proceeds to demonstrate the extent to which the values of the self-work ethics correspond to the values of a new style of managerial approach for which he uses the category of "soft capitalism" in which personal involvement, creativity, learning, development, culture, and knowledge become central attributes that bestow value upon the working subject:

Soft capitalism involves narratives, more specific discourses, and practices to do with enhancing commitment and motivation; identifying and unblocking "barriers" to success; seeking identity (what it is to become/be a good manager or telephone call center operative, for example); working as a team or as a company; exercising responsibility or initiative; engaging in work ethics, emotion work; "closing the sale"; believing in one's product; and so on. (ibid.)

In other words, Heelas argues: "We are in the land of what can be called the exploratory mode of soft capitalism. Work, that is to say, is taken to provide the opportunity to 'work' on 
oneself; to grow; to learn ('the learning organization'); to become more effective as a person" $(2002,83)$.

As a result, it becomes important to re-contextualize the cultural place of the intern within the contemporary value system as a whole. It is therefore problematic to isolate students and interns of any current generation from this complex whole and to set them apart as "new" carriers of unprecedented or surprising mentalities. Rather, the "intern" becomes a figure in which core values of our epoch coalesce, and not simply as a generational or demographic section of the population, or an economic category. It seems more productive to see the intern as a cultural place where core demands regarding work and their attendant struggles are expressed. Hansfried Kellner and Frank Heuberger synthesized these demands in their volume on "hidden technocrats" in 1994; they show that today work is itself expected to be a place that takes into account:

\begin{abstract}
the importance of an individual's quest for an "unfolded" personality; the justified demands for self-realization, autonomy, and authenticity; the prerogatives of the subjective life, emotional well-being, and intimacy against the demands of rationalized industry, with its controlling pressures, coldness, and abstractness; the rights of private over public life; the individual's search for "meaning" in a world that is held to be devoid of meaningful symbols, plausibility, and credibility; the individual's need for "spontaneity", "immediacy", and expression of hedonistic impulses; the importance of creativity and fantasy. (Kellner and Heuberger 1994, 57)
\end{abstract}

This broad context of values, ideas, and mentalities characterizing contemporary culture becomes an important source for understanding how managerial ideals have become integrated in a wider cultural process. On the one hand, management discourses have the power to shape organizational cultures and contexts through their capacity to make promises; on the other hand, however, management is in turn shaped by societal and cultural expectations with respect to how work ought to be organized, and how it ought to be approached.

Seen in this cultural-historical light, Generation $Y$ does not think about work in ways that have not already been prepared in the last three or four decades, both within management vocabularies and outside them (Rose 1999a; 1999b). The gap between generations begins to fade when we consider that the cultural apparatus through which the themes of personal potential, self-expressivism, and self-realization have been perpetuated from the 1960s onwards and eventually taken over by managerialism though the 1990s and 2000s (Tipton 1984; Thrift 1997, 2000; Heelas 2002). So what really happened to Erhardt in the cultural context and pressures of his high-flying internship?

\title{
5. The Dangers of the "Positive" and the Cultural Power of Self-Realization
}

In this section we want to draw attention to the fact that interns (and graduates more generally) face a more ambiguous and complicated set of cultural forces when joining organizations today. These cultural forces express what Kellner and Heuberger, as well as Heelas and others, have seized upon: that the self-work ethic and the self-exploratory mode of work and performativity have become omnipresent in the "new economy" (Thrift 2000).

Essentially, as shown elsewhere (Costea, Amiridis, and Crump 2012), interns become part of a cultural nexus in which personal success in work is a function of what we have termed the principle of potentiality: a representation of the human subject as capable of becoming always more than what she or he is. Work has come to be represented as a process of freeing up, liberating, and mobilizing an individual's inner qualities, qualities which are supposed to be always ready to be actualized. The managerial genre of the intern, crystallized in the new forms of recruitment materials and in the overall apparatus of employability, contains the promise that work is now a new kind of engagement between individuals and institutions, between private life and public life, between work and non-work, between selfsacrifice and self-realization. In its forms of address to potential interns, managerial culture speaks in a sustained register in which work is presented as a program of personal selfdiscovery. Perhaps a synthetic illustration of this program could make this clear. In the 2009 
edition of the publication The Times Top 100 Graduate Employers (Birchall 2009, 185), the corporations in charge of the nuclear industry in the UK-a group of six public and private institutions, including Rolls Royce for example (Nucleargraduates.com, 2009)—present their internship and graduate schemes in the following form: in the middle of a simple black page, appears a single question: "Who am I?" (At the bottom of the same page, the site nucleargraduates.com indicates the answer: "Explore the exceptional.") This question is the crucial ingredient of the new kind of invitation and promise regarding work which capable individuals like Erhardt can only find impossible to resist. Who can object to the idea that work ought to be the central place where "I" find and express "my" essential humanity? In such artifacts, management discourse articulates both the central ideal of life as well as an inalienable right in contemporary culture: to make one's self what one wants it to be. Through work any candidate can aspire to an always better future, a more fulfilled, self-realized self. It is through this promise that the imagination of potential candidates like Erhardt is captivated by a conception of work represented as a positive opportunity for self-expression and self-realization rather than self-renunciation or repression.

This is how the "Self" (seen in light of Foucault's, Rose's, or Heelas' analyses) becomes reconceptualized as a source of immanent forces and energies, of potentialities which make the "Self" in itself a store of human resourcefulness (Costea, Crump, and Amiridis 2007). The relationship between work and self is thus configured and presented as an "opportunity": the self seems to be given the chance to work upon itself in order to release its own inner potential. The resulting vocabulary, with its now ubiquitous motifs of "creativity", "innovation", "knowledge", "talent", "drive", and "vision", come to be seen and understood as inner possibilities awaiting their exploration and expression, but also as the basis for a cultural demand that work is seen to facilitate. All one needs to do is work hard, develop continuously, and take command of these innate possibilities.

An important historical nuance must be introduced here to explain the power of current images of potential. The portrayal of potential as innate is a subtle shift from the previous uses of terms such as "actualization" or "fulfillment" associated with approaches such as Human Relations, or the Human Potential Movement in the 1960s. In current management discourses, the distinctive attribute of the human subject is that potential is predicated upon an inner plenitude, an abundance of qualities already possessed by the individual. The way in which management uses this presupposition has a specific weight: by attributing innate plenitude to each and every individual, managerialism creates a platform from which it issues the demand that the individual engages with her or his potential, and takes control of its expression and mobilization. This way of portraying the human subject is different than, for example, Mayo's understanding which revolved throughout his work around the dangers of an inner subjectivity which he saw as irrational, emotionally unstable, and a threat to the moral order of work and the organization (O'Connor 1999, 225). Moreover, what he called the "mental hinterland" of the workers (ibid.) posed the further danger of spilling over into the social fabric of organized life, and lead to a collectivity contaminated by maladjustment. Against this psychological danger, the role of management was seen by Mayo in therapeutic terms, acting in the name of enlightened reason to tease out, through the "counselling interview", and control the dark side of the psyche.

The Human Potential Movement manifest in Erhard Seminar Trainings (EST, widespread in the US from the 1960s to the 1980s, and now converted into "life coaching"), or D'Aubigny's Exegesis system (in the UK in the 1970s) similarly conceived of the interiority of the human subject as a source of fears and problems, anxieties and traumatic content, which had to be forcefully, violently at times, evicted in order to make room for a rebirth, for a metamorphosis into a new "self." "Your lives don't work, assholes. Otherwise you wouldn't be here" was the irrefutable introductory statement of EST seminars (according to Tipton 1984, 177). The dynamic of the Human Potential Movement revolved around an emptying of the subject rather than a positing of its inner qualities and potential as source of personal value.

However, as Rose has shown, when analyzed in light of Maslow's, Rogers,' Frankl's, or Fromm's contributions, followed by Argyris, Vroom, or Herzberg, we can establish a substan- 
tive affinity between them and the managerial discourses of the intern today (Rose 1999b, 110). A clear and direct connection can be found in Maslow:

Now let me try to present briefly and at first dogmatically the essence of this newly developing conception of the psychiatrically healthy man. First of all and most important of all is the strong belief that man has an essential nature of his own, [...] that he has needs, capacities and tendencies [...] some of which are characteristic of the whole human species, cutting across all cultural lines and some of which are unique to the individual. These needs are on their face good or neutral rather than evil. Second, there is involved the conception that full healthy and normal and desirable development consists in actualizing this nature, in fulfilling these potentialities, [...] growing from within rather than being shaped from without. Third, it is now seen clearly that psychopathology in general results from the denial or the frustration or the twisting of man's essential nature. By this conception what is good? Anything that conduces to this desirable development in the direction of actualization of the inner nature of man. [...] What is psychotherapy, or for that matter any therapy of any kind? Any means of any kind that helps to restore the person to the path of self-actualization and of development along the lines that his inner nature dictates. (Maslow 1954, 340-341)

Whilst Maslow's conception has been at the center of academic interpretations of work motivation, in terms of its practical deployment in managerial practices, its evolution has been more or less evident over the decades. In the case of current invocations of inner potential in the operation of recruitment and selection of interns and graduates, as well as the commandment to actualize this potential, the Maslowian heritage is perhaps more discernible than ever. An important aspect of this conception is the assumption of the moral "good" of self-actualization and the way in which managerialism seeks to position itself as opening up a path for it.

The essential aspect, which must be highlighted here is that the invocations of potentiality and plenitude function on the fundamental basis that any discussion of the inherent limits of the human subject of work is silenced. The motif of unlimited plenitude revolves around the logic of this silencing, namely as an active denial of human limits. The incessant drive for more performativity, more innovation, more profitability, is the engine of a cultural process underpinned by the denial of human limits.

\section{Concluding Remarks}

Is it possible to answer the question regarding Moritz Erhardt's tragic death as an intern in a high-powered organization: was it an industrial accident, a mere coincidence of terrible misfortunes related to health and work cultures? Of course, it was all of these. Our argument, however, is that there are also other aspects which make Erhardt's story worth reflecting upon and worth bringing into the light of wider tendencies in contemporary management cultures.

We have tried to explore one of these tendencies: the gradual growth of a culture of work focused intensely and unremittingly on the self, a culture which becomes obligatory from the very early stage of careers, so much so that internships themselves become a kind of testing ground for the mettle of individuals. In this sense, the original question, what killed Moritz Erhardt?, becomes more complex and complicated. It seems that Erhardt, and so many others like him, are part of a complex process in which management discourses have appropriated the complex imperative of self-realization. This theme becomes a way of projecting work as an opportunity for the self to express itself. And this imperative is dangerous because it cannot simply be dismissed as a managerial "invention." Erhardt legitimately wanted to find what he himself was "made of." "Who am I?" is a question that functions with such intensity because it is our question, one which presses in on each of us with a legitimacy rooted deeper than its recent uses by management. In fact, management becomes able to insert its own demands in the current cultures of work precisely because it seizes upon legitimate aspirations that come from the interiority of the contemporary self. 
When the self is permanently at stake, self-expression becomes a defining mode of engaging both with the interior and the exterior of consciousness, it becomes a process of almost extreme attempts to give a physical performance of the self's interiority, both publicly and privately. This is what seems to undergird the ritual of the "magic roundabout" of sleepless working. Erhardt seems to have been caught right in the middle of contemporary culture: more precisely, in its performative middle, in that place of the contemporary condition where the binding crux of culture seems to have found its most powerful source. That is, Erhardt was caught at that juncture where the "self" manifests its dominion as the overall form which demands to be incessantly performed by each and every individual. The "self" is that cultural form generating the exhortation characterizing nowadays every social and cultural domain: that any concrete individual must express his or her "exceptional", "unique" "potentialities and talents."

The idea that the "l" has to find itself in a search for inexhaustible potentiality and uniqueness changes the terms of the promises made in various social contracts. The work contract becomes perhaps the most important place where a new horizon of promises can take shape in such a way that the result can be the extreme form of engagement to which Erhardt fell victim. Potential, self-expression, performance, self-realization-these are, in our argument, the dangerous cultural forces underpinning what has become a quasi-dogma of contemporary culture: "positivity." And this doctrine seems to feed and sustain managerial culture in a dangerously robust manner.

The case of Moritz Erhardt also presents the opportunity to open up avenues for comparative research and interpretation regarding its specific cultural context and its nature. In this paper, we have not treated it in comparative terms, but it is important to note that it is an event which occurred in the context of an American institution located in the powerful work culture of the City of London financial sector. In other words, this has to be treated as an instance of specific Anglo-American work cultures. In what way does it compare with the cultures of other regions of the world, with other sectors of activity? How these cultural themes are distributed and diffused in various parts of the world would require a systematic comparative analysis that is beyond the economy of this article, but is the next logical step in a future research agenda.

\section{References}

Birchall, Martin. 2009. The Times Top 100 Graduate Employers 2009-2010. London: High Fliers Publications Ltd.

Birchall, Martin. 2011. The Times Top 100 Graduate Employers 2011-2012. London: High Fliers Publications Ltd.

Birchall, Martin. 2013. Times Top 100 Graduate Employers 2013-2014. London: High Fliers Publications Ltd.

Boden, Rebecca and Maria Nedeva. 2010. Employing Discourse: Universities and Graduate "Employability." Journal of Education Policy 25 (1): 37-54.

Böhme, Gernot and Nico Stehr. 1986. The Knowledge Society: The Growing Impact of Scientific Knowledge on Social Relations. Dordrecht: Springer.

Castells, Manuel. 2011. The Rise of the Network Society: The Information Age: Economy, Society, and Culture. Oxford: Wiley-Blackwell.

Costea, Bogdan, Norman Crump, and Kostas Amiridis. 2007. Managerialism and "Infinite Human Resourcefulness": A Commentary on the "Therapeutic Habitus", "Derecognition of Finitude", and the Modern Sense of Self. Journal for Cultural Research 11 (3): 245-264.

Costea, Bogdan, Kostas Amiridis, and Norman Crump. 2012. Graduate Employability and the Principle of Potentiality: An Aspect of the Ethics of HRM. Journal of Business Ethics 111 (1): 25-36.

Day, Elizabeth. 2013. Moritz Erhardt: The Tragic Death of a City Intern. The Guardian. October 5. Accessed November 3, 2013. http://www.theguardian.com/business/2013/oct/05/moritz-erhardtinternship-banking.

Drucker, Peter F. 2002. Managing in the Next Society. New York: St. Martin's Press.

Drucker, Peter F. 1994. Knowledge Work and Knowledge Society: The Social Transformations of this Century. Harvard University Forum. Accessed December 15, 2014. http://forum.iop.harvard.edu/content/knowledge-work-and-knowledge-society-socialtransformations-century. 
Ewen, Stuart. 2008. Captains Of Consciousness: Advertising and the Social Roots of the Consumer Culture. New York: Basic Books.

Foucault, Michel. 1980. Power/Knowledge: Selected Interviews and Other Writings, 1972-1977. Brighton, UK: Harvester Press.

Foucault, Michel. 1972. The Archaeology of Knowledge. London: Tavistock Publications.

Foucault, Michel. 1970. The Order of Things: An Archaeology of the Human Sciences. London: Tavistock Publications.

Gallagher, Paul. 2013. Slavery in the City: Death of 21-year-old Intern Moritz Erhardt at Merrill Lynch Sparks Furore Over Long Hours and Macho Culture at Banks. The Independent. Accessed November 3, 2013. http://www.independent.co.uk/news/uk/home-news/slavery-in-the-city-death-of21 yearold-intern-moritz-erhardt-at-merrill-lynch-sparks-furore-over-long-hours-and-macho-cultureat-banks-8775917.html.

Gregg, Melissa. 2011. Work's Intimacy. Cambridge: Polity Press.

Harvey, Lee. 2000. New Realities: The Relationship between Higher Education and Employment. Tertiary Education and Management 6 (1): 3-17.

Heelas, Paul. 2002. Work Ethics, Soft Capitalism, and the "Turn to Life." In Cultural Economy: Cultural Analysis and Commercial Life, edited by Paul du Gay and Michael Pryke, 78-97. London: Sage.

Hewlett, Sylvia Ann. 2007. Is Your Extreme Job Killing You? Harvard Business Review. Accessed November 12, 2014. https://hbr.org/2007/08/is-your-extreme-job-killing-yo.

Hewlett, Sylvia Ann and Carolyn Buck Luce. 2006. Extreme Jobs: The Dangerous Allure of the 70Hour Workweek. Harvard Business Review 84 (12): 49-59.

Kellner, Hansfried and Frank Heuberger. 1994. Hidden Technocrats: The New Class and New Capitalism. New Brunswick, NJ: Transaction Publishers.

Kennedy, Maev. 2013. Bank Intern Moritz Erhardt Died from Epileptic Seizure, Inquest Told. The Guardian. November 23. Accessed June 27, 2014. http://www.theguardian.com/business/2013/nov/22/moritz-erhardt-merrill-lynch-intern-dead-inquest.

Kuehn, Kathleen and Thomas F. Corrigan. 2013. Hope Labor: The Role of Employment Prospects in Online Social Production. The Political Economy of Communication 1(1). Accessed October 13, 2014. http://www.polecom.org/index.php/polecom/article/view/9.

Labour Party (Great Britain). 1997. New Labour, Because Britain Deserves Better. London: Labour Party.

Lewis, Charlton Thomas and Charles Short. 1879. A Latin Dictionary. Revised and enlarged edition. Oxford: Clarendon Press.

Malik, Shiv. 2013. Moritz Erhardt Intern Death Spurs Bank of America Merrill Lynch Review. The Guardian. August 23. Accessed June 27, 2014. http://www.theguardian.com/business/2013/aug/23/intern-death-bank-of-america-merrill-lynch.

Marx, Karl. 1973. Grundrisse: Foundations of the Critique of Political Economy. London: Penguin Classics.

Maslow, Abraham H. 1954. Motivation and Personality. New York: Harper \& Row.

Nonaka, Ikujiro and Hirotaka Takeuchi. 1995. The Knowledge-Creating Company: How Japanese Companies Create the Dynamics of Innovation. Oxford: Oxford University Press.

Nucleargraduates.com. 2009. Our Sponsor Organizations | nucleargraduates. Accessed July 1, 2014. http://www.nucleargraduates.com/introduction/our-sponsor-organisations/.

O'Connor, Ellen. 1999. Minding the Workers: The Meaning of "Human" and "Human Relations" in Elton Mayo. Organization 6 (2): 223-246.

Paine, Carina and Sue Honore. 2011. Great Expectations: Managing Generation Y. Institute of Leadership \& Management and Ashridge Business School.

Paton, Graeme. 2014. Four-in-10 Graduate Jobs "Reserved for Student Interns." The Telegraph. January 13. Accessed June 28, 2014. http://www.telegraph.co.uk/education/educationnews/10566757/Four-in-10-graduate-jobsreserved-for-student-interns.html.

Rose, Nikolas. 1999a. Governing the Soul: The Shaping of the Private Self. London: Free Association Books.

Rose, Nikolas. 1999b. Powers of Freedom: Reframing Political Thought. Cambridge: Cambridge University Press.

Steiner, George. 2007. Interview, Part Two. Accessed 13 December 2014. https://www.youtube.com/watch?v=HPtJeGo0P6w.

Thrift, Nigel. 2000. Performing Cultures in the New Economy. Annals of the Association of American Geographers 90 (4): 674-692.

Thrift, Nigel. 1997. The Rise of Soft Capitalism. Journal for Cultural Research 1(1): 29-57. 
Tipton, Steven M. 1984. Getting Saved from the Sixties: Moral Meaning in Conversion and Cultural Change. Stanford: University of California Press.

Weeks, Kathi. 2011. The Problem with Work: Feminism, Marxism, Antiwork Politics, and Postwork Imaginaries. Durham, NC: Duke University Press.

Wright, Ben. 2014. Bank of America Eases Work Conditions For Junior Staff. Wall Street Journal. January 10. Accessed 28 June 2014.

http://online.wsj.com/news/articles/SB10001424052702303393804579312503858867722.

\section{About the Authors}

Bogdan Costea

Bogdan Costea is a Reader in the Department of Organisation, Work, and Technology at Lancaster University's Management School. He pursues three main lines of investigation: subjectivity, work, and managerialism in the context of modernity. They are connected by a common thread linking the growth of Human Resources Management during the past three decades with wider developments in the social sciences and the humanities.

Peter Watt

Peter Watt is a Lecturer in Business Management at York St. John University. His current research draws on contemporary literary fiction to explore the way in which the figure of "the graduate" has become an exemplary theme in which managerial tropes and popular understandings of value come together and intersect.

Kostas Amiridis

Kostas Amiridis is a Lecturer in the Department of Organisation, Work, and Technology at Lancaster University's Management School. His research focuses on the evolution and limits of business ethics, human resource management, and the history of management thought. 


\title{
Under the Cloak of Whiteness: A Circuit of Culture Analysis of Opportunity Hoarding and Colour-blind Racism Inside US Advertising Internship Programs
}

\author{
Christopher Boulton
}

University of Tampa, Tampa, USA, cboulton@ut.edu

\begin{abstract}
Drawing on qualitative fieldwork at three large agencies, this article adapts Richard Johnson's "circuit of culture" (1986) as a framework to examine both the material practices that help reproduce an overwhelmingly white labour force within US advertising agencies and the ideological screens that conceal them from scrutiny, critique, and reform. I argue that efforts to diversify advertising through internship-based affirmative action programs are ultimately undermined and overwhelmed by the more widespread systems of white privilege whereby agency executives and powerful clients bypass the application process and directly place personal friends and relatives into highly sought after internship slots. Furthermore, I contend that such material practices of class preference are masked, and thereby enabled, by ideological screens of colour-blind meritocracy. I argue that colour-blindness leads to meritocracy in theory, but race discrimination in practice, and conclude with a discussion of some possible implications for communication theory in general and critical media industry studies in particular.
\end{abstract}

Keywords: internships, advertising, race, class, labour, ideology, meritocracy, white privilege, affirmative action

Acknowledgement: This research project was funded by The University of Tampa Dana Foundation Grant.

To date, most of the critical work on internships has hinged on the exploitation of labour and the reproduction of class hierarchies, whether it be already indebted college graduates willing to forgo payment in order to get a foot-in-the-door of a desirable industry or those privileged enough to trade economic capital for cultural capital in pursuit of the same (Hesmondhalgh and Baker 2011; Neff, Wissinger, and Zukin 2005; Perlin 2011; Stahl 2012). Such speculative, and indeed risky, investments of time, energy, and value creation in exchange for potential, and often improbable, future pay-offs have been theorized as "venture labor" (Neff 2012), "hope labor" (Keuhn and Corrigan 2013), and even "living in the subjunctive" (Streeter 2014). As Alexandre Frenette $(2013,371-72)$ argues, internships are the most liminal of work spaces as they tend to couple provisional periods of precarious employment (often with no pay and few rights) with the prospect of self-actualization and relative autonomy through future job security and career advancement; many a master has promised his slave deferred rewards in heaven. And yet, while some have proposed eliminating unpaid internships through activism, government regulation, or class-action lawsuits, Frenette (391) warns that such an ostensibly righteous cause could eradicate many internship programs, increase the selectivity of those that remain, and foreclose one of the few points of entry for underrepresented and not-so-well-connected populations. In what follows, I suggest that internships can be problematic not just in terms of class but also race. To do so, I examine how internships in major US advertising agencies, despite being paid and occasionally designated to meet diversity objectives, nevertheless help reproduce race inequalities under the cloak of whiteness.

In May of 2009, Dan Wieden (2009), CEO of Nike's lead advertising agency, shocked a national gathering of the American Association of Advertising Agencies (4A's) - the largest advertising trade organization in the U.S-by criticizing his own agency's hiring of white people to sell black culture as "fucked up." Citing statistics on minority underrepresentation 
across the advertising industry as a whole,${ }^{1}$ he chastised his audience: "I thought, maybe, just maybe it might be more inspirational to hear from someone as screwed up as you are. And you are screwed up, aren't you? I mean look at this room: how many black faces do you see here?" Wieden's focus on African-Americans is understandable. The National Association for the Advancement of Colored People (NAACP) had just released the newest in a series of reports denouncing the advertising industry's unique and persistent inability to hire and promote blacks (Bendick and Egan 2009). Among other indicators of discrimination, the report cited a black-white employment gap thirty-eight percent larger than the labour market in general-a divergence that has doubled over the past thirty years-and a system of "glass ceilings" and "glass walls," relegating blacks to less prestigious support functions (ibid. 33). After reading the report, Nancy Hill, President-CEO of the 4A's-pled no contest: "The numbers speak for themselves" (Hill quoted in Parekh 2009).

Race inequality inside advertising is a familiar problem with a long history and a disturbing present (Chambers 2008; Turow 1997). In the 1960s and 1970s, frustrated by explicit race discrimination at large white-owned agencies, a few black advertising practitioners opened their own shops and rebranded black skin colour as a sign of unique expertise and cultural insight into the lives of black consumers. As Jason Chambers (2008) argues, this positioning of black identity as an entrepreneurial "on-ramp," though successful at first, soon turned to detour as it unwittingly provided white advertisers and agencies with a rationale for not employing blacks to market to white consumers (aka: the "general market") and, instead, resegregated the industry by relegating black employees to black accounts where they would market to their "own" people with much smaller budgets (Chambers 2008, 255). Careers stall and people leave. On-ramp turns to detour; detour turns to exit. As such, Wieden's public confession was an embarrassing, if not altogether surprising, disclosure of a well-known secret hidden in plain sight. For instance, in 2010, the NAACP found that all 52 of the major agency spots aired during the 2010 Super Bowl had white creative directors and warned that a lawsuit was imminent, prompting Advertising Age to predict that the industry's "dismally poor performance in diversity" would "hit a crescendo" in 2011 as "class action attorneys join the fray and push for reform" (Lapchick et al. 2010; Dolliver 2010; Wood 2010). By the following spring, the New York City Commission on Human Rights had concluded that advertising's aversion to hiring minorities seemed so entrenched that "they have to do something to change the entire culture" (Bush 2011). In sum, there is a clear consensus among industry insiders, the NAACP, the trade press, and governmental regulators: advertising has a serious race problem-particularly when it comes to the under-hiring and under-utilization of black employees. Less clear is why and how.

This article draws on qualitative fieldwork at three large agencies to take a closer look at both the material practices that help reproduce an overwhelmingly white labour force within US advertising agencies and the ideological screens that conceal these practices from scrutiny, critique, and reform. I argue that the industry's efforts to diversify its workforce through internship-based affirmative action programs are ultimately undermined and overwhelmed by the more widespread systems of white privilege whereby agency executives and powerful clients bypass the application process and directly place personal friends and relatives-aka "must-hires"-into highly sought after internship slots. Furthermore, I contend that such material practices are masked, and thereby enabled, by ideological screens of colour-blind meritocracy. In short, I argue that colour-blindness leads to meritocracy in theory, but discrimination in practice, and conclude with a discussion of some possible

\footnotetext{
${ }^{1}$ According to Wieden (2009), Latinos, blacks, and Asians make up 14.5 percent, 13 percent, and 4.25 percent of the US population and only 8 percent, 5 percent, and 3 percent of advertising industry employees respectively. So, while all three groups are underrepresented, Asians are faring best, by far, with employment rates around 70 percent of their population percentage while Latinos are 55 percent, and blacks trail a distant third at 38 percent. At the managerial level, the numbers are even worse. Of the 87,000 advertising and promotions managers in the United States, 5.6 percent are Latino, 1.6 percent Asian, and 1.6 percent black (Bureau of Labor Statistics 2011, 20).
} 
implications for communication theory in general and critical media industry studies in particular.

\section{Literature Review: Beyond Representation}

The current study responds to David Hesmondhalgh and Anamik Saha's (2013) call to complement the abundance of research on media content and audiences with a more systematic cultural industries approach to race and ethnicity that is at once theoretical and empirical. More specifically, I seek to go beyond demonstrating inequalities within advertising and move towards explaining why the current situation came about and how it still manages to persist despite a myriad of well-meaning efforts to correct it. Such questions matter precisely because the cultural industries' products communicate "ideas, knowledge, values and beliefs," and thus have the capacity to "exert considerable influence on societies and peoples" (187). Or, as Lee Edwards (2013) puts it, this sector's often racialized conditions of production not only affect the labourers themselves, but also, in turn, inflect the symbolic messages those labourers then work to circulate or suppress. But while the racial and ethnic identities of workers can help shape the form and content of cultural products, the "pipeline" diversity tactic of bringing more employees of colour into media organizations has not always improved the representation of racial minorities in media texts. Whether it be PR practitioners (Edwards, 2013), Latino/a advertising professionals (Dávila 2001), BBC television producers (Cottle, 1998), or Asian filmmakers (Saha 2012), researchers have repeatedly found that creative workers of colour must continue to negotiate, and often pander to, white racial assumptions in order to advance their careers. Such hedging can inhibit creative work by incentivizing conservative and risk-averse strategies such as peddling well-trodden racial and ethnic tropes that can more easily sell through white conduits of approval. Thus, as Devon Carbado and Mitu Gulati (2003) argue, even though "the illegitimacy of an all-white workforce imposes a diversity constraint" on employers, they nevertheless homogenize the hiring process by continuing to favour job candidates of colour that demonstrate their willingness and ability to assimilate, and thereby maintain, the efficiency of a monocultural workplace (1762). In this way, savvy nonwhite workers perform their raced selves through daily strategic identity transactions intended to placate white colleagues (also see Boulton 2014).

And while the preceding body of empirical work has demonstrated how people of colour must often negotiate white expectations in the workplace, critical race theory (CRT) has theorized how whites, in turn, enjoy a race-less form of invisibility-an empty category or the ground of normality against which the figures of more "raced" peoples are measured (Dyer 1997; Shome 2000). Put another way, if whiteness is the canvas, neutral and unassuming, then people of colour are the pigment, different and exotic, such that, in advertising agency settings, whiteness blends in and colour stands out. So, while race, as a category, may be constructed-has a history and is subject to change-it nevertheless produces concrete effects since whites' claims of colour-blindness are largely irrelevant to the successful reproduction of white privilege. As Eduardo Bonilla-Silva (2010) argues, whites reconcile persistent racial inequalities through "color-blind racism." Unlike Jim Crow racism, which is explicitly based on theories of biological and moral inferiority, colour-blind racism is based in a more "reasonable" philosophy of abstract liberalism that endorses equal opportunity in theory but opposes any substantive regulatory policy response (such as affirmative action). Instead, the colour-blind racist presumes prejudice to be in the past and favours free market correctives such as individual choice and the meritocratic dispersal of rewards as the appropriate means to right the scales. However, despite such "blindness," whites still seem to see, and prefer, their own colour almost all the time, choosing to "live in white neighborhoods, associate primarily with whites, befriend mostly whites, and choose whites as their mates," all the while refusing to "interpret their hypersegregation and isolation from 
minorities (in particular blacks) as a racial outcome" but rather just "the way things are" (Bonilla-Silva 2010, 263).

In another study of unperceived white affiliation, preference, and privilege, Royster (2003) found that whites benefiting from networks effectively excluding black men from blue-collar jobs still felt disadvantaged by affirmative action. Their inability to recognize whiteness blinded them to the racial pattern of the family and friendship ties used for "employment referrals, access, and mobility" and that they occurred within "persistent patterns of segregation-equivalent to an American apartheid" $(179,184)$. Royster goes on to describe this process as a form of "embeddedness" whereby any given job has a pool of qualified candidates, but getting notified and hired depends not only on what you know, but also who you know, and how. To get ahead requires being in the right place in the right time, and whites' life chances in the cultural industries are ever increased by their frequent access to those right places. For instance, Kate Oakley (2011) has found that the cultural labour market in the UK, despite its progressive reputation, engages in social exclusion along ethnic lines through unpaid internships and informal recruitment strategies favouring the white and well-connected. Similarly, John Downing and Charles Husband (2005) describe how film and television workers navigate the precarity of irregular employment by forming informal referral networks that tend to exclude minorities and women such that the mentorship of friends helping friends can quickly lead to cronyism. Carbado and Gulati (2003) praise CRT's institutional analysis of racism as structure rather than individual attitude, but also critique the tendency of such a macrocosmic perspective to miss the "microdynamics of race" as played out in complex and contested ways through social interaction in the workplace. This study takes up the challenge to look closer at the microdynamics of the everyday in advertising internship programs.

Most communication scholars addressing race in advertising have done so on the level of representation, analyzing the ads as texts (Bristor, Lee, and Hunt 1995; Cortese 1999; KernFoxworth 1994; O'Barr 1994). These studies, along with various content analyses, which count minority characters and evaluate casting decisions and depictions in advertising (Gilmore and Jordan 2012; Henderson and Baldasty 2003; Seiter 1990) as well as primetime television (Fall Colors 2003; Monk-Turner, Heiserman, Johnson, Cotton, and Jackson 2010; Signorielli 2009), have demonstrated a clear and consistent bias towards white protagonists and stereotypical portrayals of minorities. And while this literature can quantify how media representations create a cultural environment of inequality and help activists pressure advertisers and networks to cast their commercials and programs in ways that better reflect the diversity of the general population, ${ }^{2}$ even the most critical analysis of race on the level of representation only takes us so far.

Johnson's "circuit of culture" proposes that cultural studies "decenter the text" and analyze communication throughout a continuous circuit divided into moments of 1) production, 2) texts, 3) readings, and 4) lived cultures $(1986,62)$. Since representation on screen can conceal the conditions of production behind the camera, communication research that goes beyond (and indeed behind) the text can provide new insights into the everyday life of labour in the creative industries. ${ }^{3}$ As David Hesmondhalgh $(2007,37)$ puts it, cultural studies is most

\footnotetext{
${ }^{2}$ For instance, in the fall of 1999 , the NAACP protested the new slate of network television programming as a "'virtual whitewash"' (quoted in Gross 2001).

3 Though the production side of Johnson's circuit remains generally underdeveloped in communication, there are several agency-based ethnographies conducted by sociologists including William Mazzarella (2003) in India, Daniel Miller (1997) in Trinidad, Brian Moeran (1996) in Japan, and Sean Nixon (2003) in Britain. The paucity of work in the United States is curious, given that two of the four biggest holding companies (Interpublic and Omnicom) are headquartered in New York City. Though not ethnographies per se, there have also been several interview-based examinations of contemporary advertising practices in the United States: the segmentation and consolidation of Latino/a identity (Dávila 2001), the absence of female creative directors (Mallia, 2009), the development of gay marketing (Sender 2004), and the commodification of "true" blackness (Watts and Orbe 2002).
} 
useful when it asks "whose voices are heard within a culture and whose voices are marginalized" in order to better "assess the degree to which cultural production is organized in a socially just manner." This work is particularly important since, as Rosalind Gill (2014) reminds us, this sector's structural inequalities are often masked, and thus rendered "unspeakable" and more easily reproduced, by ideologies of individualism and egalitarianism. In that spirit, this project focuses on the production side of Johnson's circuit in order to interrogate the black-white labour gap within inside the US advertising industry. ${ }^{4}$ In doing so, it contributes to a rich sociological literature documenting and theorizing the reproduction of racial hierarchies within workplace settings largely through informal hiring practices based on existing social networks (Acker 2006; Branch 2011; Das Gupta 1996; McGuire 2002; Vallas 2003). Others have drawn similar conclusions through researching specific communication industries including telephony (Green 2001), journalism (Becker, Lauf, and Lowrey 1999; Drew 2011), and public relations (Logan 2011).

In what follows, I adapt Johnson's (1986) circuit model as an analytical framework for assessing the advertising sector from the inside. ${ }^{5}$ Rather than follow an ad from agency conception out the door to audience reception, I examine moments along the circuit in the manufacture and maintenance of labour inequality along racial lines. First I recount the production of white privilege through opportunity hoarding. Next I conduct a close reading of two competing texts-diversity as "smart" and diversity as "right"-that, albeit counterintuitively, help to perpetuate this inequality. Third, I consider how ideological readings through the lens of colour-blind racism and meritocracy make it difficult for even the most well-meaning of whites to behold how the structures and habits of class privilege flourish in agency settings under the cloak of whiteness. Finally, I conclude with a reflection on what the circuit of culture approach to race in the cultural industries might reveal about the theory and ethics of future work in this area.

\section{Methods}

I accessed the advertising industry through the 4A's Multicultural Advertising Intern Program (MAIP) - an effort founded in 1973, which has since "helped jumpstart the careers of more than 2,000 African-American, Asian-American, Latino-American, Native-American, multiracial and multiethnic aspiring advertising professionals" (4A's 2010). MAIP recruits and screens around 140 students of colour every year from all over the country, then places them in agencies willing to pay 70 percent of their travel and rent (in addition to the standard stipend which ranged from $200-\$ 500$ dollars per week) during their own internal summer internship programs. I entered the field through MAIP for three reasons. First, it ensured that my analysis would include a wide variety of perspectives from people of colour. Second, since the MAIP interns were placed in nineteen different agencies, their participation in my study greatly expanded the reach of my data. ${ }^{6}$ Finally, MAIP's centralized housing enabled a convenient and comfortable gathering place for focus group discussions. After negotiating MAIP's full cooperation, I spent the summer of 2010 in New York City, attending the MAIP

\footnotetext{
${ }^{4}$ Elsewhere, I have analyzed how intersections of race and gender inequalities inside advertising tend to reproduce white male leadership through informal hiring practices based on personal referrals and team-based chemistry/fit (Boulton 2013). For more on gendered labour in advertising, see Broyles and Grow (2008) and Michelle Gregory (2009).

${ }^{5}$ Though space does not permit me to include an analysis of Johnson's "lived cultures" in this work, I have taken a closer look at the contradictions of black identity inside advertising elsewhere (Boulton forthcoming).

${ }^{6} 61$ interns participated in at least one of my focus groups. Together, they represented 19 different advertising agencies in New York City: DDB, Deutsch, Draftfcb, Euro RSCG, G2, Gotham, Grey Group, Horizon Media, Kaplan Thaler Group, Kirshenbaum Bond Senecal + Partners, McCann Erickson, McGarryBowen, MEC, Mediacom, Merkley + Partners, Ogilvy \& Mather, PHD Worldwide, Publicis, TBWAIChiatlDay. As a whole, my sample of 61 interns was largely female (72 percent) and comprised almost entirely of undergraduates (college juniors and seniors). Thirty-six were MAIP interns (59 percent) and 25 were white interns (41 percent). Overall, this study includes a total of 109 unique informants that participated in 21 focus groups, filled out 149 surveys, and granted 30 interviews. I also recorded interviews and took ethnographic field notes while on-site at my host agencies.
} 
orientation, weekly evening seminars, social events, and graduation ceremonies. I also secured access to three of MAIP's host agencies, ${ }^{7}$ visiting each once a week for the duration of their eight to 10 week internship programs. In addition to ethnographic observations, I used this access to make contact with white interns, build rapport, and recruit them into focus groups.

Must-hires are a well-kept secret. When the HR practitioners at my host agencies finally acquiesced and disclosed their must-hires to me, they did so behind closed doors and in hushed whispers, insisting I pretend that I did not know who they were, who they knew, and how they got in. Such caution is understandable, since identifying a must-hire would likely embarrass the powerful actors who used their influence to secure internship slots for family and friends. In order to protect my HR informants from possible reprisals from uppermanagement, I approached the must-hires at my host agencies from an oblique angle, inviting them to participate in my research by joining focus groups based on gender. Though this strategy of forming white/must-hire focus groups involved a degree of deception at the initial stage, it is common practice in social science to misdirect the participant and thereby mitigate the effect of social desirability. ${ }^{8} \mathrm{I}$ also gained informed consent from all of my participants by clearly identifying myself throughout as a researcher interested in issues of gender, race, class, and creativity in advertising. As an additional precaution, I sent a penultimate draft of my monograph to all 65 of my quoted participants and invited them to respond to my analysis. Of those, nine MAIP interns, seven white interns (four of whom were must-hires), and seven agency staff sent back comments. ${ }^{9}$ While one participant requested the removal of a potentially identifying piece of personal information, no one opted to withdraw from the study nor mentioned any concerns about my methods-whether when recruiting of participants, conducting focus groups, or reporting results.

In what follows, I analyze a set of on-site in-depth interviews with senior advertising practitioners along with off-site focus groups ${ }^{10}$ with interns from a wide range of agenciesboth white and of colour. ${ }^{11}$ My findings indicate that race in advertising is not only a problem of "the Other," namely minorities who have been marginalized and discriminated against, but also a problem of power granted through closed social networks then rendered invisible through the articulation of whiteness and class privilege (Dyer 1997). I argue that this consensus around meritocracy amongst interns signals a wider sense of colour-blindness in the advertising industry in general-namely the refusal to see a decidedly unequal playing field where cronyism eases the burden of entry for well-connected whites.

\footnotetext{
${ }^{7}$ All three of the agencies in my study have over 500 employees in their New York offices. Two are headquartered there. Two have international reach, with offices abroad. As a condition of access, I have granted the agencies anonymity and so will not name them here.

${ }^{8}$ Just as most quantitative surveys include dummy questions unrelated to the researchers' interests in order to conceal the study's hypotheses, qualitative researchers often design interview schedules to begin with nonthreatening questions in order to put their subjects at ease (Lindlof and Taylor 2002). For instance, Sut Jhally and Justin Lewis (1992), when conducting focus groups for their landmark book Enlightened Racism, did not disclose their main interest in issues of race and class up-front. Instead, they showed their research subjects episodes of The Cosby Show then posed innocuous open-ended questions designed to encourage comfortable and freeflowing conversations.

${ }^{9}$ The feedback from my MAIP participants was uniformly positive. Most noted their agreement with my analysis and conclusions, and others went on to thank me for putting their experience into words and to express their hope that the work would be widely read and applied within the US advertising industry. The responses from my white must-hire participants were mixed. While one thanked me for not presenting the must-hires "as spoiled, privileged, obnoxious college students" and another said my analysis "truly gives me pause to rethink what I do on a daily basis," two others were more circumspect, wishing me luck while expressing disappointment about being labeled a must-hire, and thus undeserving, by my HR informants.

${ }^{10}$ I conducted my focus groups in neutral locations (such as NYU and the MAIP residence) outside the purview of the interns' agency supervisors so as to encourage them to speak freely about their experiences and opinions.

${ }^{11}$ I refer to all of my study participants using first name pseudonyms.
} 


\section{Production: Opportunity Hoarding}

Starting on the production side of Johnson's circuit, it is important to understand that advertising does not just produce promotional messages; it also reproduces white labour. One mechanism for this reproduction is the culture of "must-hires," a material practice that is endemic to advertising internship programs. Colloquially defined within agencies as interns hired because of who they know, they are also referred to as "must-takes," "favour-hires," and "asks." In practice, these "requests" function more like commands and tend to be honoured by HR since they either come from clients ("let's say the chairman of Proctor [\& Gamble] calls up and says, 'Hey, my kid, my niece, my God child"') or agency uppermanagement ("the CEO's assistant's step-daughter or so-and-so's best friend"). Of course, as we've seen in Deirdre Royster's (2003) work on "embededness," nepotism, and opportunity hoarding are nothing new. What makes this particular instance remarkable is how-even in the midst of a diversity crisis-the US advertising industry's must-hire system overwhelmingly favours whites. In the three agencies where I conducted ethnographic fieldwork, all of the must-hire interns were white and outnumbered the MAIP interns of colour 24 to nine, a ratio of more than $2: 1$.

In this section, I analyze a representative set of testimonials from each of my three host agencies that illuminate the must-hire system from a variety of white perspectives: Heather, an HR Manager, reluctantly acquiesces to her boss; Patricia, an HR Director, ponders doing a favour for a colleague; and James, a high-powered CMO, "pays it forward" to his alma mater, a co-worker, and even his own family. For Heather, who runs her agency's internship program and resents the must-hire system, "the nepotism factor is really, really tough. Like the lengths you need to go to say 'no' and the number of people who you cannot say 'no' to... What am I going to say? 'CEO, I don't like your pick?' Heather estimates that hundreds of students apply to her internship program every summer, but doesn't bother reading their materials since "to get in is word-of-mouth here with some sort of connection." Patricia, whose agency's internship program is similarly competitive, recounted her own struggle with nepotism when a white colleague asked her to consider hiring his son's friend: "and he goes, 'I'm not asking for a favour or anything' but you know what? I was torn.... So [after the interview] I said, 'Listen, he was okay, I probably wouldn't normally have passed him on, but, if you want me to pursue it, I'd be happ_-if that's what you want.... and I was all like 'Oh my God! This is how it happens!" Patricia would have made the hire if pressed. Ultimately, she didn't, but still granted her colleague a privileged form of access for his family friendreserved for him and denied to others by virtue of proximity, not qualification. And, while access alone may be an insufficient condition for getting into a highly desirable internship program at a major agency, as we learned from Heather, it is almost always a necessary one. James, a top executive at my third host agency, knows this all too well and took great pride in having helped various colleagues, friends, and family "get a foot in the door" of the industry-even managing to get his daughter's boyfriend's brother into his own agency's internship program. When I challenged this practice as nepotism, James was unrepentantarguing that the reciprocal exchange of favours "works two ways. It's a relationship bank system; you make withdrawals and deposits all the time." Thus, as a form of currency and reciprocal exchange among well-connected whites, must-hires constitute a system of noncompetitive, sole provider, and no-bid contracts. These inherently unequal opportunities are a prevalent, frequent, and expected form of white opportunity hoarding. As a structure of oppression, must-hires help to produce and maintain race inequality inside advertising. As a material practice of the everyday, depending on one's rank, must-hires can be an onerous obligation of employment or a pleasant ritual of "giving back," bestowing gifts, and/or making quid pro quo investments in the hopes of a future return-both personal and professional.

Despite vastly outnumbering interns of colour placed in agencies through programs like MAIP, must-hire interns seem to get a free pass from diversity advocates. When conducting my review of industry trade literature, I found plenty of opinion columns debating the relative 
importance of the diversity and various ways for agencies to achieve it, but none mentioning must-hires nor how they limit opportunity for people of color and perpetuate white privilege. This is remarkable-given the scarcity and desirability of internship slots as opportunities for access, training, and networking within a highly competitive industry-yet also understandable. Beyond the obvious disincentive against criticizing upper-management or resisting requests from clients, this silence, as we shall see, is further reinforced by a polarized debate over tactics pitting diversity activists against reformers.

\section{Texts: Diversity as "Smart" vs. "Right"}

In this section, I depart from the clandestine labour practice of must-hires, ensconced well within the production side of Johnson's circuit, and move out into the textual moment to consider a public debate vying to establish the discursive rationale for rectifying racial inequalities within advertising. This contest over meaning has taken place largely outside agency walls through, on the one hand, the reformist agenda of high-profile industrysponsored awards galas celebrating "rising stars" of colour and making the positive business case for diversity as "smart" given the rise of multicultural markets, and, on the other, the activist strategy of class action lawsuits and strident columns in trade magazines positioning diversity as simply the "right thing to do" in the face of injustice given the industry's longstanding and persistent resistance to hiring and promoting black employees (Parekh 2009). I interviewed several black human resource practitioners who complained that their attempts to reform the race crisis from within have been hindered by other blacks attacking the industry from without. For instance, when Omnicom, the second largest advertising holding company in the world, appointed Tiffany Warren, former director of the MAIP program, to the newly created position of Chief Diversity Officer, Sanford Moore, a pioneering black advertising practitioner and long-time civil rights activist, quickly dismissed her as a "sell out," "apologist," and "Uncle Tom" working for the owners of "the plantation" (Parekh 2009). For Moore (2009), the hiring of Warren was far too little and way too late:

We have had 40 years of pious pronouncements by the leaders of the industry, 40 years of investigations, reports and obfuscation, 40 years of denying the significance of the black consumer market. It is time to return the favor. It is time to make the CEOs of the holding companies pay a price with their own money, to affect their compensation packages and their company's stock price.

Dorothy, a senior-level woman of colour who has run internal diversity initiatives and aligns herself with Warren, worried that Moore's inflammatory rhetoric and confrontational activist tactics would backfire and undermine her more pragmatic, reformist approach. In separate interviews, many of her colleagues agreed that instead of threatening to punish the industry through penalties, Moore and his allies should emphasize diversity's potential rewards.

I heard the reformist business case for diversity early and often during my fieldwork. On the second day of MAIP's 2010 summer orientation, I joined about 40 interns in a conference room at 4A's headquarters in New York City as Executive Vice President Michael Donahue explained that, while diversity has "always been the right thing to do, now it's the smart thing to do," since multicultural people will represent half the population in the US by 2050 . This is not a new idea. Wally Snyder, president and CEO of the American Advertising Federation (AAF) argued back in 1993 that the increase of multicultural populations meant that a diversified workplace was "no longer simply a moral choice; it is a business imperative" (quoted in Kern-Foxworth 1994, 119). Donahue and Snyder's common claim underpins the central rationale of reformist discourse: structural adjustments or external regulations are no longer necessary because what was once a matter of conscience is now a necessity of capitalism: consumer demand will succeed where public activism and government intervention have failed. 
And yet, if hiring more black employees is "smart," then most agencies are still pretty dumb. The assumption that the market-on its own-will increase diversity within advertising is a dubious one, especially given Wieden's (2009) confession, cited above, that he has long enjoyed great success hiring whites to sell black culture to black consumers-a market Moore (2009) estimates to be worth just under $\$ 1$ trillion per year. Simply put, race inequality inside mainstream advertising agencies has thus far endured the kinds of financially incentivized reforms that the "emergence" of black buying power might have wrought. So, in the midst of this glaring contradiction between the professed valuation of diverse perspectives and the actual paucity of diverse employees within the advertising industry, and despite years of pressure from activists and government regulators to do the "right" thing, the internal reformist common sense still boils down to this: if we place more interns of colour into the pipeline, the free market will do the rest. The "smart" thing will bring about the "right" thing. Add colour, then stir. But what if the problem is not just too little diversity, but also too much whiteness? Not simply discrimination against people of colour, but also preference for must-hires? These questions are rarely asked because the insider vs. outsider positions personified by Warren and Moore mutually reinforce each other, creating an entrenched polemic that reduces the advertising industry's race crisis to a question of tactics for increasing "the numbers" of minority employees. By continuing to rehash debates over the relative effectiveness of threats vs. promises, penalties vs. rewards, diversity advocateswhether reformist or activist-have kept their eyes focused on the money and their backs turned to the door where whites (whether qualified or not) are free to come and go as they please.

\section{Readings: Colour-blind Racism as Meritocracy in Theory}

Thus far we have considered how whites consolidate economic power through closed social networks at the point of production and how the contested discourses of diversity activists and reformists produce texts that let them get away with it. I now turn to the readings of the interns themselves. Following Johnson's call to consider the more subjective side of social forms, or the way in which subjects interpret and understand their own material conditions, this section examines ideology and how common sense notions of meritocracy can blind us to the material practices of (white) racial preference.

I hosted six white focus groups in a seminar room at NYU. The interns came from three different agencies, so many were meeting each other for the first time. Some were musthires. Some were not. All were white. Throughout the sessions, the combination of latent class formations and manifest racial identities produced some surprising moments of mutual recognition. In one instance, John actually bragged about his relationship with his agency's Chief Operating Officer than called out Richard, who he had just met, by knowingly asking him, "So, how did you get your internship?" Richard reluctantly admitted that his uncle was the CEO of his agency. He hadn't told any of his peers but, if asked, claimed he would have said he applied, but then quickly added, "they're not going to deny the chairman's nephew." In a later interview, Richard's HR manager was blunt: "Why not let him in? He does know the right person." While this may sound rather matter-of-fact, Richard knew better than to admit it in public for this would risk exposing him to the kinds of stigma so often experienced by interns of colour.

While the white must-hires slipped past scrutiny, interns of colour-whether they were in the MAIP program or not-were easily spotted by non-must-hire whites as undeserving intruders. Gregory, a white non-must-hire, complained that MAIP hurt his chances by advantaging unqualified interns of colour: "Many MAIP kids are not ad majors or don't know the basics [...] they don't interview you, they're probably not even asked why they want to do advertising. It just seems unfair that people who have the advertising background and want to intern at a big agency can't do it when people who don't have the background are able to." 
Not yet aware of the must-hire system, ${ }^{12}$ Gregory was frustrated by the apparent ease by which interns of colour secured their internships along with a 70 percent housing subsidy. But while he might have expected commiseration from the three other whites in his focus group, what he got instead was a series of sheepish looks and awkward admissions; all three were must-hires who, prior to the internship, knew next to nothing about the industry. Thus, a critique aimed at interns of colour, the scapegoated others not in the room, landed instead on the Gregory's true rivals, sitting right across the table: unqualified, yet well-connected whites. In this case, whiteness created an ideological screen of pseudo-solidarity, blinding Gregory to the material barriers-both invisible and silent-of class privilege that separated him from the rest of the group. This kind of backlash against MAIP was common amongst all the white interns in my study. Even the must-hires, ${ }^{13}$ despite their own advantage, tended to oppose MAIP based on what Bonilla-Silva (2010) describes as the meritocratic principles of abstract liberalism: "Why should we use discrimination to combat discrimination? Two wrongs don't make a right. We should judge people by their merits and let the best person get the job or promotion" (262-63).

While whites used meritocracy to attack diversity programs, it also provided a defense for MAIP interns who were well aware of white resentment. During my focus groups with interns of colour, ${ }^{14}$ many emphasized the rigour (three rounds of elimination) of the MAIP application process: "There are no slackers in MAIP. You can't!" "I know everybody else earned this like I did." "I really feel like I earned my place here." Michele, who is Asian, was even more explicit, emphasizing the superiority of MAIP interns vis-a-vis must-hires: "every single person in MAIP is extremely qualified and has more experience and skill than many of the interns who got these internships just through connections." Amelia, who is black, was directly confronted by a must-hire and used meritocracy to fight back:

One intern guy, his brother works there and he was like "Oh, well some of us had to interview with HR" and then he turned to me and said, "Oh, no Amelia, we all know why you're here. We all know why you got in." And I let him know what it took for me to get here. Like the process that I had to go through-writing those essays, getting those letters of recommendation, those interviews-that's much more than you talking to your brother!

For Amelia, then, meritocracy offers her a defense against whites who might presume that her skin marks her as undeserving, even as they deny their own privilege in a system that already advantages them. So, while affirmative action may indeed be a necessary institutional corrective, it can mark and thereby further stigmatize individuals of color (already marked as minorities) who wish to be read by others as autonomous subjects who have earned their position through the merits of the free labour market. Given this context, it is unsurprising that most of the MAIP interns in my study opposed the idea of affirmative action, even as they took material advantage of the exclusive quotas set aside for interns of colour. Ideology is at its most powerful when it offers a simple explanation to reconcile-and thereby resolve-a complicated set of contradictions. Meritocracy, so deeply rooted in the American

\footnotetext{
${ }^{12}$ After reading a draft of this study, Gregory shared an interesting anecdote that illustrates how the domination of the must-hire system can pit working class whites against people of colour: "The non-must hires are left out to dry, we don't have the financial resources and connections of must-hires to get the opportunities nor are we eligible for the helping hand of MAIP or other affirmative action programs. Last summer my good friend, also an ad student from my school, applied and got an internship at an agency in Minneapolis. Turns out her and the one MAIP intern were the only two non must-hires who got into the program. There were 12 total interns. One MAIP, one out-of-state (my friend), and 10 must-hires. The MAIP intern was put up in an expensive, fully stocked apartment for the summer and my friend lived in the bad part of town where she could make rent with her $\$ 10 / \mathrm{hr}$ intern salary. All of the must-hires stayed with family."

${ }^{13}$ Of the thirteen white must-hires participating in my study, the majority (8/13 or 62 percent) were opposed to affirmative action while two had mixed feelings and four supported it.

${ }^{14}$ For a more developed analysis of my focus groups with black interns participating in the MAIP program, please see Boulton forthcoming.
} 
Dream's promise of upward mobility, offers the interns in my study_both white and of colour - a soothing ideological overlay that mutes the harsh material reality of unfair hiring practices in the US advertising industry.

\section{Conclusion: Seeing Whiteness}

During my interview with Elizabeth, a white Head of HR, I proposed that the must-hire system functioned as "affirmative action for whites". At first, she was defensive, "Well, they weren't all white!" But when I asked for a counter-example, she hesitated, then backtracked, conceding my point. Elizabeth's reaction suggests that, despite her awareness of the musthire system, she had never thought of it in racial terms. Similarly, while the extant critical work on internships has offered nuanced explanations of how un(der)paid internships can exploit the labour of vulnerable workers aspiring to achieve creative employment while reproducing the class advantages of the populations with enough family connections and financial subsidies to access desired opportunities and advance beyond the entry level, more work is needed on how these economic pressures intersect with, and reinforce, inequalities of race and ethnicity within the media industries (Hesmondhalgh and Saha 2013). Thus, if communication theory is to continue to develop beyond textual representation and audience reception in order to address labour at the point of production, then my research suggests that a "circuit of culture" approach might offer a way forward that accounts for subjectivities both within and around the workplace. Indeed, further research is needed on the "lived cultures" side of the circuit that further illuminates the context of racial and ethnic exclusion from the kinds of closed social networks that facilitate employment (Boulton forthcoming). Put another way, when a political economy structured in white racial dominance is obscured by ideologies of meritocracy signified both through discursive texts and subjective experiences, analysts must find new ways to detect, and then lift, the cloak of whiteness in ways that work to help liberate, and not further stigmatize or essentialize, people of colour. For example, even the most adamant critics of race inequality in the cultural industries should avoid presuming a necessary correspondence between opening more "pipelines" of diverse media workers and achieving better images of diverse populations as this assumption heaves onto people of colour an extra burden of representational responsibility from which whites are exempt.

I have argued that the debate between activists and reformers has framed the justification for more people of colour in advertising as either reparation for past discrimination or preparation for emerging markets. This framework not only overlooks the cronyism, nepotism, and white racial pattern of the must-hire system operative within the production side of the circuit, but also the readings and lived experiences of the MAIP interns of colour in my study who generally did not wish to be perceived as either affirmative action hires or spokespersons for, and thus limited to, their own race (Boulton forthcoming). In contrast, Johnson asks us to remember both the structural limits surrounding and agentive opportunities available to all social actors at every moment of the circuit. And if critical communication researchers wish to hasten the socially just organization of cultural production (Hesmondhalgh 2007), then it behooves us to ask just how our research, theoretical as it may be, will actually intervene into the lives of the most marginalized workers. The preceding analysis suggests that we might begin with a clear recognition of the class-inflected ways and means of white labour reproduction.

Must-hire interns gain unearned access to the advertising industry in secret under the cloak of whiteness. They are, in a sense, invisible: a few more familiar faces blending into a mostly white crowd. This blindness to whiteness makes whites hiring other whites on the basis of favours, "fit," and friendship hard to see (Boulton 2013). But imagine a black intern walking through the doors of a general market agency. She stands out; people that look like her are few and far between-especially at the top. Now compare this to a white intern. For him, the agency is like a fun house of mirrors, reflecting his own image from every direction. The possibilities are endless and the future looks bright. Perhaps he already knows 
someone: that friend in account services or his uncle in the C-suite. Perhaps they'll go to lunch. Perhaps not. Either way, if he's taken under their wing, it won't be seen as a race thing, even though it is.

\section{References}

4A's. 2010. MAIP. Accessed May 10, 2010. http://www2.aaaa.org/careers/internships/maip/Pages/default.aspx.

Acker, Joan. 2006. Inequality Regimes: Gender, Class, and Race in Organizations. Gender and Society 20 (4): 441-464.

Becker, Lee, Edmund Lauf, and Wilson Lowrey. 1999. Differential Employment Rates in the Journalism and Mass Communication Labor Force Based on Gender, Race, and Ethnicity: Exploring the Impact of Affirmative Action. Journalism \& Mass Communication Quarterly 76 (4): 631-645.

Bendick, Marc and Mary Lou Egan. 2009. Research Perspectives on Race and Employment in the Advertising Industry. Bendick and Egan Economic Consultants, Inc.

Bonilla-Silva, Eduardo. 2010. Racism Without Racists: Color-blind Racism and the Persistence of Racial Inequality in the United States. Lanham, MD: Rowman \& Littlefield.

Boulton, Christopher. 2013. The Ghosts of Mad Men. In The Routledge Companion to Advertising and Promotional Culture, edited by Matthew McAllister and Emily West, 252-266. New York: Routledge.

Boulton, Christopher. Forthcoming. Identities Inside Advertising: Race Inequality, Code Switching, and Stereotype Threat. Howard Journal of Communication.

Branch, Enobong H. 2011. Opportunity Denied: Limiting Black Women to Devalued Work. New Brunswick, NJ: Rutgers University Press.

Bristor, Julia M., Renee G. Lee and Michelle R. Hunt. 1995. Race and Ideology: African-American Images in Television Advertising. Journal of Public Policy \& Marketing 14 (1): 48-59.

Broyles, Sheri J., and Jean Grow. 2008. Creative Women in Advertising Agencies: Why So Few "Babes in Boyland?" Journal of Consumer Marketing 25 (1): 4-6.

Bureau of Labor Statistics. 2011. Labor Force Characteristics by Race and Ethnicity. Accessed December 15, 2012. http://www.bls.gov/cps/cpsrace2011.pdf.

Bush, Michael. 2011. Sorry State of Diversity in Advertising is also a Culture Problem. Accessed March 15, 2011. http://adage.com/article/news/lack-diversity-advertising-hiring/148565/

Carbado, Devon, and Mitu Gulati. 2003. The Law and Economics of Critical Race Theory. The Yale Law Journal 112: 1757-1828.

Chambers, Jason. 2008. Madison Avenue and the Color Line: African Americans in the Advertising Industry. Philadelphia, PA: University of Pennsylvania Press.

Cortese, Anthony J. P. 1999. Provocateur: Images of Women and Minorities in Advertising. Lanham, MD: Rowman \& Littlefield.

Cottle, Simon. 1998. Making Ethnic Minority Programmes inside the BBC: Professional Pragmatics and Cultural Containment. Media, Culture \& Society 20 (2): 295-317.

Das Gupta, Tania. 1996. Racism and Paid Work. Toronto: Garamond Press.

Dávila, Arlene M. 2001. Latinos, Inc.: The Marketing and Making of a People. Berkeley: University of California Press.

Dolliver, Mark. 2010. Creation of Super Bowl Spots a Whites-only affair. Accessed May 19, 2010. http://www.adweek.com/aw/content_display/news/agency/e3if2e371e23945e3cf8b21cd4a1a39662 2.

Downing, John and Charles Husband. 2005. Representing Race: Racisms, Ethnicity and the Media. London: Sage.

Drew, Emily. 2011. "Coming to Terms with our Own Racism": Journalists Grapple with the Racialization of Their News. Critical Studies in Media Communication 28 (4): 353-373.

Dyer, Richard. 1997. White. London: Routledge.

Edwards, Lee. 2013. Institutional Racism in Cultural Production: The Case of Public Relations. Popular Communication: The International Journal of Media and Culture 11: 242-256.

Fall Colors: Prime Time Diversity Report. 2003. Children Now.

Frenette, Alexandre. 2013. Making the Intern Economy: Role and Career Challenges of the Music Industry Intern. Work and Occupations 40 (4): 364-39. 
Gill, Rosalind. 2014. Unspeakable Inequalities: Post Feminism, Entrepreneurial Subjectivity, and the Repudiation of Sexism among Cultural Workers. Social Politics: International Studies in Gender, State \& Society 21 (4): 509-52.

Gilmore, Joelle S. and Amy Jordan. 2012. Burgers and Basketball: Race and Stereotypes in Food and Beverage Advertising Aimed at Children in the US. Journal of Children and Media (6) 2: 317-332.

Green, Venus. 2001. Race on the Line: Gender, Labor, and Technology in the Bell System, 18801980. Durham, NC: Duke University Press.

Gregory, Michelle R. 2009. Inside the Locker Room: Male Homosociability in the Advertising Industry. Gender, Work \& Organization 16 (3): 323-347.

Gross, Larry. 2001. The Paradoxical Politics of Media Representation. Critical Studies in Media Communication 18 (1): 114-119.

Henderson, Jennifer and Gerald Baldasty. 2003. Race, Advertising, and Prime-time Television. Howard Journal of Communications 14 (2): 97-112.

Hesmondhalgh, David. 2007. The Cultural Industries. 2nd ed. London: Sage.

Hesmondhalgh, David and Anamik Saha. 2013. Race, Ethnicity, and Cultural Production. Popular Communication: The International Journal of Media and Culture 11 (3): 179-195.

Hesmondhalgh, David and Sarah Baker. 2011. Creative Labour: Media Work in Three Cultural Industries. New York: Routledge.

Jhally, Sut and Justin Lewis. 1992. Enlightened Racism: The Cosby Show, Audiences, and the Myth of the American Dream. Boulder, CO: Westview Press.

Johnson, Richard. 1986. What is Cultural Studies Anyway? Social Text (16): 38-80.

Kern-Foxworth, Marliyn. 1994. Aunt Jemima, Uncle Ben, and Rastus: Blacks in Advertising, Yesterday, Today, and Tomorrow. Westport, CT: Greenwood Press.

Keuhn, Kathleen and Thomas F. Corrigan. 2013. Hope Labor: The Role of Employment Prospects in Online Social Production. The Political Economy of Communication 1 (1): 9-25.

Lapchick, Richard, Devan Dignan, Austin Moss II, Naomi Robinson, Brian Hoff, and Jamile Kitnurse. 2010. White Men Dominate Advertising Agencies' Creative Director Positions as Exemplified by Ads Aired During the Super Bowl. The Institute for Diversity and Ethics in Sport. Accessed May 15, 2010. http://www.madisonavenueproject.com/UserFiles/File/newMadisonAvenue2010.pdf.

Lindlof, Tom and Brian Taylor. 2002. Qualitative Communication Research Methods. 2nd ed. Thousand Oaks, CA: Sage Publications.

Logan, Nneka. 2011. The White Leader Prototype: A Critical Analysis of Race in Public Relations. Journal of Public Relations Research 23 (4): 442-457.

Mallia, Karen. 2009. Rare Birds: Why so Few Women Become Ad Agency Creative Directors. Advertising \& Society Review 10 (3). Accessed May 15, 2010. http://muse.jhu.edu/journals/advertising and_society_review/summary/v010/10.3.mallia.html.

Mazzarella, William. 2003. Shoveling Smoke: Advertising and Globalization in Contemporary India. Durham, NC: Duke University Press.

McGuire, Gail M. 2002. Gender, Race, and the Shadow Structure: A study of Informal Networks and Inequality in a Work Organization. Gender and Society 16 (3): 303-322.

Miller, Daniel. 1997. Capitalism: An Ethnographic Approach. Oxford: Berg.

Moeran, Brian. 1996. A Japanese Advertising Agency: An Anthropology of Media and Markets. Honolulu: University of Hawaii Press.

Monk-Turner, Elizabeth, Mary Heiserman, Crystle Johnson, Vanity Cotton, and Manny Jackson. 2010. The Portrayal of Racial Minorities on Prime Time Television: A Replication of the Mastro and Greenberg Study a Decade Later. Studies in Popular Culture 32 (2): 101-114.

Moore, Sanford. 2009. Apartheid Alive and Well on Madison Avenue. Accessed May 7, 2010. http://www.adweek.com/print/100220.

Neff, Gina. 2012. Venture Labor: Work and the Burden of Risk in Innovative Industries. Cambridge, MA: MIT Press.

Neff, Gina, Elizabeth Wissinger, and Sharon Zukin. 2005. Entrepreneurial Labor Among Cultural Producers: "Cool" Jobs in "Hot" Industries. Social Semiotics 15: 307-334.

Nixon, Sean. 2003. Advertising Cultures: Gender, Commerce, Creativity. London: Sage.

O'Barr, William M. 1994. Culture and the Ad: Exploring Otherness in the World of Advertising. Boulder, CO: Westview Press.

Oakley, Kate. 2011. In its Own Image: New Labour and the Cultural Workforce. Cultural Trends 20 (3/4): 281-289. 
Perlin, Ross. 2011. Intern Nation: How to Earn Nothing and Learn Little in the Brave New Economy. New York, NY: Verso.

Parekh, Rupal. 2009. For Diversity Officers, No Good Deed Goes Unpunished. Accessed May 21, 2010. http://adage.com/print?article_id=134418.

Royster, Deirdre. 2003. Race and the Invisible Hand: How White Networks Exclude Black Men From Blue-collar Jobs. Berkeley, CA: University of California Press.

Saha, Anamik. 2012. Beards, scarves, halal meat, terrorists, forced marriage": Television Industries and the Production of "Race". Media, Culture \& Society 34 (4): 424-438.

Seiter, Ellen. 1990. Different Children, Different Dreams: Racial Representation in Advertising. Journal of Communication Inquiry 14 (1): 31-47.

Sender, Katherine. 2004. Business, Not Politics: The Making of the Gay Market. New York: Columbia University Press.

Shome, Raka. 2000. Outing Whiteness. Critical Studies in Media Communication 17 (3): 366-371.

Signorielli, Nancy. 2009. Race and Sex in Prime Time: A Look at Occupations and Occupational Prestige. Mass Communication and Society 12 (3): 332-352.

Stahl, Matt. 2012. Unfree Masters: Recording Artists and the Politics of Work. Durham, NC: Duke University Press.

Streeter, Thomas. 2014. From Romanticism vs. Expertise to Romanticism as Expertise. Paper presented at the annual meeting for the International Communication Association, Seattle, Washington, May 22-24.

Turow, Joseph. 1997. Breaking Up America: Advertisers and the New Media World. Chicago: University Of Chicago Press.

Vallas, Stephen P. 2003. Rediscovering the Color Line Within Work Organizations: The "Knitting of Racial Groups" Revisited. Work and Occupations 30 (4): 379-400.

Watts, Eric K. and Mark P. Orbe. 2002. The Spectacular Consumption of "True" African American Culture: "Whassup" with the Budweiser Guys? Critical Studies in Media Communication 19 (1): 1-20.

Wieden, Dan. 2009. "What Old Men Think About When They Think About Getting Old." Speech presented at the 2009 4A's Leadership Conference, San Francisco, CA. Accessed May 7, 2010. http://www.aaaa.org/events/video/Pages/042909 wieden.aspx.

Wood, Doug. 2010. Book of Tens: Legal Predictions for 2011. Accessed March 15, 2011. http://adage.com/bookoftens2010/article?article id=147619.

\section{About the Author}

Christopher Boulton

Christopher Boulton is an Assistant Professor in the Department of Communication at the University of Tampa where he teaches critical media studies, television, and documentary. Before entering the academy, Boulton worked at Mister Rogers' Neighborhood, Travel Channel, CourtTV (now TruTV), and Discovery Channel. Boulton's research focuses on the intersection of communication, inequality, and activism, and his writing has been published in the International Journal of Communication, Advertising \& Society Review, The Routledge Companion to Advertising and Promotional Culture, and New Views on Pornography. 


\title{
Reality TV's Embrace of the Intern
}

\author{
Tanner Mirrlees
}

\author{
University of Ontario Institute of Technology, Oshawa, Canada, tanner.mirrlees@uoit.ca
}

\begin{abstract}
In the preface to a seminal exposé of the "intern nation," Ross Perlin (2012) writes, "reality TV truly embraces the intern" (xii). This article describes and analyzes how 20 reality TV intern job ads for 19 different reality TV studios represent the work of interns and internships in the capitalist reality TV industry. By interrogating how the job postings depict the work that reality TV studios expect interns to do, the skills that TV studios expect interns to possess as a prerequisite to considering them eligible for mostly unpaid positions, the asymmetrical power relations between studios and interns, and the studios' utilization of "hope" for a career-relevant experience to recruit interns, the article argues that the reality TV intern is actually a misclassified worker. The study demonstrates that reality TV interns are workers whose labour feeds reality TV production and that reality TV internships are a means of getting workers to labour without pay. The conclusion establishes some grounds for a reality TV intern class action suit.
\end{abstract}

Keywords: internships, cultural labour, reality TV, capitalism

In the preface to his seminal exposé of the proliferation of unpaid internships in the US, Ross Perlin (2012, xii) scrutinizes reality TV's glorification of unpaid internships in the cultural industries when he writes, "reality TV truly embraces the intern." Indeed, reality TV shows like The Hills, The Cut, and I Want to Work for Diddy represent workers doing jobs not for pay but for enriching experiences that will later help them land cultural industry careers. Reality TV studios also embrace the intern at the point of TV commodity production. A February 5, 2015 search for "reality TV internship" on US cultural industry job websites such as internships.com, simplyhired.com, and entertainment careers.net, for example, returned hundreds of ads for internship positions at US-based reality TV studios for spring and summer 2015. I have selected and analyzed 20 of these ads for internships at 19 different reality TV studios to understand how these ads represent the work of interns and internships in the capitalist reality TV industry. In this article, I interrogate how the job postings depict the work that reality TV studios expect interns to do, the skills that TV studios expect interns to possess as a prerequisite to landing mostly unpaid positions, the asymmetrical power relations between studios and interns, and the studios' utilization of "hope" for a career-relevant experience to recruit interns. I argue that the reality TV intern is actually a misclassified worker. My study demonstrates that reality TV interns are workers whose labour power feeds reality TV production and profits, and that reality TV internships are a means of getting workers to labour without pay.

To conduct this study, I closely analyzed 20 reality TV intern job postings, reading them to understand how they represent the intern's roles and tasks in the studios, the skills people are expected to possess as a prerequisite for getting hired as interns, the characteristics of internships, and the career-relevant "experience" that people supposedly get by doing them. Appendix A: Reality TV Job Search includes four tables that heuristically organize my findings. After collecting this data, I interpreted it by drawing on literature on the political economy of labour in the cultural industries (Brophy 2013; Cohen 2008, 2012; Deuze 2007; de Peuter 2014; Fuchs 2014; Huws 2007, 2010; Mosco and McKercher 2008; Mosco 2009; Ross 2004, 2009, 2013; Scholz 2013). Apropos the political economy of communication's dialectical movement between the empirical observation of capitalism and critical theorizing about it (Mosco 2009), I extrapolate from the reality TV internship job search findings to develop a Marxist critique of the 
capitalist reality TV industry's exploitation of workers via internships. By doing so, this article aims to complement and contribute to critical research on unwaged work in the cultural industries (Cohen 2008, 2012; Fuchs 2014; Scholz 2012), the reality TV industry's precarious low-to-no waged workforce (Andrejevic 2004, 2011; Blair 2010; Cianci 2009; Collins 2008; Hearn 2008, 2010, 2014; Mayer 2011; Oullette and Hay 2008; Raphael 1997; Ross 2014), and internships (de Peuter, Cohen and Brophy 2012; Perlin 2012).

Reality TV internship job postings are important to analyze because they offer an empirical snapshot of the substance of some reality TV internships at the present time. The ads do not paint a comprehensive picture of reality TV industry internships or constitute an ethnographic portrait of the lived labour experiences of the many people who do them. Rather, they provide insight into how reality TV companies rely on internships when producing reality TV shows, the types of jobs companies want interns to do, the skills and personality traits they expect interns to possess, and the appeals they use to recruit and motivate interns to work for them without pay. The job ads are significant because they participate in social struggles over the meaning of intern identities at a time when interns are surrounded by controversy and conflict (de Peuter, Cohen and Brophy 2012; Perlin 2012). Stuart Hall (1996, 3) conceptualizes identity as "being constituted within, not outside of representation," a "meeting point" between "the discourses and practices," which "construct us as subjects" and those that attempt to address us as particular kinds of "subjects" (6). This article takes it as axiomatic that reality TV intern job ads are part of a discourse about the intern in society that constructs ideal-type intern subject-positions that address people as prospective interns. My critique, then, aims to unsettle the discursive power that reality TV studios wield over the making of reality TV intern subject-positions, disrupt smooth identifications with these subject-positions, and forward a subject-position of the intern as a worker.

\section{A Capitalist Reality TV Industry}

The reality TV industry is part of capitalism, an economic system in which privately owned companies produce commodities for sale in the market with the intention of making a profit rather than for human need, using privately-owned capital goods (technology) and human labour power (the manual and mental capabilities required to complete tasks) (Mirrlees 2013). In the capitalist system, privately owned and profit-seeking media corporations are the dominant controllers of the means of producing, distributing, and exhibiting reality TV shows (Hearn 2013; Mirrlees 2013). The reality TV industry is comprised of production companies, distribution companies, and exhibition companies, all of which express a class division between the owners (the few people who own and manage the corporation: shareholders and CEOs) and the workers (the many people who labour for the corporation). In general, reality TV production companies manufacture TV shows; reality-TV distribution companies buy the licensing rights to finished TV shows from production firms and sell the use of these TV shows to exhibition companies in specific territories and languages for set periods of time. Production companies make reality TV shows to be sold to distribution companies; distribution companies wholesale the rights to reality TV show to exhibitors; exhibitors make money by delivering TV shows to consumers (via TV network schedules, cable stations, on-demand platforms, and Web-based video streaming sites) in exchange for a subscription fee or consumer attention, which they sell to advertisers. In the reality TV industry, TV distribution/exhibition companies are the consumers of content and TV production companies the sellers, meaning that TV network demand instigates the supply of reality TV shows, which feeds this multi-billion dollar and increasingly consolidated sector (Flint 2014).

In the US, many reality-TV exhibition companies (TV networks) are owned by the biggest six media conglomerates: Walt Disney Company (ABC), Time-Warner (HBO, CNN, TNT, truTV), News Corporation (Fox), NBC-Universal (NBC TV, Bravo, CNBC, USA Network), CBS 
Corporation (CBS TV, the CW, Showtime), and Viacom (MTV Networks, BET Networks, Spike) (Mirrlees 2013). Some of these conglomerate-owned TV exhibitors acquire reality TV shows from "in-house" TV studios. Warner Brothers, for example, has an Unscripted and Alternative Television division and $21^{\text {st }}$ Century Fox-owned Shine America produces reality-TV programming for Fox Networks. Most of the time, however, major TV exhibitors acquire reality TV shows that are flexibly produced "out-of-house" by studios operating in a semi-independent reality TV production/distribution sector. Among the largest of these are Freemantle North America, Endemol North America, Mark Burnett's One Three Media, Gordon Ramsay's One Potato Two Potato, and Ryan Seacrest's Ryan Seacrest Productions (Flint 2014; O'Connel 2014). So, while semi-independent producer/distributor firms control the means of developing reality TV content (and sometimes control the intellectual property to it), convergent media conglomerates control the major exhibition pipes through which reality TV shows flow to viewers. TV networks (the buyers) have the upper hand in the exchange relationship with reality TV studios (sellers), and in response to network-driven demand for cheap-to-acquire content, studios compete against each other by slashing prices and, consequently, driving down the cost of labour (Carter 2003; Hearn 2014; Slocum 2014). Reality TV shows are pervasive because they are "cheap" to buy relative to more expensive scripted TV shows, but at the base of impersonal market transactions between TV networks and TV studios and the scheduled consumption of the latest reality hit, is the capitalist exploitation of human labour, both waged and unwaged.

The reality TV industry is "paradigmatic" of post-Fordist neoliberal capitalism's flex production model and exploits low to no-waged workers as a way to maximize profits (Andrejevic 2004, 2011; Hearn 2008, 2010, 2014; Raphael 1997; Ross 2014; Waxman 2005). Behind the scenes of reality TV shows, non-unionized workers toil overtime without pay, lack health insurance and pensions, subsist on short-term contracts, and flexibly move from one project to the next, some lasting weeks, others, many months (Hearn 2014; Raphael 1997; Ross 2014). And in the contrived scenes of reality TV shows, many people create the content we see but few are actually paid for their performances (Collins 2008; Hearn 2014). Although reality TV studios rely on the labour of "dispensable celebrities" (Collins 2008) to make TV shows, they use "participation agreements" to get the people who appear in the scenes to voluntarily exculpate their rights to compensation, privacy, free speech, an attorney, and even the content of their labor (Blair 2010; Cianci 2009; Collins 2008; Hearn 2014; Kelley 2006). These dispensable celebrities will endure this largely unpaid work to cultivate "branded selves" that they hope to exchange for "attention, reputation, and potentially profit" in the future (Hearn 2014, 446). While scholars have scrutinized the reality TV production sector's exploitation of low- to no-waged workers, they have not yet addressed how the work of unpaid interns may feed this sector's bottom line. To illuminate the "blindspot" of internships in the capitalist reality TV industry, the following section demonstrates how internships are an important part of reality TV's division of labour.

\section{The Intern as a Skilled Worker in the Reality TV Studio's Division of Labour}

In the reality TV industry, studios conceptualize, produce, and sell/license the TV shows they make, and organize and administer the financial, technological, and human relations required to produce reality TV shows. The primary goal of all reality TV production companies is to accumulate profit by selling reality TV shows as commodities in TV distribution/exhibit markets for more than it costs to make them. But to make reality TV shows, companies need technology and the skills and talents of many workers. No one reality TV show is produced by a single corporate "author," but rather, is the result of many workers who are part of each studio's division of labour. In each reality TV studio's division of labour, hundreds of workers perform specific roles and complete various tasks that contribute to the manufacture of reality TV shows. 
For example, studios rely on producers to develop the TV show format and production managers and assistants to support format research and development. Studios depend upon casting agents to scout, interview, and cast people to appear in the shows. Studios need directors to direct the action, videographers to shoot it, lighting technicians to light it, and musicians to create the theme music. They rely upon set-makers, sound technicians, visual effects-makers, make-up artists, hair stylists, and wardrobe workers. In post-production, studios need editors to transform thousands of hours of film into TV-schedule ready content. Supporting each of these roles and tasks are a number of clerical workers. Reality TV's division of labour is indeed multi-faceted, and as of late, studios are hiring interns to do jobs previously done by paid TV workers.

Table 1, Reality TV Intern Roles and Tasks, summarizes how the job ads describe the role of the intern in the reality TV studio's division of labour and demonstrate that these interns perform a number of roles and complete a variety of tasks that support the production of reality TV shows. Nine of the job ads for interns are for production assistants (45 percent of the postings), three are for casting agents (15 percent), two are for videographers, one is for clerical support, one is for a post-production editor, one is for a combined intern videographer/post-production editor, one is for a hybrid internal clerical worker and production assistant, and two do not specify the role the interns will play. According to the ads, reality TV interns imagine, research, and develop new reality TV show concepts for studios; write, review, and edit the scripts of reality TV episodes; search for, attract, interview, and cast the people who appear in the content of reality TV shows; set up scenes to be shot and coordinate lighting for shoots; film the action and interactions of contestants and participants; and digitize, craft, and edit footage into TVschedule ready segments in post-production. From content development to shooting to postproduction, reality TV interns cover the gamut of roles and tasks in reality TV's division of labour. Yet the intern is often defined by companies as anything but a worker who does real work (Perlin 2012). However, as the job postings indicate, reality TV interns are actually workers because they contribute in significant ways to the production of reality TV commodities. The reality TV intern's labour helps to create the content of the TV properties that studios own, control, and sell.

In the reality TV industry, studios seek to harness the skills of many workers and channel them toward TV commodity production. "Hard skills" tend to refer to technical abilities (i.e., verbal and written communication, the ability to use hardware and software) and "soft skills" connote interpersonal competencies (i.e., etiquette, affect, positivity, and reflexivity) (Heckman 2012). Table 2, Reality TV Intern Skills: Hard and Soft, summarizes how the reality TV intern job ads represent the combined hard and soft skills that studios expect people to possess as a prerequisite to considering them eligible for internships. Seventeen of the ads require applicants to possess hard technical skills ( 85 percent), 18 ask for soft skills (90 percent), and 14 request a combination of hard and soft skills (70 percent). In the category of hard skills, six ads demand communication skills (verbal and written; 20 percent), one asks for only computer literacy skills, two call for videography skills, and seven want applicants to possess a combination of communication, computer literacy, and videography skills (35 percent). Four of the ads do not say that applicants need to possess hard skills (20 percent). In the category of soft skills, the job ads represent interns as possessing a bundle of interpersonal competencies: 10 ads say applicants must have a "positive attitude" as indicated by phrases like "fun loving" and personality descriptors such as "amicable" and "likable" (50 percent); nine want efficient interns, as highlighted by phrases such as "complete assignments in a timely manner" (45 percent); eight call for self-motivated interns with phrases like "can do attitude" and "make it happen person" (40 percent); seven emphasize intellectual acuity and adaptability with phrases like "eager to learn," "fast learner," and "able to think on their feet" (35 percent); seven want "creative" interns as implied by phrases like "out of the box thinker" and "abstract thinker" (35 percent); seven require applicants to be passionate about entertainment as suggested by 
phrases like "strong passion for pop culture genre" (35 percent); four want interns to be multitaskers (20 percent); four want trustworthy interns ( 20 percent); four call for interns with strong organization skills (20 percent); three want flexible interns that can "wear lots of different hats" and "switch gears at a moment's notice" (15 percent); three emphasize that interns should be able to work independently, while another three stipulate interns should be able to take directions; three want dependable interns; three call for team-working and collaborative interns; two ask that applicants be detail oriented; two emphasize leadership skills; and three ads emphasize that interns should have problem-solving skills, analytical skills, and confidence. In sum, the ads construct the reality TV intern as a skilled cultural worker who does creative, emotional, and knowledge labour that contributes to the production of the TV shows that studios own and sell as commodities in TV distribution/exhibition markets.

"Internship" is ostensibly a synonym for "experiential education, volunteer work, participant observation, training, or apprenticeship" (Perlin 2012, 206) that equips aspiring workers with the skills they need to compete for a paid job. But as the reality TV intern job postings indicate, reality TV interns are not simply students, volunteers, participants, trainees or apprentices that accumulate the skills they need to compete for a reality TV industry career. Rather, they are workers who must already possess the skills required to perform roles and complete tasks in the reality TV industry's division of labour. Indeed, to be considered eligible for an internship in the reality TV industry, the applicant must convince the studio that they possess hard skills covering communication, computer literacy, and videography. Moreover, they are expected to have soft skills like abstract thinking and problem solving, as well as display emotional intelligence and positive affect. The reality TV intern job profile bundles together seemingly contradictory skills that place tremendous demands upon the worker's mind, body, and time. Studios want their interns to be able to complete specific tasks and multi-task, to lead and be led, to direct and take directions, to work alone and together in groups, to be creative yet detailed oriented, and to be passionate about reality TV and happy to produce it, just without pay. The reality TV studio demand that interns possess the aforementioned skills flies in the face of the notion that the internship is just an opportunity to gain skills or upskill. When juxtaposed with the fact that reality TV studios expect their interns to already possess a combination of hard and soft skills before hiring them, the idea that these internships equip people with the skills required to compete for a real waged job or career in the reality TV industry rings false and suggests that reality TV's interns are already skilled workers, just not being classified as such. Reality TV internships may not equip people with new skills, but rather, enable studios to harness the existing skills of workers and apply them to commodity production. But are reality TV interns paid for their labour, and if not, why might they consent to work without wages?

\section{The Capital-Labour Relationship: Reality TV Interns Work for Experience}

In the capitalist reality TV industry, there are owners of reality TV studios and workers who sell their labour power to them in exchange for a wage. The wage power relationship between owners and workers appears to be "free" (because studios do not technically coerce workers to work for wages) and "equal" (because studios and workers meet in the market as individualized sellers and buyers of commodified labour). Yet, apropos Marx (1990), the capital-labour relationship is substantively unfree and unequal. In capitalist economies, all workers largely depend upon their wages to live, which means that they must sell their labour power to companies as a commodity in exchange for the wage they require to buy their basic needs. And though the owners and the workers may both enjoy juridical equality as individual citizens in a liberal democratic state, the formal equality established and upheld by the state's legal apparatus masks substantive socio-economic inequalities, class inequality in particular (Mooers 2014). So, this ostensibly "free" and "equal" exchange relationship mystifies a substantively asymmetrical power relationship between reality TV owners and workers typified by capitalism's 
silent compulsion of waged work (i.e., the worker must labour for a company to meet their needs) and the unequal outcome (i.e., the worker's labour is exploited by companies to enrich its owners, which reproduces class division and inequality).

Although a typical capital-waged labour relationship persists in the reality TV industry (Hearn 2014; Ross 2013), the relationship between the reality TV studio and the reality TV intern is not based on the wage. Table 3, The Characteristics of the Reality TV Internship, demonstrates that only two of the surveyed reality TV production studios (Stick Figure Productions and Whalerock Industries) pay their interns a wage for the jobs they do. Another two (Half Yard Productions and Vantage Media) offer their interns an undisclosed stipend following their completion of the internship. The remaining 15 companies do not offer their interns any monetary compensation. Thus, 0.5 percent of reality TV internships surveyed by this study pay a minimum wage; 10.5 percent pay a stipend, which often equals less than minimum wage; 79 percent are not paid. These findings underscore a capital-unwaged labour relationship between the studio owners and interns qua workers. Even though reality TV interns may possess the manual and mental capabilities required to make reality TV shows and do real work for profit-oriented studios, they toil in the absence of monetary compensation for their efforts. Yet, the relationship between the reality TV owners and workers still appears to be "free" (because studios do not force workers to do internships or to complete numerous value adding tasks) and "equal" (because studios and the workers meet in an ostensibly benign exchange relationship). The ostensibly "free and equal" capital-unwaged labour relationship between reality TV studios and the interns nonetheless masks a substantively asymmetrical relationship that upholds the power and profits of companies at the expense of the workers, who do not get paid for their creative labour.

In studies of the work that prosumers do for social media corporations, "free labour" (content generation) is sometimes conceptualized as a private hobby, un-alienated leisure activity or form of voluntary practice set apart from the realm of necessity (Terranova 2004). Yet, the notion that online "free labour" is purely voluntary as opposed to compulsory risks misconstruing it as something set apart from capitalist exploitation of labour for profit (Fuchs 2014). In the context of unpaid internships generally and reality TV internships in particular, this unwaged labour is something that aspiring waged workers may feel pressured to do in the present as a precondition for struggling to meet their subsistence needs in the future. Many culture industry corporations expect workers to pull themselves up from unpaid internships to the world of waged work prior to even considering them and their labour power worthy of a wage. When people "freely" choose to do unpaid reality TV internships, the silent compulsion of waged labour does not disappear, but rather, may act as the future-oriented goal that compels people to work without pay in the present.

Additionally, "few people can afford to work for free" (de Peuter, Cohen and Brophy 2012), and for this reason, internships privilege some workers at the expense of others, including some and excluding others (Perlin 2012). For the privileged workers who benefit from extra-economic support systems like wealthy families and do not rely on waged jobs to make ends meet, the reality TV intern experience may help them to achieve their goal of waged work later on. But for those less well-off workers who cannot in the present afford to trade labour power for experience and who must work waged jobs to live, the reality TV internship may not be feasible. In this respect, the reality TV internship reproduces existing class divisions by enabling the already privileged to acquire the "experience" and connections required to be considered employable while keeping the less privileged workers out of the game and trouncing their employability.

Furthermore, the relationship between reality TV studios and intern-workers is fundamentally unequal. The studio, not the worker, determines the worker's role, tasks, and time in the division of labour; the studio, not the worker, decides the skills the worker must possess as a prerequisite for being considered hireable; and the studio, not the worker, controls the intellectual property rights to the TV shows workers produce and turn a profit by selling them in 
markets. In sum, the ostensibly "free" and "equal" exchange relationship between the reality TV studio and intern worker obscures asymmetrical power relations of class (the owner-worker division), compulsion (the worker may feel pressured to gift their labour to the studio in order to gain the experience they need to possibly get a wage in the future), exclusion (most workers cannot feed or shelter themselves with "experience" and without financial support from family or government), unfreedom (the worker's role, tasks, and time are decided and controlled by the studio), and inequality (the worker is exploited to produce commodities whose sale further helps owners to prosper).

Given these objectively bad conditions, why might workers do reality TV internships? Academic credit might be one factor, and 12 of the ads frame the internship as offering academic credit (60 percent). But the remaining eight do not say whether or not the internship provides academic credit (40 percent), and the subjective motivation for the unwaged reality TV internship may be deeper. Political economists, for example, have shown how workers will consent to work without wages in exchange for symbolic rewards like peer recognition, selfactualization, or exposure (Cohen 2008, 2012; Deuze 2007; Hesmondhalgh 2010; Huws 2007, 2010; Ross 2009, 2014; Terranova 2004). Kathleen Kuehn and Thomas Corrigan $(2013,9)$ developed the concept of "hope labour" to explain the subjective dimension of unwaged work, defining this as "un- or under-compensated work carried out in the present, often for experience or exposure, in the hope that future employment opportunities may follow." Kuehn and Corrigan (2013) claim that hope is an ideology that gets workers to actively consent to unwaged labour for a media company (16-17) and is also a coping strategy that workers rely upon to negotiate "the uncertainties of the contemporary labour economy" (10). Although Kuehn and Corrigan (2013) centre on how the hope labour of digital content producers enables digital media companies to "avoid costs associated with content producers' wages and benefits" (20) while shifting "costs and risks" onto the unwaged worker (21), they say that "hope labor is not restricted to digital spaces" (15) and mention "hope labor's recent proliferation" within and beyond the cultural industries. They flag reality TV and internships as non-social media sites for examining its workings (15).

As detailed in Table 4, The Reality TV Intern Experience, most of the reality TV intern ads support the workings of "hope ideology" by framing the unwaged internship as providing aspiring waged workers with a positive career-relevant experience of some sort. Twelve of the ads (60 percent) frame the internship as a way for the worker to train for a TV industry career or acquire skills related to one by using phrases like "hands on experience" and "learn about TV and film development process first hand." Eight of the ads (40 percent) emphasize that the internship gives the worker a chance to expose themselves to industry insiders and network with professionals by deploying phrases like "gain exposure [ . . . ] and network" and "pick the brains of the leadership team." Eight of the ads (40 percent) represent the internship as a chance to be mentored by an industry leader, as suggested by phrases like "work directly with Tina Eisner, the casting Manager," "work closely with Brandi Walker Maddox" and work "with the President of the company." Clearly, the reality TV intern job ads frame the internship as a career-relevant experience that will help the worker to develop a range of skills, expose themselves to and network with industry insiders, peers, and professionals, and even be mentored by managers. By representing reality TV internships as providing a positive career relevant experience, the reality TV intern job ads may persuade prospective applicants that working for free for a reality TV studio might really help them to secure gainful waged employment within the TV industry later on. And the worker's hope that the experience they get by doing the reality TV internship will help them get a paid career in the future may encourage them to enthusiastically consent to as opposed to contest the objective fact that studios are misclassifying them as interns to dispossess their labour power, devalue the labour of all workers in this sector, and displace formally paid employees. 


\section{Conclusion: Reality TV Intern Class Action}

By interrogating 20 reality TV internship job ads for internships in the US-based, yet globalizing, reality TV production sector, this article demonstrates that reality TV studios embrace, exploit, and try to elicit the consent of workers to low to no waged work via internship programs. Although the power relationship between reality TV studios and workers is marked by division, compulsion, exclusion, unfreedom, and inequality, the ideology of "hope" for a career-relevant experience may persuade workers to accept rather than challenge these capitalist conditions.

Yet, reality TV interns are not dupes of capital, but agents who possess the collective capacities for understanding and changing their conditions, and for the better. Across the cultural industries, workers are spearheading an "emerging intern activism" by blowing the whistle on the companies that exploit them, working with unions, launching class action suits, and pressuring government to crack down on illegal programs (de Peuter, Cohen and Brophy 2012; Perlin 2012; Yamada 2013b). Perhaps the most effective way that workers have contested unpaid internships is through litigation, as highlighted by a number of high-profile intern class action suits in the United States against media corporations like Fox Searchlight, the Hearst Corporation, Condé Nast, Warner Music Group, Sirus, and Vice Media (Sterne 2014). By proving that media corporations misclassified them as interns and used them to replace paid employees, workers have won back wages for the labour they did as "interns" (de Peuter, Cohen and Brophy 2012). The most significant legal battle surrounding the rise of "intern nation" (Perlin 2012), then, centers on the power to define the intern as an "employee" or "non-employee."

According to the US Equal Employment Opportunity Commission and the Civil Rights Act, people who are not paid for the work they do are not classified as "employees," hence, the people who do unpaid internships are "non-employees" and have no "human rights" in the workplace (Perlin 2012, 78; Yamada 2013a, 2013b). Yet, the US Federal Fair Labor Standards Act (FLSA) defines an "employee" as "any individual employed by an employer" with "employ" meaning "to suffer or permit to work," and thus, when a company employs a person's labour, even when not paying them, they are dealing with employees who possess human rights, including the right to be paid a minimum wage (Nieves 2014). Furthermore, the US Department of Labor (DOL) uses six criteria for determining whether or not a company is misclassifying employees as interns: 1) the internship is similar to the training an educational environment would provide; 2) the internship is for the benefit of the intern; 3 ) the intern does not displace regular employees; 4) the employer derives no immediate advantage from the intern; 5) the intern is not entitled to a job at the end of the internship; 6 ) the intern understands that he or she is not entitled to wage (Carrigan 2012; Nieves 2014). If the company running the unpaid internship program fails to meet all of these six criteria, their interns are legally classifiable as employees and must be paid.

To date, interns have not launched any class action suits against reality TV studios. Yet, there may be solid grounds for such a case. With regard to the FLSA's definition, reality TV interns are classifiable as employees of studios because they do real work for them. And when put to the DOL's six-point test, reality TV studios would seem to get a failing grade, for reasons outlined below.

First, reality TV internships are not similar to the training an educational environment would provide with regard to context because colleges and universities are not privately owned forprofit TV studios that get students to produce reality TV show commodities. Also, training connotes a process whereby a mentor teaches a particular skill to an apprentice so as to prepare them to do certain types of work, but reality TV studios expect their interns to already possess skills prior to putting them to work. Second, reality TV internships may benefit the people who do them by providing "experience" to put on their résumé, a letter of reference, and a sense of how reality TV production happens, but these benefits are equivalent to what any 
entry-level reality TV studio employee would obtain by doing the work that interns do, so it is not apparent that reality TV studios intentionally design and run unpaid internship programs exclusively for the moral betterment or educational uplift of workers. As discussed earlier, these internships may perpetuate capitalist power relations of class division, compulsion, exclusion, unfreedom, and inequality that do not benefit interns, but instead advance the interests of reality TV studios. Third, reality TV interns perform significant roles in the reality TV industry's division of labour that would have been played by employees and complete tasks employees would get paid to do. If reality TV studios did not have interns to play productive roles and complete tasks without pay at their disposal, they would likely have to hire and pay more employees to make their TV shows. Fourth, reality TV studios derive an immediate advantage from the intern because they channel the intern's skills into the production of reality TV shows that they own the property rights to and sell for a profit in the TV market-reality TV studios exploit the labour of interns for their own financial gain. Fifth, reality TV interns do not appear to be entitled to a job at the end of the unpaid internship, but this obscures how reality TV internships are basically jobs that do not pay. Sixth, although the reality TV intern job ads make it clear to applicants that they will not be paid for their labour, given that studios seem to be misclassifying employees as interns, this is irrelevant; under the FLSA, employees are not allowed to waive their right to be paid a wage for work.

In conclusion, workers have solid grounds for a class action suit against the reality TV studios, which misclassify them as interns and a right to recuperate lost wages for the real work they do. A more substantive case for workers against reality TV studios that solidifies the preliminary one posited herein will depend upon workers themselves gaining the confidence to publicly speak out about their experiences. Yet, the prospect of speaking truth to capitalist power may intimidate interns, especially in these precarious times and in such a competitive TV labour market. Fear of being stigmatized as a militant intern, blacklisted by internship program managers, and deprived of their shot to work for free as a means to maybe one day be employed for a wage, may deter interns from speaking out. Moving forward, the lawyers and unions involved in intern activism should have dialogue with such workers. And labour-minded communication studies scholars could gain further knowledge about and publicize how these workers live and labour by doing ethnographic research. A record of the feelings, thoughts, and testimonies of the workers that the reality TV industry embraces to exploit as unpaid interns would be a valuable supplement to this study and provide new cultural material to either validate or challenge its critique.

\section{Appendix A: Reality TV Intern Job Search}

Table 1. Reality TV Intern Roles and Tasks

\begin{tabular}{|l|l|l|l|l|}
\hline Company & Intern Role/ Tasks & $\begin{array}{l}\text { Production } \\
\text { Assistant } \\
\text { "develop and pitch } \\
\text { non-scripted } \\
\text { shows," "creating } \\
\text { new ones [shows]" } \\
\text { "researching for } \\
\text { existing shows" } \\
\text { "reality TV screen } \\
\text { writing" }\end{array}$ & $\begin{array}{l}\text { Casting } \\
\text { "cast [ ... ] non- } \\
\text { scripted shows" } \\
\text { "telephone } \\
\text { interviewing } \\
\text { skills, skyping } \\
\text { interviewing }\end{array}$ & $\begin{array}{l}\text { "general } \\
\text { office support } \\
\text { (phones, } \\
\text { copies, } \\
\text { etc...) }\end{array}$ \\
\hline CK Global Trading & $\begin{array}{l}\text { "Screen } \\
\text { Writer/Reality TV } \\
\text { Shows" }\end{array}$ & & & \\
\hline
\end{tabular}




\begin{tabular}{|c|c|c|c|c|}
\hline & & & potential talent" & \\
\hline Cornwell Casting & "Casting Intern" & & $\begin{array}{l}\text { "help with } \\
\text { finding } \\
\text { applicants, } \\
\text { greeting them } \\
\text { when they come } \\
\text { in for interviews, } \\
\text { preparing } \\
\text { pitches, and } \\
\text { more" }\end{array}$ & \\
\hline $\begin{array}{l}\text { Forever Fabulous } \\
\text { Events }\end{array}$ & "Office Intern" & & & $\begin{array}{l}\text { "organize } \\
\text { and collect } \\
\text { progress } \\
\text { reports," } \\
\text { "monitor } \\
\text { project } \\
\text { calendar, } \\
\text { ensuring } \\
\text { project is on } \\
\text { schedule and } \\
\text { in budget" }\end{array}$ \\
\hline Freemantle Media (1) & $\begin{array}{l}\text { "Development } \\
\text { Internship" }\end{array}$ & $\begin{array}{l}\text { "script review and } \\
\text { internal } \\
\text { development } \\
\text { meetings," } \\
\text { "conducting } \\
\text { research as } \\
\text { directed" }\end{array}$ & & $\begin{array}{l}\text { "answering } \\
\text { phones, data } \\
\text { entry, } \\
\text { administrativ } \\
\text { e duties" }\end{array}$ \\
\hline Freemantle Media (2) & $\begin{array}{l}\text { "Scripted } \\
\text { Development } \\
\text { Intern" }\end{array}$ & $\begin{array}{l}\text { "assisting in the } \\
\text { development of } \\
\text { unscripted and } \\
\text { digital projects" }\end{array}$ & & \\
\hline Half Yard Productions & $\begin{array}{l}\text { "Post-Production } \\
\text { Intern" }\end{array}$ & & & $\begin{array}{l}\text { "answering } \\
\text { phones, } \\
\text { transcribing } \\
\text { video } \\
\text { interviews, } \\
\text { logging } \\
\text { actuality } \\
\text { footage and } \\
\text { organizing all } \\
\text { materials to } \\
\text { office } \\
\text { management }\end{array}$ \\
\hline Hart18 Entertainment & "Casting Intern" & & $\begin{array}{l}\text { "researching, } \\
\text { finding, and } \\
\text { pitching new } \\
\text { prospective } \\
\text { talents for new } \\
\text { projects," } \\
\text { "posting casting } \\
\text { calls" }\end{array}$ & $\begin{array}{l}\text { "sending, } \\
\text { vetting and } \\
\text { sorting a } \\
\text { variety of } \\
\text { email" }\end{array}$ \\
\hline HillCrest Event Center & $\begin{array}{l}\text { "TV Camera } \\
\text { Person/Videograph }\end{array}$ & $\begin{array}{l}\text { "assist in scene set } \\
\text { up", "assist in }\end{array}$ & & \\
\hline
\end{tabular}




\begin{tabular}{|c|c|c|c|}
\hline & er Intern" & $\begin{array}{l}\text { lighting } \\
\text { coordination," } \\
\text { "assist during } \\
\text { events and } \\
\text { receptions," } \\
\text { "maintain camera } \\
\text { equipment," "hand } \\
\text { valuable camera } \\
\text { equipment" }\end{array}$ & \\
\hline JBO Production Inc. & $\begin{array}{l}\text { "Videographer/post- } \\
\text { production editor } \\
\text { Intern" }\end{array}$ & $\begin{array}{l}\text { "capturing, logging } \\
\text { and digitizing video } \\
\text { footage from } \\
\text { multiple formats," } \\
\text { "assist in } \\
\text { assembling rough } \\
\text { cuts for national TV } \\
\text { shows," "help with } \\
\text { miscellaneous } \\
\text { projects," "assist on } \\
\text { video shoots" }\end{array}$ & \\
\hline $\begin{array}{l}\text { Lighthearted } \\
\text { Entertainment }\end{array}$ & $\begin{array}{l}\text { "Office and } \\
\text { Development } \\
\text { Intern" }\end{array}$ & $\begin{array}{l}\text { "supporting the } \\
\text { development team" } \\
\text { "heavy emphasis } \\
\text { on researching } \\
\text { existing show } \\
\text { ideas" }\end{array}$ & $\begin{array}{l}\text { "general } \\
\text { office support } \\
\text { (phones, } \\
\text { copies, etc.)" }\end{array}$ \\
\hline $\begin{array}{l}\text { On-Ride } \\
\text { Entertainment, LLC }\end{array}$ & $\begin{array}{l}\text { "Videographer } \\
\text { Intern" }\end{array}$ & $\begin{array}{l}\text { "videographer," } \\
\text { "participate in focus } \\
\text { groups and panels [ } \\
\text {... ] to help further } \\
\text { develop the series," } \\
\text { "may also } \\
\text { participate in the } \\
\text { editing process" }\end{array}$ & \\
\hline $\begin{array}{l}\text { One Potato Two } \\
\text { Potato }\end{array}$ & Not specified & $\mathrm{N} / \mathrm{A}$ & \\
\hline $\begin{array}{l}\text { Ryan Seacrest } \\
\text { Productions }\end{array}$ & Not specified & $\begin{array}{l}\text { "diversified } \\
\text { selection of } \\
\text { assignments with } \\
\text { an emphasis on } \\
\text { projects, rather } \\
\text { than clerical tasks" } \\
\text { "assisting with } \\
\text { special projects } \\
\text { related to Red } \\
\text { Carpet events and } \\
\text { Unscripted } \\
\text { Television } \\
\text { Development" }\end{array}$ & \\
\hline Sonassa's LLC & $\begin{array}{l}\text { "Videography Intern } \\
\text { for Reality and } \\
\text { Television Show" }\end{array}$ & $\begin{array}{l}\text { "film a weekly } 30 \\
\text { minutes Television } \\
\text { Show which } \\
\text { includes } 15 \text { minutes } \\
\text { of the Talk Show } \\
\text { and } 15 \text { minutes of }\end{array}$ & \\
\hline
\end{tabular}




\begin{tabular}{|c|c|c|c|c|}
\hline & & $\begin{array}{l}\text { the Reality Show," } \\
\text { "the end product } \\
\text { should be } \\
\text { comparable to } \\
\text { mainstream } \\
\text { Television show" }\end{array}$ & & \\
\hline $\begin{array}{l}\text { Stick Figure } \\
\text { Productions }\end{array}$ & "Production Intern" & $\begin{array}{l}\text { "help in all aspects } \\
\text { of our production } \\
\text { company," } \\
\text { "developing } \\
\text { projects," "working } \\
\text { on projects } \\
\text { currently in } \\
\text { production," "help } \\
\text { out with post- } \\
\text { production process" }\end{array}$ & & \\
\hline Superfine Films & $\begin{array}{l}\text { "TV Development } \\
\text { Intern (reality)" }\end{array}$ & $\begin{array}{l}\text { "participate HANDS } \\
\text { on in our reality TV } \\
\text { development } \\
\text { department helping } \\
\text { to develop new } \\
\text { reality television } \\
\text { shows" } \\
\text { "doing research into } \\
\text { creative trends," } \\
\text { "editing" }\end{array}$ & & $\begin{array}{l}\text { "telephone } \\
\text { interviewing," } \\
\text { "skyping and } \\
\text { interviewing } \\
\text { potential } \\
\text { talent" }\end{array}$ \\
\hline The Idea Factory & $\begin{array}{l}\text { "Reality TV } \\
\text { Development } \\
\text { Intern" }\end{array}$ & $\begin{array}{l}\text { "work in } \\
\text { development and } \\
\text { production," } \\
\text { "writing," "shooting," } \\
\text { "possibly editing" } \\
\text { "research" }\end{array}$ & & $\begin{array}{l}\text { "Basic Office } \\
\text { Duties," } \\
\text { "phones" }\end{array}$ \\
\hline Vantage New Media & $\begin{array}{l}\text { "Production } \\
\text { Assistant } \\
\text { Internship" }\end{array}$ & $\begin{array}{l}\text { "pre-to-post } \\
\text { production of a } \\
\text { segment of a } \\
\text { Nationwide Reality } \\
\text { Television Program } \\
\text { focused on the } \\
\text { making of College } \\
\text { Swimsuit } \\
\text { Calendars" }\end{array}$ & $\begin{array}{l}\text { "full involvement } \\
\text { in the casting } \\
\text { process" }\end{array}$ & \\
\hline Whalerock Industries & $\begin{array}{l}\text { "TV/Film } \\
\text { Development } \\
\text { Intern" }\end{array}$ & $\begin{array}{l}\text { "Participate in } \\
\text { creative } \\
\text { development } \\
\text { meetings with } \\
\text { Scripted and } \\
\text { Unscripted TV } \\
\text { executives," "Work } \\
\text { on projects in } \\
\text { development for } \\
\text { various television } \\
\text { networks and } \\
\text { media outlets" }\end{array}$ & & \\
\hline
\end{tabular}

Table 2. Reality TV Intern Skills: Hard and Soft 


\begin{tabular}{|c|c|c|}
\hline Company & Hard Skills & Soft Skills \\
\hline Beyond Productions & $\begin{array}{l}\text { "excellent } \\
\text { communication } \\
\text { skills" }\end{array}$ & $\begin{array}{l}\text { "initiative," "organized," "able to multi-task," "positive } \\
\text { attitude," "quick learner," "creative" }\end{array}$ \\
\hline CK Global Trading & $\begin{array}{l}\text { "must have } \\
\text { experience in } \\
\text { reality TV screen } \\
\text { writing" }\end{array}$ & $\begin{array}{l}\text { "out of the box thinker/writer," "be able to put the } \\
\text { society under critical camera lens," "work as a team," } \\
\text { "share her/his/ idea to other team members to the } \\
\text { point of completion on time" }\end{array}$ \\
\hline Cornwell Casting & $\begin{array}{l}\text { "knowledge of } \\
\text { editing software," } \\
\text { "Photoshop, and or } \\
\text { Powerpoint," } \\
\text { "excellent written } \\
\text { and verbal skills" }\end{array}$ & $\begin{array}{l}\text { "highly motivated," "ambitious," "positive and eager } \\
\text { attitude" }\end{array}$ \\
\hline $\begin{array}{l}\text { Forever Fabulous } \\
\text { Events }\end{array}$ & & $\begin{array}{l}\text { "assessing issues, defining solutions, and } \\
\text { implementing strategy," "how to implement goals," } \\
\text { "leadership, efficiency, dependability and } \\
\text { organization" }\end{array}$ \\
\hline Freemantle Media (1) & $\begin{array}{l}\text { "strong computer } \\
\text { skills," "proficient in } \\
\text { PC, Microsoft } \\
\text { Office and other } \\
\text { programs" }\end{array}$ & $\begin{array}{l}\text { "detail oriented, eager to learn and efficient, with } \\
\text { excellent follow-up and follow-through skills," "multi- } \\
\text { task, take initiative, be naturally curious, fun loving," } \\
\text { "trustworthy with sensitive and confidential } \\
\text { information" }\end{array}$ \\
\hline Freemantle Media (2) & $\begin{array}{l}\text { "knowledge of } \\
\text { editing software, } \\
\text { Photoshop, and/or } \\
\text { PowerPoint is a } \\
\text { plus," "excellent } \\
\text { written and verbal } \\
\text { skills" }\end{array}$ & "ambitious," "positive and eager attitude" \\
\hline Half Yard Productions & $\begin{array}{l}\text { "strong } \\
\text { communication } \\
\text { skills" }\end{array}$ & $\begin{array}{l}\text { "meticulous, flexible and ready to work in a fast paced } \\
\text { office" }\end{array}$ \\
\hline Hart18 Entertainment & "terrific email skills" & $\begin{array}{l}\text { "Organizational skills," "The ability to meet deadlines," } \\
\text { "follow specific directions," "ability to work } \\
\text { independently," "strong interest in TV and media," } \\
\text { "previous internship experience preferred, but not } \\
\text { necessary" }\end{array}$ \\
\hline HillCrest Event Center & $\begin{array}{l}\text { "working knowledge } \\
\text { of basic camera } \\
\text { operation," "Adobe } \\
\text { Master Collection } \\
\text { and Microsoft," } \\
\text { "excellent written } \\
\text { and verbal } \\
\text { communication" }\end{array}$ & $\begin{array}{l}\text { "multi-tasking and coordination," "passion for art and } \\
\text { film," "attention to details while maintaining } \\
\text { perspective," "able to give and take direction," "artistic } \\
\text { vision," "work in fast paced environment" }\end{array}$ \\
\hline JBO Production Inc. & & $\begin{array}{l}\text { "highly motivated," "reliable," "dedicated," } \\
\text { "enthusiastic" }\end{array}$ \\
\hline $\begin{array}{l}\text { Lighthearted } \\
\text { Entertainment }\end{array}$ & $\begin{array}{l}\text { "Mac skills," } \\
\text { "excellent } \\
\text { communication" }\end{array}$ & $\begin{array}{l}\text { "follow through," "excellent organizational, analytical } \\
\text { and prioritization skills," "quick learner," "multi-tasker," } \\
\text { "fast, quality-reinforced turnaround," "positive } \\
\text { attitude/sense of humor," "ability to maintain } \\
\text { confidentiality" }\end{array}$ \\
\hline $\begin{array}{l}\text { On-Ride Entertainment, } \\
\text { LLC }\end{array}$ & $\begin{array}{l}\text { "sufficient } \\
\text { experience using }\end{array}$ & \\
\hline
\end{tabular}




\begin{tabular}{|c|c|c|}
\hline & $\begin{array}{l}\text { DSLR camera for } \\
\text { filming," "owner of } \\
\text { DSLR camera" }\end{array}$ & \\
\hline One Potato Two Potato & $\begin{array}{l}\text { "Working } \\
\text { knowledge of Final } \\
\text { Cut Studio," } \\
\text { "Proficient in all } \\
\text { Office applications," } \\
\text { "Advanced Post } \\
\text { Production software } \\
\text { knowledge a plus," } \\
\text { "Excellent } \\
\text { communication } \\
\text { skills both verbal } \\
\text { and writing" }\end{array}$ & $\begin{array}{l}\text { "Reliable," "Honest", "Hardworking," "Proactive 'can } \\
\text { do' attitude," } \\
\text { "Interest in Television production and development," } \\
\text { "Extremely organized" }\end{array}$ \\
\hline $\begin{array}{l}\text { Ryan Seacrest } \\
\text { Productions }\end{array}$ & $\begin{array}{l}\text { "Proficient in MS } \\
\text { Office applications," } \\
\text { "previous } \\
\text { experience in } \\
\text { WordPress a plus," } \\
\text { "excellent } \\
\text { communication } \\
\text { skills" }\end{array}$ & $\begin{array}{l}\text { "highly-talented and qualified," "Ability to work } \\
\text { independently and as part of a team," } \\
\text { "a focus in broadcast journalism and/or creative } \\
\text { writing," } \\
\text { "strong passion for the pop culture genre including all } \\
\text { things television, film, celebrity, red carpet, music and } \\
\text { digital" }\end{array}$ \\
\hline Sonassa's LLC & $\begin{array}{l}\text { "excellent filming } \\
\text { skills" }\end{array}$ & \\
\hline $\begin{array}{l}\text { Stick Figure } \\
\text { Productions }\end{array}$ & & "Bright," "Ambitious",, \\
\hline Superfine Films & & $\begin{array}{l}\text { "Capable," "Smart, creative," "enthusiasm," "a } \\
\text { confident personality," "a curiosity," "make it happen } \\
\text { person" }\end{array}$ \\
\hline The Idea Factory & $\begin{array}{l}\text { "writing skills," } \\
\text { "video editing } \\
\text { software," "video } \\
\text { compositing and } \\
\text { image editing } \\
\text { programs," "general } \\
\text { layout and design" }\end{array}$ & $\begin{array}{l}\text { "amicable," "highly creative," "able to think on their } \\
\text { feet," "be ready to wear lots of different hats" }\end{array}$ \\
\hline Vantage New Media & $\begin{array}{l}\text { "strong } \\
\text { communication } \\
\text { skills" }\end{array}$ & $\begin{array}{l}\text { "great attitude," "willingness to explore all facets of } \\
\text { the world of entertainment" }\end{array}$ \\
\hline Whalerock Industries & $\begin{array}{l}\text { "a strong writer," } \\
\text { "able to cohesively } \\
\text { summarize and put } \\
\text { feedback and } \\
\text { opinions onto } \\
\text { paper" }\end{array}$ & $\begin{array}{l}\text { "team player," "an avid reader," "be ready to switch } \\
\text { gears at a moment's notice," "self-starter," } \\
\text { "passionate about TV and film," "experience and } \\
\text { knowledge of the TV and film industry is a plus," } \\
\text { "willing to take direction and see assignments through } \\
\text { completion in a timely manner" }\end{array}$ \\
\hline
\end{tabular}

Table 3. The Characteristics of Reality TV Internships

\begin{tabular}{|l|l|l|l|l|l|}
\hline Company & $\begin{array}{l}\text { Number of } \\
\text { positions }\end{array}$ & $\begin{array}{l}\text { Full-timel } \\
\text { Part- } \\
\text { Time }\end{array}$ & Paid & Duration & $\begin{array}{l}\text { Acade } \\
\text { mic } \\
\text { credit }\end{array}$ \\
\hline Beyond Productions & 2 & PT & No & $\begin{array}{l}10 \text { weeks (March 9-May } \\
16,2015)\end{array}$ & Yes \\
\hline CK Global Trading & 10 & PT & No & Ongoing (year round) & Yes \\
\hline
\end{tabular}




\begin{tabular}{|c|c|c|c|c|c|}
\hline Cornwell Casting & 2 & PT & No & Ongoing (year round) & Yes \\
\hline $\begin{array}{l}\text { Forever Fabulous } \\
\text { Events }\end{array}$ & 2 & FT & No & Ongoing (year round) & Yes \\
\hline $\begin{array}{l}\text { Freemantle Media } \\
\text { (1) }\end{array}$ & 1 & PT & No & Ongoing (year round) & Yes \\
\hline $\begin{array}{l}\text { Freemantle Media } \\
\text { (2) }\end{array}$ & 1 & PT & No & Ongoing (year round) & Yes \\
\hline $\begin{array}{l}\text { Half Yard } \\
\text { Productions }\end{array}$ & 1 & PT & $\begin{array}{l}\text { No (but } \\
\text { stipend } \\
\text { provided) }\end{array}$ & $\begin{array}{l}12 \text { weeks (March } 30-J u n e \\
15,2015) \text { 10am,-6pm, } 2 \\
\text { days a week }\end{array}$ & Yes \\
\hline Hart18 Entertainment & 5 & PT & No & 12 weeks & $\mathrm{N} / \mathrm{A}$ \\
\hline $\begin{array}{l}\text { HillCrest Event } \\
\text { Center }\end{array}$ & 1 & PT & No & Ongoing (year round) & $\mathrm{N} / \mathrm{A}$ \\
\hline JBO Production Inc. & 5 & PT & No & Ongoing (year round) & Yes \\
\hline $\begin{array}{l}\text { Lighthearted } \\
\text { Entertainment }\end{array}$ & 6 & PT & No & $\begin{array}{l}\text { Ongoing (year round), 3-5 } \\
\text { days per week }\end{array}$ & Yes \\
\hline $\begin{array}{l}\text { On-Ride } \\
\text { Entertainment, LLC }\end{array}$ & 1 & PT & No & Ongoing (year round) & N/A \\
\hline $\begin{array}{l}\text { One Potato Two } \\
\text { Potato }\end{array}$ & 1 & PT & No & Ongoing (year round) & Yes \\
\hline $\begin{array}{l}\text { Ryan Seacrest } \\
\text { Productions } \\
\end{array}$ & & PT & No & Ongoing (year round) & N/A \\
\hline Sonassa's LLC & 4 & $\mathrm{PT}$ & No & Ongoing (year round) & Yes \\
\hline $\begin{array}{l}\text { Stick Figure } \\
\text { Productions }\end{array}$ & 3 & PT & Yes & Ongoing (year round) & $\mathrm{N} / \mathrm{A}$ \\
\hline Superfine Films & 1 & & No & $\begin{array}{l}12 \text { weeks (March 1-May } \\
22,2015)\end{array}$ & Yes \\
\hline The Idea Factory & 5 & $\mathrm{PT}$ & No & Ongoing (year round) & $\mathrm{N} / \mathrm{A}$ \\
\hline Vantage New Media & 1 & PT & $\begin{array}{l}\text { No (but } \\
\text { "performa } \\
\text { nce- } \\
\text { based } \\
\text { stipend } \\
\text { provided } \\
\text { at } \\
\text { completio } \\
\text { n") }\end{array}$ & Ongoing (year round) & N/A \\
\hline Whalerock Industries & 1 & PT & Yes & $\begin{array}{l}10 \text { weeks (June } 15- \\
\text { August } 21,2015), 3 \text { days } \\
\text { a week. }\end{array}$ & N/A \\
\hline
\end{tabular}

Table 4. The Reality TV Intern "Experience"

\begin{tabular}{|l|l|l|l|}
\hline $\begin{array}{l}\text { Reality TV } \\
\text { Company }\end{array}$ & $\begin{array}{l}\text { Training/Skills } \\
\text { Development }\end{array}$ & $\begin{array}{l}\text { Exposure/ } \\
\text { Networking }\end{array}$ & Mentorship \\
\hline $\begin{array}{l}\text { Beyond } \\
\text { Productions }\end{array}$ & $\begin{array}{l}\text { "the internship is a great } \\
\text { way to learn the industry } \\
\text { and will provide practical } \\
\text { know-how," "hands on } \\
\text { experience in } \\
\text { development of non- } \\
\text { scripted television" }\end{array}$ & $\begin{array}{l}\text { "learn what it takes to create } \\
\text { reality television [ ... ] under our } \\
\text { development team" }\end{array}$ & \\
\hline $\begin{array}{l}\text { CK Global } \\
\text { Trading }\end{array}$ & $\begin{array}{l}\text { "We will teach you the } \\
\text { ins and outs of the }\end{array}$ & $\begin{array}{l}\text { "a unique } \\
\text { opportunity to work }\end{array}$ & $\begin{array}{l}\text { "work directly with Tina Eisner, } \\
\text { the casting manager" }\end{array}$ \\
\hline Cornwell Casting &
\end{tabular}




\begin{tabular}{|c|c|c|c|}
\hline & $\begin{array}{l}\text { casting world and also } \\
\text { provide training on how } \\
\text { to do different types of } \\
\text { casting positions" }\end{array}$ & $\begin{array}{l}\text { with a professional } \\
\text { and experienced } \\
\text { casting team" }\end{array}$ & \\
\hline $\begin{array}{l}\text { Forever Fabulous } \\
\text { Events }\end{array}$ & & & $\begin{array}{l}\text { "work closely with Mrs. Brandi } \\
\text { Walker Maddox interfacing with } \\
\text { all her clients" }\end{array}$ \\
\hline $\begin{array}{l}\text { Freemantle Media } \\
\text { (1) }\end{array}$ & $\begin{array}{l}\text { "A valuable look into the } \\
\text { development process } \\
\text { within a Television } \\
\text { Studio," "a very } \\
\text { educational and } \\
\text { comprehensive look into } \\
\text { the entire TV landscape" }\end{array}$ & & $\begin{array}{l}\text { "the intern will get a chance to } \\
\text { hone their screenplay analysis } \\
\text { skills with guidance from the } \\
\text { development execs" }\end{array}$ \\
\hline $\begin{array}{l}\text { Freemantle Media } \\
\text { (2) }\end{array}$ & $\begin{array}{l}\text { "a great opportunity to } \\
\text { learn about the } \\
\text { unscripted development } \\
\text { process from the ground } \\
\text { up," "an opportunity to } \\
\text { be on set of two game } \\
\text { shows," to "witness first- } \\
\text { hand what it takes to run } \\
\text { a studio based game } \\
\text { show for a major } \\
\text { broadcast network" }\end{array}$ & & \\
\hline \multicolumn{4}{|l|}{$\begin{array}{l}\text { Half Yard } \\
\text { Productions }\end{array}$} \\
\hline $\begin{array}{l}\text { Hart18 } \\
\text { Entertainment }\end{array}$ & & & $\begin{array}{l}\text { "work REMOTELY, directly with } \\
\text { the President of the company" }\end{array}$ \\
\hline $\begin{array}{l}\text { HillCrest Event } \\
\text { Center }\end{array}$ & $\begin{array}{l}\text { "boost your knowledge } \\
\text { of necessary make up } \\
\text { techniques for camera" }\end{array}$ & & $\begin{array}{l}\text { "Assistant to Director of } \\
\text { Photography," "Learn hands on } \\
\text { experience with a group of film } \\
\text { producers" }\end{array}$ \\
\hline $\begin{array}{l}\text { JBO Production } \\
\text { Inc. }\end{array}$ & & $\begin{array}{l}\text { "any projects } \\
\text { worked on by intern } \\
\text { will be provided to } \\
\text { them for demo reel } \\
\text { purposes only" }\end{array}$ & \\
\hline $\begin{array}{l}\text { Lighthearted } \\
\text { Entertainment }\end{array}$ & $\begin{array}{l}\text { "hands on experience in } \\
\text { development of non- } \\
\text { scripted television," "if } \\
\text { you are interested in } \\
\text { getting into reality } \\
\text { television, documentary, } \\
\text { game shows or casting } \\
\text { this will be practical } \\
\text { experience and a great } \\
\text { way to learn the } \\
\text { industry" }\end{array}$ & $\begin{array}{l}\text { "great referent point } \\
\text { for future positions" }\end{array}$ & \\
\hline $\begin{array}{l}\text { On-Ride } \\
\text { Entertainment, } \\
\text { LLC }\end{array}$ & $\begin{array}{l}\text { "expose intern to } \\
\text { structure and processes } \\
\text { involved in producing a } \\
\text { reality TV show" }\end{array}$ & $\begin{array}{l}\text { "great for your } \\
\text { resume!", } \\
\text { "opportunity to } \\
\text { network with }\end{array}$ & $\begin{array}{l}\text { "ability to [ ... . ] shadow } \\
\text { Producers" }\end{array}$ \\
\hline
\end{tabular}




\begin{tabular}{|c|c|c|c|}
\hline & & $\begin{array}{l}\text { Producers and } \\
\text { Directors and } \\
\text { attend focus groups } \\
\text { and corporate } \\
\text { meetings" }\end{array}$ & \\
\hline $\begin{array}{l}\text { One Potato Two } \\
\text { Potato }\end{array}$ & & $\begin{array}{l}\text { "an initial foothold } \\
\text { in television" }\end{array}$ & \\
\hline $\begin{array}{l}\text { Ryan Seacrest } \\
\text { Productions }\end{array}$ & $\begin{array}{l}\text { "hands-on/practical } \\
\text { exposure to the } \\
\text { television/entertainment } \\
\text { industry with a focus on } \\
\text { the Digital Media space" }\end{array}$ & & \\
\hline Sonassa's LLC & $\begin{array}{l}\text { "great opportunity for the } \\
\text { intern to practice their } \\
\text { talent" }\end{array}$ & $\begin{array}{l}\text { "gain exposure [ . . } \\
\text { ] and network with } \\
\text { future prospective } \\
\text { clients" }\end{array}$ & \\
\hline $\begin{array}{l}\text { Stick Figure } \\
\text { Productions }\end{array}$ & $\begin{array}{l}\text { "opportunity to work," } \\
\text { "opportunity of a life- } \\
\text { time" }\end{array}$ & & \\
\hline Superfine Films & $\begin{array}{l}\text { "participate hands on, } \\
\text { creative learning } \\
\text { experiences unlike you } \\
\text { or your friends ever } \\
\text { seen", "Learning...YOU } \\
\text { WILL NOT get coffee, } \\
\text { make copies or pick up } \\
\text { our laundry! Ever..." }\end{array}$ & & $\begin{array}{l}\text { "LEARNING with our } \\
\text { development team" }\end{array}$ \\
\hline \multicolumn{4}{|l|}{ The Idea Factory } \\
\hline \multicolumn{4}{|l|}{$\begin{array}{l}\text { Vantage New } \\
\text { Media }\end{array}$} \\
\hline $\begin{array}{l}\text { Whalerock } \\
\text { Industries }\end{array}$ & $\begin{array}{l}\text { "Learn what it takes to } \\
\text { succeed in the TV/Film } \\
\text { Industry," "Learn about } \\
\text { the TV and film } \\
\text { development process } \\
\text { first hand" }\end{array}$ & $\begin{array}{l}\text { "Have the } \\
\text { opportunity to } \\
\text { develop and pitch } \\
\text { an original idea to } \\
\text { the leadership } \\
\text { team," } \\
\text { "Participate in } \\
\text { 'Lunch \& Learns' - } \\
\text { opportunities to } \\
\text { grab a bite and pick } \\
\text { the brains of the } \\
\text { leadership team" }\end{array}$ & \\
\hline
\end{tabular}

\section{References}

Andrejevic, Mark. 2004. Reality TV: The Work of Being Watched. Lanham, MD: Rowman \& Littlefield. Andrejevic, Mark. 2011. Realizing Exploitation. In The Politics of Reality Television, edited by Marwan. M. Kraidy and Katherine Sender, 18-30. New York: Routledge.

Blair, Jennifer. L. 2010. Surviving Reality TV: The Ultimate Challenge of Reality Show Contestants. Loyola of Los Angeles Entertainment Law Review 31 (1): 1-25.

Brophy, Enda. 2013. Laboring to Learn: Lineaments of the Creative-Academic Complex in Vancouver. Line: $106-111$.

Carrigan, John R. 2012. Hollywood Intern Lawsuits: Overworked, Underpaid And Illegal? Hollywood Reporter, October 25. Accessed December 1, 2014. http://www.hollywoodreporter.com/thresq/hollywood-interns-overworked-underpaid-illegal-382190. 
Cianci, Christopher. 2009. Entertainment or Exploitation? Reality Television and the Inadequate Protection of Child Participants Under the Law. Southern California Interdisciplinary Law Journal 18 (1): 363-94.

Cohen, Nicole. 2012. Cultural Work as a Site of Struggle. triple C 10(2): 141-155.

Cohen, Nicole. 2008. The Valorization of Surveillance: Toward a Political Economy of Facebook. Democratic Communiqué 22 (1): 5-22.

Collins, Sue. 2008. Making the Most out of 15 Minutes: Reality TV's Disposable Celebrity. Television \& New Media 9 (2): 87-110.

de Peuter, Greig. 2014. Beyond the Model Worker: Surveying a Creative Precariat. Culture Unbound 6 (1): 263-284.

de Peuter, Greig, Nicole Cohen and Enda Brophy. 2012. Interns Unite! (You Have Nothing to LoseLiterally). Briarpatch Nov/Dec: 8-12.

Deuze, Mark. 2007. Media Work. Cambridge, MA: Polity Press.

Flint, Joe. 2014. Reality TV Production Deal Prices Escalate Amid Consolidation Wave. LA Times, June 3. Accessed December 1, 2014. http://www.latimes.com/entertainment/envelope/cotown/la-fi-ctunscripted-consolidation-20140603-story.html\#page=1.

Fuchs, Christian. 2014. Digital Labor and Karl Marx. New York: Routledge.

Hall, Stuart. 1996. Introduction: Who Needs Identity? In Questions of Cultural Identity, edited by Stuart Hall and Paul du Gay, 1-17. London: Sage.

Hearn, Alison. 2008. Variations on the Branded 'Self': Theme, Invention, Improvisation and Inventory. In The Media and Social Theory, edited by David Hesmondhalgh and Jason Toynbee, 194-210. New York: Routledge.

Hearn, Alison. 2010. Reality Television, The Hills, and the Limits of the Immaterial Labor Thesis. tripleC 8 (1): 60-76.

Hearn, Alison. 2014. Producing 'Reality': Branded Content, Branded Selves, Precarious Futures. In $A$ Companion to Reality Television, edited by Laurie Ouellette, 437-454. Malden, MA: Wiley-Blackwell.

Heckman, James. 2012. Hard Evidence on Soft Skills. Accessed December 1, 2014. http://www.irp.wisc.edu/publications/focus/pdfs/foc292b.pdf.

Hesmondhalgh, David. 2010. User-generated content, free labor and the cultural industries. Ephemera: theory \& politics in organization 10 (3/4): 267-284.

Huws, Ursula. 2007. The Creative Spark in the Engine: Special Issue of Work, Organization, Labor \& Globalization (1): 1-12.

Huws, Ursula. 2010. Expression and expropriation: the dialectics of autonomy and control in creative labor. ephemera: theory \& politics in organization 10 (3/4): 504-521.

Kelley, Tiffany. 2006. Reality Show Participants: Employees or Independent Contractors? Employee Relations Law Journal 32 (1): 15-38.

Marx, Karl. 1990. Capital: A Critique of Political Economy, Vol. 1. New York: Penguin Press.

Mayer, Vickie. 2011. Below the Line: Producers and Production Studies in the New Television Economy. Durham and London: Duke University Press.

Mirrlees, Tanner. 2013. Global Entertainment Media: Between Cultural Imperialism and Cultural Globalization. New York: Routledge.

Mooers, Colin. 2014. Imperial Subjects: Citizenship in an Age of Crisis and Empire. New York: Bloomsbury Academic.

Mosco, Vincent. 2009. The Political Economy of Communication. Thousand Oaks, CA: Sage.

Mosco, Vincent and Catherine McKercher. 2008. The Laboring of Communication: Will Knowledge Workers of the World Unite? Lanham, MD: Lexington Books.

Nieves, Racquel. 2014. The Future of Unpaid Internships in the Entertainment Industry. Accessed December 1, 2015. http://dlreporter.com/2014/06/25/future-of-unpaid-internships-in-entertainmentindustryl.

Oullette, Laurie and James Hay. 2008. Better Living Through Reality TV. Malden, MA: Blackwell.

Perlin, Ross. 2012. Intern Nation: How to Earn Nothing and Earn Little in the Brave New Economy. New York: Verso.

Raphael, Chad. 1997. The Political Economic Origins of Reali-TV. Jump Cut 41 (2): 102-109.

Ross, Andrew. 2004. No-Collar: The Humane Workplace and its Hidden Consequences. Philadelphia, PA: Temple University Press. 
Ross, Andrew. 2009. Nice Work If You Can Get It: Life and Labor in Precarious Times. New York and London: New York University Press.

Ross, Andrew. 2013. In Search of the Lost Paycheck. In Digital Labor: The Internet as Playground and Factory, edited by Trebor Scholz, 13-32. New York: Routledge.

Ross, Andrew. 2014. Reality Television and the Political Economy of Amateurism. In A Companion to Reality Television, edited by Laurie Ouellette, 29-39. Malden, MA: Wiley-Blackwell.

Scholz, Trebor, ed. Digital Labor: The Internet as Playground and Factory. New York: Routledge.

Sterne, Peter. 2014. Firm puts Vice in its sights for intern class action. Accessed December 1, 2014. http://www.capitalnewyork.com/article/media/2014/06/8546612/firm-puts-vice-its-sights-intern-classaction.

Slocum, Charles. B. 2014. The Real History of Reality TV: Or, How Allen Funt Won the Cold War. Accessed December 1, 2014. http://www.wga.org/organizesub.aspx?id=1099.

Terranova, Tiziana. 2004. Network culture: Politics for the information age. London: Pluto Press.

Yamada, David. 2013a. Unpaid intern cannot bring sexual harassment claim under NYC human rights law, judge rules. Minding the Workplace. Accessed December 1, 2014.

https://newworkplace.wordpress.com/2013/10/05/unpaid-intern-cannot-bring-sexual-harassmentclaim-under-nyc-human-rights-law-judge-rules/.

Yamada, David. 2013b. The Legal and Social Movement Against Unpaid Internships. Legal Studies Research Paper Series 13-34: 1-27.

Waxman, Sharon. 2005. Union Plans to File Suit for Reality TV Workers. New York Times, June 29. Accessed December 1, 2014. http://www.nytimes.com/2005/06/29/arts/television/29real.html?pagewanted=all\& $r=0$.

\section{About the Author}

Tanner Mirrlees

Tanner Mirrlees is an Assistant Professor in the Communication and Digital Media Studies Program at the University of Ontario Institute of Technology. His research centers on key topics in the political economy of communications tradition such as US empire and communications, the military-industrialcommunications-media complex, and the politics and ideology of popular culture. He is the author of Hearts and Mines: The US Empire's Culture Industry (University of British Columbia Press 2015) and Global Entertainment Media: Between Cultural Imperialism and Cultural Globalization (Routledge 2013), and articles in journals such as Alternate Routes, Cineaction, Democratic Communiqué, Global Media Journal, The International Journal of Media and Cultural Politics, and The Journal for Critical Education Policy Studies. 


\title{
Expo Milano 2015: The Institutionalization of Working for Free in Italy ${ }^{1}$
}

\author{
Roberto Ciccarelli
}

\author{
Translated by Roberta Buiani and Enda Brophy
}

\begin{abstract}
This essay reports on the temporary and unpaid forms of labour around which the 2015 World's Fair (Expo 2015) in Milan is organized and upon which it depends. The collective agreement supporting Expo 2015 is especially significant, the paper contends, in that it has been seized upon by the government of Matteo Renzi as a blueprint for the future of labour relations in Italy. Expo 2015 ushers in the institutionalization of unpaid work in the crisis-stricken Italian economy-a transformation approved by the major Italian trade unions that signed off on the collective agreement, but forcefully opposed by social movements who have decried the expansion of unpaid work permitted by the contract.
\end{abstract}

Keywords: Expo 2015, precarious employment, internships, volunteering, free labour

\section{1. "Why the Hell Are You Asking Me to Volunteer?"}

Take 18,500 young people and student volunteers, all working for free, while the judiciary investigates a million dollar bribery scheme, prosecuting and arresting entrepreneurs and corrupt lobbyists. Welcome to the Milan Expo. ${ }^{2}$ Throw in a communications team which routinely turns to the web to ask for "advice" on how to improve the event (one that senior figures in the Italian government maintain will contribute to the country's economic recovery). Add to this the most brilliant and critical activist network in Italy and you'll get a glimpse of what the future has in store for the precariat in this country: unpaid work. These are the elements that, on May 21, 2014, combined to produce what we could rightly call a communicative "epic fail." For the first time since the confederal trade unions and Expo Ltd. signed a collective agreement in July of 2013, Expo 2015 organizers clumsily sought to engage the internet in the discussion of a topic that-like the unspeakable (in Latin, nefas) in Greek tragedy-makes everybody feel uncomfortable and thus usually remains unspoken. ${ }^{3}$

Launched by the event's organizers, the hashtag \#AskExpo was soon flooded by the messages of hundreds of people demanding explanations regarding a collective agreement that, for the first time in the history of Italian labour law, enshrines free work for 90 percent of those involved in the production of what Premier Matteo Renzi sees as a "source of pride" for the country (Expo 2015). Meanwhile, only 835 people among the thousands of interns, apprentices, and limited contract workers will be "hired" for a period of 7 to 12 months. "Why is \#Expo2015-an event that was supposed to create jobs-depending on volunteers?" wrote @TwashWish. "This public event supported by public funds is $90 \%$ dependent on unpaid work. Why are the private companies the ones making money?" asked @ufo_inthesky.

It was impossible not to draw connections between all of this free labour and the arrests of a bid-rigging racket of contractors (the so-called "Cupola degli appalti") carried out on May 8, 2014. Among others, those detained included the General Manager of Expo 2015 Ltd., Angelo Paris, and a number of entrepreneurs and lobbyists recruited from the ranks of the Tan-

\footnotetext{
${ }_{2}^{1}$ An earlier version of this piece was originally published in Alias, May 24, 2014.

2 The Milan Expo is the most recent iteration of a long tradition of "World's Fairs," or public exhibitions held in cities around the world, dating back to the 19th century. Since 1928 the Bureau of International Expositions, headquartered in Paris, France, has taken on the responsibility for co-ordinating the exhibitions.

${ }^{3}$ Translators' note: The labour agreement was signed between Expo and Italy's three major trade unions: the Confederazione Generale del Lavoro (Italian General Confederation of Labour, or CGIL), the Confederazione Italiana Sindacati Lavoratori (Italian Confederation of Workers' Unions, or CISL) and the Unione Italiana del Lavoro (Union of Italian Workers, or UIL).
} 
gentopoli scandal of the early 1990s. "With all the money you've gotten (some of it mysteriously vanished), why the hell are you asking me to volunteer?" tweeted @divexdj.

\section{Anatomy of an Unpaid Workforce}

Following this controversy, Expo 2015 organizers assured the public that the number of interns and volunteers had been reduced to less than 10,000 and that 7,000 of these will be employed for a maximum of 14 days. There was no explanation offered for the diminished numbers-perhaps the organizers feared the unpaid volunteers might not demonstrate the enthusiasm that was originally anticipated. The Expo volunteer program itself includes at least three tracks. A "short-term experience" option is available for those who want to commit five and a half hours a day to the event over a two-week period. "Long-term volunteers" will be able to participate more extensively through civil service projects connected to the event or through projects coordinated by the event's volunteer program, DoteComune Expo, working for five days a week during the six months Expo is staged. A further form of volunteering is referred to as "volunteers for a day", and includes corporate volunteers who will work at Expo for a one-time, five-hour day. Students from Progetto Scuola (The School Project) will act as guides for their peers through the pavilions. Screening of candidates for all of these positions are managed by the Centri di Servizio per il Volontariato (Volunteering Service Centres) which will train the selected volunteers.

The plans laid out by Expo organizers have included the hiring of 640 workers on temporary contracts and 195 interns at a monthly pay of 516 Euro. More than 300 of these shortterm positions have prioritized workers who are either unemployed or receiving social assistance. In all likelihood, at the end of the exhibition, these individuals will return to a state of precarity, hoping for a call to work at a festival or some other event generated by the virtually bottomless reservoir of immaterial labour in the city of Milan.

One of the most disturbing aspects of the working arrangements at Expo is the creation of a two-tier system dividing temporary workers and volunteers: on one side there are the shortterm contractors, the apprentices, and the interns, who will obtain certifications with titles such as "event manager", "big event specialist", or "big event technician and manager". On the other side are the vast majority of volunteers, who work for free and must demonstrate an appreciation of Expo's "values", namely, "feeding the world" and "ensuring quality, healthy, just and sustainable nutrition"-values that are widely shared, to be sure. In short, Expo 2015 demands of its over 10,000 volunteers an (mostly) unpaid commitment in exchange for some visibility and a chance to showcase their talents and broaden their relational networks, all in the hopes of another internship, a short-term contract or perhaps even a job down the road.

\section{The Political Economy of Visibility}

The volunteers, interns, and temporary workers at Expo 2015 share a single destiny: a revolving-door scenario in which they will move between jobs in the formal and informal economy, between unemployment and apprenticeships, between precarious jobs and working for free. With the approval of the confederal trade unions, the Milan Expo has thus become a crucial first step toward the institutionalization of underpaid and free labour in Italy. By relying on a network of volunteering agencies and non-profits, this system puts precarious workers and volunteers in competition and harvests their hopes with the justification that "it's better than nothing." In other words, better to work for free than to be unemployed.

By participating in Expo, by working shifts of six hours a day for six months, these young people will acquire the most coveted commodity in circulation in the era of financialized capitalism: visibility, or, the possibility to show themselves off and prove their existence in this world, hoping that one day this existence will come to have some value in the market. Whether real or only promised, this visibility is most certainly not a commodity: in actual fact,

\footnotetext{
${ }^{4}$ Translators' note: The Tangentopoli scandal, which broke in the 1990s, revealed sweeping corruption across the major Italian political parties of the post-World War II era-the Democristians, the Italian Socialist Party, and the Italian Communist Party-effectively ending their control over Italian politics.
} 
Expo volunteers will receive no money in exchange for their efforts. Technically, theirs is neither a job contract nor can it be considered job training. Volunteers' presence around the pavilions is purely performative. Both Expo organizers and the confederal unions encourage the volunteers' participation as a form of ethical engagement. This engagement, one reads in the agreement endorsed and signed by the unions and Expo Ltd., has to be offered exclusively "with the goal of actively participating, as a gesture of solidarity and pluralism" (Expo 2015 et al. 2013).

"Ethics" here is a key concept in the neoliberal management of labour. The individual is asked to subscribe directly and without mediation to the goals and values imposed from above by the private company or by the state. Participation must be spontaneous, disinterested, and voluntary. That is, the individual has to demonstrate maximum availability and a commitment to the ethics and values of the market, as well as to the principles of the social economy, in this case the "green economy" in particular. The individual's availability must be so broad and indiscriminate as to turn the labour relationship into one of self-exploitation. In other words, the volunteer at Expo is the quintessential 21st century worker. In exchange for zero Euros, she invests what Marx called "absolute surplus labour"-or the excess of work which cannot be measured in terms of wages-in response to the requests of a given firm. Maybe one day she will receive some form of compensation from working precariously for one, two, or three months, for another big event to be programmed in an indeterminate future. It will be up to big investors or the state to organize-whether it is in Milan or in any other city in Italy or in the world-another event that might catalyze sufficient funding to pay today's precarious work force.

\section{New Labouring Subjects}

The great contractual novelty of Expo resides in the fact that the trade unions have fully endorsed an agreement that introduces the notions of "volunteering" or "volunteer" labour. In other words, free labour. Volunteering exists already everywhere in Italy, as in the rest of the world. Its nature is generally religious, political, or civic. The conventions of the big political parties are teeming with young people who lend their free time in exchange for the opportunity to participate in an event. However, Expo is neither a religious event nor the Festa dell'Unita. ${ }^{5}$ Expo is a capitalist enterprise with a long history dating back to the nineteenth century.

The co-opting of volunteers is of course a constant in big, spectacular events: the Olympics and a range of other kinds of cultural events have relied on volunteer labour for many years. This does not take away from the fact that, in the context of Italian law and the recent history of the country's trade unions, what is happening with Expo in Milan is without precedent. In fact, this event has formalized the existence of a double labour market that the trade unions intend to manage along with capital and the state: on one side, there are the precarious worker and the unemployed; on the other side, there are the younger generations, those without "work experience", as well as workers in the informal economy, the chronically unemployed, and those that are "inactive" in that they are no longer even seeking work. These figures merge into a three-fold subject: the worker/precarious/unemployed. In the past, these three conditions constituted three different statuses. Today they coexist in the same individual. This individual can gain regular working experience, as well as engage in precarious work or suffer a period of unemployment, all within a few months. She might even find herself in all three conditions at the same time. In other words, the volunteer at Milan Expo represents the future subject of work living in an immense grey area of informal and precarious labor. This is the condition of what Giorgio Allegri and I have described elsewhere as the Fifth Estate (Allegri and Ciccarelli 2013). ${ }^{6}$

\footnotetext{
${ }^{5}$ Translators' note: The Festa dell'Unità is the traditional yearly celebration of the Italian Communist Party.

6 "The Fifth Estate is an existential condition for millions of workers, whether self-employed, temporary or freelancer workers, skilled or mobile workers, 'precarious' workers or simply working poor. They are knowledge workers, chain workers, communication or health care workers, mini-job workers, or contract workers in the arts and culture sector. The Fifth Estate, however, is also the condition for millions of non-working people in the age of
} 


\section{No Future}

The Italian government's preference has been clear since July of 2013. Former premier Enrico Letta called for an extension of the Expo labour agreement to all employment contracts before he was removed from office by a party conspiracy led by the current premier, Matteo Renzi. This proposed extension only pertained to the portion of the agreement covering free work and the number of apprenticeships to be offered. What has become obvious however is that the creation of new employment in Italy occurs almost exclusively during these "big events" funded by finance capital. These spectacles are marked by ephemeral work arrangements whose duration is only equal to the event itself, a temporary interruption of structural unemployment, or an occasional variation within the recursive regime of precarity. The sole interest of the State, and likewise of capital, is to maintain a constantly flexible employment regime, as well as to regularly modify labour laws in order to keep wages low and deny individuals the fundamental legislative protections they once enjoyed. It's a regime that is demanded obsessively by transnational governance bodies ranging from the International Monetary Fund to the European Central Bank, and national governments dutifully turn it into reality, as the case of Expo 2015 so clearly demonstrates.

\section{Freedom and Slavery}

The final aspect that this Italian story contributes to a broader reflection on labour rights, precariousness, and the fifth estate is the almost compulsory participation on the part of subjects that is demanded by the governance mechanism of free labour. As a result, the emergent sensibility displayed by these subjects is the result of a double movement: a subjection of the individual to the path imposed by the firm (i.e., ongoing education at no cost to the company) and the subjectivation of the individual who freely accepts work without pay for the prospect of an income or a professional position to be secured in an uncertain future. This mixture of freedom and slavery is typical of contemporary neoliberal subjectivity. It is an attitude that characterizes the subject from the earliest days in the education system, and consigns her in adulthood to permanent failure, cultural and political impotence, and apathy in the workplace and society. It is a self-governing mechanism along the lines of what Etienne De la Boètie would call "voluntary servitude". ${ }^{7}$ In neoliberalism voluntary servitude is a model upon which states invest beginning from the subject's earliest years of existence. In turn, the subject is obliged to accept this model as the only way to achieve social inclusion, a goal important enough that she agrees even to pay for the opportunity to work and survive as a member of the working poor.

This phenomenon is not new in Italy or in the United States. It affects the middle class, independent professions, immaterial labourers, and the knowledge economy in particular. There is nonetheless something new in the situation that is unfolding: unlike the years of the economic boom that saw the rise of the middle class, today the substantial resources that are invested by households toward university education and professional training for their children are chronically undermined by unemployment and mass precarity. In the U.S., debt resulting from borrowing from the state and from the banks has generated a market bubble

unemployment in the European Great Recession (2008 onwards); a condition that affects the existence of young people Not in Education, Employment or Training (NEET) as well as that of over-40s. No rights or protection can be thought of for it. Its subjects are stateless people, as they are excluded from social citizenship, and always subjected to the chance of becoming poor. They are the 'outcasts' of traditional labour law in the crucial transition from the Welfare State to the Workfare of neoliberal governance. The subjects of the Fifth 'precarious' Estate are stateless and outcasts in that they often live without class identity and political community. Although they are the natives of the particular country in which they live, today they are as foreign and barbaric as the migrants in our midst in those same countries. Both these natives and the migrants belong to the "community of those without community'. Their citizenship is without a State, because the State does not recognize their citizenship" (Allegri and Ciccarelli 2014)

${ }^{7}$ According to De la Boètie, "voluntary servitude" is the decision of "a vast number of individuals, of towns, cities and nations" to "allow one man to tyrannize them, a man who has no power except the power they themselves give him, who could do them no harm were they not willing to suffer harm, and who could never wrong them were they not more ready to endure it than to stand in his way" (De La Boëtie 1988, 12). 
that is even bigger than the one that was created by subprime mortgages, and there is talk of a default similar to the one that hit the U.S. in 2007. Members of the so-called middle class between 30 and 40 years of age are no longer able to pay their debts due to a drastic redistribution of resources and job insecurity. Yet the only access to employment, and later on, one hopes, to a middle-class existence, remains to pay in order to find a job.

This situation is not very different from the one we are experiencing in Italy, even though the financial dimensions of this rupture are hardly comparable. In Europe the financialization of society is not as advanced as in the United States. However, the institutionalization of free labour by trade unions, businesses, and the state has evolved on both sides of the Atlantic in very similar ways. The subject with no financial resources or support is asked to pay for a graduate degree or certification courses that promise professionalization, and to work for free in the hopes of being able to get an education through precarious and temporary assignments. It is the ultimate demonstration that for at least another generation capital will need not a skilled middle class (if not in miniscule quantities) but rather a vast proletariat to shape into whatever form is required according to the economic conjuncture.

In the midst of the most postmodern economic event that there is, we are witnessing in Italy a return to the conditions of life and work that were typical of early modernity: seasonal labour, day labour, or free labour as a form of survival for subjects bereft of either financial income or social protection. This leap backwards in time could also lead to the discovery of solidarity, to those forms of individual and collective subjectivation that might bring this new kind of proletariat-as David Harvey (2012) calls it in Rebel Cities-to a radical break with exploitation. This would mean, of course, overcoming that mechanism by which the maximum freedom of the subject corresponds to her maximum self-exploitation.

\section{References}

Allegri, Giorgio and Roberto Ciccarelli. 2014. What is the Fifth Estate? Open Democracy. Accessed June 18, 2015. https://www.opendemocracy.net/can-europe-make-it/giuseppe-allegri-robertociccarelli/what-is-fifth-estate.

Allegri, Giorgio and Roberto Ciccarelli. 2013. I/ Quinto Stato: Perché il Lavoro Indipendente è il Nostro Futuro. Milan: Ponte alle Grazie.

De La Boëtie, Etienne. 1988. La Servitude Volontaire, or the Anti-Dictator [Slaves by Choice]. Egham: Runnymede Books.

Expo 2015. 2015. The Premier Renzi Visits the Site of Expo 2015: "Source of Pride for Italy." Accessed April 15, 2015. http://www.expo2015.org/en/the-premier-renzi-visits-the-site-of-expo-2015--source-of-pride-for-italy.

Expo 2015, CGIL Milano, CISL Milano Metropoli, UIL Milano e Lombardia, UIL TUCS Lombardia, FISASCAT Milano Lombardia, CGIL FILCAMS. 2013. Protocollo Sito Espositivo Expo 2015. Accessed June 18, 2015. http://www.provincia.pv.it/attachments/article/1540/Protocollo Apprendistato EXPO 2015.pdf

Harvey, David. 2012. Rebel Cities. London: Verso.

\section{About the Author}

Roberto Ciccarelli

Roberto Ciccarelli is a journalist and philosopher based in Rome, Italy. His blog can be found at furiacervelli.blogspot.it. 


\title{
A History of Internships at CBC Television News
}

\author{
Marlene Murphy ${ }^{1}$ \\ Senior Writer, Canadian Broadcasting Corporation, Toronto, Canada, \\ marlenetheresamurphy@gmail.com
}

\begin{abstract}
Internships are a common component of journalism education in Canada and, in some cases, a requirement for graduation. I look at the history and development of internships, both paid and unpaid, in the English-language national television newsroom of the Canadian Broadcasting Corporation ( $\mathrm{CBC}$ ), Canada's public broadcaster. This account is informed by interviews with CBC staff, union officials, and former $\mathrm{CBC}$ interns as well as a survey of post-secondary education institutions that place interns with the CBC. I explore the establishment of unpaid internships at the CBC and the role of the Canadian Media Guild in creating the contract language defining the parameters of internship placements. Internships at the CBC are perceived by some of the Corporation's staff as a responsibility of the public broadcaster, and representatives of the colleges and universities that participate in the program view the internships as valuable. I argue that the absence of institutional statistics on internships is a missed opportunity to deepen understanding of the role of internships at the CBC, and that systematic information-gathering by academic institutions regarding placements and offers of paid employment would be a useful resource in the debate over unpaid internships.
\end{abstract}

Keywords: internships, television, Canadian Broadcasting Corporation, Canadian Media Guild, unions

The Canadian Broadcasting Corporation $(\mathrm{CBC})$ has a significant role in disseminating news and current affairs programming to Canadians. The roots of the $\mathrm{CBC}$ were established in the 1930s with radio broadcasts, and the public broadcaster's first television stations went on the air in 1952. A Crown corporation, the CBC is one of Canada's largest cultural institutions, with total spending in $2013-2014$ of $\$ 1.87$ billion, with $\$ 975.6$ million of that provided by the federal government (CBC 2015a). The CBC's financial struggles have been widely covered in recent years. In 2012, the government announced a 10 percent cut to the CBC's funding over a three-year period, a move that reduced the government allocation by $\$ 115$ million (CBC 2012). Funding cuts and revenue shortfalls have led to staff reductions, with the CBC president noting in 2014 that he had announced three rounds of major cutbacks since taking the position in 2008, affecting the equivalent of more than 2,100 positions (CBC 2014a). As of April 2014, the CBC had the equivalent of 8,203 fulltime positions (CBC 2015b). The same month, the Corporation announced a plan that will leave the broadcaster with between 1,000 and 1,500 fewer jobs by 2020 (Wong 2014).

The CBC's mandate under the 1991 Broadcasting Act is to provide programming that informs, enlightens, and entertains as well as reflects Canada and its regions (Government of Canada 2014). The Corporation has at least one station in every province and territory in Canada, many of them in the same communities where schools offering journalism programs are located. This prominence, and the CBC's long history of news and current affairs programming, fuelled requests for internships from colleges and universities, and led to the creation of unpaid intern programs in the English and French-language national newsrooms.

This article explores the history of internships in the CBC's English-language national television newsroom, from their introduction in the 1970s with a few paid participants, to the extensive media network that exists today, which offers unpaid placements to dozens of students each year, to a paid program for a small group of students who are completing their final year of study. I address how the Corporation handled the creation and oversight of in-

\footnotetext{
${ }^{1}$ The $\mathrm{CBC}$ was aware that this research was being undertaken by an employee, but the research and publication of this article are independent of the CBC.
} 
ternship programs. I show that staff view offering internships as one of the responsibilities of a public broadcaster, and schools view the internships as a valuable resource. In conclusion, $\mathrm{I}$ argue that more systematic information gathering and information sharing by academic institutions about the CBC internships would contribute to the larger discussion surrounding internships and their efficacy.

The CBC's size and reach mean that internships, both editorial and technical, can be found in various divisions of the Corporation in cities across Canada and beyond. The goal of this research is to establish a timeline for the development of internships at national television news in Toronto, which has not been documented in a comprehensive way by the CBC. The scope of the research is limited primarily to placements handled by an office in Toronto that accepts applications from across the country for editorial internships. While the first internships in television news are exclusive to that medium, unpaid internships now offered to students from eligible academic institutions, which include television news components, may have radio news or online news components as well.

This research is based on a mixed methods approach. Interviews were conducted with six individuals who have at one time been tasked with responsibilities for the intern program that includes English television news, as well as one manager responsible for the Frenchlanguage program based in Montreal. A senior union representative with the Canadian Media Guild was interviewed on the contract language for unpaid interns. I exchanged written communication with four former executive producers in the newsroom, who provided information about the early years of the program. Four former interns from the 1970s and 1980s offered their written recollections and responses to questions, as well as six former interns whose placements were as recent as 2013. I interviewed six news producers who have been tasked with overseeing interns. In addition, I sent a survey to colleges and universities with journalism programs who participate in the $\mathrm{CBC}$ internship program, generating responses from 10 schools in five provinces. ${ }^{2}$

\section{The Early Years}

The first $\mathrm{CBC}$ initiative identified as an intern program and overseen by national television news was established in 1974. Two senior editorial staff travelled to the University of Western Ontario, Ryerson, and Carleton, the only Ontario schools offering programs in journalism studies at the time (Ryerson School of Journalism 2015). After completing interviews, eight individuals were chosen for a four-month paid summer program. Initial training was provided in Toronto, and the participants were sent to work in local CBC television newsrooms. Vancouver, Regina, Halifax, Ottawa, and Montreal are among the stations where interns were placed that first summer, with a deliberate attempt to not send interns to cities where they had lived or studied. All of the interns were integrated into the reporting staff of the newsroom for approximately 14 weeks before returning to Toronto for the final week of the internship.

One of the interns from the program's first year describes the experience as an extended job interview, suggesting that one of the goals of the program was to identify promising journalists and hire them before the competition did. The internship was regarded as a chance for the Corporation to explore and assess an individual intern's strengths and weaknesses, and a chance for the intern to get four months of full-time paid work. About half of the first group of interns stayed on in the cities where they interned, and there were similar examples in subsequent years. Internships provided local stations across the country with promising talent who had already attracted interest at the national level of the CBC.

An intern from the 1980s observed of the executives who selected him that "it was as if they were trying to shape the future national newsroom by using this training program as a conduit." He believes the intern choices were seen as "a way to bring in new blood, to train print journalists, maybe even a tool for affirmative action." Another remembers the senior editors who interviewed him as being "intense and challenging," even reporting having an

\footnotetext{
${ }^{2}$ In order to ensure frank assessments, participants were advised that while their roles would be identified, their names or those of their post-secondary institutions would be anonymized. All unattributed quotations in the article are drawn from the interviews or the survey.
} 
argument with one of them. A third former intern describes training in which "we had our thinking pushed on the conventions of TV news." Although in some years the program was put on hiatus for financial reasons, the paid summer intern program continued until 1990, with many of the interns who stayed at the CBC moving into senior level reporting and editorial positions.

While the paid summer intern program was established and well known, there are no documented examples of unpaid interns in the television newsroom in the 1970s and 1980s. Former staff during that period suggest the absence of unpaid internships was a result of strong opposition to the idea from unions. Asked about interns in Toronto, one former staff member said, "We did not use that word in the newsroom. Unpaid work would have caused a union action, I am sure." Entry-level work in the television newsroom for recent graduates of journalism programs was often as copy clerks and editorial assistants, who were generally hired on a casual or contract basis.

Developments between 1985 and 1999 saw significant changes at CBC News. In television news, these changes included the addition of a ten-minute newscast broadcast live in five different time zones for a noon-hour current affairs and lifestyle show called Midday, which began airing nationally in 1985. The establishment of CBC Newsworld in 1989 created a 24-hour cable news channel broadcast across Canada. Newsworld International, a specialty channel offered outside Canada, began broadcasting in 1994, and CBC's website, cbc.ca, launched a year later. The development of digital news platforms and newsgathering also led to reorganization and greater integration between radio and television news (Canadian Media Guild 2014).

There does not appear to be a single factor that leads to the establishment of unpaid internships in the national TV newsroom. By the late 1990s, the additional news channels had increased the number of newsroom positions in Toronto from a decade earlier. There were also more post-secondary institutions offering journalism programs. A number of current or former CBC employees had been hired as instructors and professors at various journalism programs, and that appears to be at least partly responsible for an increase in the demand for placements. Several individuals who were at the CBC during this period described receiving calls from past or current $\mathrm{CBC}$ colleagues who were teaching journalism, asking if an internship could be arranged for students. They also confirm that individuals, including students, would regularly approach $\mathrm{CBC}$ News on their own initiative in an effort to arrange an internship. One CBC manager said, "there wasn't a day someone didn't get a call," referring to inquiries about internships and the pressure from schools to offer them.

There was also interest within the CBC in creating opportunities for students to get exposure to the working environment at the Corporation. One individual involved in the development of unpaid internships describes approaching a manager to suggest that "we should be taking in interns from the schools, because that's part of who we are as a public broadcaster. We have great people here who would be really good mentors-we just need a proper system." This sentiment is echoed by virtually every CBC staff member I interviewed: the public broadcaster has a duty to offer learning opportunities. "A public broadcaster must encourage Canadian journalism students to get involved and give them opportunities," one producer told me.

There was one unique initiative in 1999 to broaden the pool of individuals working at the CBC by offering a 12-month paid internship. Open to any applicant, and widely advertised nationwide, it gave participants the opportunity to receive several weeks of training in Toronto before being sent to work in another city in a local newsroom. The ten participants, some of whom had journalism backgrounds, then returned to Toronto and were given placements at programs produced for national distribution. There were designated mentors for the participants, and a requirement to write regular updates on their experiences. There was no guarantee of work at the end of the 12-month period, although several remained with the Corporation. The initiative was discontinued after one year for budgetary reasons.

While there may have been a few informal arrangements in television news, there is no evidence of an established framework for unpaid internships during the 1990s. One CBC employee reports what happened when three university students were offered paid employ- 
ment for the summer by radio news in the 1990s to fulfill internship requirements, describing "some very disgruntled people in the newsroom, saying 'you're bringing in these students and you're getting them to do work and they're taking work away from [...] casual people,' and so we decided not to go that route again."

Individuals who participated in the creation of what is now the unpaid internship program in Toronto acknowledge that discussions about internships based in the national newsroom included questions about accessibility. One describes the number of schools the CBC worked with initially as quite small, and mostly in the Toronto area, saying, "We couldn't offer a salary or a place to stay or a bus ticket," but points out that queries about participation came from universities in other provinces, and explains students across the country are eligible to participate as long as they understand there is no money for a salary or accommodation. Another says of the program, "Yes, it is unpaid. But it is valuable, practical experience, it allows them to network, to test their own abilities, and gauge where they are. As a public broadcaster, I don't have a problem with an internship as long as it's not exploitive, and I don't think it is."

\section{Union Involvement}

Much of the opposition to unpaid internship programs came from the unions representing employees in news programming and involved concerns that internships would be used to respond to staffing shortages rather than to provide mentoring. The 1990s saw a significant organizational change involving unions representing $\mathrm{CBC}$ employees. The establishment of the Canadian Media Guild (CMG) in 1993 came about as part of an initiative to decrease the number of unions at the CBC. The newly named union saw an increase in membership from 700 to 3,000. A merger with the Canadian Broadcast Employees Union in 1998 added another 700 members to the CMG. And, in 2003, the union grew again by about 1,500 members after it won a representation vote against the Communications, Energy, and Paperworkers Union (Canadian Media Guild 2014). The same period also saw labour disputes, with union concerns about the loss of full-time staff positions to contract ones (Mosco and McKercher 2006).

An official with the CMG describes discussions within the union about the contract talks that led to the 1998 collective agreement, saying, "One of the areas people came to be concerned about was the use of interns because they were concerned about interns coming in and actually doing work and not really feeling it was a mentoring program, but it was departments making up for the lack of budget." The union official recalls a debate about an intern policy among elected union representatives and some of those same people would have been on the bargaining committee when contract discussions were underway. He suggests both sides believed in having interns, saying it was "good for the Corporation, good for the union, for the members. The interns usually end up being future members." The union official describes the union position as a quid pro quo, because training for interns acknowledges the obligation to provide training for staff as well. He points to language in a CMG policy that the national executive adopted in 1998, which states that "the interns must be used in such a way as to respect our collective agreements [...] and to enhance the training opportunities given to members of the bargaining unit" (Canadian Media Guild 1998). The policy also affirms "the Guild's first goal is to ensure that resources designated for our members are not being used to train outside individuals. When an employer proposes bringing in an intern, we must be satisfied that employees are given a chance to enhance their own skills" (ibid.).

A manager during this period agrees the union's objections to unpaid interns derive from concerns that the CBC would use interns and casual employees to replace full-time positions. He points to changes in union leadership during the period in the late 1990s, when language on unpaid interns is discussed, and suggests there is an understanding on both sides of the value of putting an internship program in place, as some interns would become future employees. He recalls a conversation with a union executive to craft the terms of the language regarding interns, with the goal of protecting jobs and not opening the door to unpaid labour. 
The union and $\mathrm{CBC}$ management approved the first contract language on unpaid internships in 1998. Key provisions are that the interns do not fill vacancies or replace existing staff, that the internship is for training purposes and to augment learning at a recognized educational institution, that interns are assigned a mentor, and that interns not be paid for their work, in recognition of the fact that they are part of a post-secondary education program and not newsroom employees who could be assigned to fill vacancies or handle duties without supervision (CBC-CMG 2014, 110-111).

The 1998 collective agreement signals a different emphasis from the first paid intern program of the 1970 s and 1980s. The early programs are regarded by the CBC as a way for managers to identify and evaluate potential employees. Managers responsible for the intern program all point to the new contract language, which defines unpaid internships as placements that support academic learning. Students who participate must be enrolled in journalism programs with an internship component, as the placements are to augment their education. One manager notes, "These are clearly short-term opportunities. We hope that we get some benefit while they're here and perhaps as a young person they have a different life view and they will give us some story ideas, but basically it's to the benefit of students and schools."

\section{Internship Parameters}

The current unpaid intern program in Toronto is set up with five distinct periods per year, to give newsroom producers and shows a fixed schedule to prepare for intern placements and identify available mentors. Colleges and universities handle the initial screening of applicants and are instructed by the CBC to permit only the best students in the class to apply, with a maximum of four students per school for an intern period. While the CBC does not set quotas for gender, race, or ethnicity, schools are made aware that the Corporation wants to ensure diversity in its workforce, and has identified priority communities, including aboriginal and visible minority candidates, and those with disabilities (CBC 2014b). Prospective interns can identify as a member of a priority group in the resume and cover letter accompanying their application.

The decision to offer internships to current college or university students in a journalism program makes internships impossible for those whose financial means or personal situations prevent them from undertaking academic studies. The lack of compensation or funding for travel also puts the possibility of placements in the national newsroom in Toronto or at foreign bureaus out of reach for students who might be outstanding candidates. While the $\mathrm{CBC}$ acknowledges that accessibility may be compromised by the lack of funding, there is no effort underway to address this barrier.

From its inception, the length of unpaid national radio and television news internships was fixed at six weeks. CBC managers argue that this time period is long enough to expose students to the internal workings of the CBC, without creating situations where interns are treated as employees and mistakenly assigned work that contravenes the collective agreement. The union confirms that contract language appears to be adhered to in most situations, with few cases brought to union attention. The CMG observes that the infrequent issues do not originate with senior management, but

where you get a problem is at an operational or department level and it may even be on occasion our own members [...] It can quite often be that they forget this is an intern. Again, I don't think there's any great plan to undermine the contract. [W] hen these things happen, we call somebody, we get back to them, and it gets fixed.

In some cases, interns move through radio, television, and online placements over two-week periods so as to ensure a diverse learning experience.

Successful applicants for an unpaid internship receive a copy of the language in the collective agreement, and the same stipulations are emphasized to CBC staff supervising interns. The union also receives the names and details of individual placements to ensure that interns are not engaged in a way that contravenes the collective agreement. Students must 
be in the graduating year of a program, and either Canadian citizens or landed immigrants, the rationale being that, following their internship, they would be eligible for any offer of paid employment on a casual or contract basis.

CBC staff stress that the agreement does not preclude unpaid interns from taking on meaningful assignments under supervision. One staff member describes feedback from past participants:

They were so excited because they actually got to do real work, because not all of their schoolmates did. They would make coffee or shadow, but they never actually got to do real work, whereas with our [students] that was the whole plan. You don't learn anything by watching; you only learn by doing. It's a lot more work for our people because obviously they had to check everything that the intern did, but in the end the interns got amazing training.

A senior union official stresses that the collective agreement is not a barrier to interns doing work, but that such work "should be under the auspices, or under the direction and guidance, of a mentor." The official also acknowledges the CBC's seriousness, saying, "I think the Corporation has been, as far as I can see, pretty rigid themselves. They try to make sure they enforce this themselves [...] the cases where it's been abused or places where the guidelines or contract [haven't been followed] are few." This is a consistent position among the interviewees in this research-far from being pressed into service to fill staffing shortages, interns are regarded as additions beyond normal levels of staffing, and subject to strict conditions during their placement.

Interns at the CBC work as chase producers, identify possible guests for live news programming and reporter stories, contribute to research on various topics, transcribe audio and video interviews, and gather public reactions to major news stories. Managers and producers had no recollection of any situation in which an unpaid intern in Toronto worked as a reporter during an internship, pointing to both contract language regarding supervision and the unlikelihood that an intern could produce work at a high enough standard for broadcast. In 2014, the Toronto program accepted applications from students at 19 academic institutions. Over a 12-month period, an average of 50 students participate in the national program, which does not include radio current affairs programs or factual entertainment.

The office of the manager of staff development, which is tasked with handling the unpaid internship program in Toronto, does not oversee any program described as an internship in other CBC locations, and does not gather specific data outside of the Toronto program. Other cities, particularly Vancouver and Ottawa, have established histories of student placements in their newsrooms. A number of other $\mathrm{CBC}$ locations have provisions for both unpaid and paid internships of varying duration. In some locations, particularly those near schools with journalism programs, those internships are of long standing, although not overseen by the national office. Others appear to be arranged on an informal basis to accommodate a request by a student fulfilling an internship requirement. There are also unpaid internship programs in CBC bureaus outside Canada, primarily Washington, D.C. and London, England. The London bureau allocates time slots each year to individual schools, which nominate the interns who are considered for the placement. As with domestic internships, students in $\mathrm{CBC}$ internships are responsible for making and paying for their own travel and living arrangements.

Radio-Canada, the CBC's French-language division, also offers unpaid internships. Formal guidelines on Radio-Canada internships were established in 2007 and differ from the model at the Corporation's English language counterpart in several respects. Applicants are not screened by schools and do not have to be studying journalism, though they are required to be in a university program with a requirement for a media course or internship. Students are interviewed by the producers of the shows that are interested in having them as interns, and the timeline is worked out after an internship offer is extended, with greater flexibility possible for the duration. The Radio-Canada program in Montreal accepts about 15 interns per year for editorial placements. 


\section{Academic Institution Participation}

To gauge the response to the CBC intern program, I sent surveys to journalism schools that have taken part in the CBC's intern program. I received responses from 10 English-language academic institutions in five provinces. Every respondent indicates that students receive academic credit for completing an internship, with eight of the 10 schools indicating an internship is a requirement for graduation. Virtually all schools receive either written or verbal communication about the individual student's performance at the conclusion of their students' internships. Five respondents indicate they have occasional contact with the CBC to offer feedback on the program.

The survey asked respondents about the fact that the internships with the national program in Toronto are unpaid, and what percentage of students had concerns about that. Three schools put the percentage at 10 percent or less, with one school putting the percentage at 50 percent. The students' concerns fell into two categories: that all internships should be paid, and the fact the internships were unpaid made it financially impossible to do the internship in Toronto. None of the respondents raised the issue when asked if there are any changes they would like to see in the CBC's intern program. One school explains: "our students expect an unpaid internship in Canada and rarely complain or comment about it being paid. We say it is part of their learning and career research." Only one school, which did not place students in unpaid internships, suggested the CBC should eliminate internships that did not have compensation, saying "unpaid internships are bad news. Get rid of them."

A survey question about how academic institutions regard the unpaid $C B C$ internships brought responses suggesting they were important and valuable. One respondent notes: "students generally get excellent experience at $\mathrm{CBC}$ and we know (anecdotally) that these postings frequently lead to contract positions at $\mathrm{CBC}$ or contract or full-time positions at other news organizations." Another reports "the students always come away feeling confident the skills they learned at the college allowed them to dive in, work and learn." A third school comments that many graduates go on to work at the CBC, and others feel the placement helps to launch their students' careers. A question about any changes schools would like to see brought responses that primarily centre on the length, with some schools suggesting they would be interested in seeing the six-week period extended.

I received written responses from six past interns for this research, who were questioned primarily about their role. One suggests the six-week structure has limitations, saying:

I rotated through the three placements every two weeks. That was hardly enough time to get to know anyone, develop their trust, and barely learn any skills. I struggled to find things to do, to show that I was capable of even writing simple copy [...] It was often very frustrating. I still think I learned a lot from being inside the building, and seeing how the giant CBC machine works-and I did eventually get some copy I wrote on air, or quotes I gathered put into a TV story. But it wasn't nearly as editorially demanding as what I did in school.

Another former intern suggests the opportunities afforded to an unpaid intern are not representative of what an entry-level position as an editorial assistant involves, pointing out that,

as an intern, the students get to learn and do a lot of things, such as chasing, writing, and going out on shoots. But if they somehow manage to get a job after, as I did, EA is the usual starting position [...] and that's a bit disappointing. It can be a long struggle to move up from the EA role!

Another suggests that the chase producer role assigned to some interns limits their interactions, and that there are few opportunities for constructive feedback. The small sample of responses confirms the $\mathrm{CBC}$ and union position that the internships are structured to prevent abuses and use of the interns as unpaid labour filling roles that would otherwise go to paid employees. The responses also suggest while the $\mathrm{CBC}$ and schools report many positive responses to the intern program, some participants do identify limitations with the structure and placements as a learning opportunity. 
The CBC does operate a program that provides graduating students with compensation and work experience, which bears some similarities to the initial summer intern program introduced in 1974. The Joan Donaldson Scholars Program, named for the first head of CBC Newsworld, was established in 1999, which was when the first unpaid interns arrived in the Toronto newsroom. Up to eight graduating students are chosen annually from nine eligible universities, and offered four months of paid work at the entry-level editorial assistant compensation pay level.

While the first summer interns in the 1970s were primarily working as reporters, Donaldson Scholars are less likely to be assigned that way. "They actually let me file four TV reports for the local newsroom, which I was absolutely thrilled about. (I don't think it's something the other Donaldsons got the opportunity to do)," writes one participant in response to questions about the program. A small group of recipients questioned about work assignments suggests that Donaldson Scholars tend to perform production-driven editorial tasks such as going out to the streets to ask people questions on a specific topic, interviewing individuals who would be included in other reporters' stories, working with editors to assemble stories, and working as chase producers identifying potential guests for news shows.

The CBC website refers to the Joan Donaldson Scholars Program as "a paid internship," which recognizes exceptional academic performance and individuals engaged in the world around them, and says the scholarships "provide the CBC with an opportunity to assess high-potential individuals for future employment" (CBC 2015c). One former manager observes of the Donaldson Scholars that "to see them go out the door was not good efficiency, particularly if they worked somewhere else [...] there certainly was an understanding and a desire to keep them." Informal estimates from former managers and participants suggest about half of Donaldson Scholars over the last 15 years are offered some form of employment at the conclusion of the program. While no specific requirements regarding class, gender, race, or ethnicity are identified by the program, 88 of the 126 Donaldson recipients since its inception are women.

\section{The Future of Internships at the CBC}

The CBC plans to reduce its workforce by 25 percent as it approaches 2020 (Wong 2014), but has given no indication it plans to make cuts to the unpaid intern program. While there has been a wider public discussion regarding compensation for internships in the media and elsewhere, there has been no indication that the CBC is considering paying interns who participate in its six-week program. At the current entry-level category of editorial assistant, compensation for fifty interns for six weeks would amount to more than $\$ 190,000$ (CBC-CMG 2014).

While virtually everyone at the $\mathrm{CBC}$ interviewed for this research strongly supports the position that the public broadcaster has a responsibility to provide training and learning opportunities, the CBC is under financial pressure and has been cutting editorial positions. Providing paid internships would also require successful negotiations and support from the CMG. The union has made its commitment to support training for students clear, and provides oversight to ensure the terms of the current collective agreement are met-but any consideration of paid internships would reopen the debate on the impact of short-term employees on staff positions.

While the CBC shows its support for interns by investing time and personnel, financial constraints would appear to rule out devoting further resources to gathering more information about intern outcomes. At no time has the CBC tracked specific employment outcomes at the Corporation for either past Donaldson Scholars or past unpaid interns on a regular basis. One manager points out that while individuals might not be hired immediately, they might become employees a year or two later or work on a short-term contract before leaving for another position, and thus tracking them would be difficult. He explains the Corporation's reasoning on unpaid interns: "If somebody great comes through here we want them for ourselves. If they work at a competitor and it enhances journalism in Canada, we've done our part, we haven't lost." The CBC maintains detailed written records of interview assessments 
from prospective interns and Donaldson Scholars, as well as evaluations from supervisors who oversee interns. These records are used to build a database of individuals who could be offered casual or short-term paid work upon completion of their placement, although interns are told not to expect that outcome.

Only four of the 10 schools that responded to my survey indicate they keep records on whether students obtain paid employment at organizations where they have interned. A survey question about where schools had placed interns at $\mathrm{CBC}$ locations in Canada in addition to Toronto and Montreal over the previous five years resulted in the names of 17 different locations, none of which would have been overseen by the manager of staff development in Toronto. While schools may have records on how many of their students complete internships at the $\mathrm{CBC}$ and at other organizations, that information is maintained internally at the academic institution and no clear national picture exists.

This adds to the case for academic institutions to take a greater role in informationgathering about the outcomes of journalism internships at the CBC and other institutions, and making this information more widely accessible in some form. A national database identifying where interns are placed, the length of placement, and a description of the job responsibilities would contribute to a deepened understanding of the role that $C B C$ internships play in journalism education. With the CBC's stated plan to move to a digital-first strategy that shifts the emphasis away from television and radio offerings and towards mobile coverage, the reality of a smaller workforce at the $\mathrm{CBC}$, and interest from academic institutions for longer internships, reliable data on the number of national placements would be valuable as part of a wider discussion with all of the participating academic institutions about future directions for intern initiatives.

The $C B C$ internship program has been in place for more than 15 years. Formal complaints and legal cases against companies in Canada and internationally has raised a number of concerns about internships, including the absence of legal protections for interns and the possibilities for exploitation by employers intent on availing themselves of unpaid labour (Sagan 2013), and worries that interns' negative comments could affect their future employment prospects (de Peuter, Cohen and Brophy 2012). Investigative series like the one conducted by media organization ProPublica also shine a spotlight on the concerns of post-secondary students unhappy about the reality of paying tuition while working without pay at internships (Hickman 2014).

The CBC's intern program demonstrates that internal structures can be put in place to deal with concerns about workplace exploitation and provide interns with a meaningful experience that offers supervision and mentorship. There is a widespread belief among CBC staff members that, as a public broadcaster, the Corporation has a responsibility to provide training and learning opportunities, and that training interns can benefit all parties, including the union. The CBC-CMG collective agreement provides clear guidelines and a dispute resolution mechanism should a concern be raised by an intern or employee. Above all, the CBC and the union have worked together to ensure that internships are consistently beneficial to the students, and that benefits to the Corporation and the union are the favourable outcome of providing a successful program. In my view, any discussion about whether interns at the CBC should receive monetary compensation opens onto a complicated reality for employers and unions at the $\mathrm{CBC}$ and beyond, namely, how to resolve demands for intern compensation with union concerns that short-term internships at entry-level pay rates would result in reduced positions and job stability for existing employees.

The debate over the pervasiveness and role of internships highlights the need for better information on internships in Canadian journalism to ascertain their use and effectiveness. A clear understanding of what changes might be desirable cannot be advanced without a more comprehensive national picture. Any discussion about making changes to the current internship system in place at the $C B C$ will require the participation of all stakeholders. The $C B C$ and the CMG have a long history of working to respond to the needs of journalism educators. The question now is whether educational institutions are prepared to add to the understanding of the role of internships at the $\mathrm{CBC}$ and beyond by developing a systematic, reliable 
method of gathering information about them. This knowledge could prove crucial in shaping the next chapter in the history of internships at the CBC.

\section{References}

Canadian Media Guild. 1998. Interns. Accessed April 23, 2015. http://www.cmg.ca/en/your-rights-andresources/policies/interns/.

Canadian Media Guild. 2014. About the CBC/Radio-Canada Branch. Accessed November 22, 2014. http://www.cmg.ca/en/cbcradiocanada/about/.

CBC. 2012. CBC Budget Cut by $\$ 115$ million over 3 years. CBC. Accessed February 14, 2015. http://www.cbc.ca/news/politics/cbc-budget-cut-by-115m-over-3-years-1.1147096.

CBC. 2014a. Speaking Notes for Hubert T. Lacroix, President and CEO, CBC/Radio-Canada, at the Canadian Club of Montreal. CBC, Media Centre. May 5. Accessed April 23, 2015. http://www.cbc.radio-canada.ca/en/media-centre/2014/05/5a/.

CBC. 2014b. Our Commitment to Talent and Diversity. CBC. Accessed November 22, 2014. http://www.cbc.radio-canada.ca/en/explore/jobs/talent-diversity/.

CBC. 2015a. Corporate Plan Summary 2014-2015 to 2018-2019. CBC. Accessed April 23, 2015. http://www.cbc.radio-canada.ca/ files/cbcrc/documents/corporate-plan/corporate-plan-summary2014-15-2018-19.pdf.

CBC. 2015b. Compensation Summary. CBC. Accessed February 14, 2015. http://www.cbc.radiocanada.ca/en/reporting-to-canadians/transparency-and-accountability/proactivedisclosure/compensation/.

CBC. 2015c. About the Joan Donaldson CBC News Scholarship. CBC. Accessed April 23, 2015. http://www.cbc.ca/joandonaldsonscholars/about/.

CBC-CMG. 2014. Canadian Broadcasting Corporation-Canadian Media Guild Collective Agreement 2014-19. Accessed November 22, 2014. http://www.cmg.ca/en/wpcontent/uploads/2014/09/CMGCBCCollectiveAgreement20142019.pdf.

de Peuter, Greig, Nicole Cohen and Enda Brophy. 2012. Interns, Unite! You Have Nothing to LoseLiterally. Briarpatch, November 9, 2012.

Government of Canada. 2014 (1991). Broadcasting Act S.C. 1991, c. 11. Accessed April 5, 2015. http://laws-lois.justice.gc.ca/eng/acts/B-9.01/.

Hickman, Blair. 2014. What We Learned Investigating Unpaid Internships. ProPublica, July 23, 2014. Accessed February 14, 2015. http://www.propublica.org/article/what-we-learned-investigatingunpaid-internships.

Mosco, Vincent and Catherine McKercher. 2006. Convergence Bites Back: Labour Struggles in the Canadian Communication Industry. Canadian Journal of Communication 31 (3): 733-751.

Ryerson School of Journalism. 2015. About Us: School History. Accessed November 22, 2014. http://www.ryerson.ca/journalism/about us/history.html.

Sagan, Aleksandra. 2013. Unpaid Intern Hell: Overtime, Tuition Fees. CBC. Accessed April 6, 2015. http://www.cbc.ca/news/canada/unpaid-intern-hell-overtime-tuition-fees-1.1699105.

Wong, Tony. 2014. CBC to Lose up to 1,500 More Jobs. Toronto Star, June 26. Accessed April 23, 2015. http://www.thestar.com/entertainment/television/2014/06/26/strategic plan cuts hubert lacroix.ht $\mathrm{ml}$.

\section{About the Author}

Marlene Murphy

Marlene Murphy is a senior writer at the Canadian Broadcasting Corporation. She has also worked at the CTV Television Network. She has a B.A. (Hons.) from McGill University, and an M.A. in Journalism from Western University. 


\title{
(De)valuing Intern Labour: Journalism Internship Pay Rates and Collective Representation in Canada
}

\author{
Errol Salamon
}

\author{
McGill University, Montreal, Canada, errol.salamon@mail.mcgill.ca
}

\begin{abstract}
Unpaid journalism internships have attracted increasing media coverage, but they have received limited scholarly attention. This paper traces the connections between trade unions (in unionized media organizations) and the labour conditions marking journalism internships. While some unions can be complicit in sustaining the exploitation and devaluation of interns with regard to the standard market value of entry-level labour, other unions have fought to establish internships, locking higher salaries into collective agreements. Building on the concept of precarity, this article surveys internships at 19 mainstream English-language newspapers and magazines in Canada. It draws on documentary evidence from and personal communication with labour unions and journalism organizations, internship advertisements, and media coverage to offer a typology of the relationships between pay rates and collective representation within journalism internships: unpaid/low paid and not under union jurisdiction; unpaid/low paid and under union jurisdiction; paid at intern rates and not under union jurisdiction; paid at intern rates and under union jurisdiction; and paid at entry-level employee rates and under union jurisdiction.
\end{abstract}

Keywords: low-paid internships, interns, journalism labour, unions, exploitation, precarity, newspaper crisis, political economy, Canada

Acknowledgement: Special thanks to the reviewers and guest editors for their helpful comments. Also thank you to Beth Knobel for comments on an earlier version of this paper, which was presented at the 2015 International Communication Association Conference.

In Canada, unpaid journalism internships received a surge of media coverage in early 2014 after the popular Canadian magazines Chatelaine, Flare, and Toronto Life ceased their internship programs. These programs ended in the midst of the Government of Ontario's clampdown on unpaid internships that contravened the province's Employment Standards Act (Houpt 2014; McKnight 2014). Journalism organizations have used the term "internship" to refer to a variety of work placements typically ranging in length from a period of one week to one year. As in other sectors, most journalism students enrolled in university degreegranting programs are required to do an internship as part of their training and in order to graduate (Internship 2014; Thornton 2011). Many journalism internships or professional fulltime field placements are unremunerated, but students can obtain course credits for doing them as part of their university education. In many Canadian provinces, including Alberta, British Columbia, Manitoba, and Ontario, interns must be paid at least minimum wage unless internship programs provide training for particular professions or training as part of a postsecondary educational program or work experience program (Employment Standards Code, RSA 2000; Employment Standards Act, RSBC 1990; Employment Standards Code, CCSM 1998; Employment Standards Act, SO 2000). Yet many journalism organizations have used the challenges facing the print media industries to justify a growing reliance on unpaid journalism internships (Perlin 2012).

Canadian print media industries (newspapers and magazines) have experienced declining revenues and circulation as the longstanding advertiser-supported and subscription-based business model has waned dramatically (CMCRP 2014; Edge 2014; Winseck 2010). The strategies of print media publishers to sustain profitability and regain audiences have been varied since the 2008 global recession and as digital platforms have continued to spread. For example, between 2009 and 2012, the Postmedia chain reduced the publishing schedules of 
some of its daily newspapers to six days, among them the National Post, the Calgary Herald, the Edmonton Journal, and the Ottawa Citizen (CBC News 2012). Publishers have also transitioned rapidly from print to digital platforms. Since the Victoria Times-Colonist introduced a paywall in 2011, other print publications in Canada followed suit, requiring readers to pay to access content online (CMCRP 2014). ${ }^{1}$ In 2014 Canada had 91 paid daily newspapers, 38 of which had paywalls or metered access, accounting for more than half of the country's daily newspaper circulation (Newspapers Canada 2015,10$){ }^{2}$ In this new digital-first world, print media outlets are publishing on multiple platforms - mobile, tablet, and the weband competing with broadcasters and other digital operations. Additionally, publishers have closed print media outlets, including eight local Quebecor publications in 2013 and one Glacier Media newspaper in 2014 (Dobby and Canadian Press 2013; Lee 2014). Some companies have also laid off employees: for instance, between 2012 and 2014 Sun newspapers eliminated more than 1,000 jobs, and Torstar's Toronto Star reduced its workforce by nine percent (CMCRP 2014; CMG 2013). In addition to instituting paywalls, closures and layoffs, consolidation has marked the strategies of print media publishers. In October 2014, Postmedia purchased Quebecor Media's Sun Media chain for $\$ 316$ million, heightening concerns about newspaper monopolies in Calgary, Edmonton, and Ottawa, and increasing ownership concentration in the country more broadly (Edge 2014).

Turbulence in the print media industries is nothing new. Market instability affected print publishers after a mild recession took hold in the early 1990s, following the onset of the digital transition in the mid-1990s, and after the media were re-regulated in 1996, paving the way for two waves of media consolidation in Canada, 1995-2000 and 2003-2007 (Edge 2014; Skinner, Compton and Gasher 2005; Winseck 2010; Winseck 2011). Amid this upheaval in the sector, two additional facts stand out. First, between 1995 and 2013, most print media companies in Canada have maintained enviable profits. Second, preceding and paralleling these transformations, a wide variety of journalism internships have suddenly emerged and have seemingly become necessary, some of which have been low-paid or unpaid. This paper explores the emergence of journalism internships and offers a typology of the pay relationships and collective bargaining agreements (or lack thereof) that can be used to better understand these work placements.

Journalism internships can be situated within a longer history of struggles that junior and entry-level workers have faced in the print media industries. In the $19^{\text {th }}$ and $20^{\text {th }}$ centuries, young apprentice printers and adolescent newspaper carriers also struggled with their employers over low wages and organized labour unions to negotiate better working conditions and higher pay (Bekken 1995, 2009; Zerker 1975, 42; Zerker 1982, 24-25). In the early 1830 s, printers in particular were at the forefront of the burgeoning labour movement in Canada. Employers were increasingly hiring "halfway journeymen" (printers who had not completed their apprenticeships) and paying them less than the customary wage. This use of cheap apprentice labour was one of the major issues that motivated printers to form the Toronto Typographical Union in 1832, one of Canada's first print media unions.

Although the phenomenon of unpaid and underpaid internships has increasingly been exposed to the international and national media spotlight (e.g., Davis 2013; de Peuter, Cohen and Brophy 2012; Internship 2014; Tatelman 2015), and has been the subject of legal scrutiny (e.g., Doorey 2013; Langille 2014; LCO 2012; Stewart and Owens 2013), more scholarly research is needed. ${ }^{3}$ Media, legal, and scholarly accounts have highlighted the roles of journalism employers, postsecondary journalism programs, government labour legislation, and interns themselves in sustaining an exploitative internship system within an economy increasingly marked by precarious-flexible and insecure-forms of employment. How-

\footnotetext{
${ }^{1}$ In 2004, the Whitehorse Star in the Yukon Territory became the first newspaper in Canada to implement a paywall and still maintains one (Newspaper Canada 2015, 10).

2 By mid-2015, some paywalls had been cancelled. Notably, the Toronto Star (2015) ended its "Digital Access" program, effective April 1, 2015.

${ }^{3}$ Brief scholarly discussions of internships include Bakker (2014), de Peuter (2014a), Gollmitzer (2014), Hesmondhalgh (2010), Madison (2014), McKercher (2014), and Thornton (2011).
} 
ever, these dynamics alone do not offer a complete understanding of the phenomenon without considering the role of labour unions in the internship system.

Building on these media, legal, and scholarly insights, this paper argues that for-profit journalism organizations exploit and devalue the labour of editorial interns ${ }^{4}$ with regard to the standard market value of entry-level labour. By comparing internships that are under union jurisdiction and internships that are not under union jurisdiction, this article also foregrounds the ambivalent role of labour unions, one that illustrates a contradictory tension. In the case of unpaid and low-paid interns that are under union jurisdiction, labour unions have enshrined exploitative and underpaid internships by writing them into collective agreements. Nevertheless, various union locals have fought to establish paid internship programs and collective agreements that have also guaranteed interns entry-level salaries. Within the struggling (but profitable) print media industries, journalism unions must balance conflicting dynamics regarding internships, including union members' professional commitment to the institution of journalism, members' and media corporations' economic interests, and labour movement strategies to protect a growing and a more diverse membership that includes new job classifications-among them interns who may have a desire to work in a creative field such as journalism, regardless of the pay.

To ground this argument, I survey the pay rates and collective representation of interns at 19 mainstream English-language magazines and newspapers in Canada, measuring them against corporate revenues and profits. This paper relies on documentary evidence from, and personal communication with 11 representatives of, labour unions and journalism organizations, internship advertisements, and media coverage of internships. This sample of organizations was selected because of their proximity to many of the country's university-level journalism programs, most of which are based in large urban population centres with 100,000 or more people. ${ }^{5}$ As a point of critique and advocacy, this article builds on the concept of precarity to address internships as not only a "(quasi-) employment status" (de Peuter 2014a, 267) and as work that is unpaid or low-paid (de Peuter 2014b, 32) but also as work that is well paid. The paper examines the specific dimensions of journalism internships to highlight key contradictions within a single industry. As such, it contributes the only comprehensive scholarly study published to date on the varied relationships existing between journalism internship pay rates and collective representation in Canada. Scholars, practitioners, and activists outside of journalism and beyond Canada could learn from this case study, as precarious work and internships are cross-disciplinary, cross-sectoral, and international phenomena. In what follows, this paper discusses these phenomena and examines five contradictory relations between journalism intern pay rates and collective representation: unpaid/low paid and not under union jurisdiction; unpaid/low paid and under union jurisdiction; paid at special intern training rates and not under union jurisdiction; paid at special intern training rates and under union jurisdiction; and paid at entry-level employee rates and under union jurisdiction.

\section{Precarity, Exploitation, Journalism Labour, and Unions}

Precarity and exploitation are concepts that describe historical transformations of work and labour conditions under post-Fordist capitalism. In contrast to the labour relations that prevailed under Fordism, labour precarity is a condition that has expanded since the 1970s (Brophy and de Peuter 2007; Hardt and Negri 2009; Huws 2014). The concept refers to "all forms of insecure, contingent, flexible work-from illegalized, casualized and temporary employment, to homeworking, piecework and freelancing" (Gill and Pratt 2008, 3). Precarity also refers to the "massive reduction of permanent employment contracts...sometimes calling for a high degree of mobility, with or without minimal social security benefits, such as health insurance, paid holidays, or pensions" (Lorey 2010). Another key characteristic of precarity is "earning low income" (LCO 2012, 11, 27). To articulate a social subject united across a range

\footnotetext{
${ }^{4}$ Editorial internships typically fall under the following job classifications: reporter, copy editor, and photographer.

${ }^{5}$ Given the difficulties in obtaining this kind of information, some major journalism organizations are not sampled in this paper due to a lack of available data.
} 
of diverse employment conditions, Guy Standing $(2011,1)$ describes the "precariat," a global political subject "without an anchor of stability." Linking "precarious" with "proletariat" (7), this neologism names a subject that-unlike the Marxian proletariat-is defined by intermittent participation in the labour force. The precariat must accept a range of unpaid employment relationships, ones that are increasingly necessary to maintain access to permanent jobs and a living wage.

Precarity, along with marketization, government deregulation, privatization, and digitalization, has also weakened the collective bargaining power of trade unions, including in cultural industries such as journalism (Hesmondhalgh and Baker 2011). Unions have typically organized for stable, predictable employment, a living wage, and benefits, but they have struggled to organize workforces made flexible and temporary, with workers who tend to have short-term employment relationships with their employers and unions (Huws 2014; Ursell 2000). Overall union membership as a percentage of the workforce has declined steadily. Between 1981 and 2012 Canada's unionization rate decreased from 38 percent to 30 percent, even though it has remained relatively stable since 1999 (Galarneau and Sohn 2013, 1). At the same time, "alt-labour" groups such as the Canadian Intern Association have emerged to organize among the precariat by using direct action, legal action, and other tactics (Cohen and de Peuter 2013). Alt-labour groups are among the alternative social movement organizational forms that have emerged alongside trade unions to help renew, diversi$\mathrm{fy}$, and raise equity issues within the established labour movement (Fletcher, Jr. and Gapasin 2008; Foley and Baker 2009; Kumar and Schenk 2006; Milkman and Ott 2014; Mosco and McKercher 2008). Labour unions bargain collectively, which could guarantee precarious workers ongoing labour protection. Regardless of unions' decline, then, it is difficult to argue with the sentiment that unions still serve as "the worker's best defence" in an increasingly unpredictable labour market (Head 2003, 172).

Underpaid and unpaid internships are one of a constellation of these precarious employment relationships (LCO 2012, 11, 27). Internships are precarious in a number of respects, most significantly because they are temporary positions by definition and rarely come with the labour force protections or social security benefits enjoyed by permanent and full-time workers. These conditions are especially pronounced among Canadian youth aged 15 to 24 , who in 2012 had a considerably higher unemployment rate-14.3 percent-compared to the national average of 7.2 percent (Galarneau, Morissette and Usalcas 2013, 1). The challenges faced by youth to break into the workforce have led many of them to accept underpaid internships, and young people are now increasingly expected to undertake these placements before entering the paid labour force (Huws 2014; LCO 2012).

Precarious labour is evident in the print media industries (Deuze 2007, 20-27). At for-profit journalism organizations, due to factors such as technological change, decreased revenues, and constrained organizational budgets, the processes contributing to precarious employment of white-collar editorial workers include offshoring, outsourcing, mass layoffs, and slower pay increases (Cohen 2012; Deuze and Marjoribanks 2009; Örnebring 2010; Paulussen 2012). For example, from 2001 to 2011, journalists' median incomes increased proportionally less than the overall median income in Canada and did not keep up with inflation (Skelton 2013). While journalism organizations have remained profitable, they have exploited the labour of journalists by making them work for less than the standard market value that is generated from their labour.

A focus on editorial workers, who typically identify as professionals, can illuminate the exploitative social relations within the organizational division of labour in journalism production (Hesmondhalgh and Baker 2011, 67) and the "hierarchical division of newsroom labour" (Solomon 1995, 111). ${ }^{6}$ Editorial workers elucidate what William S. Solomon calls a "middleclass ideology of newswork" and what Erik Olin Wright $(1997,19)$ refers to generally as "the problem of the 'middle class' among employees": workers who do not own the means of pro-

\footnotetext{
${ }^{6}$ Workers can be placed on different levels of the hierarchy, for instance, middle-level managers, higher-skilled editors, reporters, and photographers, and non-skilled workers who do routine jobs, such as delivery drivers and mail sorters.
} 
duction and sell their labour, but do not identify as members of the working class, tend to be well educated, and have privileged positions relative to other occupations. Nevertheless, editorial workers are still exploited because they do not occupy powerful positions within the broader social division of labour (Hesmondhalgh and Baker 2011,69).

Journalism internships are one of a constellation of these precarious and exploited employment relationships. In order to provide more nuance to the organizational division of labour in the print media sector, this paper includes an analysis of internships by way of offering what is referred to as a job classification division of labour within editorial work. This notion highlights the fact that although the journalistic labour of all editorial workers may be exploited, underpaid and unpaid intern labour is more exploited relative to that of other editorial employees. Part of the reason for the greater levels of exploitation is the growing "reservoir of labour" of junior workers competing for paid positions, resulting in a surplus of labour in the print media industries (Hesmondhalgh and Baker 2011, 114). This surplus can be attributed to several factors, including job cuts and an increase in the number of university graduates. It is in this context that journalism internships have multiplied, many of which are unremunerated or low paid. Competition for internships, especially of the paid variety, is stiff. By 1997 in the United States only 57 percent of journalism students reported that they could get a paid internship. Since 2010, only 34 percent of students could find a paid placement (Internship 2014). ${ }^{7}$

Although today's internships may offer only minimal legal protections, some young workers still accept these placements, hoping that unpaid and low-paid positions lead to wellremunerated and stable employment (de Peuter 2014a; Perlin 2012; Ursell 2000; Ursell 2003). Aspiring journalism workers sometimes feel obligated to accept this partial participation in labour, as they "self-exploit" and "gift" their free labour to secure access to continuous employment and a living wage (Ursell 2000, 814, 821). Workers also willingly accept these positions because of the hype that has been generated about the "desirability of creative labour" in the media industries (Hesmondhalgh 2010, 279). To offer low-paid or unpaid internships is ultimately to lower the market value of entry-level labour, that is, to pressure labour to work for less (Gould 1981, 147).

One way that editorial workers-including interns-can resist the devaluation of their labour is through collective organization. Since 1891, print media labour unions have fought for higher wages and better working conditions for editorial workers. At that time, a wage disparity between unorganized editorial workers and the organized newspaper workers in mechanical departments became an issue around which the former initially mobilized in Pittsburgh, Denver, Sacramento, and New York (Bernstein [1969] 2010, 127; Solomon 1995, 127-128). Editorial workers also organized because newspaper work was insecure: editors and publishers would fire employees at will, and a plethora of newspaper mergers in the early 1930 s led to massive job cuts (Bernstein [1969] 2010, 127-128). As these workers lacked job security and labour protections, it is clear that precarity is not only a contemporary condition.

Until 1891, editorial employees had remained nonunionized because they typically viewed themselves as "intellectuals of the fourth estate" (Lord 1950, 25) whose professional journalistic standards were irreconcilable with collective organizing in trade unions. The professional identity of editorial workers was characterized by individualism, competitiveness, and a belief that they had a commitment to the craft of journalism rather than to the interests of other workers. As newspaper work became more specialized at the turn of the $20^{\text {th }}$ century, university-level journalism programs emerged as a training ground for aspiring journalism professionals (Salcetti 1995, 60-65). However, this commitment to journalistic professionalism could "obscure relations of exploitation" among other journalism workers (Cohen 2011, 123), as editorial workers were expected to pay their dues before earning higher wages. The idea

\footnotetext{
${ }^{7}$ Paid internships have a longer history. For instance, the Dow Jones Newspaper Fund established a paid reporting internship program in 1960 to bolster the quality of journalism education and the pool of job applicants in the United States (DJNF 2015). That year the Fund supported 53 university students with summer internships at 45 newspapers. In 1964108 interns received \$500 at the completion of their 10-week placements (Logan 1965, 624).
} 
that journalism workers should pay their dues has shaped unions' approaches toward internships.

It was a growing awareness of these precarious conditions that led the International Typographical Union (ITU) to organize 59 newswriters' locals in more than 40 cities across the United States and Canada between 1891 and 1923 (Leab 1970, 13). Most of them lasted for fewer than five years, however. In 1923, the ITU relinquished jurisdiction of newswriters to the American Federation of Labor (AFL), with the exception that the two remaining ITU newswriter locals in Milwaukee and Scranton could stay in the international union (Bernstein [1969] 2010, 127). The AFL chartered newswriters locals in seven cities, including Montreal, between 1923 and 1930, but by 1933, only the Boston and Chicago locals had survived. In September 1936, the American Newspaper Guild (ANG) began to organize editorial newsworkers in Canada, three years after the Guild was founded in the United States (Unifor87-M 2013). A small group of editorial workers at Toronto newspapers aimed to unionize the city's four daily papers, and the Toronto Newspaper Guild (TNG), Local 87 of the ANG, was born. This drive to unionize journalists and other cultural industries workers was precipitated by the Great Depression and a broader industrialization of culture (Denning 2010; Lord 1950).

Since the 1940s, editorial newspaper workers have organized around the country, as labour legislation established provisions on union certification and compulsory collective bargaining. Although labour relations fell under provincial jurisdiction in Canada, the federal government established the Wartime Labour Relations Regulations, 1944 to oversee labour relations across the country during World War II. In 1947, the federal government introduced amendments to the Regulations to return jurisdiction to the provinces, but provincial governments enacted similar legislation, for instance, British Columbia's Industrial Conciliation and Arbitration Act, $1947^{8}$ and Ontario's Labour Relations Act, 1948 (Dorsey 1977, 391; Fudge and Tucker 2001; OLRB 2013). ${ }^{9}$ These legislations enabled labour relations boards to certify unions as the official bargaining agents for employees.

Despite this long history of unionizing editorial workers, some of the Ontario-based newspapers and magazines examined below have been organized only since the early 1980s. In the 1960s and 1970s the TNG developed a "cosy" working relationship with print media companies and did not see organizing new groups of employees as a priority (Unifor87-M 2013). Still, in the late 1970s TNG changed its name to the Southern Ontario Newspaper Guild (SONG), acknowledging that it represented members outside of Toronto, too. In the early 1980s, union members elected new officers with a mandate to organize more newsrooms, and unionization drives took off, leading to a long period of expansion that extended into the early 2000s. The dual aims of the earlier organizing attempts still mark the journalistic culture to which members of editorial unions subscribe: attaining and maintaining professional standards and higher wages.

In a precarious media labour market characterized by weakened labour union protection and employment legislation, and declining union membership, media unions have merged and consolidated collective bargaining negotiations to strengthen their power (Hesmondhalgh and Baker 2011; McKercher 2002; Mosco and McKercher 2008). Unions such as Unifor and the Communications Workers of America-Canada (CWA-Canada) now represent media workers across the print, telecommunications, broadcasting, and online industries, among others. Their print media members come from both editorial and mechanical departments across Canada and the United States. For example, the CWA initiated labour "convergence" as a gradual strategy around 1980 and this process intensified after 1991, when the union proclaimed that its goal was to organize entire workplaces rather than only groups of workers (Mosco and McKercher 2008, 115). By the 1980s, corporate concentration of media corporations had accelerated, with government re-regulation facilitating further cross-media corporate expansion (McKercher 2002, 186). A major outcome of labour convergence was that Local 87 left The Newspaper Guild (formerly known as the American

\footnotetext{
${ }^{8}$ The Act was amended in 1948 to create the Labour Relations Board.

9 Ontario's Collective Bargaining Act, 1943 was among the first attempts to establish compulsory collective bargaining in Canada.
} 
Newspaper Guild) in 1994 and affiliated with the Communication, Energy, and Paperworkers Union (CEP), the biggest union of print media workers in the country, which had 15,000 members in its media section (Unifor87-M 2013). The Newspaper Guild also granted its Canadian members more autonomy in 1995, founding TNG Canada, around the same time that it merged with the CWA; in 2007, TNG Canada became CWA Canada (CWA Canada 2015). In 2013, the CEP merged with the Canadian Auto Workers Union, forming Unifor to deal with declining union membership following the 2008 global recession (Unifor87-M 2013).

Thus, journalism unions have struggled to balance a series of strategic objectives, including a commitment to professional growth, a fight for higher wages in industries that have experienced declining revenues and profits, and the development of strategies to protect an expanded and more diverse group of workers that includes new job classifications. Among this diverse group are interns, who, as we have seen, still manifest a desire to work in creative industries despite the precarious working conditions marking them.

\section{Journalism Internships in Canada}

Table 1 summarizes the varied set of relationships that exist between journalism internship pay rates and collective representation at the publications I surveyed. The table includes the most recent information on annual revenues, earnings, and profit margins of the publications' owners, ${ }^{10}$ as well as the number of interns working at these magazines and newspapers at any one time.

First, many internships are unpaid or low paid and not under union jurisdiction. Unpaid magazine internships in Canada emerged after a mild recession in the early 1990s, when some magazine owners experienced a slight decline in revenues (Jay 1995; Winseck 2010; Winseck 2011). One example is Flare's internship program, which has been unpaid since it was introduced in 1991. Although this program was temporarily shut down in 2014, the Rogers Communications-owned fashion magazine has begun to offer unpaid internships to students who can receive university course credits for their placements (Flare 2014; Jay 1995; McKnight 2014; Tant 2010; Alicia Cox Thomson, pers. comm.). Flare generally hires about six interns at a time, three times per year, each of whom work full-time for four months in one of the following departments: fashion, beauty, entertainment, design, research, or Flare.com. Chatelaine, a Rogers-owned women's magazine that also recently ceased its internship program, compensated interns only $\$ 400$ monthly. The magazine began an experimental internship program in 1994-1995 by hiring interns from community colleges (Jay 1995). Before cancelling its program in 2014, Chatelaine hired web, editorial, and copy/research interns to work between three and five days per week over four or six months (Baluja 2013). In 2013, while interns earned little to nothing, Rogers Media, which includes the company's media assets, generated $\$ 1.7$ billion in operating revenue and $\$ 160$ million in adjusted operating profit, with a profit margin of 9.4 percent (Rogers Communications 2014, 1, 47). ${ }^{11}$

Like Chatelaine, Toronto Life also paid its interns a stipend from the time it started its internship program in 1993 until after the global financial crisis unfolded in 2009, when internships became unpaid placements (Houpt 2014; Jay 1995). Editorial interns (general, fashion and lifestyle, and food and drink) were expected to work full-time for four months, except online interns, who could work part-time for at least three days per week (Toronto Life 2014). In 2014 the magazine ended its internship program after 21 years, dismissing five interns (Houpt 2014). Soon after, Toronto Life (2015) reopened its unpaid internship program to students enrolled in academic programs who require intern experience to graduate. Despite a lack of remuneration for interns, the magazine is owned by St. Joseph Communications, a company that generated $\$ 32.3$ million in revenue in 2013 , an increase from $\$ 28.5$ million in 2008 and $\$ 29.8$ million in 2010 (CMCRP 2013). ${ }^{12}$

\footnotetext{
${ }^{10}$ Based on 2013 data from publicly traded companies, as available.

${ }^{11}$ Rogers Media includes television, radio, digital media, sports entertainment, and magazine publishing, the latter of which generated 14 percent of the total Media operating revenue. Information about publishing profit was unavailable.

12 Earnings and profit margin data for St. Joseph Communications were unavailable.
} 
ELLE Canada (2011) pays its editorial-beauty and editorial-web interns, but only $\$ 750$ at the end of a four-month placement. Interns are expected to work seven hours per day over three to four days per week. The magazine tends to hire recent graduates and students with journalism experience. The publication is owned by TC Transcontinental, whose assets from TC Media (its newspaper and magazine division) generated $\$ 712$ million in revenue and $\$ 40$ million in adjusted operating profit in 2013 (TC Transcontinental 2013, 13). Although these companies are profitable, they pay all of their interns significantly below the $\$ 11.25$-per-hour student minimum wage in Ontario, where the magazines are based.

Second, interns at some organizations are unpaid or low paid and under union jurisdiction. Since Toronto Sun workers organized with SONG, a local of Unifor, in 2003, its collective agreement has stipulated that it may hire up to four unpaid journalism student interns at a given time including a photo intern (CEP 2008a, 18; CEP 2011d, 18-19; Unifor87-M 2013). By contrast, the paper's multimedia journalists earn $\$ 51,538$ yearly, and columnists make $\$ 77,216$ annually (CEP 2011d, 72, 78). ${ }^{13}$ Similarly, since Ottawa Sun workers first organized with SONG in 2006, its collective agreement has allowed up to three journalism student interns to work unremunerated in the paper's newsroom for a maximum of eight weeks (CEP 2007c, 6; CEP 2011c, 18; Unifor87-M 2013). Compared to this free intern labour, multimedia content providers are paid $\$ 707$ weekly, and columnists earn $\$ 1,033$ per week (CEP 2011c, 54-55). Likewise, according to SONG's collective agreement with the London Free Press, which has been organized since 1989 , the paper has also been able to hire unpaid interns since at least 2007 (CEP 2007a; Unifor87-M 2013). In 2013 the newspaper could hire up to four unremunerated student interns per year but only one intern at any given time to work for a maximum of one month (CEP 2007a, 42; CEP 2013b, 44). This free intern labour is in stark contrast to the profit of the papers' owners. The Sun and Free Press newspapers are owned by Sun Media Corporation, a subsidiary of Quebecor Media, whose news media operations generated $\$ 784.2$ million in revenue and $\$ 97.7$ million in adjusted operating profit in 2013, with a profit margin of 12.5 percent (Quebecor Media 2014, 37).

Other unionized publications run low-paid internships. Since at least 2009, the Rogersowned Maclean's $(2009 ; 2014)$ has offered a full-time program that pays $\$ 22,500$ annually and a full-time three-month summer program paying $\$ 1,750$ monthly, both of which are open to anyone interested in journalism. When hiring summer interns, the magazine tends to prioritize students entering their final year of study. The magazine's editorial workers have been represented by SONG since 1983 (Unifor87-M 2013). In the 1990s, when competing magazines Flare, Chatelaine, and Toronto Life started internship programs, SONG prevented the use of interns and unpaid work at Maclean's. After 2003, the Guild incorporated a paid internship program into the magazine's collective agreement (CEP 2001; CEP 2007b; Jay 1995). Although Maclean's currently remunerates its interns, the salaries may seem surprising considering it classifies yearlong interns as "full-time entry-level journalists" (Maclean's 2014). According to its collective agreement, though, Maclean's is obligated to provide students with only an "honorarium of not less than $\$ 1,000$ for a four month period or $\$ 250$ per month or part thereof" (CEP 2007b, 10; CEP 2011b, 26-27). By contrast, Maclean's pays its full-time entry-level staff significantly higher yearly starting rates: $\$ 35,000$ for reporters and $\$ 48,000$ for researchers/reporters (CEP 2011b, 59-62). The agreement has limited the magazine to only two internship placements at any given time, and up to two placements annually in each department, except for the research department, which may offer one student placement and two Ann MacGregor Memorial Internships yearly.

Third, some interns are paid at intern rates and not under union jurisdiction. Canadian Business hires two early-career journalist interns full-time for 12-month periods each year, remunerating them $\$ 2,000$ monthly (Canadian Business 2014; Graham F. Scott, pers. comm.). The program was founded in 1995, becoming "the first paid magazine internship in Canada" and "one of the country's highest paid internship positions" (quoted in Baluja 2014). The company has even increased its intern salary with inflation: from 1998 to 2004, for example, it paid $\$ 1,500$ monthly (Renzetti 1998; Scratch 2004). However, Canadian Business

\footnotetext{
${ }^{13}$ In 2015, the Toronto Sun sought multimedia journalists for "paid" summer internships (Gaulin 2015).
} 
and Maclean's are based in Toronto-one of Canada's most expensive cities for housingand these salaries are insufficient to financially support interns. These earnings hover around the low-income cut-off of $\$ 23,647$ before taxes for one person in metropolitan areas of 500,000 or more inhabitants, such as Toronto (Statistics Canada 2013).

Like the Canadian Business internships, the Calgary Herald's summer program is neither unpaid, nor low-paid, nor under union jurisdiction. The paper's internship program has existed since at least 1985 (Lorne Motley, pers. comm.). The Herald hires three or four students or recent graduates during the summer, paying them around $\$ 20$ per hour to work full-time for four months. This pay rate has outpaced inflation-in 2000 the Herald paid its interns $\$ 14$ per hour (Motley, pers. comm.). To determine the appropriate rate, the "HR department conducts regular reviews of competitive starting and internship salaries in the marketplace" (Motley, pers. comm.). Nevertheless, the Herald is part of the Postmedia conglomerate, which generated $\$ 751.6$ million in revenue and $\$ 130.4$ million in earnings in 2013 , with a profit margin of 17.3 percent (Postmedia 2013, 9, 21). Although Canadian Business (a Rogersowned publication) and the Herald may pay a competitive wage, they also leave interns with little power to bargain collectively for higher wages. In 2000 the Herald even resisted CEP Local 115A's fight to get a first contract for the newsroom during a legal strike by hiring replacement workers, among them a Carleton University summer intern (CEP 2000). The strike led the union local to decertify.

Fourth, interns at some publications are paid at intern rates and under union jurisdiction. The Victoria-Vancouver Island Newspaper Guild (VVING), Local 30223 of the CWA-Canada, represents Victoria Times-Colonist interns. When VVING first established the newspaper's paid editorial internship program in 2002 , it negotiated a weekly intern salary of $\$ 530$, and in 2006 , the rate increased to $\$ 554$ weekly, permitting the paper to hire up to four interns yearly (Chris Carolan, pers. comm.; VVING 2011, 133). The program is open to students, and interns are hired to work full-time for up to a maximum of 20 weeks between May and September. However, the intern pay rate has not increased since 2006, even though other editorial employees have received pay raises: for example, in 2013, first-year reporters and photographers earned $\$ 1,033$ weekly, more than double the intern rate (VVING 2011, 39). Despite this salary difference, the Times-Colonist has not hired interns every year (Carolan, pers. comm.). Nevertheless, the newspaper is owned by Glacier Media, a company that in 2013 generated \$295.6 million in revenue and \$32.7 million in earnings, with a profit margin of 11.1 percent (Glacier Media 2013, 14).

Another company in this category, the SONG-unionized Toronto Star, hires 30 to 32 interns annually across its four internship programs, with varying special intern training pay scales (CEP 2013c, 70; Peter Cooney, pers. comm.; Toronto Star 2014). The summer reporting internship is a full-time position that ranges from 10 to 14 weeks. The one-year reporting internship is also a full-time placement and is only open to recent graduates. The fall and winter radio room internships are part-time placements that are open to students, whereas the summer radio internships are full-time positions for students. In 2013 Star editorial interns earned $\$ 954$ weekly, and this salary has increased with inflation from about $\$ 700$ in 1999 (CEP 2013c, 158, 172; Stone 1999). In 2013 the paper's first-year journalists earned only marginally more-\$1,046-up from around $\$ 700$ in 1999 (CEP 2013c, 154; Stone 1999). Nevertheless, radio room interns earned $\$ 17$ per hour in 2013 (CEP 2013c, 94).

SONG did not passively lock these interns into a lower-paid contract, though. In the late 1990s the local fought to create the radio room internship program in order to integrate younger voices into the newsroom. Its aim was to "staff [the radio room] with cheaper students," providing the students with part-time newsroom experience and enabling experienced journalists to work on the "bigger news" (Laidlaw 2013). Like VVING, the Guild also established a "special editorial trainee wage category and pay rate" in collective bargaining. Simultaneously, SONG launched its bigger "editorial intern program," which provides 12 one-year reporting internships. The radio room is generally staffed with 12 interns during any particular contract period (Ladurantaye 2013). In 2013 the Guild agreed to an hourly pay decrease from $\$ 25$ to $\$ 17$ for radio room students to prevent the Star from terminating that internship program (CEP 2013a; Ladurantaye 2013; Laidlaw 2013). As a result of declining advertising 
revenues, the paper planned to reduce the radio room's $\$ 250,000$ annual cost and outsource the work to Pagemasters, a company that could provide the same services at a discounted rate. In March 2013, Stuart Laidlaw, SONG unit chair of the Star, said that the radio room program has trained many Star reporters, and the pay cut was a way to balance an investment in young journalists' professional training with the paper's economic interests: "[The radio room] is a real incubator-you get to test drive a young reporter at a relatively affordable rate" (quoted in Ladurantaye 2013). Although the Star pays its interns a training rate, the media segment of the Torstar-owned newspaper generated $\$ 984$ million in revenue and $\$ 130.7$ million in earnings in 2013 , with a profit margin of 13.3 percent (Torstar 2013,18).

The Winnipeg Free Press is another unionized newspaper whose internship programs are subject to a special intern training pay class. The paper's summer and school-year internships are open to journalism students or recent graduates. Since at least 2008, Free Press interns have been covered under the collective agreement of Unifor Local 191 (CEP 2008b, 48). The paper's full-time summer reporter interns are "paid in accordance with the collective agreement at 65 percent of the starting wage for a reporter" (CEP 2013d, 59; Steve Pona, pers. comm.). According to this agreement, the starting weekly rate for reporters is $\$ 866$ (CEP 2013d, 56), even though reporter interns "perform all of the functions of a working journalist" (Winnipeg Free Press 2014). Still, the Free Press offers similar six-week (30 working day) school-year internships, paying students a $\$ 50$ weekly honorarium. This program is open to two students at any one time, except in December and January, when the paper may hire up to four interns (CEP 2013d, 59). FP Canadian Newspapers, the publication's owner, generated $\$ 106.3$ million in revenue and $\$ 20$ million in earnings in 2013 , with a profit margin of 18.8 percent (FP Newspapers $2013,20,44$ ). Significantly, most of work placements in this category still demonstrate that it is feasible to pay interns at least minimum wage and the equivalent of the low-income cut-off.

Fifth, at other publications interns are paid at entry-level employee rates and under union jurisdiction. The Globe and Mail is one such publication that pays summer interns the equivalent of the SONG rates for reporters, editors, and digital specialists (Stead 2013). The Globe's full-time summer program was established and well recognized by 1974 . Since then, the paper has offered between 10 and 25 summer positions annually; since the 2000s, it has hired around 18 to 20 summer interns yearly (Sue Andrew, pers. comm.; Sylvia Stead, pers. comm.). These internships are not typical, though, as they are open to students and experienced journalists. They have always been covered under the collective agreement because these interns are considered contract staff. However, this internship or "vacationreplacement" program differs from the paper's school-year work-study program, created in the early 2000s (Andrew, pers. comm.). From 2009 to 2013 the Globe's work-study programs of up to six weeks paid post-secondary students a $\$ 125$ weekly honorarium (Andrew, pers. comm.; CEP 2009, 32, 73). Yet, from 2002 to 2009, up to 10 students per calendar year were permitted to participate in a work-study program and were paid a $\$ 250$ weekly honorarium (CEP 2002a, 3, 22). In 2013, Woodbridge, the holding company for the Thomson family that owns the majority interest in the paper, generated $\$ 272.1$ million in revenue (CMCRP 2013). ${ }^{14}$

Some unionized newspapers pay all of their interns an entry-level salary. One exemplar is the Waterloo Region Record, a newspaper that has been represented by SONG since 1989 (CEP 2011e, 22; Unifor87-M 2013). Torstar subsidiary Metroland Media Group publishes the Region Record, where reporters and photographers were paid $\$ 703$ weekly, and copy editors earned $\$ 1,134$ weekly in 2013 (CEP 2011e, 24). Since at least 1999, this pay class has applied to interns who are hired on full-time placements of at least one month (CEP 2003a, 24). Yet in 2013 the Region Record employed only one rather than two news interns, and hired only three summer interns (compared to four in 2011 and in 2012) to reduce organizational spending (Haddrall 2011; Haddrall 2012; Haddrall 2013; Learn 2013). The paper tends to hire journalism students or recent graduates.

\footnotetext{
${ }^{14}$ Earnings and profit margin data for the Globe were unavailable.
} 
Metroland Media's Guelph Mercury interns also "become members of [SONG's] editorial bargaining unit, subject to all contract provisions" (CEP 2011a, 13). Interns must be journalism school graduates, have postsecondary education in journalism, or possess journalism experience as a student. Mercury editorial workers certified with SONG in 1991 (Unifor87-M 2013), and the internship program was launched in the early 2000s under union jurisdiction (Joanne Shuttleworth, pers. comm.). In May 2003 the Guild ratified a new contract, "tightly" limiting the paper's proposal for editorial interns (CEP 2003b). In 2013 the starting rate for reporters and photographers was about $\$ 564$ weekly, and for copy editors it was around $\$ 876$ weekly (CEP 2011a, 14). The Mercury may hire full-time interns for terms of up to one year, with no more than a single one-year intern at one time, a condition that was written into the collective agreement when the internship program began (CEP 2002b, 16-17; Ray 2009). Sometimes the paper hires a summer intern, too (Shuttleworth, pers. comm.). Due to the global recession, however, the intern program was suspended in 2009 after Torstar laid off employees across its chain, 13 of whom were Guelph Mercury newsroom employees (Canadian Press 2009; Ray 2009; Shuttleworth, pers. comm.). The Mercury transferred editorial positions to the Waterloo Region Record, its sister paper. After 2009, the internship program was revived, but its status varies from year to year. The program is reconsidered annually when the Mercury plans its budget, so it is uncertain if interns will be hired in the following year.

The Postmedia-owned Ottawa Citizen is another newspaper that pays interns the starting rates for copy editors, photographers, and reporters, as outlined in its collective agreement with CWA-Canada Local 30205, the Ottawa Newspaper Guild (ONG). The latter fought to establish an intern "orientation" and "training" program, which the Citizen was obligated to implement by January 1, 2001 (ONG 2013, 43). The collective agreement currently limits the paper to six full-time interns at one time, including one copy editor, one photographer, and four reporters (ONG 2013, 5). In 2013 copy editors earned $\$ 1,143$ weekly, and photographers and reporters earned $\$ 1,024$ weekly (8).

Likewise, Postmedia's Pacific Newspaper Group-owned Vancouver Province and Vancouver Sun have always tied their intern pay rate to the full-time entry-level wage of regular employees (Valerie Casselton, pers. comm.; Gary Engler, pers. comm.). By 1968 the Sun ran what was considered the biggest internship program in Canada for student journalists at the time (Valpy 1968). In 2013 the Province and the Sun could hire up to six interns (reporters, copy editors, and photographers) at one time per newspaper, as outlined in their joint agreement with Unifor Local 2000, the Media Union of B.C. That year reporters and photographers earned $\$ 1,038$ weekly, and copy editors earned $\$ 1,113$ per week (CEP 2007d, 15, 25-27, 29; Mercer 2012). Interns must be graduates of a journalism program. However, the Province hired only four interns in 2012 and in 2013, including for its 3.5-month full-time summer program, but it did not employ any interns in 2014 or 2015 (Engler, pers. comm.; Mercer 2012). Similarly, the Sun hired only three interns in each 2013 and 2014, but it was unable to hire interns in 2015 due to budget constraints (Casselton, pers. comm.; Engler, pers. comm.). By contrast, the paper hired as many as 14 summer interns around three decades ago. When set against unpaid, low-paid, and special intern rate placements, these internships demonstrate that it is possible to pay interns an entry-level salary.

\section{Tensions and Contradictions Within Journalism Internships Under Union Jurisdiction}

I have argued that, just as the printing firms of the 1830s exploited young apprentices (Zerker 1975; Zerker 1982), some of today's for-profit magazines and newspapers exploit and devalue the labour of interns with respect to the standard market value of entry-level labour. Just as editorial work during the late 1800 s and early 1900 s was insecure and employees lacked labour protections (Bernstein [1969] 2010), many of today's journalism internships are exemplars of precarious employment relationships. Yet unlike the earlier print media unions, which became workers' best defence against exploitation, devaluation, and precarity, the case of journalism internship pay rates and collective representation in Canada demonstrates the 
contradictory roles that labour unions play in this system today: while some unions have perpetuated exploitation by locking interns into unpaid, low-paid, and training rate placements, others have actively aimed to ensure that interns have been paid well above minimum wage for their work and been offered training and mentorship.

On the one hand, some unions have locked unpaid, low-paid, and training rate internships-the category with the highest number of placements-into their collective agreements. The pay rates of some internships under union jurisdiction are comparable to placements that are not under union jurisdiction. Like the nonunionized magazines Flare and Toronto Life, unionized newspapers such as the Toronto Sun, Ottawa Sun, and London Free Press have offered unpaid internships. Even the nonunionized magazines Chatelaine and Elle Canada have paid interns at least a stipend. Similarly, the nonunionized publications Canadian Business and Calgary Herald have paid a special intern training wage that is comparable to the intern-training rate of unionized publications such as the Winnipeg Free Press. Although the Herald has paid a competitive wage that has increased with inflation, it used an intern as a replacement worker to help defeat CEP Local 115A after the newsroom union struck to get a first collective agreement. The outcome of this strike contradicts Gregor Gall's $(1997,157)$ claim that union de-recognition in the print media industries leads to "[p]ay rises below the level of inflation" and "lower starting rates" (at least for interns at one publication), but it confirms that interns are contingent, expendable, and precarious workers.

The pay for these internships is low when compared to the salaries of permanent employees whose jobs interns have been sometimes expected to temporarily replace during vacations. Although most of these internships are considered postsecondary "training" and journalism organizations are therefore not legally obliged to remunerate interns, the positions closely resemble paid and stable entry-level jobs. Some of the intern pay rates have varied even within unionized publications, among them placements at the Toronto Star, the Winnipeg Free Press, and the Globe and Mail. Thus, they are indicative of not only an organizational division of labour and a "hierarchical division of newsroom labour," but also what I refer to as a job classification division of labour within editorial work (cf. Hesmondhalgh and Baker 2011, 67; Solomon 1995, 111). While all editorial workers at print media companies may be exploited, the conditions for many if not most interns are relatively more exploitative. Entrylevel journalism workers are part of the precariat and must increasingly accept these unpaid or low-paid internships to secure access to continuous employment and a living wage (Standing 2011).

Media companies have used underpaid internships as well as cuts to stable jobs and the limitation of salary increases to reduce organizational spending. Companies have claimed that the cuts and limits are necessary because their revenues and profits have declined since 1990, especially following the 2008 global recession. Yet many of the internship programs surveyed here emerged after 1990, under the increasingly precarious labour market conditions brought about by post-Fordist capitalism. The rise of unpaid and low-paid internships in the Canadian print media sector, a relatively well-unionized setting historically, seems to confirm Ross Perlin's $(2012,71)$ observation that "union presence seems to have made little difference" in stemming the growth of this emergent form of precarious employment.

On the other hand, unions have also created opportunities for aspiring journalism workers by launching paid editorial internship programs. These union-initiated internships have become part of a strategy to balance competing objectives, such as protecting a larger and more diverse labour force, negotiating economic interests, and committing to professional journalism training. Exemplars surveyed here have included VVING's the Victoria TimesColonist, SONG's the Toronto Star, the Guelph Mercury, and The Globe and Mail, as well as ONG's the Ottawa Citizen. Most of these programs were established in the late 1990s and early 2000s. It is not surprising that certain paid unionized internships emerged after 1990, as journalists at some publications became organized only around that time, such as the Guelph Mercury and the Waterloo Region Record. These internships and organizing drives were arguably an outcome of labour union convergence, illustrating the expanded scope of collective bargaining in the print media industries (McKercher 2002; Mosco and McKercher 2008). 
Yet union-created journalism internships have highlighted tensions within unions, especially following the 2008 recession. Time-Colonist interns have earned the same salary since 2006, even though other editorial employees have received raises. Conversely, the Globe's low-paid work-study honorarium was cut by 50 percent. Likewise, SONG negotiated an intern pay decrease to save the Toronto Star's radio room internships after the paper considered outsourcing the labour, while other editorial workers received pay increases. Despite this pay cut, the $\$ 17$ hourly rate of radio room interns is high compared to most journalism internships that are not under union jurisdiction. These examples demonstrate that media unions have struggled to meet similar objectives since the late $19^{\text {th }}$ century, but they have increasingly established and protected internship programs as a key priority in balancing those objectives.

Union members have also ratified collective agreements that guarantee interns an entrylevel salary. Of the journalism internships surveyed here, it is clear that only internships under union jurisdiction have been remunerated at this rate at The Globe and Mail (summer program), the Waterloo Region Record, the Guelph Mercury, the Ottawa Citizen, the Vancouver Province, and the Vancouver Sun. Many of these internships have paid workers nearly $\$ 1,000$ weekly, and at some newspapers interns have earned more per week. Similarly, editorial interns at the Toronto Star earned a high weekly salary of nearly $\$ 1,000$ at the special intern rate. These placements are evidence that unions are not necessarily complicit in devaluing intern labour.

However, some newspapers have not hired or have reduced the number of interns who are paid an entry-level salary, among them the Guelph Mercury, the Vancouver Sun, and the Vancouver Province. Likewise, the Victoria Times-Colonist has not hired interns who are paid a special training rate. In addition to the job cuts mentioned above, these newspapers have attributed their decisions to declining revenues and profits. The purported necessity of these cuts has been called into question, though, by highlighting the profit margins of journalism organizations: all of the eight ownership groups surveyed in this paper and for which data were available remain profitable, with six maintaining double-digit profit margins. Marc Edge (2014) refers to the disparity between figures such as these and the dire claims coming from industry observers and executives as pointing to the "myth" of the newspaper crisis. My research for this paper suggests that unions should consider debunking this myth by exposing the enviable profits that media companies have secured and advocating that these profits be redistributed among interns and other journalism workers. Ultimately, unions must continue to fight for higher wages and resist exploitative internships, just as they resisted the use of cheap apprentice labour and the lack of editorial worker job security in the $19^{\text {th }}$ century and early $20^{\text {th }}$ century.

In light of broader discussions about a declining unionization rate under post-Fordist capitalism, the "embattled state of the union" (de Peuter 2014b, 41), and labour movement renewal (Foley and Baker 2009; Kumar and Schenk 2006), the relationship between collective representation and entry-level journalism intern pay rates in Canada illuminates the vital role of mediation that unions continue to play. The relatively high-paid journalism internships under union jurisdiction seem to bolster Simon Head's $(2003,172)$ claim that unions can still be "the worker's best defence." They are also evidence that well-paid internships are both possible and desirable. Unionized newspapers that pay interns entry-level rates could serve as a model for organizing unpaid and low-paid magazine interns and other precarious workers whose labour is devalued, both beyond the media industries and outside of Canada. 
Table 1: Journalism Internship Pay Rates and Collective Representation in Canada

\begin{tabular}{|c|c|c|c|c|c|}
\hline $\begin{array}{l}\text { Magazine (m)/ } \\
\text { Newspaper (n) }\end{array}$ & Owner & $\begin{array}{l}\text { Revenues }^{15} / \\
\text { Earnings }^{16} / \\
\text { Profit } \\
\text { Margin }^{17}\end{array}$ & Union & Interns $^{18}$ & Pay Rate (\$) \\
\hline Flare (m) & $\begin{array}{l}\text { Rogers } \\
\text { Media }\end{array}$ & $\begin{array}{l}1,700 / 160 / \\
9.4 \%\end{array}$ & No & $\begin{array}{l}6 \\
\text { (18 per year) }\end{array}$ & Unpaid \\
\hline Chatelaine (m) & $\begin{array}{l}\text { Rogers } \\
\text { Media }\end{array}$ & $\begin{array}{l}1,700 / 160 / \\
9.4 \%\end{array}$ & No & N/A & $\begin{array}{l}400 \\
\text { (per month) }\end{array}$ \\
\hline Toronto Life (m) & $\begin{array}{l}\text { St. Joseph } \\
\text { Communications }\end{array}$ & $\begin{array}{l}32.1 / \mathrm{NA} / \\
\mathrm{NA}\end{array}$ & No & 5 & Unpaid \\
\hline $\begin{array}{l}\text { ELLE } \\
\text { Canada }(\mathrm{m})\end{array}$ & TC Media & $\begin{array}{l}712 / 40 / \\
5.6 \% \\
\end{array}$ & No & N/A & $\begin{array}{l}750 \\
\text { (4 months) }\end{array}$ \\
\hline Toronto Sun (n) & Quebecor Media & $\begin{array}{l}784.2 / 97.7 / \\
12.5 \%\end{array}$ & $\begin{array}{l}\text { Unifor } \\
\text { Local } \\
87-M\end{array}$ & 4 & Unpaid \\
\hline Ottawa Sun (n) & Quebecor Media & $\begin{array}{l}784.2 / 97.7 / \\
12.5 \%\end{array}$ & $\begin{array}{l}\text { Unifor } \\
\text { Local } \\
87-M\end{array}$ & 3 & Unpaid \\
\hline $\begin{array}{l}\text { London Free } \\
\text { Press (n) }\end{array}$ & Quebecor Media & $\begin{array}{l}784.2 / 97.7 / \\
12.5 \%\end{array}$ & $\begin{array}{l}\text { Unifor } \\
\text { Local } \\
87-M\end{array}$ & $\begin{array}{l}1 \\
\text { (4 per year) }\end{array}$ & Unpaid \\
\hline Maclean's (m) & $\begin{array}{l}\text { Rogers } \\
\text { Media }\end{array}$ & $\begin{array}{l}1,700 / 160 / \\
9.4 \%\end{array}$ & $\begin{array}{l}\text { Unifor } \\
\text { Local } \\
87-M\end{array}$ & 2 & $\begin{array}{l}22,500 \text { (per year) } \\
1,750 \text { (per month) }\end{array}$ \\
\hline $\begin{array}{l}\text { Canadian } \\
\text { Business (m) }\end{array}$ & $\begin{array}{l}\text { Rogers } \\
\text { Media }\end{array}$ & $\begin{array}{l}1,700 / 160 / \\
9.4 \%\end{array}$ & No & 2 & $\begin{array}{l}24,000 \\
\text { (1 year) }\end{array}$ \\
\hline $\begin{array}{l}\text { Calgary } \\
\text { Herald (n) }\end{array}$ & Postmedia & $\begin{array}{l}751.6 / 130.4 / \\
17.3 \%\end{array}$ & No & $3-4$ & 20 (hourly) \\
\hline $\begin{array}{l}\text { Victoria Times- } \\
\text { Colonist }(\mathrm{n})\end{array}$ & Glacier Media & $\begin{array}{l}295.6 / 32.7 / \\
11.1 \%\end{array}$ & $\begin{array}{l}\text { CWA- } \\
\text { Canada } \\
\text { Local } \\
30223\end{array}$ & 4 per year & $\begin{array}{l}554 \\
\text { (weekly) }\end{array}$ \\
\hline Toronto Star (n) & Torstar & $\begin{array}{l}984 / 130.7 / \\
13.3 \%\end{array}$ & $\begin{array}{l}\text { Unifor } \\
\text { Local } \\
87-M\end{array}$ & $\begin{array}{l}\text { 30-32 } \\
\text { per year }\end{array}$ & $\begin{array}{l}954 \\
\text { (weekly) } \\
17 \text { (hourly) }\end{array}$ \\
\hline $\begin{array}{l}\text { Winnipeg Free } \\
\text { Press (n) }\end{array}$ & $\begin{array}{l}\text { FP Canadian } \\
\text { Newspapers }\end{array}$ & $\begin{array}{l}106.3 / 20 / \\
18.8 \%\end{array}$ & $\begin{array}{l}\text { Unifor } \\
\text { Local } \\
191\end{array}$ & $\begin{array}{l}\text { N/A summer } \\
\text { 2-4 school } \\
\text { year }\end{array}$ & $\begin{array}{l}65 \% \text { of } \\
\text { start rate } \\
50 \text { (weekly) }\end{array}$ \\
\hline $\begin{array}{l}\text { Globe and Mail } \\
(\mathrm{n})\end{array}$ & Woodbridge & $\begin{array}{l}350.4 / \mathrm{NA} / \\
\mathrm{NA}\end{array}$ & $\begin{array}{l}\text { Unifor } \\
\text { Local } \\
87-M\end{array}$ & $\begin{array}{l}18-20 \text { sum- } \\
\text { mer } \\
10 \text { per year } \\
\text { work study }\end{array}$ & $\begin{array}{l}\text { Entry level } \\
125 \\
\text { (weekly) }\end{array}$ \\
\hline $\begin{array}{l}\text { Waterloo } \\
\text { Region } \\
\text { Record (n) }\end{array}$ & Torstar & $\begin{array}{l}984 / 130.7 / \\
13.3 \%\end{array}$ & $\begin{array}{l}\text { Unifor } \\
\text { Local } \\
87-M\end{array}$ & 4 & Entry level \\
\hline $\begin{array}{l}\text { Guelph } \\
\text { Mercury (n) }\end{array}$ & Torstar & $\begin{array}{l}984 / 130.7 / \\
13.3 \%\end{array}$ & $\begin{array}{l}\text { Unifor } \\
\text { Local } \\
87-M\end{array}$ & 1-2 per year & Entry level \\
\hline $\begin{array}{l}\text { Ottawa } \\
\text { Citizen (n) }\end{array}$ & Postmedia & $\begin{array}{l}751.6 / 130.4 / \\
17.3 \%\end{array}$ & $\begin{array}{l}\text { CWA- } \\
\text { Canada } \\
\text { Local } \\
30205\end{array}$ & 6 & Entry level \\
\hline
\end{tabular}

\footnotetext{
${ }^{15}$ All dollar amounts are expressed in millions annually in Canadian dollars.

${ }^{16}$ Based on Earnings Before Interest, Taxes, Depreciation and Amortization (EBITDA).

${ }^{17}$ Calculated as revenues divided by earnings.

${ }^{18}$ Based on the number of interns at any one time in 2013 , unless otherwise noted.
} 


\begin{tabular}{|l|l|l|l|l|l|}
\hline $\begin{array}{l}\text { Vancouver } \\
\text { Province }(\mathrm{n})\end{array}$ & Postmedia & $\begin{array}{l}751.6 / 130.4 / \\
17.3 \%\end{array}$ & $\begin{array}{l}\text { Unifor } \\
\text { Local } \\
2000\end{array}$ & 4 & Entry level \\
\hline $\begin{array}{l}\text { Vancouver Sun } \\
(\mathrm{n})\end{array}$ & Postmedia & $\begin{array}{l}751.6 / 130.4 / \\
17.3 \%\end{array}$ & $\begin{array}{l}\text { Unifor } \\
\text { Local } \\
2000\end{array}$ & 3 & Entry level \\
\hline
\end{tabular}

\section{References}

Bakker, Piet. 2014. Mr. Gates Returns. Journalism Studies 15 (5): 596-606.

Baluja, Tamara. 2013. Chatelaine Seeking Web, Copy Editing and Editorial Interns. J-Source, December 3. Accessed June 26, 2015. http://j-source.ca/article/chatelaine-seeking-web-copy-editingand-editorial-interns.

Baluja, Tamara. 2014. Canadian Business Hiring One-Year Intern. J-Source, January 9. Accessed March 3, 2015.

http://j-source.ca/article/canadian-business-hiring-one-year-intern.

Bekken, Jon. 1995. Newsboys: The Exploitation of 'Little Merchants' by the Newspaper Industry. In Newsworkers: Toward a History of the Rank and File, edited by Hanno Hardt and Bonnie Brennen, 190-225. Minneapolis: University of Minnesota Press.

Bekken, Jon. 2009. Newsboy Strikes. In Encyclopedia of Strikes in American History, edited by Aaron Brenner, Benjamin Day and Immanuel Ness, 609-619. Armonk: M.E. Sharpe.

Bernstein, Irving. 2010. Unrest in Odd Places. In The Turbulent Years: A History of the American Worker, 1933-1941, 126-171. Boston: Houghton Mifflin. Reprint, Chicago: Haymarket Books. First published 1969.

Brophy, Enda and Greig de Peuter. 2007. Immaterial Labor, Precarity, and Recomposition. In Knowledge Workers in the Information Society, edited by Catherine McKercher and Vincent Mosco, 177-191. Lanham: Lexington Books.

Canadian Business. 2014. The Canadian Business Internship. Accessed March 22, 2015. http://www.canadianbusiness.com/blogs-and-comment/internship/.

Canadian Press. 2009. Torstar's Mercury, Spectator, Record Announce Layoffs. Guelph Mercury, February 23. Accessed March 11, 2015. https://web.archive.org/web/20090413210401/http://news.guelphmercury.com/News/BreakingNews larticle/444110.

CBC News. 2012. Postmedia Cutting Jobs, Sunday Editions. CBC News, May 28. Accessed March 6 , 2015. http://www.cbc.ca/news/business/postmedia-cutting-jobs-sunday-editions-1.1153950.

CEP (Communications, Energy and Paperworkers Union of Canada). 2000. PrintCEPles: Newsletter of CEP Local 191: Media Union of Manitoba and Northwest Ontario, September, 1 (3). Accessed March 23, 2015.

http://web.archive.org/web/20030622061850/http://www.cep191.ca/newsletters/2000_September.p df.

CEP. 2001. Maclean's Magazine Collective Agreement: January 1, 2001-December 31, 2003. Accessed March 18, 2015. https://web.archive.org/web/20050515104240/http://song.on.ca/macleans0103.pdf.

CEP. 2002a. The Globe and Mail Collective Agreement: July 1, 2002-June 30, 2005. Accessed March 23, 2015. http://web.archive.org/web/20050111122615/.

CEP. 2002b. The Guelph Mercury Collective Agreement: May 24, 2002-May 23, 2005. Accessed March 18, 2015. https://web.archive.org/web/20050515105704/http://song.on.ca/guelph0205.pdf.

CEP. 2003a. The Kitchener-Waterloo Region Record Collective Agreement: January 1, 1999December 31, 2003. Accessed March 18, 2015. https://web.archive.org/web/20030811135607/http://www.song.on.ca/PDF/kw_edit_99.pdf.

CEP. 2003b. Mercury Newsroom Gets Deal: Chain-Wide Support Gives Boost. SONG Sheet, June. Accessed March 18, 2015. https://web.archive.org/web/20040309115348/http://www.song.on.ca/songsheet june03.html.

CEP. 2007a. The London Free Press Collective Agreement: January 1, 2007-December 31, 2009. Accessed March 22, 2015.

http://www.unifor87m.org/sites/default/files/bargaining\%20Contract/LFPFinalAgreementPrinting.pdf.

CEP. 2007b. Maclean's Magazine Collective Agreement: January 1, 2007-December 31, 2009. Accessed March 18, 2015. 
https://web.archive.org/web/20111207234630/http://song.on.ca/files/MacleansCA-Jan12007Dec312009 000.pdf.

CEP. 2007c. The Ottawa Sun Collective Agreement: January 1, 2007-December 31, 2010. Accessed March 20, 2015.

http://www.unifor87m.org/sites/default/files/bargaining\%20Contract/OttawaSunJan12007Dec312010.pdf.

CEP. 2007d. Pacific Newspaper Group Collective Agreement. Accessed March 12, 2015. http://mediaunion.ca/wordpress/wp-content/uploads/2014/06/PNG-Part-A-Granville-Square.pdf.

CEP. 2008a. The Toronto Sun Collective Agreement: January 1, 2008-December 31, 2010. Accessed March 20, 2015. http://www.unifor87m.org/sites/default/files/bargaining\%20Contract/SunEdit20082010CARev.pdf.

CEP. 2008b. The Winnipeg Free Press Inside Workers Collective Agreement: October 1, 2008-June 30, 2013. Accessed March 23, 2015.

http://web.archive.org/web/20110912030659/http://www.cep191.ca/files/CA\%20\%20FP\%20Inside\%20Workers\%2008-13.pdf.

CEP. 2009. The Globe and Mail Editorial, Advertising, Circulation \& Maintenance Collective Agreement: July 1, 2009-June 30, 2014. Accessed March 12, 2015. http://www.unifor87m.org/sites/default/files/bargaining\%20Contract/652201 CEP GlobeAndMail 02.pdf.

CEP. 2011a. The Guelph Mercury Collective Agreement: May 24, 2011 to May 23, 2014. Accessed March 12, 2015. http://www.unifor87m.org/sites/default/files/bargaining\%20Contract/Guelph\%20MercuryCOLLECTIVE\%20AGREEMENT\%202011-2014\%20FINAL\%5B1\%5D.pdf.

CEP 2011b. Maclean's Magazine Editorial Collective Agreement: January 1, 2010-December 31, 2013. Accessed March 12, 2015.

http://www.unifor87m.org/sites/default/files/bargaining\%20Contract/Macleans\%20Editorial\%202010 -2013\%20Print\%20Ready.pdf.

CEP. 2011c. The Ottawa Sun Collective Agreement: January 1, 2011-December 31, 2013. Accessed March 12, 2015

http://www.unifor87m.org/sites/default/files/bargaining\%20Contract/Ottawa\%20Sun\%20CBA\%20Ja n\%201\%202011-\%20Dec\%2031\%202013 doc.pdf.

CEP. 2011d. The Toronto Sun Editorial and PrePress Collective Agreement: January 1, 2011December 31, 2013. Accessed March 12, 2015. http://www.unifor87m.org/sites/default/files/bargaining\%20Contract/Sun\%20Agreement\%20\%20Jan\%201-11\%20-\%20Dec\%2031\%20-\%2013.pdf.

CEP. 2011e. The Waterloo Region Record Editorial Collective Agreement: January 1, 2011-December 31, 2014. Accessed March 12, 2015.

http://www.unifor87m.org/sites/default/files/bargaining\%20Contract/WRREdit\%20CA\%20Final\%20Dec\%202012.pdf.

CEP. 2013a. Toronto Star Edition: News from the Star and Our Industry. SONG Sheet, May 21. Accessed March 4, 2015.

https://web.archive.org/web/20131021055333/http://www.song.on.ca/files/SONG\%20Sheet\%20Ma y\%2021\%281\%29.pdf.

CEP. 2013b. The London Free Press Editorial Collective Agreement: January 1, 2013-December 31, 2016. Accessed March 22, 2015. http://www.unifor87m.org/sites/default/files/LFP-EDITORIALAgreement-2013-READY\%20FOR\%20PRINT.pdf.

CEP. 2013c. The Toronto Star Newspapers Ltd. Collective Agreement: January 1, 2013-December 31, 2016. Accessed March 20, 2015. http://www.unifor87m.org/sites/default/files/Toronto\%20StarCollective\%20Agreement-January\%201\%2C\%202013\%20\%20December\%2031\%2C\%202016 0.pdf.

CEP. 2013d. The Winnipeg Free Press Inside Workers Collective Agreement: July 1, 2013-June 30, 2018. Accessed March 20, 2015. http://cep191.ca/wp-content/uploads/2012/10/WFP-CEP-July-12013-to-June-30-2018-Collective-Agreements.zip.

CMCRP (Canadian Media Concentration Research Project). 2013. Newspapers and Magazines. Accessed March 1, 2015. http://www.cmcrp.org/wp-content/uploads/2014/11/Pres-and-Mags-Eng2013.xlsx.

CMCRP. 2014. The Growth of Network Media Economy in Canada, 1984-2013. Accessed March 9, 2015. http://www.cmcrp.org/2014/11/20/the-growth-of-the-network-media-economy-in-canada1984-2013/. 
CMG (Canadian Media Guild). 2013. Preliminary Numbers 2013. Accessed October 25, 2014. http://www.cmg.ca/en/wp-content/uploads/2013/11/Preliminary-numbers-Print-Media-Job-cutsbetween-2008-2013-CMG.pdf.

Cohen, Nicole S. 2011. Negotiating Writers' Rights: Freelance Cultural Labour and the Challenge of Organizing. Just Labour: A Canadian Journal of Work and Society 17-18: 119-138.

Cohen, Nicole S. 2012. Cultural Work as a Site of Struggle: Freelancers and Exploitation. tripleC: Cognition, Communication, Cooperation 10 (2): 141-155. Accessed August 17, 2015. http://www.triple-c.at/index.php/tripleC/article/view/384.

Cohen, Nicole and Greig de Peuter. 2013. The Politics of Precarity: Can the Urban Worker Strategy Address Precarious Employment for All? Briarpatch, November 1. Accessed March 22, 2015. http://briarpatchmagazine.com/articles/view/urban-worker-strategy-andrew-cash.

CWA (Communications Workers of America) Canada. 2015. About Us. Accessed March 20, 2015. http://www.cwa-scacanada.ca/EN/menu/about us.shtml.

Davis, Charles. 2013. The Exploited Laborers of the Liberal Media. VICE, December 2. Accessed March 6, 2015. http://www.vice.com/read/the-exploited-laborers-of-the-liberal-media.

de Peuter, Greig. 2014a. Beyond the Model Worker: Surveying a Creative Precariat. Culture Unbound: Journal of Current Cultural Research 6: 263-284.

de Peuter, Greig. 2014b. Confronting Precarity in the Warhol Economy. Journal of Cultural Economy 7 (1): 31-47.

de Peuter, Greig, Nicole Cohen and Enda Brophy. 2012. Interns Unite! (You Have Nothing to LoseLiterally). Briarpatch, November 9. Accessed March 22, 2015. http://briarpatchmagazine.com/articles/view/interns-unite-you-have-nothing-to-lose-literally.

Denning, Michael. 2010. The Cultural Front: The Laboring of American Culture in the Twentieth Century. New York: Verso.

Deuze, Mark. 2007. Media Work. Malden: Polity Press.

Deuze, Mark and Timothy Marjoribanks. 2009. Newswork. Journalism 10 (5): 555-561.

DJNF (Dow Jones News Fund). 2015. History of the Fund. Accessed June 25, 2015. https://www.newsfund.org/PageText/AD HomePages.aspx?Page ID=AD HistoryOfFund.

Dobby, Christine and Canadian Press. 2013. Sun Media to Cut 360 jobs and Close 11 of its Newspapers, Including Three Free Urban Dailies. Financial Post, July 16. Accessed March 6, 2015. http://business.financialpost.com/2013/07/16/sun-media-job-cuts-closing/? Isa=1110-bc46.

Doorey, David. 2013. Doorey's Law of Work Blog: A Discussion of Issues and Debates for Students and Others. Accessed March 22, 2015. http://lawofwork.ca/.

Dorsey, James E. 1977. Industrial Relations Officers of the British Columbia Department of Labour. The Advocate 35: 381-404.

Edge, Marc. 2014. Greatly Exaggerated: The Myth of the Death of Newspapers. Vancouver: New Star Books.

ELLE Canada. 2011. ELLE Canada Editorial Internships. Accessed March 22, 2015. http://www.ellecanada.com/elle-canada-print-editorial-internships/a/47166\#.U3Lia6xgKnw.

Employment Standards Act, RSBC 1990, c 113.

Employment Standards Act, SO 2000, c 41.

Employment Standards Code, CCSM 1998, c E110.

Employment Standards Code, RSA 2000, c E-9.

Flare. 2014. Job and Internship Opportunities. Accessed March 4, 2015. http://www.flare.com/about/job-and-internship-opportunities/.

Fletcher, Jr., Bill and Fernando Gapasin. 2008. Solidarity Divided: The Crisis in Organized Labor and a New Path Toward Social Justice. Berkeley: University of California Press.

Foley, Janice R. and Patricia L. Baker, eds. 2009. Unions, Equity, and the Path to Renewal. Vancouver: UBC Press.

FP Newspapers. 2013. 2013 Annual Report: FP Newspapers Inc. Accessed March 2, 2015. http://www.fpnewspapers.com/investor-centre/annual-reports/annualrpt2013.pdf.

Fudge, Judy and Eric Tucker. 2001. Recognition and Responsibility: The Achievement of Industrial Pluralism, 1943-1948. In Labour Before the Law: The Regulation of Workers' Collective Action in Canada, 1900-1948, 263-301. Toronto: Oxford University Press Canada.

Galarneau, Diane, René Morissette and Jeannine Usalcas. 2013. What Has Changed for Young People in Canada? Catalogue no. 75-006-X. Ottawa: Statistics Canada. Accessed March 22, 2015. http://www.statcan.gc.ca/pub/75-006-x/2013001/article/11847-eng.pdf. 
Galarneau, Diane and Thao Sohn. 2013. Long-Term Trends in Unionization. Catalogue no. 75-006-X. Ottawa: Statistics Canada. Accessed March 16, 2015. http://www.statcan.gc.ca/pub/75-006x/2013001/article/11878-eng.pdf.

Gall, Gregor. 1997. The Changing Relations of Production: Union Derecognition in the UK Magazine Industry. Industrial Relations Journal 29 (2): 151-161.

Gaulin, Jeff. 2015. Multimedia Journalists - Summer Intern: Toronto Sun. Accessed June 25, 2015. https://web.archive.org/web/20150411073435/http://jeffgaulin.com/jobs/JobDetails.asp?id=19122.

Gill, Rosalind and Andy Pratt. 2008. In the Social Factory?: Immaterial Labour, Precariousness and Cultural Work. Theory, Culture \& Society 25 (7-8): 1-30.

Glacier Media. 2013. 2013 Glacier Annual Report. Accessed March 3, 2015. http://www.glaciermedia.ca/sites/gmg.tidaldevel.com/files/news/2013\%20Glacier\%20Annual\%20Re port.pdf.

Gollmitzer, Mirjam. 2014. Precariously Employed Watchdogs? Perceptions of Working Conditions among Freelancers and Interns. Journalism Practice 8 (6): 826-841.

Gould, Mark. 1981. The Devaluation of Labor-Power. Berkeley Journal of Sociology 26: 139-155.

Haddrall, Lynn. 2011. Four New Interns Will Be Combing Our Region for News. The Record, May 21. Accessed March 12, 2015. http://www.therecord.com/opinion-story/2580297-four-new-interns-willbe-combing-our-region-for-news/.

Haddrall, Lynn. 2012. Interns Bring Fresh Perspective to Local Coverage. The Record, May 26. Accessed March 12, 2015. http://www.therecord.com/opinion-story/2603243-interns-bring-freshperspective-to-local-coverage/.

Haddrall, Lynn. 2013. Record's Summer Students Will Be Flying High. The Record, May 18. Accessed March 12, 2015. http://www.therecord.com/opinion-story/3243227-record-s-summer-students-willbe-flying-high/.

Hardt, Michael and Antonio Negri. 2009. Commonwealth. Cambridge: Harvard University Press.

Head, Simon. 2003. The New Ruthless Economy: Work \& Power in the Digital Age. New York: Oxford University Press.

Hesmondhalgh, David. 2010. User-Generated Content, Free Labour and the Cultural Industries. Ephemera: Theory \& Politics in Organization 10 (3-4): 267-284.

Hesmondhalgh, David and Sarah Baker. 2011. Creative Labour: Media Work in Three Cultural Industries. New York: Routledge.

Houpt, Simon. 2014. Unpaid Internships at Magazines New Target of Ontario Labour Ministry. The Globe and Mail, March 27. Accessed March 22, 2015. http://www.theglobeandmail.com/arts/booksand-media/unpaid-internships-at-magazines-new-target-of-ontario-labourministry/article17694055/.

Huws, Ursula. 2014. Labor in the Global Digital Economy: The Cybertariat Comes of Age. New York: Monthly Review Press.

Internship, The: Generation i. 2014. The Economist, September 6. Accessed March 20, 2015. http://www.economist.com/news/international/21615612-temporary-unregulated-and-often-unpaidinternship-has-become-route.

Jay, Paul. 1995. All Work, No Pay. Ryerson Review of Journalism, Spring. Accessed February 25, 2015. http://www.journalism.ryerson.ca/m6047/.

Kumar, Pradeep and Christopher Schenk, eds. 2006. Paths to Union Renewal: Canadian Experiences. Peterborough: Broadview Press.

Ladurantaye, Steve. 2013. Toronto Star Union Says Paper is Looking to Outsource Radio Room Program. The Globe and Mail, March 4. Accessed March 4, 2015.

http://www.theglobeandmail.com/globe-investor/toronto-star-union-says-paper-is-looking-tooutsource-radio-room-program/article9284111/.

Laidlaw, Stuart. 2013. Star Bulletin: CEP Local 87-M, SONG. Accessed March 4, 2015. http://www.unifor87m.org/sites/default/files/bargaining\%20Contract/Radio\%20Room.pdf.

Langille, Andrew. 2014. Youth and Work: A Website about Youths, Workplace Law, Economics, Labour Markets, Education, \& Public Policy. Accessed March 22, 2015. http://www.youthandwork.ca/

LCO (Law Commission of Ontario). 2012. Vulnerable Workers and Precarious Work: Final Report. Accessed March 22, 2015. www.lco-cdo.org/en/vulnerable-workers-final-report.

Leab, Daniel J. 1970. A Union of Individuals: The Formation of the American Newspaper Guild, 19331936. New York: Columbia University Press. 
Learn, Joshua Rapp. 2013. Internship Opportunities Shrinking Across the Country. J-Source, May 1. Accessed March 20, 2015. http://j-source.ca/article/student-internship-opportunities-shrinkingacross-country.

Lee, Jenny. 2014. Newspapers Healthy Despite Kamloops Daily News Closure, Industry Spokesman Says. The Vancouver Sun, January 6. Accessed March 6, 2015. http://www.vancouversun.com/news/Newspapers+healthy+despite+Kamloops+Daily+News+closur e+industry+spokesman+says/9355158/story.html.

Logan, Edgar. 1965. Journalism: A Wide Open Field. The English Journal 54 (7): 623-625.

Lord, Titus. 1950. Unionism in Journalism. The Canadian Forum 30 (352): 25-29.

Lorey, Isabell. 2010. Becoming Common: Precarization as Political Constituting. e-flux 17. Accessed March 6, 2015. http://www.e-flux.com/journal/becoming-common-precarization-as-politicalconstituting/.

Maclean's. 2009. Internship Information. Accessed March 18, 2015. https://web.archive.org/web/20090415212412/.

Maclean's. 2014. Internship Information. Accessed March 20, 2015. http://www.macleans.ca/internship-information/

Madison, Eddie. 2014. Training Digital Age Journalists: Blurring the Distinction between Students and Professionals. Journalism \& Mass Communication Educator 69 (3): 314-324.

McKercher, Catherine. 2002. Newsworkers Unite: Labor, Convergence, and North American Newspapers. Lanham: Rowman \& Littlefield.

McKercher, Catherine. 2014. Precarious Times, Precarious Work: A Feminist Political Economy of Freelance Journalists in Canada and the United States. In Critique, Social Media and the Information Society, edited by Christian Fuchs and Marisol Sandoval, 219-230. New York: Routledge.

McKnight, Zoe. 2014. Unpaid Interns Dropped from Rogers-Owned Magazines. Toronto Star, April 3. Accessed March 3, 2015. http://www.thestar.com/news/gta/2014/04/03/unpaid interns dropped from rogersowned magazi nes.html.

Mercer, Katie. 2012. The Province is Hiring Summer Interns. The Province, October 25. Accessed March 12, 2015. http://blogs.theprovince.com/2012/10/25/the-province-is-hiring-summer-interns-2/.

Milkman, Ruth and Ed Ott, eds. 2014. New Labor in New York: Precarious Workers and the Future of the Labor Movement. Ithaca: ILR Press.

Mosco, Vincent and Catherine McKercher. 2008. The Laboring of Communication: Will Knowledge Workers of the World Unite? Lanham: Lexington Books.

Newspapers Canada. 2015. Circulation Report: Daily Newspapers 2014. Accessed June 22, 2015. http://www.newspaperscanada.ca/sites/default/files/2014_Circulation_ReportDaily Newspapers in Canada_FINAL 20150603 0.pdf.

OLRB (Ontario Labour Relations Board). 2013. About Us. Accessed June 25, 2015. http://www.olrb.gov.on.ca/english/aboutus.htm.

ONG (The Ottawa Newspaper Guild). 2013. Ottawa Citizen Contract, November 2013-November 2015. Accessed March 22, 2015. http://ottawanewsguild.ca/website/wpcontent/uploads/2009/07/Final-Nov-2013-Nov-2015-ONG-Ottawa-Citizen-Contract.doc.

Örnebring, Henrik. 2010. Technology and Journalism-as-Labour: Historical Perspectives. Journalism 11 (1): 57-74.

Paulussen, Steve. 2012. Technology and the Transformation of News Work: Are Labor Conditions in (Online) Journalism Changing? In The Handbook of Global Online Journalism, edited by Eugenia Siapera and Andreas Veglis, 192-208. Malden: Wiley-Blackwell.

Perlin, Ross. 2012. Intern Nation: How to Earn Nothing and Learn Little in the Brave New Economy. New York: Verso.

Postmedia. 2013. Postmedia Annual Report 2013. Accessed March 12, 2015. http://www.postmedia.com/wp-content/uploads/2013/11/2013-Annual-Report.pdf.

Quebecor Media. 2014. Quebecor Media 20-F 2013. Accessed March 2, 2015. http://www.quebecor.com/sites/default/files/QMI-20F-2013.pdf.

Ray, Regan. 2009. Layoffs at 3 TorStar Papers. J-Source, February 24. Accessed March 11, 2015. http://www.projetj.info/article/layoffs-3-torstar-papers.

Renzetti, Elizabeth. 1998. News Media Divided Over Unpaid Internships. The Globe and Mail, March 12, C1.

Rogers Communications. 2014. 2013 Annual Report. Accessed March 12, 2015. http://www.rogers.com/cms/investors/pdf/annual-reports/2013 Annual-Report.pdf. 
Salcetti, Marianne. 1995. The Emergence of the Reporter: Mechanization and the Devaluation of Editorial Workers. In Newsworkers: Toward a History of the Rank and File, edited by Hanno Hardt and Bonnie Brennen, 48-74. Minneapolis: University of Minnesota Press.

Scratch, Emma. 2004. Internships: The Good, the Bad, and the Ugly. Ryerson Review of Journalism, March. Accessed March 22, 2015. http://rrj.ca/internships-the-good-the-bad-and-the-ugly/

Skelton, Chad. 2013. No Fewer Journalists Today than 10 Years Ago: Statistics Canada. Vancouver Sun, August 19. Accessed March 22, 2015. http://blogs.vancouversun.com/2013/08/19/no-fewerjournalists-today-than-10-years-ago-statistics-canada/.

Skinner, David, James R. Compton and Mike Gasher. 2005. Mapping the Threads. In Converging Media, Diverging Politics: A Political Economy of News Media in the United States and Canada, edited by David Skinner, James R. Compton and Mike Gasher, 7-23. Lanham: Lexington Books.

Solomon, William S. 1995. The Site of Newsroom Labor: The Division of Editorial Practices. In Newsworkers: Toward a History of the Rank and File, edited by Hanno Hardt and Bonnie Brennen, 110134. Minneapolis: University of Minnesota Press.

Standing, Guy. 2011. The Precariat: The New Dangerous Class. London: Bloomsbury Academic.

Statistics Canada. 2013. Table 2: Low Income Cut-offs (1992 Base) Before Tax. Accessed March 22, 2015. http://www.statcan.gc.ca/pub/75f0002m/2013002/tbl/tb/02-eng.htm.

Stead, Sylvia. 2013. Public Editor: How Do Internships Work at The Globe? Find Out Here. The Globe and Mail, May 3. Accessed March 22, 2015. http://www.theglobeandmail.com/community/insidethe-globe/public-editor-how-do-internships-work-at-the-globe-find-out-here/article11704803/.

Stewart, Andrew and Rosemary Owens. 2013. Experience or Exploitation?: The Nature, Prevalence and Regulation of Unpaid Work Experience, Internships and Trial Periods in Australia. The University of Adelaide. Accessed March 22, 2015. http://www.fairwork.gov.au/Publications/Research/UWcomplete-report.pdf.

Stone, Felicity. 1999. Chasing the News beyond Ryerson. The Toronto Star, November 25, H8.

Tant, Lisa. 2010. An Honest Look at Internships. Flare, April 12. http://www.flare.com/fashion/anhonest-look-at-internships/.

Tatelman, Sara. 2015. Unpaid News: Are J-Schools Teaching Young Journalists to Work for Free? Briarpatch, February 23. Accessed March 6, 2015. http://briarpatchmagazine.com/articles/view/unpaid-news.

TC Transcontinental. 2013. 2013 TC Transcontinental Annual Report. Accessed March 12, 2015. http://tctranscontinental.com/documents/10180/37760/2013 Annual Report.pdf.

Thornton, Leslie-Jean. 2011. The Changing Role of Internships as Newsrooms Shrink and Evolve: Collaboration and Intern-as-Teacher. In Journalism Education, Training and Employment, edited by Bob Franklin and Donica Mensing, 130-142. New York: Routledge.

Toronto Life. 2014. Toronto Life Internship Program. Accessed June 25, 2015. https://web.archive.org/web/20140215084303/http://www.torontolife.com/internships/.

Toronto Life. 2015. Internships. Accessed June 25, 2015. http://www.torontolife.com/internships/.

Toronto Star. 2014. Star Internships. Accessed March 4, 2015. http://www.thestar.com/about/starinternships.html.

Toronto Star. 2015. Note to Readers: Star to End Paid Digital Subscriptions on April 1. Accessed June 22, 2015. http://www.thestar.com/news/gta/2015/03/07/note-to-readers-star-to-end-paid-digitalsubscriptions-on-april-1.html.

Torstar. 2013. Torstar 2013 Annual Report. Accessed March 2, 2015. http://www.torstar.com/images/file/2013/2013AnnualReport.pdf

Unifor87-M. 2013. Our History. Accessed March 20, 2015. http://www.unifor87m.org/our-history.

Ursell, Gillian. 2000. Television Production: Issues of Exploitation, Commodification and Subjectivity in UK Television Labour Markets. Media, Culture \& Society 22 (6): 805-825.

Ursell, Gillian. 2003. Creating Value and Valuing Creation in Contemporary UK Television: Or 'Dumbing Down' the Workforce. Journalism Studies 4 (1): 31-46.

Valpy, Michael. 1968. Black and White, and Yellow and Grey. The Globe and Mail, January 27, A6.

VVING (Victoria-Vancouver Island Newspaper Guild). 2011. Victoria Times-Colonist Memorandum of Agreement, January 2, 2011-January 1, 2015. Accessed March 1, 2015. http://vving.ca/wpcontent/uploads/2013/09/CWAContract_final.pdf.

Winnipeg Free Press. 2014. Internships at the Free Press. Accessed March 22, 2015. http://www.winnipegfreepress.com/internships.html.

Winseck, Dwayne. 2010. Financialization and the 'Crisis of the Media': The Rise and Fall of (Some) Media Conglomerates in Canada. Canadian Journal of Communication 35 (3): 365-393. 
Winseck, Dwayne. 2011. Part I: The Growth of the Network Media Economy. The Globe and Mail, August 23. Accessed March 23, 2015. http://www.theglobeandmail.com/technology/digitalculture/part-i-the-growth-of-the-network-media-economy-1984-2010/article626447/.

Wright, Erik Olin. 1997. Class Counts: Comparative Studies in Class Analysis. Cambridge: Cambridge University Press.

Zerker, Sally. 1975. George Brown and the Printers' Union. Journal of Canadian Studies 10: 42-48.

Zerker, Sally. 1982. The Rise and Fall of the Toronto Typographical Union, 1832-1972: A Case Study of Foreign Domination. Toronto: University of Toronto Press.

\section{About the Author}

Errol Salamon

Errol Salamon is a PhD candidate in communication studies at McGill University. He researches in the areas of critical political economy and communication history, especially as they intersect with creative work and labour, journalism, media policy, activism, alternative media, and digital technologies. He is co-editor and contributor to the forthcoming book Journalism in Crisis: Bridging Theory and Practice for Democratic Media Strategies in Canada (University of Toronto Press). 


\title{
Internships, Workfare, and the Cultural Industries: A British Perspective
}

\section{David Lee}

\author{
University of Leeds, Leeds, UK, d.j.lee@leeds.ac.uk
}

\begin{abstract}
While media work has long been characterized as being structurally dependent on internships, "work experience," and other forms of free labour (Banks 2007; Hesmondhalgh and Baker 2010), the recent shift towards internships has served to normalize what has become known as the media industries "dirty little secret" (Silver 2005). This article contextualizes internship culture within the British cultural industries against a wider political and social frame. Internships and other modes of "apprenticeship" across the British economy reflect a continuation and transformation of national workfare policies, which seek to avert inflationary pressures by coercing people to work or risk losing their welfare benefits. Internship culture has been highly pronounced in the cultural industries and other attractive white-collar sectors such as law and finance (Perlin 2012). Yet, the provision of internships to young people in previously unimaginable contexts such as fast food, retail, and other low-pay service sectors represents a significant shift in policy, compounded by increasingly draconian demands on young people to comply in order to receive state benefits. Discursively, unpaid media work is now seen as an opportunity for the lucky few, rather than a mode of exploitation servicing corporate gain. This has particular relevance for battles over equality and exploitation which have been fought in these sectors, which this discursive shift makes appear increasingly archaic.
\end{abstract}

Keywords: internships, workfare, precarity, cultural industries, neoliberalism, inequality

\section{Introduction}

Over the last ten years, reference to internships has become a familiar refrain in debates around labour in the cultural industries and other professional fields, such as law, accounting, management consultancy, and so forth. These areas are often destination fields for graduates seeking paid labour after many years accumulating debt in an increasingly expensive higher education market (Crawford and Jin 2014). If the "new precariat" is the major emerging class within post-industrial capitalist society (Standing 2011a), then the "intern" has become a poster child for this class, conjuring up images of endless unpaid episodic labour, with the "carrot" of paid, gainful, and, potentially, "creative" work dangled as an elusive reward at the end of it.

This article critically positions the internship phenomenon within a broader politicaleconomic context by considering how this form of labour exploitation fits in with structurally embedded shifts within contemporary modalities of neoliberalism. In particular, it seeks to understand internship labour in relation to established and deepening models of workfarism (Jessop 1995) within advanced liberal economies, as governments seek increasingly punitive and coercive ways to deal with the growing welfare "crisis." As Joanna Figiel argues, we can understand workfarism as the "stick" to the internship "carrot" (2013), yet it is increasingly important to think through the connection between the two in more detail. Are they polar opposites? Is workfarism largely focused on the long-term unemployed, who are recipients of state support? And are internships largely designed for highly educated graduates seeking to enter the professional classes? Or, as "internships" are now "offered" for relatively low-skill, low-pay employment in retail and other segments of the service sector, is the discourse of internships serving to entrench workfarism socially and economically? Does the discursive and political shift away from welfare and towards workfare since the 1970s, particularly in the US and UK, underpin wider changes to labour with a broader acceptance of working for no pay? 
This article provides a synthesis of the political, economic, and social history behind the rise of internships within a new phase of neoliberalism, and the implications of this transformation for the cultural industries. The discursive terrain of the battle against internships has changed, and as it becomes the norm, unpaid media work is seen as an opportunity for the lucky few, rather than a mode of exploitation servicing corporate gain. This has particular relevance for battles over equality and exploitation which have been fought in these sectors, and which this discursive shift makes appear increasingly archaic. The focus of this article is largely on the UK experience, with some discussion of international developments.

\section{From Work Experience to Internships}

Back in the late 1990s, when I left university to seek employment in the television industry in London, the term internship was relatively unknown, and was largely isolated to America, where it had been in circulation since the 1980s (Spradlin 2009). If the term was used in the UK, it "denoted a structured period of experience with a guaranteed stipend" (Winter 2011). At the time, "work experience" was the dominant term for those seeking to enter the highly competitive fields of the creative industries, and this discourse formed the terrain for some key labour conflicts in the 1990s and the early 2000s. "Work experience" was often exploitative, taking advantage of the oversupply of labourers seeking careers in the creative industries; however, there was a shared understanding of what the term meant, and some concessions to workers' rights were made during this period.

In television production, for example, a number of more ethically minded independent production companies had signed up to the voluntary Broadcasting, Entertainment, Cinematograph and Theatre Union (BECTU) agreement that work experience must not last for more than four weeks, and should ideally be paid at the National Minimum Wage; this advice has been adopted far more widely in the television industry since 2007 (BECTU 2009). ${ }^{1}$ When the influential Television Workers' Rights Advocacy Petition (TVWRAP) campaign took shape in the early 2000s and sought to challenge the harsh and exploitative working conditions for young entrants to the television sector in the UK (Saundry et al. 2006, 2007), unpaid "work experience," which often extended over months and even years, was identified as one of the key obstacles to a more equitable creative labour market. TVWRAP actively campaigned against the exploitation and bullying of junior television workers, making use of anonymous testimonies to expose a widespread culture of abuse of workers in the sector. It mounted a successful petition against these conditions and also ran a highly effective media campaign, with a number of stories appearing in the national and industry press during 2004$5 .^{2}$

Since this time, "work experience" has largely disappeared from the lexicon of human resources, replaced with the seemingly more progressive, innocuous term, internship, with its connotations of opportunity, learning, and, crucially, progression.

The term internship first referred to a period of training in the medical profession, and was gradually appropriated by the spheres of politics and business during the 20th century. As Ross Perlin (2012) notes, what had been a preserve for high-prestige graduate recruitment into classic white-collar occupations such as law and finance quickly became far more prevalent during the 1990s, as labour market deregulation and the decline of union membership meant that increasing numbers of companies were seeking competitive economic advantage through the internship route. Most notable during this period is the rise of internships offered in the relatively lower paid, but highly desirable, fields of the cultural industries, in particular, film, broadcasting, and journalism (ibid.). The extent to which internships have become routine is evident in figures published in the 2010 Job Outlook Survey by the National Associa-

\footnotetext{
${ }^{1}$ BECTU is the British trade union for broadcasting, entertainment, and theatre workers. It currently has around 25,000 members.

${ }^{2}$ See www.tvfreelancers.org.uk for full details of the campaign. This was the first internet campaign in British broadcasting history for better working conditions for television production staff, and it received significant coverage in The Guardian and Broadcast. Notably, the campaign was without union involvement, and shows the potential for networks as a means of campaigning. See Saundry et al. (2007) for a full discussion of this campaign, and the implications for trade unions in the audio-visual industries.
} 
tion of Colleges and Employers, which reported that "75 percent of employers prefer job candidates with relevant work experience [and $\mathrm{m}$ ]ore than 90 percent prefer to hire interns or coops who have worked for their organization" (Aoun 2010).

In the UK, the discourse of the internship gained public prominence when the Panel on Fair Access to the Professions, led by Member of Parliament Alan Milburn, reported on the challenges facing social mobility in the UK, and attention turned to the growing number of internships for young graduates, particularly in the high profile fields of media, politics, and law (Cabinet Office 2012). The panel's report provided much needed empirical data on the prevalence of internships in "white-collar" work and argued that these informal arrangements are a key barrier to social mobility, as they exclude potential entrants to professional fields unable or unwilling to take on unpaid work, or lacking the contacts necessary to secure the opportunity of an internship (as well as those without somewhere to live for free within proximity to London while undertaking an internship). The report, and associated debates about "social mobility," elevated the issue of internships to the public and media spotlight, and stories in the national press exposing the conditions of internships became a staple for some months (Prince 2011; Malik 2012). Despite the rich irony of politicians berating the inequity of internships, whilst having benefited from similar arrangements themselves (Prince 2011), the discussion merely reflected what had by then already become a key political-economic reality for many graduates seeking paid employment. However, a number of activist interventions were made, in particular the creation of campaign groups such as Intern Aware and Interns Anonymous (the latter is now defunct, but provided many first-hand accounts of exploitative internships in the UK) and renewed focus was given to the inequities of a culture where the most prestigious jobs demanded extensive unpaid work, and were often facilitated by shared personal and social networks (Lee 2011).

Despite highly vocal campaigns such as Interns Anonymous, Internocracy, Interns Aware, and the Carrotworkers' Collective, internship culture now appears to be embedded within contemporary labour markets. And internships are increasingly being "offered" beyond socalled "white-collar" or "no-collar" work (Ross 2004) in the low-pay service economy, to young people who risk losing their benefits if they refuse the "offer" of work (Malik 2011). ${ }^{3}$ This recent shift of the discourse of internships into the low-pay service economy is significant, indicating not only how the concept of the internship has become normalized within the economy, but also reflecting a mutation in the meaning of the term internship when they are "offered" to individuals in the context of a threat to their social security benefits if they are not accepted. Here, the hitherto voluntary nature of the internship begins to shift to the involuntary arrangements of workfare, which I will outline in the next section.

Making links between workfare and internships means recognizing that there are very different types of "precariat," which, as Guy Standing has argued, encompasses a

multitude of insecure people, living bits-and-pieces lives, in and out of short-term jobs, without a narrative of occupational development, including millions of frustrated educated youth who do not like what they see before them, millions of women abused in oppressive labour, growing numbers of criminalised tagged for life, millions being categorised as 'disabled' and migrants in their hundreds of millions around the world. (Standing 2011b, 1)

In particular, Standing argues there are three clearly identified groups within the precariat:

\footnotetext{
${ }^{3}$ For example, the JobBridge scheme in Ireland, jointly funded by the Youth Employment Initiative, the European Social Fund, and the Department of Social Protection, provides "work experience placements for interns" for six to nine months, and is specifically aimed at the unemployed, who receive an allowance of 50 Euros a week on top of their social welfare entitlement (https://www.welfare.ie/en/Pages/JobBridge-Interns.aspx). Similar programmes in the UK "offer" work experience opportunities which are in fact mandatory: if a claimant is advised to participate in schemes such as The Work Experience Scheme or The Work Programme, they must do so or risk losing their Job Seeker's Allowance. For further details, see http://www.adviceguide.org.uk/wales/work_w/work_selfemployed_or_looking_for_work_e/government_employment_schemes.htm.
} 
The first variety consists of those drifting from working-class backgrounds into precariousness, the second consists of those emerging from a schooling system overcredentialised for the flexi-job life on offer, and the third are migrants and others, such as the criminalised, in a status denying them the full rights of citizens. Each has a distinctive view on life and society. (Standing 2012)

While internships have predominantly been on offer to the second variety, those more highly educated, it seems clear that the language of internships is now impacting on workfare discourse, with unpaid "internships" in supermarkets, call centres, and other traditionally lowpay environments being "offered" as a mandatory requirement for benefit claimants. High profile cases include that of Cait Reilly, a 22-year old geology graduate who stacked shelves at Poundland in Birmingham and was led to believe that her jobseeker's allowance would be cut if she refused to do so (Topping 2012). Absurdly, as Sam Hardy (2014) points out, the National Trust recently offered a Cider and Apple Internship, which essentially meant providing manual labour for free. According to the advertisement, "The work pattern can be flexible with days and hours to suit the harvesting programme with a 30 minute break for lunch. Some occasional weekend work will be required" (National Trust 2014). These examples and the many more that are available (Interns Anonymous 2013), indicate not only how the discourses and practices of the internship have become embedded within British economic life, but also how the terrain of internships has now expanded into workfare politics, with the "carrot" dynamic of the internship increasingly coexisting with the "stick" of punitive measures for individuals on social benefits who refuse the "opportunity."

\section{Workfare and Internships}

In seeking to make links between workfare and internships, it is important to note how workfare has developed and become increasingly normalized within the British economy, following its policy transfer from the United States (Jones 1996, Lindsay and Mailand 2004). Internships and other modes of "apprenticeship" across the British economy reflect a continuation and transformation of workfare policies such as Jobseeker's Allowance instituted under the Conservatives in the 1990s, aggressively pursued under New Labour in the UK, influenced by policies set up under Bill Clinton's presidency. While under New Labour this was achieved through the rhetoric of social inclusion (Jessop 2003), under the ConservativeLiberal Democrat coalition, the justification was largely economic, and often highly gendered (MacLeavy 2011). Workfare politics are being implemented in increasingly radical and coercive forms, driving a hegemonic embedding of policies with the economic aim of averting inflationary pressures by coercing people to work under the threat of incrementally losing their social benefits. It is in the cultural industries that the internship culture has been most pronounced, along with other attractive white-collar sectors such as law and finance (Perlin 2012). Yet, policies designed to provide "apprenticeships" to young people in previously unimaginable contexts (such as fast food, retail, and other low pay service sectors) represent a significant shift in policy, compounded by the imposition of increasingly draconian demands on young people to comply in order to receive state benefits (MacLeavy 2011).

Workfare has a number of definitions. An early, and fairly narrow definition, states that workfare is "[a]ny public welfare program that requires welfare recipients to work (work + welfare $=$ workfare) or to enroll in a formal job-training program" (Shafritz 1988, 595, quoted in Peck 1998). But since the mid-1990s, the term is used far more broadly "to include, as a condition of income support, the requirement that recipients participate in a wide variety of activities designed to increase their employment prospects" (Evans 1995, 75). For the purposes of this paper, workfare is defined as schemes with a mandatory obligation to carry out work or "work-related activity" in order to obtain social welfare payment from the state (Hinton 2012).

Workfare was first coined by civil rights leader James Charles Evers in 1968 and was given mass publicity by US President Richard Nixon in a speech in 1969, who placed it within the politics of welfare reform (Peck 1998, 138). It seeks to offer an alternative to traditional social welfare policies, and in its many different guises, internationally, has a common thread 
which involves welfare recipients providing some form of labour for social welfare benefits. As Jamie Peck argues:

The notion of workfare-particularly where it involves mandatory participation in work or in work programmes - runs counter to established norms of public policy such as passive income support, entitlement, and needs-based provision. So conceived, workfare begins to define an alternative philosophical and political base not only for labour market and social policy ... but also for the structure and strategic orientation of the capitalist state itself. (Peck 1998, 134)

Considered this way, workfare is at the heart of neoliberal governance, shifting responsibility and risk from the state to the individual:

The new imperative is to end welfare, not poverty per se, the objective being to correct those individual behavioural dysfunctions-such as moral laxity, inadequate work discipline-which are seen as a cause of poverty but more importantly as a consequence of the welfare system. (ibid., 136)

Under New Labour, workfare programmes were intensified, although they had first been developed during the Thatcher/Major Conservative period of rule which preceded New Labour's victory in 1997. During the New Labour years, such schemes proliferated and intensified through their three terms of office (1997-2010). As Bob Jessop argues, we can distinguish between the "soft" workfare from 1986, with programmes such as Restart, which invited the unemployed to accept job and training opportunities in return for benefits, and "hard" workfare, which began with the Social Security Act 1989, which forces individuals to look for work and also accept private sector jobs in return for welfare (Jessop 2003, 11). The Jobseeker's Allowance scheme in 1994 and Jobseeker's Act of 1995 entrenched these principles and made it increasingly tougher to access benefits. New Labour embraced these schemes, and Blair promised that New Labour would be a "Welfare to Work Government," claiming that the aim was "to bring [the] workless class back into society and into useful work" (Blair 1997). As Jessop has argued, New Labour policy has been to force the unemployed into the labour market, often into low-wage jobs; as such,

unemployment is no longer seen in terms of a shortage of jobs and hence of a need to manage aggregate demand in order to secure full employment but is interpreted instead in workfarist terms as the product of a shortfall in job-readiness that is reflected in a lack of full employability. (Jessop 2003, 13)

Since the Coalition Government took over from New Labour in 2010, we have seen an even harder line taken in regard to workfare, which is justified through rhetoric around austerity and the stated aim to reduce public spending. Considerable welfare reforms took place on the Coalition's entry into power, culminating in the Welfare Reform Act 2012. In 2011, the number of benefit sanctions imposed upon welfare claimants more than tripled in comparison to 2009 , from 139,000 to 508,000 (Corporate Watch 2012). Ultimately, sanctions arising from a perceived infringement of the terms of an individual's benefit claim, if approved by the Department of Work and Pensions, will lead to the claimant's benefits being stopped. Increasingly, workfare programmes are being contracted out to private providers, and the number of programmes is increasing, with two schemes being compulsory if the claimant is to keep their benefits: the Mandatory Work Activity and Community Action Programme. These programmes have been sharply criticized by journalists on the left as "slave labour" (Toynbee 2012), and as pandering to corporate greed (Clark 2012). And all of this has happened during a period of intensifying class hatred, specifically towards the working class, which has been fuelled by the media and government (Jones 2012).

Of course, there are significant differences between internships and workfare programmes which are aimed at forcing the long-term unemployed to work for no pay, with the threat of a complete withdrawal of their social benefits if they refuse (see Void 2013 for a discussion of 
the differences and similarities). Both are "voluntary," though naturally there is a huge difference between the implications of refusing an internship and refusing to participate in a workfare programme: with the former, the subtext of refusal will be the implicit message that in order to succeed in a knowledge-based economy the internship is a structural requirement, whereas with the latter, the threat is that of the loss of the essential means for subsistence. Still, the parallels are clear: no pay (the normalization of working for nothing), coercion through the discursive threat of failure and material need, and the ongoing, Sisyphean nature of both activities, which function on the basis of the promise of paid employment in the future. Furthermore, as the examples above show, "internships" are becoming part of the language of workfare programmes, alongside the discourse of the "apprentice" (Couldry and Littler 2008).

Paid work seems to be further and further out of reach for interns and for apprentices taking part in workfare schemes. For example, in its expansion of workfare programmes, the UK coalition government offered zero-pay "traineeships" to individuals in order for them to be eligible to gain the opportunity of receiving a place on an unpaid apprenticeship scheme (ibid.). At both the material and discursive level, there is a growing integration of workfare and internships: the unpaid internship as an increasingly prerequisite mandate for those seeking paid employment in the professions and the workfare contract as a mandate for subsistence for those on welfare benefits. Yet the two are often treated separately, particularly by parts of the British political class who have been quick to condemn unpaid internships, but have been actively involved in the development and promotion of workfare programmes for the unemployed (Blears 2013). Underlying this is a deep-seated class hypocrisy, whereby unpaid work for the (largely) middle classes is seen as unacceptable, but perfectly acceptable for those at the more deprived axes of society. Finally, both internships and workfare programmes are structured around conditions and reciprocity, a "something for something" culture, which functions to erode the right to remuneration (Hinton 2012).

\section{Implications}

The rise of unpaid internships within the broader political-economic context of workfare has a number of significant social, cultural, and political implications which demand analysis.

\subsection{Cultural Implications}

Given the prevalence of internships within the cultural industries, we need to consider the cultural and political implications of a further narrowing of the labour pool within these sectors to those who can afford to support themselves without pay for months or years on end. As Kate Oakley (2013), David Lee (2011), Jane Holgate and Sonia McKay (2009), and Doris Ruth Eikhof and Chris Warhurst (2013) have noted, creative work has become a zone of stratification and exclusion for non-white, middle-class entrants. From a normative perspective, this is a major cause for concern, undermining the rhetoric of diversity and equality within the creative industries. Commentators who are unconcerned with the ethical and moral issues involved in this narrowing of the labour pool have shown that there are pragmatic, commercial reasons why diversity is so important in the cultural industries. Creativity and innovation require difference. There is increasing research that shows that the conditions required for creativity to flourish are ones where there is dialogue, difference, and diversity (Amabile et al. 1996). However, this is not simply about making an economic case for diversity, but also a moral case about the kind of culture that is produced. As Chris Land argues in his arresting critique of the film Kingsman, "Middle class, heterosexual, white men will tend to produce films that take their own identity for granted and not even realise that they are making films for people like themselves" (Land 2015). Culture, the means by which we create and circulate shared symbolic forms of expression, is diminished through the reproduction of a highly stratified, homogenous workforce.

As internships proliferate across the cultural sectors, the creative labour market, already highly socially stratified, is becoming ever more so. The normalization of the internship, which favours those with high levels of economic and social capital, is steadily eroding the 
conditions for diversity in the media industries. It also creates a striking mismatch between evidence (that diversity is economically and social important for cultural industries, as cited above), rhetoric (around the creative industries as the "engines" of economic growth and deliverers of socio-economic development free from the social inequalities in work and employment (Florida 2004), and policy (which facilitates the culture of internships and actively promotes the promotion of workfare programmes, as we have seen). Despite the widespread belief amongst policymakers and certain academics that the creative industries have the potential to create a meritocratic world of work (e.g., Howkins 2001), the evidence clearly shows that, in the UK at least, these sectors are still underrepresented by women (38 percent compared to 46 percent of the UK's workforce as a whole) and by ethnic minority workers (five percent compared to nine percent across the UK economy) (Skillset 2010). While data on socio-economic backgrounds is difficult to obtain due to the way in which data is collected by statistical agencies (Randle et al. 2007), we can use higher education degrees as proxies of socio-economic background (Wolf 2002; Eikhof and Warhurst 2013). According to Skillset (2010) figures, over two-thirds of workers in the creative media industries are graduates compared to under 37 percent of the economically active working population in the UK as a whole. Creative workers are also increasingly educated in private schools, particularly in journalism: the last 20 years have seen the percentage of UK leading news journalists educated at private schools rise steadily to 54 percent (compared to seven percent of the overall UK school population) (Sutton Trust 2006).

\subsection{Socio-economic Implications}

The socio-economic implications of internships and their growing alignment with workfare remain unclear as the phenomenon plays out across the contours of a rapidly shifting and uncertain global economic landscape. However, certain factors should be considered. Internships in the professions are largely driven by the oversupply of labour, weak or non-existent unions, and the neoliberal restructuring of the economy, which prioritizes capital accumulation over labour demands. Workfare programmes, as outlined above, are also linked to neoliberalism in terms of the shift from a Keynesian interventionist statist approach (with its principles of universal benefits) to a Schumpeterian welfare state, which focuses on the entrepreneurial individual as the locus of self-responsibility and self-government (Jessop 1995). They offer neoliberal governments a mode of dealing with the "welfare crisis," and place a moral emphasis on labour. Both are based on a belief in entrepreneurialism and the dismantling of labour market regulations which hamper individual development. Yet, both also point to a wider issue, that of transformations in labour markets and the dwindling supply of secure, regularly paid work in advanced capitalism. Other writers have dealt with these issues, and many have posited the crucial importance of a "living wage" to deal with the developing crisis in labour supply.

The debate about a universal basic income has been resurrected in recent years, with a resurgence of interest in the ideas of writers such as Andre Gorz (1999) who advocated a basic income for all, as work was seen to be becoming increasingly automated. Basic income was justified on the basis that it would leave time for all to work less, would be beneficial to society (in terms of community activities and volunteering), and would provide the basis for a more democratic, equal, and just society. There has been a critical backlash against these ideas on the grounds that labour is based on a reciprocal arrangement where money is provided for labour given, whereas the idea of a basic income lacks this quality, as it is unconditional and it is argued that the basic income would impact negatively on work incentivisation and also on labour supply (Tcherneva 2013).

However, in recent years, writers such as Standing (2002), Fran Bennett (2014), and Stephanie Luce (2004) have rejuvenated the discussion, and the political-economic issues at stake are coming more sharply into focus because of the lack of meaningful secure employment for a younger generation accustomed to internships and having grown up with the discourse of workfare rhetoric and activity. Standing has argued that a basic income is an urgent matter of security and a means of addressing the growing inequality crisis on the basis 
of distributive justice (Standing 2002). But he has also argued that it should be nonpaternalistic, and that it needs to be "basic," or otherwise "it leads to indolence and loss of motive to function." Both workfare and internships point to a labour crisis and political crisis which a basic income could help address.

\subsection{Political and Organizational Implications}

Campaigns such as TVWRAP attempted to bring the issues of equality and exploitation in the media industries to the fore nearly ten years ago now. Yet, the rise of internships has worked against many of the advances that were made, undermining the pressure for greater equality and diversity in the media industries, and for more equitable means of accessing employment in these competitive industries.

As a number of writers have explored, the cultural industries remain opaque to enter, exploitative (especially at the entry level jobs), and can cause stress and anxiety for those working in them because of the "club culture" and the long hours worked within precarious employment conditions (Gill 2002; Banks 2007). With the marginalization of unions in the creative industries now widespread, it is left to activists amongst pressure groups, providing first-hand, largely anonymous accounts of work in the internship economy, to try to mobilize for change. Interns Anonymous and Interns Aware are notable in this respect; so too is the writing of Perlin (2012). Yet, as some network-based campaigns have found to their cost, a lack of an organizational base and strong links to unions can hamper efforts to effect meaningful change. For example, TVWRAP, discussed earlier, was ultimately sidelined by the Producers Alliance for Cinema and Television, the influential British media trade association, on the basis that the testimonies were anonymous and therefore unprovable; also the fact that the group was temporary and formed by freelancers meant that it was not able to sustain pressure on employers once the initial press interest had died down (Broadcast Now 2005). As recent research has shown, the issue of exploitation in the British media industries has not disappeared as a result of the TVWRAP campaign, despite its short-term success. For meaningful change to occur, it would surely need legislative and regulatory change against exploitative and iniquitous working conditions, and in the current economic and political climate this seems a distant prospect (Khalsa 2013).

Despite these challenges, there are increasing signs of a cultural and social backlash against the low-pay, no-pay internship culture, particularly amongst educated graduates working in the cultural sector. New collectives such as Bow Arts described by the journalist and author Paul Mason (2014) offer progressive alternatives to the labour crisis by allowing individuals to work for themselves, but within a shared co-operative space. New organizations are emerging, such as AltGen, which indicate new possibilities for a generation frustrated and jaded by the harsh economic contours of contemporary British life (ibid., 2014). Furthermore, anti-workfare campaigning is becoming more widespread and vocal, with groups such as Boycott Workfare (http://www.boycottworkfare.org/) providing online resources, organizing boycotting activities, and "naming and shaming," or exposing the often dubious practices of the private companies delivering such programmes on behalf of the public sector. While there is little evidence as yet of formal links between anti-internship and antiworkfare activists, it appears that they are being critically linked at the discursive level, as evidenced by recent articles on the blogs of anti-workfare campaigners (Void 2013; Arky 2013). The pressing need to forge a link between workfare and internships can be clearly detected in these articles; for as "Ann Arky" (2013) argues in relation to employers making use of intern and workfare labour, "They are both doing the same thing, exploiting free labour." However, currently the depth of analysis offered by such articles is limited, and fails to establish a programme by which these two different activist groups could be linked. This would involve the need for thinking through the commonalities and differences between workfare and internships. There is indeed critical power in Void's statement:

About the only real difference between unpaid internships and work experience schemes is that internships usually lead to well paid careers in popular sectors like fashion, the media or entertainment. In contrast Work Experience generally leads back to the dole as 
grasping employers maintain a rolling stock of free workers instead of paying wages. (Void 2013)

However, in my view, it is also necessary to think about internships and workfare programmes in a way, which does not play down the significant divergences between these two groups of exploited labour. It is only through establishing commonalties but also acknowledging differences that we can begin to forge a shared politics of the precariat which rejects such exploitation on normative grounds, and which both groups might identify with and support.

\section{Conclusion}

This article has sought to make links between workfare and internship culture in the hope that it will provide a shared resource for the many disparate elements of the "new precariat." While it may be hard to imagine a shared politics between groups as diverse as media interns and street cleaners, as Standing points out, all groups of the precariat are experiencing the sharp end of the accumulation crisis, the crisis of contemporary labour markets, and the prospect of "recovery without jobs," and, as such, need to find common cause if a progressive politics is to emerge from the current context (Standing 2011a). Workfare programmes are an attempt to "fix" neoliberal capital accumulation and act against inflationary pressures. Internships are a phenomenon of often unpaid labour that provides companies with a ready, educated labour supply. Both workfare programmes and internships erode individual security, and this is not without social risk. As Standing has argued, the politicization of the precariat may have potentially worrying prospects, with neofascism on the increase globally, as it offers some form of security to neoliberalism's "others" (ibid.).

In a recent article, John Lanchester reflected on the increasing automation of work, previously carried out by humans and now being done by robots (Lanchester 2015). In a wideranging analysis, which considers the use of robots in Amazon's "fulfilment centres," Google's driverless cars, as well as the political-economic implications of Apple's recent firstquarter profit announcement (\$74.6 billion in turnover, $\$ 18$ billion in profit), Lanchester considers the human cost of improved "productivity." For example, Apple is now the most profitable business in the world; in the past it was Ford Motors. Yet Apple employs 92,600 workers, while Ford employed 600,000 (ibid.). As he argues, "Capital isn't just winning against labour: there's no contest. If it were a boxing match, the referee would stop the fight" (ibid.).

Given this context, and that outlined above in the discussion of workfare and internships, what might be the political ways forward for a more progressive approach to labour markets which are rapidly transforming under conditions of technological innovation? Most immediately, diagnosis of the problem needs to lead to political mobilization on these issues. Greater discussion is needed about the hypocrisy of politicians who are quick to condemn internships for the middle and upper classes, but happy to promote workfare programmes. This tells us a great deal about the inequities within contemporary politics on work and labour. But we also need new ways of thinking about work and society, which draws on the new possibilities that automation might provide for greater human flourishing and social justice. It may be too optimistic to suggest, as Lanchester does, that this could lead to an "alternative future" which "would be the kind of world dreamed of by William Morris, full of humans engaged in meaningful and sanely remunerated labour" (Lanchester 2015). However, as William Davies (2014) has argued, there are increasing signs of progressive movements which seek to find new ways of working and living that look beyond the limits of neoliberalism.

\section{References}

Amabile, Teresa, Regina Conti, Heather Coon, Jeffrey Lazenby and Michael Herron. 1996. Assessing the Work Environment for Creativity. Academy of Management Journal 39 (5): 1154-1184.

Arky, An. 2013. Internship-Workfare Exploitation. Accessed January 13, 2015. http://radicalglasgowblog.blogspot.co.uk/2013/04/internship-workfare-exploitation.html.

Auon, Joseph. 2010. Protect Unpaid Internships. Inside Higher Education. Accessed June 12, 2014. http://www.insidehighered.com/views/2010/07/13/aoun. 
Banks, Mark. 2007. The Politics of Cultural Work. London: Palgrave.

BECTU. 2009. Work Experience Guidelines. London: BECTU.

Bennett, Fran. 2014. The "Living Wage," Low Pay and In Work Poverty: Rethinking the Relationships. Critical Social Policy 34 (1): 46-65.

Blair, Tony. 1997. Speech at the Aylesbury Estate, June 2, Southwark, London.

Blears, Hazel. 2013. Name and Shame Firms which Employ Unpaid Interns, says Hazel. Accessed January 3, 2015. http://www.hazelblears.co.uk/news/name-and-shame-firms-which-employ-unpaidinterns-says-hazel.

Broadcast Now. 2005. Pact Rejects Compulsory Code for Indies. Accessed January 8, 2015. http://www.broadcastnow.co.uk/pact-rejects-compulsory-code-for-indies/1025206.article.

Cabinet Office. 2012. Fair Access to Professional Careers: A Progress Report by the Independent Reviewer on Social Mobility and Child Poverty. London: Cabinet Office.

Clark, Warren. 2012. A World on Workfare. New Internationalist 453: 38-39.

Corporate Watch. 2012. Revealed: The Punishing Reality of the Coalition's Welfare Reforms. Accessed August 17, 2012. http://www.corporatewatch.org/?lid=4371.

Couldry, Nick and Jo Littler. 2008. The Work of Work: Reality TV and the Negotiation of Neoliberal Labour in The Apprentice. In Rethinking Documentary: New Perspectives and Practices, edited by Thomas Austin and Wilma de Jong, 258-267. Maidenhead: Open University Press.

Crawford, Claire and Wenchao Jin. 2014. Payback Time? Student Debt and Loan Repayments: What Will the 2012 Reforms mean for Graduates? London: Institute of Fiscal Studies. Accessed June 10, 2014. http://www.ifs.org.uk/comms/r93.pdf.

Davies, William. 2014. The Limits of Neoliberalism: Authority, Sovereignty, and the Logic of Competition. London: Sage.

Eikhof, Doris and Chris Warhurst. 2013. The Promised Land? Why Social Inequalities are Systemic in the Creative Industries. Employee Relations 35 (5): 495-508.

Evans, Patricia. 1995. Linking Welfare to Jobs: Workfare, Canadian Style. In Workfare: Does it Work? Is it Fair?, edited by A. Sayeed, 75-104. Montreal: Institute for Research on Public Policy.

Figiel, Joanne. 2013. Class Action or Class Struggle? ephemera: theory \& politics in organization 13 (4): 903-910.

Florida, Richard. 2004. The Rise of the Creative class and How It's Transforming Work, Leisure, Community and Everyday Life. New York: Basic Books.

Gill, Ros. 2002. Cool, Creative, and Egalitarian? Exploring Gender in Project-based New Media Work in Europe. Information, Communication \& Society 5 (1): 70-89.

Gorz, Andre. 1999. Reclaiming Work: Beyond the Wage-based Society. Oxford: Blackwell.

Hardy, Sam. 2014. There is No Such thing as a "Cider and Apple Juice Internship." There is Only Unpaid Manual Labour. Accessed July 20, 2014. http://unfreearchaeology.wordpress.com/2014/07/08/free-archaeology-internship-national-trustunpaid-manual-labour/.

Hesmondhalgh, David and Sarah Baker. 2010. "A very complicated version of freedom”: Conditions and Experiences of Creative Labour in Three Cultural Industries. Poetics 38 (1): 4-20.

Hinton, Eleanor. 2012. The Social and Political Significance of Workfare in the United Kingdom. Unpublished Masters thesis. London: School of Advanced Study.

Holgate, Jane and Sonia McKay. 2009. Equal Opportunities Policies: How Effective are they in Increasing Diversity in the Audio-visual Industries' Freelance Labour Market? Media, Culture \& Society 31 (1): 151-163.

Howkins, John. 2001. The Creative Economy. London: Penguin.

Interns Anonymous 2013. Accessed July 20, 2014. http://internsanonymous.co.uk/.

Jessop, Bob. 1995. Towards a Schumpeterian Workfare Regime in Britain? Reflections on Regulation, Governance, and Welfare State. Environment and Planning A 27 (10): 1613-1626.

Jessop, Bob. 2003. From Thatcherism to New Labour: Neo-Liberalism, Workfarism, and Labour Market Regulation. In The Political Economy of European Unemployment: European Integration and the Transnationalization of the Employment Question, edited by Henk Overbeek, 137-153. London: Routledge.

Jones, Martin. 1996. Full Steam Ahead to a Workfare State? Analysing the UK Employment Department's Abolition. Policy \& Politics 24 (2): 137-157.

Jones, Owen. 2012. Chavs: The Demonization of the Working Class. London: Verso.

Khalsa, Balihar. 2013. Bectu Survey Highlights "Exploitation" in Factual. Accessed January 8, 2015. http://www.broadcastnow.co.uk/bectu-survey-highlights-exploitation-in-factual/5051265.article. 
Lanchester, John. 2015. The Robots are Coming. London Review of Books 37 (5). Accessed March 20, 2015. http://www.Irb.co.uk/v37/n05/john-lanchester/the-robots-are-coming.

Land, Chris. 2015. The Cinematic Spectacle that Class War has Become. Accessed March 20, 2015. http://staffblogs.le.ac.uk/management/2015/03/18/the-cinematic-spectacle-that-class-war-hasbecomel.

Lee, David. 2011. Networks, Cultural Capital, and Creative Labour in the British Independent Television Industry. Media, Culture \& Society 33 (4): 549-565.

Lindsay, Colin and Mikkel Mailand. 2004. Different Routes, Common Directions? Activation Policies for Young People in Denmark and the UK. International Journal of Social Welfare 13 (3): 195-207.

Luce, Stephanie. 2004. Fighting for a Living Wage. Ithaca, NY: Cornell University Press.

MacLeavy, Julie. 2011. A "New Politics" of Austerity, Workfare, and Gender? The UK Coalition Government's Welfare Reform Proposals. Cambridge Journal of Regions, Economy, and Society 4 (3): 355-367

Malik, Shiv. 2011. Young Jobseekers Told to Work without Pay or Lose Unemployment Benefits. The Guardian. Accessed July 30, 2014. http://www.theguardian.com/society/2011/nov/16/youngjobseekers-work-pay-unemployment.

Malik, Shiv. 2012. Internships Should be Subject to Labour Market Rules, says Social Mobility Tsar. The Guardian. Accessed January 8, 2015. http://www.theguardian.com/society/2012/may/30/internships-labour-market-social-mobility.

Mason, Paul. 2014. The Young, Skint, and Self-employed Need a Radical New Labour Market. The Guardian. Accessed July 24, 2014. http://www.theguardian.com/commentisfree/2014/jul/20/youngskint-self-employed-new-labour-market.

National Trust. 2014. Cider and Apple Intern. Accessed July 24, 2014. http://www.nationaltrustjobs.org.uk/join-us/search?job-type=\&regionoptions $=0 \&$ seasonal role num $=63 \&$ vacancy reference $=63$.

Oakley, Kate. 2013. Making Workers: Higher Education and the Cultural Industries Workplace. Cultural Work and Higher Education, edited by Daniel Ashton and Caitriona Noonan, 25-44. London: Palgrave.

Peck Jamie. 1998. Workfare: A Geopolitical Etymology. Environment and Planning D: Society and Space 16 (2): 133-161.

Perlin, Ross. 2012. Intern Nation: How to Earn Nothing and Learn Little in the Brave New Economy. London: Verso.

Prince, Rosa. 2011. Nick Clegg: I was Wrong to use Father's Help to Secure Bank Internship. The Telegraph. Accessed July 29, 2014. http://www.telegraph.co.uk/news/politics/nickclegg/8430087/Nick-Clegg-I-was-wrong-to-use-fathers-help-to-secure-bank-internship.html.

Randle, Keith, Leung Wing-Fai and Juno Kurian. 2007. Creating Difference: Overcoming Barriers to Diversity in UK Film and Television Employment. University of Hertfordshire: Creative Industries Research and Consultancy Unit. Accessed June 29, 2014. http://researchprofiles.herts.ac.uk/portal/en/publications/creating-difference-overcoming-barriers-todiversity-in-uk-film-and-television-employment\%2810b5867a-7129-4e20-a9b50d469ba7f566\%29.html.

Ross, Andrew. 2004. No-Collar: The Humane Workplace and its Hidden Costs. Philadelphia: Temple University Press.

Saundry, Richard, Mark Stuart and Valerie Antcliff. 2006. "It's More than Who you Know": Networks and Trade Unions in the Audio Visual Industries. Human Resource Management Journal 16 (4): 376-392.

Saundry, Richard, Mark Stuart and Valerie Antcliff. 2007. Broadcasting Discontent-Freelancers, Trade Unions, and the Internet. New Technology, Work and Employment 22 (2): 178-191.

Shafritz, Jay. 1988. The Dorsey Dictionary of American Government and Politics. New York: Dorsey Press.

Silver, James. 2005. Exploitation is More Widespread than Ever. The Guardian. Accessed March 20, 2014. http://www.theguardian.com/media/2005/apr/11/broadcasting.mondaymediasection.

Skillset. 2010. Creative Media Workforce Survey 2010. London: Skillset.

Spradlin, Isaac. 2009. The Evolution of Interns. Forbes. Accessed May 2, 2014. http://www.forbes.com/2009/04/27/intern-history-apprenticeship-leadership-careers-jobs.html.

Standing, Guy. 2002. Beyond the New Paternalism: Basic Security as Equality. London: Verso.

Standing, Guy. 2011a. The Precariat: The New Dangerous Class. London: Bloomsbury. 
Standing, Guy. 2011b. The Precariat: The New Dangerous Class. Policy Network Essay. Accessed July 20, 2014. http://www.policy-network.net.

Standing, Guy. 2012. The Precariat and Why it Needs Deliberative Democracy. Open Democracy. Accessed July 20, 2014. https://www.opendemocracy.net/guy-standing/precariat-why-it-needsdeliberative-democracy.

Sutton Trust. 2006. The Educational Background of Leading Journalists. London, Sutton Trust.

Tcherneva, Pavlina. 2013. The Job Guarantee: Delivering the Benefits that Basic Income Only Promises-A Response to Guy Standing. Basic Income Studies 7 (2): 66-87.

Topping, Alexandra. 2012. Workfare that Shames UK plc, or a Left-wing Plot by the Job Snobs? The Guardian. Accessed July 14, 2014. http://www.theguardian.com/society/2012/feb/28/workfare-ukplot-job-snobs.

Toynbee, Polly. 2012. Protest Really Does Work-Just Look at Tesco and Workfare. The Guardian. Accessed July 21, 2012. http://www.guardian.co.uk/commentisfree/2012/feb/22/protest-tescoworkfare.

Void, Johnny. 2013. Wages for Interns, Workfare for the Poor, says Jo Swinson MP. Accessed July 20, 2014. http://johnnyvoid.wordpress.com/2013/11/11/wages-for-interns-workfare-for-the-poorsays-jo-swinson/.

Winter, Anna. 2011. Intern Nation by Ross Perlin-Review. The Guardian. Accessed June 2, 2014. http://www.theguardian.com/books/2011/may/15/intern-nation-ross-perlin-review.

Wolf, Alison. 2002. Does Education Matter? London: Penguin.

\section{About the Author}

David Lee

David Lee is a Lecturer in Cultural Industries and Communication in the School of Media and Communication at the University of Leeds. He is the author of a number of articles and chapters on creative work, cultural policy, copyright, and television studies in international journals including the International Journal of Cultural Policy; Cultural Trends; Media, Culture \& Society; and Television and New Media. Before working in academia, David worked in documentary production, on series such as Newsnight, Panorama, and The Money Programme. 


\title{
Nothing for Money and Your Work for Free: Internships and the Marketing of Higher Education
}

\author{
Mara Einstein \\ Queens College, City University of New York, Flushing, New York, USA, \\ Mara.Einstein@qc.cuny.edu
}

\begin{abstract}
American universities have significantly increased their marketing expenditures over the last decade. The high cost of education, reductions in government funding, and precipitous declines in the traditional college-aged population (18-21 year olds) are some of the key factors forcing universities to be more aggressive with the promotional techniques they use to attract prospective students. In this competitive marketplace, schools promote the attributes they believe will be most compelling to high schoolers and their parents, including academics, sports, campus life, and careers. Tied into this last factor is the promotion of internship opportunities. While some of these hands-on experiences lead to jobs, there are no guarantees that attending college and engaging in an internship will translate into fulltime employment. Using content analysis and auto-ethnography, I examine how universities use internships to market higher education, and argue that this is a particularly pernicious practice within the area of media studies.
\end{abstract}

Keywords: internships, marketing, college student recruitment, higher education, universities and colleges

Acknowledgements: I would like to thank the editors for seeing the promise of this piece in its early stages and to the reviewers who provided thoughtful, specific commentary. In addition, I would like to thank my student interns, my research assistant Marykate Byrnes, and my high school assistants, Victoria Stempel and Naomi Langer, who provided much needed texts for analysis.

Over the last two decades, internships have evolved from a voluntary learning experience to become what is perceived to be a mandatory step up the US career ladder (Shoenfelt, Stone and Kottke 2013; Knouse, Tanner and Harris 1999). Students, therefore, feel compelled to take on one or more internships during their college years. ${ }^{1}$ Simultaneously, changes in the higher education business environment have led universities to become more aggressive marketers. Employing an array of marketing tools and techniques such as branding, social media, and direct marketing, universities now sell their institutions to high school students and their parents in much the same way that consumer products are sold (Banet-Weiser 2013; LayHwa 2011; Hearn 2010; Black 2008; Brunzel 2007; Lowrie 2007). Specifically, higher education marketers identify the most important attributes and benefits their institution has to offer, learn the needs and wants of their target audience, and then promote these to prospective students. Thus, the promise of landing an internship becomes integral to marketing US universities to prospective students and their parents.

This article analyzes the convergence of higher education marketing and the internship economy. I start with a short examination of the changing business conditions that led to the proliferation of marketing in higher education and the industry that grew up around it. This is followed by a content analysis of university marketing materials with a specific focus on how internships are presented in direct marketing materials. Internships are most often promoted as

\footnotetext{
${ }^{1}$ Best estimates are that half of the 1.5 million annual internships in the United States are unpaid. However, that figure is suspect as unpaid internships are frequently illegal and employers have no incentive to report them (Howe 2014).
} 
a career or résumé-building tool with emphasis placed on access to famous alumnae and the breadth of opportunities available, or as an aspect of co-op or experiential learning, which is more focused on learning in the present rather than money-making in the future. I conclude by reflecting on internships within the media industry, based on my 15-year experience administering a college internship program within a media studies department as well as my 20 years of experience marketing major television networks and working at advertising agencies, where I often hired and worked with university interns. As other scholars have noted, while these on-the-job opportunities give students first-hand experience, they rarely come with a paycheque or the guarantee of a future job assignment, particularly in the "glamour industries" of media and marketing (Frenette 2013; Perlin 2011; Frederick 1997). My central argument is that internships are a facile yet misleading attribute for promoting higher education; these pseudo-jobs are a tempting lure for young adults, yet they perpetuate the myth that a university education combined with an internship leads to full-time employment. In truth, internships are free labour for corporations, a moneymaker for universities, and, incredibly, a successful promotional tool to sell students on programs that provide these opportunities.

\section{Corporatization, Commoditization, and the Creation of a Competitive Marketplace}

Numerous scholars have written about the corporatization of higher education (Tuchman 2009; Woodhouse 2009; Bousquet 2008; Washburn 2006; Bok 2004; Steck 2003; Aronowitz 2001; Slaughter and Leslie 1997). They note the many ways that universities reflect their corporate counterparts, including employing an "academic temp system" where the university is made up of a continually reduced number of full-time workers in favour of part-time unprotected labour; implementing changes in funding structures that rely on "consumer purchases," and marrying curriculum to the market rather than societal needs, i.e., favouring practical, skills-based courses over the arts and humanities. Concomitant with corporatization is the commoditization of higher education-the transformation of distinguishable entities (universities) into homogeneous commodities (Reimann, Schilke and Thomas 2008)-and with that comes the increased use of marketing and promotion (Natale and Doran 2012; Twitchell 2005).

Universities became commodities because of changes in the business environment of higher education, particularly over the last three decades. Specifically, government funding moved from direct support of the institution to indirect support through students, i.e., providing financial aid. Some scholars peg this change to the Higher Education Act of 1965 (Heller 2011), others to the Nixon administration (Naidoo, Shankar and Veer 2011), but putting the burden of funding education squarely on the backs of students and their families became more fully the norm in the 1980s, when neoliberal philosophies prevailed (Mills 2012). Anya Kamenetz (2006) demonstrates the consequences of this shift when she notes, "In 1981, 45 percent of all federal undergraduate student aid came in loans, 52 percent in grants. By the end of the 1990s, the proportion was more than reversed; loans made up 58 percent of federal financial aid, and grants just 41 percent" (18). Thus, funding for universities increasingly became the responsibility of individuals who could rely less on grants, which do not have to be repaid, and more on loans, which most decidedly do. Today, more than half (57 percent) of students can expect to leave college with an average debt load of $\$ 24,000$-this in an economy where the starting salaries of many college students will be around $\$ 30,000$ a year if they are lucky enough to find a job. These statistics become ever more startling when understanding that the same education 30 years ago cost less than $\$ 6,000$ in current dollars (US Department of Education 2013). Rising tuition is exacerbated by American incomes remaining flat over the last several decades, making university tuition an ever-larger part of the household budget. Given this, it is not surprising that students and their parents are looking for a return on their investment (ROI). ROI translates into the ability to get a job immediately after graduation-a job that now will likely 
require a college-credit bearing internship. Therefore, higher education marketers make internships part of the recruitment effort.

As universities have become progressively tuition driven according to the State Higher Education Officers Association (Bidwell 2014), they have had to promote themselves directly to "consumers." ${ }^{2}$ Further driving the aggressive and competitive marketing is the annual rankings of US News \& World Report (Twitchell 2005; Meredith 2004; Monks and Ehrenberg 1999). This rating system began in the mid-1980s, and because parents, students, and guidance counsellors depend on the information it contains, institutions are obliged to increase their rankings in an attempt to entice more applicants and decrease their acceptance rate-a figure that makes the university appear more exclusive and ultimately more appealing. ${ }^{3}$ In addition to promoting exclusivity, universities market the majors offered, consumer-driven amenities like climbing walls and sports arenas, and, finally, the affinity they have with their alumni network and the expertise of the career center-valuable resources for internships and career counselling (Kirp 2004; Twitchell 2005). ${ }^{4}$

Compelled to increase enrolments because of reduced government spending as well as being measured based on quantitative corporate standards, considerable budgets are allocated to marketing. In the first half of 2013 , colleges spent $\$ 570.5$ million on advertising, with nonprofit institutions spending more than for-profit schools- $\$ 302$ million versus $\$ 268.5$ million respectively (Brock 2013). Some schools reportedly spent upwards of $\$ 5$ million on their advertising campaigns, though typically marketing budgets are a tenth of that amount (Miley $2009,6)$. Not included in these numbers is the monies spent on direct marketing-one of the most expensive forms of promotion, which must be considerable given the amount of mail these institutions disseminate. Whether direct mail or traditional brand advertising, it is estimated to have cost $\$ 2,143$ per student to recruit a prospect for a four-year college in 2013 (Noel-Levitz 2013).

But even these expenditures are unlikely to be enough to sustain universities moving forward. For a time, higher tuition combined with more people going to college assuaged the imbalance due to cuts in government spending, but no longer. Enrolment statistics in recent years are striking: while 15.3 million students went to college in 2000 , by 2012 the number was 21.6 million-more than ever before (US Department of Education n.d.). The recession played an important role in that increase because students enrolled in college either to upgrade their skills or because of lack of employment. Also, jobs that once required a high school education now require a college degree (Rampell 2013). In the last two years, however, enrolment figures have begun to decline (Bidwell 2013), which is likely due in some part to the precipitous declines in the traditional college-aged population. This cohort reached its peak in 2011, after which it had an abrupt decline and is not expected to return to current levels again until 2024 according to the Western State Commission for Higher Education (WICHE 2012). As the number of prospects decline, we can expect to see marketing - and the marketing of internship opportunities-intensify further still as universities increasingly compete for top traditional high school prospects as well as pursue "non-traditional" college students.

\footnotetext{
${ }^{2}$ In the last five years alone funding per student is down 26 percent and it is only in the last year that funding has begun to increase, though not enough to make up for years of losses (Belkin 2014).

${ }^{3}$ While universities market to students they want to join their freshman class, they also market to students who have little chance of getting into the school. The higher the number of applicants, the lower the acceptance percentage, which increases the school's ranking.

${ }^{4}$ Universities also compete against for-profit institutions and online college offerings, but this is beyond the scope of the current study.
} 


\subsection{The Business of Marketing and Branding Higher Education}

Higher education marketing is not a new phenomenon. Strategic business marketing was introduced into United States universities in the 1970s (Barton and Treadwell 1978) and by the 1980s there existed conferences, associations, and journals devoted to marketing higher education (Carrocci 2009, 7). Today, these conferences and associations continue to grow while an industry in consultancies devoted to higher education marketing has flourished alongside them. Nothing is more telling about the importance of marketing, though, than the creation of the Higher Education Chief Marketing Officer (CMO), a title that began to burgeon only in the last 10 years (Glazer and Korn 2012). These high-paid executives, many of whom come out of corporate marketing backgrounds, are tasked to sell the university, but they are also hired to create and solidify the institution's brand, or identity, a term more accepted within higher education (Toor 2002).

Whether called identity or branding, the creation of an instantly recognizable symbol, image, and mythology is essential to the marketing process (Sargeant and Ford 2007; Goldman and Papson 1996). In much the same way Disney is conceived of as "magic," colleges are "unconventional" (Reed College) or "independent" (Brown) or "intellectual" (University of Chicago) (Forbes n.d.). American University's (AU's) "Wonk" campaign is a recent extensive (and expensive) example of the lengths to which universities are moving toward branding. Started in 2011, this branding effort plays on the colloquialism of the policy wonk-a term appropriate for a university based in Washington D.C. It also aligns with the growth of "nerd culture," made hip by things like the success of Silicon Valley computer "nerds" and the popularity of events like Comic-Con, a conference devoted to all things comics-based. In sum, "Wonk" defines the university as smart, but one that doesn't take itself too seriously. While the campaign has met with significant backlash from alumni (Gibson 2014), the language continues to appear in marketing materials. This may, in part, be due to the cost of the Wonk campaign: AU reportedly spent $\$ 550,000$ on brand development and on the initial launch (Kelly 2013), and materials for the university were some of the most expensive analyzed as part of this study. One piece of direct mail was a 106-page book-the largest by far-that looked more like a highly designed fashion catalog than a view book for an institution of higher learning. The school also sent personalized four-colour brochures customized with student's names: "Hello! Susan. Here's the information you requested on mathematics." This piece of mail contained the name, phone number, and email address of a representative who can help with the admissions process, displayed next to their picture, making the document feel still more personal. Lastly, and important to this discussion, internships are integral to the university's brand message. Among the materials sent from AU were over-sized postcards stating, "Study at a wellconnected University, ranked first in the nation for internships by U.S. News \& World Report."

Creating a university brand identity is necessary because prospective students need to differentiate one school from another in an environment where schools look alike and, for many, the product cannot be sampled before purchase (Balmer, Liao and Wang 2010; Anctil 2008; Sung and Yang 2008). Further, university marketing is more complex than for typical brand marketers (Waeraas and Solbakk 2008). First, there is a limited window of opportunity-typically six months to a year-within which to sell the product, and second, students and parents are making this decision with significant emotional investments attached. Because of this, higher education marketers must reach prospects with compelling sales messages in intrusive ways. Therefore, if a university's brand is based on athletics, academics will be promoted on an equal footing with sports. An example from my study is a postcard from a major state school that shows a football mascot teaching in front of a classroom, an image that grabs attention because of its cognitive dissonance. Similarly, if a school promotes career preparation, they demonstrate 
that in marketing materials. I share some examples in the analysis below. Using attributes other than academics to sell an institution is not unusual. Except for the most elite schools, academics are promoted side-by-side with sports, the bucolic setting, and career preparation (Hartley and Morphew 2008).

\section{Marketing Universities Through Internships}

\subsection{Research Background and Methodology}

In 2011 I began researching the marketing of higher education as part of a popular book project aimed at educating parents about how universities use promotion during the search process, a topic of particular interest since I am a former marketer and the parent of a high school student. Working with a consultant who advises students on how to get into a university, we examined the environment that ignited the proliferation of higher education marketing, including the widening demographics for college students, the growth in for-profit institutions, the rising expenditures in marketing costs, and the messaging used to attract prospects. Research consisted of multiple methods-participant observation, auto-ethnography, and content analysis. Integral to that project, and the content analysis here, is the examination of direct marketing materials from institutions of higher learning.

To ascertain what messages were being presented to prospective students and their parents, I attended fairs for high school students needing preparation to get into college and college fairs attended by dozens of colleges from around the country. ${ }^{5}$ At these events I added my name to mailing lists as a parent of a high school student and in turn received dozens of emails and pieces of direct mail asking me first to visit the college and later to apply to colleges because I was "such a good candidate." I received messages that sold the institutions based on the availability of scholarships or the percentage of students who had gotten jobs, as well as faculty accomplishments. Some of the most sophisticated, funny, and amenities-based marketing that I received was from Towson University, including a rap video in one email and a video in another email from the university president saying that I had been accepted into the school. The offer was later rescinded with an email stating: "Although you did not apply and you are not admitted to Towson University, we hope that you will consider us in the future as your college choice."

While universities move toward promotion online, direct mail continues to be the predominant method for marketing. ${ }^{7}$ Therefore, to supplement the direct mail I acquired, I asked two high school students to save the mailings they received from universities around the country. I chose these students because they were going to competitive schools, one in New York City and one in the Washington D.C. area. They also had high SAT scores, which is important because universities send direct mail to students based on their test score. The higher the score, the more mail a student can expect to receive.

\footnotetext{
${ }^{5} \mathrm{An}$ industry has built up around preparing high school students to get into college, including test preparation companies, companies run by former admissions officers working with high school students to develop their résumé starting in their sophomore year, and multiple volunteer organizations.

${ }^{6}$ While I signed up as a parent of a student from Bronx Science (which is true), the systems only recognized me as a student. Also, I registered as being connected to Bronx Science because it is one of the top New York City high schools, and it was likely to induce more interest on the part of universities.

${ }^{7}$ It might seem surprising that direct mail, which is expensive to produce and to send, is still being widely used to target this young demographic that spends significant time online. However, marketers find that catalogs in particular enable them to "break through the clutter." Moreover synergy exists between catalogue readership and digital marketing (Holmes 2014) - people view products in print then move to digital formats for more information and to purchase.
} 
Working with an assistant, we sorted the materials and discovered that most schools began their marketing pitch with an almost identical letter that provides students with a user name and password, which they can use to go online and fill out an e-quiz, presumably to find a strong connection between the student and the school. The mailings also contain a smaller piece of paper with a space to fill out the student's name and phone number, and an envelope so they can return this information via snail mail if they do not want to go online. Alternatively, universities send postcards with a business reply card or ask students to go online to a special website that the school has created with the student's name (Naomi.xyzu.edu). The primary goal of these mailings is to get the student to respond so that the university can capture the student's information and add them to their official mailing list, enabling the school to send more descriptive content once the student demonstrates interest. ${ }^{8}$

These direct marketing pieces initiate the sales process. However, it is personal selling and the opportunity to experience the product that is most likely to complete the sale. Thus, at the beginning of senior year, universities connect with high school students in three ways: college admissions officers hold in-school meetings (Toor 2002), colleges participate in college fairs or hold individualized events at a local hotel, and students are invited for an on-site visit-either an open house or an "overnight experience." These events are heavily promoted through postcard mailings to entice students to sample the university.

In all, we received more than a thousand pieces of mail with as many as a dozen pieces coming from the same institution. Boston University, for example, sent 11 pieces of mail to one student including letters, postcards, booklets on financial aid, and a view book. Some sent university magazines; others used postcards, a series of postcards or postcards in a single envelope. Many schools sent elaborate view books, beautiful catalogs that present key attributes, like the diversity of students, types of majors, financial aid, successful faculty and alumni, and career preparation (Hartley and Morphew 2008). These books are widely used by universities and they are the most important marketing tool next to the on-campus visit (Klassen 2000).

Some culling was done in order to arrive at the final sample set. Initial postcards and letters, which asked the recipient to contact the university or to attend an open house, are "call to action" marketing and were not included in the sample because they did not mention attributes or benefits. After eliminating these mailings, 97 pieces from 92 different institutions remained for analysis. Most of these pieces were either view books or brochures of varying sizes, though one school sent a newspaper and another a deck of cards describing aspects of the school. Six postcards were included in the analysis as they did not contain a "call to action," but rather presented university attributes. In total, 84 marketing pieces-87 percent-contain some mention of internships.

\subsection{Internship Effect-Learning or Debt}

In university marketing materials, internships are presented either as part of career building, or as experiential or co-op learning. They are offered in relationship to careers in more than half of the pieces (57 percent), while experiential learning was the focus in 30 percent of the pieces analyzed. We found this distinction to be helpful in that it highlights the extent to which the university promotes higher education as a stepping stone to employment versus an institution promoting knowledge acquisition supplemented with "real world" experiences. For example, career-building schools make claims such as "...you and your parents want your college experience to provide you with the tools you need for life after college. You need to have a

\footnotetext{
${ }^{8}$ Companies, in this case universities, buy mailing lists from list brokers or other institutions such as the testing companies. The universities do not have access to the names until a student contacts them directly.
} 
résumé with internships and/or field experiences that will enable you to walk into a job interview and land that first job" (College of Saint Rose), or "Punch up your résumé and polish up your career credentials through experiential learning. Who knows? You may even parlay your parttime internships into full-time employment" (Rutgers University, emphasis in the original). While Northeastern-an institution well known for its co-operative experiences-promotes its programs as "the integration of study and practice, creating an unparalleled way to learn." The former seems to promote college as something to get through simply as a path to a career; the latter is a journey of acquiring knowledge. We will look into these ideas more deeply here.

First, internships discussed as part of career building were presented in a number of different ways. Sometimes this was a simple line of copy. More often, however, internship information appeared as part of a two-page spread highlighting the university's career office. Included in this content would be how the university could help students acquire internships by providing access to databases or career counselling sessions or workshops. The level of importance placed on this is also evident in universities creating easily remembered URLs for the career office, such as careers. villanova.edu.

Location, access to expert faculty, and the specific internships the university could provide are used to differentiate a school's career-building internships. In terms of location, for example, Florida International University promoted its Miami location as having "amazing internships and potential careers-as well as countless opportunities for entertainment, arts, culture, recreation, restaurants, night life, and just plain fun!" More typically, New York University, the University of Houston, University of Southern California, Pomona College, University of Albany, and Emory promote the benefits of being in a large city and use that as a way to highlight their access to top-level internships. An example of promoting faculty experts and the types of internships available was a strategy used by Manhattan Marymount College (MMC):

An average MMC class includes just 18 students, giving you direct access to faculty who are experts in their fields. Learn from New York's finest authors, artists, entrepreneurs, economists, and performers, as they connect you to opportunities across the city. That includes some of the country's most interesting internships at places like Bravo, Citigroup, Versace, and the New York City Ballet. MMC internships give you a chance to apply what you've learned in the classroom in the real world of work.

Note here the list of companies promoted. Three out of four are in the media or glamour industries. If universities used this tactic of listing specific internships, entertainment-oriented companies were always included. Here are a couple typical examples:

Make professional connections and intern in New York City. St. John's students have interned at a wide range of organizations, including Madison Square Garden, U.S. Secret Service, Estee Lauder, Morgan Stanley, MTV, New York Mets, SONY and Time Inc.

Recent LIU Post internships placements include: Museum of Natural History, CHANEL, St. Jude's Children's Hospital, United Nations, New York Times, Z100. Our students earn an average of $\$ 2,500-\$ 4,000$ per semester through internships and co-ops.

What is disturbing about this last piece is the line that suggests students will earn a salary through the internships listed. I know from my own experience that these "glamour field" internships are not paid opportunities. This is not to say that students never make money from internships. In some cases they do. However payment comes from the well-endowed and prestigious university, not the hiring company. Hamilton College boasts its "larger-than-average Career Center staff, with a larger than average budget," which enables the college to financially support 55 students who pursue unpaid internships. Similarly, the University of Chicago promotes the Jeff Metcalf Internship Program, which "provides paid, substantive internships 
exclusively to UChicago students." Tufts also notes in their materials that they have grant funding to support full-time unpaid summer internships.

Additionally, statistics and alumni-particularly those in cultural industry careers-help to sell the university internship experience. Many schools listed the number of opportunities they had available (one school claiming as many as 1,500 ) as well as the percentage of students who had done one or more internships while at school. Villanova took this farther than any other university. Its view book included a chart called "Class of 2011: Internship statistics." This information was broken down by field of study and categorized into students with one internship, and students with two or more internships. Looking at the "all" internship line, 796 students did one internship and 362 did two internships or more. This is at a university where a class size is approximately 1,600 students, so nearly half the class participated in at least one internship. Among the statistics schools now quote is their ranking on the U.S. News \& World Report internship list. Pace, for example, exclaims in bold type: "One of the top 10 schools in the nation for placing undergraduates in internships," a line shown next to a copy of U.S News \& World Report - a readily recognizable symbol of excellence for prospective students. Alumni, notably those in glamour fields, are also used to promote internships. The University of Miami, for example, shows pictures of successful alums and provides quotes about their internship experience. From Erin Moyer, supervising producer for NBC digital entertainment: "I quickly tapped resources available to me to land two incredible internships in California between my junior and senior year." Misericordia University's brochure takes this one step further, devoting a full-page picture of a recent graduate standing in Yankee Stadium with the following quote:

Misericordia prepared me from day one. I was able to graduate early and start my internship search. Within a few weeks, I had a call from the New York Yankees-Mario J. Oliveri, Sports Management, Consultant, Premium Sales and Service, New York Yankees.

The emphasis on career over college is quite evident in the quote noting that "I was able to graduate early" as an important benefit because it allowed the then-student to finish his academics quickly in favour of his career path.

One extreme case of placing career before traditional college learning is Champlain College. As it states on its Open House postcard: "Champlain College offers the best career-focused education in the country." The school touts its "Upside-Down Curriculum" in which students select their major and begin internships in their first year, an obvious point of pride for the school since it appears multiple times throughout their materials. In a booklet highlighting why students chose Champlain, one states, "The internship possibilities. The one thing I was looking for after college was a job, and since Champlain has such amazing opportunities for internships, it was a main reason I came here." The school also uses a series of foldout brochures, each with a different rule. One, called "Rule No. 67: Develop Your Skills for a Career. Develop Yourself for a Lifetime," explains that students will learn to "market yourself strategically." "Rule No. 16: At Champlain, You Won't Just Receive an Education, You'll Experience One" reiterates the school's career focus and claims, "Our students' internships offer exceptional immersion in their field, doing work that often leads to job offers before graduation."

In contrast, those universities that promote service learning or experiential learning strongly underscore knowledge acquisition over career development. Internships are most often discussed as some element of off-campus study or out-of-the-classroom experience, which also might include co-op, field study, or study abroad. Some examples include:

King's College: "Our curriculum extends beyond the classroom and students are encouraged to study abroad, intern and participate in service projects to broaden their experience." 
Smith: "Through innovative programs, cross-disciplinary learning, and internship and service opportunities outside the classroom, she will explore why and how to make her unique mark in the world."

Alfred University: "Many of our programs require internships, clinical experiences that may include professional cooperative agreements for paid employment and internships..."

It is easy to see how very different the language is in contrast to universities that focus on internships as steps in the career ladder. Experiences outside the classroom are seen as opportunities to translate in-classroom learning to the field. Moreover, the emphasis is on the student and not the value of the internship, as the Smith example demonstrates.

Schools with long histories of experiential learning primarily promote their cooperative learning experiences, though a few also mentioned internships as a possible option. For example, Rochester Institute of Technology has the fourth oldest co-op program and according to their materials, "is a world leader in experiential education with distinct and diverse opportunities to apply your education to real-world problems and projects." Rensselaer, another technically oriented university, also promotes experiential learning through co-ops and internships as "an essential component of a Rensselaer education." Other schools promoting experiential learning stress the value and advantages of a co-op experience over an internship. For example, Drexel University says in its brochure, "Co-op is a lot more than an internship. It's a full-time, six-month professional position (\$16,000 average 6-month salary)." Notes a postcard from Antioch: "[...] our students can design aspects of their own course of study and are required to work four terms in full-time positions at nonprofits, in business or in the arts [...]" Rice University promotes experiential learning by highlighting the research opportunities associated with these; internships are barely mentioned. And, of course, Northeastern University (NU) promotes its cooperative education because the school "is recognized as the world leader in co-op." One NU piece-“"The Husky Handbook"-explains co-op opportunities and how a student might put together their four or five year plan, which includes classes, study abroad, several service or research co-ops or internships, and professional/business co-ops or internships. The school also sends out Northeastern Magazine, which explains this process in more detail over four pages. The magazine notes, "A Northeastern education is built on the transformative power of study integrated with experience..."

In total, twelve pieces (13 percent) had no mentions of internship. Two of these were religious institutions, such as Albert A. List College of Jewish Studies and LaSalle University. Several were private, prestigious research institutions, such as Amherst, Haverford, Rice, Vanderbilt, and Union. ${ }^{9}$ Rather than career and résumé building, these institutions promoted experiential learning and academic research as well as community and public service programs that would "make a difference in the world." Beyond academics, they promote attributes that enable them to differentiate them from the competition, what marketers call the "unique selling proposition." For example, Vanderbilt University promotes quality, claiming it is "Among the Best" and using the following statistics to support its claim: National Universities $17^{\text {th }}$, Best Value $11^{\text {th }}$, Economic Diversity Among Top-Ranked Schools $17^{\text {th }}$ (U.S. News \& World Report) and Best Value Among Private Universities $18^{\text {th }}$ (Kiplinger). Alternatively, Haverford focuses on its core benefit-its identity-which is one of being a tight-knit learning community, and University of Maryland promotes its student body. Many of the others mentioned jobs or the possibility of a big paycheck, but not specifically internships.

\footnotetext{
${ }^{9}$ Union had a series of view books and I only saw one of four. It is possible that internships are mentioned in one of the other three pieces I did not receive.
} 
Tellingly, the overuse of internships as a marketing tool for universities has become recognized. Boston University's view book says as much when it notes: "The fact that an elite university like BU offers internships is nothing to get excited about." The piece goes on to explain that it is the type of internships, the Boston location, and international experiences that set them apart from other universities. Given the current analysis, that is not likely to be true.

\section{Media Internships: A Misleading Sales Tool}

Experiential learning, international internships, co-op learning, and paid internships provide valuable experience and aid students in integrating class learning with real world experience. These positions are atypical, however, in the media industry despite the emphasis placed on these positions in marketing for US universities. Both from my experience working in the media industry as well as directing the internship program in a media studies department, I rarely saw a student receive a job offer after completing an internship. This is so unusual I can count the number of job offers on one hand, and this is not because the students were unprepared or underqualified.

One student I advised as an intern is a perfect example. Debbie (not her real name) was a solid A student who had completed all her coursework with the intention of doing an internship with a private media company that produces a magazine as well as being a cutting-edge film and television production company. She worked with this organization for four months putting in almost full-time hours, and both she and the company were more than satisfied with the experience. The company told her they were hoping to have a job for her when the internship was over. They were waiting to hear about whether there was funding for the position. After waiting several weeks and putting off her job search because of expectations of having this position, the student was told there would not be a job opportunity (a year later, the company had half a billion dollars in investment funding).

Debbie couldn't help but get swept up in the tide that is the internship economy. Sixty-three percent of students graduating in 2012 completed an internship while 28 percent completed two or more (Smith 2012). Large companies made offers to 69 percent of students while small companies made offers to only 39 percent of their interns (ibid.). This is important to note because the media industry is increasingly made up of smaller companies-the type less likely to make a full-time offer. Debbie was also typical in that being female and having an unpaid internship within the media industry is the norm, a situation that is sparking increasing criticism (Schwartz 2013; Perlin 2011). Further, according to the National Association of Colleges and Employers, students who participate in unpaid internships-the kind media students are likely to have-are less likely to secure a full-time position than those who had paid positions. Moreover, unpaid interns were hired at a rate of 37 percent, while those who did no internship fared only slightly less well at 35 percent (Holland 2014).

Not doing an internship, though, is unrealistic. As Ross Perlin (2011) notes, "the internship ... has emerged victorious as the unrivalled gateway to white-collar work..." (xi). As true as that is for students generally, it is more so for those interested in positions in the cultural industries. Employers in this category expect multiple internships to be on a graduate's résumé. I know this not only from my corporate experience, but also because graduates call me after being out of school for a year or two wanting to know if they can come back just to do an internship because they did not do one while they were still a matriculated student. Add to this that the often suboptimal experience at a media internship (Frenette 2013; Frederick 1997) -as opposed to a cooperative experience-is exacerbated by the fact that the positions are unlikely to be paid. This is because there is an oversupply of cultural workers and wages are suppressed by professionals transferring fields, such as musicians writing movie scores (Hesmondhalgh 2012). As long as people (students and other cultural workers as well) are willing to work for free or 
close to it, there is no rationale for corporations to either hire more people or to hire them at a reasonable wage.

Bidding wages to zero is bad enough. Worse still, the internship economy has reduced the value of the experience because there is a glut of ex-interns in the marketplace. The obvious next step to sustain internship value is for "employers" to increase the amount of time students must work to differentiate their experience. We are already seeing this: O Magazine, for example, requires students to work eight-hour days, five days a week, and some sports teams require a six month commitment.

The overworking strategy has backfired, however. A number of lawsuits involving entertainment properties have generated significant publicity and led companies-and universities - to re-examine their internship programs. One of these cases involved Hearst, parent company of $O$ Magazine as well as other publications, which was sued by interns and no longer lists internship opportunities on their career website. The most well-known of these cases was the 2012 case against another magazine publisher, Condé Nast, which was brought by two former interns who claimed they were paid less than a dollar an hour for labour that was equivalent to that performed by full-time employees (Bridges 2013). In response, Condé Nast cancelled its internship program beginning in 2014. Other cases involved Fox Searchlight, NBCUniversal, and a number of music companies, including P. Diddy's Bad Boy Entertainment. These suits have forced companies to rethink how they manage their internship programs. In the case of WABC-TV, for example, student interns are now being paid, which is a good thing. However, according to Jackson Lewis, a law firm that specializes in employment issues and consults with universities on internship policy, companies are becoming more cautious about even implying that an internship is the gateway to a job. On its website, the firm advises companies that "if the program is unpaid, the business should strongly consider asking interns to sign an agreement acknowledging the educational nature of the program, the program is unpaid, and the internship is not a direct route to employment" (Jackson Lewis n.d.)

Given all this, it is not surprising that there has been a backlash. Greig de Peuter, Nicole Cohen, and Enda Brophy (2012) note that there is a nascent movement to fight against the unfair enterprise of the internship economy and its implications for workers more broadly. This appears to be more active outside of the United States, which may be because US graduates have unrealistic expectations about what the job market holds. According to the Accenture 2014 College Graduate Employment Survey, only 18 percent of recent graduates thought they would earn $\$ 25,000$ or less, while in truth more than double that number (41 percent of those who had graduated in 2012 and 2013) are earning salaries in that range. In addition, the number of underemployed college graduates working in jobs that do not require their degree increased from 41 percent in 2013 to 46 percent in 2014 (O'Shaughnessy 2014).

\section{Conclusion: Toward a More Valuable University/“Real World” Experience}

Not all off-campus experiences are created equal. A research internship at a prestigious medical institution or a co-operative learning experience at a tech lab is not the same as an internship at MTV or Sony records or The Maury Povich Show. The former provide opportunities for students to expand their learning, enhance their classroom knowledge, and receive a salary, sometimes a very substantial salary. The latter more often may not. Even so, it is these glamour industry opportunities that are used to market higher education because they so appeal to the target prospect.

Misleadingly, internships in media and elsewhere are presented as the gateway to full-time employment. I say misleading because there is little evidence that an internship will lead to a job. In fact, companies are being advised to make sure that students know an unpaid internship is in no way a guarantee of a job offer, yet colleges and universities are doing the oppositepromoting internships as the conduit to employment. 
Marketing universities, both local and less prominent colleges as well as prestigious institutions, as purveyors of internships positions higher education as an adjunct to corporate concerns. Internships have been intertwined with universities because they require college credit, turning institutions of higher learning into de facto temp agencies. Students "need" to have an internship, but they cannot get one, particularly from a major media company, unless they are getting college credit. Colleges, then, have to set up a system for students to access internships. This includes not only developing relationships with corporations that can hire students, but also helping students with résumés and interview skills and providing tools and guidance for developing a career plan. In the end, it is a limited win for the student who may get some training, a win for the college who makes money from the student, and a win-win-win for the corporation which gets free labour, and a workforce trained by the university and paid for by the student. And while students can do non-credit internships, these too vary widely and none of them are with the major media institutions that aid in significant résumé building.

Universities will certainly continue to promote themselves in more intrusive ways given today's competitive and corporatized landscape. It is unlikely, however, that the trend of using internships to market higher education can continue. This is because students assume they need to do an internship and therefore they assume the college will provide them access to these positions. In conjunction with that, promoting internships is an attribute-based strategy that does not distinguish one college from another and is unlikely to work long term; as internships are becoming increasingly the norm it will be branding-or access to co-ops or paid opportunities-that enables a school to differentiate itself from its competitors. What that means, then, is that internships will need to be financed either by companies paying students for their labour or by colleges providing funding for these experiences or a combination of the two. Finally, the internship economy for media companies is going through considerable adjustments given the recent lawsuits and increasing criticism and anti-internship activism This is already leading to an increasing number of paid internships for students, but also a shrinking number of opportunities in some areas, notably magazines. The full fallout from these changes is yet to be seen.

More important, however, is for universities and companies to reevaluate what a mutually beneficial relationship might look like. Experiential learning when integrated into class work can prove invaluable without making the experience about a career. For example, I teach a class in social innovation. I bring in executives from companies working on socially conscious marketing and have students develop marketing campaigns with the assistance of these people in the field. Students get to work on real world problems contextualized within a critical frame, the company gets insights from young adults who are typically their target audience, and the students present a final product to a working client. That is a true win-win-win. Universities should require this sort of in-classroom participation as quid pro quo for providing student interns. It puts the emphasis back on learning and critical thinking, and lessens the focus on careers and paycheques.

In doing this research, I was most impressed with Haverford University, an institution that does not talk about internships. Rather, the school makes its mission to develop the whole student within a community of learners: "Once again, it all comes down to community: a shared sense of values, challenging and inspiring each other in the joy of pursuing our ambitions, looking at life through the eyes of all others around us, and imagining ways to enrich a world of which we are all a part." That is what marketing higher education should be: presenting a vision of learning that nurtures the real product-the student.

\section{References}

Anctil, Eric. 2008. Recommendations for Selling Higher Education. ASHE Higher Education Report 34

(2): 89-98. 
Aronowitz, Stanley. 2001. The Knowledge Factory: Dismantling the Corporate University and Creating True Higher Learning. Boston: Beacon Press.

Balmer, John, Mei-Na Liao and W. Wang. 2010. Corporate Brand Identification and Corporate Brand Management: How Top Business Schools Do It. Journal of General Management 35 (4): 77-102.

Banet-Weiser, Sarah. 2013. Rate Your Knowledge: The Branded University. In The Routledge Companion to Advertising and Promotional Culture, edited by Matthew McAllister and Emily West, 298-312. New York: Routledge.

Barton, David and David Treadwell. 1978. Marketing: A Synthesis of Institutional Soul-Searching and Aggressiveness. In Marketing Higher Education, edited by D. Barton, Jr. 77-84. San Francisco: Jossey-Bass.

Belkin, Douglas, 2014. State Funding for Colleges Rebounds Still, Support Remains 11\% Below Five Years Ago in Real Dollars. The Wall Street Journal, January 20. Accessed June 1, 2014. http://online.wsj.com/news/articles/SB10001424052702304757004579333001917794012.

Bidwell, Allie. 2013. College Enrollment Falls for Second Year in a Row. U.S. News \& World Report, December 12. Accessed June 1, 2014. http://www.usnews.com/news/articles/2013/12/12/collegeenrollment-falls-for-second-year-in-a-row.

Bidwell, Allie. 2014. Colleges Get More Funds, but Rely on Tuition. U.S. News \& World Report, April 14. Accessed October 18, 2014. http://www.usnews.com/news/articles/2014/04/21/states-increase-highereducation-spending-rely-on-tuition-in-economic-recovery.

Black, Jim. 2008. The Branding of Higher Education. Accessed June 1, 2014. http://www.semworks.net/papers/wp The-Branding-of-Higher-Education.php.

Bok, Derek. 2004. Universities in the Marketplace: The Commercialization of Higher Education. Princeton: Princeton University Press.

Bousquet, Marc. 2008. How the University Works: Higher Education and the Low-Wage Nation. New York: New York University Press.

Bridges, Frances. 2013. How Condé Nast Should Have Fixed Its Internship Program. Forbes, August 11. Accessed August 17, 2015. http://www.forbes.com/sites/francesbridges/2013/11/08/how-conde-nastshould-have-fixed-the-internship-program/.

Brock, Bob. 2013. How Much Do You Spend on Advertising. Accessed June 1, 2014. http://emgonline.com/blog/2013/09/how-much-do-you-spend-on-advertising/.

Bunzel, David 2007. Universities Sell their Brands. Journal of Product and Brand Management 16 (2): 152-153.

Carrocci, Lindsay. 2009. Representing the Promotional University: Undergraduate Student Recruitment Strategies in Ontario 1997-2007. Master's Thesis, University of Western Ontario.

de Peuter, Greig, Nicole Cohen and Enda Brophy. 2012. Interns, Unite! You Have Nothing to LoseLiterally. Briarpatch, November 9, 8-12.

Forbes. n.d. 10 Colleges that are Great Brands. Accessed June 1, 2014. http://www.forbes.com/pictures/eikh45ejjd/babson-college-babson-park-mass/.

Frederick, Jim. 1997. Internment Camp: The Intern Economy and the Culture Trust. The Baffler 9, 51-58.

Frenette, Alexandre. 2013. Marketing the Intern Economy: Role and Career Challenges of the Music Industry Intern. Work and Occupations 40 (4): 364-397.

Gibson, Carter. 2014. AU Needs To "Kill its Darling" WONK, and it Just Might. Accessed June 1, 2014. http://inthecapital.streetwise.co/2014/03/10/american-university-why-au-needs-to-end-its-wonkcampaign/.

Glazer, Emily and Melissa Korn. 2012. Marketing Pros: Big Brand on Campus: Under Pressure, Universities Hire Outsiders to Advise on Identity, Admissions Brochures, Twitter Feeds. Wall Street Journal, August 15. Accessed January 15, 2013. http://online.wsj.com/news/articles/SB10000872396390444233104577591171686709792.

Goldman, Robert and Stephen Papson. 1996. Sign Wars: The Cluttered Landscape of Advertising. New York: Guilford Press.

Hartley, Matthew and Christopher Morphew. 2008. What's Being Sold and To What End? A Content Analysis of College Viewbooks The Journal of Higher Education, 79 (6): 671-691.

Hearn, Alison. 2010. "Through the Looking Glass": The Promotional University 2.0. In Blowing Up the Brand: Critical Perspectives on Promotional Culture, edited by Melissa Aronczyk and Devon Powers, 195-218. New York: Peter Lang. 
Heller, Donald. 2011. The States and Public Higher Education Policy: Affordability, Access, and Accountability. Baltimore: Johns Hopkins University Press.

Hesmondhalgh, David. 2012. The Cultural Industries. Thousand Oaks: Sage Publications.

Holland, Kelley. 2014. That Unpaid Internship May Have Been a Waste of Time. CNBC, February 3. Accessed May 15, 2014. http://www.cnbc.com/id/101378307.

Holmes, Elizabeth. 2014. Why Online Retailers Like Bonobos, Boden, Athleta Mail So Many Catalogs: Shoppers Spend More Online After Browsing through Lavish Print Spreads. Wall Street Journal, April 16. Accessed April 16, 2014. http://www.wsj.com/articles/SB10001424052702304311204579505532568168984.

Howe, Neil. 2014. The Unhappy Rise of the Millennial Intern. Forbes, April 22. Accessed February 20, 2015. http://www.forbes.com/sites/realspin/2014/04/22/the-unhappy-rise-of-the-millennial-intern/.

Jackson/Lewis. 2014. Wage and Hour Considerations with Interns. Accessed May 30, 2014. http://www.jacksonlewis.com/resources.php?NewsID=4848.

Kamenetz, Anya. 2006. Generation Debt: How Our Future Was Sold Out for Student Loans, Bad Jobs, No Benefits, and Tax Cuts for Rich Geezers-And How to Fight Back. New York: Riverhead Trade.

Kelly, Kim. 2013. 10 Awesome Education-Related Advertising \& Marketing Campaigns of 2012. Accessed October 22, 2014. http://sparkroom.com/blog/2013/01/10-awesome-education-related-advertisingmarketing-campaigns-of-2012/.

Kirp, David. 2004. Shakespeare, Einstein, and the Bottom Line: The Marketing of Higher Education. Cambridge: Harvard University Press.

Klassen, Michael. 2000. Lots of Fun, Not Much Work, and No Hassles: Marketing Images of Higher Education. Journal of Marketing for Higher Education 10 (2): 11-26.

Knouse, Stephen, John Tanner and Elizabeth Harris. 1999. The Relation of College Internships, College Performance, and Subsequent Job Opportunity. Journal of Employment Counseling 36 (1): 35-43.

Lay-Hwa, Jana. 2011. Engaging the Student as a Customer: A Relationship Marketing Approach. Bowden Marketing Education Review 21 (3): 211-228.

Lowrie, Anthony. 2007. Branding Higher Education: Equivalence and Difference in Developing Identity. Journal of Business Research 60 (9): 990-999.

Meredith, Marc. 2004. Why Do Universities Compete in the Ratings Game? An Empirical Analysis of the Effects of the US News and World Report College Rankings. Research in Higher Education 45 (5): 443-461.

Miley, Melissa. 2009. Universities Finally Espousing Branding. Advertising Age 80 (20): 6.

Mills, Nicolaus. 2012. The Corporatization of Higher Education. Dissent, Fall, 6-9.

Monks, James and Ronald G. Ehrenberg. 1999. The Impact of US News and World Report College Rankings on Admission Outcomes and Pricing Decisions at Selective Private Institutions. NBER Working Paper No. 7227.

Naidoo, Rajani, Avi Shankar and Ekant Veer. 2011. The Consumerist Turn in Higher Education: Policy Aspirations and Outcomes. Journal of Marketing Management 27 (11-12): 1142-1162.

Natale, Samuel and Caroline Doran. 2012. Marketization of Education: An Ethical Dilemma. Journal of Business Ethics 105 (2): 187-196.

Noel-Levitz. 2013. Cost of Recruiting an Undergraduate Report. Accessed June 1, 2014. https://www.noellevitz.com/papers-research-higher-education/2013/2013-cost-of-recruiting-anundergraduate-student-report.

O'Shaughnessy, Lynn. 2014. New College Grads Too Optimistic About Job Prospects. CBS MoneyWatch, May 8. Accessed May 15, 2014. http://www.cbsnews.com/news/new-college-grads-toooptimistic-about-job-prospects/.

Perlin, Ross. 2011. Intern Nation: How to Earn Nothing and Learn Little in the Brave New Economy. New York: Verso.

Rampell, Claudia. 2013. It Takes a B.A. to Find a Job as a File Clerk. New York Times, February 20, A1.

Reimann, Martin, Oliver Schilke and Jacquelyn S. Thomas. 2008. Toward an Understanding of Industry Commoditization: Its Nature and Role in Evolving Marketing Competition. International Journal of Research in Marketing 27 (2): 188-97.

Sargeant, Adrian and John B. Ford. 2007. The Power of Brands. Stanford Social Innovation Review 5 (1): 41-47.

Schwartz, Madeleine. 2013. Opportunity Costs: The True Price of Internships. Dissent Magazine Winter. http://www.dissentmagazine.org/article/opportunity-costs-the-true-price-of-internships. 
Shoenfelt, Elizabeth L., Nancy J. Stone and Janet L. Kottke. 2013. Internships: An Established Mechanism for Increasing Employability. Industrial and Organizational Psychology, 6 (1): 24-27.

Slaughter, Sheila and Larry Leslie. 1997. Academic Capitalism: Politics, Policies and the Entrepreneurial University. Baltimore: The Johns Hopkins University Press.

Smith, Jacquelyn. 2012. Internships: The New Interview. Accessed June 1, 2014. http://blogsimages.forbes.com/jacquelynsmith/files/2012/12/internshipsinfographic.jpg.

Steck, Henry. 2003. Corporatization of the University: Seeking Conceptual Clarity. Annals of the American Academy of Political and Social Science, 585: 66-83.

Sung, Minjung and Sung-Un Yang. 2008. Toward the Model of University Image: The Influence of Brand Personality, External Prestige, and Reputation. Journal of Public Relations Research 20 (4): 357-376.

Toor, Rachel. 2002. Admissions Confidential: An Insider's Account of the Elite College Selection Process. New York: St. Martin's Griffin.

Tuchman, Gaye. 2009. Wannabe U: Inside the Corporate University. Chicago: University of Chicago Press.

Twitchell, James. 2005. Branded Nation: The Marketing of Megachurch, College Inc., and Museumworld. New York: Simon \& Schuster.

U.S. Department of Education, National Center for Education Statistics. n.d. Back to School Statistics, 2012. Accessed May 2, 2013. http://nces.ed.gov/fastfacts/display.asp?id=372.

U.S. Department of Education, National Center for Education Statistics. (2013). Digest of Education Statistics, 2012 (NCES 2014-015). Accessed January 26, 2012. http://nces.ed.gov/fastfacts/display.asp?id=76.

Waeraas, Arild and Marianne N. Solbakk. 2008. Defining the Essence of a University: Lessons from Higher Education Branding. Higher Education 57 (4): 449-462.

Washburn, Jennifer. 2006. University Inc.: The Corporate Corruption of Higher Education. New York: Basic Books.

WICHE (Western Interstate Commission for Higher Education). 2012. Knocking at the College Door: Projections of High School Graduates. Accessed June 1, 2014. http://www.wiche.edu/info/publications/knocking-8th/ch2.pdf.

Woodhouse, Howard. 2009. Selling Out: Academic Freedom and the Corporate Market. Durham: Acumen Publishing.

\section{About the Author}

\section{Mara Einstein}

Mara Einstein has been working in or writing about the media industry for more than 25 years. She is the author of Compassion, Inc.: How Corporate America Blurs the Line Between What We Buy, Who We Are and Those We Help (University of California Press 2012), which examines the growing trend of promoting and selling consumer products as a means to fund social causes and effective social change. This builds on her continuing research into the effects of consumerism on social and cultural institutions, ideas considered at length in her last book, Brands of Faith: Marketing Religion in a Commercial Age (Routledge 2007), a critique of promoting religion. She has a PhD in Media Ecology from New York University, an MBA from the Kellogg Graduate School of Management at Northwestern, and a BFA in theatre performance from Boston University. She is currently working on a new book entitled Black Ops Advertising: Native Advertising, Content Marketing and the Covert World of the Digital Sell (O/R Books 2016). 


\title{
"You Kind of Have to Bite the Bullet and do Bitch Work": How Internships Teach Students to Unthink Exploitation in Public Relations
}

\author{
Michelle Rodino-Colocino* and Stephanie N. Beberick** \\ *Penn State, University Park, USA, michelle@psu.edu \\ **Penn State, University Park, USA, snb182@psu.edu
}

\begin{abstract}
Based on critical analysis of three focus groups with PR students at Penn State, we argue that describing PR internships as "bitch work" highlights key material and ideological lessons about labour, gender, and exploitation. Analysing interviews of PR interns through Marxist and feminist perspectives, we explain the dynamics of viewing PR internships as "bitch work." We discuss how internships come to signify good luck in a lottery-like market while also instilling a love of work and the hope that "good work" will follow "bitch work." Such lessons, furthermore, teach interns to unthink work, our phraseology for the ideological process of viewing internships as almost-but-not-quite labour. We conclude with a call to rethink internships as work, recognize the gendered exploitation of interns, and compensate interns for their real labour.
\end{abstract}

Keywords: bitch work, college students, consolation, compensation, feminization, feminist critique, gender, ideology, internships, exploitation, free labour, hope labour, precarious work, public relations

Acknowledgement: The authors would like to thank Colleen Connolly-Ahern, Enica Castañeda, Bob Martin of the College of Communications at Penn State, special section reviewers and editors Enda Brophy, Nicole Cohen, and Greig de Peuter for their insights, and Isabel Fine for her editorial assistance. Thanks also to our audience and co-panelists at the Union for Democratic Communications conference in Toronto 2015 for feedback on an earlier draft of this essay.

"You kind of have to bite the bullet and do bitch work before you can work your way up the ladder, which is totally relevant in the PR industry" (Jessie, female senior Public Relations major). Jessie's assessment of her internship, shared during one of three focus groups we conducted at Penn State in central Pennsylvania with public relations majors who had previously worked as interns, serves as an apt description of the problem of internships. The essay explores how students conceptualize their labour as not labour but as "bitch work" that registers as close-to-but-not-quite exploitative. We also hope that the term "bitch work" can be appropriated as a rallying cry for collective mobilization against the exploitative aspects of internships.

To intern in public relations is to do "bitch work." Bitch work is the term one interviewee used and others expanded upon to describe aspirational grunt work undertaken as interns. Such language underscores interns' material and gendered exploitation, functions ideologically through distortion of such exploitation, and, through our appropriation of it here, offers a feminist critique of its material and ideological dimensions.

In public relations (PR), the field Jessie is studying, women make up 70-85 percent of the workforce below the executive level, whereas men make up 80 percent of upper management (Makovsky 2013). At Penn State, where Jessie attends school, 87 percent of Advertising/Public Relations (AD/PR) majors are women. Additionally, over three-fourths of unpaid interns in the US are women (Gardner 2011). According to three focus group interviews we conducted AD/PR majors enrolled in a PR course, women account for an overwhelming majority of unpaid internships. ${ }^{1}$ Our sample was 85 percent female (reflecting

\footnotetext{
${ }^{1}$ During the final week of the Spring 2014 semester we conducted three focus groups (of seven to 10 students each) that included 27 student interns (23 female and four male) who declared AD/PR majors in a PR course. The gender split parallels that in the major at Penn State. Participants were all juniors except for one senior. We
} 
enrolments in Penn State's AD/PR major), but women were even more disproportionately represented in the number of unpaid internships taken. ${ }^{2}$ Only one out of the 30 unpaid internships that participants listed in our pre-focus group survey was completed by a male student, whereas women worked in the remaining 29. Men, while comprising 15 percent of our sample, completed 30 percent of the paid internships. Over three-fourths of internships completed by students were unpaid (76 percent). ${ }^{3}$

Unpaid internships, however, do not seem to help graduates ascend career ladders. One national study finds that students without internship experience are only 2 percent less likely to receive a job offer than those who complete unpaid internships, and that those who complete unpaid internships are paid less in their first career-related jobs after graduation than those with no internship experience (Weissman 2013). Although the term bitch work connotes a feminized form of exploitation, both male and female undergraduates negotiate bitch work. As we explain in this essay, bitch work both names the gendered, exploitative realities of working as a PR intern and denies them.

Before proceeding it is worth considering the promise and pitfalls of centering the following critique around the term bitch work. For Jessie, bitch work constitutes grunt work that precedes the "good work" (Ashton and Noonan 2013, 5) that awaits her upon her ascent "up the ladder." Popular culture texts further elaborate on bitch work. As Urban Dictionary puts it, bitch work constitutes those tasks "given to lower level employees to keep them occupied for hours at a time, usually assigned by managers or higher level employees who are either too fat or lazy to complete the task at hand themselves." Putting a sexually objectifying spin on such language, Britney Spears' song "Work Bitch" asks, "You want a hot body? You want a Bugatti? You better work bitch. You want a Lamborghini? Sippin martinis? [...] Live fancy? Live in a big mansion? Party in France?" Jessie's and popular cultural notions of "bitch work," of course, derive from the derogatory word for "overbearing," "spiteful" women, to "lewd" or "immoral" women, and to female dogs ("Bitch" in MerriamWebster 2015). ${ }^{4}$ This essay, then, explores what it means to work like a "bitch."

The present essay puts Jessie's and the popular notion of bitch work into dialogue with our Marxist-feminist critical interpretation of the term. We critique bitch work by drawing attention to how the phrase works ideologically (as a cover or not-so-sweet-sounding euphemism for exploited labour) and materially as a descriptor of gendered exploited labour. Thus, we render the feminized aspects of "bitch work" visible. In so doing, we hope to appropriate the term as a feminist one as does Bitch Media, a feminist magazine, blog, and

recruited participants through a faculty colleague who announced the opportunity in an AD/PR majors-only PR class. Students participated for nominal extra credit points. All names have been anonymized-in place of students' real names we use pseudonyms suggested by participants. In all but one case, participants chose to express gender through a gendered pseudonym. In one case in which an interviewee selected a gender-neutral name, we asked if the student wanted to be perceived as male, female, or other (she wanted to be perceived as "female"). Focus groups ran approximately one hour and consisted of questions about what internships taught students. To initiate discussion, we asked participants to complete a short survey about their internship experiences. We also asked students to list the internships they completed and whether they were paid (and how much) or for credit (and in that case for how many credits). Survey and focus group questions are available from the authors upon request. Although interns found only four of the 48 internships they listed on their pre-interview survey through our College of Communication's internship office, we wanted to further contextualize our interviewees' experiences. To get a sense of the history of the program we interviewed Bob Martin, Dean of Internships and Career Placement. According to Martin's figures, the almost tenfold increase in the number companies listing internships with the office from $1999(450)$ to $2014(3,500)$ points to growing demands for intern labour. Martin expressed concerns about potential exploitation of interns and suggested that some form of monetary compensation for interns is warranted.

${ }^{2}$ These are the latest figures provided by the Advising Office of the College of Communications, October 27, 2014. Additionally, because we asked students to describe each of the internships completed during their college career, our list of paid and unpaid internships yields more internships than interns interviewed.

${ }^{3}$ Although these are not generalizable figures, they confirm findings of studies based on larger samples such as Gardner (2011).

${ }^{4}$ Merriam Webster Online, "Bitch," accessed July 15, 2015.

http://www.merriam-webster.com/dictionary/bitch. 
online media forum launched in 1996 as Bitch: Feminist Response to Pop Culture. ${ }^{5}$ Further, we agree with Bitch's editors that 'bitch' is an epithet hurled at women who speak their minds, who have opinions and don't shy away from expressing them, and who don't sit by and smile uncomfortably if they're bothered or offended." We hope that someday "bitch work" might gain traction in this way as a term for "talking back" as feminist media scholar Susan Douglas encourages readers to do (2010). At the very least, we hope that internship workers will understand and be able to discuss their exploitation as exploitation. We further hope interns will come to view their "bitch work" as a cause for collective political mobilization.

To explain how the PR interns we interviewed came to view internships as "bitch work" (but not quite as "exploitation"), we discuss how three smaller lessons teach interns that doing bitch work means not being a real employee who does real work. For interns, these smaller and often inter-related lessons also mean learning that internships signify good luck in a lottery-like market. Interns learn to "love" internships and learn to "hope" (Kuehn and Corrigan 2013) that internships will lead to the "good work" for which creative industries are celebrated (e.g. as work that yields personal satisfaction, happiness, and respectable pay; Ashton and Noonan 2013, Hesmondhalgh 2008). These three lessons teach interns to unthink work, our phraseology for the ideological process of viewing internships as almostbut-not-quite labour, and therefore not exploitable.

The following sections critically analyse each lesson as our interviewees described them. We attend to how these lessons may teach interns to unthink work by thinking about it as bitch work. We begin by discussing key theoretical concepts and our methodology. We conclude with a call to rethink internships as work, recognize the gendered exploitation of interns, and compensate interns for their labour. We hope that critical and feminist scholars of communication will work to eliminate the system that demands "bitch work" as a form of exploitation and utilizes it as a form of ideological cover.

\section{Exploitation, Ideology, and Feminization}

By "exploitation" we reference a more specific process beyond the word's connotative meanings of "use" and "to take advantage of." We apply Marx's (1876/2010) conceptualization of exploitation as it occurs through the extraction of surplus value in the labour process. According to Marx, surplus value is the ratio of "surplus labour" to "necessary labour." Socially necessary labour time is the amount of labour time it takes for workers to produce their wage. Surplus labour is the amount of time workers labour for the capitalist beyond the limit of necessary labour. The more surplus labour, the more surplus value workers produce. Surplus value may be increased by extending or intensifying the workday, thereby expanding absolute surplus value, or by shortening the amount of time it takes for workers to produce their subsistence, thus expanding relative surplus value. Relative surplus value increases as an effect of reducing the amount workers need to produce to cover living expenses, by devaluing labour power, or by making workers more productive for the wage they earn. "The rate of surplus-value," Marx argues, "is therefore an exact expression for the degree of exploitation of labour-power by capital, or of the labourer by the capitalist" (Marx $1867 / 2010,6)$. Thus workers may be exploited in multiple ways throughout their lives and differently according to their gender, race, class and a host of other divisions (Roediger and Esch 2012).

Without using Marx's terminology, the US Department of Labor (DOL) defines interns generally as "trainees" who, as opposed to workers, generate no surplus value for employers (United Sates Department of Labor 2010). Following Supreme Court precedent, one DOL fact sheet specifies "the term 'suffer or permit to work' cannot be interpreted so as to make a

\footnotetext{
${ }^{5}$ This feminist publication acknowledges that the term bitch may be "off-putting" to some people, but, they write, "we think it's worth it" because of the critical work the term does: "we stand firm in our belief that if we choose to reappropriate the word, it loses its power to hurt us" (About US 2015). We are, thus, in dialogue with Bitch's conviction about the critical potential of the term. First, by naming the problem of "bitch work," feminist and other critical communication scholars gain a useful conceptual tool for getting at the very kind of exploitation internships re/produce.
} 
person whose work serves only his or her own interest an employee of another who provides aid or instruction." More to the point, when a trainee's labour benefits employers, the DOL deems the trainee (intern) to be an employee. Putting it in Marx's terms, such interns, then, produce surplus value. Rates of unpaid interns' production of surplus value may be especially high compared to workers who earn income. Additionally, rates of surplus labour extraction are not consistent among industries that exploit interns. Some, especially men in the science and technology fields, are paid handsomely by internship standards prevailing in other sectors. Computer science majors in the US, 72 percent of whom upon graduation are men, reportedly enjoy the highest paid internships in the US, earning from $\$ 4,000$ to $\$ 7,000$ per month (Bort 2014; Miller 2014). Other interns, as essays in this issue of tripleC discuss, may earn no wages, sub-minimum wages, forms of payment-in-kind, or coverage of some costs of work. Additionally, some interns pay for their positions through college credits that cost tuition and registration fees.

Our ideological critique is attentive to both the real material exploitation of interning and the common sense that interns shared with us. We borrow Marx's concept of ideology to illuminate real material forms of exploitation. As interpreted by Michelle Rodino-Colocino (2012; see also Larrain 1991, 1996), Marx's concept of ideology describes the process of representing capitalist relations of production in ways that distort, and more specifically invert, such relations. These relations, furthermore, are inverted in reality. We explain ideology further below, but share one example for now: wages themselves are ideological as they make it appear to workers that they are paid for their time, when in actuality there is work time for which they are unpaid (i.e., "free labour" is an integral part of "paid labour" under the capitalist wage system). We discuss how lessons that internships teach make such ideological moves by rendering an already inverted material reality in ways that conceal, justify, and offer compensation and consolation for interns' exploitation. Without forgetting such real exploitation, we also argue that to understand the many layers of meaning "bitch work" signifies, we also need to "ask what is true," as Stuart Hall (1988) does when analysing the persuasive powers of Thatcherism. Here it is important to distinguish "true"-that which makes sense or rings true-from "truth," or that which refers to objective reality. "True," means "faithful, loyal, constant" and "in tune" (Oxford English Dictionary 2014). The hallmark of "true," Hall argues, is that it "makes good sense, which...is usually quite enough for ideology" $(1988,46)$. Conducting an ideology critique of internships means attending to both the "truth" and the "true" by considering how "bitch work" rings true and yet euphemizes the truth of exploitation.

Viewing internships as bitch work also points to the contention that the "new economy" demands the "cultural feminization" of labour (Adkins 2001). As feminist sociologist Lisa Adkins (2001) explains, the "cultural feminization" thesis holds that the post-industrialized First World requires workers to perform an "aesthetics of femininity" that attends to physical style and appearance (674). Linda McDowell (1997) finds evidence for the cultural feminization of work in interviews with financial workers. As Adkins (2001) argues, however, men and women are disparately rewarded for their feminine performances. Employees at one workplace interpreted men's feminine performance as springing from a skill set that merits reward, whereas women's feminine performance appeared as an unremarkable facet of their nature. Conservatives, meanwhile, have argued that today's job growth in the caring industries favours women, and thus, men should learn to be more feminine to compete (Perry 2008; Rosin 2010). Our interviews with undergraduate AD/PR majors find that the extent to which "bitch work" references cultural feminization (albeit not in such precise terms) illuminates a complicated set of gender relations caught between capitalism and patriarchy. Like Adkins, we argue that to the extent bitch work signifies exploitation, it should be contested. Additionally, as Madeleine Schwartz (2013) points out in her critique of internships, interns' free labour also mirrors the unpaid household labour women have long been expected to undertake (viewed as "helping" instead of as "work", paid by affective forms

\footnotetext{
${ }^{6}$ Below we discuss the six criteria the Department of Labour specifies as exempting interns from qualifying as "employees."
} 
of compensation).

The following three sections explore how interns come to view their labour as bitch work through the more narrow lessons of experiencing the internship market as a lottery, learning to love their internships, and hoping that bitch work indeed leads to good work. These lessons are intertwined, and at times one lesson leads to or supports another, as we explain in the sections below.

\section{Unthinking Work, Lesson One: Learning to View Internships as a Lottery Ticket}

The students we interviewed unthink work when they use language that describes the internships market as a lottery. As Nicole (who interned for a professional baseball team) describes her position: "it just made me feel really lucky because I was like, 'wow all of us are here because we are lucky'." Nicole's sentiments about "luck" suggest how competitive internship positions have become and what students are doing to find one. Vince boosts his odds of winning the intern lottery by blanketing the internship market with applications: "I applied to a bunch of places, too. I didn't really [get] anything. So I pretty much just took something local, like in my town." Similarly, Jill admits, "I probably contacted, like, literally 75 places and none of them responded, and the one I ended up getting was from a list from a club l'm in."

Anxiety about the future job market is palpable in the words of some interviewees like Nicole, who describes internships as a lottery ticket of sorts. Nicole expressed concern about companies like Condé Nast that eliminated its internship program during a class action lawsuit because, "if all of these awesome internships with these cool companies... say 'screw it', we just won't have interns." Consequently, an already tight contingent market will grow impossibly tighter, she explains. For Nicole, landing an internship is the prelude to landing a job, and thus, the internship position itself serves as a ticket in the job lottery-a chance to compete with the "hundreds of thousands of people just like us." The odds are steep. As she attests, despite her personal connection at the baseball team, Nicole applied for over 100 internships and was offered three. She chose to intern for the professional baseball team at $\$ 9.50$ per hour. Thus, Nicole describes herself as "lucky," especially after working as an unpaid intern in the retail fashion industry.

To boost their odds of getting an internship, interviewees combine the quantitative strategy Vince and Jill describe with the qualitative strategy of calling in personal connections. Nicole used a family connection to land an internship. Competition for any internship, let alone a "cool job" in a "hot industry" (Neff, Wissinger, and Zukin 2005) like professional sports is so intense that personal connections were described as even more important. Nicole thought her tactics were unique but soon learned they were hackneyed. As she says, "every single intern knew someone even more important than I did." Personal connections begat an internship for Elena: "I got my internship because I knew two people who worked at the PR firm that I worked at..." Summing up the importance of such connections, Elena concludes, "I don't know, I just think it all comes back to who you know." Jill agrees:

It's all because I know someone. And like I said it's becoming more and more the prominent thing. It's so much more competitive. Like, if you come out of college and you don't know anyone you're kind of screwed. And l've seen it more with the bigger companies... with the big name you need to know someone.

Thus personal connections, especially to an "important" person at a "bigger," "big name" company, increase the odds of landing "hot" internships in "cool" industries that advertising/PR majors seek. Internships, in turn, increase the odds of producing key personal connections. As Ross Perlin (2012) tersely puts it, "If personal connections grease the wheels of the job market, they are the motor powering the trade in internships" (165).

Understood in this way, internships also signify a classed and more subtly raced and gendered achievement. As David Lee (2013) argues, the importance of personal connections 
underscores the very social exclusivity of internship labour in high status fields that are attractive to students from middle-class professional families. Personal connections both signify class achievement and help reinforce it through the process of landing internships.

Jessie, who describes internships as "bitch work" recalls her reaction to the College of Communications' PowerPoint presentation:

[Y]ou should have four internships before you graduate. And I was like, "four?" That means I'll have to have one like every summer in between now and my senior year. One during the school year-or two [...] And I was like, how is that even possible? I remember last year, I applied so many places and it's so competitive. And taking something that was part time and unpaid and I just [...] some days I sat there and said "why am I doing this?"

Conversations we had with interns revealed a great deal of contradiction in students' perceptions of internships as means to improve their odds of landing future work, proving that in addition to the specific lessons internships teach it is difficult to nail down interns' own perspectives on their internship labour. One conversation turned from the greater anxiety students experienced about landing internships than landing jobs (Sarah shares, "I feel like I was more worried about not getting an internship than I am about getting a job") to the idea that one's college degree improved one's odds greater than did internships in the great career lottery. As Frank (a participant who wishes to be identified as female but chose a traditionally masculine pseudonym) responds to Sarah's concern, "I think that, like you said, [l am] more worried about getting an internship than getting a job." Frank explains, "I think that [concern] comes from the fact that we're so conditioned to feel that if we don't have an internship we're going to fail miserably at life and never get a job." Then Frank turns that logic around by arguing against the very necessity of internships and instead for the value of formal degrees, "Everyone feels like they need sixteen [internships] at a time, and we're also are more afraid of not getting internships than not getting jobs because once you have a degree, you are probably going to get a job." Thus, Frank describes the job market as competitive, but her university degree-not her internship-is the ingredient that in the last instance increases her odds of landing a job. In this way, Frank argues against the notion of internships as aspirational, lucky-to-get bitch work that improves chances of finding postgraduate paid work in the great career lottery.

We also want to flag that the notion of "bitch work" co-exists with other gendered language around internship labour. Frank prefaces her back-and-forth discussion of internships as lottery tickets and ends in themselves through masculinizing language she uses to describe pressure from her parents to find an internship:

Like I remember in February I went home for a weekend [and] my parents were busting my balls because I didn't have an internship in the summer. I was like, 'Dude, it's February!' So I immediately went back to school and started to apply for stuff and then I got something.

We find it significant that before conceding that a college education increases odds of landing future work more than do internships, Frank masculinizes herself ("busting my balls") and her parents (whom she collectively calls "dude"). Frank casts her active pursuit of an internship in the well-worn masculine mantle of seeking paid work as a breadwinner.

Although internships figured as lottery tickets to improve labour market odds, interviewees did not describe them as the kind of work or labour that is covered by US minimum wage laws. It is worth emphasizing the importance of Marx and Engels' (1996) argument that ideology operates like a "camera obscura" that turns real life phenomena on their heads. Interviewees are not merely imagining the long odds of landing internships; these odds exist in material reality. Nor are they alone, as students working in creative industries beyond advertising and public relations can attest (Hesmondhalgh 2010; Neff, Wissinger, and Zukin 2005). Discussing the internship and labour markets as lotteries of sorts, based on "luck," denies, or rather, unthinks the work they do as interns. It also glosses over the class privilege that interns mobilize to land such positions and the gender 
discrimination they will continue encounter-if the predominance of men in upper management is any indication-as public relations professionals. We are concerned that such logics prepare interns to endure bitch work instead of resist it.

For interviewees, therefore, internships did not feel exploitative in the Marxist sense. The interns we spoke with viewed their exploitation in an inverted way as a boon rather than as exploitation. Internship and job markets are highly competitive, however. Thus in today's contradictory and exploitative capitalist labour force, interns have reasons to feel "lucky" to work for free (or little, or at cost to them) in positions that may not guarantee future work and instead train them to expect low wage, precarious employment. Interviewees' discussion of internships, furthermore, suggests that the real (not false) competition for the positions combined with the (real) training received and (real) enjoyment experienced makes interns feel compensated. As Kira puts it,

You get paid kind of in knowledge and experience...in PR, in advertising, and communications in general, there's a 150 people who want the position that you have. So I think that you may not be getting paid, but if you're working a nine to five job where you love it and you're getting actual experience-things you can put in your portfolio, things you can talk about in a real job interview then you are kind of being paid.

Understood through the lens of Marx's ideology critique, internships provide consolation and justification for the creeping sense of exploitation that Kira experiences but does not explicitly recognize. Nor is Kira alone.

Sarah comes the closest to calling her unpaid internship exploitative, but then backs away by recourse to the internship-as-lottery theme:

I still think they [the company] made us do a lot more like [...] not exploit us, but they definitely had us do a lot and it's not like they don't have any money. So I don't understand why they didn't even pay us $\$ 8$ an hour.

As she equivocates, Sarah further illustrates the process of unthinking the work she is doing by expressing the luck and gratitude she feels in landing the position:

I don't want to say exploited because they did give me valuable experience. I applied to so many internships and this one, I was so lucky to get an interview with them because I didn't know anyone and a lot of people were there who did. I don't want to go and trash talk them, I just feel bad. They did give me such valuable experience.

Interns are not necessarily being duped by the enticement of winning the lottery or the promise of immaterial benefits, but they are being exploited. Interviewees may not experience their internship labour as labour and as exploitation, but the mechanism for their consent comes from the ways interns are taught to view (and emotionally experience) their internships. Another key lesson interviewees learned is to love their internships.

\section{Unthinking Work, Lesson Two: Learning to (Love) Labour}

Feeling compensated beyond wages (and credits) enables interviewees to think about internships as not work. ${ }^{7}$ But here lies a contradictory belief interns hold: hard work can indeed be its own reward, but what interns do is not necessarily experienced as "real work." Interns learned to love their internships. Loving their internships helps interns believe that their efforts are not worthy of pay and therefore do not constitute labour. Here Paul Willis' (1977) critical ethnography of working class lads is illuminating. Learning to Labour shows how working-class schoolboys participate in creating a culture where their manual labour (as opposed to white-collar, middle class labour) is expected, even if they resisted such expectations in some ways. Visiting factories where the boys would one day work, Willis

\footnotetext{
${ }^{7}$ Many of the interns we spoke with preferred doing not-for-credit internships during the summer so that they could avoid paying registration fees.
} 
observed a "masculine chauvinism" in shop floor culture. Families and schools taught this ethos to the lads, despite the rebelliousness they performed within their social groups. Thus, the lads were also engaged in ideological work that reflected and affected their working class status. Willis calls this process "learning to labour."

Instead of finding masculine chauvinism that teaches students to labour, we find that among interns we interviewed, learning to love labour reflects a cultural feminization. The cultural feminization of labour is not new, however. Loving one's labour has long justified women's free familial labour and helped represent such labour as not really (i.e., not productive) labour. Silvia Federici made the point poetically in 1975, "They say it is love. We say it is unwaged work" (Federici 2012; see also Fortunati 1996). Or as Giovanna Dalla Costa (2010) explains, the "ideology of love" whereby women in industrialized capitalism are taught to do unpaid work for family members (and above all, husbands) in exchange for "love" casts women's free domestic labour as "a labour of love" (location 253). It is really women's free labour that is being exchanged in what Dalla Costa describes as "the heaviest of ideological mystifications imposed on a labour relation" (location 253).

Women have been working under such relations since the mid 19th century in developed industrial capitalist countries.

Recognizing this history is especially helpful to account for how PR interns, most of whom are women, come to unthink labour through love and explains how such love may reproduce gender inequality in the field's intern and labour markets. PR as an industry demands women's emotional labour to such an extent that even female PR executives view the distinctive qualities required by the work as springing from women's natural essence (Pan 2014). As Arlie Hochschild (1983) argued over thirty years ago, learning to love work and working with a smile constitute emotional labour, a kind of work that is increasingly expected of women as paid employees. "Pink collar" workers, women working as flight attendants, secretaries, sales clerks, and PR professionals, for example, not only "sell" their personalities as C. Wright Mills (1915) discussed, but they perform the labour of showing their love for their work and indeed, loving their labour (Pan 2014). As early as the 1920s when 50 percent of secretaries in the US were women (Hesse-Biber, Nagy, and Carter 2000), they began figuring in management texts and popular culture as "office wives" who served as extradomestic spouses and sexual objects of desire (Davies 1982; Marcellus 2006). Scholars' attention to the "immaterial labour" (Hardt 1999; Lazzarato 1996) through which workers produce appropriate affect has extended interest in these questions, and is part of the broader "affective turn" of critical labour and sociological studies (Clough and Halley 2007). ${ }^{8}$

The ideological work of learning to love intern labour, as it has long operated for women as paid and unpaid workers, may help our interviewees unthink their intern labour as human power that produces surplus value (Marx 1867/2010) and, in the legal sense, as falling under the regulatory purview of the US Department of Labor. Like factory men imbued with a sense of masculine self-esteem attributed to their hard work well done (Willis 1977), Crystal's love of her internship springs from the pride she takes in the long hours she dedicated to her unpaid work for a fashion magazine:

Even though you're supposed to work from nine to five, it's not a nine-to-five job. It's really whenever you finish a job; you do it well. I would stay well past $5 \mathrm{pm}$ and leave with a smile on my face, and it wasn't just me. It was all the interns all the [time]. It just it sucks when it's summertime and you leave at $8 \mathrm{pm}$, but you do with a smile on your face and you are getting the job done and we had a great product and it's worth it.

"Getting the job done," in Crystal's description, made her so happy that she told us twice that

\footnotetext{
${ }^{8}$ While loving one's work serves as a labour discipline integral to a new economy dependent on image-selling (Gregg 2011; Wissinger 2007), we also recognize that encouraging internalized labour discipline has a longstanding history. Industrial managers overseeing male factory workers during the Progressive Era in the US from 1890-1920 wanted workers with "the type of discipline which wells up from beneath and is at least partially self enforcing" (Haber 1964, 130).
} 
her long work hours left her with a "smile on her face." Despite the lack of self-care brought on by long hours and tight deadlines, Crystal completed such work with a smile on her face because she had produced a "great product." Similarly, Frank states that, "Internships are absolutely essential to our happiness in life so that's why [...] it's so competitive to get an internship."

Nevertheless, it is also possible to read ambivalence in such statements. Happiness may indeed be seen as a form of payment when interns enjoy the work. Domingo alternates between happiness and dread (caused in part by parental pressure to find an internship) when describing his feelings during the internship application process:

I really put my focus into the places that I want to work, and my whole thing is like, I am not very concerned about the pay or whether it's paid or unpaid. It's just, I want to enjoy every second of what I'm doing. So I applied to a lot of places that would give me the opportunity to do that, but I know there's places that I applied to that I like would not even want to work there at all.

Domingo suggests here that compensation is of no consequence. Payment need not be exchanged for labour if he enjoys it. Domingo also demonstrates how compensation may take forms other than wages for interns, who in turn learn what to love about their work.

Interviewees' love of internships also springs from a sense that classes do not fully prepare them for future employment. This sentiment echoes critical scholarship on higher education and internships (Berger, Wardle and Zezulkova 2013; Lee 2013). Students like Kira value internships for teaching job-ready skills. An unpaid internship for a fashion magazine taught Crystal "what I really needed to learn for the job." As she puts it, internships prepared her to enter the workforce in PR "better than any of my classes." Other interviewees elaborated on the value of specific skills they learned. Kira appreciates learning "all the different parts of corporate PR," both "external" and "internal," right down the details of "doing... recruitment pitches for STEM [science, technology, engineering and mathematics] like how to get more kids into STEM and more [female] engineers." For Domingo, who worked with a university athletics department for one credit, "the biggest thing I took away is just to learn how to be a networker just in your everyday life." Watching his boss offer rides to new students, take people to lunch, and be available for his clientele taught Domingo that "Just really being connected with as many different people as you can...I think that's...the biggest thing I took away from the internship." Jessie is grateful for her unpaid internship because she "learned a lot about media planning [and] placement that I had not learned before." The most valuable thing Jessie learned was "responsibility," by which she meant, "taking charge of researching...interviewing, and showing up for work every day." "That type of experience," Jessie adds, "you don't get in the classroom."

Jessie, Domingo, Crystal, and Kira appreciate that form of compensation-training-that distinguishes "interns" from "employees." After all, gleaning knowledge and skills helps constitute the legal definition of internships as nonwork, and thus as training that is exempt from federal regulations and minimum wage laws in the US. As students gaining job training, interns are supposed to learn job-ready skills that their classes do not provide. As the DOL's Field Operations Handbook (FOH) specifies, "training is for the benefit of the trainees or students." To be exempt from minimum wage laws, moreover, internships must meet all six criteria outlined in the $\mathrm{FOH} .{ }^{9}$ Based on our focus group discussions, the criterion that internships fail to accomplish is the fourth, in which "the employer that provides the training derives no immediate advantages from the activities of the trainees or students, and on

\footnotetext{
${ }^{9}$ The US Department of Labor has determined that unpaid internships must meet all six unpaid internships must meet all six requirements: (1) the training, even though it includes actual operation of the facilities of the employer, is similar to which would be given at a vocational school; (2) training is for the benefit of the trainees or students; (3) the trainees or students do not displace employees; (4) the employer that provides the training derives no immediate advantages from the activities of the trainees or students, and on occasion operations may be actually impaired; (5) the trainees or students are not necessarily entitled to employment at the conclusion of their training period, and, (6) the employer and the trainees or students understand that the trainees or students are not entitled to wages during training (United States Department of Labour 2013; see also Perlin 2012, 66).
} 
occasion operations may be actually impaired." No matter how well-compensated students actually are in terms of training, no matter how deeply interns believe that the training they receive makes up for gaps in their education, by law a "trainee" becomes a "worker" who is due wages when an employer enjoys "immediate advantages" from the internship. Thus, interviewees' appreciation of the training offered through particular internships points not to their false consciousness about their exploitation but to the real conditions that enable it. As Perlin (2012, xiv) puts it, internships constitute "mass exploitation hidden in plain sight."

Such sleight of hand is possible because interns learn to love their labour, and further, because some interns feel loved by those for whom they labour. Such love is further justified, as our interviewees explained, because they come to believe that their bosses care about their welfare. Crystal, who interned for a corporation that faced a class action lawsuit for its unpaid internship program explained that the recent spate of interns' lawsuits may lack merit:

I didn't feel exploited because, sorry if I did stay late, like I said, if we had to work late hours, they did buy us dinner, and it wasn't like they didn't care about us. My boss... invested in me and she knew that I was commuting from Long Island so if I needed to leave a little earlier than some of the girls who were living in NY dorms, I could.

For Crystal, payment in kind/ness served as an acceptable substitution for wages. It is also telling that Crystal references a caring community where her co-workers are "girls" who live in dorms and her boss is a woman. Does Crystal take for granted this feminized work community, given the feminization of public relations? Would she have perceived the boss's concern for her as caring had her boss been a man? As Adkins (2001) suggests, male workers who engage in feminized work performances are more likely to be rewarded than are women. Women's caring labour is overlooked as an essential trait of femininity (thus not deserving of promotion or higher pay when women perform it). Does Crystal's boss, then, get paid materially for her empathetic treatment of her workers? These questions suggest lines for future research.

Nevertheless, this sense of belonging to a female work community that cares about individuals gets at what Hector Postigo (2009) calls "passionate labour" in his study of the making and unmaking of such labour among AOL volunteers. As Postigo notes, potential for challenging that passion is ever-present in working conditions that are exploitative but do not "feel" that way. Confirming Postigo's findings, interviewee Parker maintains that she is "really passionate" about the interns' lawsuits; she finds unpaid internships to be "ridiculous." She further faults unpaid internships as "the bullet you have to bite" so that it "will all be worth it." Interviewees, moreover, imagine future gain to explain present exploitation as something else. Kathleen Kuehn and TC Corrigan (2013) call working in anticipation of future reward "hope labour," and it serves here as a key ingredient in unthinking work.

\section{Unthinking Work, Lesson Three: Got Hope (Not Exploitation)?}

As Kuehn and Corrigan $(2013,10)$ conceptualize it, hope labour is that "un- or undercompensated work carried out in the present, often for experience or exposure, in the hope that future employment opportunities may follow." Working for hope provides a feeling of immediate pay: although interns understand they are deferring material pay and security, they maintain hope in the present for a better future. Hope labour, therefore, provides ideological compensation and consolation. For our interviewees, a pervasive sense of hope seemed to make up for, if not displace, a sense of exploitation. Without recognizing the labour they did or the surplus value they created, the students we spoke with hoped their internships would make them attractive job applicants. Rachel explains how a combination of hard work and recognition of self-improvement for a future job served as compensation in unpaid internships at one Chamber of Commerce and athletics department,

I think especially taking initiative and going the extra mile and doing things beyond what you're expected. Like they really take notice of that and, like, take that to heart and know, like, you're not just there for an internship. Like you really are invested in making yourself 
better, a better person for the future and helping their company or whatever organization you're working for.

Here Rachel expresses the importance of showing future employability through hard work that registers with employers. Rachel's hard work is, furthermore, performative: it demonstrates being "invested in making yourself a better person for the future." Like the AOL workers Postigo studied, Sarah learned to appear "really passionate and [to] conduct yourself well" to gain an advantage over other job applicants "by the time you get to that real interview process." Rachel and Sarah hope that their internships provide advantages in "the future" and in "that real interview process." For them lessons learned about loving labour and being "passionate" about it underwrite hope labour.

Bitch work is necessary grunt work interviewees endure because it improves their résumé and thus hopefully increases the odds of finding work after graduation. As Frank explains, "[W]e don't have a choice. It's either take these kind of grunt work internships for absolutely no compensation or have nothing on your résumé and never get hired." Guy, the male student in our sample who completed an unpaid internship, adds that playing for the future is an understandable strategy: "Well the way I see it, you take the unpaid now; I mean it's justifiable. Take the unpaid now for further experience, and then when you come out of school that's when you really go for the job you really want." In other words, if postgraduate jobs are "real," internships by comparison are not.

Furthermore, hoping for a better job ideologically distorts the exploitation interns experience by making internships feel like not-quite-real labour, as a liminal but not quite exploitative experience. Describing the online free labour of Yelp.com posters and sports bloggers on SB Nation, Kuehn and Corrigan (2013) argue that "[h]ope labour functions because it is largely not experienced as exploitation or alienation, despite the commodification processes inherent to digital and cultural production" (12). Hope may nudge Yelpers, bloggers, and intern labourers into feeling their work as not real work and thus, as not possibly exploitative. For Jessie the telos of her "bitch work" was landing a $\$ 22 / \mathrm{hr}$. plum internship that she calls a "job." When we asked her to specify whether this position was a job or internship, Jessie answered, "It's an internship that hopefully will be leading to a job."

Hoping that bitch work will one day lead to paid work, interviewees communicated ambivalence about whether interns should sue employers for being exploited as free or cheap labour. ${ }^{10}$ When asked if they thought the recent spate of class action lawsuits in the US against interns' employers had merit, Cecily explains,

I feel like there's a really big fine line between like exploitation and just like you're not getting the right amount of compensation. And I feel a lot of these lawsuits are about the interns want to be paid like they're actual employees. But we don't have our degree, so it's kind of ridiculous to ask for that amount [...]

Cecily locates the "really big fine line" between "exploitation" and "you're not getting paid the right amount of compensation" by considering the presence of harm. Far from supporting the lower threshold for exploitation that the Department of Labor applies, Cecily argues, "I feel like I would only file a lawsuit if I was actually seriously being harmed in some way. Like if it were really big." Although she does not specify how she may be harmed, she emphasizes the damage would have to be significant for her to sue her internship employer. Rachel agrees and articulates a lack of harm with presence of training, hope, and luck:

[I]f you're not being harmed and you're being treated [respectfully], and you're learning things from these people that's going to help you more in the long run than being paid $\$ 10$ an hour. Like, that money's going to go out the window anyway. So just be thankful that you have an internship that a lot of people would be looking for.

\footnotetext{
${ }^{10}$ See Daniel Miller's (2014) discussion of class action lawsuits that were being reported in the media around the same time as our focus group interviews.
} 
Nadia echoes Rachel's views, citing the temporary nature of internships that also promises upward mobility:

\begin{abstract}
Yeah I agree with that. Because I feel that people forget that an internship is supposed to be a learning experience. It's not supposed to be your job. Like you're not going to be there for the rest of your life. You're there for the summer to learn about the company or the work that it does or if that's like the work that you want to be in. I think people forget that it's supposed to be a learning experience [...] [T]hat's where, like, the boss starts. The boss did that once.
\end{abstract}

The boss, Nadia proposes, started their career as an intern, thus Nadia has reason to hope for such upward mobility in her PR career. Allison calls this "a benefit in the negative of internships."

Other interviewees' ambivalence about deeming internships to be exploitative connects the three smaller lessons that teach the broader ideological lesson of viewing internships as bitch work that precedes real, good work. According to Kira,

I think if it is something where they are making you run rampant and get food for the office-and I kind of think Devil Wears Prada, like Andy—but not getting paid, not a full time employee, like, being treated poorly by your boss and not being treated like a person, then that's something where you might want to take legal action. [...] But I think that it is a very fine line. We're in college and times have changed and there's even post grad internships now for agencies. You leave college. You have a degree and they're still going to pay you $\$ 10$ an hour in an agency and call you an intern because they can because this industry is getting so competitive. And so popular that they can do it, and as long as you are getting something real out of it I don't think it's necessarily exploiting them.

Instead of portending further exploitation in the job market, postgraduate internships signify the reality of heightened competition and thus low pay. Kira looks at one of the six criteria the DOL lists as necessary for exempting pay as the one that precludes interns from being exploited. While this perspective does not extend as far as that of the DOL, it seems to ring true among interviewees who do not see internships as exploitative. Borrowing the language of hope labour to communicate ambivalence about the highly competitive media industries of sports and fashion, Parker explains:

You know everyone like wants to be in the industry whether it be like sports or just like being in New York or fashion, whatever. They're so competitive that someone's going to take it whether it's you, or when you walk away, someone else. So yeah, it makes me really mad. But $[\ldots]$ hope it pays off.

Parker is "mad" and yet "hopeful." She is mad at the thought of not getting paid for her work but hopeful that the unpaid work will pay off in the future by helping her find work in the media industry of her choice. Thus, the bitch work in which interviewees engage as interns also works like the "aspirational labour" Brooke Duffy (2015) describes in her study of female digital cultural producers in beauty, fashion, and retail. These workers combine the second and third lessons we discuss here by engaging in "productive activities that hold the promise of social and economic capital" and promise the more immediate payoff of "doing what you love" (1-2).

Thus, internships do pay. They do compensate and console in the way that ideology does. Most of the internships discussed by our interviewees, however, did not pay materially in the present, even when interns engaged in enjoyable tasks. In this way, internships teach ideological lessons as they exploit labour in Marx's sense of the word and according to the US Department of Labor.

\title{
5. Conclusion
}


Our public relations students view internships as the bottom rung on a ladder constructed by bitch work and made bearable by hope, love, and luck. Such a view enables them to unthink work, and with it their exploitation as workers who produce surplus value. Therefore, we propose that critical scholars of communication intervene in the ideological work of internships and the exploitation they enable.

First, we should encourage our students to rethink work. We find it significant that at the end of each focus group when the recorder was off, participants discussed a sense of relief in finally giving voice to pent-up frustrations around internships and future employment. Students are ready to have such conversations. Public relations courses, job preparation seminars, and campus internship offices should inform students of their rights as workers. At the very least we should make the laws governing work accessible to students. More than this, however, we can help them understand the law. Furthermore, in an atmosphere in which higher education instructors feel pressure to train job-ready students, we should not abandon our ethical responsibility to prepare labour-force-ready graduates. By this we mean preparing students to respond to unethical and illegal exploitation of their labour as interns. We should also become engaged in policy building around internship labour. Penn State's Bob Martin, our head of internships and career services, suggests paying interns. We agree that paying interns is warranted (legally and ethically), and we support compensation for interns when they are engaged in work that provides "immediate advantages" to employers, as the US Department of Labour requires. We advocate debate around how to pay and when to pay interns as employees. Additionally, we should share feminist and Marxist critiques of labour and bitch work in the classes we teach. We want to challenge ourselves and our students to interrogate "bitch work" as symptomatic of patriarchal and capitalist exploitation.

The term is, furthermore, ripe for appropriation as a rallying cry for collective mobilization. Much as "sweatshop labour" names the exploitation of un- and under-paid, overworked workers who make university logo memorabilia, "bitch work" can so name that labour that universities tacitly and often publicly endorse. Additionally, we hope that "bitch work," like "sweatshop labour," enters the campus social movement lexicon and inspires action, challenge, and change. As the editors of Bitch Media intend for their audience, we hope that tripleC's readers-as academics who may supervise student interns and promote internships more broadly - will cease to "smile uncomfortably if they're bothered or offended" by the exploitation they witness or hear about when teaching and advising students. We want readers to work for the day when we can say (borrowing from Bitch), "if being an outspoken [worker] means being a bitch, we'll take that as a compliment" (About Us 2015). We want readers to join with interns in "bitch sessions" that collectively mobilize workers in effecting systemic change. Then we may turn our inverted relations of production upside-up, spreading the benefits among those whose labour creates the very industries students hope they are lucky enough to love.

\section{References}

About Us. 2015. Bitch Media. Accessed May 14, 2015. http://bitchmagazine.org/about-us. Adkins, Lisa. 2001. Cultural Feminization: "Money, Sex and Power" for Women. Signs 26 (3): 669695.

Ashton, Daniel, and Caitriona Noonan. 2013. Introduction: Cultural Work and Higher Education. In Cultural Work and Higher Education, edited by Daniel Ashton and Caitriona Noonan, 1-24. Palgrave New York: Macmillan.

Berger, Richard, Jonathan Wardle and Marketa Zezulkova. 2013. No Longer Just Making the Tea: Media Work Placements and Work-Based Learning in Higher Education. In Cultural Work and Higher Education, edited by Daniel Ashton and Caitriona Noonan, 87-109. New York: Palgrave MacMillan.

Bort, Julie. 2014. 7,000 A Month! Look at the Incredible Salaries Summer Tech Interns Are Earning. Business Insider, June 29. Accessed December 2, 2014. http://www.businessinsider.com/insanesalaries-for-tech-interns-2014-6?op=1\#ixzz3IIPValGr.

Clough, Patricia Ticineto and Jean Halley, eds. 2007. The Affective Turn: Theorizing the Social. Durham: Duke University Press. 
Dalla Costa, Giovanna Franca. 2010. The Work of Love: Unpaid Housework, Poverty and Sexual Violence at the Dawn of the 21st Century. Translated by Enda Brophy. New York: Autonomedia. Kindle.

Davies, Margery W. 1982. Woman's Place is at the Typewriter: Office Work and Office Workers 18701930. Philadelphia, PA: Temple University Press.

Douglas, Susan. J. 2010. Enlightened Sexism: The Seductive Message that Feminism's Work is Done. New York: Times Books.

Duffy, Brooke Erin. 2015. The Romance of Work: Gender and Aspirational Labour in the Digital Culture Industries. International Journal of Cultural Studies. Accessed May 14, 2015. Online first at: http://ics.sagepub.com/content/early/2015/02/25/1367877915572186.full.pdf+html.

Federici, Silvia. 2012. Wages Against Housework. In Revolution at Point Zero: Housework, Reproduction and Feminist Struggle. Oakland: PM Press.

Fortunati, Leopoldina. 1996. The Arcane of Reproduction: Housework, Prostitution, Labour and Capital. New York: Autonomedia.

Gardner, Phil. 2011. The Debate Over Unpaid College Internships. Austin: Intern Bridge.

Gregg, Melissa. 2011. Work's Intimacy. Cambridge: Polity Press.

Haber, Samuel. 1964. Efficiency and Uplift: Scientific Management in the Progressive Era 1890-1920. Chicago: University of Chicago Press.

Hall, Stuart. 1988. The Toad in the Garden: Thatcher among the Theorists. In Marxism and the Interpretation of Culture, edited by Cary Nelson and Larry Grossberg, 35-58. Urbana: University of Illinois Press.

Hardt, Michael. 1999. Affective Labor. Boundary 226 (2): 89-100.

Hesmondhalgh, David. 2008. Cultural and Creative Industries. In The SAGE Handbook of Cultural Analysis, edited by Tony Bennett and John Frow, 552-569. Thousand Oaks: Sage.

Hesmondhalgh, David. 2010. User-Generated Content, Free Labour and the Cultural Industries. ephemera: theory \& politics in organization 10 (3/4): 267-284.

Hesse-Biber, Sharlene Nagy and Gregg Lee Carter. 2000. Working Women in America: Split Dreams. New York: Oxford.

Hochschild, Arlie. 1983. The Managed Heart: Communication of Human Feeling. Berkeley: University of California Press.

Internship PowerPoint. Accessed June 18, 2014. http://comm.psu.edu/career-services-andinternships.

Kuehn, Kathleen and Thomas F. Corrigan. 2013. Hope Labour: The Role of Employment Prospects in Online Social Production. The Political Economy of Communication 1 (1): 9-25.

Larrain, Jorge. 1991. Marxism and Ideology. Vermont: Gregg Revivals.

Larrain, Jorge. 1996. Stuart Hall and the Marxist Concept of Ideology. In Stuart Hall: Critical Dialogues in Cultural Studies, edited by David Morley and Kuan-Hsing Chen, 47-70. New York: Routledge.

Lazzarato, Maurizio. 1996. Immaterial Labour. In Radical Thought in Italy: A Potential Politics, edited by Paolo Virno and Maurizio Lazzarato, 133-147. Minneapolis: University of Minnesota.

Lee, David. 2013. Creative Networks and Social Capital. In Cultural Work and Higher Education, edited by Daniel Ashton and Caitriona Noonan, 195-213. New York: Palgrave MacMillan.

Makovsky, Ken. 2013. Women in Leadership in PR. Forbes, February 25. Accessed December 2, 2014. http://www.forbes.com/sites/kenmakovsky/2013/02/25/davos-blog-1-women-in-leadership-inprl.

Marcellus, Jane. 2006. Women as Machine: Representation of Secretaries in Interwar Magazines. Journalism \& Mass Communication Quarterly 83 (1): 101-115.

Marx, Karl and Frederick Engels. 1996. The German Ideology. Edited by C.J. Arthur. New York: International Publishers.

Marx, Karl. 1867/2010. Capital: A Critique of Political Economy, Vol. I. Accessed October 31, 2014. http://www.marxists.org/archive/marx/works/1867-c1/.

McDowell, Linda. 1997. Capital Culture: Gender at Work in the City. Malden: Blackwell.Miller, Claire Cain. 2014. Some universities crack code in drawing women to computer science. The New York Times, July 17. Accessed December 2, 2014. http://www.nytimes.com/2014/07/18/upshot/someuniversities-crack-code-in-drawing-women-to-computer-science.html? $\quad r=0 \& a b t=0002 \& a b g=1$.

Miller, Daniel. 2014. NBCUniversal to settle suit by former interns for $\$ 6.4$ million, Los Angeles Times, October 24. Accessed November 17, 2014. http://www.latimes.com/entertainment/envelope/cotown/la-et-ct-nbc-interns-lawsuit-settlement20141024-story.html.

Mills, C. Wright. 1951. White Collar; the American Middle Classes. New York. Oxford University Press. 
Neff, Gina, Elizabeth Wissinger and Sharon Zukin. 2005. Entrepreneurial Labour Among Cultural Producers: "Cool" Jobs in "Hot" Industries. Social Semiotics 15 (3): 307-334.

Oxford English Dictionary. 2014. In Oxford Reference Online, Penn State Library databases. Accessed November 14, 2014.

Pan, Jennifer. 2014. Pink Collar. Jacobin. Accessed May 14, 2015. https://www.jacobinmag.com/2014/06/pink-collar/.

Perlin, Ross. 2012. Intern Nation: How to Earn Nothing and Learn Little in the Brave New Economy. London: Verso Books.

Perry, Mark J. 2008. It's a "Man-Cession" in a Lipstick Economy. Carpe Diem, December 9. Accessed December 2, 2014. http://mjperry.blogspot.com/2008/12/its-man-cession-in-lipstick-economy.html.

Postigo, Hector. 2009. America Online Volunteers: Lessons from an Early Co-Production Community. International Journal of Cultural Studies 12 (5): 451-469.

Rodino-Colocino, Michelle. 2012. "Feminism" as Ideology: Sarah Palin's Anti-feminist Feminism and Ideology Critique. TripleC: Cognition, Communication, Co-operation 10 (2). Accessed June 13, 2014. http://www.triple-c.at/index.php/tripleC/article/viewFile/414/372.

Roediger, David. R. and Elizabeth. D. Esch. 2012. The Production of Difference: Race and the Management of Labour in US History. New York, NY: Oxford University Press.

Rosin, Hanna. 2010. The End of Men. The Atlantic. Accessed June 8, 2015. http://theatlantic.com/magazine/archive/2010/07/the-end-of-men/308135.

Schwartz, Madeleine. 2013. Opportunity Costs: The True Price of Internships. Dissent Magazine: $A$ Quarterly of Politics and Culture. Accessed June 13, 2014. http://www.dissentmagazine.org/article/opportunity-costs-the-true-price-of-internships.

United States Department of Labor. 2010, April. Fact Sheet \#71: Internship Programs under the Fair Labour Standards Act. Accessed October 31, 2014. http://www.dol.gov/whd/regs/compliance/whdfs71.pdf.

United States Department of Labor. 2013. FLSA Coverage-Employment Relationship, Statutory Exclusions, Geographical Limits, Trainees and Student Trainees, Chapter 10, Sectionb11. Field Operations Handbook. Accessed October 27, 2014. http://www.dol.gov/whd/FOH/FOH_Ch10.pdf.

Weissman, Jordan. 2013. Do Unpaid Internships Lead to Jobs? Not for College Students. The Atlantic. Accessed June 13, 2014. http://www.theatlantic.com/business/archive/2013/06/do- unpaidinternships-lead-to-jobs-not-for-college-students/276959/.

Willis, Paul E. 1977. Learning to Labour: How Working Class Kids Get Working Class Jobs. New York: Columbia University Press.

Wissinger, Elizabeth. 2007. Modelling a Way of Life: Immaterial and Affective Labour in the Fashion Modelling Industry. ephemera: theory \& politics in organization 7 (1): 250-269.

\section{About the Authors}

Michelle Rodino-Colocino

Michelle Rodino-Colocino serves as Associate Professor of Media Studies and Women's Studies at Penn State. Her research and teaching interests focus on labour and new media from perspectives spanning critical-cultural and feminist studies. Rodino-Colocino has received awards for her research and teaching and has served on the Steering Committee of Union for Democratic Communications and as program planner for the National Communication Association's Critical and Cultural Studies Division. Her research articles have appeared in Communication and Critical/Cultural Studies; Communication, Culture \& Critique; Critical Studies in Media Communications; New Media \& Society; and Feminist Media Studies, among others.

\section{Stephanie N. Berberick}

A doctoral student in the College of Communications at Penn State, Stephanie "Stevie" Berberick conducts research and teaches in critical-cultural and feminist media studies. Berberick earned her MA from the University at Buffalo (SUNY), where she was awarded a prestigious Arthur A. Schomburg Fellowship. She has published her research in The New York Sociologist and has presented her scholarship around the US and at international conferences. 


\title{
Negotiating Educated Subjectivity: Intern Labour and Higher Education in Hong Kong
}

\author{
Ip lam Chong
}

\author{
Lingnan University, Hong Kong, chong@ln.edu.hk
}

\begin{abstract}
This article examines interns' negotiation of their work identity, with a focus on the nexus of transformations in higher education and the "new" capitalist economy. The existing literature on internships emphasizes the restructuring of employment in creative and cultural industries, the surplus cultural labour supply, and the impact of internships on the career paths of educated youth mostly in western countries. Based on interviews and participant observation in Hong Kong, I argue that the intern's "educated subjectivity", nurtured by new values and practices of higher education such as selfreflexive learning and interfacing with community, plays an important role in the making of the intern economy. These values and practices contribute to the ambiguity and elasticity of the role of interns identified in previous research on internships.
\end{abstract}

Keywords: internships, cultural work, higher education

Acknowledgement: The author thanks the special issue editors and the anonymous reviewers for their helpful comments and suggestions.

Since 2001, my colleagues and I have taught a summer internship course, which was set up by the Department of Cultural Studies of Lingnan University in conjunction with partner institutions in three areas: media, performing arts groups, and community organizations. Over the past four years, the course has been an elective credit in the Bachelor of Arts program. ${ }^{1}$ According to course evaluations, most students appreciate this course and are satisfied with what they learn from their internship. However, I eventually discovered that few of the students enter full-time employment in the areas of the internship program upon graduation. This outcome does not seem to be tied to the availability of jobs; in fact, some of the participants were not eager to find employment in the areas in which the interned. In light of this, I was increasingly puzzled as to why students reported that their unpaid internships were significant and valuable to them.

Despite the lack of official figures on student interns, internship schemes, and their contribution to Hong Kong's economy, the number of schemes and placements is growing. For instance, the number of participants in internship programs offered by Lingnan University has climbed from 185 in 2011 to 295 in 2014, growing an average of 17.4 percent per year. ${ }^{2}$ While the Hong Kong government affirms universities' effort to extend internship programs, the "employability" agenda does not loom large over educational concerns. The primary reason is that Hong Kong's job market looks healthier than that of most advanced economies (Government of the Hong Kong Special Administrative Region 2012, 83). In the second quarter of 2014, the youth unemployment rate for the 25-29 age group and university graduates was merely 3.5 percent and 2.7 percent respectively, which is close to Hong Kong's overall unemployment rate (Government of the Hong Kong Special Administrative Region 2014, 73).

But low unemployment does not mean that life is easy for university students and graduates, who are expected to work long hours for a meager income, pay off student loans, and save enough money to purchase a tiny flat in an extremely expensive property market (The Hong Kong Federation of Youth Groups 2013). According to a survey by Randstad (2014, 13-14), local workers suffer from extended working hours and stressful work environments,

\footnotetext{
${ }^{1}$ Some partner institutions offer a stipend ranging from $\mathrm{HK} \$ 2,000-\mathrm{HK} \$ 5,000$. Students whose host organizations do not offer a stipend are entitled to a subsidy of HK\$2,000 provided by the department.

${ }^{2}$ This information is provided by the Student Services Centre of Lingnan University. These figures do not include the programs run by departments that did not report to the Centre.
} 
and their job satisfaction is almost the lowest in the world. Although Hong Kong has almost full employment, many young people feel pessimistic about securing a bright future for themselves.

This article explores how interns negotiate their work identity, with a focus on the nexus of transformations in higher education and the "new" capitalist economy. While existing literature on internships emphasizes the restructuring of employment in creative and cultural industries, the surplus cultural labour supply, and the impact of internships on the career paths of educated youth mostly in western countries (Frenette 2013; Hesmondhalgh 2010; Overell 2010), my case study sheds light on the relationship between higher education and student interns' labouring experience. Theorizing universities' involvement in the development of intern labour is crucial to understanding the expansion of internships in non-professional fields.

\section{Intern Labour: Working or Learning?}

Critics of internships often see the proliferation of unpaid or low-paid internships as a consequence of a deterioration of industrial relations or the rise of creative industries. For example, critical accounts of internships are attentive to cultural workers' irregular employment patterns and insecure conditions and global socio-economic inequality (International Labor Organization 2004; Neff and Arata 2007; Pun and Chan 2012, 391-392). The rising numbers of interns are seen as newcomers in the army of precarious labour (Standing 2011; Perlin 2012), and the prevalence of internships can also be linked to the policies of various neoliberal regimes such as New Labour in the U.K., whose policy initiatives promoted creative industries and small business as solutions to economic problems (Oakley 2011).

In the critical literature on internships, some scholars draw attention to work culture, in particular, the new values and practices of the creative industries. For instance, David Hesmondhalgh and Sarah Baker $(2011,145-146)$ notice in their study of creative industries that unpaid internships and poorly paid freelancing are often naturalized as the first step of self-realization and necessary for entry into these industries. Instead of focusing on the requirement of an internship for entering professions in creative industries, Alexandre Frenette $(2013,372)$ looks at the "ambiguous" nature of intern labour, such as its temporary basis, the flexibility of the work role, and the emphasis on adaptable skills, which appeals to aspiring interns. On the one hand, companies may find it difficult to formalize internship programs, and cater to interns whose backgrounds, interests, and commitments are diverse. Companies may leave space for interns to pick up tasks, ranging from mundane, administrative duties to professional responsibilities, according to the interns' abilities and preferences and the organization's immediate needs. On the other hand, the lack of well-defined objectives or tasks in the use of intern labour can attract young people with different motivations and little working experience to join internship programs.

The ambiguity of the internship, implicitly defined against the relative clarity of a traditional employment relationship, is usually assumed to be consistent with the unstable and unpredictable conditions of creative industries and their organizational cultures (Frenette 2013, 368). However, the role played by the higher education sector in shaping the "ambiguity" of intern labour needs closer examination. There is a growing literature on work-based learning and higher education, which variously confirms the benefits of internships to students and educators (Swail and Kampits 2004), develops effective models for aligning education paths with career plans (Howard 2004), or identifies the conditions for critical pedagogy (Breunig 2005; Lester and Costley 2010; Berger, Wardle and Zezulkova 2013). Some scholars evaluate the employability agenda of higher education and its impact on professional practices and identities (Thornham and O'Sullivan 2004; Willis 2010). Further study is needed to understand the uniqueness of student interns' working-learning experience, which is located at the intersection of labour and educational practices. As most interns are students or recent graduates, the nuance and complexity of their roles as learners and their relationship with pedagogical practices and workplace conditions deserve scrutiny. Interns often shift between the role of worker and learner, especially in a well-designed program. While interns perform their daily work, they continually examine their own thoughts, motivations, feelings, and behaviours, and ask why more than how. My study attempts to address the subjective experi- 
ence of student interns by exploring some of the ways they negotiate their identities at the intersections of a professional field and an education institution.

\section{Data, Method, and Background}

Data presented in this article are drawn mainly from my participant-observation as an instructor of an internship course since 2010 and semi-structured interviews in 2014 with 10 young graduates (three men and seven women). ${ }^{3}$ Interviewees were selected from the 110 people who participated in the internship course since 2010. The sample consists of respondents who had worked in the three fields associated with the internship program: media, performing arts, and community organizations. Interviewees were asked 53 questions regarding their initial expectations for their internship, the process of selecting an organization and securing their position, first impressions, pleasures, and frustrations in the placement, and their assessments and memories. The interviews also addressed the relevance of the internship to the participants' studies, career aspirations, and current jobs. In addition to former interns, I interviewed two internship course instructors about the program's institutional history, their teaching philosophy, pedagogical practices, and course design.

The internship course is intended to encourage students majoring in Cultural Studies to put theory into practice, to gain better knowledge of the nature and skills of "cultural work", and to develop a professional ethos to prepare them for their career (Department of Cultural Studies, Lingnan University 2013). The course is characteristic of the curriculum design of the B.A. (Hons.) in Cultural Studies at Lingnan University, the first undergraduate program of its kind in Chinese-speaking societies. The central idea of the degree's curriculum structure, according to its initiator and designer, Ching-kiu Chan, is "strategic border re-alignment" (Chan 2002, 231). That is, it has a trans-disciplinary orientation that not only consists of bringing multiple disciplines together, but also highlighting the social and cultural contexts of Hong Kong and China, and emphasizing local issues.

Most faculty members in the department were attracted to Cultural Studies because they were previously frustrated by disciplinary constraints. Being liberated from conventional disciplines informs the curricular design of the B.A., which has a vision of a field of study and engagement beyond established disciplines and professions. As the external examiner of the program, Graeme Turner, notes, the Lingnan students-non-elite students with low economic and cultural capital-are encouraged to facilitate intellectual and practical dialogues between cultural studies concepts and their own social engagement, rather than read theoretical canons (Turner 2012, 87). The areas covered by the internship course are not limited to a specific professional field or definition of "cultural work", but, rather, are developed from the socio-cultural concerns of the faculty members of the department and their alignment with the themes of the required courses and two streams of study ("Social and Historical Studies" and "Literary and Media Studies"). While the internship is defined as an opportunity for interfacing with community, the partner institutions are mainly selected through instructors' personal networks and community involvement.

In what follows, I summarize respondents' common expectations and analyze how these expectations come about in their learning environment. Next, I attend to cases in which students report having both enriching and frustrating experiences, and articulate the patterns of their adaptation to their labour conditions. Finally, I foreground the process of "labouring to learn" and its relationship with tertiary education. I conclude by thinking through the significance of these experiences for the working life of educated youth in Hong Kong.

\footnotetext{
${ }^{3}$ Approximately half of the interviews were conducted by Chan Pui Ming.
} 


\begin{tabular}{|l|l|l|l|}
\hline Name $^{4}$ & Sex & Age & Host Organization \\
\hline Josephine & F & 25 & Media \\
\hline Kelvin & M & 29 & NGO \\
\hline Eva & F & 24 & Performing Arts Group \\
\hline Fiona & F & 23 & NGO \\
\hline Patrick & M & 26 & Media \& Arts \\
\hline Erica & F & 25 & Performing Arts Group \\
\hline Holden & M & 24 & Media \& Arts \\
\hline Emily & F & 24 & Media \\
\hline Sussie & F & 23 & NGO \\
\hline Pinky & F & 23 & Media \\
\hline
\end{tabular}

Table 1: List of anonymized interviewees

\section{Findings}

\subsection{Expectations}

While internship experiences vary, students' initial expectations for their internships are similar. For example, the interns in this study are not necessarily aspiring for a career, even though instructors emphasize the benefits of getting a foot into industries and expanding social networks. All but one intern admitted that earning academic credits within two months-a period shorter than an academic semester-is the most immediate reward of the internship course. This seems to be a stronger incentive to participate than acquiring professional skills and building up personal networks for a future career. Instead of thinking seriously about career planning, students usually chose host companies that they found to be interesting and challenging.

There are also cases of participants seizing an internship as a chance to do something radically different from their way of life and personalities. Josephine, for example, had concentrated on her studies but rarely participated in class discussions and extra-curricular activities. Nor was she eager to engage in social and political debates. So, I was somewhat surprised by her decision to intern as a reporter for an independent media outlet. She expected a special experience: "I wanted to try it and see if it was suitable for me. I wondered if I am qualified for a job related to public affairs." Despite Fiona's religious beliefs and her family's moral conservatism, she learned about gay and lesbian issues and pro-sex feminist theories in Cultural Studies and was puzzled by local debates on sexual discrimination, pornography, and the legal recognition of same-sex marriage in recent years. Unsure about her standpoint, Fiona chose to work with a queer community group, which she saw an opportunity to learn more about sexual rights issues. Fiona's ambiguous role as an intern, neither an advocate nor a staff member, allowed her to engage in advocacy, yet without an obligation to identify with the activists' causes: "After graduation, given my religious background, I probably would not have any chance to think about the controversies on sex and religion, especially listening to sexual minorities' views."

Josephine and Fiona assumed that their placements would allow them to depart from mainstream work and life-though, sometimes, the nature of an internship is not significantly different from regular office work. According to my interviews and observation, students saw their internship as a learning process extending beyond the classroom. Filing, making cold calls, entering information into databases, sitting idly, or nervously attempting to have conversations with busy staff-most students worked patiently and diligently. Although some organizations expected them to be the next generation of employees, the interns primarily saw themselves as learners and their work as taking on new challenges and gaining exposure to the real world outside the ivory tower and their normal life.

\footnotetext{
${ }^{4}$ Pseudonyms are used for the research participants.
} 


\subsection{Exploitation and Pleasure}

More than half of the interns in my study described their working experiences as exploitative in one way or another, yet they expressed this idea without a strong sense of injustice. Apart from concerns about unpaid or underpaid labour, some interns lamented their mundane tasks and their status as disposable labour. Eva, who interned with a performing arts group as a customer service worker answering phone calls, occasionally prepared Chinese herbal medicine for her director. Kelvin and Patrick, who interned in a small documentary company, were assigned to mail delivery. They were sometimes drowned in tedious tasks without a clear understanding of the job or the mission of the organization. Patrick, grumbling about his supervisor's paternalism, re-defined the role of the intern as "assistant": "Interns are supposed to learn, but I can only assist [the host organizations]." Eva invoked the idea of flexibility: "You can't ask why you have to do this or that. The scale of the company is so small. The staff and director always emphasize flexibility and my job [...] is by nature ambiguous."

According to the interns in this study, what matters most to their feeling of being exploited is not unpaid labor or heavy duties. Instead, their working conditions and experience could be summarized by Richard Sennett's notion of the three social deficits of the "new capitalism": low institutional loyalty, lack of informal trust among workers, and weakening of institutional knowledge (Sennett 2006, 63-72). On the one hand, students do not receive professional training related to the sectors of their host companies; on the other, most companies fail to offer formalized programs such as orientation sessions, formal training, systematic instruction, and sufficient guidance. Interns have to familiarize themselves with the working environment from scratch.

However, the ambiguity inherent in the intern's role, which largely defines their working conditions, can also be a source of pleasure. Erica enjoyed her work much more when she shifted to the role of an audience member. She was invited by her supervisor to attend the show run by the company with which she interned and to share her opinion and suggestions for improvement, because the director wanted to make his production more appealing to young people. What affects job satisfaction is not simply the nature of the tasks, however. What matters most is whether and to what extent interns can articulate the meanings of their roles and work for themselves. While Patrick bemoaned the fact that his supervisor treated him as a teenage student, subject to paternalistic discipline and surveillance, Holden, who worked as an intern with Patrick, enjoyed multi-tasking very much: "It is really interesting. We had so many different tasks. As soon as you learned one, you are assigned to another one. I have a lot of eye-opening experiences." What made Holden happy about his internship was the opportunity to learn how to run a small arts group and it helped him think about his longterm career plan. Kelvin worked for a community group raising public awareness about the detrimental impact of redevelopment projects on local neighborhoods. Despite performing fragmented tasks, Kelvin shared the mission of the group and appreciated his internship as eye-opening and consciousness-building. Both Holden and Kelvin viewed their hardships as necessary for gaining special learning experience.

\subsection{Labouring to Learn}

Researchers have noted the disparity between interns' expectations and the knowledge interns develop or the networks they build through their placements (Frenette 2013; Tayler and de Laat 2013; Figiel 2013). What interests me is how interns negotiate his gap. Despite occasional complaints about their working conditions and skill cultivation, none of the students interviewed for this study felt that there was nothing received in return for the labour they provided to the organization for which they interned. Students were inclined toward compliance in the hopes that they would acquire skills, maintain good relationships with colleagues, and keenly observe the organizations where they interned. Some felt disappointed but nonetheless submerged their critiques. Rather than leading to conflict, debate, and re-evaluation in host organizations, the interns' frustration, disillusionment, or perplexity were taken up as topics in the reflexive essays submitted to instructors and shared informally among peers. Interestingly, all the students in this study characterized their internship as a kind of "enlight- 
enment" and highly recommended others to take the course, because they found it invaluable for reflecting upon their background knowledge, social roles, and career planning. Here, reflection is not simply a component of assessments such as a writing journal and a reflective essay. It is also about interns' self-development, career preparation, and life planning, which are essential for their compliance with unpaid internships and their feeling of being "enlightened".

While all participants agreed that their internship was educational, almost no one found Cultural Studies theories and concepts to be useful in the workplace. Internships do, however, become a lens through which students come to understand and reflect on a variety of academic issues and concepts. The daily work they performed and observed in internships, regardless of whether their experience was positive or negative, was introduced as a concrete example in their coursework and becomes the subject of their reflexive essay. For instance, most students said that they finally understood the meaning of "cultural institution" and "culture industry" after their internship, and reflected upon these ideas in their assignments for the internship course.

What the students learn from their internships is not confined to academic knowledge, however. Josephine's experience as an intern reporter turned out to be disappointing. She attributed this to a lack of supervision, her poor knowledge of political issues, and passive personality. Yet Josephine still saw the internship as a good learning experience: "If you go to work, you can only learn how to accomplish particular tasks, but the internship allows me to think more." What she meant by "think more" is not only academic, but also in the sense of thinking about her future. After the internship, she gave up her dream to be a journalist and gave serious thought to other careers. Kelvin, who worked for a group advocating community involvement in an urban redevelopment project, characterized his internship as bringing new perspectives on his life course: "How could I imagine myself standing on the street, delivering leaflets or talking to the passersby about things happening in our society? If I didn't [take an] internship, I would never do this [policy advocacy] by myself." Despite currently working as an office worker rather than a campaigner, Kelvin believes that he is no longer politically apathetic, as he was before he took the internship. And Holden decided to work in a large and more bureaucratic organization rather than a small group like his host organization after his internship. He expected to learn more about the operation of media or arts organizations by working in a more institutionalized environment. Interning with a small organization gave him a lot of freedom and flexibility, yet insufficient guidance and formal training. Now Holden works as a full-time editor for one of the biggest newspapers in Hong Kong.

Emily interned at a commercial radio station for more than 12 hours every day and regularly shifted roles between production assistant, reporter, and program host. After her internship, Emily initially abandoned media as her dream field because she believed that such a heavy workload would ruin her life. However, after a few months, she changed her mind and looked for a media job: "Commercial radio gives me something more than particular skills-[it gives me] news sense. It is difficult to describe what it is. It is a mode of thinking and an ability to present information from a sharp angle. For example, I never knew what a sound bite was until I worked at that company." She decided to follow her passion for media, but attempted to strike a balance between work and life. After their internships, most of the students, like the cases above, do not end up working in the particular industries of their hosts. But the students do feel more eager to clarify their career plans and to pursue meanings in work and life.

\section{Conclusion}

While the instructors leading the internship course repeatedly highlight the significance of "practices" in Cultural Studies, most student interns position themselves as learner rather than practitioner. For these students, internships are less about gaining transferable skills in exchange for unpaid labour or engaging themselves in community organizations and cultural work. Instead, internships involve a process of "active searching", in which students try, challenge, and rework ideas they learn in the classroom, and enhance the capacity to think about 
the fields with which students are not acquainted. What concerns them is their ability to be reflective about themselves and their surroundings. Disappointing work experience does not deter interns from "labouring to learn". Finding comfort in discomfort, they appreciate Cultural Studies for equipping them with knowledge, intellectual tools, and guidance to build critical accounts of their work, the organization where they interned, and themselves.

Interns, as Judith Tayler and Kim de Laat note, replace their "work selves" with "internship selves", attributing unpleasant experiences to a lack of supervision, unfriendly co-workers, or bad luck, rather than being critical of unpaid internships as exploitative $(2013,93)$. My smallscale study suggests that interning is a process of negotiation over subjectivity, engendering a high-level learning that enables students to play the role of self-directed learners. Student interns, with their ambiguous roles, could keep psychological distance from depressing workplaces or tedious tasks. They perceive their role as that of a learner looking for new experiences and reflecting upon their work, and thereby find the unpaid or low-paid labour bearable. In this light, internships stand as an example of "knowledge capitalism", or university reform in the period of neoliberal restructuring, whereby learning and working are becoming blurred to the extent that capitalist power relations are obscured by the discourse and practice of experiential learning (Burton-Jones 1999; Marginson and Considine 2000; Olssen and Peters 2005).

Interns, rather than being trained as followers of procedures and rules, are encouraged to develop themselves as an "educated subject" who voluntarily adjusts "the innermost aspects of the self" to comply with a changing institutional environment (Fendler 2001). This is the reason why the participants in this study view their internships as a sort of "enlightenment." The substance to be educated in an internship is, I argue, not necessarily intellectual ability, specific skills, and behavioural discipline. Instead, the key is to develop a self-enabling subject, one who is embodied with a temperament, a motivation, and a desire to take on various challenges, which are perceived as highly beneficial experiences, adventures in learning, or, even, a blessing.

\section{References}

Berger, Richard, Jonathan Wardle and Marketa Zezulkova. 2013. No Longer Just Making the Tea: Media Work Placements and Work-Based Learning in Higher Education. In Cultural Work and Higher Education, edited by Daniel Ashton and Caitriona Noonan, 87-109. Hampshire: Palgrave Macmillan.

Breunig, Mary. 2005. Turning Experiential Education and Critical Pedagogy Theory into Praxis. Journal of Experiential Education 28 (2): 106-122.

Burton-Jones, Alan. 1999. Knowledge Capitalism: Business, Work, and Learning in the New Economy. Oxford: Oxford University Press.

Chan, Ching-kiu. 2002. Building Cultural Studies for Postcolonial Hong Kong: Aspects of the Postmodern Ruins in between Disciplines. Cultural Studies: Interdisciplinarity and Translation 20: 217237.

Department of Cultural Studies, Lingnan University. 2013. Internship Course (CUS 299): Student Handbook. Accessed June 10, 2015. http://www.In.edu.hk/cultural/students/internship/2013/Internship course Student Handbook 2013.pdf.

Fendler, Lynn. 2001. Educating Flexible Souls: The Construction of Subjectivity through Developmentality and Interaction. In Governing the Child in the New Millennium, edited by Kenneth Hultqvist and Gunilla Dahlberg, 119-142. London: Routledge.

Figiel, Joanna. 2013. Work Experience Without Qualities? A Documentary and Critical Account of an Internship. ephemera: Theory \& Politics in Organization 13 (1): 33-52.

Frenette, Alexandre. 2013. Making the Intern Economy: Role and Career Challenges of the Music Industry Intern. Work and Occupations 40 (4): 364-397.

Government of the Hong Kong Special Administrative Region. 2012. Third Quarter Economic Report 2012. Hong Kong: Hong Kong SAR Government.

Government of the Hong Kong Special Administrative Region. 2014. Half-yearly Economic Report 2014. Hong Kong: Hong Kong SAR Government. 
Hesmondhalgh, David. 2010. User-generated Content, Free Labour, and the Cultural Industries. ephemera: Theory \& Politics in Organization 10 (3/4): 267-284.

Hesmondhalgh, David and Sarah Baker. 2011. Creative Labour: Media Work in Three Cultural Industries. New York and London: Routledge.

Howard, Adam. 2004. Cooperative Education and Internships at the Threshold of the Twenty-First Century. In Handbook for Research in Cooperative Education and Internships, edited by Patricia L. Linn, Adam Howard and Eric Miller, 3-10. Mahwah, NJ: Lawrence Erlbaum Associates.

International Labor Organization. 2004. Economic Security for a Better World. Geneva: ILO.

Lester, Stan and Carol Costley. 2010. Work-based Learning at Higher Education Level: Value, Practice, and Critique. Studies in Higher Education 35 (5): 561-575.

Marginson, Simon and Mark Considine. 2000. The Enterprise University: Governance, Strategy, Reinvention. Melbourne: Cambridge University Press.

Neff, Gina and Giovanni Arata. 2007. The Competitive Privilege of Working for Free: Rethinking the Roles that Interns Play in Communication Industries. Paper presented at the meeting of American Sociological Association, New York City, August 11.

Oakley, Kate. 2011. In its Own Image: New Labour and the Cultural Workforce. Cultural Trends 20 (34): 281-289.

Olssen, Mark and Michael A. Peters. 2005. Neoliberalism, Higher Education, and the Knowledge Economy: From the Free Market to Knowledge Capitalism. Journal of Education Policy 20 (3): 313-345.

Overell, Stephen. 2010. The Role of Internships. In Disconnected: Social Mobility and the Creative Industries, edited by Ryan Shorthouse, 80-89. London: Social Market Foundation.

Perlin, Ross. 2012. Intern Nation: How to Earn Nothing and Learn Little in the Brave New Economy. London: Verso.

Pun, Ngai and Jenny Chan. 2012. Global Capital, the State, and Chinese Workers: The Foxconn Experience. Modern China 38 (4): 383-410.

Randstad. 2014. Randstad World of Work Report: The Talent Strategy Game-changer Series. Accessed September 26, 2014. http://www.randstad.cn/FileLoad/Attachment/20140224141329449.pdf.

Sennett, Richard. 2006. The Culture of the New Capitalism. New Haven and London: Yale University Press.

Standing, Guy. 2011. The Precariat: The New Dangerous Class. New York: Bloomsbury Academic.

Swail, Watson Scott and Eva Kampits. 2004. Work-based Learning \& Higher Education: A Research Perspective. Washington, DC: Educational Policy Institute.

Tayler, Judith and Kim de Laat. 2013. Feminist Internships and the Depression of Political Imaginations for Women Studies. Feminist Formations 25 (1): 84-110.

The Hong Kong Federation of Youth Groups. 2013. The Daily Needs and Financial Pressures of Young People with Government Loans. Hong Kong: HKFYG.

Thornham, Sue and Tim O'Sullivan. 2004. Chasing the Real: "Employability" and the Media Studies Curriculum. Media, Culture \& Society 33 (2): 289-298.

Turner, Graeme. 2012. What's Become of Cultural Studies? Los Angeles: SAGE.

Willis, Jenny. 2010. How do Students in the Creative Arts Become Creative Professionals? In Learning to be Professional through a Higher Education, edited by Norman Jackson. Accessed September 13, 2014. http://learningtobeprofessional.pbworks.com/f/JENNY+WILLIS+D4+FINAL.pdf.

\section{About the Author}

Ip lam Chong

Ip lam Chong is an Assistant Professor of Cultural Studies at Lingnan University in Hong Kong. His research interests include urban studies, social movements, and neoliberalism in non-Western contexts. 


\title{
Interrogating Course-Related Public Interest Internships in Communications
}

\author{
Sandra Smeltzer \\ Western University, London, Canada, ssmeltze@uwo.ca
}

\begin{abstract}
This article examines the benefits and drawbacks of for-credit, unpaid internships geared towards the public good. Attention is focused specifically on communication internships with nongovernmental, non-profit, and community-based organizations. Drawing on a series of semi-structured interviews with students, staff, faculty, and host organizations, the author advances a critical model of service learning that more fully recognizes the labour of community partners and encourages students to consider what role they can and should play in advancing the public good. The article also highlights two key issues vis-à-vis public interest internships that are of particular relevance to the field of communications. The first is a disconnect between, on the one hand, communications as a theoretical field of study and, on the other hand, the skills communication students are typically expected to bring with them into their placements. The second is a growing tension between what different members of the university community expect out of public interest internships: politically safe forms of community engagement palatable to university administrations versus more activist-oriented placements with organizations and movements that contest structures of control both on and off campus. The author contends that communication programs must critically reflect upon how politically benign and/or contentious internships support their pedagogical goals and what resources need to be in place to meet these objectives.
\end{abstract}

Keywords: internships, communications, public good, activism, service learning

Significant media attention has focused recently on a range of concerns related to unpaid student internships that deserve greater critical scrutiny. Academic and media critiques have, quite rightfully, targeted exploitive labour practices undertaken by companies benefitting from students and graduates struggling to find employment in an increasingly difficult job market (see, as examples, Harris 2014; Lurie 2013; Neff 2011; Perlin 2012; Sagan 2013; Wood 2011). In addition to calls for interns to be paid a fair wage and a limit to be placed on the number of hours they work, other issues revolve around ensuring that they engage in meaningful work and receive appropriate training and support during their placements. Internships are also often available only to those with the financial means to afford foregoing paid employment during the school year and/or intersession months. Conversely, these placements provide students with real-life experience, an opportunity to put their theoretical training into practice, and a means of gaining a more in-depth and nuanced understanding of their respective fields. As tuition continues to rise and students increasingly feel the brunt of what Jeffrey Williams (2006) calls the "pedagogy of debt" and its attendant pressure to secure employment immediately post-graduation, internships can also serve a utilitarian, résumébuilding function for future employment.

In Canada, regulation of internships varies according to each province's standards. In Ontario, for example, unpaid internships are legal only if they adhere to one of three exceptions set out by the province's Employment Standards Act. ${ }^{1}$ In this article, I explore the implications of unpaid, for-credit placements that are, as per the first of these exceptions, "part of

\footnotetext{
${ }^{1}$ The other two criteria stipulate that internships must "provide training for certain professions (e.g., architecture, law, public accounting, veterinary science, dentistry, optometry)" and/or that they meet "six conditions required for the intern to be considered a 'trainee'" (for a list of these conditions, see http://www.elaws.gov.on.ca/html/statutes/english/elaws_statutes_00e41_e.htm). If an internship fails to meet these standards, the intern "must be paid at least the Ontario minimum wage" (Canadian Intern Association 2014a).
} 
a program approved by a secondary school board, college, or university" (Canadian Intern Association 2014a). More specifically, attention is focused on university-level, communication internships geared towards the public good-that is, placements with local and international non-governmental, non-profit, and community-based organizations (NGOs, NPOs, and CBOs, respectively). ${ }^{2}$ Research in this area is particularly timely as universities promote what appears to be a natural fit between communication programs awash with students wanting hands-on experience, and organizations, often facing budget cuts under conditions of neoliberal austerity, looking for additional support in terms of writing, research, public relations, and social media outreach. Although these internships are part of an academic program and meant to advance the public good in some capacity, it does not necessarily follow, however, that they are always of benefit to the student or the host organization.

The primary objectives of this article then are threefold. First, to interrogate some of the benefits and drawbacks of this form of experiential learning from the perspective of the student (focusing on undergraduates), the university (primarily at the departmental/faculty level), and the host organization (local and international NGOs, NPOs, and CBOs). Second, to challenge a more traditional, institutionalized service learning model that has students unilaterally 'serving' the 'other.' Instead, the article promotes a critical paradigm that more fully recognizes the labour of community partners and encourages students to consider what role they can and should play in advancing the public good. Third, to highlight two key issues vis-à-vis public interest internships that are of particular relevance to the field of communications. The first is a disconnect between, on the one hand, communications as a theoretical field of study and, on the other hand, the skills communication students are typically expected to bring with them into their placements. The second is a growing tension between what different members of the university community expect out of public interest internships: politically safe forms of community engagement palatable to university administrations versus more activistoriented placements with organizations and movements that contest structures of control both on and off campus. Although many students prefer the former option, others request the latter, raising questions regarding the legitimacy, safety, supervision, and evaluation of placements that fall outside the traditional service learning archetype. In the end, I contend that communication programs need to consider why they offer politically benign and/or contentious internships, how this form of experiential learning is integrated into their respective curricula, and what mechanisms and resources need to be in place to meet their stated pedagogical goals.

The discussion that follows is informed in part by semi-structured interviews conducted with individuals who have, in some capacity, been involved with unpaid, for-credit, public interest internships as part of a communication program at three universities in Ontario. To capture a range of first-hand perspectives, non-identifying interviews were held with three faculty members and two staff members engaged in administering and supervising internships, two mid-level university administrators, representatives from four organizations that have hosted such interns, and seven former undergraduate students who have completed local and/or international internships. ${ }^{3}$ These interviewees were chosen based on my previous knowledge of the individual and his/her relationship with a specific internship program. Recognizing, however, my own bias towards emphasizing the positive benefits accruing from public interest-oriented experiential learning, I consciously choose to interview individuals as part of this convenience sample whom I expected would also be able to speak to some of the challenges associated with this kind of pedagogy.

Through these interviews, I gained valuable personal and professional insight into my own subjective perceptions of internships, helping to nuance my experiences serving as the academic supervisor for internships in the Faculty of Information and Media Studies (FIMS)

\footnotetext{
${ }^{2}$ For a useful overview of these and other similar context-specific organizational frameworks, see Haque, 2010.

3 Interviews were conducted between April and June, 2014, and ranged in length from 30 minutes to two hours. To mitigate the power dynamics inherent in student-professor relationships, the former interns interviewed for this research have all graduated from their undergraduate programs.
} 
at Western University. ${ }^{4}$ To date, I have overseen approximately 70 internships and practicum placements with local and international NGOs, NPOs, and CBOs for our undergraduate Media and the Public Interest program (MPI), and 125 internships with local private sector companies for our undergraduate Media, Information \& Technoculture (MIT) program. The MPI program, which I co-coordinate, is specifically committed to social justice issues and actively works to connect "media theory learned in the classroom to real world experiences" (FIMS 2014). Along with the possibility of participating in voluntary national and international internships, MPI students must complete a capstone placement in the final semester of their fourth year with a local organization. The placement includes a minimum number of contact hours with the host NGO, NPO, or CBO, one-on-one meetings with the instructor of the course, and time spent in a classroom setting with peers in the program. Given the generally left-leaning approach of my faculty and its commitment to critical, praxis-oriented pedagogy (DyerWitheford 2007, 56), I enjoy significant political latitude in this process.

\subsection{Context and Framework}

Scholarly literature about public interest internships falls primarily under the aegis of service learning, a rapidly expanding subset of experiential learning that intends to prepare "students for civic life" (Ward 2005, 220). Instead of simply a form of 'volunteerism,' this type of handson education "aspires to be an active process of 'real life' experience formation and intellectual reflection by enabling students to combine insights gleaned from their theoretical course content with their community-based learning activities" (Smeltzer and Grzyb 2009, 9). Concerns have been raised, however, that the rhetoric of 'service' connotes unequal power relationships in which one group (e.g., university students and faculty) unilaterally serves another group (e.g., marginalized citizens in the community) in need of external help. Indeed, the idea of 'service' underpinning most institutionalized community placements mirrors forms of inequity that are a hallmark of diminishing welfare states under contemporary capitalism. In this environment, expectations that students will 'serve' the other function to "reinforce prejudice and replicate power differentials between those conferring and those receiving the service" (King 2004, 123; Brown and Bruce 2010, 10-12; Bruce, Martin and Brown 2010; Mitchell 2008). Notwithstanding these critiques, service learning programs have become increasingly popular with university administrations eager to demonstrate "community engagement as 'core business'" (Flood, Martin and Dreher 2013, 21). As a case in point, according to its 2014 Strategic Plan, Western University vows to "[p]romote and support [...] service-learning projects with non-profit community groups; study-abroad and academic exchange programs; and social justice or international development initiatives with non-governmental agencies... In these contexts students learn to apply the knowledge and skills they learn in the classroom to practical 'real world' situations" (2014b). While a substantial commitment by universities to the wider community should be welcomed, this excerpt reflects a more traditional approach to service learning in which charity figures "as a solution to social problems, [and] establishes a hierarchy between academic communities and minoritized contexts" (Porfilio and Hickman 2011, x; Pompa 2002).

By comparison, the term critical service learning is often used to signal a pedagogy that, if thoughtfully designed and implemented, encourages students to instead "develop the critical awareness in relation to what gives rise to the dark social realities of the present as well as gain the desire to remake the social world for the purposes of improving the lives of all people" (Porfilio and Hickman 2011, x-xi; Mitchell 2008; Rice and Pollack 2000). As Brazilian educator Paulo Freire argued in his highly influential The Pedagogy of the Oppressed (1970), "Education either functions as an instrument which is used to facilitate integration of the

\footnotetext{
${ }^{4}$ Recently, the institution has been rebranded (for rather opaque reasons) as Western University, jettisoning its original name, The University of Western Ontario. Located in London, Ontario, Canada, Western is a public research institution home to over 30,000 undergraduates and more than 5,000 post-graduates.

${ }^{5}$ Given that service learning programs are well-established in the United States (with Canada quickly following suit), much of this literature is American-focused (Benham, Rennick and Desjardins 2013, 5).
} 
younger generation into the logic of the present system and bring about conformity or it becomes the practice of freedom, the means by which men and women deal critically and creatively with reality and discover how to participate in the transformation of their world" (34). My focus in this article is explicitly on unpaid, for-credit internships that strive for the latter-a specific form of self-reflective education that operates in the spirit of critical service learning insomuch as it forefronts "the public good, public issues, and public life" to help young people "develop a sense of agency, particularly in relation to the obligations of critical citizenship and public life in a radically transformed cultural and global landscape [...]" (Giroux 2011, 174).

To contextualize my experience at Western University with other communication/media studies programs, I will briefly survey comparable programs in the province of Ontario. At the time of writing, only Brock University's Department of Communication, Popular Culture and Film explicitly offers "service-learning internship opportunities" for its students. ${ }^{6}$ Specific internships and co-op placements offered at other universities may be geared towards the public interest, but the departments do not specifically advertise their experiential learning opportunities in such manner. The University of Ottawa's Department of Communication, the University of Toronto Mississauga's Institute of Communication, Culture, Information and Technology, and the University of Windsor's Department of Communication, Media, and Film are good examples of programs that actively promote the pedagogical and professional benefits of unpaid, for-credit internships and co-ops, but do not overtly forefront the public good. It is also important to note that there are no agreed-upon definitions of what constitutes an internship between these communication programs. Based on their publicly available objectives, however, some common themes emerge: the benefits accruing from hands-on work experience, including the acquisition of practical skills; the potential for professional networking; and in many, although not all, cases, the importance of integrating theory and practice.

According to Stirling et al.'s (2014) inventory of the panoply of internships available across disciplines to post-secondary students in Ontario, "the lack of a standardized definition of what an internship entails ${ }^{7}$ is further complicated by the fact that it is not always clearly distinguished from other work-integrated learning opportunities such as co-operative education, apprenticeships, placements and practica" $(10){ }^{8}$ As a salient case in point, in my faculty we offer students in different programs specialized forms of experiential learning. In addition to the MPI practicum placements described above, we also coordinate competitive paid co-ops for one program; short- and long-term, paid and unpaid internships for another program; and short-term, unpaid internships for yet another program. Faculty and staff involved in supervising and administering all of these programs have come together to discuss best practices. We realized that although diverse formats and descriptors have emerged over time to suit the needs of particular units, we all agree that placements/internships/co-ops must critically integrate theory and practice. Equally important, all parties involved must feel empowered by this form of pedagogy rather than exploited in any way, shape, or form. Ensuring this level of support and care is, however, more easily stated than implemented.

Consequently, in the discussion that follows, I first consider some of the empowering aspects of public interest placements, including potential benefits for students, faculty members and their home institutions, and host organizations. In the next section, I examine possible undesirable consequences for individuals and organizations participating in, hosting, or supervising the internships. Subsequently, I highlight issues particularly relevant to the field of communications and conclude with a critical examination of how activist faculty and universities are willing to be in their commitment to public interest pedagogy.

\footnotetext{
${ }^{6}$ McMaster University offers a community-based internship program called CORE (Community Organizations Reaching Everyone) for all humanity students.

${ }^{7}$ Even within the wider Western University community, internships are defined in very broad terms: they "can be short-term or long-term, for academic credit or for a non-credit course. Some internships are mandatory and some are optional. [...] Opportunities for internship work can be local, national, or international." (Western 2014a).

${ }^{8}$ For a recent overview of unpaid internships in Ontario written for the Canadian Intern Association, see Attfield and Couture (2014).
} 


\section{Potential Benefits of Public Interest Internships}

\subsection{Students' Intellectual Labour, Personal Growth, and Job Market Prospects}

In our MPI program, students are required to complete mid-term and final papers for their fourth-year public interest placements that critically draw upon readings and theoretical concepts from across the curriculum. Students also attend regular seminar sessions facilitated by a faculty member to reflect upon internship experiences openly with their peers. The objective of these course requirements is to support students intellectually and emotionally as they consider how and in what ways their intellectual labour informs their public interest placements and vice versa. In other words, by critically combining theory and practiceknowing and doing-students are encouraged to incorporate "reflection and action upon the world in order to transform it" (Freire 1970, 36). In our interview, one former student referred to her public interest internship as "putting the theory l've learned into practice." Another stated that her two internships "gave context and meaning to the theory and course material I had learned in my BA, and dramatically shaped my graduate work." A third commented that "being able to talk to other students in my program doing similar kinds of NGO internships [...] that really helped me understand better my experience at [unnamed organization] and what I was trying to achieve." These selected interview excerpts illustrate some of the benefits of praxis-oriented, public interest pedagogy if we accept, as I do, that "[t]heory informs practice, while experiential and practical knowledge can be employed as a means to understanding and interpreting theory" (Breunig 2005, 109; Boyd and Sandell 2013; Banerjee and Hausafus 2007).

Internships can also provide students with, what one faculty member referred to as, a set of oars "to help steer their own 'life journey' boat," an analogy he preferred over the seemingly more aggressive action of trying to get a 'foot in the door' of a specific sector of the economy. In a similar vein, a staff member believed quite strongly that although students think they should complete a public interest internship for professional reasons, almost all of them want to do it for less utilitarian reasons: "At a fairly young age these students get to tap into their desire to make a difference [...] an experience that most people don't get until much later in life."

As a pragmatic corollary to their intellectual and personal development, students often acquire useful skills during their placements-e.g., how to compose a press release or construct a political lobbying campaign. They also receive course credit and an institutionsanctioned internship to add to their résumé, as evidence of hands-on experience is increasingly of value to distinguish job applicants in a competitive employment market (Boyd and Sandell 2012; King 2004). Lastly, students can benefit from networking opportunities, insight into a 'real world' workplace environment, and the chance to learn what a faculty member described as "the vernacular of the industry you're working in [...] understanding the culture and the language that you can only 'pick up' in situ." While the potential job market benefits of internships should incontrovertibly be of secondary importance to overarching academic/intellectual objectives, it is clear that many students want this kind of on the ground experience for a range of tangible and intangible reasons. ${ }^{9}$

\subsection{Faculty Benefits}

\footnotetext{
${ }^{9}$ One concern, however, is that we simply do not have hard figures regarding employment outcomes stemming from internships in the Canadian context to justify claims that internships directly lead to jobs upon graduation (Attfield and Couture 2014; Rigsby et al. 2013). Through continued personal contact, I know that a majority of our former MPI students either received contracts or job offers after the conclusion of their placement, or they enrolled in a graduate program, often in areas outside of communications/media studies (law, public policy, global studies). In writing this article, however, it became clear that we need to conduct a more comprehensive longitudinal study of the relationship between internships and students' pursuits after they graduate.
} 
In addition to the positive press coverage universities can derive from community engagement activities, individual faculty members can also benefit both personally and professionally from helping to coordinate and supervise internships geared towards the public good. As Flood, Martin and Dreher (2013) contend, even though faculty must devote significant time and energy to facilitating this type of experiential learning (as discussed below), they can also find "meaning and comfort in the sense that their work contributes to the greater good [...] Their personal and political investments in 'making a difference' can give impetus to their professional work, motivating both intensified research and public engagement" (18; see also Darby and Newman 2014; O'Meara and Neihaus 2009). As a potential added benefit, public accolades and/or positive performance evaluations may also encourage some individuals to continue their commitment to such labour-intensive critical pedagogy that usually goes above and beyond the expected workload of a faculty member.

\subsection{Community Partner Benefits}

As governments move farther and farther away from their welfare state responsibilities, public interest organizations are saddled with expanding workloads, trying to make ends meet in the face of diminishing financial support from the state and dwindling individual and corporate donations. For many local and international NGOs, NPOs, and CBOs striving to fulfil their mandates, additional labour in the form of a student intern can help support mission objectives and strengthen the economic bottom line. As a former student commented, for "nonprofit, public interest-oriented organizations [...] the existence of these sorts of programs [forcredit internships] can be a tremendous help... With human resource limitations, having a skilled volunteer/intern join the organization, even for a short while, can have a big impact." Host organizations may also benefit from the vigour and excitement many students bring with them into the placement. As a CBO representative remarked in our interview, "The students keep me young. They help me remember why I got into this kind of work in the first place [...] because it really does matter."

Notwithstanding the range of benefits potentially accruing to internship stakeholders within and beyond the university described above, there are myriad challenges associated with coordinating, hosting, and participating in public interest placements. In the following section, I consider some of these struggles, beginning with the emotional and financial costs of this form of experiential learning.

\section{Balancing Meaningful Placements with Labour, Time, and Finance Expendi- tures}

\subsection{Emotional Labour Peaks and Valleys: Guiding Self-reflective Students}

Given the amount of time required for students to acclimatize to their new working environment (whether in the office or in the community), to contribute meaningfully to an organization, and to engage in theoretically driven action and reflection, internships should include a minimum number of on the ground "contact" hours. As argued by a former student, short timeframes can be "a limiting factor" not only in terms of a student's knowledge and skills development, but also in what roles s/he can play beyond "helicopter voluntourism." Entreaties for longer internship periods are particularly compelling for emotionally fraught placements during which students bear witness to human, animal, and/or environmental injustice and require additional time and support for a productive experience. While many students anticipate an emotionally charged experience, their internship may be one of the first times they have faced up-close acutely disturbing forms of socio-economic inequity and marginalization. Certainly, many students have faced discrimination during their lives and struggled financially to complete their education, making them more attuned to the multitude of difficulties associated with minority positions and poverty. Nevertheless, universities remain spaces of privi- 
lege (Hall 2007, 10), which necessitates students engaging in the difficult but important process of interrogating "their own subjectivities and preconceptions of "others" (Smeltzer and Grzyb 2009, 5). Even though I encourage students to believe that they have agency and can make a positive difference in the world, I do not want them to be unrealistic about the political and economic frameworks that control their daily lives. Participating in a public interest internship can, depending on the placement, bring this difficult balancing act to life in a way that is quite unsettling for some students. Another former student, for instance, commented that while her local and international internships made her realize that she has "responsibilities in this world," the extent of the problems both at home and abroad made her feel "almost paralyzed by it all."

An intellectually and emotionally challenging experience can also expose students to the difficulties many organizations face in trying to fulfil their public interest mandates. While students are keen to carry out their internships with a range of organizations-from small-scale, municipal, or community-level organizations to large, relatively well-funded organizations with extensive staff complements-they often do not have a sense of what the working conditions will actually be like until they are in their placements or how much agency they might have to make a difference while there or after graduation. Students often articulate how much respect they have for the dedication and commitment to a movement, cause, or community they encounter during their internships. However, they are also sometimes disillusioned with how NGOs, NPOs, and CBOs operate, and express surprise that they can be hierarchical, political places that struggle financially without always achieving their hoped-for objectives. As an NGO representative stated quite honestly, students "have to learn that they shouldn't put all of us - this sector-on a pedestal, in the same way that we shouldn't treat all private companies as inherently immoral." For all of the reasons outlined above, a level of personal and emotional support is necessary to ensure that students are not only productive in their placement, but are also guided through the action/reflection process without feeling paralyzed in the aftermath.

\subsection{The 'Cost' of Internships}

As a counterbalance to arguments advancing lengthy internship placements, three important factors need to be taken into consideration. First, the case has been made that internships should be kept both "short and non-extendable" to limit their "substitution and displacement effects since it would be more difficult for employers to use interns as cheap substitutes for regular employees" (Standing 2014, 164; see also Perlin 2011). Second, there are constraints inherent to a semestered university system and its degree requirements, including potential limits placed on allowable out-of-class credits, which would also serve to keep the internship timeframe more compressed. Third, it is simply not financially feasible for the majority of students to participate in an extended unpaid internship during the summer/intersession months or to take a semester away from school to participate in a full-time placement (see, for example, Benham Rennick and Desjardins 2013, 5; MacDonald 2013; Standing 2011,2014$)$. Students wanting to participate in an international internship must also cover additional expenses, including the cost of flights, visas, and accommodations. One former student, who described her experiences abroad as personally and professionally invaluable, captures well the dilemma:

My internships/placements were fairly well supported [...] But I still took a hit in terms of the lack of any savings for a 14 month period-which had a big impact on my being able to support myself during graduate school—resulting in more student loans... However, if they had been entirely unpaid, there would have been absolutely no possibility for me to participate, given my (and my family's) financial situation, and the maximum student loans I had already incurred.

Interviewees conveyed deep ambivalence about the common response to this domestic and international problem: interns should be paid. While some organizations possess the finan- 
cial and personnel resources to manage, support, and pay interns, others (especially smaller and community-based ones) do not have the funds to provide students with a wage. Arguably, the intellectual, academic, personal, and professional benefits hopefully accruing to students offset some expectation of financial remuneration. As a former student commented, echoing some of the benefits describe above:

It never occurred to me that I would get paid [...] my internship was the best learning experience because it actually incorporated my theory from class in a real way. I saw how power works and how hard it is to get media coverage for important issues. And, the people I got to know [...] they weren't examples or stories anymore. They were real people facing real systemic prejudices. I suppose I already knew that, but being at [unnamed organization] brought it all to life.

This situation is, however, thorny. Canadian Intern Association ${ }^{10}$ president, Claire Seaborn, explains: "I think in some instances the credit is enough because of its educational value, but in other instances the position is sort of hiding behind the credit when it should be paid work" (qtd. in MacDonald 2013). When a public interest placement falls into Seaborn's latter category, we have at least two problems. First, even when students receive academic credit for completing an internship geared towards the public good, concerns have been raised that they are still paying a post-secondary institution for the privilege of working in the community for free (Neff 2011). Second, we should censure internships that contribute to the "non-profit industrial complex' (Smith 2007) by offering what Standing calls "cheap, disposable labour" $(2014,162)$ that, as noted, serves to replace already hard-to-come-by employment in this sector. ${ }^{11}$ As a former student commented, "new graduates who are pursuing careers in the public interest sector find themselves stuck in a perpetual cycle of internships. Unpaid internships could potentially displace the kind of paid, entry-level positions that are appropriate for new graduates, especially those who have just completed an undergraduate degree." The difficulty then lies in trying to strike a balance between ensuring that an intern learns, grows, and contributes to an organization in meaningful ways without replacing the job of an existing or would-be employee.

Additionally, the more prestigious the internship and the organization, the more competitive the placements can be even when they are social justice-oriented and coordinated through a university program. Several years ago, I placed a very strong student with a wellrespected NGO that did not regularly accept interns. Promising that the student was a selfstarter with excellent writing and research skills, I was thrilled when the NGO agreed to host her for a semester. In retrospect, I can now see how, given the student's knowledge of the work required to secure this unique internship combined with her personal commitment to the organization's cause, the pressure to perform could have impelled her to devote more than the requisite number of course credit hours to the placement, especially if she hoped to receive a letter of reference from her NGO supervisor. In this particular example, the workplace environment was supportive and respectful of our program's parameters and, in the end, the internship proved to be a positive experience for both parties. However, it raises another serious issue discussed by Beth A. Uzwiak (2013) in her hard-hitting critique of a US-based women's human rights NGO. Notwithstanding the very real economic challenges many NGOs, NPOs, and CBOs face, Uzwiak cautions against assuming that public interest organizations always prioritize the interests of their interns, volunteers, and employees. In her case study she describes how working conditions at the NGO were "glossed as ideological: those who truly care about women's human rights will 'volunteer' based on a commitment to the mission and goals of the agency" $(2013,127)$. This mind-set, she contends, serves to obfus-

\footnotetext{
${ }^{10}$ Founded in 2012, the association is a non-profit organization, which "advocates against the exploitation of interns and aims to improve the internship experience for both interns and employers" (Canadian Intern Association 2014b).

${ }^{11}$ For a useful discussion of some of the gender-related labour issues associated with internships in the communications/media sector, see Shade (2014).
} 
cate very real labour concerns, including unreasonable overtime hours and workload expectations, and even a hostile and heavily hierarchical working environment. In one of my interviews a university staff member made comments that reflect Uzwiak's misgivings, stating that students often want to "put in more hours than they're supposed to" during their placements because they see their work as "supporting good causes." This is just as serious of a concern as students committing too many hours at a private sector internship. If a student genuinely wants to spend time above and beyond his or her internship in a volunteer position with an organization, I do not think it is in the purview of the university to stop him or her from doing so; however, this is not a practice we should encourage or we are rightfully subject to the same criticism levied at other types of internships (Sagan 2013). To mitigate such a possibility, faculty and/or staff must be in regular and open contact with the student and organization to ensure that the internship is proceeding as agreed upon at the outset and that both parties are fulfilling their obligations. It is to these types of labour demands that the discussion now turns.

\subsection{The Labour of Departments, Faculties, and the University}

Staff, faculty, and administrators interviewed for this research all commented that offering internships is strategically advantageous for recruitment to their respective programs, as potential students (and often their parents) are, more than ever, explicitly looking for experiential learning opportunities. However, the kind of public interest internships described in this article are possible if, and only if, the time and energy are earmarked by departments, faculties, and universities to ensure the process is properly supported. In addition to its moral responsibility, the university also has a fiscal obligation to contribute to the internship experience in a way that justifies the tuition it exacts from students.

From the outset, a significant amount of work goes into matching students with the right organization. Knowing what local NPO or international NGO might be appropriate for a placement, including its supervisory/managerial capacities, and then building a relationship with representative(s) from that organization, requires a genuine commitment to this form of critical pedagogy. Previous knowledge of the student, including his/her interests, strengths, weaknesses, and short- and long-term goals, is similarly beneficial to ensuring a meaningful placement for both parties. In an ideal scenario, students then undertake relevant theoretical training prior to and during their placements, attend regular meetings with an academic supervisor and peers involved in similar internships, and participate in thorough debriefing sessions post-placement.

Given the range of work involved in mounting and implementing these internships, who then in the university should administer and supervise such resource-intensive experiential learning? I contend that a central role must be played by individuals who can draw on relevant theory and help students to thoughtfully consider their own subjectivities vis-à-vis their placements in order to facilitate the action/reflection at the heart of this form of pedagogy (Molee et al. 2010). The labour required to meet these objectives includes, but is not limited to, developing a syllabus, facilitating in-class discussions, and administering and evaluating assignments, all of which should be in the hands of a faculty member. Yet, most departments and faculties are facing deepening cutbacks and are stretched to the limit trying to cover undergraduate and graduate teaching assignments. Moreover, the pressure to publish or perish outweighs the time faculty members can devote to "outreach, engagement, and community service", which do not figure prominently in an academic's performance evaluation (Ward 2005, 219; Chertkovskaya et al. 2013; Few et al. 2007; Hearn and Hanke 2012; hooks 1994). Although qualified staff personnel can play an important role in administering aspects of public interest internships, they too, as a university administrator stressed in our interview, "are already overworked." In the case of our MPI program, I strongly believe that the placements we offer are possible only because we have limited enrollment in the program to 20 students 
per year. There is, however, always the fear that higher administration will want more 'bums in seats' to justify our faculty expenditure. ${ }^{12}$

The labour required to coordinate international placements is particularly daunting. For many students, the chance to live and work abroad with an organization dedicated to the public good can be transformative. The experience affords students "a broader perspective of local and global practice, and potentially new forms of knowledge in social justice, equity, and rights perspectives, along with practical and ethical challenges that demand our attention" (Drolet 2013, 186). However, as Desjardins (2013) quips, it takes "a whole university to raise an international program" (225) and, unfortunately, "in many cases a great deal of catch-up work needs to happen on the ground for that cart to follow the overworked Clydesdale" (219). In addition to the logistical labour associated with international internships, university programs must also dedicate the pedagogical resources necessary for students to understand and interrogate complex international power relations and cultural imperialism, especially when the internship takes place in the Global South (MacDonald 2013; Tiessen and Huish 2014; Wehbi 2009).

\subsection{The Central Role of Community Partners}

Clearly, substantial work occurs on the university's end to coordinate and implement local and international internships. As a result of this commitment, the president of Western University describes service learning as "a win-win for everyone involved-students get the opportunity to apply the knowledge and skills they learn in the classroom to real-world challenges, while community partners enjoy the tangible benefits of the services our students provide" (Chakma 2013). This more traditional approach does not, however, recognize the considerable time, energy, and resources community partners also dedicate to the process in a variety of capacities. First, they play an important managerial role in ensuring the productive integration of students into the workplace environment and determining projects achievable within a specified time period in line with an intern's capabilities. As a local CBO representative acknowledged, this managerial role can be difficult as she sometimes struggles to "identify meaningful projects to dovetail with the students' schedule and varying nature of their other commitments." She also pointed to the "lack of supervisory time" and a "lack of space/resources" as key challenges, especially given her organization's size, financial constraints, and the very sensitive nature of its work. Second, as Rowe, Mackaway and Winchester-Seeto (2012) describe, host organizations offer support in the form of "nurturing the personal and professional development of students" (118). This kind of care is especially important in cases where, as noted, students encounter first-hand unjust socio-economic inequities. Third, organizations play a vital educational role in providing "access to 'real life' learning opportunities... or helping students construct knowledge through talking and reflecting on practice...or actually providing training for specific workplace skills" (Rowe, Mackaway and Winchester-Seeto 2012, 118).

To meet the demands of these obligations, organizations must not only have the time and energy, but also the skills necessary to supervise, nurture, and educate young people. In a related vein, I admit to feeling trepidation placing certain students with specific organizations. Naturally, some students are more scholastically capable, have more 'practical' skills, and/or are more capable of working independently than other students, which means that careful and diplomatic maneuvering is sometimes needed to get the match right. In a select number of instances and for a range of reasons, I have not in fact succeeded in my matchmaking and the experience was less constructive and rewarding than I think both parties had hoped. As a case in point, I arranged a semester-long placement for a fourth-year student with a local organization s/he requested, hoping that the placement would be mutually beneficial. Over the

\footnotetext{
${ }^{12}$ Our much larger MIT undergraduate internship program requires a full-time staff member to coordinate logistics, and the equivalent of a half-course teaching load for a faculty member (over the course of a 12 month period) to supervise and mark the academic papers students write that connect their hands-on experience with the program's theoretical content.
} 
course of the internship, which included various research, writing, and event planning assignments, I saw first-hand that the student learned valuable lessons about media relations, non-profit labour in the 'real world,' and how to act in a professional manner in a workplace environment. However, I could also see that s/he required a fair amount of guidance by the host supervisor who became increasingly frustrated throughout the semester, especially given that the organization was already understaffed. From the student's perspective though, the host supervisor was too 'hands-off' during the internship and s/he was discouraged by what s/he considered to be a lack of direction and feedback. As the supervising faculty member, I could not determine exactly how or where things fell apart but could see that, despite the best efforts and intentions of the organization, it did not perhaps have the capacity to effectively mentor this young adult who, in turn, perhaps required more support than the majority of his/her peers. This example not only illustrates the labour-intensive responsibilities of community partners, but it also speaks to an issue of particular relevance to the field of communications: the gap between what participants expect out of internships and what actually happens on the ground during placements (see Frenette 2013, 367-368).

\section{Communications for the Public Good}

In this section, I examine some of the unique challenges associated with coordinating, hosting, and participating in communications-oriented internships with local and international NGOs, NPOs, and CBOs. I begin with what interviewees pointed to as a disconnect they often see between what students study in their critical communications programs and what skills community partners expect students from these programs to possess. Understandably, organizations anticipate that communication interns will bring to the table hands-on public relations or marketing skills, or are able to build websites and/or manage social media campaigns. While many students do in fact possess such expertise, which they develop themselves or learn as part of their educational training, most university communications programs are founded on interdisciplinary, critical approaches to analyzing social theory, the aesthetic dimensions of communications, and the socio-cultural, political, and economic forces at play in the intersection of media and power. The overarching objective of these programs then is to provide students with a critical education, not to impart practical skills for the job market. As a result, "it's harder to quantify what we 'do' in a comms program," a former student said, "so the onus is on us to prove ourselves to organizations in a way that's more tangible." An NGO representative concurred, explaining that from her perspective communications programs are predominantly theory-heavy, whereas "communications as a job title is often about practical, skills-based, day-to-day work tasks. The two don't always match up but the organization has an important role to play in making sure that the internship isn't just technical, but connects back to what the student is learning in school in a meaningful way."

As a corollary, organizations often expect that if interns are young communication students they instinctively bring social media expertise to their placement. A former student argued quite passionately that this expectation is highly problematic because the non-profit sector must, in like manner to the private sector, invest in and take more seriously their communication strategies instead of relying on temporary, young interns to manage their social media. There is, she maintained, "a massive difference between using Twitter as a technical tool and building a communications campaign that is content-driven. If an NGO relies on interns to bring the organization up to a certain level, they're [the student] not learning anything because they're coming in as the supposed expert." The NGO representative quoted directly above agreed-even if students come into an internship with social media experience and know-how, it is essential that they receive what she called "real learning value added" that builds on their existing knowledge base.

Communication placements with international organizations can complicate the situation even further. As a salient example, I have coordinated and supervised undergraduate student internships with two well-respected communication rights NGOs in Malaysia and Thailand. The internships have, I believe, been a life-changing experience for participating students as they live and work in a socio-political, economic, and media environment very dif- 
ferent from their own. ${ }^{13}$ In these countries, freedom of expression is significantly more limited and constrained than at home in Canada, and the political landscape can shift dramatically in a very short timeframe. When journalists are imprisoned for reporting the news or bloggers are charged with sedition for criticizing a political figure, safety considerations take precedence over all else and emotional support for interns is vital. Of course, not all international communications internships are as politically sensitive or activist-oriented as these placements. Nevertheless, understanding and respecting the local landscape is absolutely essential in every instance, as is a solid working relationship between the university and local representatives. Again, this work requires a serious commitment of time and energy by all involved in the process. If the requisite resources are not made available, then this type of experiential learning simply cannot be offered even if it is meant to advance the public good at home and/or abroad.

\section{Activism and the Public Good}

The word 'activism' is seldom used in discussions about internships or in service learning literature more broadly as attention is focused more on sanctioned, non-disruptive forms of community engagement. There is, however, a growing subset of material addressing just how far critical service learning can go in its "explicit aim toward social justice" (Mitchell 2008, 50; Bickford and Reynolds 2002; Bruce and Brown 2010; Johnston 2011; Mitchell 2007; Vogelgesang and Rhoads 2003). When asked whether limits should be placed on how activist an internship could be, interviewees overwhelmingly responded that although they would be concerned with activities that might jeopardize a student's personal safety and/or legal security, all thought that students should be allowed to undertake internships that directly challenge structures of control and the status quo both on and off campus. A student may, for example, request a communications-oriented internship with a movement aimed at freezing or abolishing university tuition. Another student may ask to intern with the Occupy movement, an international campaign contesting socio-economic inequalities, or Idle No More, a grassroots Canadian-based movement in support of indigenous rights. In these examples students would work with social change advocates to contest the institutionalization of community engagement that is, as noted, the hallmark of most experiential learning programs in higher education. As a result, their labour would likely be framed by university administrators as the kinds of "disruptions" that "rarely are seen as raising important political and ideological concerns, but instead are viewed as potential threats to the generation of revenue" (Vogelgesang and Rhoads 2003). While university administrations have moved towards "breaking down the 'ivory tower' and connecting academia to the "community"' (Dyer-Witheford $2007,58)$, they do not want to do this at the expense of jeopardizing their institution's brand or its relationship with sponsors or alumni benefactors. While neither I nor any of my interviewees have come into direct conflict with an administrative body over a specific internship, all interviewees said that they fully expected that their respective institutions would dissuade or even prevent a placement that in some manner directly challenged the university's political and economic status quo. As a faculty member lamented in reference to his home institution, "I am pretty certain that the admin would do just about anything to protect the university's image."

The extent to which an administration would discourage or suppress activist-oriented internships depends in large part, of course, on context. While I enjoy a considerable amount of pedagogical freedom in my position, colleagues in other locales at home and abroad do not have the same flexibility, often facing "reprisals, both externally from political opponents and internally from those within the university who perceive their involvement as nonconformist" (Flood, Martin and Dreher 2013, 18). ${ }^{14}$ Moreover, it can be significantly more difficult for

\footnotetext{
${ }^{13}$ See Tiessen and Huish (2014) for an insightful edited collection addressing a range of issues related to international experiential learning.

${ }^{14}$ See also the impressive work of the Scholars at Risk Network, which promotes academic freedom worldwide: http://scholarsatrisk.nyu.edu/.
} 
some individuals-e.g., precarious teaching and research labour without the (relative) security of tenure, or staff members more beholden to university management-to advance internships that run counter to an administration's trajectory for its service learning.

Recognizing that "social activism is not necessarily a more 'mature' form of service" (Bickford and Reynolds 2002, 240), my aim here is not to privilege activist internships over other forms of communications-related placements that engage with the community. Moreover, it is difficult to make clear delineations between various labels used to describe, for example, 'activist,' 'public interest,' 'community-based,' or 'critical service learning' placements. One interviewee outside of my home faculty eschewed use of the word 'activist' because of its rather radical overtones and instead preferred 'advocacy' to describe the kinds of experiential learning he has helped to coordinate. It seems then that there is a broad spectrum at play, as internships aimed at the public good range from the politically benign (e.g., Big Sisters), to more advocacy-oriented (e.g., Unity Project for the Relief of Homelessness), to overtly activist (e.g., Idle No More). For many students and faculty there is value in trying to reclaim the latter two categories of internships, especially "the activist potential of service-learning, which the process of institutionalization obscures" (Bickford and Reynolds 2002, 230). While it may not be easy, part of this process necessitates a willingness to question how and in what ways many of our well-intentioned public interest internships might actually help maintain structures of inequity. Instead of undertaking incremental actions to address systemic problems, what may be needed is to provide students with the opportunity to interrogate how and why conditions of inequity exist in the first place and what they can do to about it. Indeed, as Mitchell (2007) maintains, "[h]elping students understand the consequences of serviceparticularly the way that service can perpetuate need by placing 'Band-Aids' on community problems -is an important aspect of critical service-learning" (103). Students should, for example, be allowed to direct their energies towards advancing a stronger role for the state in protecting the interests of citizens over consumers (e.g., through placements with Occupy or Idle No More). In so doing, they play an active role in seeking "to change the social climate and structures that make volunteerism necessary" (Bickford and Reynolds 2002, 238; Boyd and Sandell 2012; Vogelgesang and Rhoads 2003).

If we agree that education "has the potential to generate citizens/professionals who work for social justice rather than reproducing conformity to the status quo" (Johnston 2011, 177), then institutions should be willing to facilitate pedagogy that encourages students to think critically about the role of internships within a wider socio-political, economic, and historical context and which allows them, if they want, to participate in placements that seek to change the social climate both within and beyond the 'ivory tower.' As part and parcel of this approach, students should be permitted to participate in internships that do not fit a standard organizational structure (e.g., placements with an international movement or local protest). This is, however, no easy task. To ensure appropriate educational standards three factors need to be taken into consideration. First, the home department/faculty must have wellreasoned selection criteria to vet credible placements. Second, in like manner to any other type of internship, students need to be matched with an appropriate host supervisor capable of fulfilling the managerial, supportive, and educational roles described above. Third, evaluation mechanisms must be in place to allow for the fair adjudication of an intern's work.

In the case of something like Occupy or Idle No More, it would likely be difficult to identify a suitable supervisor, one capable of not only hosting but also appropriately assessing a student's work. In the past, I have placed a handful of students with rather non-contentious politically oriented groups and networks. I have also placed two students with what I would consider to be more activist-oriented movements that seek a radical shift in the political landscape. In all of these cases, the only reason the placement was acceptable is because, as the supervising faculty member, I was well-acquainted with an individual in the network/group/movement whom I trusted could fulfil the above criteria and would help ensure 
that the student did not engage in hazardous activities during the placement. ${ }^{15}$ This form of experiential learning clearly needs to be arranged on a case-by-case basis and is contingent upon myriad ambiguous factors that are out of the students' control, including the faculty member's personal and professional contacts. In one case, I believe the placement was not very successful primarily because the student did not seem to take it as seriously as s/he might have if $s /$ he was expected to be present in an office with set 'work' hours along with other employees and/or volunteers. Although this individual was given clear instructions from, and attended regular meetings with, the host supervisor, I should have recognized that s/he needed more structure to the placement.

As part of this discussion, communication programs must also consider how they would respond to a student's request for an internship placement with a network, group, movement, or organization whose work, cause, and/or perspective runs counter to personal and collective beliefs about what is in the 'public good'. A faculty interviewee insisted that we cannot make the 'public good' or 'activist' "shorthand for 'leftist'," arguing that there is an important line between not trying to reproduce students in our own political likeness and steering them away from regressive politics. My own conception of what constitutes the public good, for instance, may be very different from that of one my students or colleagues, but where can the line be drawn and who should be responsible for the decision? Amber Dean (2008) offers readers a particularly honest look into her own struggles with how she would approach a student requesting to engage in a form of experiential learning that she personally considers politically problematic (e.g., a pro-life organization). For Dean, and I agree, context matters and each situation should be approached on its own merit. Instead of deciding in advance that certain internships are acceptable and others are not, we should be clear about our parameters, our reasons for incorporating public interest internships into our academic programs, and our overarching objectives. Next, we must have procedures in place based on these objectives allowing us to determine what placements are in the 'public good,' acknowledging that neither answers nor consensus may come easily.

In the end, I draw attention to the pressing need for all stakeholders-students, community representatives, university faculty, staff, and administrators-to openly discuss and reflect upon what they expect out of internships billed as being of benefit not only for students, but also for organizations and society writ large. This is particularly important for the field of communications as the number of university programs swells and the calls from students for relevant 'real life' experience continue to grow louder. Instead of playing catch-up to the internship wave in an ad hoc manner, communication departments and faculties need to be clear about their intentions and provide the necessary resources to meet them.

\section{References}

Attfield, James and Isabelle Couture. 2014. An Investigation Into the Status and Implications of Unpaid Internships in Ontario. Accessed October 2, 2014.

https://dspace.library.uvic.ca/bitstream/handle/1828/5294/Attfield_James and Couture Isabelle M PA 2014.pdf?sequence=1\&isAllowed=y.

Banerjee, Madhumita and Cheryl O. Hausafus. 2007. Faculty Use of Service-Learning: Perceptions, motivations, and impediments for the human sciences. Michigan Journal of Community Service Learning 10 (3): 32-45.

Bickford, Donna M. and Nedra Reynolds. 2002. Activism and Service Learning: Reframing Volunteerism as Acts of Dissent. Pedagogy: Critical Approaches to Teaching Literature, Language, Composition, and Culture 2 (2): 229-252.

Boyd, Nan Alamilla and Jillian Sandell. 2012. Unpaid and Critically Engaged: Feminist Interns in the Nonprofit Industrial Complex. Feminist Teacher 22 (3): 251-265.

Breunig, Mary. 2005. Turning Experiential Education and Critical Pedagogy Theory into Praxis. Journal of Experiential Education 28 (2): 106-122.

\footnotetext{
${ }^{15}$ In addition to other required paperwork, students must sign an 'acknowledgement and assumption of risk' form prior to their placement. International internships include supplementary orientation sessions with the academic supervisor and students must sign health insurance forms.
} 
Bruce, Judy and Seth Brown. 2010. Conceptualising Service-Learning in Global Times. Critical Literacy: Theories and Practices 4 (1): 6-15.

Bruce, Judy, Tammi Martin and Seth Brown. 2010. Seeking Change: A Model for Critical ServiceLearning in Physical Education Teacher Education. In Service-Learning in Physical Education and Related Professions: A Global Perspective, edited by Marybeth P. Miller and James D. Nendel, 333-341. Sudbury: Jones and Bartlett Publishers.

Canadian Intern Association. 2014a What is the law? Accessed September 19, 2014. http://www.internassociation.ca/what-is-the-law/.

Canadian Intern Association. 2014b. About Us. Accessed September 19, 2014. http://www.internassociation.ca/about/

Chakma, Amit. 2013. Community Service Learning. The Student Success Centre, Western University. Accessed January 13, 2014. http://www.success.uwo.ca/experience/community engaged learning/index.html.

Chertkovskaya, Ekaterina, Peter Watt, Stefan Tramer, and Sverre Spoelstra. 2013. Giving Notice to Employability. ephemera: theory \& politics in organization 13 (4): 701-716.

Darby, Alexa and Gabrielle Newman. 2014. Applying Motivation Theory to Faculty Motivation to Utilize Academic Service-Learning Pedagogy. Journal of Higher Education Outreach and Engagement 18 (2): 91-119.

Dean, Amber. 2008. Teaching Feminist Activism: Reflections on an Activism Assignment in Introductory Women's Studies. Review of Education, Pedagogy, and Cultural Studies 29 (4): 351-69.

Desjardins, Michel. 2013. Practicalities and Pedagogies: Implementing International Learning Opportunities for Students. In The World is my Classroom: International Learning and Canadian Higher Education, edited by Joanne Benham Rennick and Michel Desjardins, 215- 235. Toronto: University of Toronto Press.

Drolet, Julie. 2014. Getting Prepared for International Experiential Learning: An Ethical Imperative. In Globetrotting or Global Citizenship?: Perils and Potential of International Experiential Learning, edited by Rebecca Tiessen and Robert Huish, 185-197. Toronto: University of Toronto Press.

Dyer-Witheford, Nick. 2007. Teaching and Tear Gas: The University in the Era of General Intellect. In Utopian Pedagogy: Radical Experiments against Neoliberal Globalization, edited by Mark Coté, Richard J.F. Day and Greig de Peuter, 43-63. Toronto: University of Toronto Press.

FIMS (Faculty of Information and Media Studies). 2014. Media \& The Public Interest. The University of Western Ontario. Accessed September 5, 2014. http://www.fims.uwo.ca/acad_programs/undergrad/mpi.htm.

Few, April L., Fred P. Piercy and Andrew Stremmel. 2007. Balancing the Passion for Activism with the Demands of Tenure: One Professional's Story from Three Perspectives. NWSA Journal 19 (3): 4766.

Flood, Michael, Brian Martin and Tanja Dreher. 2013. Combining Academia and Activism: Common Obstacles and Useful Tools. Australian Universities Review 55 (1): 17-26.

Freire, Paulo. 1970. Pedagogy of the Oppressed. New York: Herder and Herder.

Frenette, Alexandre. 2013. Making the Intern Economy: Role and Career Challenges of the Music Industry Intern. Work and Occupations 40 (4): 364-397.

Giroux, Henry A. 2011. On Critical Pedagogy. New York: Bloomsbury.

Hall, Stuart. 2007. Universities, Intellectuals, and Multitudes: An Interview with Stuart Hall. In Utopian Pedagogy: Radical Experiment against Neoliberal Globalization, edited by Mark Coté, Richard J.F. Day and Greig de Peuter, 108-28. Toronto: University of Toronto Press.

Hanke, Bob and Alison Hearn. 2012. Introduction: Out of the Ruins, the University to Come. Topia: Canadian Journal of Cultural Studies 28: 11-20.

Haque, M. Shamsul. 2010. Non-Governmental Organizations (NGOs). In Handbook of Governance, edited by Mark Bevir, 330-341. Los Angeles, California: Sage Publications.

Harris, Sophia. 2014. Unpaid Academic Internships Called Exploitation by Students. CBC News, September 22. Accessed October 2, 2014. http://www.cbc.ca/news/business/unpaid-academicinternships-called-exploitation-by-students-1.2770424.

hooks, bell. 1994. Teaching to Transgress: Education as the Practice of Freedom. New York: Routledge.

Johnston, Jessica. 2011. Interrogating the Goals of Work-Integrated Learning: Neoliberal Agendas and Critical Pedagogy. Asia-Pacific Journal of Cooperative Education 12 (3): 175-182.

King, John T. 2004. Service Learning as a Site for Critical Pedagogy: A case of Collaboration, Caring, and Defamilarization Across Borders. Journal of Experiential Education 26 (3): 121-137. 
Lurie, Stephen. 2013. How Washington Abandoned America's Unpaid Interns. The Atlantic, Nov. 4. Accessed February 23, 2014. http://www.theatlantic.com/business/archive/2013/11/howwashington-abandoned-americas-unpaid-interns/281125/.

MacDonald, Moira. 2013. The Plight of the Unpaid Intern. University Affairs, Sept. 11. Accessed February 22, 2014. http://www.universityaffairs.ca/features/feature-article/plight-of-the-unpaid-intern/.

Mitchell, Tania D. 2008. Traditional vs. Critical Service-Learning: Engaging the Literature to Differentiate Two Models. Michigan Journal of Community Service Learning 14 (2): 50-65.

Mitchell, Tania D. 2007. Critical Service-Learning as Social Justice Education: A Case Study of the Citizen Scholars Program. Equity \& Excellence in Education 40 (2): 101-112.

Molee, Lenore M., Mary E. Henry, Valerie I. Sessa and Erin R. McKinney-Prupis. 2010. Assessing Learning in Service-Learning Courses Through Critical Reflection. Journal of Experiential Education 33 (3): 230-257.

Neff, Gina. 2011. The Competitive Privilege of Working for Free: Rethinking the Roles that Interns Play in Communication Industries. International Communication Association Conference. Boston.

O'Meara, KerryAnn and Elizabeth Niehaus. 2009. Service-Learning is ... How Faculty Explain Their Practice. Michigan Journal of Community Service Learning 16 (1): 17-32.

Perlin, Ross. 2012. These Are Not Your Father's Internships. The New York Times (The Opinion Pages online). Accessed February 26, 2014. http://www.nytimes.com/roomfordebate/2012/02/04/dounpaid-internships-exploit-college-students/todays-internships-are-a-racket-not-an-opportunity.

Perlin, Ross. 2011. Intern Nation: How To Earn Nothing and Learn Little in the Brave New Economy. Brooklyn: Verso.

Pompa, Lori. 2002. Service-Learning as Crucible: Reflections on Immersion, Context, Power, and Transformation. Michigan Journal of Community Service Learning 9 (1): 67-76.

Porfilio, Brad J. and Heather Hickman. 2011. Introduction. In Critical Service-Learning as Revolutionary Pedagogy: A Project of Student Agency in Action, edited by Brad J. Porfilio and Heather Hickman, ix-xx. Charlotte, NC: Information Age Publishing.

Rennick, Joanne Benham and Michel Desjardins. 2013. Towards a Pedagogy of Good Global Citizenship. In The World is my Classroom: International Learning and Canadian Higher Education, edited by Joanne Benham Rennick and Michel Desjardins, 3-15. Toronto: University of Toronto Press.

Rice, Kathleen and Seth Pollack. 2000. Developing a critical pedagogy of service learning: Preparing self-reflective, culturally aware, and responsible community participants. In Integrating Service Learning and Multicultural Education in colleges and universities, edited by Carolyn R. O'Grady, 115-134. Mahwah, NJ: Erlbaum.

Rigsby, John T, Noel Addy, Clyde Herring and Donna Polledo. 2013. An Examination of Internships and Job Opportunities. Journal of Applied Business Research 29 (4): 1131-1143.

Rowe, Anna, Jacqueline Mackaway and Theresa Winchester-Seeto. 2012. 'But I Thought You Were Doing That'-Clarifying the Role of the Host Supervisor in Experience Based Learning. Asia-Pacific Journal of Cooperative Education 13 (2): 115-134.

Sagan, Aleksandra. 2013. Unpaid Internships Exploit 'vulnerable generation.' CBC News, July 2. Accessed January 11, 2014. http://www.cbc.ca/news/canada/unpaid-internships-exploit-vulnerablegeneration-1.1332839.

Shade, Leslie Regan. 2014. 'Give us Bread, But Give us Roses': Gender and Labour in the Digital Economy. International Journal of Media \& Cultural Politics 10 (2): 129-144.

Smeltzer, Sandra and Amanda Grzyb. 2009. Critical Media Pedagogy in the Public Interest. Democratic Communiqué 23 (2): 1-22.

Smith, Andrea. 2007. Introduction: The Revolution Will Not Be Funded. In The Revolution Will Not Be Funded: Beyond The Non-Profit Industrial Complex, edited by INCITE! Women of Color Against Violence, 1-18. Cambridge: South End Press.

Standing, Guy. 2014. A Precariat Charter: From Denizens to Citizens. London: Bloomsbury.

Standing, Guy. 2011. The Precariat: The New Dangerous Class. London: Bloomsbury.

Stirling, Ashley, Gretchen Kerr, Jenessa Banwell, Ellen MacPherson, Ahad Bandealy, and Anthony Battaglia. 2014. What is an Internship? An Inventory and Analysis of 'Internship' Opportunities. Toronto: Higher Education Quality Council of Ontario.

Tiessen, Rebecca and Robert Huish, eds. 2014. Globetrotting or Global Citizenship?: Perils and Potential of International Experiential Learning. Toronto: University of Toronto Press.

Uzwiak, Beth A. 2013. Fracturing Feminism: Activist Research and Ethics in a Women's Human Rights NGO. In Feminist Activist Ethnography: Counterpoints to Neoliberalism in North America, edited by Christa Craven and Dána-Ain Davis, 119-136. Landham, MD: Lexington Books.

Vogelgesang, Lori and Robert Rhoads. 2003. Advancing a Broad Notion of Public Engagement: The Limitations of Contemporary Service Learning. Journal of College and Character 4 (2). 
Ward, Kelly. 2005. Rethinking Faculty Roles and Rewards for the Public Good. In Higher Education for the Public Good: Emerging Voices from a National Movement, edited by Adrianna J. Kezar, Tony C. Chambers and John C. Burkhardt, 217-233. San Francisco: Jossey-Bass.

Wehbi, Samantha. 2009. Deconstructing Motivations: Challenging International Social Work Placements. International Social Work 52: 48-59.

Western University. 2014a. Western's Internship Program. The Student Success Centre. Accessed September 18, 2014. http://success.uwo.ca/experience/internships/.

Western University. 2014b. Achieving Excellence on the World Stage. Accessed March 9, 2014. http://president.uwo.ca/pdf/strategic-plan/WesternU_Full_StratPlan_2014.pdf.

Williams. Jeffrey. 2006. Debt Education: Bad for the Young, Bad for America. Dissent (Summer). Accessed December 14, 2013. http://www.dissentmagazine.org/article/debt-education-bad-for-theyoung-bad-for-america.

Wood, Will. 2011. Unpaid Internships are Exploited by the Wealthiest in the Creative Industry. The Guardian, Nov. 30. Accessed December 10, 2013. http://www.theguardian.com/cultureprofessionals-network/culture-professionals-blog/2011/nov/30/internships-unpaid-arts-culture.

\section{About the Author}

Sandra Smeltzer

With a background in Anthropology, International Development, and Political Economy of Communication, Dr. Smeltzer's primary areas of research and publication include the scholar-activist dialectic, communication in transitioning and developing countries, the ethics of activist research, and ICTs for social justice. Dr. Smeltzer is a Teaching Fellow (2015-2018) at Western University with a focus on international critical service learning. She has been awarded the USC Teaching Honour Roll Award of Excellence for every year she has taught at Western University and is the recipient of the FIMS Undergraduate Teaching Award. Dr. Smeltzer was awarded Western's inaugural Humanitarian Award for her international work, named one of Canada's Top 25 Most Influential Women by Women of Influence Magazine and one of Western's Top Newsmakers, and is profiled in the Winter 2014 issue of the philanthropy magazine, Lifestyles. 


\title{
Educating the Precariat: Intern Labour and a Renewed Approach to Media Literacy Education
}

\author{
Doug Tewksbury \\ Niagara University, Lewiston, USA, dtewksbury@niagara.edu
}

\begin{abstract}
As internships have become more common in the production of media content, the media literacy movement has been neglectful in addressing the role of labour in general and internship labour in particular as a necessary component in deconstructing media content. This paper argues that media literacy educators should teach citizens to understand not just the content and grammar of media production, but also the labour conditions that underlie the creation of this content, with internships being among the most exploitative development in recent years and representative of a larger issue of worker precarity. The paper concludes with a call for reforms to media literacy pedagogy to address workers' rights and dignity in media and creative industries.
\end{abstract}

Keywords: internships, media literacy, media education, precarity, labour, education, cultural studies, inequality

Acknowledgements: The author thanks the editors of this special issue for their comments, along with Dr. Christine Quail for her assistance in discussing and developing the themes of this article. I am especially grateful to my students who volunteered to share their internship experiences with me for use in this article.

From January through August of 2011, Diana Wang was an unpaid intern at Harper's Bazaar, a Hearst-owned magazine, in New York City. She was 28; it was her seventh internship. She served as "head intern" in the magazine's accessories department, supervising eight other interns while shuttling bags across New York City and overnighting hats to London, for 40 to 55 hours per week. She received no pay for this work (Adams, 2013). Similarly, in 2009-2010, Eric Glatt was a 41-year old unpaid intern, one of 20 on the Fox Searchlight film Black Swan. Hoping the experience would translate into a film editing position, Glatt instead was a personal assistant to the film's executive staff, sent on errands to purchase scented candles and hypoallergenic pillows (Miller and Horn 2014). Both Wang and Glatt successfully sued in lawsuits that were noticed in both the popular and business press, but they were not alone: from June to August 2013, lawsuits were filed by current or former interns against Condé Nast Publications, Warner Music Group, Atlantic Recording, Gawker Media, Fox Entertainment Group, NBC Universal, Viacom, Sony, Universal Music Group, Bad Boy Entertainment, Donna Karan, and Charlie Rose, Inc. (Becker 2013; Jacobs 2013; Greenhouse, 2013; Perlin 2013a; Spitznagel 2013). As Glatt stated of the Black Swan case, "It was nauseating to see how easily employers could get free labor just by slapping the title 'internship' on something" (Perlin 2013b).

To date, media studies and communication scholarship has generally moved slowly on the issue of labour until its recent turn toward the subject (Fuchs and Sevignani 2013). The field's shift in attention toward labour is important, not only because exploitative material and immaterial labour practices are tightly woven into the business model of many Web 2.0 participatory platforms, but also due to the increasingly precarious status of media workers in these positions (Berlant 2011; Standing 2011).

The time has come for labour to be, as Vincent Mosco states, "placed high on the agenda of projects for the renewal of cultural studies" $(2011,230)$. Capital's unchecked drive to secure cheap labour is a central force leading to exploitative working conditions-human slavery being perhaps the most extreme example-but has also resulted in the rise of hegemonic cultural and political mechanisms that reinforce class divisions. Capitalist production has always had labour at the center of its attention, and inherent in the logic of this production is 
the drive to reduce labour costs in a race to the bottom to increase profits for investors and owners. Today that logic has resulted in the spread of internships, an increasingly troubling development in modern labour practices and in media industries in particular.

The need for renewed critical scholarship on this issue among researchers is clear. It is also necessary that educators develop a pedagogy of media education that includes addressing the labour conditions involved in the production of media. I argue that the media literacy movement must begin to take seriously not only media production labour considerations in general, but the role of internships in particular, as a fundamental part of a holistic, critical media education.

Neither issue has been particularly well addressed in media literacy education. James W. Potter (2004), for example, provides 41 definitions of media literacy from a variety of scholars, educators, or organizations, yet not a single one mentions the subject of work or labour $(24-28,257-260)$. As interns are increasingly being asked to function as de-facto replacements for paid employees as a cost-saving measure to return value to shareholders or owners (Becker 2013; Harrison 2012; Miller and Horn 2014), they currently fall into a precarious space where they neither enjoy the compensation nor possess the rights of employees (Perlin 2011).

Laws and policies protecting both paid employees and unpaid interns from exploitation are already on the books in the United States through the Fair Labor Standards Act, in Canada through a number of provincial regulations, and through similar policies in many developed nations, but are generally unenforced (United States Department of Labor 2010; Ontario Ministry of Labour 2000; British Columbia Ministry of Labour 1996). Many unpaid internships could be read as a violation of the assertion in the United Nations' Universal Declaration of Human Rights that "Everyone has the right to work, to free choice of employment, to just and favourable conditions of work and to protection against unemployment... [and] without any discrimination, has the right to equal pay for equal work" (1948, Article 23).

If the media literacy movement is designed to teach media audiences the skills to identify and resist hegemonic structures in terms of media content, then it is equally important that it teach citizens and future media workers to identify and resist hegemonic structures inherent in the labour processes that produce that media. That is, for our students to be more fully media literate, media educators must teach them to understand not just the content and grammar of production, but also the material labour conditions that underlie the creation of content in media industries.

\section{Educating a Media Literate Public}

Media literacy is a broadly based, democratically rooted, interdisciplinary approach of citizen media education and empowerment (Kellner and Share 2005; Lewis and Jhally 1998; Potter 2004, 2013). A fundamentally critical endeavor that "must be conceived as a political, social, and cultural practice" (Sholle and Denski 1994, 17), the roots of media literacy lie in critical literary studies-based arguments, namely that it is necessary to cultivate citizens who have the capacity to use socially constructed forms of communication and media representation, particularly through deconstructing media discourses, and through both classroom curricula and popular discursive campaigns. Importantly, media literacy also provides a productionbased method of teaching citizens the skills necessary to make their own media (Macedo 2006).

Among its strengths, the media literacy agenda has a tradition of focusing its attention on media content itself, casting a critical eye toward issues of representation and identity, as well as political economic arguments about media ownership and consolidation as reinforcing mechanisms for hegemonic media content. It is important to remember that the media literacy movement is a political project. It encourages individuals to consume media critically and create content that works toward creating more democratic media structures, and aims to contribute more voices to the public sphere, particularly those that cross disciplinary boundary lines or challenge structures that reinforce hegemonic or ideological systems. 


\section{Internships and Media Literacy Education}

A weakness, however, is that media literacy education has not been especially adept at addressing the issue of labour conditions in the production of media content. And in the creation of media content, among the most exploitative labour practices in recent years has been the unpaid internship. Internships-both paid and unpaid-have become such a common practice in the media and creative industries that there has been an explosion in the number of such positions in firms both large and small, as intern labour has become a de-facto replacement for the paid worker, if not a prerequisite for those who wish to eventually work in these fields (Kuehn and Corrigan 2013; Perlin 2011).

The unpaid internship has become an increasingly prominent topic in both scholarly and popular consciousness, most notably through Ross Perlin's Intern Nation: How to Earn Nothing and Learn Little in the Brave New Economy (2011). Media industries have been called out for being among the worst offenders in exploiting unpaid labour. The consolidation of media industries, the high salaries at the top of the star system, the gutting of union protections, and the ever-present pressure to provide strong quarterly returns to investors has led media producers in a race to the bottom to control costs (Mansell 2004; McChesney 2008, 2013; Mosco 2011). Labour is usually among the most important financial costs to companies in large-scale productions, but this is also true in smaller fields, such as advertising, web programming, music recording, and book publishing.

And the numbers are troubling. Perlin (2011) notes that no exact figures are kept by the U.S. Department of Labor or Bureau of Labor Statistics, but it is estimated that there are between one and two million interns in the United States as of 2013. Canada does not keep statistics on internships, but Toronto labour lawyer and activist Andrew Langille estimates the number of interns to be between 100,000 and 300,000 (Sagan 2013). Kate Harrison (2012) claims that approximately two-thirds of North American internships are unpaid, most often those taken for college credit. Media industries in particular tend to offer the unpaid internship as an entry point for future media careers (Cumming 2014; Harrison 2012; Olson 2013). However, what has come to light through the recent spate of lawsuits is that the business models in these industries are in effect reliant on the unpaid labour of interns to offset the cost of production assistants, studio assistants, journalists, game testers, and personal assistants (Becker 2013; Jacobs 2013; Perlin 2013a; Spitznagel 2013). In addition to the often unpaid and vulnerable nature of these positions, media firms have the added advantage of no costs associated with healthcare, other benefits, or overtime, let alone worrying about the workplace protections that are available to full-time employees. If interns complain, companies can send them home. As Matthew Saccaro (2014) notes,

Employers already pay interns a low wage for the amount of work they do. One manager derisively referred to an intern as a "22-22-22," as in a 22-year-old who's willing to work 22-hour days for $\$ 22,000$ a year. With waves of high school students entering the internship market, why hire a 22-22-22 when you can hire a 16-year-old and pay them in exposure, experience and exhaustion?

Despite the recent lawsuits filed against a number of media conglomerates, the cultural acceptance of internships has proven to be difficult to overturn. Media industries were decades ahead of others in building the internship model into the prerequisite for employment, and as such, the reliance on unpaid labour is central to the business model of many commercial media. Christopher Knab (2008), for example, echoes commonplace advice for interns in the recording industry:

Nothing is more impressive than having done some work as an intern. Businesses that offer internships may demand a lot of you. They may (and will) test your patience by having you do what you think are mundane, boring, or menial tasks [...] Stick it out. Most likely you are being given a form of initiation. Most people in the recording industry started out doing menial tasks and when given the chance to express their skills [...] did so, and were rewarded with jobs, job-leads, promotions or recognition of some kind. 
While anecdotal, there are many similar stories reported from my own Media Studies advisees placed in for-credit internship positions in recent semesters. One student spent her unpaid internship semester grocery shopping for bands' tour riders every week, including being ordered to pick up a cake for her office from across town. Another student's video production internship involved one task, which was the single-take, hours-long filming of hockey practices every week. A third spent ten weeks doing nothing but logging tape for one of the largest network news affiliates in the nation. As a condition of her unpaid internship, another was required to sign a one-year non-compete agreement that did not allow her to work for another company in the same industry within a 60-mile radius for one year. My student advisees regularly take out loans to take advantage of their summer internships, particularly those in television news. One took out a $\$ 5,000$ loan to live in New York City for her internship, which paid her $\$ 16$ per day for ten weeks.

In each of these cases, although advised of their rights, students did not want to file a complaint with the university's co-op office about illegal or abusive internships, either out of fear that they would not get a letter of recommendation, the loss of class credit (and the financial burden associated with that), or the stigma of being labeled as a troublemaker. In a piece entitled "4 Coping Tips for Surviving a Crummy Internship," Lindsay Olson (2013) recommends toughing out the bad working conditions and "Comfort[ing] yourself with the fact that it'll look good on your résumé," because "It may not be clear to you how pouring coffee prepares you for a career in marketing, but your boss may be testing you to see how committed you are to learning the ropes."

Indeed, the usual subtext to most advice on internships is rooted in the discourse of "paying one's dues" and "sticking it out," ignoring rights violations, tolerating illegal activity, or living with harassment. The line on the resume or the letter of recommendation both function as reinforcements for hegemonic structures, keeping the workers in line through the fear of a bad review. Yet each of these threadbare arguments disregards identity- or class-based discrimination, whether structural or overt, in place of an idealized meritocracy where individual hard work and perseverance is the formula for a prosperous future. It is difficult, to be sure, as the role of media literacy educators isn't to encourage students to forego the career options that would put them in the very positions where they will be able to make ethical decisions in the production of media content. However, this can only occur by cracking open the critical question of how media educators can build a coordinated, interdisciplinary curricular effort to teach those students interested in entering the creative industries to not only identify exploitative working conditions, but to organize to work against these practices through educational, political, and personal efforts.

\section{A Renewed Approach to Media Literacy Education}

The next step for media literacy education is to continue its development of a rights-based pedagogy that highlights conditions of social class and dignity in labour through advocating for workplace protections as part of a regime of worker and human rights. The democratic promise of a healthy public sphere requires equality of opportunity and leveling of unequal structures, an ethics that demands a worker environment that benefits workers, not capitalists, in the labour practices of media-making.

To implement these shifts, the media literacy movement must put into practice several common-sense reforms to incorporate labour considerations into its tradition of critical pedagogy. Awareness raising, particularly in terms of empowering students to push for the enforcement of law and policy, is a first step. One of the great success stories of the media literacy movement thus far is the way that it has drawn on critical intellectual traditions to normalize the discussion of themes such as media representations of beauty and body image, race and gender performativity, or sexuality and sexual orientation, all of which are topics raised by resistant narratives through oppositional readings of dominant discourses.

But providing an oppositional reading of labour considerations is not enough: media educators need to empower their students, intern and non-intern alike, to exercise their rights as 
cultural workers, and to work together toward principles of equitable worker treatment. Students who plan on a future career in media work need to start early to develop an identity that places an emphasis on themselves as workers, professional labourers with rights, skills, and experience, and as valuable beyond simply their ability to provide cheap freelance labour or free content in exchange for an abstract promise of experience in an internship. Yet these principles can be difficult for many students to grasp, given that the predominant tendency of the Web 2.0-era business model is to offload the labour of media-making onto users, usually for no pay, and digital-native students have spent their adolescence with the political conjuncture of free content and free labour as their reference point for how media industries work.

To convince them otherwise is a critical, normative pedagogical project, one that must provide an oppositional reading of labour considerations that translates awareness raising into action. Hearing from current media and cultural workers can be beneficial for future workers (provided those speakers don't reinforce the "pay your dues" narrative that has long dominated much of the career advice given to students). Getting university internship and coop offices to protect the interns that they are sending out into the field can also be difficult, particularly as these offices often rely on metrics regarding placements instead of the quality of the internship or legality of the intern's position in the workplace. A general involvement with activism and direct democratic action can only help, as well, particularly as the goal of all of these efforts is enabling students to understand that social change is possible, and that the first step is empathy for and solidarity with the less powerful.

Similarly, collective worker action within and unionization of media workplaces are especially useful as protective measures-several of my own interns have not been allowed to touch a camera or editing equipment during their internships due to union rules-and educating students about their rights as workers is paramount. Furthermore, the incorporation of unions, collectives, or organizations into educators' curricula can show future media workers that the benefit of a intern and future worker education can actually provide relevant job training when done for the student's benefit but only when also focused on this practice within a framework of human and worker rights and dignity.

The Canadian Intern Association (2014), for example, is an advocacy group that unites interns for organized protection, comments on the legality of intern positions under Canadian provincial labour laws, and offers workshops and seminars to student groups. Lawsuits, both class action and individual, have already helped to pressure employers to realize that unpaid internships might not be as cheap as they think they are, as was the case in the recent Condé Nast and Charlie Rose, Inc. lawsuits led by unpaid former interns (Miller and Horn 2014; Perlin 2013a; Spitznagel 2013).

The labour conditions that underlie the creation of commercial media content directly affect the production of that content. But when those precarious conditions have become the norm for an exploitative system that enables the endless pursuit of profit and reinforces hegemonic structures of inequality, the problem becomes not one of future career preparation but one of ethics.

\section{References}

Adams, Susan. 2013. Is The Unpaid Internship Dead? Forbes, June 14. Accessed June 12, 2015. http://www.forbes.com/sites/susanadams/2013/06/14/is-the-unpaid-internship-dead/.

Becker, Amanda. 2013. PBS' Charlie Rose Settles with Unpaid Interns as Lawsuits Spread. Reuters, July 1. Accessed June 12, 2015. http://www.reuters.com/article/2013/07/01/entertainment-usinterns-lawsuit-charlie-idUSBRE9601E820130701.

Berlant, Lauren. 2011. Cruel Optimism. Durham: Duke University Press.

British Columbia Ministry of Labour. 1996. Employment Standards Act. Victoria, British Columbia. Accessed June 24, 2015.

http://www.bclaws.ca/EPLibraries/bclaws new/document/ID/freeside/00 9611301.

Canadian Intern Association. 2014. About Us. Accessed June 24, 2015. http://www.internassociation.ca/about/. 
Cumming, Ed. 2014. Interns Should Stop Complaining and Do a Proper Day's Work. The Telegraph, September 30. Accessed June 12, 2015. http://www.telegraph.co.uk/men/thinkingman/10340044/Interns-should-stop-complaining-and-do-a-proper-days-work.html.

Fuchs, Christian and Sebastian Sevignani. 2013. What Is Digital Labour? What Is Digital Work? What's Their Difference? And Why Do These Questions Matter for Understanding Social Media? tripleC: Communication, Capitalism \& Critique. Open Access Journal for a Global Sustainable Information Society 11 (2): 237-93.

Greenhouse, Steven. 2013. Judge Rules for Interns Who Sued Fox Searchlight. The New York Times, June 11, sec. Business Day. Accessed June 24, 2015.

http://www.nytimes.com/2013/06/12/business/judge-rules-for-interns-who-sued-foxsearchlight.html.

Harrison, Kate. 2012. Why Interns Are Your New Best Friends. Forbes, November 7. Accessed June 24, 2015. http://www.forbes.com/sites/kateharrison/2012/07/11/why-interns-are-your-new-bestfriends/.

Jacobs, Deborah. 2013. Unpaid Intern Lawsuits May Reduce Job Opportunities. Forbes, September 24. Accessed July 11, 2015. http://www.forbes.com/sites/deborahljacobs/2013/09/24/unpaid-internlawsuits-may-reduce-job-opportunities/.

Kellner, Douglas, and Jeff Share. 2005. Toward Critical Media Literacy: Core Concepts, Debates, Organizations, and Policy. Discourse: Studies in the Cultural Politics of Education 26 (3): 369-86.

Knab, Christopher. 2008 July. Do's and Don't for Audio and Other Music Oriented Interns: Or, How to Impress Your Internship Employer and Become Successful in the Recording Industry. Music Biz Academy. Accessed June 24, 2015. http://www.musicbizacademy.com/knab/articles/interns.htm.

Kuehn, Kathleen and Thomas F. Corrigan. 2013. Hope Labor: The Role of Employment Prospects in Online Social Production. The Political Economy of the Media 1 (1): 9-25.

Lewis, Justin and Sut Jhally. 1998. The Struggle over Media Literacy. Journal of Communication 48 (1): 109-20.

Macedo, Donaldo P. 2006. Literacies of Power: What Americans Are Not Allowed to Know. Boulder, CO.: Westview Press.

Mansell, Robin. 2004. Political Economy, Power and New Media. New Media and Society 6 (1): 7483.

McChesney, Robert W. 2008. The Political Economy of Media: Enduring Issues, Emerging Dilemmas. New York: Monthly Review Press.

McChesney, Robert W. 2013. Digital Disconnect: How Capitalism is Turning the Internet Against Democracy. New York: The New Press.

Miller, Daniel and John Horn. 2014. Lawsuit Challenges a Hollywood Pillar: Unpaid Internships. Los Angeles Times, April 6. Accessed June 24, 2015. http://articles.latimes.com/2014/apr/06/business/la-fi-ct-hollywood-interns-unpaid-internships/3.

Mosco, Vincent. 2011. Communication and Cultural Labour. In The Renewal of Cultural Studies, edited by Paul Smith, 230-37. Philadelphia, PA: Temple University Press.

Olson, Lindsay. 2013. 4 Coping Tips for Surviving a Crummy Internship. US News \& World Report, August 8. Accessed June 24, 2015. http://money.usnews.com/money/blogs/outside-voicescareers/2013/08/08/4-coping-tips-for-surviving-a-crummy-internship.

Ontario Ministry of Labour. 2000. Employment Standards Act. Toronto, Ontario. Accessed June 24, 2015. http://www.e-laws.gov.on.ca/html/statutes/english/elaws statutes 00e41_e.htm.

Perlin, Ross. 2011. Intern Nation: How to Earn Nothing and Learn Little in the Brave New Economy. Brooklyn, NY: Verso Books.

Perlin, Ross. 2013a. Unpaid Interns: Silent No More. The New York Times, July 20. Accessed June 24, 2015. http://www.nytimes.com/2013/07/21/jobs/unpaid-interns-silent-no-more.html.

Perlin, Ross. 2013b. Black Swan Event: The Beginning of the End of Unpaid Internships. Time, July 13. Accessed June 24, 2015. http://business.time.com/2013/06/13/black-swan-event-thebeginning-of-the-end-of-unpaid-internships/.

Potter, W. James. 2004. Theory of Media Literacy: A Cognitive Approach. Thousand Oaks, CA: SAGE Publications.

Potter, W. James. 2014. Media Literacy. Thousand Oaks, CA: Sage.

Saccaro, Matthew. 2014. High-Schoolers' Free Labor: Why the Internship Problem Will Get Even Worse. Salon, May 22. Accessed June 12, 2015.

http://www.salon.com/2014/05/22/high_schoolers_free_labor_why_the_internship_problem_will_ge t even worse/. 
Sagan, Aleksandra. 2013. Unpaid Internships Exploit 'Vulnerable Generation.' CBC News, July 2. Accessed June 12, 2015. http://www.cbc.ca/1.1332839.

Sholle, David, and Stan Denski. 1994. Media education and the (re)production of culture. Westport, CT: Bergin \& Garvey.

Spitznagel, Eric. 2013. Unpaid-Intern Lawsuits Explained. BusinessWeek: Lifestyle, June 27. Accessed June 12, 2015. http://www.businessweek.com/articles/2013-06-27/unpaid-intern-lawsuitsexplained.

Standing, Guy. 2011. The Precariat: The New Dangerous Class. London: Bloomsbury Academic.

United Nations Universal Declaration of Human Rights. 1948, Dec. 10. Accessed June 12, 2015. http://www.un.org/en/documents/udhr/.

United States Department of Labor. 2010. Internship Programs under the Fair Labor Standards Act. Accessed June 12, 2015. http://www.dol.gov/whd/regs/compliance/whdfs71.htm.

\section{About the Author}

Doug Tewksbury

Doug Tewksbury (Ph.D., Penn State, 2010) is Assistant Professor of Communication Studies at Niagara University where he teaches media studies and social justice. His current research explores the way that social movements are using participatory social/mobile technologies, digital labour, and civic engagement to build citizen empowerment. 


\title{
Unwaged Posts in UK Universities: Controversies and Campaigns
}

\author{
Kirsten Forkert* and Ana Lopes** \\ *Birmingham City University, Birmingham, UK, kirsten.forkert@bcu.ac.uk; **University of \\ the West of England, Bristol, UK, Ana2.Lopes@uwe.ac.uk
}

\begin{abstract}
This article examines unwaged posts at UK universities, using recent examples of advertised job posts. While unpaid work is common in the UK higher education system, unwaged posts are not. The posts under scrutiny in this article differ from traditional honorary titles as they target early career academics, who are unlikely to have a paid position elsewhere, rather than established scholars. The article contextualizes the appearance of these posts in a climate of increasing marketization of higher education, entrenching managerialism in higher education institutions, and the casualization of academic work. We also discuss resistance to the posts, arguing that the controversy surrounding unpaid internships in the creative industries created a receptive environment for resisting unwaged posts in academia. We analyze the campaigns that were fought against the advertisement of the posts, mostly through social media and the University and College Union. We explore the tactics used and discuss the advantages and limitations of the use of social media, as well as the role of trade unions in the campaigns against these posts, and we reflect on what future campaigns can learn from these experiences.
\end{abstract}

Keywords: universities, internships, academic labour, academia, precarity, unwaged work, social media, unions, casualization, activism, inequality

Acknowledgement: We wish to thank Vicky Blake for contributing to this article and other activists who shared their experiences with us.

\section{Introduction}

This article examines the phenomenon of unwaged posts in UK universities. It uses the examples of unwaged posts recently advertised at four higher education institutions as cases: unpaid research assistants at the University of Birmingham (UoB) and University College London (UCL) advertised in 2012; an "honorary junior research fellowship" at the University of Essex (UoE) advertised in 2013; and an unwaged "extracurricular" teaching post at Durham University, also advertised in 2013 (see the appendices for the adverts). The advertising of these posts provoked resistance on a national scale through public pressure, naming and shaming on social media, and campaigning by the University and College Union (UCU), causing the posts to be withdrawn (except for the post at Durham University). Subsequently, the universities issued defensive statements framing the unwaged posts as philanthropic goodwill, arguing they were "helping" postgraduates and recent postdoctoral researchers get teaching or research experience in a difficult job climate (Anna Freud Centre 2012; Birmingham Post 2012; University of Essex 2014).

In this article, we reflect on the extent to which these posts represent the exploitation of a worsening situation of labour precarity in the academic sector. We discuss these cases in the context of a hyper-competitive job market, which not only intensifies publishing demands on permanent staff, creating pressures to outsource routine teaching and research tasks to casualized workers, but also exacerbates desperation for postgraduates and early career academics for teaching and/or research experience. We reflect on a worrying normalization of the idea that academic work, particularly at the lower end of the professional hierarchy, does not have to pay a living wage, and that nobody's job is really secure. We also discuss the 
similarities between academic labour in the neoliberal university and cultural labour under precarious conditions.

It is in response to these deteriorating, generalizing conditions that the campaigns against the unwaged posts developed. We focus on these campaigns through an examination and thematic analysis of the expressions of public outrage and issues raised via union campaigns and social media. Finally, we will discuss how these campaigns led most of the universities involved, with the exception of Durham University, to withdraw the advertisements in question. We reflect on the potential of social media to capitalize on public outrage and enable a swift response, and we consider the limitations of relying on social media in such campaigns when the goal is to achieve permanent change.

\section{Context: Casualization and Precarity in UK Higher Education}

The cases explored in this article need to be understood in the context of debates surrounding precarity, that is, a broad state of existential, financial, and social insecurity that is underpinned by the flexibilization and casualization of labour markets (de Peuter 2011). Shortterm, insecure, and low-wage jobs are becoming the norm in sectors we used to see as secure. Isabell Lorey (2015) has recently argued that far from being an episodic condition, precarity is now normalized, while the welfare state is the exception. According to Lorey, the normalization of precarity has become an instrument of governance: it enables governing through insecurity. Through insecurity and fear, precarization embraces the whole of people's existence.

Internships are common in what are seen to be glamorous fields, such as politics, media, and the cultural industries (Curiale 2010; Perlin 2012; Intern Aware 2014; National Union of Journalists 2012; Carrotworkers' Collective 2012). Unwaged internships have been problematized for benefitting exploitative employers and those who can afford to work for free and thus restricting access to certain professions to those from privileged backgrounds. Internships started to become both common (Gregory 1998) and controversial in the 1990s, when 52 former interns of a U.S. public relations firm sued their employer for back wages (Perlin 2012,68 ) and "The Intern Trap," an article exposing the exploitation of unpaid interns in architecture, was published (Fisher 1994). However, the issue has gained special prominence since the Great Recession in 2008, which has had a significant impact on youth unemployment. In the academic sector, researchers expect internships will become even more common in the near future (Curiale 2010). Although unpaid internships are technically illegal in the UK, with the exception of specific circumstances such as student placements and work shadowing (United Kingdom Government 2014), monitoring and enforcement remain problematic.

Controversies surrounding unpaid internships in general are tied to their pedagogical, legal, and ethical implications (Burke and Carton 2013) and questions are raised concerning inequality, particularly with respect to the exclusion of those who cannot afford to work for free (or, in the UK, live in expensive cities such as London, where many of these opportunities are located) and the consequences of this for different fields and society as a whole. Commentators point to the "stark class divide between entry-level job seekers who can afford the luxury of unpaid experience and those who cannot" (Curiale 2010, 1534). Furthermore, the more prevalent unpaid internships become, the less incentive employers have to pay interns. Internships may also indirectly contribute to unemployment, as organizations realize that work can be done for free by unpaid interns (ibid., 1537). Sabina Siebert and Fiona Wilson (2013) analyze the consequences of unpaid internships for those who already work in the creative industries sector, highlighting the perspective of those who may be or are displaced by unpaid internships, as well as those who are excluded from taking part in unpaid internships.

Most literature on internships appears in the context of sectors such as politics, media, and cultural industries. In this article, however, we focus on a somewhat less glamorous sector, higher education, where unwaged positions are becoming more common. As with unpaid internships in other sectors, unwaged positions in higher education have the potential to ex- 
clude certain people from academic careers and contribute to the casualization of academic work. The framing of graduate teaching assistant work as "training" rather than work has been explored (see Krause et al. 2008, 5; Perlin 2012); however, the role of unwaged posts in the higher education sector, a similar and related issue, remains largely un-researched.

Part of the context of unwaged posts is the casualization or proletarianization of academic labour that has been underway for decades (see Wilson 1991; Guillory 1994; Aronowitz 2001). However, the phenomenon of unwaged academic posts has gained particular prominence since 1998, as the years that followed saw unprecedented changes impacting the higher education sector in the UK, which created an uncertain funding climate. Prior to 1998, students in the UK received grants to attend university and did not pay tuition fees. Fees were introduced in England in 1998 at $£ 1,000$ and grants were replaced with incomecontingent loans; different situations existed in Scotland, Northern Ireland, and Wales (UK House of Commons and Browne 2013). The passing of the 2004 Higher Education Act under the Labour government of Tony Blair allowed universities to charge up to $£ 3,000$ ( $£ 3,225$ after 2007) (ibid.). The Browne report, Securing a Sustainable Future for Higher Education: An Independent Review of Higher Education Funding and Student Finance (U. K. Government 2010), recommended the lifting of the fees cap and the removal of government funding for all courses, except "priority" courses, i.e., medical and some scientific courses, based on the principle of market liberalism (Couldry 2011). Despite widespread student protests (see Kumar 2011 for a discussion of the limitations of this movement), the cap to fees remained but was raised to $£ 9,000$. This was accompanied by cuts in direct university funding for subjects outside of science, technology, engineering, and medicine. The 2011 Higher Education White Paper also enabled a greater role for private colleges through easier criteria for institutions to call themselves "universities" and therefore access the student loan system (UK Department for Business, Innovation and Skills 2011; for analysis see McGettigan 2013).

What these reforms amounted to then was a re-classification of what a university should be: a move away from a view of a university education as a public good toward education as a commodity in a market that is only lightly regulated (Fenton 2011). Beyond these reforms, the sector has also been impacted by external factors, such as rising unemployment and pressures on household finances caused by the post-2008 economic recession. The combination of these changes has had significant impact on the academic workforce, which has been increasingly casualized and rendered precarious.

The casualization of the academic workforce is symptomatic of the neoliberalization of academia, and should be considered in relation to the changes discussed above. Employers have framed the use of casualized contracts in terms of "flexibility" and claim that only a small minority of staff are employed on such contracts, but figures recently obtained by the UCU through Freedom of Information requests suggest otherwise. According to these statistics, more than 40 percent of teaching-only staff in UK universities work on zero-hours contracts, ${ }^{1}$ while many more work under other forms of contractual casualization, such as hourly paid teaching (where employees are paid by the hour rather than an annual salary) and other temporary contracts (UCU 2013a). In fact, researchers claim that the number of lecturers and researchers in temporary, hourly paid, or zero-hour contracts has grown exponentially in recent years (Bauder 2006; Herbert, Hannam, and Chalmers 2002; Smith and Coombe 2006). In both the Australian (Coombe and Clancy 2002; Kimber 2003) and American (Bauder 2006) higher education sectors, nearly half of all teaching-related duties are undertaken by sessional staff (Halcomb et al., 2009, 528). In the UK, the number of temporary staff on teaching-only contracts increased by a third between 2009-2010 and 2011-2012 (Fazackerly 2013).

Moreover, the unwaged posts discussed in this article emerged within the context of the increasing use of graduate teaching assistants and graduate research assistants by UK universities. Such positions were not common a few decades ago, and can be seen as symptomatic of casualization and intensifying managerialism (Amaral, Meek, and Ingvild 2003;

\footnotetext{
${ }^{1}$ Zero-hours contract are a type of contract where "the employer is not obliged to provide the worker with any minimum working hours, and the worker is not obliged to accept any of the hours" (ACAS n.d.).
} 
Chandler, Barry, and Clark 2002). The effects of the expansion of the use of graduate teaching assistants on postgraduate researchers are pernicious. Instead of receiving a grant or scholarship to conduct doctoral research, increasing numbers of PhD students are now expected to pay tuition fees and teach or conduct "grunt" research work for low wages under such titles.

These conditions have also produced a situation where very few permanent entry-level posts exist compared to the numbers of applicants. In 2010 only 19 per cent of PhD graduates in the UK held permanent academic jobs three and a half years after completion (Else 2014). Within this hyper-competitive job market, a PhD qualification on its own is not enough, and both publications (particularly those which can boost a department's research culture) and substantial teaching experience have become standard expectations for hiring to a permanent post, allowing universities to justify unpaid posts of the kind investigated in this article as providing valuable teaching experience. Another aspect of this situation is the mounting publishing pressure for full-time academics. In order to satisfy the pressure to publish, academics are increasingly incentivized to outsource project fieldwork and or/lab research to (frequently low-paid) research assistants and routine teaching work to graduate teaching assistants. The latter are increasingly desperate to take on this sort of work for financial reasons (due to under-funding) and, faced with an extremely competitive job search, to gain and be able to demonstrate both teaching and research experience.

It is in this context of growing workforce casualization and marketization of post-secondary education in the UK that the cases explored in this article arise. Before we examine the specific cases however, we consider the emerging attitudes around unpaid work, which contribute to its justification as a necessary sacrifice for a rewarding and personally meaningful career. According to Andrew Ross, academic work shares characteristics with cultural work in that:

artistic and academic traditions extol sacrificial concepts of mental or cultural labour that are increasingly vital to newly important sectors of the knowledge industries. No longer on the margins of society, in Bohemia or the Ivory Tower, they are providing a rationale for the latest model of labour exploitation in core sectors of the new industrial order, and pioneering the workplace of tomorrow. (Ross 2000, 2)

Furthermore, Ross points out that unwaged work in the cultural industries (and increasingly in academia) is subsidized by workers themselves:

[...] the largest subsidy to the arts has always come from workers themselves. To this day, all such workers, even those employed on market-driven contracts, tend to earn compensation well below that commensurate with their skills and levels of educational attainment. The cruel indifference of the marketplace does not seem to deter the chronically discounted. Indeed, and largely because of artists' traditions of sacrifice, it often appears to spur them on in ways that would be regarded as self-destructive in any other economic sector. (ibid., 6)

Rosalind Gill also highlights the parallels between academics in the neoliberal university and cultural workers in precarious employment: "for example, DIY biographies, that is, the strong sense of needing to be adaptable and ready to try anything in one's working life, opportunities based significantly on reputation, and the prevalence of network sociality" $(2014,13)$. Given these parallels, in this article we borrow Ross's (2000) concept of self-subsidy to help us understand ongoing transformations in academia, where qualified and experienced tutors and lecturers perform a significant amount of labour that is unpaid. This concept of selfsubsidy is close to Angela McRobbie's (2010) analysis of "self-exploitation" on the basis of a passion for one's work, or what she calls the "pleasure in work" factor (McRobbie, 2015. However, Gill $(2014,25)$ argues that when it comes to academic work, "self-exploitation" may not be an accurate concept and instead urges researchers to develop a politicized vocabulary that will enable us to think about exploitation and privilege together in analyses of academic and cultural work. The normalization of a culture of overwork and subsidizing universi- 
ties by providing work that is not paid for helps explain, at least in part, the appearance of advertised unwaged positions.

As elsewhere, in higher education precarity is not only limited to those on temporary contracts. Gill (2014), for example, maintains that in the context of UK universities there is a sense that, to some extent, everyone feels their job to be insecure. The Research Excellence Framework (REF), an evaluation process for the allocation of research funding, has exacerbated these conditions. Like its predecessor, the Research Assessment Exercise, the REF requires academics whose contracts include research to have a selection of their publications evaluated and ranked according to a set of criteria, from 1 ("nationally recognized") to 4 ("world leading"), with only research outputs attaining 3 and 4 being funded. University departments and institutions compete against each other for the top scores, which then factor into league tables and other ranking systems. This procedure frames academics' publications as the "property" of individual departments and, for individual academics, functions as performance management. The consequence is that those academics who are not included in the REF are increasingly under threat of being demoted to teaching-only contracts. The REF has also had pernicious effects on hiring. The UCU's REFWatch blog has flagged "institutional gaming" in the hiring process, including the creation of "transfer markets" of research superstars (UCU 2013b) and also increasing pressures for early career academics to produce REF-ready outputs whilst employed "on a variety of precarious contracts, including hourly paid teaching (sometimes on zero hours contracts) and fixed-term contracts for short term research projects, making the production of the necessary outputs rather difficult to achieve" (UCU 2013c).

These circumstances require many academics, both on temporary and permanent contracts, to engage in a dual process of what Ursula Huws (2006) terms "begging and bragging." Huws contends that the academic labour process is permeated by continual rituals of supplication and boasting, for example, in the process of applying for jobs, funding, and research time. There is also a prevalence of working for free across all levels of the academic workforce, ranging from working beyond the hours of one's contract just to stay employable to performing tasks without pay such as peer reviewing academic articles.

Such conditions underpinning the academic labour process make it very difficult to develop solidarity among the workforce. Instead, there is an increasing sense that academics, regardless of their contractual situation, are constantly in competition against each other. As a result, many precarious academics feel they have no choice but to accept unwaged work as it becomes normalized and institutionalized.

\section{Unwaged Positions in UK Universities}

In this section we discuss four cases of unwaged work advertised in UK universities: unwaged research assistants at the UoB and UCL, an "honorary junior research fellowship" at the UoE, and "extra-curricular teaching opportunities" at Durham University (See Appendices: Adverts). Despite the above-discussed pressures to perform unpaid work and work more than what is technically required by one's contract, unwaged positions are not common in UK universities. However, and in contrast to other countries, there exists in many UK universities the possibility of appointing scholars to honorary titles such as research fellow, reader, or professor. Such titles confer an academic, typically employed by another university (often in a different country), access to the university facilities, and associate their name (often bearing prestige) to the institution to the latter's advantage. This would, in principle, be a mutually advantageous relationship. What is different about the posts under discussion in this article is that they target early career academics who are unlikely to hold a paid position elsewhere.

The first post that provoked a critical response was an "honorary research assistant" post at UoB, advertised on Jobs.ac.uk, an academic job search website, in June 2012. The job, connected to a research project on mental illness in children and adolescents, required "conducting clinical assessments of adolescents and young adults seeking help for mental health issues," as well as "ongoing assessment of participants and some data entry and manage- 
ment." The holder of the post was required to submit "a recent enhanced Criminal Records Bureau clearance," and to have access to his/her own vehicle to drive to work, although petrol costs were apparently to be covered (UCU 2012).

Shortly after the UoB position was posted, the Anna Freud Centre at UCL advertised for an unwaged research assistant for a project on health risks associated with depression. The post involved contacting and explaining the research project to participants, completing forms and filling out questionnaires, and entering data (Anna Freud Centre 2012). In June 2013, an "honorary junior research fellowship" was advertised at UoE. The advert stated that "whilst there is no salary attached to these fellowships the Fellows appointed will be entitled to shared office and study space equipped with computing facilities, and the use of all library and school services. Whilst there is no attendance requirement Fellows are expected to take part in school activities" (UoE 2013). The final case, "extra-curricular teaching" at Durham University, is the only post that was not withdrawn. In October 2013, Durham University advertised "extra-curricular teaching opportunities," explicitly framing them as "teaching experience" and a "voluntary development opportunity." The advert read:

The Department is offering a voluntary development opportunity for PhD students to apply to design and offer a short course of Extracurricular Seminars for undergraduate students. The scheme allows postgraduates to acquire valuable experience of designing and delivering an entire short taught course. If your application is successful, you will design and run an extra-curricular course comprising one contact hour per week for four weeks, primarily but not exclusively geared toward Level 1 undergraduates. [...] Your seminars will appear on your departmental training transcript. (Durham University 2013)

Both the casualization of academic work discussed earlier and the increasingly politicized nature of internships in the cultural industries (discussed elsewhere in this journal issue) made these unwaged posts controversial, provoking outrage and accusations of cynical exploitation.

The four unwaged posts provoked resistance for different reasons. The first two, at UoB and UCL, were research assistant posts, which involved carrying out assigned tasks on projects led by other academics. These positions were similar to unwaged internships elsewhere in that they involved performing routine tasks without payment. The UoB post also involved health and safety risks and additional costs. The third post was an "honorary stipendiary research fellowship," that is, in essence, an institutional affiliation, providing library and IT access, at UoE. This post was different in that unlike the research assistant posts it had previously been advertised for five years without concern. There is also a tradition at Oxford and Cambridge of offering honorary fellowships to staff with permanent academic positions at other universities (meaning that they are quite different from an internship in a conventional sense). However, the growing politicization of internships, combined with the ambiguous wording of the job advert (which included language framing it as a job), and its timing towards the end of the REF cycle (in relation to the institutional game-playing and intellectual property issues discussed earlier in this paper), contributed to the outrage provoked by the post. The final post discussed here, promising "extra-curricular teaching" at Durham University, was different from the other three in that it neither involved carrying out assigned tasks nor an institutional affiliation advertised competitively (with expectations attached). Rather, the position consisted of teaching undergraduate students unpaid as part of regularly timetabled sessions, and was framed as teaching experience-and can thus be understood in terms of the pressures to demonstrate this experience within the job market.

\section{Campaign Tactics and the Role of Unions}

In an atomized and hyper-competitive environment, academics regularly engage in individualized acts of resistance (Harvie 2006). In this section, however, we explore collective resistance and the role of unions in the response to these posts. Unions have been criticized for failing to recruit casualized employees, who have been traditionally seen as difficult to organize (Gallagher and Sverke 2005). However, unions can play a role in encouraging and 
creating solidarity among casualized workers. The University and College Union (UCU) is the main union in higher, further, and adult education in the UK, representing more than 116,000 staff at 715 workplaces (UCU South West, e-mail correspondence, December 17, 2014). UCU's structure includes a number of equality standing committees and special employment interest groups, one of which is the Anti-Casualisation Committee (ACC), which campaigns on behalf of fixed-term and hourly paid staff. The ACC produces specialist campaign materials and career advice materials tailored to the needs of casualized staff. It organizes regular training on anti-casualization campaigns and an annual day of action. By doing so it provides casualized staff with networking opportunities, something that the very nature of their contracts tends to render difficult. The ACC also produces a newsletter, hosts an e-mail discussion list, and maintains a visible presence on social media. Along with local UCU branches, informal networks, and individual campaigners, the ACC played a key role in the four cases discussed in this article.

Following the appearance of the adverts, social media-and particularly Twitter-were frequently used by academics and activists to raise awareness and to alert journalists to the unpaid posts, the adverts, and the issues surrounding them. The use of social media in such protests and campaigning is worthy of mention. Given the role the union played in the campaigns we discuss in this article, we are interested in how trade unions such as the UCU use social media. This topic has been investigated in previous literature, although this literature has suggested that unions are more commonly characterized as a residual form of activism, unlike the more spontaneous, populist forms of activism associated with the network society and social media (see, for example, Gerbaudo 2014, Castells 2007). Natalie Fenton and Veronica Barassi (2011) examine how trade unions in the UK use social media. They critique the assumption, particularly within the work of Bernard Stiegler $(2008,2009)$ and Manuel Castells (2009), that social movements can arise from "a realization of the politics of the self," arguing that such assumptions risk ignoring or marginalizing collective uses of social media $(2011,181)$. Based on a study of the Cuba Solidarity Campaign (CSC), which is a UK-based campaign to end the U.S. blockade of Cuba, Fenton and Barassi examine how social media can both present possibilities and challenges for union campaigns, enabling political participation in some cases, but undermining the specifically collective nature of campaigns (exacerbated by popular discourses about enabling individual creative autonomy but not solidarity) or degenerating into lazy "clicktivism" in others. As one of their respondents mentions: "members start to think that merely joining a Facebook group shows that you are committed. But actually it doesn't mean anything... it doesn't change things. There is too much information around, to be 'effective'" (Fenton and Barassi 2011,186). Unlike the example of the CSC examined by Fenton and Barassi, activists in the cases we describe were responding to particular situations (the advertising of the unwaged posts). Social media enabled rapid responses and generated media interest, but also presented certain limitations in the building of sustained campaigns.

The cases highlight how both the campaign responses and the statements issued by the universities present the posts as a response to a highly competitive job climate, in which early career academics are desperate to gain experience. The campaign responses highlight the discriminatory nature of the unwaged posts, as well as the damage that they could cause to higher education by restricting these opportunities to those who can afford to work for free. However, the public statements issued by universities present the posts as a form of training, support, and a philanthropic gesture of goodwill to desperate early career academics in need of "experience" (Anna Freud Centre 2012; Birmingham Post 2012; UoE 2014). The universities also claim they are democratizing the hiring process. These statements reveal deeper fault-lines around elitism in higher education, reflected in an implied normalization of unwaged posts and informal hiring. By framing the posts specifically as "training," rather than "work," they also infantilize early career academics as needing "help" in the form of unwaged opportunities.

In the next section, we turn to a discussion of the resistance against each of these unwaged posts through an analysis of social media interactions, blog entries, and online cam- 
paign communications and statements. In the process, we highlight the main themes that emerge from such communications.

\section{1. "Honorary Research Assistant," University of Birmingham}

The advertising of the honorary research assistant post at the University of Birmingham provoked outrage for UCU's ACC, particularly in light of the issues around casualization and inequality discussed earlier. Vicky Blake, ACC chair, flagged these issues in an e-mail to other committee members:

As a research assistant employed on a fixed term 0.3 FTE basis, I cannot adequately describe how angry this makes me. I rely on my (small) income to survive. To recruit candidates for 2 days a week in return for petrol money is disgusting, exploitative and will also mean that only someone with another income (or perhaps lottery winnings/trust fund?!) will be able to get the experience it offers. But with more "jobs" like this being advertised, will there even be any opportunities at the other end of something like this? (July 2, 2012)

Blake's e-mail expressed the frustration that these sorts of posts not only would be limited to those with access to private means, but also that there was no guarantee that they would lead to paid employment. A decision was made to react quickly, using both the ACC Twitter account and the personal Twitter accounts of several ACC members. This use of social media is significantly different from that described by Fenton and Barassi (2011) in the case of the Cuba Solidarity Campaign, as in this case the individual and collective uses of Twitter were seen to complement each other. Parody was also used as a strategy to raise issues about the unfairness of the post, as Blake described:

We developed a campaign around making mock applications to the listed e-mail address, for example offering to cycle the entire way from my home (many miles) to make it affordable, if only they would allow me to sleep under the desk to save energy in the week. This caught on with a number of people doing similar (or writing in as if they were totally privileged making the other side of the case). (e-mail correspondence, April 27, 2014)

There were also attempts to raise the issue within the context of open chats in the Guardian Higher Education Networks (the Higher Education section of the Guardian newspaper), such as the discussion provoked by the article "Freelance, Fixed-term or Part-time: Is this the Future of Academic Careers?" (Anyangwe 2012). The issue of unwaged positions was also debated on \#phdchat and \#ecrchat Twitter discussions, forums normally dedicated to career advice. Attempts were made to involve journalists in the discussion, as in a debate using \#phdchat which highlighted the difficulties of turning down unwaged work within the context of informal hiring practices in academia.

These debates drew out some of the ambivalence around the issue, including the perception that opportunities within academia frequently develop out of informal relationships, and the advertising of such posts simply formalizes them. This shows that while these posts did provoke outrage, responses are not unanimous in such cases, as some might feel they have no choice but to apply for these kinds of posts given the difficult conditions faced by precariously employed scholars.

The online discussions were followed by official communications. The UCU branch at UoB had been made aware of the post, particularly through postgraduate students "via less formal activist networks/channels" such as the now-defunct Postgraduate Workers' Association (Vicky Blake, email correspondence, April 27, 2014). The UCU's headquarters then put out a press release condemning the post, stating that "not paying researchers undermines the principles of equal pay and is discriminatory" and also making the point that "clearly not everyone can afford to work for nothing" (UCU 2012).

The post was withdrawn in early July of 2012, and the UoB released a statement framing the post as training and support. The response also claimed the university was merely formalizing what would normally have been an informal process: "rather than responding to 
individual enquiries, which is common practice, the university wanted to make this opportunity available to all and not just favour those with existing networks and contacts" (Jump 2012). The University's spokesperson also told the Birmingham Post that, "The University is strongly committed to providing appropriate training and support to students and graduates" (Birmingham Post 2012).

The framing of these posts as "training and support" rather than "work" is significant in absolving the University from its responsibility as an employer. It also represents an attempt to win public sympathy by explicitly referring to (or at least alluding to) the difficulty faced by many PhD candidates and early career academics by offering "experience" in an extremely competitive labour market, and depicts institutions as providing support and training opportunities in the form of unwaged posts. This is consistent with a wider tendency to frame unwaged internships in a range of sectors in terms of their specific benefit to the post-holder, rather than as an activity that would benefit both the intern and the employer. For example, in a semantic network analysis of paid and unwaged internship offer letters, Maynard (1997) found that words connoting benefit to the post-holder were used more frequently in offers of unwaged internship pitch letters than in offers of paid internships. The most commonly used "benefit" word used was "opportunity," often linked to the word "experience."

However, the dangers of the institutionalization of unwaged work were outlined in a collectively written letter to the Vice-Chancellor from the UoB UCU branch and others calling for all posts in the future to be properly remunerated:

If the UoB or others like it were to build unpaid positions into its structure in a serious way then a career within universities would become unaffordable to a vast swath of the population. This is yet another example where opportunities for young people are becoming far more based on ability to pay over the ability of the student themselves. (Craig 2012)

The letter established the connection between the unwaged posts and other ways in which young people are now living in an increasingly unequal society (exemplified by the increase of university tuition fees to $£ 9,000$, implied by the letter).

\subsection{Unwaged Research Assistant, Anna Freud Centre, University College London}

In the summer of 2012 the Anna Freud Centre at University College London (UCL) advertised an unwaged research assistant post. This provoked further concerns about the role of unpaid work in research projects, and more generally about the normalization and institutionalization of unwaged posts.

These concerns motivated postgraduate student and UCU activist Bill (pseudonym) to become involved in the campaign:

I got involved because I thought it was exploitative to extract unpaid labour from early career researchers by playing on desperation caused by the state of the academic career ladder and job market; because research institutions should be fighting their continued underfunding by government, not hiding, legitimising and potentially entrenching it by adapting and shifting to a reliance on unpaid work; and because the more that career progression depends on your capacity to spend extended periods working without income, the more exclusive academic careers will become. That not only locks people out and entrenches privilege, but also stands to damage the academy itself, by narrowing the perspectives and experiences of the community that produces research. (e-mail correspondence, May 19, 2014)

As with the UoB post, Twitter was used to name and shame:

I was then one of the people who started putting it out on Twitter-that's what really got it picked up, and pretty soon the story had created a minor storm, all over Twitter and with public commentators writing very critically, including high profile ones like [science commentator] Ben Goldacre. (ibid) 
An open letter was also posted to the Postgraduate Workers Association blog, highlighting how such posts exploit the desperation of postgraduates and early career researchers, legitimate the underfunding of research, and threaten to restrict careers in academia to the privileged (2012). Bill also felt one of the successes of the campaign was to capitalize "on a general level of semi-latent concern that was already out there about unpaid internships" (Bill's e-mail correspondence 19 May 2014)—notably making the connections between unwaged posts in academia and internships in other fields. The key issues raised by the campaign reflected concerns around internships in general, including the inaccessibility of desirable professions (in this case academia), the damaging belief that personally meaningful work does not have to be paid a living wage, the exploitation by employers of a highly competitive job climate, and the dangers of using unwaged internships to replace paid jobs. The familiarity of these concerns highlights similarities in the labour politics characterizing academia and fields such as the cultural industries in which unpaid internships became controversial.

On August 8, 2012, the UCU branch at UCL also issued an open letter to the Pro Vice Chancellor and the head of the Psychoanalysis Unit, arguing that unwaged posts harm research and calling for the University's senior management to "endorse and join those protests [about the underfunding of Higher Education] as a more just and appropriate response to the underfunding crisis than asking early career researchers, who are not responsible for it, to shoulder the burden" (University College London UCU 2012).

In "Another Unpaid Researcher Post, This Time at UCL. Shameful," Goldacre made many similar arguments: that such posts damage academia, as they already have media and politics, where

it is now recognized that unpaid internships are harmful to the culture of these professions: unpaid entry posts mean that the children of wealthy parents get in, get ahead, and do better, because their families can afford to give them money to pay rent and live in London while they earn no salary. (Goldacre 2012)

Others, such as blogger Martin Eve, also framed these posts as exploitative of younger generations: "Yet again a certain group of people are being screwed over [...] guess who? That's right! The people who paid tuition fees to go to university and are now trying to get their first academic post" (2012a).

Writing in the Guardian's Higher Education Network, Eve also argued that these posts create a race to the bottom in wages, pointing out the contradictions between the exclusivity of unwaged posts and imperatives to expand university education to a wider section of the population:

This setup, which confuses privilege with perseverance, creates several additional problems for academia. At a time when we are trying to ensure the continued diversity of our student body, we are restricting to a specific socio-economic class the pool from which applicants are drawn to sit on the other side of the desk. (Eve 2012b)

Moreover, Eve argued that unwaged posts give the impression that "the university is wellfunded" while in reality "quiet exploitation goes on undercover" (ibid.). That is, students may assume their lecturers are paid properly, and, if, for example, money is invested in buildings and facilities, that universities are in good financial health, without realizing that teaching or research are being performed unwaged.

In response to this public protest, UCL withdrew the post, issuing the following statement, which (similarly to the UoB statement) framed the post as training and "experience":

Their investment of time in learning these skills in methods of assessment, both physiological and psychological, would have served young people extremely well in terms of finding suitable paid employment on a wide range of research studies. (Anna Freud Centre 2012) 
The statement also pointed out that "none of the senior researchers involved will receive financial remuneration for the time they invest" (ibid.), ignoring the fact that the researchers involved presumably have permanent posts and research forms part of their workload (bearing in mind the issues discussed earlier).

Both the UoB and UCL posts were for research assistants, and thus involved working on others' projects (see Harvie 2000), and in many cases on the mundane but necessary tasks of research projects. The reactions caused by both posts could in part be attributed to contradictions between their status as "work" and their framing as "training" and "experience." However, the two cases we turn to now are less clear-cut.

\subsection{Honorary Junior Research Fellowship, University of Essex}

The advertisement of an "honorary junior research fellowship" at the University of Essex in June 2013 also provoked negative responses, such as this tweet, which, significantly, mentions UoE's official Twitter account:

Wow what an awesome opportunity! you have just finished your $\mathrm{PhD} \&$ now you may apply for an UNPAID job @Uni_of_Essex http://www.jobs.ac.uk/job/AGQ626/nonstipendiary-junior-research-fellowships/ ... (Schaefer 2013)

In an email to the national UCU activists' list, one of the authors of this article flagged the post:

It's essentially a research post with no salary attached. It also says "whilst there is no attendance requirement Fellows are expected to take part in school activities" - presumably unpaid. http://www.jobs.ac.uk/job/AGQ626/non-stipendiary-junior-research-fellowships/. I've spoken to a few other people and they've mentioned that other universities have advertised similar posts in the past. In the current climate, these sorts of posts could exploit desperate people, similar to unpaid internships. (June 2, 2013)

The UoE post could be interpreted as attempting to emulate the Oxford and Cambridge fellowship models, and, by implication, the prestige of these institutions. However, it presented what was in reality an institutional affiliation, desk space, and internet access as a "junior researcher post" and advertised it competitively. The requirement to participate in school activities (notably not defined in the advert) framed the post at least partly within the terms of employment (otherwise no such expectations would exist). It also means that the post-holder would play a role within the "REF environment" (the overall research culture), which accounts for 15 percent of REF funding (the post-holder would not be submitted as an individual researcher, but this was not made clear in the advert, although it was eventually clarified within the withdrawal statement).

The post was withdrawn after complaints from the UoE UCU branch. In response, the university issued this statement:

Our Junior Research Fellowship scheme was introduced five years ago and has been extremely successful in supporting post-doctoral students at the very beginning of their careers. However, in the current climate, where unpaid positions are proliferating, there is a danger that our intentions for the scheme are at risk of being misunderstood and misrepresented. (UoE 2013)

As mentioned, the post had been advertised for five years without controversy. However, increasing competition for jobs, casualization, and the intellectual property issues associated with the REF made it contentious, a fact acknowledged in the withdrawal statement. More generally, the broader controversy over internships had led to very similar questions being asked about academia that had been asked about internships in the cultural industries: If unwaged internships become a standard prerequisite for getting a job in academia, does this result in the exclusion of those from less privileged backgrounds from the field, and in what ways does this restrict the production of knowledge? Writing about unwaged internships in 
journalism in the United States, David Dennis Jr. argues that inequity of access results in those with first-hand experience of inner-city poverty, crime, and racism being shut out "from the national conversation" and thus not being able to "influence the direction of national discourse" (2013). Similar questions need to be asked about the implications of casualization and unwaged posts on teaching, research, and public debate.

Another similarity to the kinds of discourses and controversies characterizing unwaged internships was the framing of the post as training and support, and, more generally, an offer of "help" in a very difficult climate which would benefit the post-holder (similar to the internship offer letters in the Maynard study mentioned earlier). There was no discussion of how the University itself would benefit from the involvement of the research fellow in "school activities."

Following the withdrawal of the post, one of the authors of this article became part of an email exchange with the individual at UoE who had advertised the post. In that exchange, the author said:

I originally flagged up this post... because it was advertised as a competitive post, rather than simply offered as an affiliation [for PhD students without an academic post]; and that it sets a disturbing precedent in that, through being framed as a 'research fellowship', it is an appointment that could be listed on a CV that is limited to those who can afford to go without pay [...] Also-on a personal note-I am an early career researcher, having completed my PhD two years ago. I am now lucky to be employed full-time as a lecturer (after 8 job interviews and 2 temporary contracts) so I am well aware of the competitive nature of the job market at the moment, and many of my former classmates are struggling. (June $15,2013)$

Others in the email discussion pointed out that presenting access to a desk, computer, and online journals as a research post will make the post-holder look as though he/she has "research experience" and thus gain comparative advantage in the job search.

\subsection{Extra-curricular Teaching, Durham University}

Like the other unwaged posts, the "extra-curricular teaching" post advertised at Durham University provoked resistance and was debated in Palatinate, the University's student newspaper. A PhD student (who wished to remain anonymous) was quoted in the newspaper as saying, "I teach a few classes and it's incredibly useful for postgraduates to have the opportunity to do that, especially if you are not funded and need the extra money [...] I personally wouldn't volunteer to do any teaching for free" (cited in Bransgrove 2013). UCU Headquarters also sent out a press release stating that they had received a letter from the Director of Human Resources at the Durham University stating that "it is neither policy nor practice at Durham to recruit unpaid research staff" (UCU 2013d), pointing out the contradictions between the letter and the advertising of the posts.

However, in an article in the Independent, a mainstream daily newspaper, the University spokesperson claimed that the seminars had been set up in response to "demand from our postgraduate students, who wanted to broaden their teaching experience for their own professional development" (Mendelsohn 2013). This claim could be interpreted both as an attempt to disavow responsibility and as reflecting (and possibly exploiting) desperation for teaching experience and the resulting willingness (if the claim is true) to teach for free in order to gain this experience. Characterizing the post as an individual choice (as in desires to "broaden their teaching experience for their professional development") conceals how such "choice" might be underpinned by hierarchies of privilege within an extremely competitive environment; one where casualized staff, as well as many staff on permanent contracts, are frequently not paid for the full range of their duties. It is also worth reflecting on Gill's critique of "self-exploitation" as blaming individuals $(2014,25)$, and, in this way, ignoring the conditions and power structures that lead to apparently self-exploitative behaviour. It is possible that this rhetoric of choice (in addition to the lack of a visible campaign that marked the other cases) contributed to the post not being withdrawn. 


\title{
5. Conclusion
}

This article has explored the appearance of advertisements for unwaged posts at four UK universities. We have discussed this phenomenon in the context of precarity, casualization of work, and significant reforms to the UK higher education sector. Moreover, we have drawn connections between the controversy surrounding unpaid internships in the creative industries and academia by discussing aspects of the "mental labour problem" (Ross 2000) that characterize labour in both academia and the creative industries. The issues raised by campaigns against unpaid work in the cultural industries also provided a vocabulary for articulating the issues, particularly around how it would exclude those who could not work for free from desirable professions. We analyzed cases of resistance against the advertisement of unwaged posts in academia, cases which may signal a growing critique of the tendency to tolerate self-exploitation.

Despite the fact that the campaigns represented important successes in that they forced most of the posts to be withdrawn, there were limitations to the campaigns we analyzed. The starkest one may have been the fact that the campaigns and activists involved were not able to consolidate these quick successes into long-term change. Indeed, this was mentioned by Bill in reflecting on the limitations of the UCL campaign:

\begin{abstract}
We attempted to press for a revision of internal policies that would be a more permanent solution. However, that's where we fell down-we failed to follow through and effectively capitalise on the situation, and the issue kind of died away before we'd secured a more permanent change. Perhaps one factor here was our failure to turn the publicity campaign into an industrial one-we didn't get workers and students in the university organised into the kind of campaign on the ground that could have generated the necessary lasting pressure [...] (email correspondence, May 19, 2014)
\end{abstract}

A more permanent solution would involve, as Bill suggests, policy changes designed to prevent such posts from being advertised in the future. This would require pro-active involvement of casualized staff and early career academics in the union, as well as greater overall awareness of the conditions (e.g., scarcity in the job market, the neoliberalization of the university) contributing to such posts being advertised.

A possible reason for why more sustained gains were not achieved may lie in the strategies adopted, specifically the great reliance on social media to organize the campaigns. An important lesson deriving from the cases examined here is that the utilization of social media is useful for sparking interest and creating momentum. As Bill pointed out, the use of social media allowed the activists to capitalize on public outrage and respond swiftly. However, social media as a key campaign tool can be, in our view, of limited use in the long term. Bill alludes to this limitation in the following excerpt from an e-mail communication:

Regardless, I think that's probably an important general lesson-you can get quick wins from publicity-based efforts, that play on the PR effects of outrage in the media and social media, but that can't substitute for the slower work of building a lasting level of organisation among workers and in a student body, allowing them to exert real power in our education institutions. (Bill's email correspondence, 19 May 2014)

Another significant factor affecting the outcome of these cases is the relative lack of clout of the ACC within UCU, despite the important role it has played within these campaigns (although it has since become more prominent). This is partly explained by the fact that casualized academic staff are still largely under-represented within the union's membership and governance. In higher education, as in other sectors, casualized staff is less likely to be union members than permanent members of staff (Sverke et al. 2004).

Ultimately, the difficulties presented by the wider political and employment-relations climate should not be underestimated. The normalization of precarity and the neoliberalization of academia are significant barriers to solidarity and collective rejections of further exploitation. While, as we have shown, these processes do not make resistance impossible, they do 
present some very concrete challenges. The impulse to keep one's head down for fear of being branded a "troublemaker" can be very strong, and the continual condition of being in competition with one's peers can make collective action very difficult.

Nevertheless, important lessons can be learned from these campaigns. They are significant in terms of the rapid responses they triggered, as well as the multiple approaches taken (including blog posts, alerting journalists, social media) by commentators, campaigners, and the UCU. They represent important successes in terms of challenging the normalization and institutionalization of unwaged teaching and research, since the campaigns were successful in moving the universities to remove the advertisements and unwaged positions, with the exception of Durham. These campaigns are especially meaningful in that they also effectively capitalized on the mounting public outrage around unwaged internships in the cultural industries and politics. As such, they may constitute inspiration for activists elsewhere, as proof that unwaged work and precarity can be successfully challenged.

\section{References}

ACAS. n.d. Zero Hours Contracts. Accessed December 28, 2014. http://www.acas.org.uk/index.aspx?articleid=4468.

Amaral, Alberto, Vincent Meek and Larsen Ingvild. 2003. The Higher Education Managerial Revolution? Boston, M.A.: Kluwer Academic Publishers.

Anna Freud Centre. 2012. Statement Regarding the Recently Advertised ERIC-D Pilot Study Internships (02.08.2012). Accessed May 5, 2014. http://www.annafreud.org/jobs.php?id=350.

Anyangwe, Eliza. 2012. Freelance, Part-time or Fixed-term: Is this the Future of Academic Careers? The Guardian, July 11. Accessed April 15, 2014. http://www.theguardian.com/higher-educationnetwork/blog/2012/jul/11/careers-options-for-academics.

Aronowitz, Stanley. 2001. The Last Good Job in America. Lanham, M.D.: Rowman and Littlefield.

Bauder, Harald. 2006. Learning to Become a Geographer: Reproduction and Transformation in Academia. Antipode 38 (4): 671-679.

Birmingham Post. 2012. University of Birmingham Withdraws Unpaid Intern Advert After Protests. Birmingham Post, July 5. Accessed March 10, 2014. http://www.birminghampost.co.uk/news/localnews/university-birmingham-withdraws-unpaid-intern-3910956.

Bransgrove, Charlotte. 2013. Durham University Criticised for Offering Voluntary Unpaid Teaching Opportunities. Palatinate, October 24. Accessed May 1, 2014. http://www.palatinate.org.uk/?p=42093.

Burke, Debra and Robert Carton. 2013. The Pedagogical, Legal, and Ethical Implications of Unpaid Internships. Journal of Legal Studies Education 30 (1): 99-130.

Carrotworkers' Collective. 2012. Surviving Internships: A Counter Guide to Free Labour in the Arts. Accessed January 8, 2015. https://carrotworkers.files.wordpress.com/2009/03/cw web.pdf.

Castells, Manuel. 2007. Communication, Power and Counter-Power in the Network Society. International Journal of Communication 1: 238-266.

Castells, Manuel. 2009. Communication Power. Oxford: Oxford University Press.

Coombe, Kennece and Susan Clancy. 2002. Reconceptualizing the Teaching Team in Universities: Working with Sessional Staff. International Journal for Academic Development 7 (2):159-166.

Chandler, John, Jim Barry and Heather Clark. 2002. Stressing Academe: The Wear and Tear of the New Public Management. Human Relations 55 (9): 1051-69.

Couldry, Nick. 2011. Fighting for the University's Life. In The Assault on Universities: a Manifesto for Resistance, edited by Michael Bailey and Des Freedman, 37-46. London: Pluto.

Craig, Hattie. 2012. Letter to the University of Birmingham Vice-Chancellor. Facebook post. Accessed June 1, 2014. https://www.facebook.com/notes/hattie-craig/no-to-unpaidunwaged-work-an-openletter-to-the-vc/10151066897366894.

Curiale, Jessica L. 2010. America's New Glass Ceiling: Unpaid Internships, the Fair Labor Standards Act, and the Urgent Need for Change. Hastings Law Journal 61: 1531-1560.

de Peuter, Greig. 2011. Creative Economy and Labor Precarity: A Contested Convergence. Journal of Communication Inquiry 35 (4): 417-425.

Dennis, Jr., David. 2013. Unpaid Internships are Ruining Journalism. The Guardian, 28 May. Accessed January 5, 2015. http://theguardian.com/commentisfree/2013/may/28/unpaid-internshipsprivilege-ruin-journalism.

Durham University. 2013. Extracurricular Seminars. Accessed May 10, 2014. https://www.dur.ac.uk/theology.religion/postgrad/prof.dev/extracurricular.seminars/. 
Else, Holly. 2014. The PhD Experience: This Far and No Further. Times Higher Education, August 14. Accessed September 3, 2014. http://www.timeshighereducation.co.uk/features/the-phd-experiencethis-far-and-no-further/2015113.fullarticle.

Eve, Martin. 2012a. More Unpaid Academic Positions and Apparent "Culture of Entitlement." Accessed May 15, 2014. https://www.martineve.com/2012/08/02/more-unwaged-academic-positionsand-apparent-culture-of-entitlement.

Eve, Martin. 2012b. Unpaid Research Internships Reveal a Dangerous Hypocrisy in Academia. Guardian, August 2. Accessed May 15, 2014. http://www.theguardian.com/higher-educationnetwork/blog/2012/aug/02/unpaid-research-internships-academic-hypocrisy.

Fazackerly, Anna. 2013. Why are Many Academics on Short-Term Contracts for Years? The Guardian, February 4. Accessed January 5, 2015. http://www.theguardian.com/education/2013/feb/04/academic-casual-contracts-higher-education.

Fenton, Natalie. 2011. Impoverished Pedagogy, Privatised Practice. In The Assault on Universities: $A$ Manifesto for Resistance, edited by Michael Bailey and Des Freedman, 103-110. London: Pluto.

Fenton, Natalie and Veronica Barassi. 2011. Alternative Media and Social Networking Sites: The Politics of Individuation and Political Participation. The Communication Review 14: 179-196.

Fisher, Thomas. 1994. The Intern Trap: How the Profession Exploits its Young. Progressive Architecture 75 (7): 69-73.

Gallagher, Daniel G. and Magnus Sverke. 2005. Contingent Employment Contracts: Are Existing Theories Still Relevant? Economic and Industrial Democracy 26 (2): 181-203.

Gerbaudo, Paolo. 2014. Populism 2.0 Social Media Activist, the Generic Internet User, and Interactive Direct Democracy. In Social Media, Politics and the State: Protests, Revolutions, Riots and Policing in the Age of Facebook, Twitter and YouTube, edited by Daniel Trottier and Christian Fuchs, 6787. London: Routledge.

Gill, Rosalind. 2014. Academics, Cultural Workers and Critical Labour Studies. Journal of Cultural Economy 7 (1): 12-30.

Guillory, John. 1994. Literary Critics as Intellectuals: Class Analysis and the Crisis of the Humanities. In Rethinking class: Literary Studies and Social Formations, edited by Wai-Chi Dimock and Michael T. Gilmore, 107-149. New York: Columbia University Press.

Goldacre, Ben. 2012. Another Unpaid Researcher Post, This Time at UCL. Shameful. Accessed May 10, 2014. Post archived at http://web.archive.org/web/20120804184856/http://bengoldacre.posterous.com/another-unpaidresearcher-post-in-uk-academia.

Gregory, David. 1998. The Problematic Employment Dynamics of Student Internships. Notre Dame Journal of Law, Ethics and Public Policy 12: 227-64.

Halcomb, Elizabeth, Sharon Andrew, Kath Peters, Yenna Salamonson and Debra Jackson. 2009. Casualization of the Teaching Workforce: Implications for Nursing Education. Nurse Education Today 30 (6): 528-532.

Harvie, David. 2000. Alienation, Class and Enclosure in UK Universities. Capital \& Class 71 (Summer): 103-132.

Harvie, David. 2006. Value Production and Struggle in the Classroom. Capital \& Class 88 (Spring): 133.

Herbert, Debra, Rachel Hannam and Denise Chalmers. 2002. Enhancing the Training, Support and Management of Sessional Teaching Staff (HER02448). Accessed July 20, 2015 http://publications.aare.edu.au/02pap/her02448.htm.

Huws, Ursula. 2006. Begging and Bragging: the Self and the Commodification of Intellectual Activity. Inaugural Professorial Lecture, Working Lives Research Institute, London Metropolitan University, June 7. Accessed August 27, 2014. http://www.asah09.dsl.pipex.com/uhinaugural.pdf.

Intern Aware. 2014. About Us. Accessed July 20, 2015. http://www.internaware.org/about_us.

Jump, Paul. 2012. Advert for Unpaid Research Position Withdrawn. Times Higher Education, July 2. Accessed April 1, 2014. http://www.timeshighereducation.co.uk/420451.article.

Kimber, Megan. 2003. The Tenured "Core" and the Tenuous "Periphery": The Casualisation of Academic Work in Australian Universities. Journal of Higher Education Policy and Management 25 (1): 41-50.

Krause, Monika, Mary Nolan, Michael Palm and Andrew Ross. 2008. The University Against Itself: The NYU Strike and the Future of the Academic Workplace. Philadelphia: Temple University Press.

Kumar, Ashok. 2011. Achievements and Limitations of the UK Student Movement. In The Assault on Universities: A Manifesto for Resistance, edited by Michael Bailey and Des Freedman, 132-142. London: Pluto

Lorey, Isabell. 2015. State of Insecurity: Government of the Precarious. London: Verso. 
Maynard, Michael L. 1997. Opportunity in Paid vs. Unpaid Public Relations Internships: A Semantic Network Analysis. Public Relations Review 23 (4): 377-390.

McGettigan, Andrew. 2013. The Great University Gamble: Money, Markets and the Future of Higher Education. London: Pluto.

McRobbie, Angela. 2010. Re-thinking Creative Economy as Radical Social Enterprise. Sociology-ofCulture Blog. Accessed June 8, 2014. http://www.variant.org.uk/pdfs/issue41/amcrobbie41.pdf.

McRobbie, Angela. 2015. Is Passionate Work a Neoliberal Delusion? OpenDemocracy, April 22. Accessed July 20, 2015. https://www.opendemocracy.net/transformation/angela-mcrobbie/ispassionate-work-neoliberal-delusion.

Mendelsohn, Tom. 2013. Teaching is Not its Own Reward: Durham University in Unpaid Jobs Row. Independent, October 21. Accessed May 1, 2014. http://www.independent.co.uk/student/news/teaching-is-not-its-own-reward-durham-university-inunpaid-jobs-row-8894458.html.

National Union of Journalists. 2012. Submission to the Low Pay Commission on Internships. Accessed December 28, 2014. http://www.nuj.org.uk/documents/the-nujs-submission-to-the-low-paycommission-on-internships/.

Perlin, Ross. 2012. Intern Nation: How to Earn Nothing and Learn Little in the Brave New Economy. London: Verso.

Postgraduate Workers Association. 2012. Beating Unpaid Internships at UCL. Accessed May 28, 2014. http://postgraduateworker.wordpress.com/2012/08/14/beating-unpaid-internships-at-ucl/.

Ross, Andrew. 2000. The Mental Labor Problem. Social Text 18 (2): 1-31.

Schaefer, Mirko Tobias. 2013. Twitter post, June 5, 5:13 am. Accessed May 10, 2014. https://twitter.com/mirkoschaefer/status/342252743890706432.

Siebert, Sabina and Fiona Wilson. 2013. All Work and No Pay: Consequences of Unpaid Work in the Creative Industries. Work, Employment and Society 27 (4): 711-721.

Smith, Erica and Kennece Coombe. 2006. Quality and Qualms in the Marking of University Assignments by Sessional Staff: An Exploratory Study. Higher Education 51 (Spring): 45-69.

Stiegler, Bernard. 2008. "The Alternative of Metadata: Automated Voluntary

Servitude or Economy of Contribution." Lecture, Force of Metadata

Conference, Goldsmiths, London, UK, November 28.

Stiegler, Bernard. 2009. Teleologics of the Snail: The Errant Self Wired to a WiMax

Network. Theory, Culture and Society 26 (2-3): 33-45.

Sverke, Magnus, Johnny Hellgren, Katharina Näswall, Antonio Chirumbolo, Hans De Witte and Sjoerd Goslinga. 2004. Job Insecurity and Union Membership: European Unions in the Wake of Flexible Production. Brussels: P.I.E.-Peter Lang.

United Kingdom Department for Business, Innovation and Skills. 2011. Putting Students at the Heart of Higher Education. Accessed June 5, 2014. https://www.gov.uk/government/news/puttingstudents-at-the-heart-of-higher-education.

United Kingdom Government. 2010. Securing a Sustainable Future for Higher Education: An Independent Review of Higher Education Funding and Student Finance [Browne Report]. Accessed July 20, 2015.

https://www.gov.uk/government/uploads/system/uploads/attachment data/file/422565/bis-10-1208securing-sustainable-higher-education-browne-report.pdf.

United Kingdom Government. 2014. Employment Rights and Pay for Interns. Accessed June 72014. https://www.gov.uk/employment-rights-for-interns.

United Kingdom House of Commons and Michael Brown. 2013. Tuition Fee Statistics (Briefing Paper). Accessed June 5, 2014. http://www.parliament.uk/briefing-papers/SN00917.pdf.

University and College Union. 2012. Universities Should Pay Researchers. Accessed January 5, 2015. http://ucu.org.uk/index.cfm?articleid=6159.

University and College Union. 2013a. Over Half of Universities and Colleges use Zero-hour Contracts. Accessed January 5, 2015. http://www.ucu.org.uk/6749.

University and College Union. 2013b. Quality Thresholds and Institutional Gaming. REFWatch. Accessed August 30, 2014. http://ref.web.ucu.org.uk/2013/09/23/quality-thresholds-and-institutionalgaming/.

University and College Union. 2013c. Impact of the REF on Early Career Academics. REFWatch. Accessed August 30, 2014. http://ref.web.ucu.org.uk/2013/10/01/impact-of-the-ref-on-early-careeracademics/.

University and College Union. 2013d. Durham University in Unpaid Jobs Row. Accessed May 1, 2014. http://www.ucu.org.uk/index.cfm?articleid=6800. 
University College London University and College Union. 2012. Letter to Malcolm Grant (President and Provost, UCL) and Peter Fonagy (Psychoanalysis Unit, UCL). Accessed April 15, 2014. http://www.ucl.ac.uk/unions/UCU/campaigns/unpaid-internships-letter080812.pdf.

University of Essex. 2013. Junior Research Fellowships. Accessed April 15, 2014. http://www.essex.ac.uk/philosophy/staff/jrf/.

University of Essex. 2014. Philosophy: Junior Research Fellowships. Accessed May 11, 2014. https://www.essex.ac.uk/philosophy/staff/jrf.

Wilson, Tom. 1991. The Proletarianization of Academic Labour. Industrial Relations Journal 22 (4): 250-262.

\section{About the Authors}

Kirsten Forkert

Kirsten Forkert is a lecturer in the School of Media at Birmingham City University. Her research has explored cultural labour, anti-austerity activism, and migration. She is also an activist with the University and College Union.

\section{Ana Lopes}

Ana Lopes is a senior lecturer at the University of the West of England, Bristol. She is associated with the Centre of Employment Studies Research, Faculty of Business and Law. She has written on a variety of topics, including sex work, migrant labour, and community organizing. She is an active member of the University and College Union. 


\section{Appendices: Adverts}

Appendix 1: Honorary Research Assistant, University of Birmingham

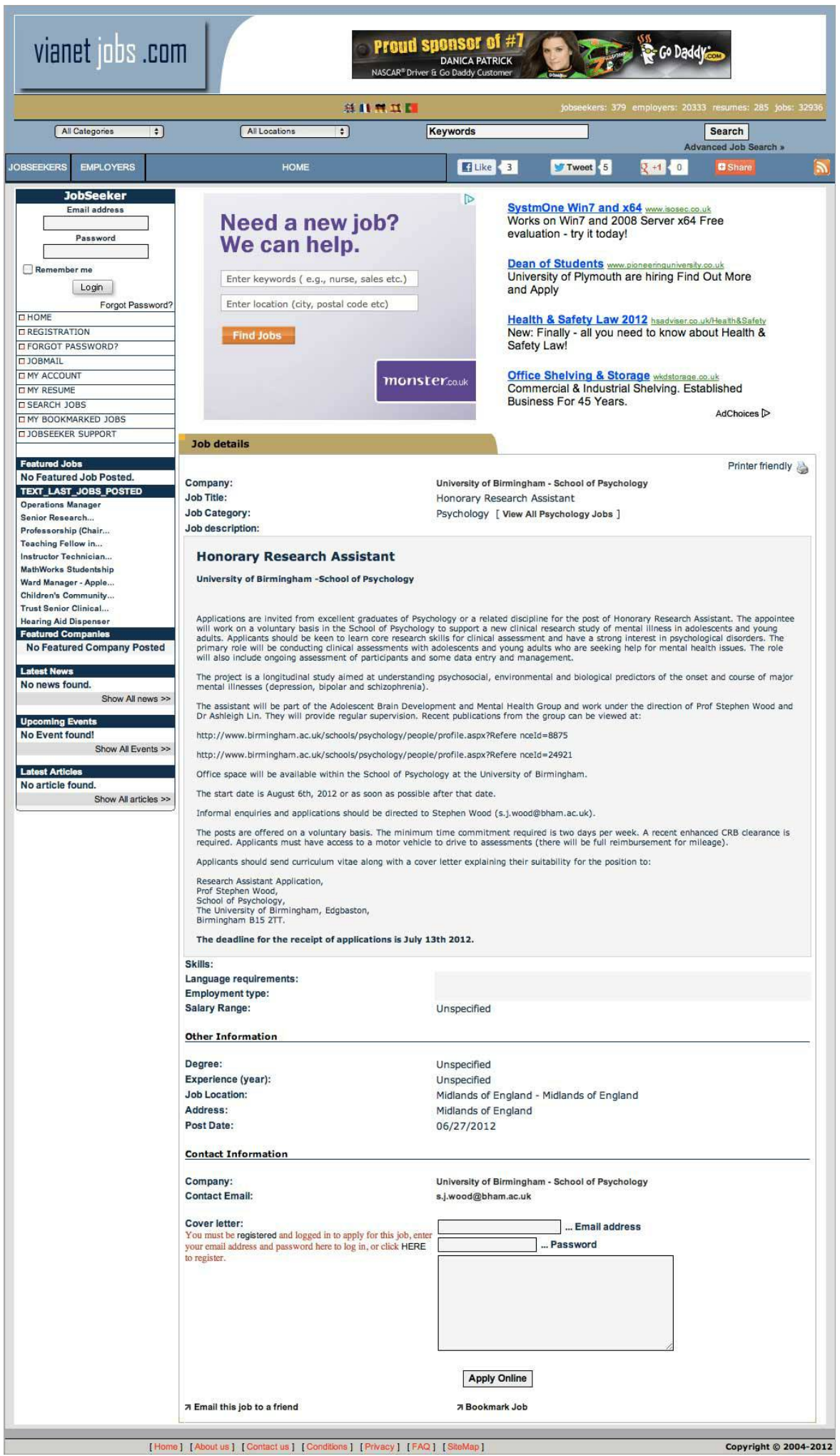

Post archived at: http://www.ucu.org.uk/index.cfm?articleid=6159 
Appendix 2: Research Assistant Internship, University College London

Cemite

\begin{tabular}{|c|c|c|}
\hline \multirow{2}{*}{$\begin{array}{l}\text { In this section } \\
\text { Current jobs }\end{array}$} & \multicolumn{2}{|c|}{ Research Assistant Internship on the ERIC-D Pilot } \\
\hline & \multicolumn{2}{|c|}{ Study } \\
\hline & $\begin{array}{l}\text { Contract } \\
\text { type }\end{array}$ & Fixed-term \\
\hline & $\begin{array}{l}\text { Contract } \\
\text { length }\end{array}$ & From 28th August 2012 for six months \\
\hline & Location & $\begin{array}{l}\text { Research Department of Clinical, Educational and Health Psychology, UCL, 1-19 } \\
\text { Torrington Place, London, WC1E 7HB and Improving Access to Psychological } \\
\text { Therapies (IAPT) services in Camden and Sutton. }\end{array}$ \\
\hline & Salary & Unpaid \\
\hline & Hours & Two or three Full time or Part time positions \\
\hline
\end{tabular}

Search for...

Get involved

Commission us

CAMHS Evidence

Based Practice Unit

Job details

\section{Job detalls}

The Anna Freud Centre supports distressed children and their families through innovative therapeutic practice and research, training and promoting awareness of mental health issues.

These internships are to assist on the 'Pilot study to Evaluate the Reduction of Increased Cardiovascular risk linked to Depression' (ERIC-D Pilot), which aims to establish the feasibility of conducting a large randomised controlled trial comparing a collaborative-care, exercisefocused enhancement to the treatment provided by the Improving Access to Psychological Therapies (IAPT) programme with standard IAPT treatment for depression.

The interns will be involved in all practical aspects of the research project:

- Recruitment - calling, emailing and sending invitation letters to potential participants. Explaining the project, seeking consent and booking appointments. Liaising with IAPT Psychological Wellbeing Practitioners.

- Data collection - within a session, the interns will complete the consent forms with the participant, carry out pulse wave velocity (PWV) assessments, take measurements of height, weight, blood pressure, and waist circumference, and collect questionnaire data face-to-face with the participant.

- Data entry and analysis - all questionnaire data will be entered by the interns.

- Other administrative duties that from time to time may be required.

These posts offer excellent opportunities to develop research expertise in primary care settings. Candidates should have an interest in working with clinical populations. Data collection will take place at participating IAPT services in Camden and Sutton. Travel expenses will be reimbursed.

Post archived at: https://www.martineve.com/2012/08/02/more-unpaid-academic-positions-andapparent-culture-of-entitlement/ 


\section{Appendix 3: Honorary Junior Research Fellowship, University of Essex}

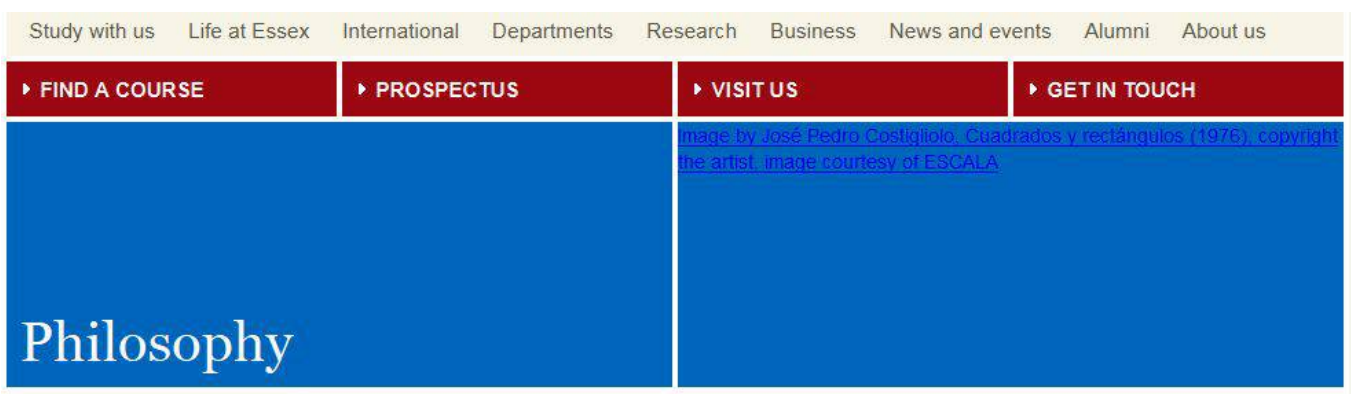

\begin{tabular}{l} 
Philosophy home \\
Dndergraduate study \\
Postgraduate study \\
Dow to apply \\
- Rees and scholarships \\
- Careers and skills \\
- About us \\
Dews and events \\
D For current students \\
\hline
\end{tabular}

home philosophy staff jiff

\section{Junior Research Fellows}

\section{Current fellows}

- Dr Lisa Grover, e-mail Igrover (non-Essex users add @essex.ac.uk)

- Timothy Secret

\section{About the Junior Research Fellowships}

Our School of Philosophy and Art History offers up to three non-stipendiary Junior Research Fellowships each year, commencing in October. These are available for one year and, in exceptional cases, may be extended for a further period of no more

\section{Research}

\section{Research}

Our research is ranked among the top ten philosophy departments in the UK and we are internationally recognised for our expertise in critical theory, phenomenology and classical German philosophy

Although no salary is attached, Fellows are entitled to shared office space with computing facilities, and the use of all library and School facilities. There are no teaching duties associated with the positions, however Fellows may be entitled to take on teaching, if available, for which they are paid at the usual University rate.

Candidates should have recently completed their PhD, or should have done so by the time their Fellowship starts. Normally applicants will not be considered if more than three years have elapsed since they received their $\mathrm{PhD}$, (exceptions will be made where a candidate's postdoctoral career has been interrupted by, for example, maternity leave, childcare, or illness)

Preference will be given to candidates who have not already held a Junior Research Fellowship in our School or elsewhere. Selection of candidates takes place in June/July each year. For further information about applying for non-stipendary Junior Research Fellowships, please contact our deputy School Administrator Hannah Whiting.

Post archived at:

http://web.archive.org/web/20130603141131/http://www.essex.ac.uk/philosophy/staff/jrf/ 


\section{Appendix 4: Extracurricular teaching, Durham University}

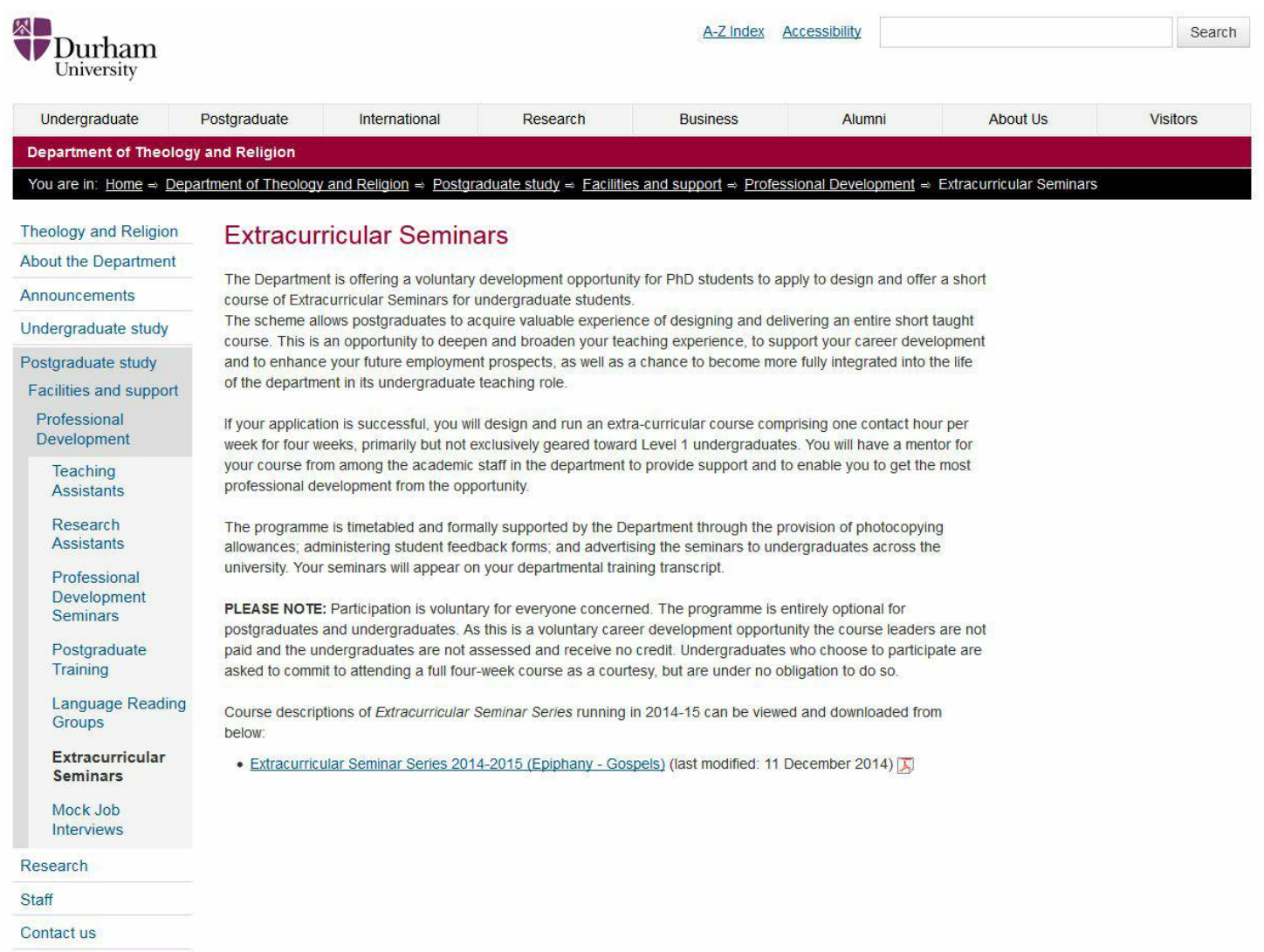

Available at: https://www.dur.ac.uk/theology.religion/postgrad/prof.dev/extracurricular.seminars/ 


\title{
Art Struggles: Confronting Internships and Unpaid Labour in Contemporary Art
}

\author{
Panos Kompatsiaris \\ National Research University, Higher School of Economics, Moscow, Russia, \\ panoskompa@gmail.com
}

\begin{abstract}
This article explores the practices of recently formed and mainly UK-based art workers' collectives against unpaid internships and abusive work. The modes through which these collectives perform resistance involve activist tactics of boycotting, site-specific protests, counter-guides, and whistleblowing and name and shame approaches mixed with performance art and playful interventions. Grappling with the predicaments of work in contemporary art, a labouring practice that does not follow typical processes of valorization and has a contingent object and an extremely loose territorial unity, this article argues that while the identity of the contemporary artist is systemically and conceptually moving towards fluidity and open-endedness, these groups work to re-affirm a collective in whose name it is possible to advance certain claims, assumptions, and demands. The contradictions and dynamics of art workers organizing against internships and voluntary work within a highly individualized, self-exploitative, and often privileged field are useful for informing labour organizing in the framework of ongoing capitalist restructuring.
\end{abstract}

Keywords: art labour, contemporary art, internships, art activism, the labour turn

Acknowledgement: I am grateful to the editors of this issue as well as to the anonymous reviewers for their very helpful comments and suggestions.

Art Monthly's September 2012 issue appeared with an unusual front cover. The widely-read and well-established contemporary art magazine in Britain, not exactly famous for an explicitly activist orientation, encouraged workers in the art world to "bust" their bosses with questions such as the following: "When shall we agree [to] the terms of the contract? What is the compensation fee if the work gets cancelled? What is the maternity/paternity pension provision?" What Art Monthly termed "the Occupy effect" on contemporary art, citing an article by Maja and Reuben Fowkes in the same issue, was the cause of this unusual urging. The Occupy effect triggered the formation of an array of groups and artist-activist collectives emerging in relation to and from within recent social movements. Groups such as OWS Arts \& Labor, a working group "dedicated to exposing and rectifying economic inequalities and exploitative working conditions" (2011), or Occupy Museums, wishing to free up "a space of dialogue and fearlessness for the 99\%" (2011), were key for popularizing an anti-neoliberal structure of feeling across the art world. Following the Occupy movement, these groups demarcate a dividing line between the 'privileged'-the few high profile artists, collectors, gallerists, and curators-and the 'exploited,' the invisible mass of art workers on whose labour the art system depends (what Gregory Sholette terms "creative dark matter" [2010]).

A critical aspect of this revolting tendency taking place in the field of contemporary art is protest against unpaid and abusive internships. ${ }^{1}$ Departing from this assumption, the aim of

\footnotetext{
${ }^{1}$ An internship in contemporary art refers to a broad spectrum of training positions offered in museums, galleries and biennials where art workers, usually employed full-time and for an prearranged period of time, perform diverse duties (from guarding the artworks and handling social media to writing reports and funding applications) in order to develop their professional careers. In contrast to volunteering positions that tend to emphasize the volunteer's contribution to a "higher cause" (e.g., the social role of the host organization in the case of an NGO), internships put more emphasis, at least in theory, on coaching the practitioner in exchange of the latter's commitment to regular work for free or very low payment. While in this sense internships are closer to apprenticeships, they differ from the latter in that they do not offer official qualifications or professional licenses (as apprenticeships often do), while they usually last for a shorter period of time than apprenticeships (e.g., some months). This article seeks
} 
this article is threefold. First, I argue that the movement against internships is key not only for launching a rights-based campaign, but also for shaping a renewed class awareness in the art world within a neo-Marxist theoretical framework. The anti-volunteering rhetoric, unravelled through campaigns, protests, and the spread of counter-information, expands art resistance beyond the ways that artworks represent political questions, topics and concerns. According to the collectives that I will discuss, whose origins can be tracked back to artists' experimentation with unionizing in the 1960s and '70s (Art Workers Coalition, for example), artworks disclose themselves in museums, galleries, fairs and biennials by concealing often abusive relations of production. In the recent anti-internship mobilizations there is thus an apparent combination of Marxist ideology critique, gesturing at "revealing" the hidden relations of production that lie beneath the spectacular display of objects, and the deployment of an anarchist ethos based on self-organization, self-management, and horizontality in decision-making.

Second, I argue that the movement against abusive internships, as a demands-based movement, temporarily crystallizes a worker identity in relation to the contemporary artist. The classic idea of union activism implies a group of people sharing a labour identity that is invoked in order to foreground collective demands. Traditionally, this identity could be either affirmed through a medium-specific application of a skill, some sort of territorial unity or a combination of both. This technical or territorial unity is what regularly affirms a group of professionals as a collective of workers, a collective having the capacity to advance its demands to a higher form of authority that controls or benefits from their labour-the employer. In contrast to this unity, as I describe in the second section of this article, the qualities of artistic work thwart what we commonly accept as worker identity. Work in contemporary art does not follow standard measures of valorization, has a contingent object, has an extremely loose spatial aggregation, and the distinction between workers and employers is less clear-cut than in other professional sectors (Moore 2014).

I should note that not all interns working in galleries and other art institutions describe themselves as "artists," and that there is an obvious disconnection between what is considered as artistic work "proper" - namely creative, improvisational, and experimental doingsand intern work, which usually involves more standardized activities, related to administration, guard duties, or guided tours. Rather than seeing how these different types of labour inhabit the figure of the artist today, what interests me in this article is how the artistic-activist ethos that the anti-volunteering campaigns nurture momentarily fixes an art worker identity (and indeed a militant one), an identity that is otherwise difficult to conceptualize and theoretically support (Bryan-Wilson 2012, 46).

Finally, in the last section of the article, I discuss identitarian claims in relation to larger processes and conceptions of social transformation. From a certain perspective, the movement against internships can be seen as regressive as it threatens to reify the capitalist division of labour by reinstating a worker's identity, rather than abolishing it altogether (i.e., from the perspective of the theory of communization) or accelerating its dissolution. I would argue, however, that in the anti-volunteering struggles there is neither a straightforward and unproblematic affirmation nor negation of artistic identity. By deploying a blend of performative, ethical, affective, and legalistic language, moving in and across disciplines and orientations, the artistic-activist groups tend to both affirm and negate dominant conceptions of what it means to be an artist today (a conception determined to a large extent by market forces, or through the system of authorship and ownership rights). Anti-volunteering activists affirm an artistic identity insofar as they make demands as art workers and negate it by remaining anonymous and seeking to connect with larger social struggles that exceed the capitalist division of labour. In this regard, the aim of this article is neither to advocate a programmatic affirmation of artistic identity nor its abolishment, but rather to illustrate how a structurally challenged notion of artistic identity comes to be reinstated by anti-internship campaigns as a militant one, un-

less to compare internships in opposition to other similar placements than to explore how the anti-internship rhetoric, growing during this period and emerging from within wider social movements, underscores the structural affinities of internships with new forms of capital accumulation as well as reactivates the ambivalent category of the art worker (or of the artist as worker) as a militant-left wing one. 
derscoring the value of strategic organizing and tactics in developing forms of anti-capitalist constituent power (Toscano 2011).

The debate on the unfairness of unpaid internships has in recent years reached mainstream European institutions. When asked whether an unpaid internship is a form of exploitation, the Social Democrat politician Martin Schultz, candidate for president of the EU in the recent European elections, replied that "unpaid internships are one of the biggest problems that we have," admitting that, indeed, "this is a modern style of exploitation."2 In the UK, the MPs in the House of Commons recently voted with a remarkable 181 to 19 for a proposal to ban unpaid internships. The Labour Party declared that if it won the general election in 2015 it would ban unpaid internships lasting more than four weeks, while even the Conservative MP Alec Shelbrooke stated that unpaid internships are socially harmful, an "impediment to social mobility" (BBC 2014). Among other organizations, Intern Aware was founded in 2010 in the UK to address internships from a wide range of professions, assisting interns in understanding their rights and claiming wages owed by appealing to the law and undertaking legal procedures. A similar legal framework as a means to combat free internships is invoked by ArtQuest, an arts organization whose paper Intern Culture (2012) reviews policy documents and reports providing practical guidelines to current and future interns on their rights and responsibilities.

The activities of the art worker groups I focus on differ from the above-mentioned, more mainstream organizations in certain respects. Groups such as the UK-based Precarious Workers Brigade and Future Interns, the US-based Occupy Museums and W.A.G.E., and the international ArtLeaks employ a language that is not primarily legalistic, but a hybrid, blending vocabularies related to law, ethics, irony, and performance art. ${ }^{3}$ Their vocabularies transcend the critique of internships, moving towards a wider critique of current social, political, and economic relations. The modes in which they perform this form of institutional critique involve classic activist tactics of boycotting, site-specific protests, pressure groups counterguides, whistleblowing, and name and shame approaches mixed with performance art and playful interventions. By articulating the multifaceted state of art work as a state of exploitation, these groups perform a sense of unity and renewed class awareness, hailing a temporary worker identity in a field where work is imbued with the promise of emotional fulfilment and desiring investments.

Over the past four years I developed a sustained engagement with discourses around contemporary art and labour and with the sites where resistance against internships manifest. I treat the material I present-mainly collected through face-to-face discussions, social media, blog posts, and scholarly publications-as indicative of the ways that the labour turn is performed in the past decade (Dimitrakaki 2011), and especially since the eruption of the 2008 global crisis, in and around contemporary art. In this way, I attempt to map the rise of contemporary art labour activism as a "discursive field" (Foucault 2012), which although heterogeneous and diverse, suggests alternative ways to think and talk about the subject and, as such, can potentially be mobilized in the context of general social antagonism. The political articulations within this field possess a hybrid character in the sense that they incorporate a language derived from Marxist theory, law, and legality as well as performance art. I emphasize how in the recent artistic-activist performances the ethical is performed alongside the affective, seeking to activate discourses concerning what should be the "moral," the "right," or the "responsible" in addressing internships and unpaid labour. The mobilization of ethical frameworks as a means to advance political articulations is often regarded as a problematic, if not a post-political way of practicing politics (e.g., Swyngedouw 2010). Without losing sight of this critique, I argue here that the strategic use of ethics and morality fused together with

\footnotetext{
${ }^{2}$ The phrase can be heard after 09:05 at the following link http://www.debatingeurope.eu/2014/04/28/big-crunchpresidential-debate/\#.U2NxN1fn2z5.

3 This emerging militancy is manifested in the formation of an array of collectives emphasizing larger structural relations between contemporary art and exploitative labour. An example is the group Gulf Labor Coalition, based in the US, whose focus is on the exploitative labour conditions in the construction of the Guggenheim Abu Dhabi, Louvre Abu Dhabi, and the Sheikh Zayed National Museum (which is built in collaboration with the British Museum).
} 
affective utterances and larger ideas on power and resistance can be employed as vehicles towards a more profound class consciousness amongst the oppressed and the exploited. The contradictions and dynamics of art workers organizing against internships and voluntary work within a highly individualized, self-exploitative, and often privileged field are thus helpful for thinking through general constellations of labour organizing in the framework of recent capitalist restructuring.

\section{Contemporary Art Labour and the Art Worker}

Contemporary art has a paradoxical character: It is a specific creative discipline that arrogates itself to the status of representing creativity in general [...] contemporary art as opposed to every other type of creative labour (music, film, acting, graphic design, cake decoration) has no specific medium - that is to say no specific form of labour- attached to it $[\ldots]$

Ben Davis, 9.5 Theses on Art and Class $(2013,32)$

Internships and similar short-term placements are considered to be a stage in an artist's development and, increasingly, an inevitable one, representing opportunities for networkbuilding and hands-on experience within art institutions. In such placements, artists normally perform mostly standardized and repetitive work, ranging from administration and planning to guarding and installing artworks. This kind of work, in its many variations and forms, seems indispensable for raising the exposure and value of artistic objects and careers. Besides, it is now commonplace in discussions around contemporary art and its economies to regard the value of the artworks less as the outcome of a particular technique applied to certain palpable media (say, the canvas of a painter or the marble of a sculptor) and more as having to do with processes of social interaction taking place around and about objects, performances, or events (Roberts 2007; Shukaitis 2012; Gielen 2009; Helguera 2013). So, while the production of art objects still constitutes the primary target area of the art market and the academy, the valuation of these objects is mainly enacted in and through processes of socialization such as networking, self-branding, public relations, or even idle chatting (Gielen 2009). In the past decade, contemporary artists and theorists mobilized Marxist and neo-Marxist vocabularies to underscore this complex nature of artistic labour, its deep interrelation with neoliberal work models, but also its latent subversive potential (Gielen 2009; Shukaitis 2012; Noys 2013; see Graeber 2008). ${ }^{4}$ As the ideal "cognitariat" that puts its "soul at work" (Berardi 2009), arranging signs amidst labyrinths of information, contemporary art workers both embody the dominant labouring practices of current economic regimes and possess increased subversive potential due to their strategic position in the current division of labour (Beech 2013). Elevating the contemporary artist to a worker who performs and exemplifies the contradictions of contemporary capitalism, however, discloses tensions having to do with privilege as well as raises wider questions on the effectiveness of the art struggles at hand. If, as Julia Bryan-Wilson provocatively claims, art work is not really work, in the sense that it constitutes itself as the opposite of the custom conception of work and its repetitive rhythms $(2012,46)$, how and to what extent do anti-internship struggles challenge and reconfigure the current division of labour?

Before tackling such questions, let us first take a brief look at the ways that art has been recently conceptualized in relation to labour. One of the most explicit attempts to read artistic practice as a form of labour in relation to larger social and economic developments comes from recent writings by art theorist John Roberts (2007). Roberts argues that visual art since Marcel Duchamp and his industrial "readymades" tends to generate value by increasingly incorporating "non-artistic" hands in artistic production processes. Since then, artistic skill

\footnotetext{
${ }^{4}$ Given the general politicization of the field at least since documenta $X(1997)$, which announced the art institution as capable of instigating social interventions, and Documenta 11 (2002), which engaged with Hardt's and Negri's Empire (2001), questions of art and labour have gradually occupied a central place in critical debates about contemporary art.
} 
means less crafting artisanal objects destined for aesthetic appreciation in the salon or the academy and more the exercise of intellectual, managerial, and executive abilities. Against voices that lament the loss of artistic skills in contemporary art, Roberts argues that rather than loss, there is a displacement of the nature of artistic skill: such skills find their legitmization not through the application of handcraft techniques but in the demonstration of some sort of conceptual sharpness (Roberts 2007,3). Thus, the abandonment of painterly skills by Duchamp and later by minimalist and conceptual artists is, for Roberts, "a productive process ... which represents a technical and social readjustment on the part of the artist to the increasing socialization of labour" (ibid., 23). Under this lens, as part of a broader "reskilling" process, an internship in a museum or a gallery offers to the artist the opportunity to cultivate such managerial, administrative, and communicative skills in an official and recognized institutional structure. There is, then, a certain correlation between the current need for occupying such short-term, multi-skilling training placements in order to develop professional artistic careers and the increased tendency to replace handcraft with administrative skills in art practice and education.

The shift from the "hand" to the "intellect" was already identified implicitly or explicitly by art critics of the 1960s and 1970s writing about post-war artistic movements, such as minimalism and conceptualism, that reinvented the Duchampian readymade and its legacy. For instance, writing in 1967, Michael Fried (1998 [1967]) uses-albeit in a derogatory sensethe notion of "theatricality" to describe minimalist art, that is to say, an art form that displays an extreme self-consciousness and seeks to activate effects of self-reflective and intellectual qualities in the viewer, instead of pictorially absorbing them. Lucy Lippard, a champion of conceptual art practices, writes in 1973 that conceptual art "means work in which the idea is paramount and the material form is secondary, lightweight, ephemeral, cheap, unpretentious and/or 'dematerialized'" (1973: vii). More recently, the conception of artist as enabler of socialities achieved canonical status in the context of a globalizing art field. The rise and popularization of the movement of "relational aesthetics" at the end of the 1990s, although criticized for ignoring antagonism (Bishop 2004), sidelining questions of political economy (Martin 2007), and uncritically praising the figure of the artist as nomad (Hatherley 2009), has moved to the mainstream an univocal grasping of the artist as a "generator" of social relations. Relational art, propagated by the French curator and critic Nicolas Bourriaud (2002), conceives of the artist-as-administrator, or recycler, re-programmer, ideas-manager, bricoleur, monteur and so on, who rearranges, reorders, reshuffles, and ultimately 'glues' together certain signs to produce new meanings that are contextual or can be contextualized by a curator at a later stage. Again, here the condition of the artist as an enabler of meaning comes about not through the application of manual skills to a certain material object but through the exercise of administrative and communicational abilities associated with the thought and intellect. An important consequence of such historico-theoretical developments for theorizing the figure of the contemporary art worker is that any object can rightfully become an artwork insofar as it is appropriately framed. In other words, the object upon which the artwork is performed is "contingent" (Buskirk 2003, 16) insofar as it envelops a limitless range of materials and processes, varying, indicatively, from film and readymade objects to lecture-performances.

Thus, we can assume that the idea of the contemporary art worker challenges what is commonly meant by a worker identity. Rather than constituted through a shared engagement with a specific labouring practice, subject to formal rules, objectives, and regulations, the identity of the artist embraces a certain open-endedness, valorized through processes that are not subject to formal criteria. Apart from the absence of a shared technique that could function as a measure of value, however, there is not equally a certain spatial arrangement that engulfs and enables this formal heterogeneity, a workplace in which artists can be hailed together as "workers" in the long-term. While galleries, museums, or biennial exhibitions are the privileged global spaces of art showcasing, they function more as short-term outlets rather than customary conceived workplaces, and in this sense they cannot interpellate traditional, territorially-bound workers' subjectivities. Actual artistic workplaces, generally artists' studios, are mostly dispersed and, given the mobility that characterizes the field, these spac- 
es are less likely to develop a clear-cut antagonistic collective of workers pushing forward a set of common interests. In this sense, labour-wise, the contemporary art worker essentially performs an open-ended identity, insofar as the multiplicity of different kinds of labour, materials, and spaces with which they engage prevents a straightforward mobilization of collective interests and demands against a territorially or conceptually bound authority.

The special status of work in contemporary art has given rise to a dual representation of its character by theorists, understood as a site of tension upon which struggles against internships and unpaid work unfold. ${ }^{5}$ Art work is potentially liberating and also inherently exploitative. In the first case, the emotional nature of artistic work has prompted scholars to associate it with a potentially utopian practice bound to the Marxian conception of labour in communist society as a self-fulfilling and self-realizing activity (Bishop 2012). The activity of labour in communism, Marx believed, does not function as an external constraint, as wage labour does; it will not be "a means of life but itself life's prime want" $(1938,11)$. Yet, at the other extreme of the spectrum, contemporary art is the ideal site of exploitation. The "pleasure in work" (Hesmondhalgh and Baker 2010), or work as the site where one is most capable of realizing ideas and desires (Smith 2013,37), coincides with creative modes of capital accumulation (Vishmidt 2013). Life becomes work and work becomes life, although neither in Marx's sense nor in the sense of the early avant-gardes, which hoped for the dissolution of art into life. In this highly abstract mode of analysis, it is capitalism that has colonized the very fabric of human desire and emotion.

The terms "biopolitics" or "real subsumption" are key for providing a contextual theoretical backdrop against which artistic labour as a desiring and emotional working practice can be conceived as exploitative. ${ }^{6}$ In the context of biopolitics, as articulated by Foucault (2008) and later commentators (e.g., Read 2009), ideas of self-fulfilment and self-realization become a technology of subjectivation through which the lives of the population are put to reproduce capitalist relations. In this sense, the biopolitical mode of production concerns not only the production of commodities as objects but also as relations, lifestyles, and subjectivities through which control and systemic preservation is achieved (Read 2009, 26). By believing that they realize themselves in the objects and relations they produce, artists have been regularly seen as the tipping point of such biopolitical arrangements and configurations. The prospect of a creative fulfilment that an internship promises then becomes, as the group Carrotworkers Collective puts it, the "carrot," a "disciplinary device" signifying "the hope that we might organise our work around 'creativity' rather than drudgery [...] used to prompt, cajole and sometimes blackmail workers into long-term and recurring periods of free and precarious labour" $(2011,3)$. The term real subsumption, deriving directly from Marxian analysis, produces similar effects to those of biopolitics when applied to discussions of contemporary art. Since the 1970s, there has been a gradual transition to societies of real subsumption, or a stage in capitalist development wherein all production is tainted by the capitalist valueform, as the capitalist now organizes the totality of social relations in a distinctly capitalist way. ${ }^{7}$ This transition hails "virtuosic" subjectivities (Virno 2004), that is to say labouring subjectivities that put their soul to work, embracing performative and artistic skills. ${ }^{8}$ Virtuosity typifies "the totality of contemporary social production" (52), and thus characterizes not only artists, but increasingly all labouring subjects. Along these lines, contemporary art seems to be one of the sites spearheading this process. Alexei Penzin (2010) notes that contemporary art "provides the quintessence of virtuosic practices" since the contemporary artist is probably "the brightest expression of the flexible, mobile, non-specialized substance of contempo-

\footnotetext{
${ }^{5}$ For some of the routine predicaments among workers in contemporary art stemming from representations of artistic work as inherently autonomous see also my own past ethnographic research on the subject (Kompatsiaris 2014).

${ }^{6}$ One could add here terms such as governmentality, immaterial labour, and cognitive capitalism.

7 Real subsumption is counterpoised to the 'formal subsumption' of the earlier years of capitalism, where the capitalist captured an existing labour process (i.e. the labour of independent artisans) turning it to a valueproducing activity.

${ }^{8}$ Virno, however, is one of the few post-operaismo philosophers characterising the current moment as a mixture of formal and real subsumption. See for example Virno 2009 and Penzin 2010.
} 
rary 'living labor"' (81). Internships in contemporary art not only serve to reskill and thus redraw the qualities of the professional artist, but operate as a technique of interpellation within a dominant economic paradigm.

I should note here that the conclusions that the above theorizations induce appear as somehow totalizing, relying too much on ambiguous periodizations, or even self-referential. ${ }^{9}$ When they attribute "special status" to the arts sector, they usually diminish the importance of other kinds of labour upon which the development of this sector is based, including the massive amounts of factory labour in the global South or elsewhere, exploited by the same forces that raise the symbolic and economic capital of art. As soon as the figure of the art worker is put at the forefront of contemporary struggles due to its alleged critical position in the capitalist division of labour, the struggles of less prestigious workers (or even groups that do not identify themselves as workers, such as residents or debtors) can easily be overlooked. The idea of the artist as the 'model worker' of neoliberalism, though, has gained significant currency in debates at conferences and in the blogosphere, journals, and publications. One can thus draw a certain link between its popularity and the recent articulation of art as a site of exploitation by groups mobilizing against internships. The tensions emerging as soon as the terms "art" and "work" are put side by side (or, inversely, the "gap" between art and work, in Bryan-Wilson's terms [2012]), are, as we shall see, always already present threatening to undermine the rationale of artist-activist struggles.

\section{Resistance Against Internships and the Labour Turn in Contemporary Art}

The above framework, which conceptualizes the figure of the contemporary artist as a bearer and potential destabilizer of the complexities of current labour landscapes, came emphatically to the forefront shortly before as well as during the recent economic crisis. One of the most visible consequences of Occupy for theory, journalism, criticism, and practice around contemporary art is an intensified questioning of artists' working conditions (Sholette 2010; Cox and Bazzichelli 2013). When, for instance, the New York-based art critic Ben Davis began his 9.5 Theses on Art and Class with the phrase "class is an issue of fundamental importance for arts" $(2013,27)$, he eloquently performed the widespread desire across visual art landscapes in the years following the 2008 recession in the U.S. and the Eurozone to expand, modify, or challenge an understanding of art principally as an aesthetic practice. Here, the political nature of an art exhibition is sought not only in the affects, emotions, and discourses it mobilizes, but also in the ways it relates with issues such as class, labour, and the commons. By assuming the position of the "exploited," art worker groups founded in the past five years, such as OWS Arts and Labour, Occupy Museums, Carrotworkers Collective (a predecessor to Precarious Workers Brigade), Future Interns, ArtLeaks, and Ragpickers, expand not only on how art is an activity of representational, affective, or critical engagement, but an activity that generates economic value; or, as again Bryan-Wilson puts it in respect to the movements of art unionizing of the 1960s, how art works $(2009,3)$. Despite limitations, the tactics art worker movements undertake and the ways they deploy them can prove illuminating for wider struggles in the context of labour flexibilization (de Peuter 2014, 267). In this section, I selectively focus on how some of these groups, mainly those in the UK, attempt to combat and delegitimize dominant narratives of internship culture.

A main tactic anti-internship groups employ is whistleblowing, involving the name and shame approach (i.e., calling out and making public the wrong-doings of an organization on social media) as well as boycotts, which usually takes the form of circulating advertisements released from galleries and museums that promote unpaid internships or other unremunerated positions in blogs and social media accounts. As these campaigns rely on publicity for accomplishing their aims, the number of visitors to blogs, newspaper coverage, or Facebook "likes" are an important factor for their realization. For instance, one such successful action took place in December 13, 2013, when Precarious Workers Brigade issued a letter to the established London-based Serpentine Gallery. The letter complained about a non-paid placement and warned that "over the coming months we will be engaging in a series of tar-

\footnotetext{
${ }^{9}$ For a useful critique of the idea of the artist as "model worker" see Greig de Peuter (2014).
} 
geted actions at yours and other institutions to encourage the creation of such a policy [one that involves a fair pay]" (2013a). The letter was followed a day later by a public action against the gallery organized by Future Interns in which protesters dressed as Santa Claus entered the gallery holding a banner that said "All that we want for Christmas is pay" while handing out leaflets denouncing the gallery's unfair internship listings. The protest can be thought of as performance art piece in itself, bringing together, playfully and bitterly, the issue of unpaid work, the custom of Christmas gift giving, and a humorous masquerade. After the protest, which attracted media attention, including a supportive article in Guardian, ${ }^{10}$ circulated online through various artistic and activist channels, Serpentine drafted a second response to the initial letter of the group. This second response, unlike the first, was apologetic for the decision to post the advert and admitted that "the points you make in your letter to us are valid and we have listened to your protest" (Precarious Workers Brigade 2013b). It is telling of the noise created around the incident that it managed to reach art institutional routes as in its February 2014 issue Art Monthly noted how the "Serpentine Gallery managed a spectacular PR own goal in December when it advertised for unpaid interns, causing a backlash that forced it to withdraw the positions" (2014: 16). The withdrawal of the advert demonstrates the success of the action, which proved useful in exposing the gallery's abusive work tactics through a hybrid discourse of legal references, moral questioning, performative elements, and effective publicizing.

The action brings to mind the first wave of "institutional critique" of the 1960s and 1970s, in which artists such as Daniel Buren and Hans Haacke wished to expose the workings of art institutions, rather than its post-2000s version where curators or even the art institutions themselves took on the role of social critique. ${ }^{11}$ In contrast to this first wave, however, the artists of anti-internship critique are largely anonymous and not commissioned by a curator or museum, and, thus, more cautious of the possible capitalization of their struggles by the market (and in this sense seem closer to artist-activist groups such as Guerrilla Girls that consciously choose to act anonymously). Moreover, following the interdisciplinary lineage of institutional critique, the anti-internship protests involve co-operation entailing a decisively intersectional character. For instance, a more recent action came out as a co-operation of three London-based groups, Future Interns, the Precarious Workers Brigade, and Ragpickers, which targeted the London Symphony Orchestra (LSO), an institution not linked to contemporary art but to the world of opera. LSO was interrogated for "advertising for and currently using unpaid interns" as well as "exploiting the desperation of young people and undermining the responsibility of organisations to pay for labour" (Future Interns et al. 2014). Similar to the Serpentine Gallery case, the initial letter was posted to the groups' blogs and social media accounts. The institution here was questioned on even stricter moral grounds with questions such as: "we wonder how you expect that person [the unpaid intern] to survive in London?" or "are you only expecting to receive applications from those who are from a very wealthy background, or someone whose parents live in London?" or "do you think it is responsible to be further widening the gap between those who can and can't pursue a job within the arts?" (ibid.). This class-based ethical questioning is again followed by accusations of law-abiding ("putting aside the moral and ethical issues of asking someone to work for you for free, you are breaking the law..."), attempting to delegitimize and discredit the institution, and suggesting an alternative constituent ethical, legal, and normative framework to rationalize art work. ${ }^{12}$ Here, too, the letter was followed by an action from Future Interns during a concert at the LSO, in which members of the group wore masks of famous composers and held placards reading: "Your Policies are Out of Tune: Pay your Interns." Following some

\footnotetext{
${ }^{10}$ The Guardian coverage of this protest can be found at http://www.theguardian.com/education/2013/dec/16/unpaid-internship-christmas-protest-serpentine-gallery.

${ }_{11}^{11}$ For an overview of the different waves of institutional critique see Raunig and Ray (2009).

12 The invocation of "ethics" and "morality" as a means to address the unjust practices of galleries and art institutions of this kind are very usual. In another letter Precarious Workers Brigade asked the gallery FACT in Liverpool to "consider the ethics of offering volunteer positions that used to be paid in your organisation." The full letter can be found at http://precariousworkersbrigade.tumblr.com/post/81277448894/open-letter-to-fact-liverpool.
} 
wider public fury, the LSO introduced a paid internship scheme to replace the unpaid one. The cooperating groups, coming together on the basis of a common cause of challenging unpaid internships, enact here a guerrilla-style, cross-sectional solidarity that re-animates the energies of the institutional critique of the 1960s by addressing the failings of the institutions in which the artists are called upon to work and showcase.

Another aspect of internship cultures that these groups wish to address refers to the discursive/ideological one. The overall consensus in job adverts circulated by galleries, museums, biennials, and other mainstream art institutions is to portray internships and volunteer placements as exciting opportunities for exercising skills and meeting high-profile artists. While the promise for self-realization in the domain of work takes here a mythical status implying some sort of future autonomous working life (Ross 2000), these groups produce counter-information in order to deconstruct this narrative. The spread of counter-information concerning aspects of social and political life is an established activist practice mobilized to discredit official and dominant narratives (Coyer, Dowmunt and Fountain 2011). Counterinformation in this context enables an alternative or oppositional discursive field that enables antagonistic ways of speaking about a subject, and here acts as a means of potentially transforming common conceptions about what internships are as well as setting in motion wider cultures of dissent. The forms of counter-information vary from the release of counter-guides to publicizing "leaks" concerning abusive work relations. For example, one of the most widely circulated manuals concerning internships, Surviving Internships: A Counter-Guide to Internships in the Arts, which was published in 2011 by the Carrotworkers' Collective, aims, in the tradition of ideology critique, to "explore and debunk some commonly held myths" concerning internships and creative careers (2). The document was released in PDF format and has been distributed through an array of sources, from self-managed ventures to more institutional actors such as the European Institute for Progressive Cultural Policies and large-scale art projects such as Truth is Concrete, which took place in Graz, Austria in September 2012. Carrotworkers' 66-page leaflet, similarly to the protests above, not only describes how unfair and unethical internships are, but also employs affective and playful ways to communicate the "irresponsibility" of art institutions by recounting personal internship stories. Again, here, the ethical language targeting the exploitative side of institutions is performed alongside references to larger systemic deficiencies as well as calls for solidarity with other professional sectors: "[n]ow, more than ever is the time for cultural workers to resist and work in solidarity with other social struggles" (3).

An ongoing platform of counter-information mainly operating online is the group ArtLeaks, whose members are not only artists but also international curators and critics. Employing Wikileaks' method of leaking undisclosed information and the rhetoric of the Occupy movement in distinguishing between the 'exploited' and the 'exploiters,' ArtLeaks wishes to serve as a tool for disempowered art workers, formed "in response to the abuse of their professional integrity and the open infraction of their labor rights" (2011). ArtLeaks maintains a webpage where artists and cultural workers who have been mistreated by institutions are invited to report their story. Similarly to Carrotworkers, ArtLeaks employ a language that moves emphatically beyond a demands-based campaign to connect internships and unpaid labour to wider structures of exploitation. The division between workers and the employers, or the $99 \%$ and the $1 \%$, becomes here a discursive trope for articulating inequality, fixing a militant artistic identity, and furthering critique against the capitalist system as a whole. Expressed as such, artistic labour is reclaimed as a site of conflict against dominant neoliberal discourses of optimization, productivity, and standardization (Bishop 2012; Roberts 2007).

If between art and work rests a wide gap holding these two categories in permanent tension, then efforts to re-draw this tension by anti-internship groups in oppositional terms tend to challenge how such placements are presented as creative or artistic opportunities by official art institutions. The recounting of actual experiences by those hired as interns in art institutions re-articulates this tension and endows such campaigns with some evidential force. Ragpickers, for example, aims to generate a kind of an "archive of the oppressed," comprised of personal stories from ex-interns who designate abusive experiences and the unfulfilled promises they have encountered during intern work (Ragpickers 2013). Art workers 
who are or have been interns in the past are invited to send objects or photographs of objects that convey such traces of abuse. By means of narrating an 'oppressed history,' the artist here becomes the 'exploited,' someone who has been treated unfairly, and thus a potential subversive agent subject against structures of ill-treatment. As the collective wishes to "blur the difference between the artistic and forensic" (ibid.) issues of inequality and exploitation are voiced through storylines interweaving the personal, the affective, and the legalistic in humorous and absurd ways. Here, institutional critique as a form of denaturalizing the discourse of official structures comes through the performing of an archive crafted by work experiences that challenge the self-attributed naturalness of intern adverts, or experiences that, as the collective remarks, are "unfair, absurd, or abusive, but were originally disguised with the initial promise of 'valuable insight' and 'exciting opportunity"' (ibid.). Likewise, here, ethical judgements ("unfair," "absurd," and "abusive") are interwoven with affective forms that transcend cognition and moral coding.

\section{Artistic Identity and the Social Dynamics of Struggles Against Internships}

The above actions of anti-internship groups inhabit a curious paradox in relation to the qualities of artistic work: while the identity of the contemporary artist is systemically and conceptually moving towards an impossibility, or a "non-identity," a fluid and open-ended labouring practice that gets valorized indeterminately, these groups aim to re-affirm a collective in whose name it is possible to progress certain claims, assumptions, and demands. It is obvious that especially in post-object art practices, it is hard to measure and thus evaluate artistic labour in terms of units of time, as there is an inherent difficulty, if not absolute impossibility, to measure the amount of time put to generating an idea or somehow trace its valorization. In this sense, and especially when artistic labour is understood within the framework of biopolitics and real subsumption, there can be no reliable normative criteria against which to put a set of wage demands for art workers. This enigmatic condition generates tensions and complications, able on the one hand of informing contemporary workers' struggles in the context of the neoliberal restructuring, and, on the other, of manifesting the limits of struggles organized around concrete workers' identities.

The "zealotry" that these groups display seeks to "redefine the 'common sense' of society and to reshape what we regard as 'normal' or 'moral,' 'legitimate' or 'moderate'" (Olson 2014). This happens, as we saw, not through only through calculated strategies seeking hegemonic alliances, but through performances with an open-ended character that often blur the boundaries of art and activism or of the ethical and the affective. In this sense, the reassertion of the artistic identity as an oppositional and antagonistic one occurs through the appropriation of aesthetic and artistic vocabularies that invoke affective and not just cognitive responses. As demonstrated by the relative success of such initiatives in mobilizing and enabling a "discursive field," the blending of the ethical and legal address with forms of expression that incite playfulness can provoke powerful mediated actions capable of influencing policy decisions. The tension, however, generated by the privileged position of artists as workers who strive to reach self-fulfilment through work within a climate of general social disaffection is ever present in such discussions. It is not a coincidence, in this sense, that the Carrotworkers in its guidebook sense the need to respond to the widespread objection that "organising cultural labour reinforces the privilege of a "creative class"' $(2011,56)$. Again, here, the gist of this questioning lies on the socially prevalent disjunction between the terms art and work.

Benjamin Noys (2013) offers a way to think about the predicaments of conceptualizing an artistic identity in relation to larger struggles. Noys reads certain artistic practices, including those of Warhol, the Situationists, and Duchamp, as efforts to abolish the identity of the artist by blurring it with processes of mass production and the commodity form (2013). Drawing from the perspective of communization, ${ }^{13}$ Noys explores the idea that the overthrowing of capitalist relations can only take place, as Jaleh Mansoor et al. put it, through a "continuous

\footnotetext{
${ }^{13}$ For a better perspective on the communization thesis see Noys' edited book Communization and its Discontents (2011), as well as the International Journal of Communization at http://sicjournal.org/.
} 
process of instituting communist relations," that is to say of relations unmediated by the capitalist value-form, the state, and wage labour $(2012,48)$. The institution of communizing practices needs to pass through the abolition of the division of labour and the overthrowing of all worker identities. A break with the capitalist mode of production is impossible, the communizing current believes, by clinging to a certain kind of worker identity as in that case the struggle will always tend to lapse to a demands struggle that divides rather than communizes. In this sense, struggles can only negatively prefigure, rather than affirm, a freer futurity. In contrast to Roberts, Noys (2013) sees the process of pushing artistic identity to its limits less as an affirmative response to socio-technical processes that could re-instate artistic autonomy, and more as an artistic gesture that negatively prefigures some future abandonment of artistic identity in the process of revolutionary transformation.

Extrapolating from Noys' position, the affirmation of artistic identity that activists perform through their struggles against unpaid internships can be seen as a reactionary path, threatening to re-institute a unionistic and self-enclosed worker identity. However, insofar as these actions remain anonymous, beyond, against, and within institutional channels, tactical, irregular and aiming at instigating alternative ethical and legal 'regimes of truth' rather than merely re-affirm a bonding relationship between identity and practice, they seem to hail an artistic subjectivity that involves fluidity, open-endedness and thus potential to transform. In other words, insofar as the anti-internship actions favour the qualities of practice rather than an exclusive identity formation, they have the capacity to thwart and transverse the rigidity of artists' unions, or worker unions in general, while opening the ground for future struggles that could involve workers (or even more promisingly, non-workers) from all strata of life.

In general, the social division suggested by the artist-activist groups between on the one hand politically engaged and underpaid artists and on the other the art system that capitalizes on and exploits critical practices, is characteristic of the class-based discourse in contemporary art. While post-Marxist art and cultural theory finds the division between the "dominant" and the "dominated" simplistic, favouring participation and social engagement, antiinternship artistic activism, drawing on the spirit of Occupy, works to re-activate this division through boycotts, whistleblowing, and withdrawals. ${ }^{14}$ Invisibility and anonymity are also fundamental in these mobilizations. All groups, apart perhaps from ArtLeaks, which has certain eponymous members (although ArtLeaks as well states that it "counts among its greatest supporters the invisible army of cultural workers worldwide... striving to make invisibility a great strength" [2011]), hide participants' identity in their actions. This practice both protects participants from exposure as well as "protects" their actions from the gaining of some possible future symbolic capital in the art market. Through these multivalent tactics, these groups enable a certain "discursive field" that envelops moral and legal ways to speak about internships and unpaid labour. This field is oppositional, in the sense that it counters the official narratives of high profile actors in the art world, such as museums, galleries, and biennials. It can also be thought of as a constituent power insofar as it carries the potential of instituting counter-logics in the treatment of the phenomenon. The struggles against internships and unpaid work are, then, not only reflective, but also constitutive of the emergence of a new artistic activism that re-instates the category of the art worker against the odds and the complexities of its increasingly abstract character.

\section{References}

Art Monthly. 2014. News-Art Notes. Accessed May 24, 2015. https://www.questia.com/magazine/1G1359130509/serpentine-slips-up.

ArtLeaks. 2011. About. Accessed May 24, 2015. http://art-leaks.org/about/.

\footnotetext{
${ }^{14}$ This can be seen as part of a larger recent tendency among contemporary artists wishing to make political statements who prefer to withdraw from art exhibitions rather than participate in them and enable counter discourses through their work. Examples of this kind include the withdrawal of several artists from the $19^{\text {th }}$ Sydney Biennial as a form of protest against its main sponsor, the corporation Transfield, which is the main stakeholder of an off-shore notorious detention camp in Papua New Guinea, or the withdrawal from the current Manifesta, scheduled to open in June 2014 in St. Petersburg, as a protest against the current political situation in Russia that includes the violation of LGBT rights and the waging of war against Ukraine.
} 
ArtQuest. 2012. Intern Culture. Accessed May 24, 2015.

http://www.artquest.org.uk/articles/view/intern culture.

BBC. 2014. MPs Vote to Back Call For End to Unpaid Internships. Accessed May 24, 2015. http://www.bbc.com/news/uk-politics-27389272.

Beech, David. 2013. Art and the Cognitariat. Accessed May 24, 2015. https://dbfreee.wordpress.com/2013/09/19/art-and-the-cognitariat/.

Berardi, Franco. 2009. The Soul at Work: From Alienation to Autonomy. Los Angeles: Semiotext(e).

Bishop, Claire. 2004. Antagonism and Relational Aesthetics. October 110: 51-79.

Bishop, Claire. 2012. Artificial Hells: Participatory Art and the Politics of Spectatorship. London: Verso.

Bourriaud, Nicolas. 2002. Relational Aesthetics. Dijon: Les presses du reel.

Bryan-Wilson, Julia. 2009. Art Workers: Radical Practice in the Vietnam War Era. CA: University of California Press.

Bryan-Wilson, Julia. 2012. Occupational Rrealism. The Drama Review 56 (4): 32-48.

Buskirk, Martha. 2003. The Contingent Object of Contemporary Art. Cambridge, MA: MIT Press.

Carrotworkers' Collective. 2011. Surviving Internships: A Counter-Guide About Surviving Free Labour in the Arts. London: CW Collective.

Cox, Geoff, and Tatiana Bazzichelli. 2013. Disrupting Business: Art and Activism in Times of Financial Crisis. New York: Autonomedia.

Coyer, Kate, Tony Dowmunt, and Alan Fountain. 2011. The Alternative Media Handbook. London: Routledge.

Davis, Ben. 2013. 9.5 Theses on Art and Class. Chicago: Haymarket Books.

de Peuter, Greig. 2014. Beyond the Model Worker: Surveying a Creative Precariat. Culture Unbound: Journal of Current Cultural Research 6: 263-284.

Dimitrakaki, Angela. 2011. The Spectacle and Its Others: Labor, Conflict, and Art in the Age of Global Capital. In Globalization and Contemporary Art, edited by Jonathan Harris, J., 191-211. London: Wiley-Blackwell.

Foucault, Michel. 2008. The Birth of Biopolitics. New York: Palgrave Macmillan.

Foucault, Michel. 2012. The Archaeology of Knowledge. New York: Random House.

Fried, Michael. 1998 (orig. 1967). Art and Objecthood: Essays and Reviews. Chicago: University of Chicago Press.

Future Interns, Precarious Workers Brigade, and Ragpickers. 2014. Letter to The London Symphony Orchestra. Accessed May 24, 2015. http://thefutureinterns.tumblr.com/post/80514683281/letter-tothe-london-symphony-orchestra.

Gielen, Pascal. 2009. The Murmuring of the Artistic Multitude Global Art, Memory and Post-Fordism. Amsterdam: Valiz.

Graeber, David. 2008. The Sadness of Post-Workerism: or 'Art and Immaterial Labour' Conference: A Sort of Review. The Commoner. http://www.commoner.org.uk/?p=33.

Hatherley, Owen. 2009. Post-Postmodernism. New Left Review 59: 153-60.

Helguera, Pablo. 2013. Art Scenes: The Social Scripts of the Art World. New York: George Pinto Books.

Hesmondhalgh, David and Sarah Baker. 2010. A Very Complicated Version of Freedom: Conditions and Experiences of Creative Labour in Three Cultural Industries. Poetics 38: 4-20.

Kompatsiaris, Panos. 2014. "To See and be Seen": Ethnographic Notes on Cultural Work in Contemporary Art in Greece. European Journal of Cultural Studies 7 (5): 507-524.

Lippard, Lucy. 1973. Six Years: The Dematerialization of the Art Object from 1966 to 1972. Los Angeles: University of California Press.

Mansoor, Jaleh, Daniel Marcus and Daniel Spaulding. 2012. Occupy Response. October 142: 48-51.

Martin Schultz. 2014. Debating Europe. Accessed May 24, 2015. http://www.debatingeurope.eu/2014/04/28/big-crunch-presidential-debate/ - .U2NxN1fn2z5.

Martin, Stewart. 2007. Critique of Relational Aesthetics. Third Text 21 (4): 369-386.

Marx, Karl. 1938. Critique of the Gotha Programme. New York: International Publications.

Moore, Alan W. 2014. Art Workers Want to Know. Ephemera 14 (3): 465-473.

Noys, Benjamin. 2013. Communization and the End of Art. In TIME AND (IN)COMPLETION: Images And Performances Of Time In Late Capitalism, edited by Tomislav Medak, Goran Sergej and Pristaš Bezimeno, 59-71. Zagreb: BADco.

Occupy Museums. 2011. About. Accessed May 24, 2015. http://occupymuseums.org/index.php/about. Olson, Joel. 2014. Rethinking the Unreasonable Act. Theory \& Event 17 (2). 
OWS Arts \& Labour. 2011. About. Accessed May 24, 2015. http://artsandlabor.org/about-al/.

Page, Libby. 2013. Intern protest: 'All I want for Christmas is pay.' Guardian. Accessed May 24, 2015. http://www.theguardian.com/education/2013/dec/16/unpaid-internship-christmas-protestserpentine-gallery.

Penzin, Alexei. 2010. The Soviets of the Multitude: On Collectivity and Collective Work, an interview with Paolo Virno. Mediations 25: 81-92.

Precarious Workers Brigade. 2013a. Dear Serpentine Management, we have recently been made aware that you are advertising 3 month volunteer placements. Accessed May 24, 2015. http://precariousworkersbrigade.tumblr.com/post/69877673667/dear-serpentine-management-wehave-recently-been.

Precarious Workers Brigade. 2013b. Serpentine Gallery's response to PWB letter and FI action (before and after). Accessed May 24, 2015. http://precariousworkersbrigade.tumblr.com/post/70204946178/serpentine-gallerys-response-topwb-letter-and-fi.

Ragpickers. 2013. UNHAPPY WITH YOUR INTERNSHIP? SPEAK OUT! Accessed May 24, 2015. http://ragpickers.tumblr.com/opencall.

Rancière, Jacques. 2004. The Politics of Aesthetics: The Distribution of the Sensible. London: Continuum.

Raunig, Gerald and Gene Ray, eds. 2009. Art and Contemporary Critical Practice: Reinventing Institutional Critique. London: MayFly.

Read, Jason. 2009. A Genealogy of Homo-Economicus: Neoliberalism and the Production of Subjectivity. Foucault Studies 6: 25-36. Accessed May 24, 2015. http://rauli.cbs.dk/index.php/foucault-studies/article/viewFile/2465/2463.

Roberts, John. 2007. The Intangibilities of Form: Skill and Deskilling in Art after the Readymade. London: Verso

Ross, Andrew. 2000. The Mental Labor Problem. Social Text 18 (2): 1-31.

Sholette, Gregory. 2010. Dark Matter: Art and Politics in the Age of Enterprise Culture. London: Pluto.

Shukaitis, Stevphen. 2012. Symphony of the Surplus/Value: Notes on Labour, Valorization, and Sabotage in the Metropolitan Factory. Performance Research 17 (6): 48-55.

Smith, Jason. 2013. Soul on Strike. In The Psychopathologies of Cognitive Capitalism: Part One, edited by Arne de Boever and Warren Neidich, 33-45. Berlin: Archive Books.

Swyngedouw, Erik. 2010. Impossible/Undesirable Sustainability and the Post-Political Condition. In Strategic Spatial Planning: Urban and Landscape Perspectives, edited by Maria Cerreta, Grazia Concilio and Valeria Monno. London: Springer.

Toscano, Alberto. 2011. Now and Never. In Communization and its Discontents, edited by Benjamin Noys, 85-104. London: Minor Compositions.

Virno, Paolo. 2004. A Grammar of the Multitude. New York: Semiotext(e).

Virno, Paolo. 2009. The Dismeausure of Art: An Interview with Paolo Virno (Interviewed by Pascal Gielen and Sonja Lavaert). In Being an Artist in Post-Fordist Times, edited by Pascal Gielen and Paul De Bruyne, 17-44. Rotterdam: NAi Publishers.

Vishmidt, Marina. 2013. "Mimesis of the Hardened and Alienated": Social Practice as a Business Model. E-flux 43. http://www.e-flux.com/journal/“mimesis-of-the-hardened-and-alienated"-socialpractice-as-business-model/.

\begin{abstract}
About the Author
Panos Kompatsiaris

Panos Kompatsiaris has received a Ph.D. in art theory from the University of Edinburgh. His thesis, Curating Resistances: Crisis and the Limits of the Political turn in Contemporary Art Biennials, explores the ways in which the current economic crisis and the rise of anti-capitalist activism affected contemporary art and its institutions. He has published articles in edited volumes and academic journals on art theory, social media, creative economies, and visual ethnography. He works as an academic consultant at the MACAT project and was recently appointed an Assistant Professor of Media and Communication at the National Research University, Higher School of Economics in Moscow.
\end{abstract}




\title{
Report on Intern Rights Advocacy in 2013-2014
}

\author{
Intern Labor Rights
}

New York City, USA, internlaborrights.com

Abstract: 2013-2014 was a milestone for intern rights, with significant accomplishments in the fight to have interns recognized as employees with rights to both pay and workplace protections. This article reviews activist efforts to bring an end to the precarious position of unpaid and underpaid interns in the United States, from the work of the advocacy group Intern Labor Rights and other organizations, to efforts on the judicial and legislative levels. We highlight the movement's accomplishments in 2013-14 and look forward to the goals it hopes to attain in the near future, all the while contextualizing this issue within the larger framework of national labour and wage movements.

Keywords: interns, internships, activism, wages, labour

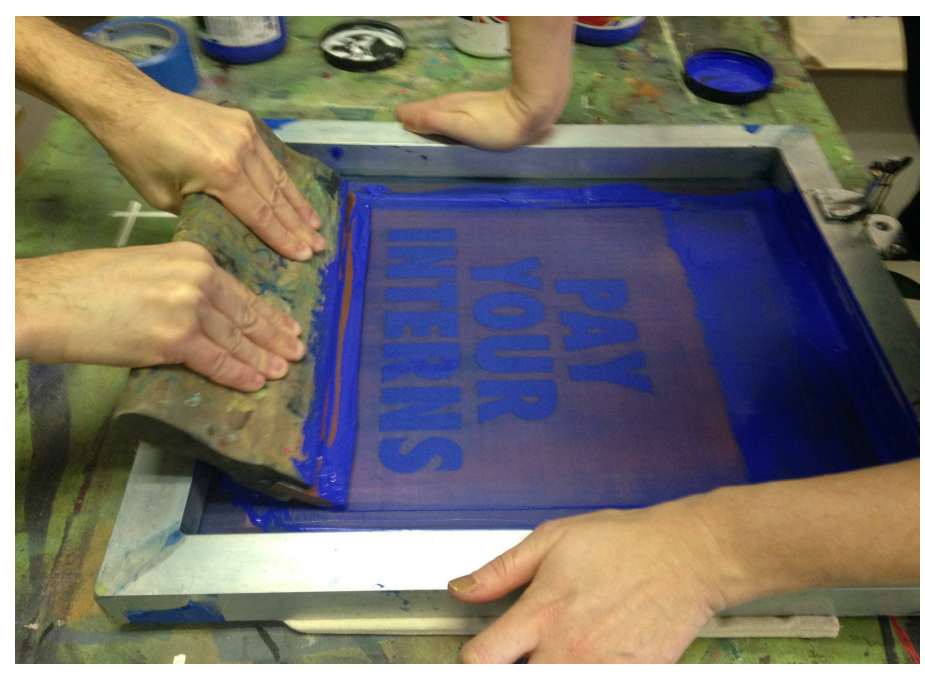

Tote bag screen-printing (Intern Labor Rights)

2013-2014 was a milestone for intern rights, with significant accomplishments in the fight to have interns recognized as employees owed wages and granted rights to new workplace protections. Substantial court decisions, local governments, and corporations in the United States have brought unfair internships to the fore, prompting many employers to change their practices for the better. Several media conglomerates have changed their hiring policies, from terminating their exploitative internship programs to paying their interns. Significant information was released that began to fill in the data gap on unpaid work across the nation. Unpaid and underpaid interns are filing lawsuits against their employees for wage theft. Students are taking matters into their own hands, from demanding that their universities stop posting illegal internships on their job boards to writing theses on the detrimental effect of unpaid internships and free labour. Local governments are beginning to institute policy changes, such as extending sexual harassment and discrimination protections to unpaid interns.

Intern Labor Rights has compiled this report to serve as a resource guide. The report includes a summary of important developments at the legislative and institutional levels; actions and corresponding public responses; links to pivotal articles, panel discussions, and

\footnotetext{
${ }^{1}$ This text is a revised and updated version of an earlier year-end report published on Intern Labor Rights' website.
} 
interviews; an overview of the related struggles in the U.S.; and our most recent activities in 2014.

We welcome feedback and hope to generate further discussion to broaden our point of view. If you are in New York City, Intern Labor Rights meets weekly. For meeting locations and schedules, visit internlaborrights.com, join us on Facebook (facebook.com/internlaborrights), or follow us @InternLabor.

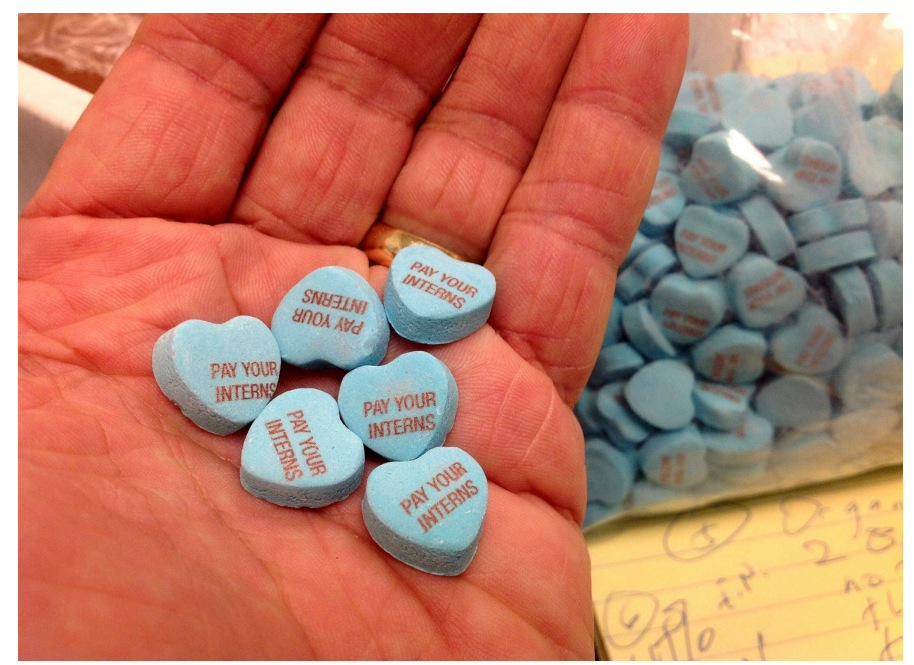

Photo: Intern Labor Rights

\section{History of Intern Labor Rights}

Intern Labor Rights (ILR) has been active since 2012. On February 6, 2012, the Arts \& Labor (2012) working group of Occupy Wall Street published an open letter, "Arts \& Labor \#OWS Call to NYFA: Stop Publishing Classifieds for Unpaid Internships," calling on the New York Foundation of the Arts to "cease posting classified listings for unpaid interns at for-profit institutions on the NYFA website." The letter caught the attention of other activists in New York City dedicated to eliminating the harmful effects of unpaid internships, and dialogue was initiated both in person and online. On March 7, 2012, the first meeting of ILR was held in Brooklyn, New York, when the dedicated group began formulating the long-term, evolving strategy that animates it to this day. Weekly meetings open to anyone interested in contributing to the movement have become one of the signature features of ILR. Since early 2012, ILR continues to grow, attracting participants with varied backgrounds and experiences in the intern economy.

\section{Significant Strides for Interns}

In a landmark judgment in the summer of 2013, a federal court in New York ruled in the case of Glatt v. Fox Searchlight Pictures, Inc. that the plaintiffs' internships did not meet the legal tests under both federal and state law for interns to be considered "trainees" (Greenhouse 2013a). The "interns" were found to be "employees" and therefore owed back pay. The verdict is currently under appeal, but the ruling by Judge William H. Pauley III was explicit, and rejected the suggestion that internships for college credit might somehow be exempt from labour law (United States District Court n.d.). In 2013, we also saw the passage of a crucial bill signed into law by Oregon Governor John Kitzhaber, which extended workplace protections to unpaid interns (Rubin and Stait 2013). Interns are now afforded legal protections from sexual harassment, discrimination, unlawful termination, and other abuses covered under employment law. Similar bills have been passed in New York City and New York State, Washington, D.C., California, and Illinois. Such legislation, however, has stopped shy of the federal court ruling by not actually classifying interns as employees, avoiding the question of 
payment altogether (Hickman and Thompson 2013). Generally, the legislation is limited to banning discrimination and harassment of unpaid interns under the jurisdictions' respective human rights and civil rights laws.

In the context of these legal initiatives, some well-known companies have begun to change their internship policies. In the broadcasting industry, Viacom, the media conglomerate that owns properties including Paramount Pictures, BET, MTV Networks, and Comedy Central, started paying interns in 2013, as did NBC Universal. An AOL article (Gordon 2013) appears to be the sole coverage of many of the changes at major broadcasters, which remain largely under the radar-quite likely because such employers do not wish to draw attention to their prior practices. The AOL article cites an Arizona State University study that claims the Phoenix area saw a 14 percent increase in paid internships in broadcasting and a 20 percent increase in paid publication internships over a one-year period, which represent significant increases.

In August 2013, COO of Facebook and author of the popular book Lean In, Sheryl Sandberg, was scrutinized after an executive of her Lean In Foundation-which encourages women to ask for fair compensation-posted an advertisement for an unpaid editorial internship in New York (Edwards and Smith 2013). Given that unpaid internships are disproportionately held by women (Schwartz 2013), the posting elicited widespread criticism, with Sandberg's foundation ultimately agreeing to offer a formal paid internship program (Kleinman 2013).

The journalism and print media fields saw significant changes. VICE magazine published an article examining the exploited labour of left-leaning media outlets (Davis 2013). Personal narratives and critical analyses of underpaid and unpaid interns exposed unfair labour practices in various liberal news sources, such as Mother Jones, Democracy Now!, and The New Republic. On the day the VICE piece was published, Mother Jones, which had been offering $\$ 1,000$ a month to its interns (approximately $\$ 6$ per hour, or $\$ 4$ below its California home state's minimum wage), announced it would increase its budget for interns and fellows so to pay them $\$ 1,500$ per month. This is slightly above the minimum wage in California. It is worth noting that Mother Jones and other publications may refer to these low-paid, short-term employees as "fellows" rather than "interns," a trend we observe with concern. The Mother Jones fellowships replaced their internship program in 2012, attracting qualified and experienced writers for low pay. VICE itself made use of unpaid interns as late as July 2013, but in the process of preparing its story, brought that practice to an end (Who Pays Interns? n.d. a).

Elsewhere in the media, the political magazine Dissent announced in the Fall of 2013 that its internships would begin paying a $\$ 2,000$ per semester stipend. Gawker Media now runs a minimum wage Editorial Fellowship program (Who Pays Interns? n.d. b). Last summer, Gawker was sued for wage theft by three former unpaid interns (Anonymous 2013). And the online magazine Slate announced a new round of paid internships at the end of 2013, including some positions that had previously been unpaid (Who Pays Interns? n.d. c).

Widely discussed was the decision of Conde Nast-the media company that owns The New Yorker, Vogue, Vanity Fair, Glamour, and other popular magazines (Condé Nast is owned by one of the country's largest privately held companies, Advance Publications) - to suspend its internship program amidst a lawsuit claiming it paid interns less than minimum wage (Maza 2013). Some commentators saw the ending of a prestigious internship program as a loss, but others saw the cessation of an already elitist and exploitative practice as a sign of the beginning of the end for unpaid and underpaid internships (McMorris-Santoro 2013). Others still have speculated that the decision was a cynical and calculated move meant to engender a backlash against interns who step forward to assert their rights-thus "ruining the party" for everyone else-while also minimizing the company's legal exposure. Given the prominent role interns play in the publishing giant's day-to-day operations, however, there's hope that it will lead to a flurry of hiring for paid entry-level positions. When Condé Nast settled the lawsuit in early 2014, it suggested it would now be free to "devote [its] time and resources towards developing meaningful, new opportunities to support up-and-coming talent" (Kelly 2014). Presumably its new program will be paid, both to avoid further lawsuits and to 
remain competitive in the search for talent as other journalism outlets shift to paid internship programs (NYU Journalism, Career Services n.d.).

In a particularly inspiring case, interns at The Nation, the long-running liberal and progressive magazine, successfully fought in 2013 to raise compensation in their internship program, which was increased to match the minimum wage, up from a previous weekly stipend of $\$ 150$ (\$3.75 per hour for a full work week) (Hickman 2013). In their statement, the interns requested a living wage from a magazine that itself plays host to arguments that the current minimum wage for American workers is not high enough (Cockburn 2012). We view this campaign as a step in the right direction, which could potentially inspire more workplace organizing amongst interns around the country. ${ }^{2}$

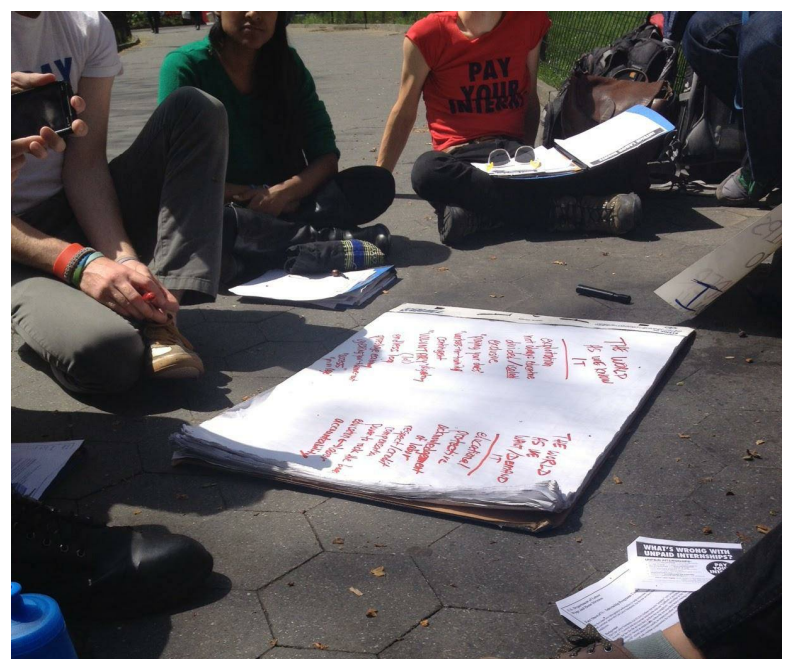

Intern Labor Rights leads the workshop, What Does a Just Internship Look Like? New York, May 2014 (Intern Labor Rights)

\section{Recent Major Advocacy Initiatives}

\subsection{Intern Labor Rights}

ILR members have expanded outreach efforts locally and internationally in the past two years. We were instrumental in the formation of the International Coalition for Fair Internships, a global alliance that came to fruition through a series of virtual global summits beginning in January 2013 (Intern Labor Rights 2014a). We also extended our awareness campaign to various sectors affected by unpaid internships, from fashion to politics. In collaboration with the Student Union of the University of Arts London and Intern Aware, we targeted the Spring 2013 season of Fashion Week in London and New York City, handing out promotional Pay Your Interns "swag bags" to hundreds of Fashion Week attendees (Page 2013; Odell 2013). In summer 2013, we stood in solidarity with unpaid interns at the United Nations, leafleting at the UN's landmark General Assembly and Secretariat building (see unpaidisunfair.org). We also hosted a series of "happy hours" to generate one-on-one conversations that connected activists and organizers with future and past interns in New York City.

In response to the federal court ruling that recognized unpaid interns as employees, we organized a panel discussion in New York in late 2013 that examined the future of internships now that employers will be forced to find new footing on uncertain legal ground. At the panel, Intern Nation author Ross Perlin presented a historical perspective on the formation of the internship and its detrimental effect on our economy; Irma Rodriguez from the Queens

\footnotetext{
2 View the former interns' press release at unpaidlabor.tumblr.com/post/57161802625/press-release-internaction-at-the-nation-leads-to, and our letter of support addressed to the editors of The Nation at internlaborrights.s3.amazonaws.com/wp-content/uploads/2014/02/2013-08-10-Letter-to-The-Nation.pdf.
} 
Community House shared her concerns regarding the widespread phenomenon of unpaid work in activism and its conflict with social and racial justice aims; partner Rachel Bien from Outten \& Golden LLP detailed the legal aspects of intern, volunteer, and worker struggles and rights; and ILR member Dedunu Suraweera addressed the importance of speaking out and organizing. ${ }^{3}$

In Spring 2014, we turned our focus to legislation efforts in New York City and New York State. After 12 years under the contested oversight of Mayor Michael Bloomberg, New York City is moving in a different direction under the progressive-backed leadership of Mayor and former Public Advocate, Bill de Blasio. During the mayoral run, ILR members called for an end to de Blasio's role in proliferating unpaid internships (Schonfeld 2013)-participating in his Reddit AMA (de Blasio 2013), sending letters to his unpaid Organizing Fellowship staff, and speaking with de Blasio during an impromptu campaign meet-and-greet in Greenwich Village. In March, we were invited to make a public statement at the City Council's Civil Rights committee hearing regarding a policy amendment that extends harassment and antidiscrimination protections to unpaid interns (CBS New York 2014). We found the changes to be insufficient, as the manner in which the amendment is phrased excludes many interns from these protections. We reiterated our opinion at the bill-signing ceremony in April (Intern Labor Rights 2014b, 2014c). Also in April, we initiated a campaign calling on Mayor de Blasio to lead by example by instructing New York City's offices and agencies, the companies it contracts, and the organizations engaging city and city-financed resources to cease hiring unpaid interns and begin paying at least minimum wage (Intern Labor Rights 2014d).

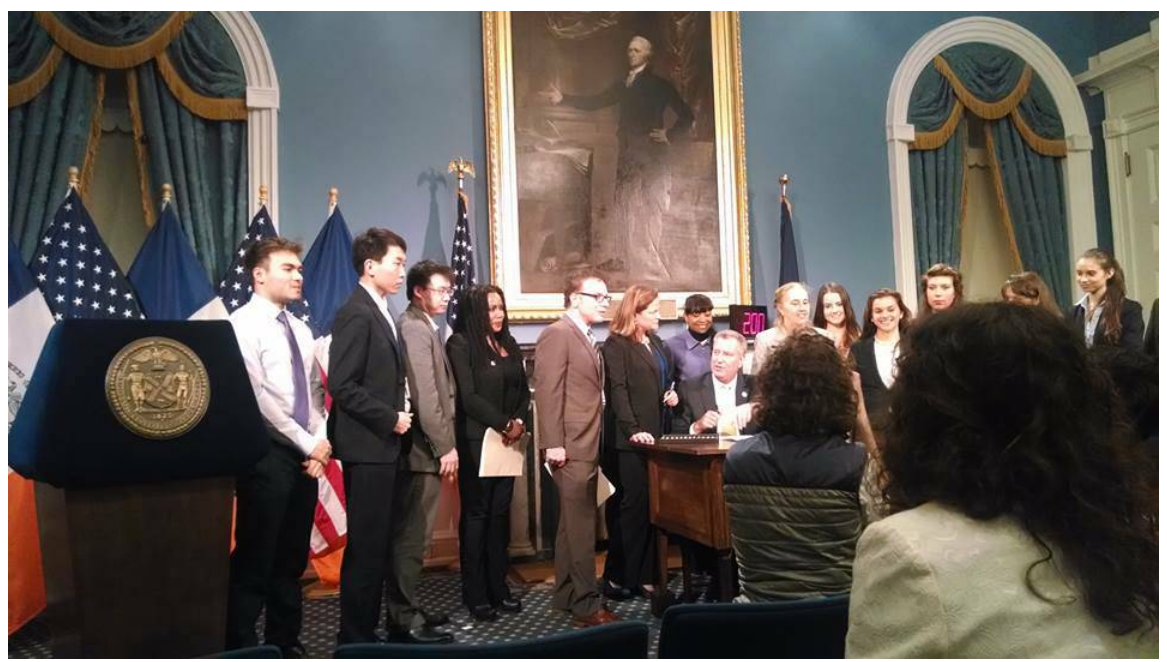

NYC mayor Bill de Blasio signing bill Intro 173-A into law, April 2014 (Intern Labor Rights)

Currently, unpaid interns in the private sector are afforded some avenues to claim back pay (United States Department of Labor 2010). Similar protections for interns in the nonprofit and public sector are, however, less than clear. By advocating for interns to be recognized as employees, ILR hopes the national stage will be set not only for adequate workplace protections, but also for fair wages, greater compliance by employers, and better oversight from educational institutions.

Attendance in our weekly meetings has increased significantly, frequented by not only interns and organizers, but also intern supervisors from publishing, visual art, music, design, and fashion industries. Graduate and undergraduate students have joined us as well to develop their research on unpaid internships, student debt, minimum wage, and workers' rights. Litigators, journalists, and organizers have often served as advisors in these meetings. We continue to hold public workshops and private discussions with individuals wishing to make a

\footnotetext{
${ }^{3}$ Visit internlaborrights.com to watch videos of these presentations.
} 
change in the internship program at their workplace.

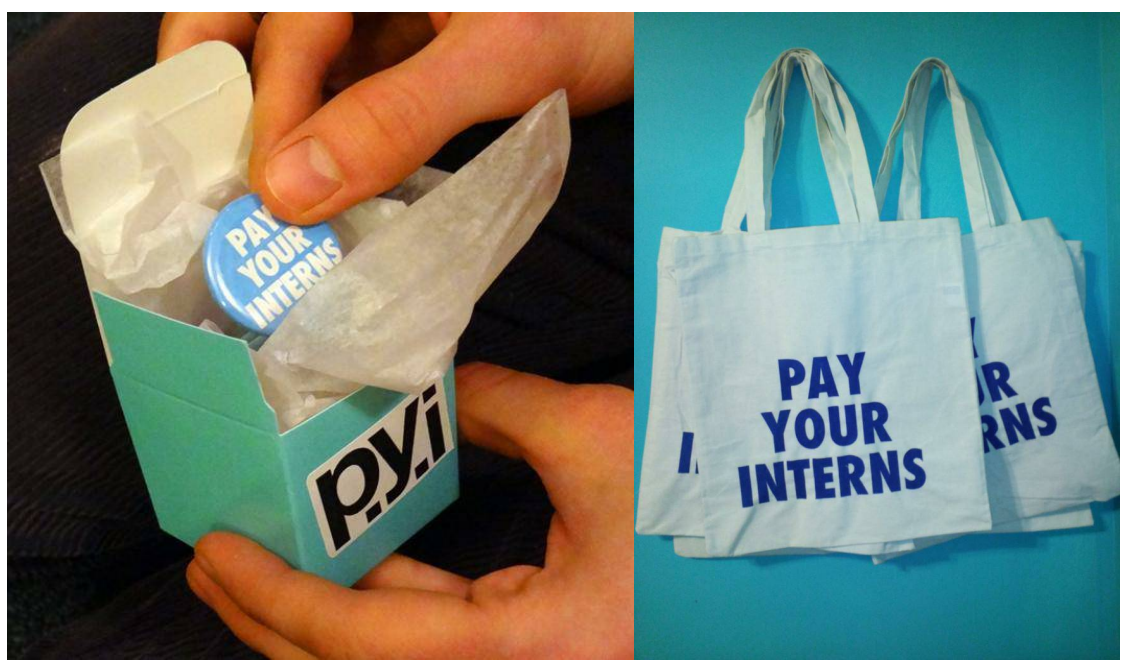

Gift boxes made for Fashion Week 2013 action (L). "Pay Your Interns" Tote Bags (R) (Intern Labor Rights).

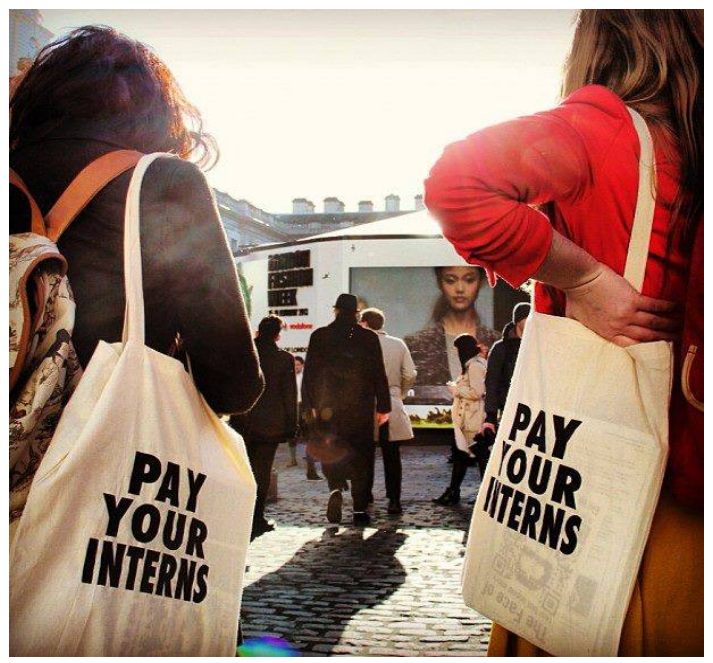

London Fashion Week 2013 (Fairooz Aniqa and Student Union of the University of Arts London)

\subsection{Students Organizing}

In another advocacy development, New York University (NYU) undergraduate Christina Isnardi and several co-organizers ran a petition campaign calling on the school's Career Development office to cease promoting illegal unpaid internships to NYU students. Their effort confronted the paradox that university career offices often overlook labour law violations. This absence of oversight- - defended by university administrations under the claim of satisfying student demand for experiential learning opportunities (Aoun et al. 2010)-harms students' prospects in the long run. The campaign collected over 1,000 signatures and instigated a series of meetings with the petition organizers, the leadership of NYU's career management center, and its general council.

In response, NYU inaugurated several changes:

- An improved screening process has been implemented. All employers must agree that their internship position abides by the Department of Labor guidelines. 
- Although the number of unpaid internships posted on the website have remained steady, there is a stronger emphasis on paid internships and jobs. Samples taken before and after the campaign show that the number of paid internships posted by NYU's career center increased by over 800 percent (from under 500 to over 4,000).

- An internship directory, which lists the Internship Coordinators and Employment Directors at each NYU school, was created to facilitate better oversight of student internships.

- More specific language is being used on the career center website to reduce ambiguous compensation arrangements; instead of only listing whether internships are "Paid" or "Unpaid," now the options listed are "Paid," "Unpaid in compliance with NYU and DOL guidelines," "Both Paid \& Academic Credit," "Academic Credit," and "Stipend."

- To promote greater awareness, NYU has added links providing more detailed information about related labour laws and illegitimate job postings to the career management site.

Despite the above-mentioned plans for reform, NYU continues to post unpaid internships at for-profit companies on its job board.

In early 2014, Columbia University's Dean of Academic Affairs announced that undergraduate colleges have ceased to provide credit for internships. This is a major step forward: the University is no longer encouraging and legitimizing a practice that excludes those who cannot afford to work for free from essential experience in their field (Zhang 2014). This decision followed a series of panels hosted by students on campus, where they raised their issues regarding the University's practice of requiring internships without providing sufficient oversight (Hendrickson 2012).

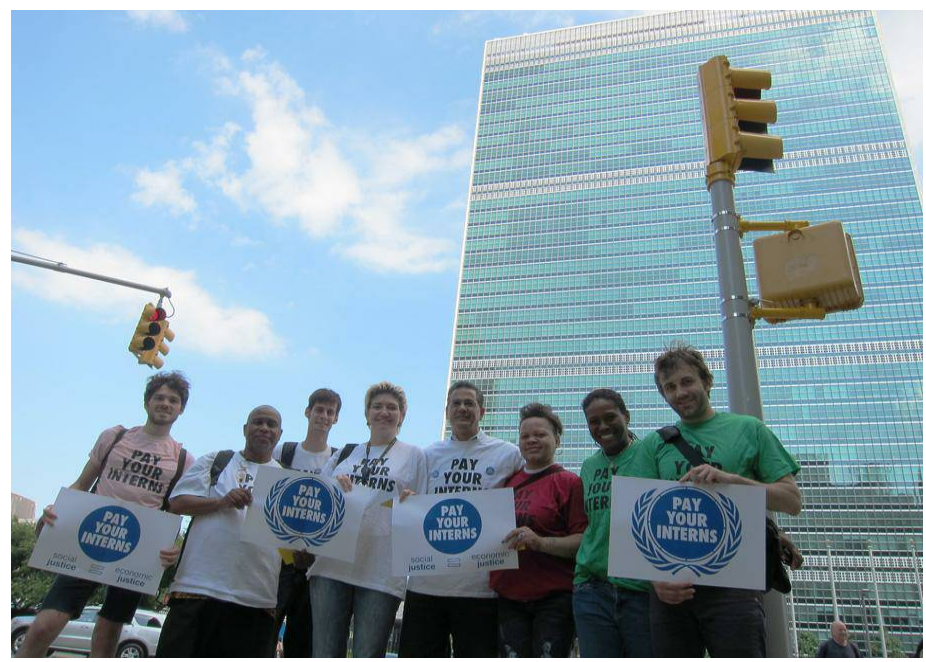

Solidarity protest with United Nations' interns, June 2013 (Intern Labor Rights)

\subsection{ProPublica Series}

To begin filling the data-gap that is endemic to the issue of unpaid internships, in 2013, independent journalism organization ProPublica launched an investigative series on internship programs, which are often conducted without documentation: no personnel records are created or maintained and no income tax withholdings or payroll deductions are made (ProPublica n.d.).

To date, ProPublica has tracked 35 lawsuits that have been filed in the United States 
(Suen and Brandeisky 2014). Some of these lawsuits have been filed in federal court, many on behalf of hundreds, if not thousands, of unpaid interns alleging wage theft.

Before launching its series, ProPublica began a crowdsourcing campaign to fund the research of a paid intern-journalist, Casey McDermott, as she travelled across U.S. campuses collecting stories from interns. The project includes an explanation of applicable laws; appeals for stories from employers and career counselors; a platform for interns-and for those who had to turn down unpaid internships for financial reasons-to share much needed data; an online tool to help calculate the true price of academic internships; a Tumblr page; hashtags to follow the series on Twitter (\#ProjectIntern, \#MyInternStory); and more.

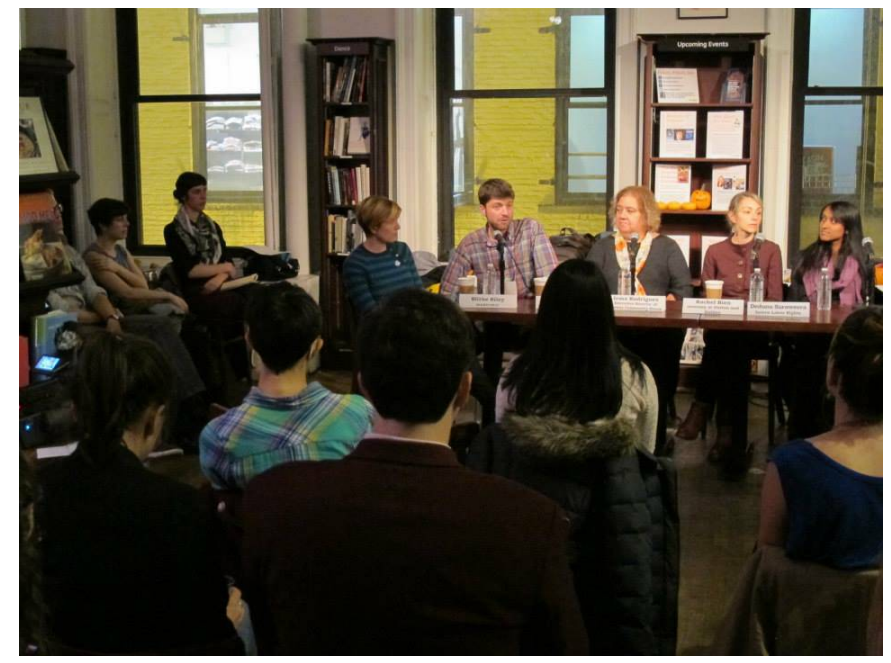

Panel discussion, "Will Work For Free: Breaking Down the Intern Economy," New York, October 2013 (Intern Labor Rights)

\subsection{National Movement}

In 2013-14, issues of income disparity, lack of workplace protections, and the ambiguous value of student labour found overdue attention from the national media. The voices of exploited interns echoed a growing sentiment among unpaid and underpaid workers across academia and the service sector that the current situation is neither just nor sustainable, and that something must be done to turn the tide.

Graduate assistants at New York University voted "overwhelmingly to unionize," making them the only graduate student union currently recognized by a private university in the United States (Greenhouse 2013b). Their affiliation with the United Automobile Workers puts them in a stronger position to negotiate for health benefits and increased stipends in return for the valuable role they play in keeping the University's distinguished academic programs credible and competitive.

Meanwhile, some of the largest revenue generators for universities-student athletesliterally took their message to the field in one of the most high-profile displays of discontent in collegiate sports history. Several college football players marked their armbands with the letters "A.P.U." (All Players United) to call attention to the goals of the National College Players Association (Uthman 2013). Their demands included greater attention to the risks of brain trauma, protecting financial aid for players who have suffered debilitating injuries, and allowing players greater control over how their likeness is used for commercial purposes.

Some of the most important actions in 2013-14 against insufficient wages and precarious working conditions came from workers in the retail and foodservice sectors. Workers from both sectors came out in historic displays of solidarity. On Black Friday in 2013 and 2014, protests erupted in cities across the nation to target Walmart, the flagship among big-box retailers who have capitalized on the fears of both employees and customers, still reeling from the 2008 recession, by keeping wages low (Pilkington 2013). After being given disturb- 
ing financial advice by their employers that encouraged them to sign up for government benefits, fast food workers came out in droves to say, "Can't Survive on \$7.25!" (Picche 2013; Pierson 2013). In September 2014, fast food workers across the U.S. went on their biggest strike yet to demand a raise to $\$ 15$ per hour (Napach 2014). Popular demands for an increase in the minimum wage have been amplified by these low-waged workers, who are organizing to change the system of impoverishment by advocating for fair pay.

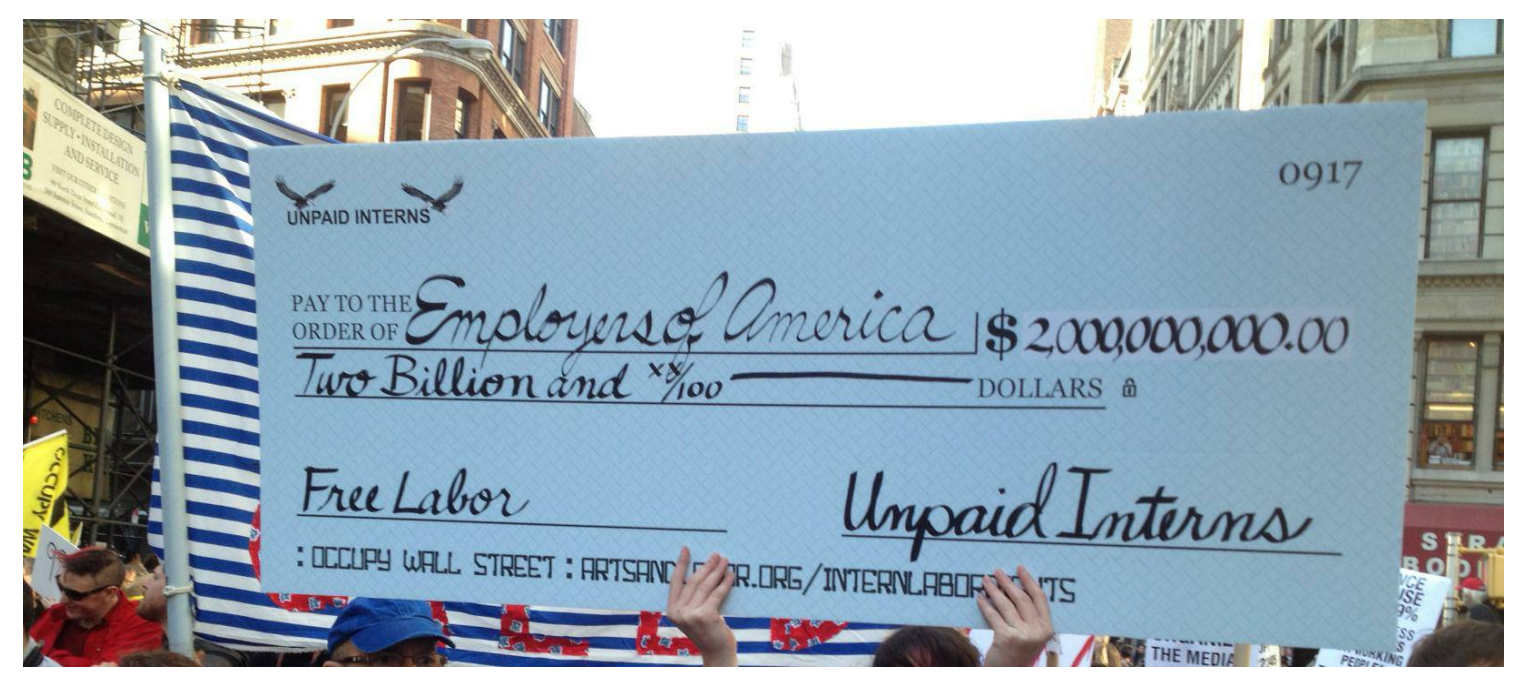

May Day protest, 2012 (Intern Labor Rights)

In September 2014, ILR joined a coalition of labour organizations, led by National Mobilization Against Sweatshops, calling for the New York State Department of Labor and New York Governor Cuomo to enforce existing guidelines to protect workers from wage theft (Intern Labor Rights 2014e).

As all of these campaigns have gained wider recognition and tangible victories in the past year, the intern rights movement sees itself as part of a broader movement to fairly compensate workers who have seen wages and benefits decline steadily in recent decades. We stand in solidarity with these movements as we work together towards a more just and sustainable economic future.

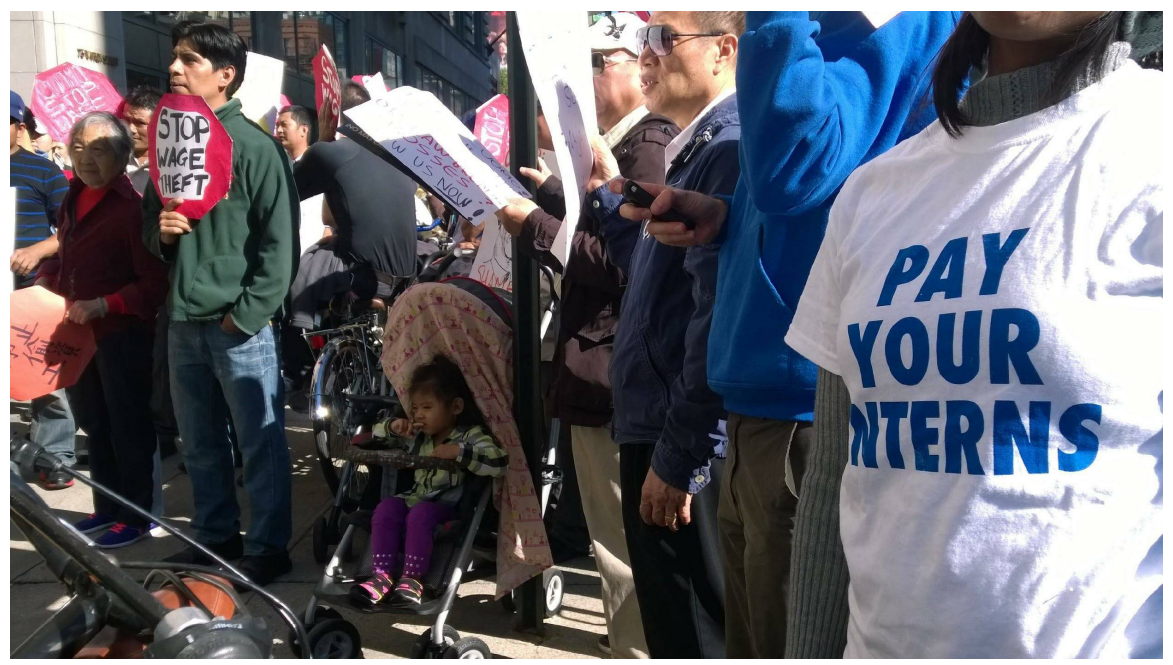

Wage theft rally, New York, September 2014 (Intern Labor Rights) 


\section{Moving Forward}

Despite tremendous victories in and out of the courtrooms, mounting media scrutiny, and an increasingly visible movement against wage theft, the challenges to organizing around internships remain vast. A quick search on almost any online job board will reveal the extent to which employers continue to expect applicants to be willing to offer unpaid labour in exchange for "life experience," "connections," or "professional references." Occasionally these employers even have the audacity to require these uncompensated recruits to have previous experience. This is not surprising, given that high schools are increasingly encouraging their students to take on internships in order to stand out on college applications. This trend prematurely exacerbates the opportunity gap between high- and low-income students, especially for the many students whose families rely on earnings from their part-time employment.

On the legal front, much hinges on the fallout of the July 2015 decision by the U.S. Court of Appeals for the Second Circuit in the Wang v. The Hearst Corporation and Glatt v. Fox Searchlight Pictures cases. The appeals court vacated a lower court's decision that the Fox Searchlight interns were employees owed wages and it articulated new, more employerfriendly standards to evaluate the legal permissibility of unpaid internships under U.S. labor law. At the time of publication, the interns' legal representatives are planning to petition the appeals court for a rehearing. In short, the legal ambiguities surrounding this practice will likely persist for quite some time.

No matter the decision, the need for continued attention to this issue and ongoing advocacy efforts have never been more urgent. Statistics point to record increases in economic inequality and decreases in social mobility. We strongly believe that radical changes to the ethically flawed internship economy can play a significant part in reversing these currents.

\section{References}

Anonymous. 2013. Former Interns Sue Gawker Over No Pay, Allege Media Company Violated Federal Law. Huffington Post. June 22. Accessed March 28, 2015. http://www.huffingtonpost.com/2013/06/22/interns-sue-gawker-unpaid-no-pay_n_3483706.html.

Aoun, Joseph E. et al. 2010. Letter to The Hon. Hilda Hilda L. Solis. Accessed March 28, 2015. http://www.chronicle.com/items/biz/pdf/FINAL US Department of Labor letter.pdf.

Arts \& Labor. 2012. Arts \& Labor \#OWS Call to NYFA: Stop Publishing Classifieds for Unpaid Internships. February 6. Accessed March 28, 2015. http://artsandlabor.org/arts-labor-ows-call-to-nyfastop-publishing-classifieds-for-unpaid-internships/.

CBS New York. 2014. City Council Proposal Would Give Unpaid Interns Right To Sue For Sexual Harassment, Discrimination. CBS New York. March 17. Accessed March 28, 2015. http://www.newyork.cbslocal.com/2014/03/17/city-council-proposal-would-give-unpaid-interns-rightto-sue-for-sexual-harassment-discrimination/.

Cockburn, Alexander. 2012. Why We Must Raise the Minimum Wage. The Nation. April 3. Accessed March 28, 2015. http://www.thenation.com/article/167183/why-we-must-raise-minimum-wage.

Davis, Charles. 2013. The Exploited Laborers of the Liberal Media. VICE. December 2. Accessed March 28, 2015. http://www.vice.com/read/the-exploited-laborers-of-the-liberal-media.

de Blasio, Bill. 2013. I am Bill de Blasio, Democratic Candidate for Mayor of New York City, AMA. Reddit. October 8. http://www.reddit.com.

Edwards, Jim and Kevin Smith. 2013. Sheryl Sandberg's Lean In Foundation is Damaging Her Reputation by Refusing to Pay its Interns. Business Insider. August 15. Accessed March 28, 2015. http://www.businessinsider.com/sheryl-sandbergs-lean-in-foundation-is-damaging-her-reputationby-refusing-to-pay-its-interns-2013-8.

Gordon, Claire. 2013. Media Giants Buckle and Start Paying their Interns. AOL Jobs. June 20. Accessed March 28, 2015. http://www.jobs.aol.com/articles/2013/06/20/media-internships-unpaidlawsuit/.

Greenhouse, Steven. 2013a. Judge Rules that Movie Studio Should Have Been Paying Interns. The New York Times. June 11. Accessed March 28, 2015. http://www.nytimes.com/2013/06/12/business/judge-rules-for-interns-who-sued-foxsearchlight.html? $r=0$.

Greenhouse, Steven. 2013b. N.Y.U. Graduate Assistants to Join Auto Workers' Union. The New York Times. December 12. March 28, 2015. http://www.nytimes.com/2013/12/13/nyregion/nyu-graduateassistants-to-join-auto-workers-union.html? $\quad \mathrm{r}=0$. 
Hendrickson, Zachary. 2012. LectureHop: Internships, Labor Rights, and the Columbia Community. BWOG. November 21. Accessed March 28, 2015. http://www.bwog.com/2012/11/21/lecturehopinternships-labor-rights-and-the-columbia-community/.

Hickman, Blair. 2013. Nation Institute to Pay Interns Minimum Wage. ProPublica. August 2. Accessed March 28, 2015. http://www.propublica.org/article/nation-institute-to-pay-interns-minimum-wage.

Hickman, Blair and Christie Thompson. 2013. How Unpaid Interns Aren't Protected Against Sexual Harassment. ProPublica. August 9. Accessed March 28, 2015. http://www.propublica.org/article/how-unpaid-interns-arent-protected-against-sexual-harassment.

Intern Labor Rights. 2014a. Announcing the Formation of the International Coalition for Fair Internships. January 30. Accessed March 28, 2015. http://www.internlaborrights.com/2014/01/30/announcing-the-formation-of-the-internationalcoalition-for-fair-internships/.

Intern Labor Rights. 2014b. Intern Labor Rights Response to NY City Council Amendment to Protect Interns from Sexual Harrassment. March 27. Accessed March 28, 2015. http://www.internlaborrights.com/2014/03/27/intern-labor-rights-response-to-ny-city-councilamendment-to-protect-interns-from-sexual-harrassment/.

Intern Labor Rights. 2014c. NYC Mayor Bill de Blasio Signs Intern Anti-Discrimination Bill into Law. Intern Labor Rights. April 18. Accessed March 28, 2015. http://www.internlaborrights.com/2014/04/18/nyc-mayor-bill-de-blasio-signs-intern-antidiscrimination-bill-into-law/.

Intern Labor Rights. 2014d. Intern Labor Rights Letter to Mayor de Blasio Regarding Internships in New York City. April 3. Accessed March 28, 2015.

http://www.internlaborrights.com/2014/04/03/intern-labor-rights-letter-to-mayor-de-blasio-regardinginternships-in-new-york-city/.

Intern Labor Rights. 2014e. Governor Cuomo Enforce the Labor Law. September 18. Accessed March 28, 2015. http://www.internlaborrights.com/2014/09/18/governor-cuomo-enforce-the-labor-law/

Kelly, Keith J. 2014. Condé Nast Settles Intern Suit, Hints at New Program. New York Post. April 8. Accessed March 28, 2015. http://www.nypost.com/2014/04/08/conde-nast-settles-intern-suit-hintsat-new-program/.

Kleinman, Alexis. 2013. Sheryl Sandberg's Nonprofit to Start Paid Internship Program After Controversy. Huffington Post. August 16. Accessed March 28, 2015. http://www.huffingtonpost.com/2013/08/16/sheryl-sandberg-interns_n_3767359.html.

Maza, Erik. 2013. Condé Nast Discontinuing Internship Program. Women's Wear Daily. October 23. Accessed May 6, 2015. http://www.wwd.com/media-news/fashion-memopad/internships-ending7242603.

McMorris-Santoro, Evan. 2013. Advocates for Paid Internships Say Condé Nast Just Proved Their Point. BuzzFeed News. October 23. Accessed March 28, 2015.

http://www.buzzfeed.com/evanmcsan/advocates-for-paid-internships-say-conde-nast-just-provedth.

Napach, Bernice. 2014. Fast Food Workers Strike for Higher Pay, Dozens Arrested: "Whatever it Takes." Yahoo! Finance. September 4. Accessed March 28, 2015. http://www.finance.yahoo.com/news/fast-food-workers-stage-their-seventh-one-day-strike--thistime-many-risk-arrest-152933957.html.

NYU Journalism, Career Services. n.d. Fellowship and Paid Internship Programs. Accessed March 28, 2015. http://www.journalism.nyu.edu/career-services/fellowship-and-paid-internship-programs/.

Odell, Amy. 2013. Occupy Movement to Protest Unpaid Internships at Fashion Week. BuzzFeed. Accessed March 28, 2015. http://www.buzzfeed.com/amyodell/protesst-against-unpaid-internships-todescend-on.

Page, Libby. 2013. Push for Paid: A Student Guide to Internships. The Guardian. October 15. Accessed March 28, 2015. http://www.theguardian.com/education/2013/oct/15/student-guide-tointernships.

Picche, Aimee. 2013. McDonald's Blunders with Holiday Tip Advice for Workers. CBS News, Money Watch. December 6. Accessed March 28, 2015. http://www.cbsnews.com/news/mcdonaldsblunders-with-holiday-tip-advice-for-workers/.

Pierson, David. 2013. McDonald's McResources Line Urges Worker to Seek Federal Assistance. LA Times. October 23. Accessed March 28, 2015. http://www.latimes.com/business/money/la-fi-momcdonalds-worker-20131023,0,4084029.story - axzz2if3oFsOr.

Pilkington, Ed. 2013. Black Friday Protests Demand Improved Conditions from Walmart. The Guardian. November 29. Accessed March 28, 2015. http://www.theguardian.com/world/2013/nov/29/black-friday-walmart-protests-wages-jobs. 
ProPublica. n.d. Internships. Accessed March 28, 2015. http://www.propublica.org/series/internships Rubin, Howard and Don Stait. 2013. Oregon Passes Workplace Protection Law for Unpaid Interns. Littler. June 21. Accessed March 28, 2015. http://www.littler.com/publicationpress/publication/oregon-passes-workplace-protection-law-unpaid-interns.

Schonfeld, Zach. 2013. Bill de Blasio Won't Be Paying his Graphic Design Interns. The Wire. September 19. Accessed March 28, 2015. http://www.thewire.com/politics/2013/09/bill-de-blasio-wontbe-paying-his-interns-fall/69636/.

Schwartz, Madeleine. 2013. Opportunity Costs: The True Price of Internships. Dissent. Winter. Accessed March 28, 2015. http://www.dissentmagazine.org/article/opportunity-costs-the-true-price-ofinternships.

Suen, Stephen and Kara Brandeisky. 2014. Tracking Intern Lawsuits. ProPublica. April 14. Accessed March 28, 2015. http://www.projects.propublica.org/graphics/intern-suits.

United States Department of Labor, Wage and Hour Division. 2010. Fact Sheet \#71: Internship Programs Under the Fair Labor Standards Act. April. Accessed March 28, 2015. http://www.dol.gov/whd/regs/compliance/whdfs71.htm.

United States District Court, Southern District New York. n.d. Eric Glatt, et al., against Fox Searchlight Pictures Inc.. Accessed March 28, 2015.

http://www.hollywoodreporter.com/sites/default/files/custom/Documents/fox interns.pdf.

Uthman, Daniel. 2013. College Teams Wear "APU" in Organized Protest of NCAA. USA Today. September 21. Accessed March 28, 2015.

http://www.usatoday.com/story/sports/ncaaf/2013/09/21/college-football-apu-all-players-unitedncpa-ramogi-huma/2847203/.

Who Pays Interns? n.d. a. VICE. Accessed March 28, 2015. http://www.whopaysinterns.tumblr.com/post/68785789118/vice-yes.

Who Pays Interns? n.d. b. Gawker. Accessed March 28, 2015. http://www.whopaysinterns.tumblr.com/post/58807053493/gawker-yes.

Who Pays Interns? n.d. c. Slate. Accessed March 28, 2015. http://www.whopaysinterns.tumblr.com/post/69077040097/slate-yes-finally.

Zhang, Christina. 2014. CSA Announces Changes to Course Withdrawal, Internship Policies. Columbia Spectator. February 21. Accessed March 28, 2015.

http://www.columbiaspectator.com/2014/02/21/csa-announces-changes-course-withdrawalinternship-policies.

\section{About the Author}

Intern Labor Rights

Intern Labor Rights (ILR) is an advocacy group that has been active in the U.S. since early 2012. It grew out of a letter published by Arts \& Labor (originally a working group of Occupy Wall Street) in February 2012 calling on the New York Foundation of the Arts to cease posting classifieds for unpaid interns at for-profit institutions on their online job board. On March 7, 2012, the first ILR meeting was held in Brooklyn, New York, where the dedicated group began formulating the long-term, still-evolving strategy that animates it to this day. ILR continues to grow, attracting to its meetings and actions participants with varied backgrounds and experiences in the intern economy. More information is available at internlaborrights.com. 


\title{
Ontario Interns Fight Back: Modes of Resistance Against Unpaid Internships
}

\author{
William Webb \\ Wilfrid Laurier University, Waterloo, Canada, webb7140@mylaurier.ca
}

\begin{abstract}
In this article I report on three ways that interns and those sympathetic to their plight are opposing unpaid internships, focusing on the Canadian province of Ontario as a case. First, I analyze the ways that interns engage in social activism to raise awareness about problems with unpaid internships. Second, I examine several lawsuits that interns have waged against companies in an attempt to secure back pay. Third, I analyze the Ontario Ministry of Labour's response to the growing concerns surrounding unpaid internships, and recent proposals that aim to strengthen governmental regulations. Arguing that possibilities for change have arisen largely due to the efforts of interns themselves, I conclude each section by noting some of the strengths and limitations afforded by each type of resistance.
\end{abstract}

Keywords: unpaid Internships, internships, Ontario, Labour, Canada, social activism, lawsuits, litigation, policy, Ontario Ministry of Labour

Acknowledgement: I would like to thank Greig de Peuter, Enda Brophy, and Nicole Cohen for their helpful comments on this article

\section{Introduction}

Unpaid internships have recently been subject to a host of social and ethical criticisms. Scholars and activists have argued that unpaid internships are often unfair, illegal, exploitative of vulnerable demographics, and negatively impact social mobility (de Peuter et al. 2012; Oakley 2013; Perlin 2011; Siebert and Wilson 2013). In light of these problems, many are challenging the status of unpaid internships. In this article I report on three ways that interns and those sympathetic to their plight are opposing unpaid internships in Ontario. First, I explore the ways that intern organizations in Ontario are raising awareness about problems with unpaid internships. Next, I examine several lawsuits that interns have waged against companies in an attempt to secure back pay, namely, Girex Bancorp v Hsieh, Sandhu v Brar, and Patel $v$ Bell Mobility Inc. Finally, I explore the Ontario Ministry of Labour's response to the growing concerns surrounding unpaid internships and proposals that aim to strengthen governmental regulations. Arguing that possibilities for change have arisen largely due to the efforts of interns themselves, I conclude each section by noting some of the strengths and limitations afforded by each type of resistance.

\section{Social Activism and Intern Organizations}

Over the past few years, interns have spearheaded a movement to secure pay and gain respect for their work. Interns have commonly used the following tactics to oppose unpaid internships in Ontario: informing and educating the public, naming and shaming those who offer unpaid internships, and lobbying for the reform and enforcement of existing labour laws.

Intern-led groups such as the Canadian Intern Association (CIA) and Students Against Unpaid Internship Scams (SAUIS) offer resources that address a variety of intern-related issues. Both of these organizations were formed in order to improve working conditions for interns: the Canadian Intern Association is a federal not-for-profit organization that was founded in 2012 by a group of students, whereas SAUIS is a provincial organization that operates in Ontario and was formed by a group of students, and youth and labour activists in 2013. Each of these groups outline Ontario's internship laws and offer commentary in an attempt to 
make understanding the law more accessible to students, young workers, and employers. These activist groups also highlight several of the problems associated with unpaid internships in Ontario and Canada, such as exploitation, higher unemployment rates, and "socioeconomic, gender, and intergenerational inequality" (Canadian Intern Association 2014a). The CIA has also partnered with Master's students at the University of Victoria to help fill the gap in research on internships in both Ontario and Canada (Attfield and Couture 2014). In addition to their strong online presence, intern activist groups have publicized intern issues by hosting events and meetings, and maintaining a presence on mainstream Canadian news media, such as CBC, CTV, The Toronto Star, and Maclean's magazine. These activist groups have found support from blogs by Ontario lawyers, such as Youth and Work, Law of Work, and Wise Law Blog, which offer a more in-depth analysis of legal issues, but also provide a compilation of legal, governmental, and NGO resources to aid interns in pursuing social and legal modes of resistance against unpaid internships.

In Ontario, critics of unpaid internships have participated in "naming and shaming" employers that offer unjust or illegal internships (de Peuter et al. 2012). For example, the Canadian Intern Association has a 'Wall of Shame' on its website, where illegal internships are identified and criticized from legal and ethical perspectives, and a 'Wall of Fame,' where employers are praised for their legal and ethical internship practices. While its website offers analytical depth, the Canadian Intern Association, alongside SAUIS and Toronto labour lawyer Andrew Langille, have used social media, namely Twitter, to name and shame a wider range of employers who use unpaid interns. One benefit of naming and shaming online is that interns may remain anonymous, and thus avoid negative social and financial repercussions that may otherwise accompany criticizing their own or other employers (ibid). While it is difficult to determine the effectiveness of these tactics, they at least serve the purpose of raising awareness, and at most have caused some companies to remove their advertisements for unpaid internships. Nevertheless, name and shame tactics have had some success in provinces that have stricter internship laws, such as British Columbia. For instance, in 2013, the social media website Reddit posted a thread about an illegal internship offered by HootSuite. The online backlash against the Vancouver-based social media company was enough to make the company issue an apology and state that it would reform its intern program to comply with the law (Reddit 2013).

Intern activists have also lobbied for the reform and enforcement of existing regulations. ${ }^{1}$ SAUIS and the Canadian Intern Association have submitted proposals that urge the Ontario Ministry of Labour (MOL) to review existing laws on unpaid internships. Moreover, SAUIS and the Youth Alliance for Progress (YAP) ${ }^{2}$ offer a template e-mail that demands a review of labour law (the email is addressed to the Premier of Ontario and the MOL). SAUIS and YAP have also started petitions that call the MOL to review existing labour law; these petitions have received over 1,000 and 100 signatures, respectively. Others, such as the Canadian Intern Association, have met with federal party leaders, Members of Parliament, and Members of Provincial Parliament to voice their concerns about unpaid internships. Without reforming and enforcing existing labour laws, the influence of intern activists will likely be limited; activists may serve as watchdogs for instances of illegal internships, but their bite is limited without increased support from the MOL.

Social activism, in contrast with litigation and policy proposals, offers several advantages as a means for those seeking to change the status quo of internships in Ontario. For one, activism has been a valuable and pragmatically necessary starting point for changing the status of unpaid internships by raising awareness about the social, ethical, and legal issues surrounding internships. Activist groups also provide a place for connectivity, support, and visibility for those who are experiencing or have experienced the negative consequences of an unpaid internship. Additionally, social media provides an opportunity for anonymity that can

\footnotetext{
${ }^{1}$ I examine the content of these proposals in greater depth in the final section of this article.

${ }^{2}$ Founded in 2013, YAP is a not-for-profit organization that is committed to intergenerational equality in Canada.
} 
help shield interns from negative repercussions that may accompany speaking out against unpaid internships.

The veil of anonymity, however, only goes so far. The pressures facing young people who want to enter into internship-saturated industries may discourage them from participating in broader intern activism, including signing petitions, going to events, connecting with social media linked to their identity, or becoming members of intern activist organizations. These pressures are especially prevalent in the cultural industries, where unpaid internships are now industry standards. In her study of young workers in the cultural industries, Angela McRobbie notes that the "emphasis on presentation of self is incompatible with a contestatory demeanour" $(2002,523)$. Simply put, "[i]t's not 'cool' to be difficult" (ibid). In addition, young workers in Ontario face a high unemployment rate, which fluctuated between 16 percent and 17.1 percent in 2013 (Geobey 2013). Given that the odds are already stacked against them, young people may not want to participate in activities that could further limit the possibility of securing employment. Fortunately for young workers, however, support for intern activist organizations extends beyond interns themselves, and includes efforts from lawyers, activists, academics, and former interns.

Interns also face issues of inter-group and intra-group solidarity. Regarding the former, Ontario intern organizations are primarily concerned with the internship problem itself, and are less focused on engaging in a broader type of solidarity on a legislative level. Given that several of the work issues associated with interns, such as social and financial insecurity, are also present in other types of precarious work (de Peuter 2011; Vosko 2006), it might be beneficial for interns to formally unite with other workers in precarious employment situations, such as freelancers, the self-employed, and contract workers. To their credit, intern activists often use rhetoric that characterizes unpaid internships as precarious work, and engage in meaningful discussions with other workers in precarious employment. The issue here is not merely descriptive, but also conceptual; it is difficult to arrive at a collective labour politics that garners the benefits of including many different types of voices, while also not sacrificing the specificity of issues faced in different sectors and types of work. Solidarity is also difficult to develop due to the spatial and temporal fragmentations among interns. Since internships typically last a short period of time, and organizations only employ a limited number of interns, interns face difficulty in connecting and arriving at common interests. Nevertheless, activists are using social media, websites, and events to help overcome some of these fragmentations. Despite these attempts to bridge the temporal and spatial gaps, other issues of fragmentation still arise. For instance, those interns who have since secured jobs may not wish to support present internship movements at the expense of damaging their professional reputation or career. There are also differing views about unpaid internships amongst young workers and interns themselves; some view internships as unfair, while others view unpaid internships as necessary, normalized, or legitimate (Siebert and Wilson 2013).

\section{Litigation}

Although there are relatively few cases in Ontario where interns have used litigation to claim back their pay, most of the cases have been ruled in favour of the intern. At present, the leading case on internships in Ontario is Girex Bancorp $v$ Hsieh, in which two unpaid interns were successful in claiming back pay for the work they completed at Girex Bancorp (Langille 2011). Despite originally agreeing to be unpaid, the two interns were able to secure pay because the work they completed violated the criteria for what constitutes a legal unpaid internship as outlined in ss. 1(2) of Ontario's Employment Standards Act (ESA). In particular, the interns were eligible for receiving back pay because they did not receive training similar to that provided by a vocational school, they did not benefit from either the training they received or the work they completed, and the work they completed primarily benefited the employer (Girex Bancorp 2004). Similar issues were present in the more recent case of Sandhu $\checkmark$ Brar, where Harpreet Brar filed a claim against Chamkaur Singh Sandhu and his father Jagrup Singh Sandhu after initially agreeing to work an unpaid co-op position as a computer technician. Like Hsieh, Brar's position breached the ESA because the tasks he performed 
were for the benefit of the employer, they did not benefit Brar, and Brar did not receive training similar to that offered at a vocational school (Sandhu v. Brar 2013). These two cases are beneficial for the interests of unpaid interns not only because they serve to illustrate and publicize some of the legal issues surrounding unpaid internships in Ontario, but also because the legal precedent they have set is in favour of unpaid interns. The success of these cases may encourage other interns to pursue litigation, and may discourage employers from offering unpaid internships due to the costs of litigation and negative publicity.

Not all unpaid internship cases have been as straightforward. In Patel v Bell Mobility Inc., Jainna Patel filed a labour complaint against Bell's Professional Management Program in Toronto. Patel claims that she did work that would have normally been completed by paid employees, and did not benefit from the work experience or training (Oved 2013). While the work that Patel completed violates Ontario's ESA, Bell Mobility Inc. falls under federal jurisdiction and is governed by the Canadian Labour Code (CLC). Accordingly, a federal labour inspector examined Patel's case, concluding that she was not eligible for back pay because the modules she participated in were "not based on the needs of Bell at any given time and Bell did not use the work prepared by [Patel] to support or benefit its business operations" (Oved 2013). The inspector also claimed that Patel was aware the program was unpaid and that there was no guarantee of employment after the training was complete. Unfortunately for Patel, the CLC has no exclusions for interns, and consequently is less clear about the legal status of internships (Canadian Intern Association 2014b). Although Patel's claim was initially rejected, she appealed the decision in the hopes of securing back pay and proving the point that Bell Mobility's program is illegal, unfair, and exploitative. Less than one year after Patel filed her appeal, Bell cancelled its unpaid internship program (Bell's official statement failed to provide reasons why the program was terminated and whether the termination would be permanent). In response, Patel's lawyer, Tim Gleason, noted that Bell likely cancelled its program in part due to concerns about "ongoing liability" (Goodman 2014).

While there is hope for interns who want to use litigation for securing back pay, there are risks that accompany this type of resistance. One of the greatest difficulties is that the costs of pursuing a lawsuit may outweigh the potential benefits. Along with litigation come a host of resources that one has to invest, including time, money, and intellectual and emotional effort. Given that those who work unpaid internships are often young, it is likely that they may either simply not have the resources to pursue litigation or may want to commit their resources to advancing their career in a more substantive way. The recuperation of minimum or low wages for a relatively short period of time and the rectification of injustice may also not be sufficient to outweigh the risk of committing the time, energy, and expense. While there are a number of legal services that offer free consultations to young workers and interns, many young workers do not have the luxury of being able to afford lawyers without being taken on pro bono. Even if interns find legal representation, it is improbable that their pockets run as deep as their employer's, and cases may be dropped due to prolonged resource depletion. In addition, interns may be reluctant to pursue litigation because it may harm their professional reputation. If one's reputation and connections are a considerable part of why one undertakes an internship (Attfield and Couture 2014; Siebert and Wilson 2013), it is unlikely they will sabotage these goals to receive a small amount of pay that they might not have expected to receive in the first place. This issue is exacerbated given that interns run the risk of being blacklisted if they pursue litigation; blacklisting is a practice that serves to deny entry into a particular industry to those who have openly opposed the interests of other employers in the same industry (Langille 2012a; SAUIS 2014).

One alternative to pursuing litigation individually is to form a class action lawsuit against employers who have offered illegal unpaid internships. Langille suggests that a class action lawsuit is waiting to happen in Ontario: "the environment exists where a class-action lawsuit could possibly work, the trick is you have to find the people... but they're out there" (2012b). While a class action lawsuit may help to ease some of the aforementioned challenges, it may be difficult to find individuals to represent given the temporal and spatial fragmentation of internships. Trying to arrange a successful class action lawsuit may also be difficult given that the type of work interns perform and the companies for which they work are diverse. This 
issue surfaced in the Harper's Bazaar class action lawsuit in the United States, which was dismissed on the grounds that the work completed by the plaintiffs was too dissimilar (Greenfield 2013).

\section{Government Involvement}

In June 2011, the Ontario Ministry of Labour (MOL) introduced the first fact sheet on internships. The need to produce a fact sheet has arisen alongside the increase in number of internships, demands by activists, and relevant case law. At the core of internship-related laws is the MOL's commitment to "ensuring fairness and protecting young workers" (2014). From this basic principle, the MOL notes that it is illegal to offer an unpaid internship unless it meets all of the following criteria:

1. The training is similar to that which is given in a vocational school. 2 . The training is for the benefit of the individual. 3. The person providing the training derives little, if any, benefit from the activity of the individual while he or she is being trained. 4. The individual does not displace employees of the person providing the training. 5 . The individual is not accorded a right to become an employee of the person providing the training. 6 . The individual is advised that he or she will receive no remuneration for the time that he or she spends in training. (Ontario Ministry of Labour 2014)

One exception to these criteria is work that is performed "under a program approved by a college of applied arts and technology or a university" (ibid). While this factsheet is a step in the right direction, many argue there is a need for greater government involvement with intern-related issues. In what follows, I highlight three of the central concerns that have been raised: education and research, strengthening enforcement standards, and reviewing existing labour laws. These proposals to the MOL have come in the form of pre-budget recommendations from the Youth Alliance for Progress, Students Against Unpaid Internship Scams, the Canadian Intern Association, and Andrew Langille, a Private Member's Bill from Member of Provincial Parliament Peggy Sattler, ${ }^{3}$ and a Government Bill from then-Ontario Labour Minister Yasir Naqvi. I also discuss Members of Parliament Andrew Cash and Laurin Liu's Private Members Bill, the Intern Protection Act, which has been introduced at the federal level.

Students Against Unpaid Internship Scams, the Canadian Intern Association, Langille, and Sattler recommend that the MOL should raise awareness about the law on unpaid internships. Together these proposals suggest that the MOL should develop an education campaign that includes informing all relevant parties through advertising, the use of social media, and "the development of audience-specific educational materials" (Langille and Mandryk 2013). Furthermore, these proposals, alongside Sattler's Bill 22 and Naqvi's Bill 146, recognize the lack of research on unpaid internships in Ontario and Canada, and propose that Statistics Canada and the MOL conduct data collection in order to better develop labour laws and enforcement tactics. Included in the areas requested for data collection are the school to labour market transition, "the number of paid and unpaid internships, whether they are part of a formal educational program," and identifying which industries offer the most internships (Canadian Intern Association 2014c, 5).

Although the foregoing proposals request that the MOL educate the public about internship laws, they fail to explicitly recommend that the MOL raise awareness about social issues surrounding unpaid internships; many of the problems with unpaid internships go beyond mere legality and deal with issues of race, gender, exploitation, age, and social mobility (de Peuter et al. 2012; Oakley 2013; Perlin 2011; Seibert and Wilson 2013). While it is debatable whether certain social issues fall outside the domain of government responsibility, the proposed educational campaign may benefit from this kind of supplementation. Providing this

\footnotetext{
${ }^{3}$ This bill was originally introduced by then-Member of Provincial Parliament Jonah Schein, and was later reintroduced by Sattler in July 2014 after Schein was not re-elected in Ontario's 2014 election.
} 
background on internships would help strengthen intern efforts by highlighting wider points of connectivity with their cause at the level of race, gender, and class. Furthermore, these proposals are scarce on putting any onus on employers to (at least minimally) inform their interns about the legal status of internships in Ontario. One exception is Sattler's Bill 22, which calls for an 'interns' bill of rights poster that employers would be required to post in the workplace" (Sattler 2014). While having a poster in the workplace would help to bring visibility to the issue, the MOL could place further responsibility on employers. For instance, the MOL could require employers to include a clause in internship contracts that states the intern was explicitly made aware of and understands the laws on unpaid internships. Placing minimal responsibility on employers to inform their interns has the potential to help promote, and start to normalize, legal and fair standards for internships in the workplace.

Second, SAUIS, the CIA, YAP, and Langille all note that the enforcement of internshiprelated laws is inadequate, and demand proactive enforcement standards. The MOL responded to some of these concerns in 2013 by investing $\$ 3$ million to hire and train 20 officers to conduct 1,400 labour inspections annually. This initiative found recent success with the termination of two illegal internship programs at Toronto-based magazines The Walrus and Toronto Life. Despite this success, none of the officers are specifically dedicated to inspect internships, and only "a very limited number of sectors were selected for inspection blitzes regarding vulnerable workers and unpaid wages" (Canadian Intern Association 2014c, 4). Accordingly, activists propose that the MOL assign officers to inspect internship programs, target high-risk employers, and increase the number of inspections. They also recommend that the MOL strengthen enforcement tactics by developing an anonymous tips hotline and by targeting unpaid internships that are advertised online. While these proactive tactics would help ease the present burden that interns face with reporting illegal internships, a better long-term enforcement solution is needed. One possible strategy is a permit system that would require internships to be registered with either a vocational school or the MOL (Doorey 2013; SAUIS 2014). Central to the permit system would be a code of conduct that clearly outlines criteria for fair internships; either a vocational school or the MOL would monitor and oversee internships to ensure the code of conduct is followed. Since the permit system would have clearly established guidelines and institutions overseeing the internship, enforcement would be more reliable.

Third, these proposals and bills seek to change labour laws to better reflect the concerns of interns, focusing on the areas of workplace rights, litigation and fines, and exclusions. Receiving support from intern activists, Cash and Liu's Intern Protection Act would allow unpaid interns who work in federally regulated industries to qualify for workplace standards and protections (Cash 2014). Their bill addresses a critical loophole in federal legislation, which is presently unclear about whether interns qualify for these employment rights. As exemplified by Patel $v$ Bell Mobility Inc., this loophole has been an enabling condition for hundreds of unpaid internships in Bell's Professional Management Program alone. While the Intern Protection Act would help crack down on these federally regulated organizations, it fails to address the two other primary concerns that were raised in proposals to the MOL: awareness and enforcement. If the Intern Protection Act passes, Cash and Liu should draw from the policy groundwork currently being laid in Ontario in order to avoid a number of enforcement-related issues that Ontario has encountered in the past; a proactive approach that extends beyond simply strengthening labour laws would help to reduce the number of (illegal) unpaid internships in federally regulated industries.

In Ontario, Naqvi's Bill 146 proposes to give unpaid interns equal protections as paid employees in the Occupational Health and Safety Act. Sattler's bill would also ensure greater rights for interns, including a regular workday, eating periods, holidays, and the right to file a complaint with the MOL. The bill would change the time limit for filing a complaint for back pay from six months to two years, and remove the $\$ 10,000$ cap on claiming unpaid wages. In addition to loosening these legal restrictions, the Youth Alliance for Progress notes that the current penalty for offering an unpaid internship is grossly inadequate. Instead of the existing fine- $\$ 250$ for the first offence-YAP argues that the MOL should charge "corporations who break the law a meaningful fine, one that costs more than the value of free work they re- 
ceive" (2013). Additionally, the Canadian Intern Association recommends amending exclusions pertaining to trainees, professionals, and students. The association states that the trainee exclusion in the ESA should be removed due to the definitional ambiguity it raises with interns; removing this exclusion would entitle interns to "minimum wage unless they are part of a formal educational program or ... [a] professional exclusion"4 (Canadian Intern Association $2014 \mathrm{c}, 6)$. The association also recommends that there should be workplace guidelines for internships that come under the student exclusion, such as the six criteria for trainees, and a cap on the number of unpaid hours that can be worked per semester.

Alongside these changes, the MOL needs to address the structural employment changes that accompany unpaid internships. More specifically, the fourth criterion of the MOL's policy on internships inadequately reflects the broader economic shift that is accompanying the rise of unpaid internships. While research on internships is limited, findings indicate not only that unpaid internships tend to replace paid jobs, such as summer jobs and entry-level positions, but they also take away new growth positions (Langille and Mandryk 2013; Perlin 2011; Seibert and Wilson 2013). Since unpaid internships are replacing paid positions on a structural level, unpaid internships as a type of work breach the fourth criterion. If the MOL wishes to remain consistent, they need to enact stricter laws that address this employment shift.

While these issues need to be addressed by the MOL, one unavoidable pitfall of a comprehensive legislation review is that the educational campaign will be further delayed; it would be counterintuitive to launch a campaign informing people about the laws on unpaid internships until the comprehensive review would be completed. The temporal hurdle here should not be undersold. Legislation takes a considerable amount of time and effort to prepare and pass, let alone publicize and enforce in an effective manner. Moreover, policies are "rooted in having an understanding of the dimensions of an issue and [this] presents a barrier to formulating appropriate regulatory responses" (Langille 2013). That is, the legislative proposals and bills on internships face the obstacle of trying to succeed with a limited amount of research on internship-related issues. Nonetheless, changing labour laws to better reflect the needs of interns appears necessary if the problems they face are to be properly addressed.

\section{References}

Attfield, James and Isabelle Couture. 2014. An Investigation into the Status and Implications of Unpaid Internships in Ontario. Master's Thesis, University of Victoria.

Bill 170, Employment Standards Amendment Act (Greater Protection for Interns and Vulnerable Workers), 2nd Sess., 40th Legislature, Ontario 63 Elizabeth II, 2014. http://www.ontla.on.ca/bills/bills-files/40 Parliament/Session2/b170.pdf.

Bill 146, Stronger Workplaces for a Stronger Economy Act, 2nd Sess., 40th Legislature, Ontario 63, Elizabeth II, 2013. http://www.ontla.on.ca/bills/bills-files/40 Parliament/Session2/b146.pdf.

Cash, Andrew. 2014. Read the Text of the Intern Protection Act. Accessed September 10, 2014. http://andrewcash.ca/read-the-text-of-the-intern-protection-act/.

Canadian Intern Association. 2014a. About Us. Accessed May 24, 2013. http://www.internassociation.ca/about/.

Canadian Intern Association. 2014b. What is the Law? Accessed May 24, 2013. http://www.internassociation.ca/what-is-the-law/.

Canadian Intern Association. 2014c. Pre-Budget Consultations. Accessed May 24, 2014. http://www.internassociation.ca/wp-content/uploads/2014/02/CIA-Ontario-Budget-Submissions.pdf.

de Peuter, Greig. 2011. Creative Economy and Labor Precarity: A Contested Convergence. Journal of Communication Inquiry 35 (4): 417-425.

de Peuter, Greig, Nicole Cohen and Enda Brophy. 2012. Interns, Unite! You Have Nothing to LoseLiterally. Briarpatch, November 9.

Doorey, David. 2013. A Three Step Solution for Tackling the Problem of Unpaid Internships in Ontario. Accessed November 5, 2013. http://lawofwork.ca/?p=7123.

Geobey, Sean. 2013. The Young and the Jobless: Youth Unemployment in Ontario. Canadian Centre for Policy Alternatives. Accessed May 24, 2014.

\footnotetext{
${ }^{4}$ The Canadian Intern Association also advocates for removing the professional exclusion in order that those entering a profession are guaranteed a minimum wage.
} 
http://www.policyalternatives.ca/sites/default/files/uploads/publications/Ontario\%200ffice/2013/09/ Young_and_jobless_final3.pdf.

Girex Bancorp v. Hsieh [2004] ON L.R.B. 24679.

Goodman, Lee-Anne. 2014. Bell Mobility Scraps Unpaid Internship Program. The Globe and Mail, August 8.

Greenfield, Rebecca. 2013. Class Action or Not, the Unpaid Intern Lawsuit at Hearst Will Go On. The Atlantic Wire, May 9.

Langille, Andrew. 2011. The Legality of Unpaid Internships in Ontario. Accessed May 24, 2014. http://www.youthandwork.ca/2011/07/unpaid-internships-in-ontario.html.

Langille, Andrew. 2012a. Scaling Asshole Mountain (and Other Adventures in Nerdistan). Accessed May 24, 2014. http://www.youthandwork.ca/2012/10/scaling-asshole-mountain-and-other.html.

Langille, Andrew. 2012b. Are Class Action Lawsuits Over Unpaid Internships Coming to Canada? Accessed May 24, 2014. http://www.youthandwork.ca/2012/03/are-class-action-lawsuits-overunpaid.html.

Langille, Andrew. 2013. Why Canada Needs Better Labour Market Data and the Canadian Internship Survey. Accessed May 24, 2014. http://www.youthandwork.ca/2013/10/why-canada-needs-betterlabour-market.html.

Langille, Andrew. 2014. Pre-Budget Consultations. Accessed May 24, 2014. https://www.academia.edu/6302484/Recommendations_Re_Regulation_of_Unpaid_Internships_In Ontario.

Langille, Andrew and Josh Mandryk. 2013. Ontario Must Take Urgent Action on Unpaid Internships. The Toronto Star, November 4.

McRobbie, Angela. 2002. Clubs to Companies: Notes on the Decline of Political Culture in Speeded Up Creative Worlds. Cultural Studies 16 (4): 516-531.

Oakley, Kate. 2013. Making Workers: Higher Education and the Cultural Industries Workplace. In Cultural Work and Higher Education, edited by Daniel Ashton and Caitriona Noonan, 25-44. New York: Palgrave Macmillan.

Oved, Marco. 2013. Unpaid Intern's Claim for Wages Rejected. The Toronto Star, October 24.

Ontario Ministry of Labour. 2014. Are Unpaid Internships Legal in Ontario? Accessed May 30, 2014. http://www.labour.gov.on.ca/english/es/pubs/internships.php.

Patel v. Bell Mobility Inc., [2013] ON L.R.B. 52247

Perlin, Ross. 2011. Intern Nation: How to Earn Nothing and Learn Little in the Brave New Economy.

London: Verso.

Reddit. 2013. Hootsuite is Hiring Unpaid Interns, This is Illegal in BC. Accessed May 28, 2014. http://www.reddit.com/r/vancouver/comments/1bqytv/hootsuite is hiring unpaid interns this is/.

Sandhu v Brar, 2013 ON LRB 43024.

Sattler, Peggy. 2014. NDP MPP Continues Fight to Stop Exploitative Internships. Accessed September 7, 2014. http://peggysattler.ca/ndp-mpp-continues-fight-to-stop-exploitative-internships/.

Siebert, Sabina and Fiona Wilson. 2013. All Work and No Pay: Consequences of Unpaid Work in the Creative Industries. Work, Employment and Society 27 (4): 711-721.

Students Against Unpaid Internship Scams. 2014. Taking Action on Unpaid Internships: Pre-Budget Submission. Accessed May 24, 2014. http://payyourinterns.files.wordpress.com/2014/02/prebudget.pdf.

Vosko, Leah. 2006. Precarious Employment: Understanding Labour Market Insecurity in Canada. Montreal and Kingston: McGill-Queen's University Press.

Youth Alliance for Progress. 2013. Ontario: Stop Unpaid Internships. Accessed November 29, 2013. http://www.change.org/en-CA/petitions/ontario-stop-unpaid-internships.

\section{About the Author}

William Webb

William Webb is a student at Wilfrid Laurier University in Honours Communication Studies and Philosophy. He is also Editor-In-Chief for the Laurier Undergraduate Journal of the Arts, Vice President of Internal Affairs for Laurier's Faculty of Arts Student Society, and a student representative to Laurier's Divisional Council of the Faculty of Arts. 


\title{
Challenging Intern Nation: A Roundtable with Intern Labour Activists in Canada
}

\author{
Nicole S. Cohen* and Greig de Peuter** \\ * Nicole S. Cohen, University of Toronto Mississauga, Canada, nicole.cohen@utoronto.ca \\ ** Greig de Peuter, Wilfrid Laurier University, Waterloo, Canada, gdepeuter@wlu.ca
}

\begin{abstract}
Internships have gained critical attention in Canada, thanks largely to the efforts of intern labour activists, who have generated media coverage, lobbied and advised politicians, conducted education and outreach, and advocated for an end to the proliferation of unpaid internships in Canada. This roundtable interview with intern labour activists Ella Henry, Andrew Langille, Joshua Mandryk, and Claire Seaborn was conducted by Nicole Cohen and Greig de Peuter in Toronto on March 1, 2015. Follow up interviewing was conducted over e-mail in May 2015. The interview has been edited and condensed.
\end{abstract}

Keywords: internships, intern activism, labour, youth, media activism

Acknowledgement: We would like to thank William Webb for research assistance and the Social Sciences and Humanities Research Council of Canada for financial support.

Can you tell us about how you became involved in activism around internships? What sparked your interest in the issue?

Andrew Langille (AL): I started a Master's program at Osgoode Hall Law School at York University in 2010. The next year, I needed to write a paper for a course on the individual contract of employment. I asked David Doorey, a professor at York, for some ideas. He had written a blog post on unpaid internships, but no research had been done on the issue. David suggested that I take a crack at writing something. So, I wrote a survey of some of the legal aspects of unpaid internships. I posted about it on my blog and it snowballed from there. More and more people got interested in the issue. I started talking about it on Twitter, and media requests were coming in. Ross Perlin's book, Intern Nation, came out shortly after I wrote that paper. So, the issue was developing. This was after Steven Greenhouse's article in The New York Times came out. ${ }^{1}$ That article sort of kicked everything off-l think it was critical. I didn't have an overwhelming interest in the issue before, but now I do. It's fascinating, because it encapsulates so many contemporary problems that young people face in the labour market and the wider economy.

Claire Seaborn (CS): I finished my first year of law school at the University of Ottawa in June 2012. At the time, I had no interest in employment law. I entered law school on an application that focused on environmental law and I had experience in activism in the environmental sphere, but not in anything workplace-related. I was socializing with friends and realized that the majority of us had done an internship (I was doing my second unpaid internship for school credit at the Ministry of the Attorney General and, prior to law school, I interned at the Canadian Embassy in Washington; that was not for credit and unpaid). As an early law student, I was eager to learn what the laws were. My first thought was that there should be a union for interns. We decided an advocacy group would be better and came up with the idea of the Canadian Intern Association. I looked up the law on interns and Andrew Langille's name came up. So, I e-mailed him: "Hi, I'm a law student. I'm interested in the issue. What's

\footnotetext{
1 Steven Greenhouse (2010) "The Unpaid Intern, Legal or Not," New York Times, April 2. Accessed March 31, 2015. http://www.nytimes.com/2010/04/03/business/03intern.html?_r=0.
} 
the law on interns? I just want to know." There was a sale that day for .ca domains, and I bought internassociation.ca for $\$ 8$ and started fiddling around with WordPress. That summer the Canadian Intern Association started having meetings. Now, our entire executive is made up of people I didn't know prior to the day the idea started. People have joined through social media or after finding out by word-of-mouth about the organization. So that's when I started. Since then, I have focused a lot more on workplace law, and now that's an area in which I hope to practice law.

Joshua Mandryk (JM): My story is a lot like Claire's. In the beginning of law school at the University of Toronto I started to read what Andrew posted online. In my third year of law school, Ella Henry and I thought that the time was right to do some organizing on campus and try to get students involved. The work that Andrew and Claire had already done and the media coverage of internship issues really made the case for it. We started reaching out to students and getting petitions going in fall of 2013. We decided to form a campaign-based organization: Students Against Unpaid Internship Scams. In Ontario, the timing made sense politically; there was a minority government and we knew that the province would announce its budget in the next six months. We thought the time was ripe to see if we could get some action on the issue.

Ella Henry (EH): I was a year behind Josh in law school, and we met through a shared interest in labour and employment law. During my undergraduate degree I was very involved in student and labour activism, first as a students' union president and later as a union organizer. It seemed to me that unpaid internships were becoming increasingly common-and other than Andrew and Claire, I didn't see many people talking about them. Josh and I formed Students Against Unpaid Internship Scams to bring a student voice to the issue. I think the issue of unpaid internships is a great entry point to begin discussing workers' rights with students.

AL: Early on, I was able to generate coverage with a number of media outlets and develop working relationships with some journalists. I was able to call them up and say, "I think you should look at this issue." Now, The Toronto Star and other media outlets devote substantial resources to covering the issue of precarious work and unpaid internships. Some of the people involved in the internship issue were, to a degree, able to mine social connections. Having some social capital to get your ideas out there is critical. There's some privilege behind getting these issues addressed.

Internships have been criticized from a variety of perspectives over the past few years. Right now, what do you see as the most pressing issues around internships in Canada?

CS: The first thing that comes to mind for me is student internships. When I first got involved it was mostly about unpaid internships outside the school context, and whether or not they're illegal, and educating people about that. Now, more employers, interns, and students are aware that unpaid internships are often illegal and know what the laws are. There's going to be growing discussion about when students' internships should be paid versus unpaid, what workplace rights student interns have, and how long an internship should be. These parts of the issue haven't been explored much. Another issue that interests me is the difference between an "intern" and a "volunteer" or an "employee" and "volunteer."

JM: The volunteer issue is, I think, the next big issue. If you look at the way people are characterizing intern positions outside of post-secondary programs, it's as "volunteer" positions. The law here is ripe to be updated. In terms of internships outside of post-secondary programs, the big issues are onus and enforcement. We talk a lot about enforcement of the laws that are on the books, but the other key idea is onus: employers should not be permitted to self-enforce and accurately apply the law themselves; instead, the onus should be on an employer to get approval for an unpaid internship before they do it. 
EH: I agree with Claire and Josh: student internships and volunteer misclassification are going to be big issues. And in a way, that's a good thing. It means unpaid internships are becoming unpopular and employers don't want to be associated with them. Employers are turning to legal unpaid internships (i.e., student internships) and are naming unpaid positions as volunteer rather than as intern positions. There has been a dramatic shift in public opinion, but we need to continue to be vigilant so we don't see the same problem by another name. The academic internship exception is something I'm particularly concerned about. Post-secondary institutions have shown that they are unwilling or unable to exercise any meaningful oversight or ensure these internships are integrated into an academic program and have pedagogical value. I think we need both law reform and external oversight of academic internships by the Ministry of Labour.

AL: Law reform is an absolute necessity. Ontario has made some reforms around occupational health and safety. There's a need for a standard across Canada. Other issues are the lack of funding for paid positions and the role of government in this respect. In the '90s, the federal government funded thousands of paid internships. I think there's a role for the federal and provincial governments in managing the school-to-labour-market transition. We have to look at deeper policy questions related to labour markets and actually intervene in the economy to help young people. The wider questions that unpaid internships raise are about intergenerational equity. Why have we made this choice that unpaid positions are acceptable? There hasn't been adequate enforcement from government. We see a great deal of ambivalence. If employers are exploiting people and there's no government response and the law is lenient, that's greatly concerning.

CS: Along with the student issue are professional programs. I speak to nurses, nutritionists, and articling law students: all of them are in versions of internships. How these professions choose to train the people that enter them will continue to be an issue. How many months is a professional internship? What is the combination of schooling and training? Is it paid or unpaid?

EH: I think there has been a shift from academic internships that are legitimately integrated into a curriculum and that don't displace paid employees to internships that are indistinguishable from summer jobs or co-op positions students might have. Post-secondary education institutions are underfunded and facing pressure to provide more practical training opportunities, and so they often leap at the chance to provide credit for unpaid internships (and often continue to collect tuition fees).

AL: Underlying a lot of this discussion is a conception of equality and how equality is treated vis-à-vis economic rights. Economic rights are a thorny issue in a market-based economy. And this issue is highlighting contradictions under capitalism. There is ongoing tension between the rights of citizens and employers.

There has been a surprising amount of media coverage of internship issues over the past few years. Do you think that there's a sense that the "battle has been won"? That there's an assumption that, well, "you can't have unpaid internships anymore, so why even talk about it?"

JM: There has been a lot of positive media coverage. I think we're winning the war of ideas on the issue, but we need to be honest that little has been accomplished. In Ontario, there was a short-term enforcement blitz. A few private member's bills, which will not pass, have been presented. There have been some incremental steps in the right direction, but the idea that it's "won" or that there's been any meaningful solution to the problems is untrue. The media coverage and the government's short-term blitz do not change the fact that the current complaints-based system doesn't work. 
CS: I don't think the battle's even gotten started. I'm only beginning to understand the breadth of issues that apply to interns, including human rights issues like discrimination and sexual harassment. And, in the student context, schools should be doing much more. The other issue is that a lot of employers are posting internships without specifying whether they're paid or unpaid, and only notifying interns in an interview. It's difficult for us to shame these companies when we don't have any documents, when they haven't posted anything online to evidence that.

EH: We shouldn't underestimate the impact of the media attention and the corresponding shift in public opinion. Even two years ago, when I talked to people my parents' age about unpaid internships almost everyone thought young people today were just unwilling to work hard and that unpaid internships were a good way to get your foot in the door in a tough economy. Now the majority of those people say that unpaid internships are wrong. I think it's fair to say we've won the first round, but the fight is far from over.

All of you are involved in organizations that advocate around internship issues. Can you describe the activities of the group that you are involved with?

JM: I was involved in Students Against Unpaid Internship Scams. We started in the fall of 2013. We were a campaign-based group. We didn't see ourselves as a permanent group, but, as I said earlier, we thought the time was right to start a campaign. We did petitioning and we had a website that we made ourselves - the website had a form that allowed you to send a message to all the political party leaders, the Minister of Labour, and labour critics. It was a formal letter calling for the demands outlined in our petition. ${ }^{2}$ We demonstrated outside the minister's pre-budget consultation in 2013, chatted with folks of different parties, and did advocacy work: media-relations, writing, and putting forward position papers. Now, I'm an articling student. As a lawyer, I plan to do test cases and continue to push this issue.

The Students' Law Society at the University of Toronto ran a OneDayofPay campaign. It got a lot of coverage. The Faculty of Law at University of Toronto, the student Law Society, and the administration had a proposal-well-intentioned, but, in our opinion, off the mark-to address the prevalence of unpaid positions in the Faculty of Law. They asked students who got a paying summer job to donate a day of their pay in order to pay for their classmates' unpaid placements. Obviously, there are many problems with this, one of which is that a lot of these positions could be illegal, and the role of the legal education institutions should be to challenge these things... The institutions themselves shouldn't be posting these sorts of positions. Who should pay the burden of underfunding? Should it be students who pay $\$ 30,000$ per year in tuition? Or should it be the government?

CS: The Canadian Intern Association advocates against the exploitation of interns. Our mission is to improve internship experiences for interns and employers through law reform, enforcement, cultural change, and awareness. The Canadian Intern Association was founded in June of 2012. One year later, it became a federally incorporated not-for-profit organization. Now, we have seven members on our executive team who are based in Ottawa and Toronto: event planners, public policy majors, people with backgrounds in the arts, in finance... The association is made up of people in their early-twenties who are interested in the issue. All our executive members have done an internship at one point, some paid, some unpaid.

We meet every two months in person, but communicate almost daily online through email, Facebook, and Twitter. We have a website that has a "Wall of Shame" and a "Wall of Fame," which have been really successful. Now, just threatening to a company that we'll put them on our Wall of Shame is enough to make them change their behaviour, or at least have a phone conversation about it.

\footnotetext{
${ }^{2}$ The letter is available at http://fs25.formsite.com/stopunpaidinternshipscams/form1/index.html.
} 
The thing that I do most with the Intern Association is law reform and lobbying. I've enjoyed talking to politicians, building understanding of the law, communicating our policy proposals, and doing media interviews. We've partnered with academics to promote research, and we also give talks at colleges and universities to educate interns and students about their workplace rights. We've done all of this with little to no money.

Andrew [Langille] is counsel to the Canadian Intern Association. He's our go-to lawyer. Interns e-mail us all the time with long descriptions of their experiences, and it's helpful to have someone who is able to discuss their specific issues with them, refer them, and sometimes take on their cases. Essentially, he's giving free legal advice.

\section{Andrew, could you give us a sense of that consultation process?}

AL: Generally, if I get a question, l'll talk to the person on the phone and tell them what to do. Often, it's a matter of directing people to the Ministry of Labour to file a complaint. Typically, they're asking if the internship is legal. Most of the time it's not legal if they're not students. I've dealt with some bad situations, where student interns are working in unsafe environments. You come across instances of sexual harassment and you do your best to direct them to the appropriate resources and give them some advice. But we can't take on every case. We're not set up to do casework.

CS: Although that would be great... One thing that we started early on was a Claim Back Your Pay campaign. We got the idea from a UK campaign. ${ }^{3}$ We posted information on our website about how interns can file a claim with the Ministry of Labour to seek retroactive minimum wage for the hours they've worked. Kyle, one of the executives of the Intern Association, successfully claimed back pay in 2011-he got his money from the employer. Now, he's a great spokesperson for the Claim Back Your Pay campaign, encouraging other interns to do the same thing he did.

There's a coalition of intern groups, called the International Coalition for Fair Internships (fairinternships.org). Can you describe this coalition and speak about your involvement in it?

AL: There is an international coalition of groups that has met over the past few years over Skype to discuss issues related to internships. It's not all that active at the moment, but it exists, and there's communication between groups. It highlights that this is an international issue: the problems that we're facing in Canada are common in other parts of the world, too.

CS: When one of the members of Interns Australia was in Canada, she came to one of our meetings. That's been a great connection. I met Intern Aware when I was in London. It is the only intern association that has enough funding to support a staff member. It was great to see their office, which is a space in a labour union's headquarters (BECTU). I also met people from the Geneva Intern Association. There are so many interns that come and go from Geneva. While Intern Aware does a lot of lobbying, the Geneva Intern Association is very social-they run monthly socials-and it's a helpful resource for interns to find housing in Geneva. l've spoken with Génération Précaire, the French intern organization in Paris, and I've also Skyped with Mikey Franklin in Washington, DC, who runs the American Fair Pay Campaign. There's the group in New York as well, Intern Labor Rights. Andrew's attended the international coalition meetings, and I try to connect with other groups. It's cool seeing what everyone's doing and watching everyone's group evolve. We share ideas and learn about what is working in other jurisdictions. If I was going to summarize the areas where each group has had the most success, I would say: Intern Aware works most closely with unions, Interns Australia works well with the business community, Canadian Intern Association has been the best at engaging politicians, Intern Labor Rights and other US groups have

\footnotetext{
${ }^{3}$ The Claim Back Your Pay campaign in the UK was run by Intern Aware: www.internaware.org/claim-back-yourpay/.
} 
had success with class action lawsuits, Génération Précaire does more demonstrations and protests, and the Geneva Intern Association has a successful petition for the United Nations.

Interns are, as you know first hand, difficult to reach for a variety of reasons, and hard to organize in the traditional sense of organizing: they're dispersed, in short-term positions, and understandably concerned about their reputations and references. But you've had success despite these challenges. In your experience, what organizing strategies have been particularly effective?

JM: I would say we're not really "organizing" interns. We can mobilize people, but I don't think we've figured out a way to organize them in any meaningful sense. People are afraid to file complaints, and people are not taking collective action. It's not as if trade unions are trying to organize interns as employees, yet, if a place has two interns, they're really employees, you could organize them. That isn't happening.

I think we need to say that we haven't really been organizing people. We can mobilize them to sign petitions and sometimes speak out in the media, but most of the times, people are not able to speak out. When I would do advocacy work on campus, people would tell me their story, but they didn't feel comfortable speaking to the media and didn't really want you to talk about their story, and, if you did, it had to be anonymized. There aren't meaningful protections for interns, and organizations like the Intern Association don't have the resources to provide legal services for all of these people, and, even when you do, things like the potential for reputational damage, you can't really do anything about that. So, it's tricky.

CS: I encourage interns to speak to the media, anonymously or not, about their story, and to speak to their employers about their rights. I can't keep track of all the stories I've heard, whether by the e-mails we receive at the Intern Association or just at social gatherings. People know that l'm interested in this issue, so, socially, someone my age or a little younger will say, "Oh, let me tell you about my intern issue." I feel like l've gained this body of knowledge about the situation, but I don't have data or a chart that tracks it: the sexual assaults that l've heard about, the dangerous work environments, or just the exploitative situations that people find themselves in... the injustices.

But I agree that we don't organize people the way a union would. We don't want to collect dues, we don't want to have mandatory meetings, and we don't want to have a formal membership scheme necessarily. We're looking at having at least a newsletter and a mailing list, so that we can contact people, that's really where we're at in terms of trying to actually keep track of individuals. Honestly, l've been struggling with how to keep in touch with such a large group of people. It's overwhelming. There are so many people that we could be helping, but we just don't have the resources.

EH: I agree that we haven't really been organizing people on an ongoing basis. One of the reasons is that interns are afraid of the consequences of speaking out. But I think beyond that there are more reasons interns and students are difficult to organize. High student debt means that many interns are working full time on top of an internship and many students are working multiple part-time or full-time jobs on top of school. One of the ways we've tried to get around these challenges is by using things like petitions, which allow us to show that our campaigns have broad support without requiring a large time commitment from students.

AL: Education is really important in terms of organizing people. There isn't enough education at the post-secondary level in terms of what labour rights people have. That's critical, but it doesn't really get taught.

JM: At the firm where I work, articling students go to high schools and speak to co-op students before they go to their placements, which is a lot of fun. We visit one high school each month maybe, so the majority of students aren't getting this. We cram a lot of labour and employment law in a two-hour session for these high school students. It's a lot of infor- 
mation at once. It's interesting to talk to them, hear their stories, ask what their positions are like, and ask them questions about labour unions. If any of them know anyone in a union, and inevitably it's, like, one or two kids who put their hands up, and one of them, their parent is a construction worker, and the other one, their parent is a public servant of some sort. Otherwise, no one else...

EH: Students Against Unpaid Internship Scams has also done workshops for college and university students, sometimes in partnership with the Communication Workers of AmericaCanada's associate membership program for young workers and students in the media industry.

CS: Something that has been really fun in terms of organizing is the purely online stuff. For example, when the unpaid internship, zero-dollar contracts at Hootsuite, the Vancouverbased company, were posted on Reddit, there was this huge outcry. Hootsuite, being a social media company, freaked. I loved reading the Reddit comments-there was obviously a significant consensus among people who weren't lawyers, weren't involved in the issue whatsoever, about how problematic this was. Within about 30 hours of posting the contracts on our Wall of Shame, I got an e-mail from the CEO of Hootsuite saying, "We're going to fix this. We can see that this is a problem." On our Wall of Shame post, we shared the contracts, some threads from the Reddit community, and basically shamed their practices. They're the best success story, because not only do they pay their interns now, but they retroactively paid their interns the six months prior. That was a great example of organizing that happened 100 percent online. I never even had a phone call with the guy from Hootsuite. It was just posted on our website, then e-mail, then it was fixed, then it was in social media and mainstream media reported that now Hootsuite is paying its interns.

How you would describe the significance of social media to intern activism? What socialmedia tactics do you use, and to what effect? In particular, is "naming-and-shaming" effective?

AL: I think naming-and-shaming is highly effective. Look at one of the biggest offenders, Bell, a major Canadian telecommunications company. Bell Mobility's Professional Management Program - which was a massive unpaid internship program at one of Canada's largest corporations-brought in young workers and asked them to work for free for months at a time. There was sustained critical media coverage of this program, including in the CBC, the Canadian Press, and The Toronto Star, which highlighted the absurdity of a hugely profitable corporation asking young workers for work for free for months on end. There was also a naming-and-shaming element involved, both on social media and on Internet forums like Reddit, where former interns in the Professional Management Program could share their experiences. Bell ended the program in summer 2014 after multiple lawsuits were launched by former interns. I think that's a big success story. So, yes, I think naming-and-shaming can work. For it to be effective, though, there has to be reputational damage that can come to the company. For a smaller employer, I don't think it's useful, but, for the larger players, it can be highly useful.

JM: I think social media is incredibly useful for connecting with people, given the nature of the work: there's not a permanent, large workplace where there's lots of unpaid interns. Interns are a very dispersed population, but they're also, generally speaking, a young and online population. So, social media is useful for connecting with interns. Social media also gives these folks a voice to share their stories: they can't speak up at work, but many will speak up online about their experiences.

CS: Many people on the Intern Association executive first found the organization through social media, usually Twitter or Facebook. Many of them had an idea of starting a similar organization and, in the process of doing that, came across the Intern Association. 
In terms of naming-and-shaming, within the first six months of the Intern Association being formed, there was an idea to start a Wall of Shame and Wall of Fame-but we didn't really know how to do it at first. I was just becoming familiar with the law at that time. We put up a posting about a company based on an e-mail that we received from an intern about a terrible experience at that company. Not only did we post the company's advertisement for the internship, but we also recounted what the intern said about the internship and how problematic it was. Soon after, I got an angry letter threatening to sue for defamation. I sent it to Andrew right away. We talked about it and decided to take that Wall of Shame posting down. Thereafter, we didn't post details about interns' stories and instead just posted the advertisements and what the law was, so that it was not as high risk for defamation. Myself, the organization, and the other executive team people, we don't want to have our names on the website if there's risk of that kind. It's not a Rate My Professor kind of thing, but it'd be cool if there were something like that for internships. We've been able to accomplish largely the same thing just through posting the advertisements.

AL: One other point on social media: Twitter allows for direct access to politicians. I think that's very important because you can tag certain politicians and they do read it.

CS: Politicians also like to re-tweet stuff when they're mentioned. So, when I'm working with a politician on something, they like it when I say, "Thanks so much for the great meeting," "for inviting me to be a witness at this event," or "for creating this great private member's bill." They re-tweet that and it does a lot for them. Lobbying is supposed to be a reciprocal relationship. I can mention them on Twitter. What they're doing for me is helping me advance the issue.

AL: The Ministry of Labour once used its Twitter account to say that they did not like my naming and shaming. They told people to go to the Law Society and file professional standards complaints against me. I called the Ministry of Labour and said that I was going to sue. I had to send a letter to the Ministry of Labour outlining what my Charter of Rights are as a citizen, saying that I can engage in political action. The tweets were removed. I had the ability to fight back, but somebody who doesn't have access to legal counsel... you can see how it would be scary.

We are interested in the kinds of collaborations, associations, and affiliations you've had with different levels, players, and contexts-for example, trade unions, student unions, and politicians, both provincial and federal. Can you describe some of your collaborations? Why are they necessary? Are there any challenges or frustrations that you encounter in these institutional interactions?

AL: There's any number of challenges in interacting with institutional bodies or more established political groups. A lot of these organizations haven't come up with solutions to the rise of precarious work. And, in terms of unpaid internships, there's a steep learning curve. Young people have not been terribly active, in the space of my lifetime, in advocating for their rights in the workplace. Activism does go on, but the issue of unpaid internships is a new issue and people are grappling with how to address it.

Unpaid internships are a controversial issue. It brings up uncomfortable realities about what's happening in the labour market and economy. Certainly, the provincial and federal governments don't want to have serious discussions on this issue. Civil servants who oversee labour regulation don't want to discuss it. They don't know what to do. There are deep, underlying problems related to internships and the school-to-labour-market transition that don't have easy solutions. It takes a long time to get up to speed on the issue, too. It's not easy to understand all the issues, because you have to have an understanding of any number of areas to have a complete picture. Even I don't claim to have a complete understanding of the issue... 
JM: There are some great examples of cooperation with students' unions, trade unions, and politicians. Sometimes, I'm frustrated at the speed at which they've taken up the issue. On the other hand, we've found tremendous support. The University of Toronto Student Union, for example, is very supportive of our campaign. A number of politicians we've worked with have put forward private member's bills on the issue: Andrew Cash, Laurin Liu, Peggy Sattler, and Jonah Schein.

If I were a student union leader, a trade union leader, or a provincial politician, I would see this as a great issue to own and to allow you to speak to your members, your potential members, and your potential supporters. Some folks have been slow to appreciate that. But I think that we've had great collaboration with student unions, trade unions, and politicians. It continues to strengthen, though there's a lot of room to grow.

CS: I'll speak to federal politicians. In the summer of 2013, Justin Trudeau, the leader of the Liberal Party, invited me to a roundtable on youth employment. That happened because I had spoken to an MP, Scott Bryson, a few times while I was at the University of Ottawa about the issue. The roundtable was the first time that I spoke to different stakeholders that I wouldn't normally speak to: it wasn't only student union leaders, but also employers of larger organizations and so on. Bryson continues to have an interest. He's the reason I appeared as a witness before the House of Commons Finance Committee. Just last week I met with Rodger Cuzner, a Liberal MP, who's taken an interest in the issue. I've had a number of meetings with provincial politicians to discuss the issue, private member's bills, amendments to the Canada Labour Code, and gathering statistics etc.

AL: It's heartening to see labour organizations such as Unifor and the Canadian Media Guild discussing unpaid internships. There's a lot of potential for organized labour in Canada to take up this issue and use it as a means to highlight to young people why unions are a necessity in the $21^{\text {st }}$ century.

EH: There are many more opportunities for collaboration with trade unions and student unions. For example, on the issue of academic internships, for those to have academic credit attached they usually need approval from a senate or faculty council. Members of both faculty and student unions (and sometimes staff unions as well) have votes. In unionized workplaces there might be other opportunities to support unpaid interns through bargaining and enforcing collective agreements.

CS: A group that is most aligned with the Intern Association is Generation Squeeze. They're from British Columbia. They have a mandate that's related to intergenerational equality. They have a deep understanding and interest in the intern issue. I see groups like this as the future and our strongest partner.

In Ontario and federally, what do you see as the most promising policy paths to change? For example, is addressing unpaid internships a matter of enforcing regulations that are already on the books? Updating regulations? Pressuring unions to regulate interns' conditions?

AL: For me, what's most important is meaningful law reform to address the conditions of precarious work, and the working conditions that young people are increasingly facing in the labour market. Part of that would be proactive enforcement programs and properly resourcing provincial ministries and departments that are carrying out labour regulation functions, giving them the adequate human and financial resources to carry out this mission. Labour ministries have been starved of resources over the past twenty to thirty years, which has stymied effective regulation.

What specific labour law reforms do you think are most pressing? 
CS: First, the law across Canada should be cohesive and clearly communicated. All internships must be paid unless the intern is receiving academic credit or a professional exemption applies. In Ontario, the Employment Standards Act should not include the "trainee" six-part test. Federally, the Canada Labour Code should include an exemption for students and ensure all non-student interns are paid. Second, all interns and students must be covered under health and safety laws. They are in some provinces; they're not in other provinces or federally. Third is enforcement: improve enforcement of the first two points, which goes back to Andrew's point about more funding for enforcement. Fourth, improve oversight for student internships and internships that are a part of professional training, which would include not just the ministries of labour but also ministries of education and training. Fifth, develop policy statements on volunteerism to distinguish the practice from unpaid labour.

JM: In terms of law reform, basically: ban unpaid internships outside of post-secondary programs; regulate and narrow the scope of unpaid internships through post-secondary programs, so that there are clear criteria and guidelines, and it's not just what exists now: complete exclusion from the Employment Standards Act for interns through post-secondary programs, regardless of what their placement looks like.

AL: Students need to have meaningful recourse within the context of academic internships. There's also the trend in some professional programs to require unpaid labour as a part of the licensing process: registered dieticians; now with law; nursing, to a degree; social work. I think this is an issue because these programs grant credentials, and people have to enter these programs to access the labour market. There are a lot of difficult questions: How do people survive when they're in these programs? How do they access financial resources?

We need to move towards a system based on co-op education, where students get paid when they're doing work. The University of Waterloo model is worthy of examination. We can also look at government-funded, paid internships. I think we need to make greater use of active labour market programs and devote greater governmental resources to paid training programs. We also need to look at apprenticeship programs. I don't think we need vast amounts of the youth population going into university, necessarily. There are other means to train and resource people with the appropriate levels of skills needed for our labour market and economy.

EH: Academic internships need to be much more narrowly defined in the Employment Standards Act, and there needs to be a mechanism for external oversight. Post-secondary education institutions have shown they're unwilling to exercise meaningful control internallywe only have to look to unpaid internships that have students cleaning rooms or serving breakfast in hotels to see this. l've also heard from students that some colleges are recruiting students to programs with mandatory co-op terms by telling them the placements are paid; after starting the program they find out most placements are unpaid. That false advertising is another problem.

Do you see any potential problems with organizing interns or analyzing the intern issue in isolation from other segments of the labour force? In other words, how does the plight of interns and the activism of intern groups relate to precarious employment more broadly? How does this issue intersect with race and citizenship, for example? Does intern activism address a privileged segment of the labour force?

AL: There's a lot of overlap between the issues that interns face and those that other historically marginalized groups face. It's all part of the puzzle of precarious work. We've created this "precariat" and young people are part of that. You also have the development of a large, low-waged service class. There are a lot of aligned issues, but there are differences. "Are interns in a privileged position?" Yes, I think that criticism can be made of some cases. But there's quite a bit of diversity in the types of interns that are out there, from older workers who are trying to retrain for a new career to women who are re-entering the workforce after 
devoting years to childcare [...] There can be recent immigrants in internships. This isn't just an issue related to young people. There are other groups that this impacts. I don't think there's an "ideal" version of the intern.

CS: We receive e-mails all the time from interns, and anecdotally, l'd say that fifty percent of the e-mails come from older workers, immigrants, and people of colour. I can think of several stories from young mothers re-entering the workforce, from immigrants to Canada who have been exploited in their internships, from people who feel they've been discriminated against in their internships, and then there's the gendered element, too, the sexual harassment. The people who email us are usually desperately looking for work experience and would of course prefer to be paid. Many feel that internships are the only way they can get the job they want.

JM: Even a paid internship is still precarious, temporary employment. In some cases, it works well for a summer student, who, for instance, does a four-month internship in the summer during their studies. In many other cases, interns are not students between semesters, and, even if they're paid, they're precariously employed, detached from any meaningful, long-term employment.

EH: It's a misconception that interns are all young and privileged. Even among young people many are funding internships through debt. Many new immigrants and women re-entering the workforce do unpaid work (although they may be more likely to be incorrectly called volunteers than interns). In certain industries, where many unpaid interns are very privileged, opening those opportunities to people who can't afford to work for free by ending unpaid internships is important. Unpaid internships shut people who can't work for free out of industries like journalism, politics, and fashion.

In the past few years, the intern issue has received a great deal of mainstream media attention. You've served as a public commentator, or media source, in the coverage. Why do you think the media has become interested in the issue in the first place? Why did the issue take off in mainstream media? And what has your experience as a source taught you about how the topic gets framed and the debate circumscribed by the media?

CS: The Intern Association started in June of 2012 and immediately started to attract interest. I had only been involved in the issue for about one month when I got an e-mail from a CBC producer to speak about the issue on The Lang and O'Leary Exchange. Why did that happen? I'm pretty sure that, with a name like Canadian Intern Association, those first reporters found us through Google. I remember feeling surprised: I came up with this idea to start an organization, and, two weeks later, CBC Radio wanted to interview me. I gained experience over time and my interview skills improved. I think a lot of the Canadian Intern Association's legitimacy has built from the media attention.

One thing I will say about the media stuff is that it's been 100 percent reactive. Before 2014 , I never reached out to a journalist to write about the issue, to say, "this is a good story." Every time, it was an e-mail or a phone call that I got from someone who was interested. Only in the past year I have called reporters that l've gotten to know to say, "You should write on this issue." 100 percent of the time that l've called a reporter to write on an issue, they have.

Do you think there are any limitations to the coverage or the debate in the media? Are there issues or perspectives that you haven't been able to get through?

CS: The limit is the individual stories. I'm able to talk to reporters about the law or the reforms and so on. But, all the time, they ask, "Can you put me in touch with someone to be my key person in the story?" The anecdotal story. I want to help them, but it's difficult. I reach out to interns to the extent that I have the time, and they never want to talk to media, understanda- 
bly. Jainna Patel is the best example because she's been so willing to talk to media. Also because she's a woman of colour, it's important that she's able to speak out about the issue (Patel received media attention in Ontario after she filed a complaint against Bell Mobility's Professional Management Program in 2013, claiming the internship was in fact menial work, not training, for which she should be paid). I often skirt the question about my own internships, because I would prefer to be a representative of the issue at large. I don't want to be an anecdote. I want to find more interns who are willing to talk about sexual harassment. It's something that so many young women have experienced in internships, and I've experienced it. It's hard to find people who want to talk to media about that, understandably. That part isn't getting enough attention.

What we need is funding to do a proper survey that's representative of the challenges with internships. But that would require a fair amount of money that we don't have. Hopefully, at some point, we could apply for a grant and do a large national survey to get information about sexual harassment in internships, about discrimination, about health and safety, all those different things.

\section{About the Participants}

Ella Henry

Ella Henry is co-chair of Students Against Unpaid Internship Scams. She has a BA in Sociology and Economics from St. Thomas University and a law degree from the University of Toronto.

\section{Andrew Langille}

Andrew Langille is a Toronto-based lawyer with a practice focused on employment, labour, and human rights law. He holds a Master of Laws from Osgoode Hall Law School. His graduate research focused on employment standards within the school to labour market transition. Currently, he acts as the General Counsel for the Canadian Intern Association. He is a frequent commentator in the media on labour market issues and blogs about youth employment issues at youthandwork.ca.

\section{Joshua Mandryk}

Josh Mandryk is a Toronto-based labour lawyer and advocate for interns' rights. He holds a Juris Doctor from the University of Toronto Faculty of Law and is called to the bar in the province of Ontario.

\section{Claire Seaborn}

Claire Seaborn holds a Juris Doctor from the University of Ottawa, Faculty of Law and a Bachelor of Arts in Political Science and Geography from the University of British Columbia. She is currently completing her Articles of Clerkship at Torkin Manes LLP in Toronto and was called to the Ontario bar in June 2015. As President of the Canadian Intern Association, Claire has appeared on the CBC's The Lang and O'Leary Exchange, The Business News Network, CTV News and Radio-Canada, and been quoted in the Globe and Mail, iPolitics, The Toronto Star, The Canadian Press, and Maclean's magazine. In the past year Claire has given submission to the House of Commons Finance Committee twice and was quoted in the 2015 federal budget. 


\title{
Exploited for a Good Cause? Campaigning Against Unpaid Internships in the UK Charity Sector
}

\author{
Vera Weghman \\ University of Nottingham, Nottingham, UK, Idxvw@nottingham.ac.uk
}

\begin{abstract}
In this activist report I aim to show that unpaid internships in charities need to be understood as both morally unjust and exploitative, and that we can do something about it. Together with my fellow interns and interns from another charity, I organized a campaign, NoPay?NoWay!, for a decent wage for all workers in the charity sector, including interns. After six months, we successfully managed to stop the use of unpaid internships in both workplaces. This is my story.
\end{abstract}

Keywords: internships, volunteering, unpaid work, placements, work-experiences, no-wage economy, charities, exploitation, protest, campaigning, employability, labour of love, United Kingdom

\begin{abstract}
Acknowledgement: I would like to thank Nicole Cohen and Greig de Peuter for very helpful comments on earlier versions of this report. I also would like to give special thanks to the Precarious Workers Brigade, as their encouragement made the NoPay?NoWay! campaign possible.
\end{abstract}

Seventy percent of people aged 16 to 76 in England believe that unpaid internships are unfair because only the wealthy are able to work unpaid (The Sutton Trust 2014). But what if this unpaid work takes place in a non-profit organization that is dedicated to a good cause, such as reducing poverty and inequality?

One might argue that internships in a charity are a win-win situation. The charity needs volunteers and the interns enhance their job prospects. From Stephen Resnick and Richard Wolff's (1989) postmodern Marxist viewpoint, non-profit organizations cannot, by definition, exploit workers, as surplus value is neither appropriated nor subsumed by the employer. Contrary to both standpoints, I aim to show that unpaid internships in charities need to be understood as both morally unjust and exploitative, and that we can do something about it. I learned this while an intern at a charity where, with my fellow interns and interns from another charity, I organized a campaign, NoPay?NoWay!, for a decent wage for all workers in the charity sector, including interns. After six months, we successfully managed to stop the use of unpaid internships in both workplaces. This is my story.

\section{Interning at a Charity}

Struggling to find a job after graduating, I took on an unpaid internship in a charity in London (which I refer to as "the charity"), hoping the position would lead to paid employment. It soon became clear to me that securing paid employment through an internship was highly unlikely. Like in many charities, almost all positions at the charity required at least five years paid work experience elsewhere. Yet paid entry-level jobs used to be a part of the charity's organizational structure. Shockingly, the charity's old entry-level job descriptions (which were leaked to me) were identical with the descriptions of its new voluntary internships. Cutting costs by replacing paid staff with unpaid interns is a common phenomenon among charities. In fact, it is even advised by the Charity Commission $(2009,3)$, which suggests that charities deal with funding difficulties by using volunteers "efficiently." The replacement of entry-level positions with internships shows that internships are in fact contributing to unemployment and job insecurity rather than decreasing it.

However, while the economic recession has burdened charities with less funding and more work, it is not the case that the charity lacked sufficient funds to pay all of its staff members, including interns. Rather, the charity's internal wage distribution had changed 
dramatically over the years. Initially, the charity had a flat pay scale under which everyone was paid the same. Now it has a hierarchical pay structure, with an executive director earning $£ 59,000$ per annum, department directors $£ 43,000$ per annum, senior officers $£ 34,000$ per annum, and officers $£ 32,000$ per annum (figures 2012 until March 2013). Clearly, senior officials saw generous increases in their own pay as more important than providing paid, entry-level positions. To take advantage of the "reserve army" of labour (Marx 1995) readily available through the false promise of employability while simultaneously paying certain employees generously must be understood as exploitation. This is principally because the labour power of unpaid interns is appropriated by other workers.

In the U.K., the replacement of (entry-level) jobs with internships is facilitated by a legal loophole. According to the National Minimum Wage Act 1998, every worker over the age of 21 is entitled to a minimum of $£ 6.50$ per hour. Unpaid internships are therefore illegal. However, section 44 of the Act provides an exemption for "voluntary workers." A voluntary worker undertakes work for a charity, voluntary organization, associated fundraising body or a statutory body and is therefore not entitled to monetary payments other than expenses. This exemption, which aimed to encourage volunteering, legalizes unpaid internships in the charity sector. Yet there is a profound difference between volunteering and an internship: the hours and tasks of an internship are fixed; a volunteer, however, must not be placed under any obligation to perform any activities as instructed by the employer. As such, a volunteer is also able to come and go as they please.

Nonetheless, the terms volunteering and interning are often used interchangeably. The first step of our campaign was thus to distinguish between the two terms. By drawing on the work of the Precarious Workers Brigade, which put together a well-researched guide called Surviving Internships: A Counter Guide to Free Labour in the Arts (Carrotworkers' Collective 2009), ${ }^{1}$ we argued that the motive is the deciding criteria for differentiating volunteering from internships: the motive to undertake an internship is first and foremost to advance one's career, whereas volunteering is without career intention and primarily about freely donating one's time to a cause they particularly identify with. In addition, we argued that volunteering is morally unjust if used to cut staff or to boost wages for the other workers in the organization. In other words, volunteering is morally good, if a) all people in the organization work unpaid, such as in small community-run organizations or activist groups, or b) there is an equal distribution of the limited funds, which is facilitated by a democratic decision-making process in which some people might disclaim their financial remuneration as they have secured incomes by other means. Overall, our aim was not to campaign against volunteering per se, but against the replacement of (entry-level) workers with volunteers/voluntary interns.

\section{The Campaign}

Angered by the injustice of our position and inspired by the book Intern Nation (Perlin 2012), my fellow interns and I decided to enter pay negotiations. Our first attempt failed terribly: our director told us that to "hire us" would result in the need to fire someone else. To no one's surprise, our arguments for internal wage distribution went unheard. At this point we had no plan to move forward. We were scared of the possible repercussions of taking industrial action, as we were hesitant to bite the hand that "feeds" us. After all, we were working for a reference and a network, so provoking the executive director of the charity was not in our best interests.

To increase our bargaining power we decided to unite with other interns. Yet interns constitute an invisible workforce, are hard to track down, and often only work for a short time in any given charity. Despite writing to over 100 charities asking for their interns' contact details under the guise of social networking, only two charities forwarded their interns' contacts. Through word of mouth and Facebook we managed to arrange a meeting with 30 interns, many of whom were in their third, fourth, or even seventh unpaid internship. Most of the in-

\footnotetext{
${ }^{1}$ Carrotworkers' Collective is the organizational predecessor to the Precarious Workers Brigade.
} 
terns attending this meeting felt that their vulnerable position in the labour market was exploited and were very angry about it.

However, almost all were faced with the moral dilemma that they also loved the charities they worked for and did not want to harm the charities' images. Protesting outside the charities or turning to the media were not feasible campaigning strategies for many of us. We debated whether we should launch a less militant campaign, and if so, what the right strategy would be. These questions divided the group. Many feared ruining one's career through campaigning and only a few were ready to take action. In the discussion it also became clear that about half of the interns came from for-profit art galleries. As such, they had the option of participating in the "claim back your pay" campaign run by the small NGO Intern Aware. This campaign helps interns who worked for for-profit companies to claim back their unlawfully deducted minimum wage.

That first meeting was a big disappointment. We had hoped that more interns in charities would take the step from complaining to campaigning. However, we had at least managed to join forces with the interns of another charity, which was similar to ours. In fact, the charities were competitors and watched each other's practices. We started to run parallel campaigns and soon realized that our strength came from our unity.

Internally, as both charities were unionized, we coordinated with the trade union representatives at both charities, who were very supportive of our campaign. On their advice we compromised to make our success more likely. We decided to focus on paid internships and left the issue of entry-level positions to another struggle. In the end we did not have much time. It was already mid-summer, which meant that the main campaigner from the other charity and I had only two more months of our internships left. In this short time, we had frequent meetings with the trade union representatives. They helped us draft letters to the directors, which set out our demands and tried to persuade them that paying their interns would improve the charities' images. This turned out to be unsuccessful. Next, we wrote to the trustees. In one charity we managed to get our issue on the agenda of their next meeting. In the other charity an extra meeting took place to debate the "intern question" with the director, trade union representatives, and trustees.

Charity staff were generally encouraging. We thought that working in a charity while campaigning against its practice of unpaid internships would turn our working life into a nightmare. Instead, we gained a lot of respect. However, it was interesting that those few people who were opposed to our campaign were those who should understand our position the best: a member of staff who undertook a paid internship in the charity a few years before and other interns who chose not to take part in the campaign. This division was frustrating and at times made us feel alone in our campaign.

Externally, we were advised and encouraged by the Precarious Workers Brigade. We felt strong because we knew that if we would choose to organize a protest we had the great support network of the Precarious Workers Brigade to back us up. We launched a group called NoPay?NoWay! and set up a blog and a Facebook page for wider outreach. Through irregular meetings, other interns joined us. In these meetings we debated our strategies. Should we emulate groups such as Boycott Workfare that have successfully named and shamed companies and charities through protests and social media? We were still hesitant to protest outside our charities. However, soon a crucial event came up, which we knew most of the directors of the charities we interned for would attend. We decided to do a leaflet action. In a group of ten, we gathered outside the building and approached the attendees of the event urging them to pay their interns. The responses were mixed: some people were sympathetic and argued that they would like to pay their interns but simply cannot afford to, and others were rather hostile. Our next idea was to use Twitter to bring the issue of unpaid internships in charities to the public and, most importantly, to the attention of the charities' supporters. When some tweets appeared on the charity Twitter feed, we quickly realized that we hit a nerve with the directors, who tweeted back in a panic. Not long after that Twitter exchange, I actually saw the book Intern Nation lying on the director's desk. This was when I 
knew we would get somewhere. We had reached the point where our director could no longer ignore us.

Our campaign was partially successful: we managed to stop unpaid internships in both organizations. One charity stopped internships entirely. The other one introduced paid internships but still continued to rely on a lot of flexible volunteering work. Stopping unpaid internships was a great step in the right direction, but to achieve intergenerational and inclusive justice, entry-level positions need to become a part of every organization, may they be for-profit or non-profit. The surest way to make this possible is by re-distributing wages, and charities should lead with a good example. In retrospect, I believe we should have struck while the iron was hot and demanded entry-level positions through loud and lively protests. Still, it is an important step that interns at these charities are no longer exploited for a good cause, and I hope our campaign might inspire other interns to step up for justice. Fellow interns, we have nothing to lose but a reference. We have a wage to win!

\section{References}

Carrotworkers' Collective. 2009. Surviving Internships. A Counter Guide to Free Labour in the Arts. Accessed February 13, 2015. https://carrotworkers.wordpress.com/counter-internship-guide/.

Charity Commission. 2009. Regional focus group discussions: A summary. How can the Charity Commission support charities through the recession. Accessed February 13, 2015. http://webarchive.nationalarchives.gov.uk/20140505102719/.

Perlin, Ross. 2012. Intern Nation: How to Earn Nothing and Learn Little in the Brave New Economy. London: Verso.

Precarious Workers Brigade. n.d.. Accessed February 13, 2015. http://precariousworkersbrigade.tumblr.com.

Marx, Karl. 1995. Capital: An Abridged Edition. Oxford: Oxford University Press.

Resnick, Stephen A. and Richard D. Wolff. 1989. Knowledge and Class. A Marxian Critique of Political Economy. Chicago: The University of Chicago Press.

The Sutton Trust. 2014. Research Brief. Internship or Indenture? Accessed February 13, 2015. http://www.suttontrust.com/wp-content/uploads/2014/11/Unpaid-Internships.pdf.

\section{About the Author}

Vera Weghman

Vera Weghman is currently doing her $\mathrm{PhD}$ at the University of Nottingham. Her thesis is entitled The Employability Promise: The Cases of Unpaid Internships and Workfare in the UK and is funded by the Rosa Luxemburg Foundation. She has also been an activist in various groups and movements and recently co-founded the grassroots trade union, United Voices of the World, which is almost entirely comprised of migrant workers in London's low wage, service sector. 